$$
\begin{aligned}
& \text { UNIVERSIDADE DE SÃO PAULO - USP } \\
& \text { INSTITUTO DE RELAÇÕES INTERNACIONAIS - IRI }
\end{aligned}
$$

LUIZ FERNANDO DO AMARAL

\title{
ICT AND AGRICULTURAL DEVELOPMENT:
}

THE IMPACTS OF INFORMATION AND COMMUNICATION-TECHNOLOGY ON AGRICULTURE

SÃO PAULO/SP 


\author{
UNIVERSIDADE DE SÃO PAULO - USP \\ INSTITUTO DE RELAÇÕES INTERNACIONAIS - IRI
}

\title{
ICT AND AGRICULTURAL DEVELOPMENT:
}

THE IMPACTS OF INFORMATION AND COMMUNICATION-TECHNOLOGY ON AGRICULTURE

Tese de doutorado apresentada ao Programa de PósGraduação em Relações Internacionais do Instituto de Relações Internacionais (IRI) da Universidade de São Paulo (USP) sob a orientação do Prof. Dr. João Paulo Cândia Veiga.

SÃO PAULO/SP 
Biblioteca do Instituto de Relações Internacionais

AMARAL, Luiz Fernando do

ICT and agricultural development: The Impact of Information and Communication Technology on Agriculture / Orientador: Prof. João Paulo Candia Veiga. São Paulo, 2017.

Tese (Doutorado). Universidade de São Paulo. Instituto de Relações Internacionais.

1. Information and Communication Technology. 2. Food and Agriculture. 3. Sustainable Development. 4. Deforestation. 5. Yields. 
To Fernanda and Eva, for simply being (my life).

To Zique and Cintia, for always putting my education first. 


\begin{abstract}
Within a context of continuous population and economic growth, the future projections for agricultural products' demand is impressive. At the same time, agriculture already exercises significant pressure on natural resources. As a consequence, the world needs to produce higher agricultural volumes while limiting agriculture's impacts on the environment. This thesis evaluates whether empirical indications exist that demonstrate how Information and Communication Technology (ICT) infrastructure development and usage could impact the sustainable development of agriculture. Drawing from the empirical literature on infrastructure's impacts on development, two statistical models are created. The first analyses impacts of Internet and mobile usage on cereal yields at a country level using Fixed Effects Panel Regression for 212 countries in five 5-year periods, from 1990 to 2014. The second uses a Propensity Score Matching Model to evaluate how the installation of $3 \mathrm{G}$ technology during the period between 2005 and 2009 in Brazilian municipalities located in the Amazon region affected deforestation. Based on the methodology and datasets used, results indicate that the growth of Internet users could have a positive impact on cereal productivity in a country. Results for mobile device users are inconclusive. Finally the second models indicate that municipalities in which $3 G$ technology was installed had lower deforestation rates than similar municipalities lacking $3 G$ technology.
\end{abstract}




\section{RESUMO}

Em um contexto de crescimento populacional e econômico, as projeções de demanda para productos agrícolas no futuro são expressivas. Ao mesmo tempo, a agricultura já exerce pressão significativa nos recursos naturais do planeta. Como consequência, é preciso obter maior oferta de produtos e, ao mesmo tempo, limitar o impacto ambiental da atividade agrícola. Essa tese avalia o papel da infraestrutura e uso de Tecnologia da Informação e Comunicação (TIC) no desenvolvimento sustentável da agricultura. Baseando-se na literatura empírica sobre impacto de infaestrutura no desenvolvimento, dois modelos estatísticos foram criados. O primeiro analisa os impactos do uso de internet e telefones celulares na produtividade de cereais utilizando uma regressão em painel de efeitos fixos para 212 países no período entre 1990 e 2014. O segundo utiliza um modelo Propensity Score Matching para avaliar o impacto da instalação de tecnologia $3 \mathrm{G}$ no desmatamento de municipios localizados na região da Amazônia Legal brasileira. De acordo com a metodologia e dados utilizados, os resultados indicam que um crescimento no uso da internet pode positivamente impactar a produtividade de cereais em um país. Para o caso do uso de telefones celulares os resultados são inconclusivos. Finalmente, de acordo com o modelo, há indicações de que municipios que receberam a tecnologia $3 G$ no período estudado tiveram taxas de desmatamento reduzidas quando comparadas a municipios similares que não receberam a tecnologia. 


\section{ACRONYMS}

$3 G$ - Third generation of wireless mobile telecommunications technology ${ }^{1}$

ANATEL - Brazilian Agency of Telecommunications

CAR - Brazilian Rural Environmental Registry

DiD - Difference in Difference model

DV - Dependent variable

ERB - Mobile transmitter antenna (Estação Radio Base)

FAO - United Nations Food and Agriculture Organization

GDP - Gross domestic product

IBGE - Brazilian Institute of Geography and Statistics

ICT - Information and Communication Technology

IV - Independent variable

MDG - Millennium Development Goals

MMA - Brazilian Ministry of the Environment

OLS - Ordinary least squares model

RCT - Randomized Control Trials

UN - United Nations

US - United States of America

\footnotetext{
${ }^{1}$ Based on International Mobile Telecommunications-2000 (IMT-2000) specifications
} 


\section{FIGURES AND TABLES}

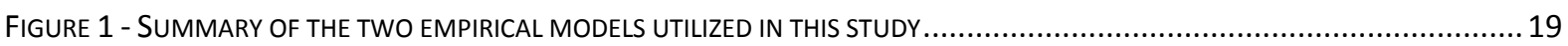

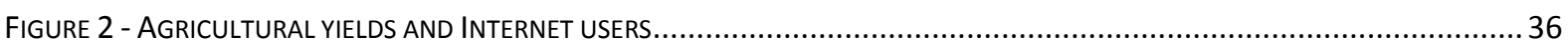

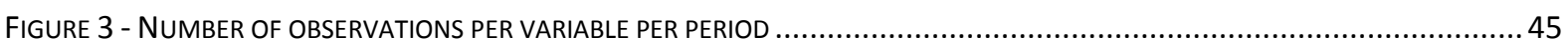

Figure 4 - Deforestation, AREA of LAND USE CATEGories, AND PRODUCTION (BEEF AND SOY) TRENDS IN THE BRAZILIAN AMAZON

FIGURE 5 - NUMBER OF MOBILE TRANSMISSION ANTENNAS ACCORDING TO MUNICIPALITIES' POPULATION (2013) ......................58

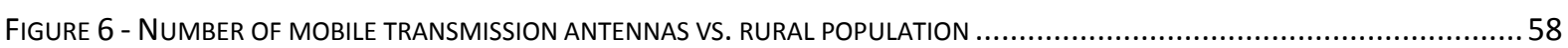

FIGURE 7 - EVOLUTION OF 3 G COVERAGE ACCORDING TO POPULATION SIZE $(B I G=>30,000)($ SMALL $=<30,000) \ldots \ldots \ldots \ldots \ldots \ldots . . . . . . . .59$

FIGURE 8 - TOTAL NUMBER OF MOBILE ANTENNAS INSTALLED IN BRAZIL ACCORDING TO THE CATEGORY OF THE MUNICIPALITIES

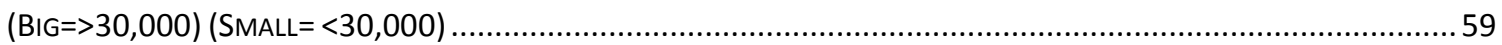

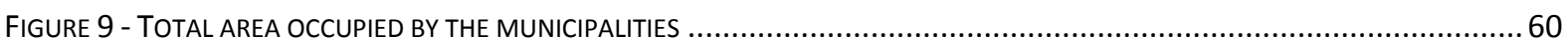

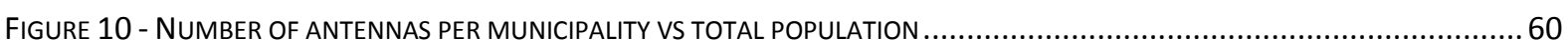

FIGURE 11 - DISTRIBUTION OF ANNUAL AVERAGE DEFORESTATION RATES IN THE SAMPLE AND TREATED MUNICIPALITIES ................68

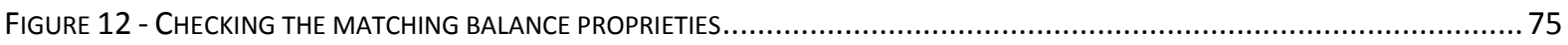

FIGURE 13 -. CONTROL VARIABLES: DIFFERENCE IN THE MEAN VALUE FOR TREATMENT AND CONTROL GROUP, BEFORE AND AFTER

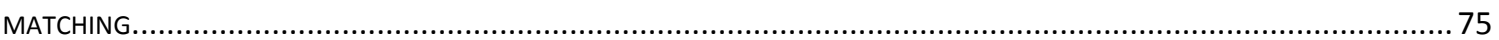

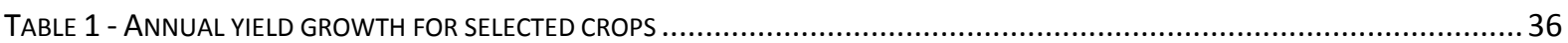

TABLE 2 - SUMMARY RESULTS OF THE GLOBAL MODEL: THE EFFECTS OF INTERNET AND MOBILE PHONE USAGE ON CEREAL

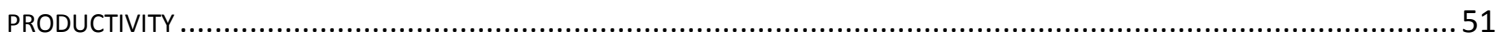

TABLE 3 - OBLIGATORY TARGETS FOR THE INSTALLATION OF $3 G$ TECHNOLOGY ACCORDING TO MUNICIPALITY POPULATION ............55

TABLE 4 - OBLIGATORY TARGETS FOR THE INSTALLATION OF 3 G TECHNOLOGY IN NON-URBAN AREAS ......................................57

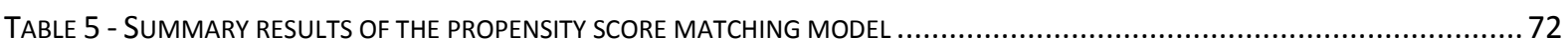




\section{TABLE OF CONTENTS}

1 INTRODUCTION: AGRICULTURAL DEVELOPMENT IN THE INFORMATION AGE...................................11

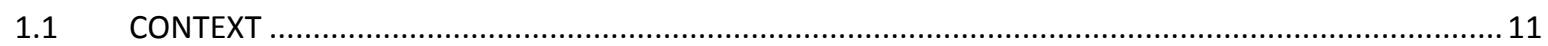

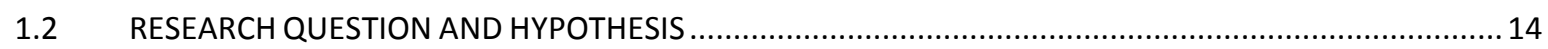

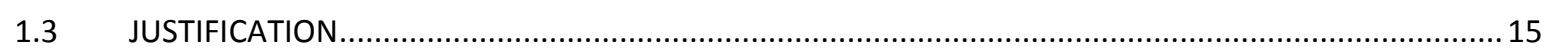

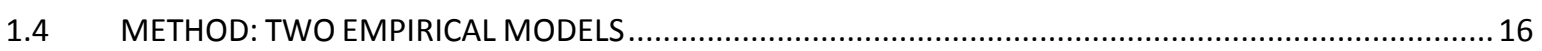

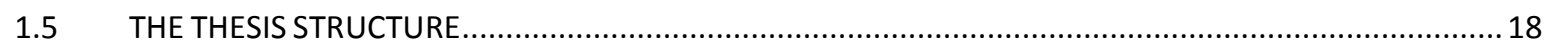

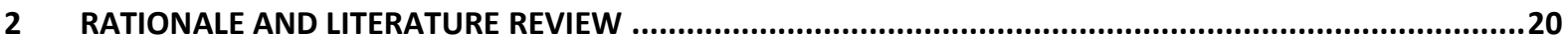

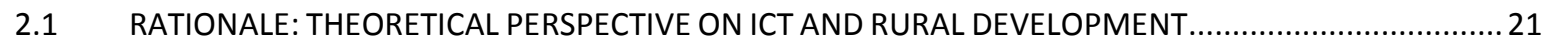

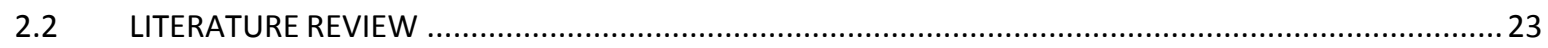

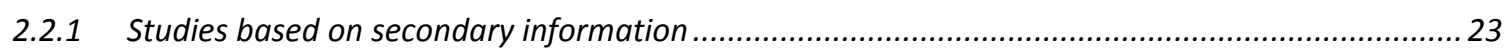

2.2.2 Studies based on primary data analysis \& evaluation of projects' results.....................................2 24

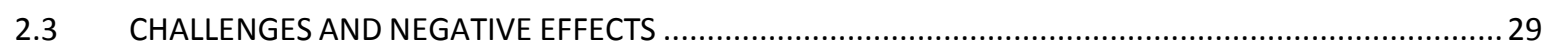

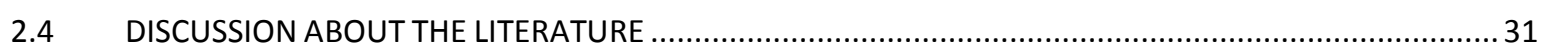

3 GLOBAL MODEL: IMPACTS OF INFORMATION AND COMMUNICATION TECHNOLOGY USE ON CROP

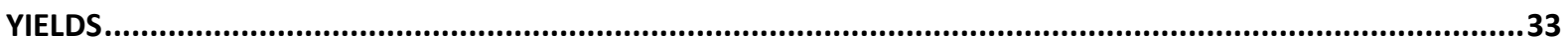

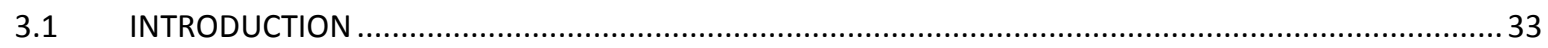

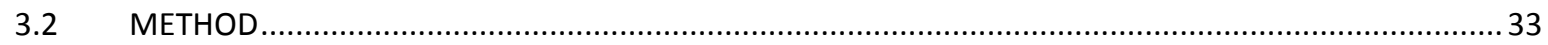

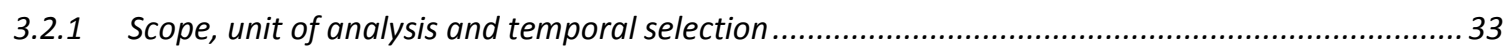

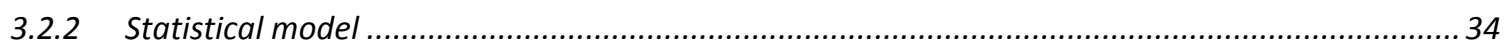

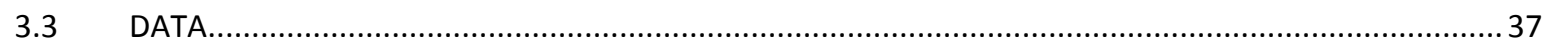

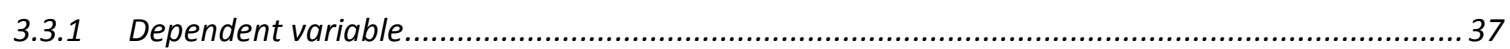

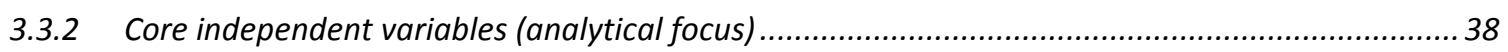

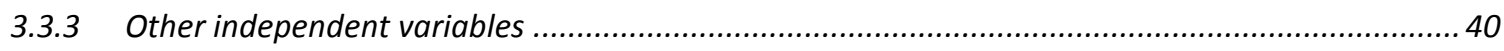

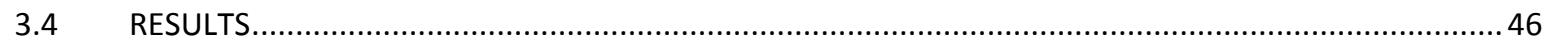

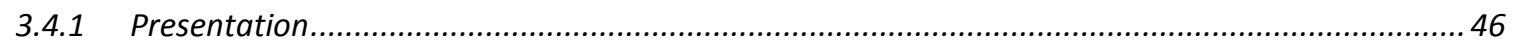

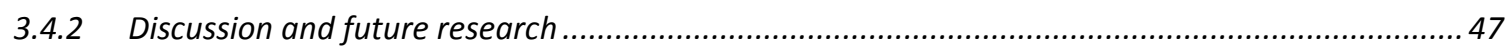

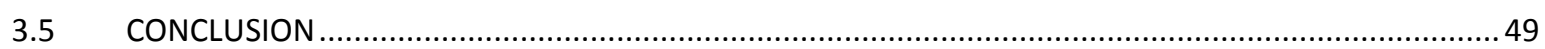

4 SUB-NATIONAL MODEL: EFFECT OF 3G MOBILE NETWORK AVAILABILITY ON DEFORESTATION RATES OF BRAZILIAN MUNICIPALITIES IN THE LEGAL AMAZON ..................................................................52

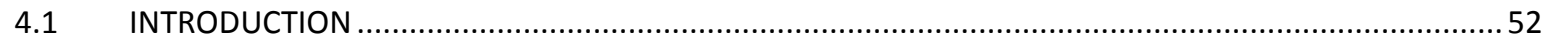

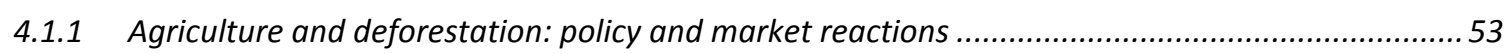

4.1.2 Brazilian regulation and the country's urban-rural digital divide .............................................55

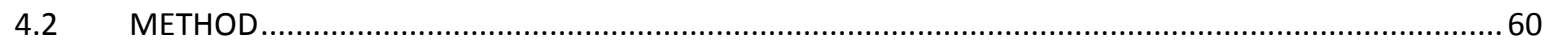

4.3 DATA

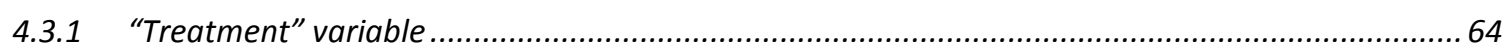

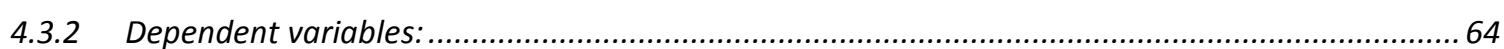

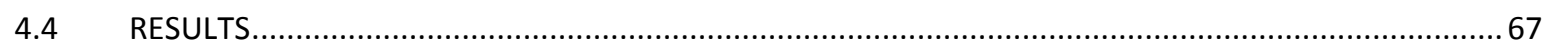

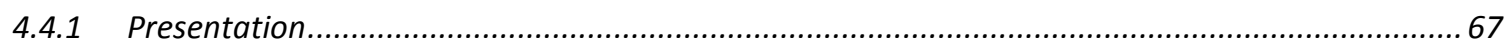

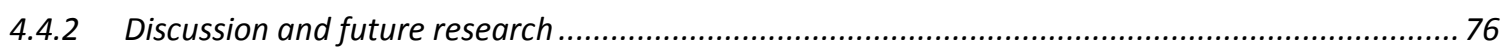

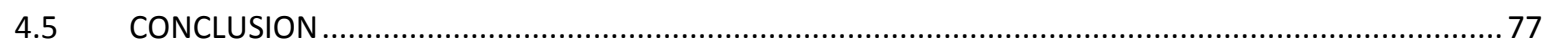

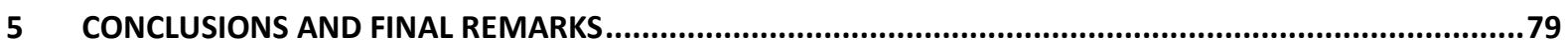

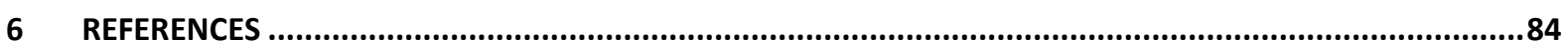

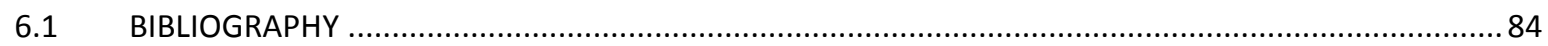




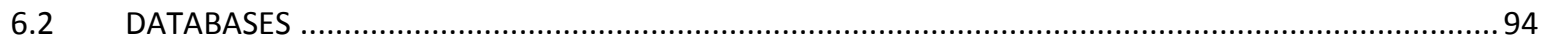

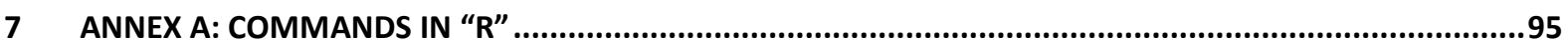

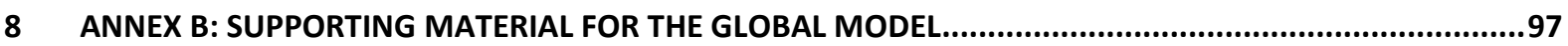

9 ANNEX C: SUPPORTING MATERIAL FOR THE SUB-NATIONAL MODEL ............................................172 


\section{INTRODUCTION: AGRICULTURAL DEVELOPMENT IN THE INFORMATION AGE}

\subsection{CONTEXT}

Two megatrends are driving substantial growth in projected demand for food: The world's population will reach 9 billion by 2050, and per capita income is rising in several regions of the world. Agriculture already exercises significant pressure on natural resources. So, how can the planet's agricultural systems produce enough calories to meet booming demand without exerting even more pressure on the planet, all while promote shared prosperity in rural areas?

Agriculture is associated with $71 \%$ of tropical deforestation (LAWSON et al 2014), occupies $40-50 \%$ of the planet's land (SMITH et al 2007) and is responsible for $1 / 4$ of total global anthropogenic emissions of greenhouse gases (GHG) (SMITH et al 2014), yet is essential for humanity's survival. Food production accounts for $69 \%$ of the world's water withdrawal' while water stress threatens critical food production. Such challenges will only increase. The world needs to close a 70 percent "food gap" between the crop-based calories available in 2006 and expected calorie demand in 2050. It must also close an 80 percent gap for animalbased calories (RANGANATHAN et al 2016). If agricultural production continues unchanged, global consumption of natural resources will outstrip the Earth's capacity to provide those resources by 2.9 times by 2050 (WWF 2012).

Therefore, the world needs to be able to "produce more with less," producing higher agricultural supply volumes while limiting agriculture's impacts on the environment. This will be a significant challenge.

Fischer et al. (2014) estimate that in order to meet projected demand, staple crops' yields must increase by an average rate of $1.1 \%$ per year in the period $(1.3 \%$ would be recommended to reduce non-predicted risks). They note, however, that staple crops' yields are currently

\footnotetext{
${ }^{2}$ Aquastat website by the UN Food and Agriculture Organization (FAO), access on January 27th 2017, available at http://www.fao.org/nr/water/aquastat/water use/index.stm
} 
increasing by only $1.0 \%$ per year. It is important to note that their model considers land expansion, so, such growth would be require additional agricultural area expansion. In other words, even given those rates, land resources would still face significant pressure, which in turn could create higher global deforestation rates. They conclude that the most effective way to increase yields would be to reduce the gaps between high and low productivity regions.

Given that cereals (staple crops) account for $58 \%$ of annual harvested crop area globally and directly provide around 50\% of world food calories (NELSON et al. 2010), the challenge is even greater.

Such productivity-gap reductions will only be achieved with technology. It seems obvious: any agricultural scientist will enumerate countless essential techniques - such as more efficient inputs or plant varieties. That was the logic behind Norman Bourlaug's first Green Revolution. In the Sixties, the American agronomist led a movement that brought technology to the fields - such as better soil management techniques or use of better seed varieties - generating immense yield gains. Commonly defined as the "Agricultural Green Revolution," it allowed global population growth and helped to increase prosperity at a global scale (BOURLAUG 1976).

In fact, some authors argue that such boosts in yields were critical to future economic growth in many countries. They argue, for example, that low agricultural productivity in Africa is a key explanatory factor for the region's relatively slow economic growth (DIAL et al. 2006).

However, it is possible that traditional agricultural technologies brought by the "Green Revolution" cannot carry agriculture through the second revolution. This research hypothesizes that the next green revolution in agriculture could be about information technology (TING et al 2011, BULL et al 2011, WORLD BANK 2012, BRONSON \& KNEZEVIC 2016). The emergence of the "big data revolution", the "Internet of things" and the "sharing economy" is changing life in cities, making urban societies more efficient across all aspects of daily life (RIFKIN 2010, CASTELLS 2010, RIFKIN 2014). However, this revolution has not yet reached the rural world (BRIDGES 2001). 
Six billion mobile subscriptions exist worldwide. So, three-quarters of the planet's population has access to a mobile phone that may or may not be connected to the Internet. In fact, in some developing countries, more people have access to mobiles than to potable water, financial services or electricity. According to the World Bank, "mobile communication now offers major opportunities to advance human development - from providing basic access to education or health information to making cash payments and stimulating citizen involvement in democratic processes". Not only that, it also concludes that mobile applications have important cascade effects that stimulate growth, entrepreneurship and productivity in the broader economy. According to its findings, a 10\% expansion of cell phone usage would increase some countries' annual economic growth by 0.6 to 0.8 percentage points (WORLD BANK 2012). In fact, some studies have shown that greater access to and use of mobile ICT can have significant effects on rural income (DIXIE \& JAYARAMAN 2011).

For example, precision agriculture is already implemented in specific and more capitalintensive operations, but it is not yet widespread. Some tractors already have GPS's that store the exact location of each planted seed. This information is valuable because it enables nearly fully automated harvesting machinery. Technology giants, such as Google, are investing more in agricultural intelligence (WALL STREET JOURNAL 2015). Fertilizers and other inputs could also be monitored and used more efficiently in controlled environments, applying more where it is needed and less where it is not (BONGIOVANNI \& LOWENBERG-DEBOER 2004).

All of these impacts, for better or for worse, are only possible with efficient Internet and mobile phone coverage. Even simpler developments depend more and more on this variable. Communications technology brings access to information on the field, a key input for human capital and, as a consequence, potentially on the way agriculture is produced.

Therefore, ICT infrastructure in rural areas can not only connect farmers to information from intelligence clusters, extension programs and markets but it can also create a feedback loop by sending information back to markets in real time, helping them adjust faster and more accurately.

One might argue that the current lack of reliable coverage could be a significant bottleneck. In Brazil, for example, the system developed by the government for farmers to finalize their Environmental Rural Registry (CAR) - a virtual map of farm property indicating production 
and protection areas - is entirely virtual and dependent on the availability of information and communication technology (TNC 2015). Therefore, the lack of cellular coverage in remote areas could already be negatively impacting this important environmental regulation.

Finally, although it lies outside the scope of this thesis, it is important to recognize that information and communication technologies' advancement will also bring challenges for rural development. One of the most significant relates to confidentiality and use of information collected from rural actors, which could impact agricultural markets' organization positively or negatively, possibly squeezing farmers' gains. For example, it has been reported that a multinational agricultural production company already possess field-by-field information, which used to be proprietary data, for roughly one-third of all United States farmland (CARBONELL 2016). While this demonstrates the power of ICT for agriculture, it also raises significant challenges over the confidentiality of information and ethical use of this technology.

\subsection{RESEARCH QUESTION AND HYPOTHESIS}

This research sheds light on debate about ICT and rural development. Are there empirical indications that information and communication infrastructure and utilization has a role to play in humanity's quest to sustainably feed itself in the future? Could such advances in access to information allow agricultural markets and farmers to become more efficient and mitigate food production's effects on the environment?

Drawing from the extensive literature about infrastructure's impacts on agricultural output, this research scrutinizes the afore-mentioned questions through econometric modeling techniques. Introducing new dependent and independent variables to the debate on infrastructure and agricultural development, the current thesis produced two empirical models to test the relationships between those variables.

In summary, the central research question is: does communication (Internet and mobile phones) infrastructure and utilization impact sustainable agricultural development? The specific research questions in each section are presented below. 
The first model analyzed this question at a global level, using countries as the unit of analysis, cereal yields as the core dependent variable and Internet and mobile users as the core independent variable. This section explores whether the increase in mobile and Internet users in a country impacts that country's agricultural commodity production.

The second model analyzed the subnational level, using municipalities as the unit of analysis, deforestation as the dependent variable and the implementation of $3 G$ coverage as the treatment (core independent variable). The specific research question in this case is whether the installation of $3 \mathrm{G}$ coverage can impact deforestation rates in a given municipality.

Based on the research questions above, some general hypotheses were formulated in order to be tested:

General hypothesis: The advance of information and communication technology infrastructure and utilization in rural areas improves sustainable agricultural development.

Specific hypothesis 1: greater ICT infrastructure utilization has a positive and significant correlation with yield increases.

Specific hypothesis 2: greater ICT infrastructure installation has a negative and significant correlation with deforestation rates.

\subsection{JUSTIFICATION}

The literature and empirical studies that intend to measure impacts of infrastructure on agricultural development are abundant. However, they tend to focus only on roads, electrification and irrigation as the main independent variables related to infrastructure. As described in the Literature Review, few studies have focused on ICT. Additionally, such studies tend to be based on individual interventions in specific regions or projects, therefore limiting the generalizable capacity of their conclusions.

Finally, dependent variables chosen to represent "development" in the literature tend to reflect the traditional vision of economic growth as a development indicator. Therefore, 
previous studies measured, primarily, the economic impacts of infrastructure. Additionally, social indicators, such as inequality reduction, are also regular objects of study as dependent variables. Other development-related issues, such as efficient land use, have not been explored according to the author's knowledge.

Therefore, the present study is innovative - it adds new analytical variables to the debate about ICT impact on global agricultural development.

First, this study introduced ICT infrastructure and utilization (especially Internet and mobile coverage) as the core independent variables. This is a research innovation in a world currently classified as an information society - a society that is more integrated into information-based networks (RIFKIN 2010, CASTELLS 2010, RIFKIN 2014).

Secondly, this study also innovated on the choice of dependent variables. Traditionally, development studies focused on agriculture's economic growth in order to measure the impact of new infrastructure. This study instead focuses on agricultural productivity, an indicator that captures not only economic but also social and environmental development. If more food is produced in a smaller area, the pressure for additional resources is diminished. The positive economic-socio-environmental impacts of higher yields are clear. Additionally, since agriculture still creates significant tropical deforestation around the world (LAWSON et al 2014), ICT impact on deforestation rates will also be tested as a dependent variable.

\subsection{METHOD: TWO EMPIRICAL MODELS}

This research used two empirical models to test the hypotheses presented. As described above, the first operated at a global scale, utilizing countries as the unit of analysis, while the second sub-national model utilized municipalities/counties as the unit of analysis.

The first model was based on cross-country analysis. Data from international databanks, such as the United Nations Food and Agriculture Organization (FAO) and the World Bank, fed into a panel-data model. ICT infrastructure information was the core independent variable and agricultural yield was the core dependent variable. Obviously, other potential explanatory variables are included in the model for control. As described in the literature review, similar 
cross-country models are important and allow for discussions at global level. However, they are also subject to technical criticisms such as endogeneity (especially due to simultaneity and omitted variables). Another frequent criticism is that the model does not capture regional differences within countries.

Therefore, a second complementary sub-national model was developed with municipal-level information from national datasets, such as Brazilian Agency of Telecommunications (ANATEL) and the Brazilian Institute of Geography and Statistics (IBGE). Municipalities were used as cross-sectional data, limiting the regional-scale limitations of the global model described above. Given idiosyncrasies such as a mobile phone regulation in Brazil that obliges investments in small cities regardless of their economic attractiveness (this topic will be thoroughly discussed in the chapter on the Brazilian model), the endogeneity issue is limited. Finally, a Propensity Score Matching and Difference in Difference model was used to estimate impacts. In short, this model compared the outcomes of a "treatment" to a "treated group" (municipalities where ICT infrastructure was installed) and a "control group" (municipalities where ICT infrastructure was not installed) by finding "matches" between the two groups (municipalities with the same characteristics). The model therefore incorporated a more detailed geographic approach by characterizing dependent and independent variables at the municipality level. It also introduced deforestation as the new dependent variable and 36 coverage at the municipality level as the treatment variable. It is important to highlight, however, that regional differences in ICT infrastructure exist even within municipalities between, for example, urban and rural areas.

This study's model selection intended to shift the logical framework from broad geographical coverage and lower data accuracy with broader generalization capacity to more concentrated geographical coverage and more accurate datasets with limited generalization capacity. The international model was based on a cross-country, fixed effects panel. It intended to set the stage for discussion since global applicability is its primary asset. However, despite the author's best efforts, any global model that tests the impact of any variable on agricultural development can be subject to criticism for endogeneity. In other words, so many factors affect yields at a global level, and countries can be such broad units of analysis with great local-level variation, that a global model will always be imperfect. Even given the legitimate criticisms, this approach is still justified as an exploratory exercise. The conclusions need to 
be interpreted with care but can still inform important policy outcomes. The sub-national model intended to address some of the aforementioned problems of endogeneity, but did not solve them all. Smaller units of analysis (such as municipalities) are, at least, helped control for other endogenous variables that could explain variations on the dependent variable.

Figure 1 summarizes the two models.

\subsection{THE THESIS STRUCTURE}

Chapter 2 is a literature review on infrastructure impacts on agricultural development. It presents both the rationale (theoretical and policy-oriented studies) and the research results (empirical studies). The global model developed is described in Chapter 3. It explains the model, describes the methodological choices, databases utilized and indicators chosen and constructed. Results are then presented and some initial conclusions drawn. Chapter 4 focuses on the sub-national Brazilian model, following a similar structure to the previous chapter. It does include, however, a critical discussion about local policies defining ICT investments. This description necessarily defends the methodological choices and, specifically, the value in choosing a propensity score-matching model. Finally, Chapter 5 presents the general discussions and conclusions, as well as suggestions for future research. 


\begin{tabular}{|c|c|c|}
\hline & Global model & Sub-national model \\
\hline Statistical model & $\begin{array}{l}\text { Fixed Effects panel } \\
\text { (OLS also tested) }\end{array}$ & $\begin{array}{c}\text { Propensity Score Matching, with } \\
\text { Difference in Difference }\end{array}$ \\
\hline Scope & Global & Brazilian Legal Amazon \\
\hline $\begin{array}{l}\text { Cross-dimensional } \\
\text { section } \\
\text { (unit of analysis) }\end{array}$ & Countries & Municipalities \\
\hline Temporal section & $\begin{array}{l}\text { Five 5-year periods } \\
\text { from } 1990 \text { to } 2014\end{array}$ & $\begin{array}{l}\text { Pre-treatment: } 2004 \\
\text { Treatment: } 2005-09 \\
\text { Post-treatment: } 2010\end{array}$ \\
\hline Dependent variable & Crop yield & Deforestation \\
\hline $\begin{array}{l}\text { Independent variable } \\
\text { (core) }\end{array}$ & Internet and mobile use & 3G availability (treatment) \\
\hline $\begin{array}{l}\text { Independent variable } \\
\text { (controls) }\end{array}$ & $\begin{array}{c}\text { Economic Development } \\
\text { Human Capital } \\
\text { Inputs and Technology } \\
\text { Agricultural Markets }\end{array}$ & $\begin{array}{l}\text { Population } \\
\text { Economic Development } \\
\text { Micro-region } \\
\text { Agricultural importance } \\
\text { Agricultural expansion } \\
\text { Size (area) }\end{array}$ \\
\hline
\end{tabular}

Figure 1 - Summary of the two empirical models utilized in this study 


\section{RATIONALE AND LITERATURE REVIEW}

In order to introduce the arguments and assumptions regarding ICT's influence on agricultural activity, this chapter presents a review of the literature describing the impacts of infrastructure on development, with a special focus on agriculture and rural development.

First, the rationale behind the main hypothesis of the paper - that ICT infrastructure and utilization could create more sustainable rural development - is introduced through papers from several fields, particularly reports by international organizations intended for policy makers. This section also specifically highlights studies that have focused on negative effects of information and communication technology on development.

The second section presents an extensive review of the academic and empirical literature on infrastructure and development. It begins with broader studies that assessed infrastructure's generalized impacts on economic development issues. The review then turns to studies of non-ICT infrastructure impacts on agriculture. It closes with studies focused specifically on ICT and agriculture.

According to Ahmed \& Donovan (1992), empirical studies about the effects of infrastructure development published since the 1950s can be classified into three groups: (a) systematic approach, based on primary data attempting to measure the impacts on specific locations; (b) appraisal, evaluation and assessment of infrastructure projects, such as the those by multilateral agencies and (c) books, articles and papers using secondary information, based on deductive logic and sometimes quoting results from studies of types (a) and (b).

It is worth highlighting that this research and the three models developed would fall under group (a) according to above classification, which justifies the more abundant literature presented under this category. 


\subsection{RATIONALE: THEORETICAL PERSPECTIVE ON ICT AND RURAL DEVELOPMENT}

One of the main assumptions behind this research lies in the theory that the advance of ICT infrastructure and utilization could catalyze increased access to information for farmers, agricultural supply chain actors, companies, policy makers and local communities. Greater access to information would, in turn, result in a better use of economic, human and environmental assets.

Zepeda (2001), in a report to the United Nations Food and Agriculture Organization (FAO), gives an overview of current economic thinking related to investments and agricultural productivity. She points that physical capital has long been recognized as one of the most important inputs for agricultural productivity. However, she indicates that economic research has also identified human capital as a crucial part of the definition of productivity. This debate is even more relevant in the context of the current study. As ICT infrastructure can be considered physical capital, it in fact also has a significant effect on human capital. Access to communication technologies is an important source of information, integration to global networks and, therefore, improved human capital. It might be one of the few infrastructure investments with such a characteristic. Furthermore, according to the author,

"... social capital is the stock of personal relationships and knowledge of institutions that an individual or household has. This affects the individual's access to risk-minimizing inputs like credit, insurance and land title. In other words, social capital measures the ability to utilize social networks and institutions. Status, gender and group affiliations are often used as proxies for social capital in economic studies. However, education and transportation, as well as the range of social institutions available, can also influence social capital" (ZEPEDA 2001).

Therefore, given the current relatively low usage rates of mobile phones and Internet connections in rural areas, one can propose that ICT infrastructure investments could improve human capital. Human capital is an important input to agricultural production and, consequently, could be a significant variable in defining productivity and awareness about sustainability and regulatory requirements.

Additionally, according to the World Bank (2012), ITC in rural areas can both increase agricultural production efficiency and accelerate long-term agricultural development. First, it 
gives farmers access to agricultural information, such as prices, disease and weather information, farming practices and market practices. It also surfaces data that creates valuechain efficiency by for example, improving logistics systems by tracing products from farm to market. The authors also argue that ICT in rural areas creates access to markets (WORLD BANK 2012). Given the preceding factors, it is possible to infer a fourth effect: improved agricultural sustainability. If farmers, value chains and markets become more efficient, it is plausible to assume that they will "do more with less", promoting the sustainable development of agriculture in all areas while staying more informed about market sustainability requirements and environmental regulations. This chain of logic justifies the rationale that ICT could contribute to the two benefits tested by this research: increased yields and reduced deforestation.

Similarly, in an African Development Bank report, Verdier-Chouchane \& Karagueuzian (2016) argue that ICT has the potential to transform agriculture across the African continent by promoting a more inclusive and sustainable model. ITC, the authors argue, would benefit smallholders, address land reform issues, provide adequate financial services, and share price and market information. It is interesting to note the authors' argument that ICT would also serve to boost global value chains connected to the continent.

As mentioned, additional arguments exist for how expanding ICT can affect not only economic and yield growth but also a wider range of sustainability-related goals. The International Telecommunications Union (ITU) listed the contribution of ICTs towards the Millennium Development Goals (MDGs) in Measuring the Information Society. It states that ICT provides more accurate weather information, which in turn helps increase agricultural production, contributing to the MDG1 - Eradicate extreme poverty and hunger (ICT 2014). In a report commissioned by the Bill and Melinda Gates Foundation, Naef et al. (2014) share the areas of highest potential impact across sectors for mobile data. According to the authors, "Mobile data offers a view of an individual's behaviors in a low-cost, high-resolution, real-time way. This provides tremendous opportunities for creative uses in development programs." While analyzing different sectors for ex-post, current and future applications, they highlight agriculture yield predictions as the highest-impact potential application for ICT data in the future. Samarajiva (2012) also compiled the results of a study about the impacts of ICT on the poor, or as it is described, the bottom of the pyramid. Research conducted in south Asian 
countries (Thailand, Sri Lanka, India, Pakistan and Bangladesh) on agricultural micro enterprises identified many benefits derived from mobile phones: maintaining or enhancing social/status/recognition, carrying out day-to-day work efficiently, maintaining relationship with family and friends, reducing travel costs and contacting others in an emergency.

Finally, recent literature describes the so-called "digital divide" - the idea that developing countries are lagging behind the developed world in adopting communication technologies, thereby, expanding the gap between developed and developing populations and driving an ever-increasing disadvantage for the poor in a globalized world (BRIDGES 2001, UN 2000, UNDP 2001, WORLD BANK 1999, WORLD BANK 2012). Although not focused on agriculture and rural development, such reports argue that a lack of access to information and communication technology prevents benefits from advances in efficiency, social integration and access to information from reaching "excluded", or disconnected, populations.

This section summarized the international political debate surrounding this topic based on reports by major international organizations that compile results and theoretic argumentation by several authors. The next session focuses on relevant academic studies and papers.

\subsection{LITERATURE REVIEW}

A large body of theoretical and empirical literature analyzes the potential effects of infrastructure on agricultural development. The preceding section (Rationale) already introduced the debate, primarily from the international development perspective, so this section turns to a literature review of empirical studies.

\subsubsection{Studies based on secondary information}

The first group of studies below amount to an interesting theoretical contextualization exercise, but prove less interesting to further development of this research. This literature 
does, however, help to define key assumptions behind this study. Conclusions from empirical studies based on secondary information tend to summarize common points and conclusions from the primary empirical literature, described by Ahmed \& Donovan (1992) as groups B and C.

Dethier \& Effenberger (2012) wrote an extensive literature review of empirical studies analyzing agricultural growth, farmer income, rural development, trade policy and food security. The authors, collectively, identified a set of critical issues for the future of agricultural development in non-traditional areas: markets and prices, agronomic research, agricultural extension, credit, rural infrastructure, connection to markets, employment and trade policy.

Cook (2013) explores the literature studying the role and relationship of infrastructure, particularly electrical infrastructure in rural areas, to economic growth and development. The author concludes that initiatives for rural electrification have influenced small agricultural business development by creating income-generating activities and improving access and affordability. A further noteworthy conclusion states that other contextual issues affected affordability of access to installed electrical infrastructure - I in this case, "participation in community-based initiatives and the availability of localized credit facilities to help develop and finance access and use of energy" (COOK 2013).

Llanto (2012) offers another informative overview of the results of several empirical studies evaluating infrastructure's effects on agricultural productivity for Asian countries. Each of the reviewed studies evaluated only three independent variables: roads, electricity and irrigation. Only one (FAN et al. 2002) evaluated the impact of a single communications infrastructure system (phones) in one single country (China).

\subsubsection{Studies based on primary data analysis \& evaluation of projects' results}

The following group of studies is the most interesting and applicable to this study's objectives. This literature compiles research based on primary data analysis, both at generalized (Group A) and project-based (Group B) levels. 
This section segregates studies according to their main dependent and independent variables. As described above, traditional empirical literature on general infrastructure and development tends to focus on logistics and energy infrastructure as independent variables and economic growth as the dependent variable. Given these studies' lower level of applicability to this study, just a few examples are given. The next section focuses on more relevant studies whose dependent variables are specifically related to traditional agricultural development variables, such as yields and agricultural market asymmetries. Nonetheless, there is a trend to analyze roads and electrification infrastructure as key independent variables. The following a group of studies utilize ICT infrastructure and utilization as the key dependent variable, but maintain traditional dependent variables for agricultural development. The final grouping refers to studies that chose new dependent variables that incorporate other aspects of sustainable development, such as deforestation.

\subsubsection{CLUSTER A: IV - traditional infrastructure (roads \& electricity) DV - general economic development indexes (GDP growth)}

A study by Canning (1998) demonstrated that while transportation infrastructure increases disproportionately relative to population, it increases proportionally to GDP per capita as the country achieves "middle-income threshold" status. Additionally, the author indicates that non-transportation infrastructure increases proportionally to population and at a more rapid pace than expected relative to GDP per capita.

Cook (2013) surveys studies in this category, with a focus on electrification and rural development. The author describes studies finding that infrastructure matters for income growth in lower-income countries (ROMP \& DE HAAN 2005 apud COOK 2013), that underinvestment in electricity and telecommunications could be help explain poor economic performance in Sub-Saharan Africa (ESFAHANI AND RAMIREZ 2003 apud COOK) and that a lack of electricity negatively impacts poorer countries' aggregate economic productivity (ESCRIBANO et al. 2010 apud COOK 2013). 


\subsubsection{CLUSTER B: IV - traditional infrastructure (roads \& electricity) DV - traditional agricultural development (productivity and market asymmetries)}

Although the literature on infrastructure and development begins in the 50s, Antle (1983) is among the inaugural studies on the effects of infrastructure on agricultural productivity using the cross-sectional data-analysis methods. He established a Cobb-Douglas production function ${ }^{3}$ model in which productivity levels were a function a series of independent variables included is his model: land, labor, livestock, fertilizers, education, research and infrastructure. Infrastructure was the key studied variable, which he defined as "GDP of transport and communication industries per square Km of land area". His datasets were based on 47 least developed and 19 developed countries. The study found a strong positive relationship between infrastructure and aggregate agricultural productivity. Critics observed that infrastructure variables used by Antle (1983) failed to capture information about the quality and extent of infrastructure coverage within the countries. Moreover, critics argued that using cross-sectional data limited inferences about causation or understanding of relationships involved (AHMED \& DONOVAN 1992), a common criticism of any similar study.

Binswanger et al. (1987) published a comparable study, but utilized a model that incorporated much more comprehensive data. The authors compiled data for 58 countries and used both cross-country analyses and in- country time-series analyses. The model also incorporated additional explanatory and variables, such as climate and extension, and price variables to explain productivity levels. Some infrastructure variables were also more detailed. Rather than using a common aggregate for all infrastructure, which Antle (1983) attempted with GDP, the authors split infrastructure into actual physical units, such as road density and irrigation use. Again, the findings showed infrastructure having a positive effect on yields: roads alone had contributed to $7 \%$ of the yield growth in the studied period (1971-1981). However, even if the study had incorporated more explanatory variables and information

\footnotetext{
${ }^{3}$ Such method originally was introduced by Cobb and Douglas in their 1929 paper entittled "The Theory of Production". Simplisticly, it defined labour and phisical capital as as the main variables to exlain production outputs. As the literature evolved, other input variables and control have been added by different research aproaches to extplain production outputs, but the rationale behind the original proposition is still maintained for regressions evaluating casuality between inputs and production outputs.
} 
about infrastructure quality, it shared Antle's (1983) flaw by ignoring distribution of infrastructure across a country's landscape.

Similarly, using cross-sectional data from 83 counties and 30 provinces in China, Felloni et al (2001) assessed the impact of electricity and transport infrastructure on the country's agricultural yield and production. They concluded that road density and electricity availability are significant predictors of production and productivity.

Assunção et al (2014) investigated the influence of electrification infrastructure on yield variation in Brazil. By using panel-data analysis and creating a "counter-factual" model for electrification-infrastructure expansion, the authors tried to mitigate the omitted factors and endogeneity problems associated with traditional OLS models. The study concluded a positive correlation appears between the expansion of electrification infrastructure and key cash crops' yield growth.

Another group of studies tested the impact of traditional agricultural infrastructure on agricultural market asymmetries.

Using spatially explicit data for sub-Saharan Africa, Dorosh et al. (2010) found that agricultural productivity is highly correlated with travel time from rural areas to urban markets. Using the same method, the authors found that adopting more productive technologies on the field is negatively correlated with travel time to urban centers. The study concludes that rural areas that within a 4-hour travel radius from a city (with more than 100,000 people) produce $45 \%$ of maximum potential production. On the other hand, areas that are more than 8 hours travel from a big consumption center produce only $5 \%$ of maximum potential production. The study, therefore, makes a strong argument for the positive influence of road infrastructure on agricultural productivity. Finally, when comparing East and West Sub-Saharan Africa, the authors conclude that the afore-mentioned effect is much more apparent in the East than in the West, because the West has more infrastructure and a relatively well-connected road network. These findings support the hypothesis that new infrastructure has a more significant impact in areas with less existing infrastructure. Additionally, such findings buttress main hypothesis driving this research: if roads reduce travel time, and shorter travel times improve agricultural productivity, it is logical to assume that other travel time-reducing factors would have the same impact. Internet and mobile connectivity increases communication and 
reduces the need to travel, thereby reducing travel times and supporting the argument that ICT would have positive effect on yields.

\subsubsection{CLUSTER C: IV - ICT infrastructure and utilization, DV - traditional agricultural development (yields and market asymmetries)}

Some empirical studies concluded that expanding ICT access in rural areas would boost agricultural development mainly through market integration and increased efficiency. Muto \& Yamano (2009) studied market participation of banana and maize farmers using panel data from 2 surveys conducted in 856 households across 94 Ugandan communities between 2003 and 2005. Mobile coverage in these communities grew from 41 to 87 in the period. Study results indicated that the number of farmers who sold bananas increased from 50 to $60 \%$ in communities more than 20 miles away from city centers. The authors did not, however, identify any influence by mobile device on maize market participation. The authors conclude that "mobile phone coverage expansion induces market participation of farmers who are located in remote areas and produce perishable crops". Studies by Abraham (2007) and Jensen (2009) produced similar results. Both analyzed the effects of mobile phone use by fisherman. Mittal et al. (2010) studied the same topic, but related to farmers in India. In all cases, evidence revealed that mobiles were used for market integration, reduced information asymmetries and, therefore, contributed to productivity enhancements. Byerlee et al (2010) presented similar conclusions. Goyal (2010) analyzed the impact of an Indian program that installed Internet kiosks in rural areas to provide price information and new marketing opportunities for farmers.

Other authors have researched ICT infrastructure effects on markets. Park \& Koo (2005) took an innovative approach to evaluating telecommunication infrastructure's impacts on agricultural trade patterns. Applying data from OECD countries between 1997 and 2001 to a gravitational model, they concluded that investments in telecommunication infrastructure had a greater influence on import than on exports. 
2.2.2.4 CLUSTER D: IV - traditional infrastructure (roads \& electricity) DV - new agricultural development variables (deforestation)

The literature on empirical cases has yielded divergent results describing infrastructure's impact on deforestation. While Pfaff (1999), Cropper et al. (1999) and Cropper et al (2001) concluded that road infrastructure increased deforestation rates in Brazil and Thailand, Assunção et al (2014) estimated that "electrification caused a small net decrease in deforestation in Brazil".

\subsection{CHALLENGES AND NEGATIVE EFFECTS}

It is clear, however, that ICT can also create negative and unintentional effects. Discussions about data privacy and ethical use of information dominate critical literature, usually from fields such as social and data sciences. The policy oriented and empirical literature on ICT impacts on agriculture contains very limited studies analyzing such undesirable outcomes, although new studies are likely in this developing field. Although these potential negative side-effects are not among this study's primary questions, this section briefly summarizes some of those challenges.

Discussion connecting so-called big data to ethical issues is plentiful. Several authors argue for the need to consider ethical issues, privacy and how algorithm use can shape social and economic conditions in several spheres of human activity (KITCHIN 2014, BOYD \& CRAWFORD 2012, CRAWFORD et al. 2014, KITCHIN 2017, SHIN \& CHOI 2015). A growing body of literature discusses the same ethical challenges from an agricultural perspective. For example, Carbonell (2016) examines how a specific large multinational currently holds unique proprietary information on a field-by-field basis accounting for roughly one-third of US farmland, putting itself in a privileged position of power asymmetry over farmers. Similarly, Bronson \& Knezevic (2016) recognizes that farming is being transformed by a digital revolution that is changing the power balance among different players in food and agricultural supply chains. They suggest that big data-focused academics should further explore the 
theory of potential material consequences, both positive and negatives, of big data in food systems.

Such discussions are important also in the policy-making arena. Even though such debate might be further away from societies in which ICT technology is not yet truly incorporated in rural areas, as is the case of most developing countries, ethics of big data in food systems is a significant issue in more technologically advanced places, such as the United States. A report by the U.S. Congressional Research Service briefly summarizes the challenges for policy makers:

"Big data may significantly affect many aspects of the agricultural industry, although the full extent and nature of its eventual impacts remain uncertain. Many observers predict that the growth of big data will bring positive benefits through enhanced production, resource efficiency, and improved adaptation to climate change. While lauded for its potentially revolutionary applications, big data is not without issues. From a policy perspective, issues related to big data involve nearly every stage of its existence, including its collection (how it is captured), management (how it is stored and managed), and use (how it is analyzed and used). It is still unclear how big data will progress within agriculture due to technical and policy challenges, such as privacy and security, for producers and policymakers. As Congress follows the issue a number of questions may arise, including a principal one - what is the federal role?" (STUBBS 2016).

Also, as discussed above, the digital divide still inhibits ICT's potential positive impacts on agriculture and rural development at a global scale. For example, some authors argue that, based on experience from the first Green Revolution, both modern technology and traditional techniques will always contribute to continuous improvement of agriculture at a global scale (ESTEVA 1996). Therefore, one would could not only use new technology, such as ICT, and would still need to rely on traditional techniques for future agricultural development.

Building on the theoretical debate about the positive and negative impacts on ICT from an ethical point of view, there are also emerging empirical questions about unintended negative spillovers. The traditional empirical literature on infrastructure and development in rural areas is extensive and dates from the 1950s. As the previously discussed, several studies created sufficient critical mass to identify negative development outcomes of infrastructure development, such as, roads increasing deforestation and registering negative consequences on nature degradation indices (PFAFF 1999, CROPPER et al. 1999 and CROPPER et al 2001). 
However, the literature studying ICT infrastructure and rural development is much newer and more limited. This does not mean, however, that one should not expect negative and unintended consequences from ICT on rural development. Among the few empirical examples, a study measured the influence of cell phone coverage on conflicts in Africa through the empowerment of collective violent action. The authors have shown that cell phone coverage significantly and substantially increases the probability of violent conflict in Africa (PIERSKALLA \& HOLLENBACH, 2013). The technology, therefore, can provide capacity for groups to better coordinate, not for good as the traditional hypothesis goes, but for violence. It is plausible that, within the scope of this thesis, negative outcomes are possible. For example, due to better Internet connectivity and mobile coverage, ill-intentioned farmers could coordinate to log illegally while alerting to possible inspections by legal authorities.

Finally, an important debate about the negative effects of ICT on the environment focuses on the equipment's footprint. In other words, environmental effects across the complete life cycle mobile phones, computers, tablets, etc. A European Commission (2004) report entitled The Future Impact of ICTS on Environmental Sustainability analyzed the footprint of ICT equipment and made policy recommendations on how to tackle negative externalities. Such issues, while extremely important, fall outside the scope of this study, which does not intend to evaluate the impact of the ICT equipment itself, but the impact of infrastructure installation and use of the technology on agriculture and rural development.

\subsection{DISCUSSION ABOUT THE LITERATURE}

The literature review revealed that the rationale and assumptions underpinning this research have been shared and tested by other authors, justifying the topic, structure, and hypotheses of the present research. In fact, the main assumption justifying this hypothesis is that ICT infrastructure and utilization can catalyze the spread of accessible information. More widespread and accessible information, therefore, would positively influence many of the agricultural development variables chosen. This assumption appears constantly and remains essentially unquestioned in the literature. 
However, it is noteworthy to mention that in some cases these assumptions yielded conclusions that support this study's hypothesis, while other cases yielded contradictory results, exemplifying the nature of academic inquiry. This research intends to shed light on that debate.

The literature on potential negative and unintended effects of ICT infrastructure and utilization on development has been briefly explored. Studies focus primarily on privacy and ethical information use, which is more often explored by social ethics and data sciences. Given the objectives of this research, these issues will not be addressed, but they remain a significant gap in the literature about infrastructure's impact on agriculture. Negative externalities beyond privacy and ethics, however, will be explored in this research; ICT's potential to accelerate deforestation, will be addressed by the results of this study.

Finally, this chapter re-emphasized the arguments stated in the Justification section, characterizing this research as innovative and original. To the extent of the author's knowledge, no study to date has evaluated the independent and dependent variables chosen by this research. Studying ICT infrastructure and utilization as primary independent variables affecting variables measuring the long-term sustainability of agricultural development is a contribution to the literature on infrastructure's impacts on rural development ${ }^{4}$.

\footnotetext{
${ }^{4}$ Regarding the model presented in Chapter 3, it is important to highlight that other studies have evaluated ICT's impacts on agricultural productivity in a similar manner to what is proposed. However, the approach and scope of this research is different. This study focus on crop yields as an indication of land-use efficiency (kg per hectare). The majority of studies have chosen agricultural value added as the indicator of yield. Also, the model presented is developed at a global scale, while the majority of others focus on specific regions. Finally, specific model and methodological choices, datasets selected and assumptions made make this research unique.
} 


\section{GLOBAL MODEL: IMPACTS OF INFORMATION AND COMMUNICATION TECHNOLOGY USE ON CROP YIELDS}

\subsection{INTRODUCTION}

This chapter intends to develop an econometrical statistical model to test the effect of ICT penetration on agricultural yields - measured as output per unit of land - and, therefore, the long-term global sustainable development of agriculture and food production.

A panel-data model was selected and built based upon its ability to capture information on ICT's impact across several countries and multiple time periods.

The panel model was developed using data from international databases, such as those hosted by the World Bank and FAO. The model is first explained, results are presented and conclusions are drawn.

\subsection{METHOD}

\subsubsection{Scope, unit of analysis and temporal selection}

The panel-data model was assembled to analyze research questions at a global scale. The unit of analysis is, therefore, countries. The chosen cross-dimensional section of this model is composed by 212 countries for which data is available. The list is available in Annex B.

With regard to temporal selection, five 5-year periods were defined: 1990-1994, 1995-1999, 2000-2004, 2005-2009 and 2010-2014. The values used for each variables are simple averages of the data available for the 5-year period in each country. This methodological choice is justified by the assumption that the majority of selected variables (such as Internet penetration) do not vary significantly from year to year. Much of the expected variation and trends can only be identified over longer periods of time. The author expected a time-lag between the cause (growth of ICT infrastructure and utilization) and the effect (yield growth). 
The relationship between cause and effect would, therefore, not be captured by an annual temporal selection.

A 5-year average temporal selection is also justified by the inherent qualities of the dependent variable in question: yields. Crops productivity can vary significantly from year to year, caused primarily by natural forces such as temperature and precipitation variations as well as pests and diseases. Such volatility is excluded from the model by using a 5-year average. Moreover, it eliminates the need to include explanatory variables that would otherwise control for volatile natural factors, such as climate conditions in a specific year and/or the occurrence of agricultural pests. Finally, regarding the last period (2010-2014), there is very little data published for the year 2014 (the majority of the databases end in 2013). However, given the methodological arguments for averaging available data, values for the last 5-year period can be used with no harm.

\subsubsection{Statistical model}

As previously mentioned, a panel-data model was chosen to test relationships among dependent and independent variables.

First, a traditional ordinary least squares (OLS) linear regression was performed, using the "pooling" method described by Croissant \& Millo (2008). Additionally, a fixed-effects model was chosen in order to control for omitted variable biases. Finally, a fixed-time effects model is also tested, controlling not only for cross-sectional fixed effects but also for time-fixed effects. Finally, a random modeling technique was also tested. Even if the testing of different modeling techniques did not solve all endogeneity-related problems, it served as a mitigation strategy, as described below.

One of the main concerns associated with an OLS model is that endogenous variables can affect both the dependent and independent variables. In other words, omitted variables could explain variations in both variables. The fixed-effects model tries to mitigate those problems. Including specific time-bound dummies to create a fixed-time effect further tackled the issue. 
The use of fixed-effects models helped mitigate omitted variable bias. However, such logic only holds under the assumption that the unobserved factors potentially affecting independent and dependent variables are time-invariant. In other words, it assumes that factors that are not captured by the model and could be impacting the dependent and independent variables at the same time do not change over time. It is a risky assumption in any modeling exercise, even though it is often used in empirical studies in economics and social sciences. One might convincingly argue that unobserved factors affecting both sides of an equation, such as institutional development or cultural priorities, can change over time.

However, this assumption is deemed plausible for the current study based on the data shown in the graphs below illustrating global cereal yield variation since the beginning of the available time series (1960s). No significant or structural modifications exist in the patters of yield growth within the period analyzed by this study. In fact, annual yield growth decreased during the study period. Therefore, it is plausible to assume that no global structural change affected yield variation over the last 20 years. It is logical to conclude that, even if omitted variables explain part of the variations in independent variables that suffered structural changes in the studied period, those omitted variables did not have major effects on the dependent variable. In other words: the time-sensitive changes in the omitted variables could affect the "right-hand side" of the model equation (independent variables) but are is unlikely to have affected the "left-hand side" of the equation (dependent variable) in the same manner. It is plausible to infer that the "identifying assumption" holds in this case and that the fixed-effects model is effectively applicable in this case. 


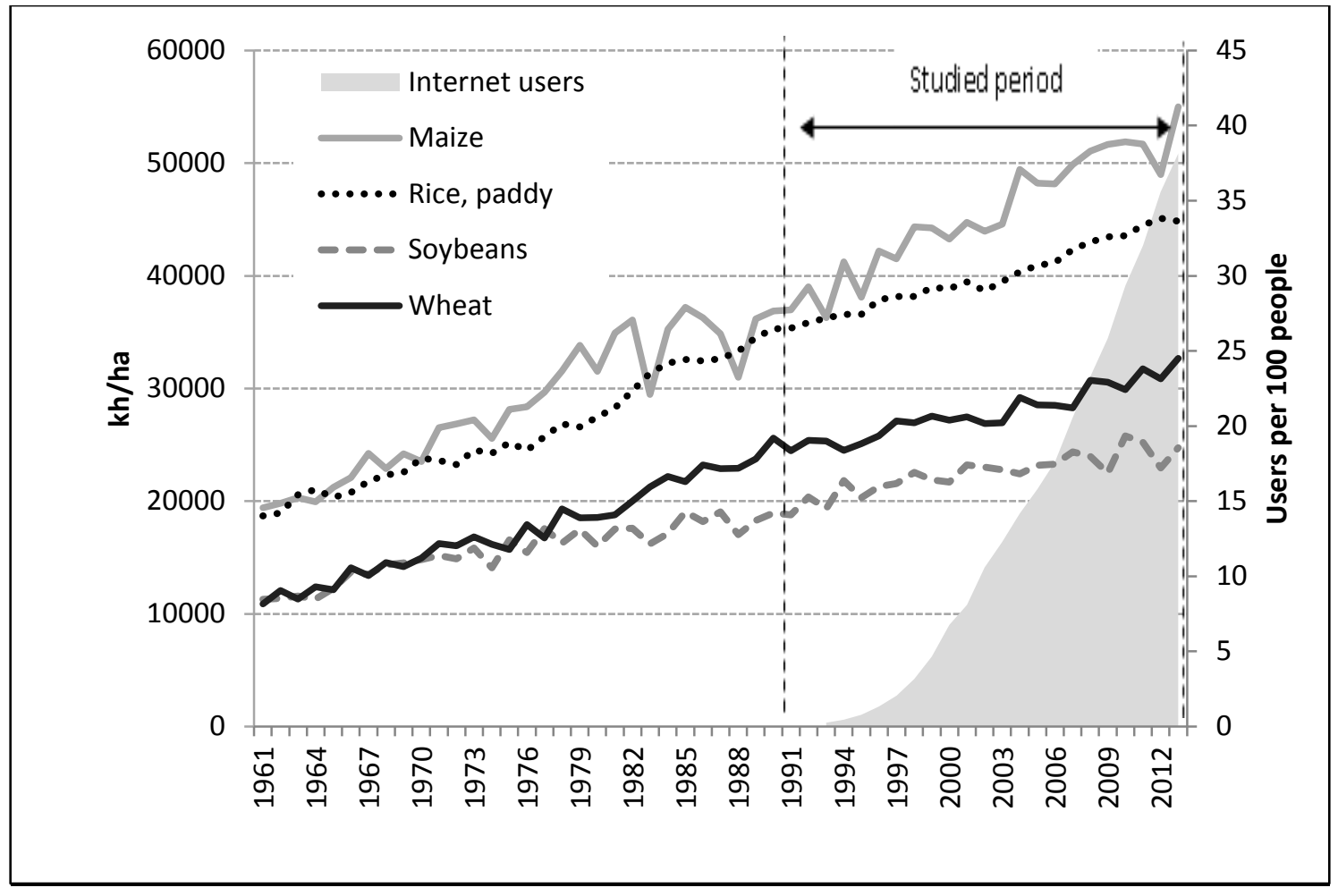

Figure 2 - Agricultural yields and Internet users

\begin{tabular}{|c|r|r|r|r|}
\hline period & Maize & Rice & Soybeans & Wheat \\
\hline $1961-1989$ & $2.4 \%$ & $2.1 \%$ & $1.7 \%$ & $2.7 \%$ \\
\hline $1990-2013$ & $1.7 \%$ & $1.1 \%$ & $1.1 \%$ & $1.1 \%$ \\
\hline
\end{tabular}

Table 1 - Annual yield growth for selected crops

Additionally, independent variables were deliberately selected to also tackle omitted variable bias, serving as potential controls. First, GDP per capita indicates not only economic development but also other non-observed factors, because it can capture structural changes in a society. In order to further test and try to measure the impact of all omitted time-variant variables on the fixed-effects model, a new control variable was created: an index representing the average yield variation in a group of countries classified based on regional and income-level factors. Omitted variables that could help explain variations in the dependent variable could be captured in this newly calculated variable, reducing the impact of potential omitted-variable bias. Finally, a dummy for region and income level was also tested. More information can be found in the Data section. Obviously, even considering the 
mitigation techniques and sensitivity analysis discussed here, conclusions should be understood with care.

Data availability further justified the modeling exercise's methodological choices. Data is not available for every single country across every time period, so the panel data is unbalanced. This research does not transform the unbalanced panel data into a balanced one by omitting dimensional data (countries) with missing values. This choice avoids bias against leastdeveloped countries and smaller economies' datasets that tend to contain more missing values. Any editing would, therefore, likely exclude those countries from the sample, creating biases. Additionally, the current modeling software accepts unbalanced panels.

The statistical software " $R$ " was used for this exercise. The package "PLM" (Linear Models for Panel Data) - developed by Croissant \& Millo (2008) - was installed in order to perform the tests. Given the preceding paragraph's discussion, it is worth noting that the authors specify that tool is adequate for modeling unbalanced panels. The commands utilized are presented in Annex A. Detailed regression results are presented in Annex B.

\subsection{DATA}

This section describes the variables chosen for the modeling exercise, indicates their source and explains their rationale.

\subsubsection{Dependent variable}

\subsubsection{Agricultural productivity}

\subsection{Cereal yield $(y / d)$}

As previously described, this study assesses the impact of ICT on agricultural development. The hypothesis is that agricultural producers can achieve better yields through greater connectivity and access to information. That hypothesis is extended to other agricultural 
supply chain. For example, commodity distributers could improve efficiency and markets could become more integrated by using ICT systems.

Many previous studies measured agricultural productivity by utilizing an index based on product value per unit of land. That approach is popular because it allows different products to be combined into a single indicator. However, that index does not specifically measure the output per hectare. Similar indicators also reflect economic and market conditions, among other off-field variables, because they incorporate prices to calculate the final agricultural value.

This study focuses on sustainable agricultural development of and is based on the hypothesis that greater access to information can help producers do "more with less" in agriculture. So, the best methodological choice was to focus on the actual agricultural output per unit of area: kg per hectare.

Additionally, wheat, rice and corn provide about two-thirds of all energy in human diets (CASSMAN 1999), making cereal yield compiled by FAO and published by the World Bank the most informative dependent variable for this model. Cereal yield is a better proxy for agricultural output per unit of land, excluding any price and market-related factors. The detailed database description reads:

\footnotetext{
"Cereal yield, measured as kilograms per hectare of harvested land, includes wheat, rice, maize, barley, oats, rye, millet, sorghum, buckwheat, and mixed grains. Production data on cereals relate to crops harvested for dry grain only. Cereal crops harvested for hay or harvested green for food, feed, or silage and those used for grazing are excluded. The FAO allocates production data to the calendar year in which the bulk of the harvest took place. Most of a crop harvested near the end of a year will be used in the following year." (WORLD BANK, database)
}

\subsubsection{Core independent variables (analytical focus)}

\subsubsection{Information and Communication Technology}

In order to evaluate the impacts of ICT on agricultural yields, the central independent variable studied was ICT utilization. As described in the literature review, many studies have discussed 
and shown that the lack of information can be a bottle neck for increased agricultural productivity. This study assessed the impact of ICT-based access to such information.

Several indicators on the subject are compiled and published at national level by international organization. An indicator representing the mobile Internet coverage (by area or by population) in all studied countries would be the ideal measurement for this variable. Unfortunately, no such indicator is available.

A private company, called Open Signal, is developing a map of geographically explicit Internet usage at a global scale. Using big data techniques, they are able to monitor the quality and use of mobile Internet services. The CEO of the company was contacted and this study's goals were presented ${ }^{5}$. It was indicated that they would be willing to share their databases for this researcher's purposes. However, discussions and deeper investigation into the data, revealed that, while their databases are impressive in some parts of the globe (eg: the US and other major urban areas), there are not as representative at a global scale. Therefore, it promises to be a very interesting data source for more locally based studies in areas in which their coverage is significant, but it did not serve the purposes of this research.

Therefore, the best-available databases to measure ICT use at a global scale in a timeframe within the scope of this study are, indeed, those published by international organizations. Every year the ITU compiles several indicators about ICT use at a national level. Many of those statistics are published by the World Bank.

\subsection{Internet users (int)}

Given the explanations above, the chosen variable to measure Internet infrastructure and utilization in the global model developed for this research was the number of Internet users per 100 habitants.

This indicator is a reliable proxy indicator for digital inclusion in a country. It is based on relative terms (users per 100 habitants), rather than absolute terms (eg: number of users),

\footnotetext{
${ }^{5}$ Contact with Brendan Gill, Open Signal's CEO, by email on January 2015
} 
indicating the level of technological penetration in the country. While the indicator is not geographically explicit, it is plausible to assume that an increase in the percentage would indicate a stable or improving situation in rural areas. In other words, it is a good proxy indicator to answer both central questions this variable intends to measure: has ICT infrastructure and utilization improved or worsened? Is this variation significant or not?

\subsection{Subscription to mobile phone lines (mob)}

Based on the same rationale, another independent variable representing ICT infrastructure and utilization was tested: the number of mobile subscriptions by 100 habitants. Even though this study focused on more innovative and promising communications technologies based on data transfer (rather than voice), this variable was still worthwhile to test. This is especially true because mobile coverage is a pre-condition for mobile data transfer. Unfortunately, database cataloging global data transfers exists. This issue was explored in more depth in the regional model (Chapter 4).

\subsubsection{Other independent variables}

As presented in the literature review, many studies modeled agricultural productivity. Independent variable selection does not vary significantly between them. A tacit consensus emerged around the most important variables. This study, therefore, drew from previously selected explanatory variables for agricultural yield, which can be synthesized as: economic development, human capital, farm-level inputs, technology use and climate. Also, as previously stated, many infrastructure studies explored irrigation and roads as potentially important variables. The current study included a final explanatory variable that is uncommon in similar studies but was found to have an effect on some models: agricultural market dynamics. The rationale for each is explained below. 


\subsubsection{Economic Development}

A country's economic development is always utilized as an independent variable in empirical, country-based modeling studies. While it is often used to quantify the effects of economic growth on the studied dependent variable, it is also a commonly utilized control for countryspecific dynamics that might affect other variables. Economic development tends to be closely correlated with other country characteristics - such as institutional development making it a valuable control variable.

\subsection{GDP per capita (gdp)}

GDP per capita was especially relevant to this study's objectives because it tends to incorporate other potentially uncontrolled variables, such as institutional development. It also mitigated the risks of the "identifying assumption" for fixed-effects models, described previously. GDP per capita was selected to satisfy these dual purposes.

\subsection{Agricultural value added per rural habitant (avr)}

In order to shift this study closer to agriculture, a new variable was added: the agricultural value added per rural habitant. The variable is a proxy measurement for the level of rural development, rather than the economy writ large, which GDP per capita captures. It was calculated by dividing the World Bank data on agricultural value added by the agricultural population.

\subsubsection{Human Capital}

\subsection{Education (edu)}

Another obvious variable in the studies about productivity is the quality of human capital. The logic is simple: the more qualified the labor force is, the better the results. 
The variable, education expenditure per capita, was calculated using two indicators published by the World Bank: GDP per capita (in 2005 US dollars) and education expenditure as a percentage of GDP.

\subsubsection{Inputs and Technology Use}

Farm-level inputs and technology use are two other important factors that define agricultural productivity. The more technology used in the field, the greater the expected outcomes. Two main independent variables were chosen for that objective: the use of fertilizers and irrigation. A more detailed description of each variable follows.

Of note, however, is that those variables contain the most availability gaps (see graph below), a limitation that is especially true for the fertilizer use.

\subsection{Irrigation (wat)}

Another factor that directly affects agricultural yields is irrigation use. As demonstrated in the literature review, some studies have already measured its importance. The World Bank publishes an index estimating the percentage of agricultural land under irrigation. That database, however, is not very extensive, omitting many countries and time periods. The data would significantly and negatively impact the quality of the results of this modeling exercise. Therefore, a proxy index for irrigation was calculated. Using three different World Bank datasets with better coverage and precision (total freshwater withdraws, percentage of water withdrawn used for agriculture and total arable land), the author was able to calculate water used per hectare of agricultural land (in $\mathrm{m} 3 / \mathrm{ha}$ ). This new indicator is a meaningful proxy to measure irrigation use and test its effect on the independent variable (yield).

\subsection{Fertilizers (fer)}

The use of modern fertilizers was one of the critical technological developments behind the Green Revolution in agriculture, which boosted yield in many parts of the globe during the 1960s. It is therefore obvious that any exercise modeling agricultural yield needs to 
incorporate fertilizer use. The World Bank publishes a database of fertilizer use per hectare, which was the index utilized to measure this independent variable. A brief description about the indicator reads:

"Fertilizer consumption measures the quantity of plant nutrients used per unit of arable land. Fertilizer products cover nitrogenous, potash, and phosphate fertilizers (including ground rock phosphate). Traditional nutrients--animal and plant manures--are not included. For the purpose of data dissemination, FAO has adopted the concept of a calendar year (January to December). Some countries compile fertilizer data on a calendar year basis, while others are on a split-year basis. Arable land includes land defined by the FAO as land under temporary crops (double-cropped areas are counted once), temporary meadows for mowing or for pasture, land under market or kitchen gardens, and land temporarily fallow. Land abandoned as a result of shifting cultivation is excluded." (WORLD BANK DATABASE)

One final issue associated with this list must be highlighted. While there is no doubt that fertilizer use plays a significant role in defining yield, the database presented is the only one available. It contains significant data availability gaps. No data is provided for any year in this study's first time period (1990-94), and the database lacks information for several countries. These factors may detract from this variable's explanatory power in this modeling exercise as it reduces data coverage for both the cross-sectional and temporal section.

\subsubsection{Agricultural Markets}

\subsection{Cereal producer price (pic)}

This study innovates relative to similar previous studies by including an uncommon independent variable: agricultural markets.

This variable adds important context to an analysis of agricultural development. When producers are offered better prices for their products, their immediate economic situation tends to improve. Therefore, farmers could invest in yield-boosting technologies and techniques when agricultural prices are higher because their returns would be greater. $\mathrm{A}$ 
positive correlation is therefore expected between agricultural prices and agricultural productivity.

The FAO Cereal Producer Price index was chosen to measure this correlation.

"The FAO Agricultural Producer Price Indices measure annual changes in the selling prices received by farmers (prices at the farm-gate or at the first point of sale). The indices are constructed using price data in Standardized Local Currency (SLC)" (FAOSTAT).

\subsubsection{Climate and pests}

Climate conditions are a key defining factor for agricultural yields in any given year. A dry period has a direct negative effect on land productivity, as does a pest infestation. However, as previously explained, the methodological decision to use average values for 5-year periods eliminates the need to include an explanatory variable that controls for volatile climate and pests occurrences.

\subsubsection{Additional controls for omitted variables}

\subsection{Index for yield variation according to region and Income Level (reg.inc)}

In additional to the traditional explanatory variables described above, an additional control variable for non-observed variables was created: an index for yield variation according to region and income. The index overlaid cereal yield data on World Bank classifications for income and regions then grouped countries. The yield average was calculated for each group and each time period. The index was then calculated, in which the average yield in 1990-94 was equal to 1 . Finally, the index was applied to all countries in the category. More information appears in Annex B. 


\subsection{Dummy for region and income level}

In addition to the index above, which described yield variation, a simple dummy for region and income level was also included following the same categories described above.

Those two strategies accomplished the same objective. Controlling for group and region anticipates the likely reality that unobserved variables had varying effects in different countries, across regions within those countries, and across different income and development levels.

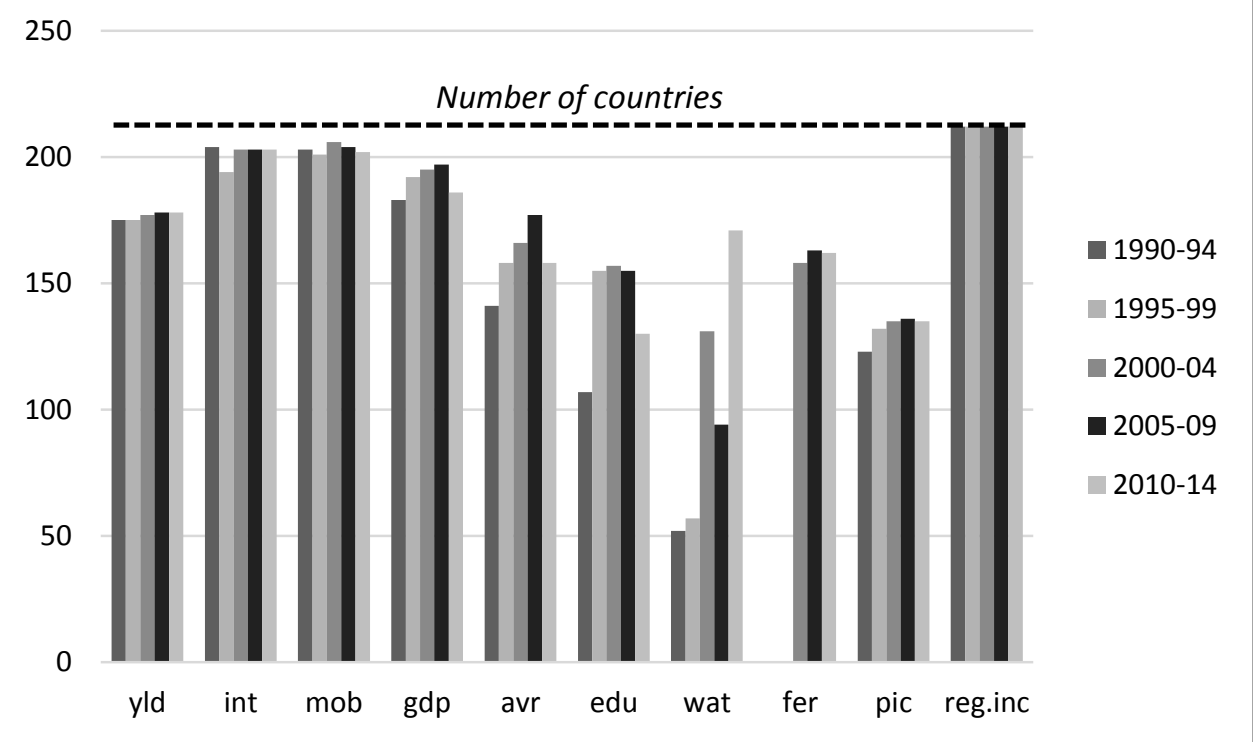

Figure 3 - Number of observations per variable per period 


\subsection{RESULTS}

Results produced by the methodology, data and models described above indicate that a growing number of Internet users would have a positive impact on a country's cereal productivity. For the case of mobile phone users, however, results are inconclusive.

\subsubsection{Presentation}

Table 2 summarizes the results of several regressions executed using different combinations of independent variables. The columns describe models used and the coefficient calculated for each of the two key variables being analyzed by the paper: Internet usage and mobile users. The rows describe the control variable utilized in each regression. The objective was to test, one by one, how control variables impacted the explanatory power of the two key variables under scrutiny (Internet and mobile users), both in relation to the value of the coefficient and, more importantly, the variable's statistical significance. The figure also serves to draw comparisons between Internet and mobile users. Finally, the last two columns show results from the complete model, incorporating all the variables and therefore This analysis revealed that, when the Internet usage and mobile user variables are tested alone (row a), their calculated coefficients are positive and significant, as defined by this paper's central hypothesis.

Then, both Internet usage and mobile users are included (rows b and c). In this case, the coefficient for mobile users loses its significance, while the coefficient for Internet usage remains at the highest level of confidence.

In fact, throughout these analyses, no matter which additional control variable is included, Internet usage consistently maintains a positive coefficient and statistical significance. In the great majority of cases, statistical significance appears at the $99 \%$ level, the exception being when educational expenditures - the proxy for human capital quality - and GDP per capita the proxy for economic development and an additional control for omitted variables - are introduced. In those cases, depending on the estimation model, the significance level drops slightly. However, it is important to note that significance is maintained above the $90 \%$ threshold level. 
The proxy variable for rural development (agricultural value added per hectare) did not always demonstrate statistical significance, nor did the proxy variable for market conditions (cereal price index). The variables for input use (fertilizer use and proxy for irrigation) were always significant at the $95 \%$ level, and maintained an equal or lower confidence level than the Internet users.

In addition to one-on-one verifications, two combined models that aggregated all variables were tested in each of estimation method. The results appear in rows $(I)$ and $(m)$ of the table. Even with simultaneous inclusion of all potential controls, the Internet usage continued to demonstrate a positive and significant coefficient. This pattern is even more apparent in the last column, in which dummy variables for region and income level were included as an additional mitigating factors to control for potential omitted-variable bias.

\subsubsection{Discussion and future research}

These results demonstrate that, no matter which estimation model was used - including traditional independent variables described in the literature and several strategies to mitigate potential endogeneity problems - Internet coefficients maintained statistical significance and positive values. The following hypothesis is, therefore, supported: a growing number of Internet users in a country would have a positive impact on that country's cereal crop productivity. These results also offer a compelling argument in favor of the general hypothesis for this thesis: the advance of communication infrastructure and utilization can improve agricultural development.

Those results are justified by a clear logical sequence. ICT infrastructure would share more information with farmers, help markets respond to on-the-ground conditions and increase efficiency gaps in agricultural supply chains by reducing information gaps from plantation to grocery store shelf.

In fact, based on the methods described and on carefully controlled regressions, the data indicate that a $1 \%$ increase in the number of Internet users could be associated with an 
increase in cereal yield of $18-33 \mathrm{~kg}$ per hectare with a $95 \%$ confidence level ${ }^{6}$. Such numbers need to be considered with care, but the mitigation strategies adopted to account for potential omitted-variable bias support the conclusion's validity.

To describe the magnitude of this conclusion (while acknowledging the limitations of the simplified calculation described), the world harvested 816 million hectares of cereals in 2014, according to the latest FAO data available. A $25 \mathrm{~kg}$ per hectare increase in productivity would create an additional 21.4 million tons of cereals per year. According to an FAO report (BRUINSMA 2003), average cereal consumption in developing countries is $156 \mathrm{~kg}$ per person per year. This means that 21.4 million additional tons of cereals would feed 131 million people, roughly equivalent to the total population across the Horn of Africa (Somalia, Ethiopia, Eritrea and Djibouti) plus South Sudan.

It is also possible to infer that economic development and human capital quality are significant explanatory variables for yield levels, a conclusion supported by previous studies' findings. Inputs such as water and fertilizers also influenced yield variation significantly, again in agreement with this study's hypothesis and expectations and previous studies' results. One particularly unique and noteworthy result, however, is that Internet usage tested as well as all any other variable -- and tested better than some -- in all regressions, models and combinations of control variables utilized. Even considering potential endogeneity issues, Internet usage is proving to be as valuable measurement for yield variation as the traditional variables used in the empirical literature.

As previously discussed, the analyzed variables with the strongest results were GDP per capita and per capita education expenditure. This connection was expected. Both are useful proxy indicators for economic development, human capital quality and, in the case of GDP per capita, physical infrastructure. Nonetheless, one interesting question arises from the fact that Internet usage tested as well as education expenditure per capita. Imagine a policy drafted to direct national government funding to initiatives that increase yields. Would investing in Internet infrastructure and utilization be more or less significant, and more or less expensive,

\footnotetext{
${ }^{6}$ For the random model with dummy variables for region and income, the confidence drops to $90 \%$ level. However, a Lagrange Multiplier Test - (Breusch-Pagan) for unbalanced panels test wheter random models were preferred. Results failed to reject the null hypothesis of the test. It is therefore possible to infer that a randomeffects model is not the most appropriate for this case, justifying why the results are presented considering only the other regressions.
} 
than investing in traditional education infrastructure? The variables used for the two issues in this research differ in form and unit, so it is impossible to draw any comparative conclusions from the coefficient numbers beyond the fact that they are both positive and statistically significant. Also, it is clear that expenditures on education support several other positive sustainable development goals. However, re-focusing on "expanding agricultural production in fewer hectares," future research could try to identify whether ICT infrastructure or education infrastructure is the most cost-effective way to develop human capacity for yield growth? This research also poses questions for rural extension services, from the traditional model of agents present on-site to a new web-based system that delivers information through ICT devices.

Finally, because the coefficients for mobile phone usage have not always tested as statistically significant due to the fact that they assumed different directions (such as negative coefficients) at time, results are inconclusive. Further research and testing is needed in order to reach more robust conclusions.

\subsection{CONCLUSION}

The results of this study support the hypothesis that the advance of information and communications technology infrastructure and utilization in rural areas improves sustainable agricultural development by helping countries increase production while reducing land area under cultivation, thereby reducing pressure for additional land resources and promoting further food security.

Technical limitations associated the methodology, data selected, and the executed model have been discussed extensively. However, due to the mitigation techniques adopted and innovative research design, the author is confident that the stated results represent a significant contribution to the fields of infrastructure installation for agricultural and sustainable development goals.

Despite the potential benefits of ICT infrastructure, it is important to recognize that: (a) yield growth could trigger other negative collateral impacts, such as indiscriminate use of fertilizers 
and other farm-level agricultural production accelerants, which could cause environmental and social problems, (b) this research does not discuss legitimate ethical challenges associated with protecting data confidentiality and avoiding greater asymmetries of market power for data owners, and (c) while food loss and waste is not within the scope of this research, addressing this critical issue would also promote food security at a global scale. Each of the three issues present promising avenues to extend the research questions posed by this study.

In an increasingly connected world, information and communication technologies are having an ever-greater impact on societies. Given the above mentioned limitations, the results of this research do not answer all relevant questions, but share new insights that may prove useful for promoting sustainable agricultural development at a global level. 


\begin{tabular}{|c|c|c|c|c|c|c|c|c|c|}
\hline & \multicolumn{8}{|c|}{ Models and core independent variables tested } \\
\hline & & \multicolumn{2}{|c|}{ OLS } & \multicolumn{2}{|c|}{ FIXED EFFECTS } & \multicolumn{2}{|c|}{ FIXED TIME EFFECTS } & \multicolumn{2}{|c|}{ RANDOM EFFECTS } \\
\hline & & Internet & Mobile & Internet & Mobile & Internet & Mobile & Internet & Mobile \\
\hline \multirow{12}{*}{ 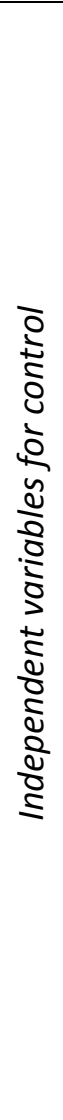 } & (a) No control & $56.351^{* * *}$ & $\begin{array}{l}22.068^{* *} \\
*\end{array}$ & $70.564 * * *$ & $\begin{array}{l}36.743^{* *} \\
*\end{array}$ & $70.475^{* * *}$ & $\begin{array}{l}36.633^{* *} \\
*\end{array}$ & $\begin{array}{l}55.887^{* *} \\
*\end{array}$ & $\begin{array}{l}21.820 * * \\
*\end{array}$ \\
\hline & (b) Internet users (int) & N.a. & -3.396 & N.a. & 9.725 & N.a. & 9.641 & N.a. & -3.662 \\
\hline & (c) Mobile users (mob) & $62.494 * * *$ & N.a. & $59.937 * * *$ & N.a. & $59.972 * * *$ & N.a. & $\begin{array}{l}62.539 * * \\
*\end{array}$ & N.a. \\
\hline & (d) GDP per capita (gdp) & $0.326 * *$ & 2.952 & $33.561 * * *$ & $14.242^{*}$ & $33.076 * *$ & 14.006 & $32.256 * *$ & 3.018 \\
\hline & (f) Agricultural value added (avr) & $57.891^{* * *}$ & -3.052 & $67.148 * * *$ & 11.082 & $67.326 * * *$ & 10.801 & $\begin{array}{l}54.759 * * \\
*\end{array}$ & -3.081 \\
\hline & (g) Education expenditure (edu) & $14.623 *$ & 4.939. & 8.194. & $4.675^{* * *}$ & 15.602. & $\begin{array}{l}15.883^{* *} \\
*\end{array}$ & $14.512^{*}$ & 4.788 \\
\hline & (h) Water use (wat) & $71.717^{* * *}$ & $-10.331^{*}$ & $77.525 * * *$ & -8.401 & $77.974 * * *$ & -8.330 & $\begin{array}{l}68.449 * * \\
*\end{array}$ & $-9.392^{*}$ \\
\hline & (i) Fertilizer use (fer) & $58.828 * * *$ & -1.162 & $62.851 * * *$ & 5.836 & $63.350 * * *$ & 5.338 & $\begin{array}{l}57.710^{* *} \\
*\end{array}$ & -1.377 \\
\hline & (j) Cereal producer price (pic) & $52.943 * * *$ & $-8.452 * *$ & $44.458 * * *$ & $8.021^{*}$ & $44.606 * * *$ & $8.030^{*}$ & $\begin{array}{l}53.283^{* *} \\
*\end{array}$ & $-8.838 * * *$ \\
\hline & $\begin{array}{l}\text { (k) Control for yield variation at } \\
\text { region and income level (reg.inc) }\end{array}$ & $68.850 * * *$ & $\begin{array}{l}- \\
17.670 * * \\
*\end{array}$ & $64.838 * * *$ & -3.173 & $64.878 * * *$ & -3.162 & $\begin{array}{l}68.915^{* *} \\
*\end{array}$ & $\begin{array}{l}- \\
17.847^{* *} \\
*\end{array}$ \\
\hline & (I) ALL CONTROL VARIABLES & \multicolumn{2}{|c|}{$r$-squared $=0.584$} & $\begin{array}{r}28.153^{* * *} \\
r \text {-squa }\end{array}$ & $\begin{array}{l}0.661 \\
0.541\end{array}$ & $\begin{array}{l}28.139 * \\
r \text {-squar }\end{array}$ & $r$-squared $=0.563$ & \multicolumn{2}{|c|}{$r$-squared $=0.563$} \\
\hline & $\begin{array}{l}\text { (m) ALL CONTROL VARIABLES + } \\
\text { DUMMY FOR REGION AND } \\
\text { INCOME }\end{array}$ & $\begin{array}{r}18.745^{*} \\
r \text {-squar }\end{array}$ & $\begin{array}{l}-4.372 \\
0.656\end{array}$ & $\begin{array}{r}33.143^{*} \\
r \text {-squal }\end{array}$ & $\begin{array}{l}-6.733 \\
0.678\end{array}$ & $\begin{array}{r}33.647^{*} \\
r \text {-squal }\end{array}$ & $\begin{array}{l}-6.798 \\
0.695\end{array}$ & $\begin{array}{r}14.240 . \\
r \text {-squa }\end{array}$ & $\begin{array}{l}-3.020 \\
=0.563\end{array}$ \\
\hline
\end{tabular}

Note a: dependent variable $=$ cereal yield $(\mathrm{kg} / \mathrm{ha} / \mathrm{yr})$

Note b: Signif. codes: $0^{(* * *)} 0.001^{* * \prime} 0.01^{\prime * \prime} 0.05 ! !^{\prime \prime} 0.1^{\prime \prime} 1$

Table 2 - Summary results of the global model: the effects of Internet and mobile phone usage on cereal productivity 


\section{SUB-NATIONAL MODEL: EFFECT OF 3G MOBILE NETWORK AVAILABILITY ON DEFORESTATION RATES OF BRAZILIAN MUNICIPALITIES IN THE LEGAL AMAZON}

\subsection{INTRODUCTION}

This chapter will assess the effect of ICT infrastructure installation on rural agricultural development from a different perspective than the previous chapter. Utilizing Brazilian municipalities as the unit of analysis, this chapter models the effects of newly installed $3 G$ mobile Internet networks on deforestation. Mobile internet network infrastructure gives farmers better access to markets and to information. Therefore, farmers and rural populations could utilize $3 \mathrm{G}$ network coverage to learn about better production techniques, understand market demands and regulatory requirements. That hypothesis extends to the added benefit that new 3G mobile ICT infrastructure in a municipality has a significant and negative effect on deforestation rates.

A quasi-experimental design was formulated to test the hypothesis with the econometric Propensity Scoring Model. Also, a difference-in-difference methodology was adopted to compare the outcomes in each municipality before and after the treatment. The model estimates impacts on the analyzed variable by matching similar municipalities - according to control variables - where new 3 G mobile Internet infrastructure was (treatment group) or was not (control group) installed. The model then compares outcomes before and after the treatment.

In this study, the treatment variable for mobile communication infrastructure installation in municipalities is $3 G$ technology availability. The dependent variable is total accumulated deforestation as a percentage of the municipality's area. The control variables used to match similar municipalities are: economic development, the importance of agricultural activity to the municipalities' economy, agricultural expansion (which increases the likelihood of deforestation), a proxy index for the range of mobile coverage, and the sub-national region's land area and population. 
This chapter introduces the subject by describing deforestation challenges and ICT infrastructure investments, with a focus on Brazil. An explanation of methodology follows, detailing the model, data and methodological choices. Results are then presented. Finally, outcomes are discussed, conclusions are presented, and suggestions for further research are shared.

\subsubsection{Agriculture and deforestation: policy and market reactions}

Agricultural production can expand vertically or horizontally. That means that production can increase by improving output per hectare or by expanding the planted area. The latter can cause exert pressure to convert forested land surrounding farms to farmland and therefore trigger deforestation (LAWSON et al 2014, SMITH et al 2007). Brazil offers a quintessential example. In the early 2000s, the country experienced in the highest deforestation rates on historical record, which in many cases was caused by horizontal agricultural expansion. Nepstad et al. (2014) effectively summarize how the process evolved over time and explain how different measures by public sector, private and civil society actors attempted to curb deforestation associated with agricultural commodities.

Many of the attempts to combat deforestation were led by governmental authorities. In 2004, the government launched the Detection of Deforestation in Real Time (DETER) system and the Plan for Protection and Control of Deforestation in the Amazon (PPCDAm) linked directly to the President's office (NEPSTAD et all 2014). In 2007, the list of Municípios Prioritários in the Amazon (Priority Municipalities in the Amazon) was created, ${ }^{7}$ which coordinated environmental protection authorities' actions. This last program slowed deforestation by an estimated 35\% relative to business as usual (ASSUNÇÃO \& ROCHA, 2014).

\footnotetext{
${ }^{7}$ Decree no. 6.321 of December $21^{\text {st }} 2007$
} 


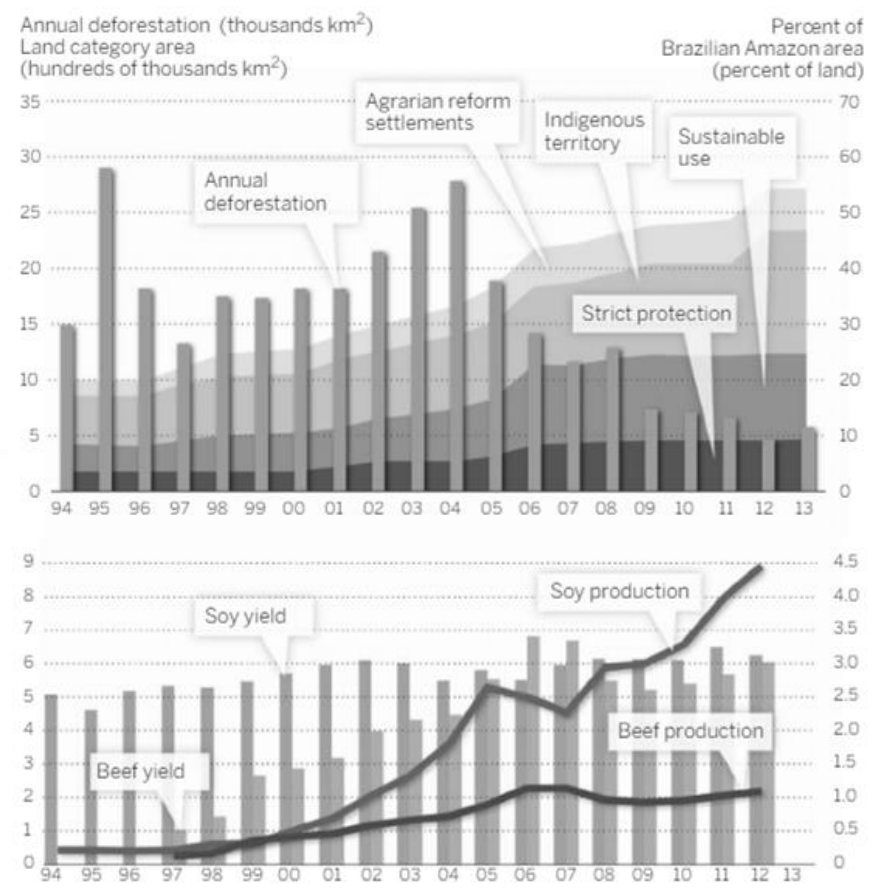

Figure 4 - Deforestation, area of land use categories, and production (beef and soy) trends in the Brazilian Amazon

Source: NEPSTAD et al. 2014

It is important to note, however, that despite these deforestation-control programs, some forest clearance is allowed by Brazilian legislation. According to the Forest Code ${ }^{8}, 20-80 \%$ of a farmer's private land must be set-aside for conservation purposes but, subject to governmental authorization, individuals do have the right to clear native vegetation. For context, $53 \%$ of Brazil's native vegetation grows on privately owned land (SOARES-FILHO et al 2014).

Non-governmental actors also played fundamental roles in this debate. International civil society organizations launched several campaigns aiming to expose links between growing agricultural commodity markets and deforestation in the region. Two Greenpeace reports ("Eating up the Amazon"9 from 2006 targeting soy supply chains and "Slaughtering the Amazon"10 from 2009 targeting beef supply chains) are the most well-known examples. The campaigns motivated many public commitments by companies and banks to work toward

\footnotetext{
${ }^{8}$ Law no. 12.651, of Mai 25th 2012.

${ }^{9}$ Available at: http://www.greenpeace.org/international/Global/international/planet-2/report/2006/7/eatingup-the-amazon.pdf. Accessed Janurary 2017.

${ }^{10}$ Available at: http://www.greenpeace.org/international/Global/international/planet-

2/binaries/2009/7/slaughtering-the-amazon-part1.pdf. Accessed Janurary 2017.
} 
eliminating deforestation from their supply chains. The Soy Moratorium - an agreement signed by the soy industry association, companies and civil society - promised to remove soy grown in deforested areas in the Amazon from mainstream agricultural markets. The Moratorium was the first voluntary zero-deforestation agreement, setting the stage for similar initiatives in other commodities, such as beef and palm (GIBBS et al 2015). Since then, several other corporate commitments emerged promising to eliminate and/or reduce deforestation from agricultural supply chains, including the UN New York Declaration on Forests ${ }^{11}$, the Deforestation Resolution by the Board of Directors of Consumers Goods Forum $(\mathrm{CGF})^{12}$ and the Soft-Commodities Compact by the Banking Environment Initiative $(\mathrm{BEI})^{13}$. Each of these initiatives and processes have, regardless of how effectively they were implemented, created market signals that dis-incentivize agricultural commodity-driven deforestation.

It is clear that these policy and market dynamics had differing levels of influence on deforestation rates in the Amazon. This research introduces a discussion about a different component of this process: the impact of access to information at the local level in rural areas, as facilitated by $3 \mathrm{G}$ mobile network installation, on the evolution deforestation-reduction processes. In other words, could access to information have accelerated the implementation of these market and policy mechanisms by communicating their existence and implications more easily to local actors?

\subsubsection{Brazilian regulation and the country's urban-rural digital divide}

The Brazilian Telecommunications Agency (ANATEL) is the country's sector regulator, responsible for auctioning new mobile phone frequencies for both voice and data transfer. Within its auctioning process, ANATEL demands compromises by the bidding companies regarding coverage for rural municipalities lacking urban areas' commercial appeal. In the last

\footnotetext{
${ }^{11}$ Available at: http://www.un.org/climatechange/summit/wp-content/uploads/sites/2/2014/07/New-YorkDeclaration-on-Forest-\%E2\%80\%93-Action-Statement-and-Action-Plan.pdf. Accessed Feburary 2017.

${ }^{12}$ Available at: http://www.theconsumergoodsforum.com/sustainability-strategic-focus/sustainabilityresolutions/deforestation-resolution. Accessed Feburary 2017.

${ }^{13}$ Available at: http://www.cisl.cam.ac.uk/business-action/sustainable-finance/banking-environmentinitiative/pdfs/the-bei-and-cgfs-soft-commodities-compact.pdf. Accessed Feburary 2017.
} 
call for bids ("editais") on frequencies for 36 technology, companies were obliged to follow an investment schedule to extend $3 G$ coverage to rural areas that would not otherwise be covered. According to ANATEL's call for bids n. 002/2007/SPV ("Edital 3G") and no002/2010/PVCP/SPV ("Edital Banda H")" such investments need to comply with the following schedule:

\begin{tabular}{|l|l|}
\hline \multicolumn{1}{|c|}{ Class of municipalities by population } & \multicolumn{1}{c|}{ Obligatory targets } \\
\hline above 100,000 people & $100 \%$ by May 2013 \\
\hline between 30,000 and 100,000 people & $70 \%$ by May 2013 \\
& $100 \%$ by June 2016 \\
\hline \multirow{2}{*}{ below 30,000 people } & $20 \%$ by May 2013 \\
& $75 \%$ by June 2016 \\
$100 \%$ by December 2019 \\
\hline
\end{tabular}

Source: ANATEL 2015a

Table 3 -Obligatory targets for the installation of $3 G$ technology according to municipality population

Subject-area experts indicated that is very plausible to assume that any investments in cities with smaller populations would not have occurred without the obligations imposed by the regulator $^{14}$. Data from ANATEL shows that 78\% of the investment in new ERBs between 2012 and 2015 were made in municipalities with more than 30,000 people. In fact, Rezende (2014) studied economic feasibility and return on investments earned by the four top mobile technology companies, using the call for bid no. 004/2012/PVCP/SPV as the parameter. Using two different methodologies in order to analyze the return on investment, the author concluded that "when traditional metrics for evaluating investments were applied [discounted cash flow], nearly all these projects were unfeasible since they presented low probabilities of achieving a positive NPV (Net Present Value)". Following the other methodology, investments were expected to yield positive results in $80 \%$ of the cases.

Finally, the call for bids n. 004/2012/PVCP/SPV ("Edital Banda Larga Rural e Urbana") also created additional obligations to expand non-3G coverage. It focuses on coverage for rural and remote areas. The companies were again obliged to follow a pre-established schedule to

\footnotetext{
${ }^{14}$ Interview with Newton Scartezini, an experienced telecommunication executive and former CEO of a mobile infrastructure company, conducted on April $6^{\text {th }}, 2015$ by phone.
} 
guarantee (non-3G) voice and data coverage in non-urban areas located up to $30 \mathrm{~km}$ from the city center of all Brazilian municipalities in accordance with the following schedule:

\begin{tabular}{|c|}
\hline Obligatory targets for non-3G voice and data coverage \\
\hline $30 \%$ of municipalities by June $30^{\text {th }} 2014$ \\
\hline $60 \%$ of municipalities by December $31^{\text {st }} 2014$ \\
\hline $100 \%$ of municipalities by December $31^{\text {st }} 2015$ \\
\hline
\end{tabular}

Table 4 - Obligatory targets for the installation of 3G technology in non-urban areas

These national-level obligations, and the assertion that investments to expand 3G technology to rural areas would not have been made without the regulatory requirement, strengthen the quality of this study's results. Investment requirements and their implications significantly limit any potential omitted-variable bias that explaining both the occurrence of the treatment (installation of $3 G$ technology) and the variation on the dependent variable (deforestation rate) at the same time. This control will be further discussed in the Method section.

However, despite the government's best efforts and indisputable development in Brazil's large urban centers, mobile coverage is still included in the country's long list of infrastructure challenges. While some cities still suffer poor cellular signals, the situation is worse in more remote and rural areas. The government's requirements in public bids did not eliminate the challenge of reaching $100 \% 3 \mathrm{G}$ network coverage in a sparsely-populated country such as Brazil.

The expansion of mobile data networks and transmission antennas were mapped on the graph below, separating municipalities with more than $30^{\prime} 000$ people from municipalities with less than 30,000 people. A sharp increase in the number of antennas in small municipalities appears clearly in two years: 2007 and 2010, the years of the "editais" that established obligatory infrastructure investments in smaller municipalities. It is worth noting that, while the number of municipalities with $3 G$ coverage is very similar across small and large cities, the majority of municipalities in the country have less than 30 '000 people. So, $3 G$ coverage in smaller cities is much lower in relative terms. In $2014,95 \%$ of municipalities with more than $30^{\prime} 000$ people were covered by $3 G$, but coverage extended to only $62 \%$ of smaller cities. Also, as expected, the number of antennas is positively correlated with the total 
population in a municipality (see graphs below). However, there is also an apparent negative correlation between the rural population percentage in a municipality and $3 G$ coverage. In other words, municipalities with larger rural populations have less coverage.

Given the above, it appears that the digital divide in Brazil is no longer characterized by socioeconomic factors - such as wealth inequality - but by geographic isolation.

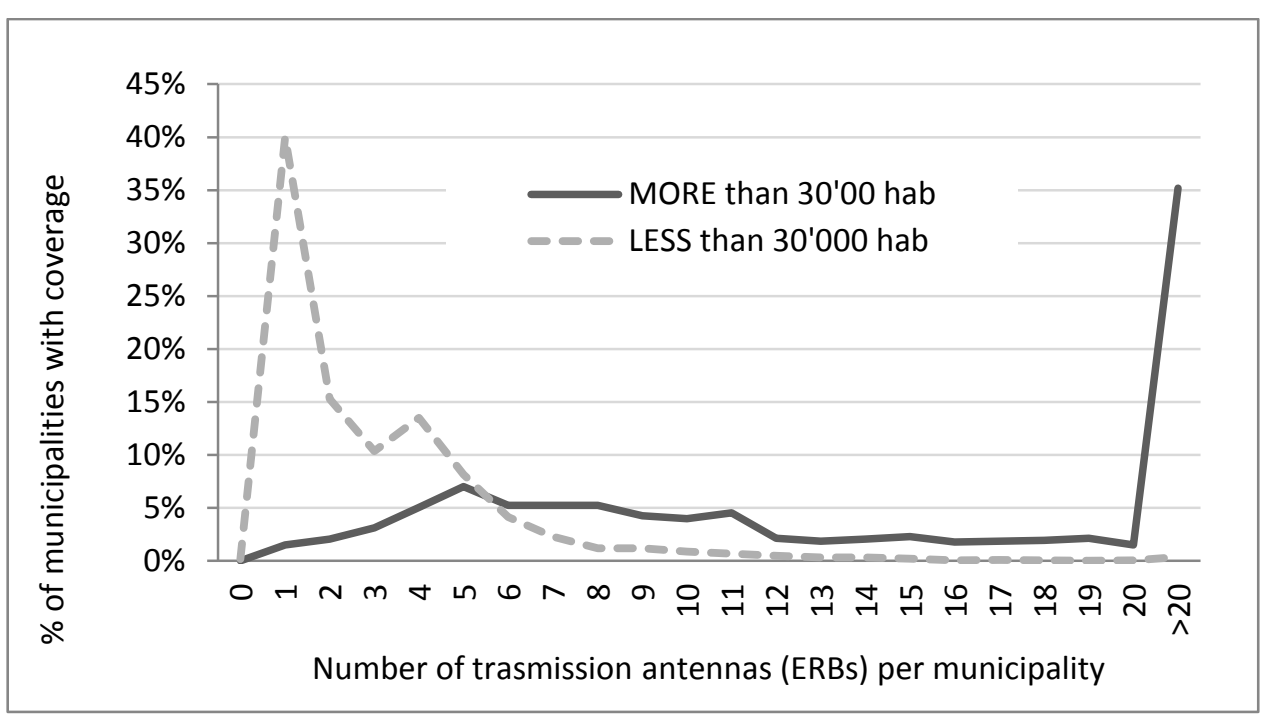

Figure 5 - Number of mobile transmission antennas according to municipalities' population (2013)

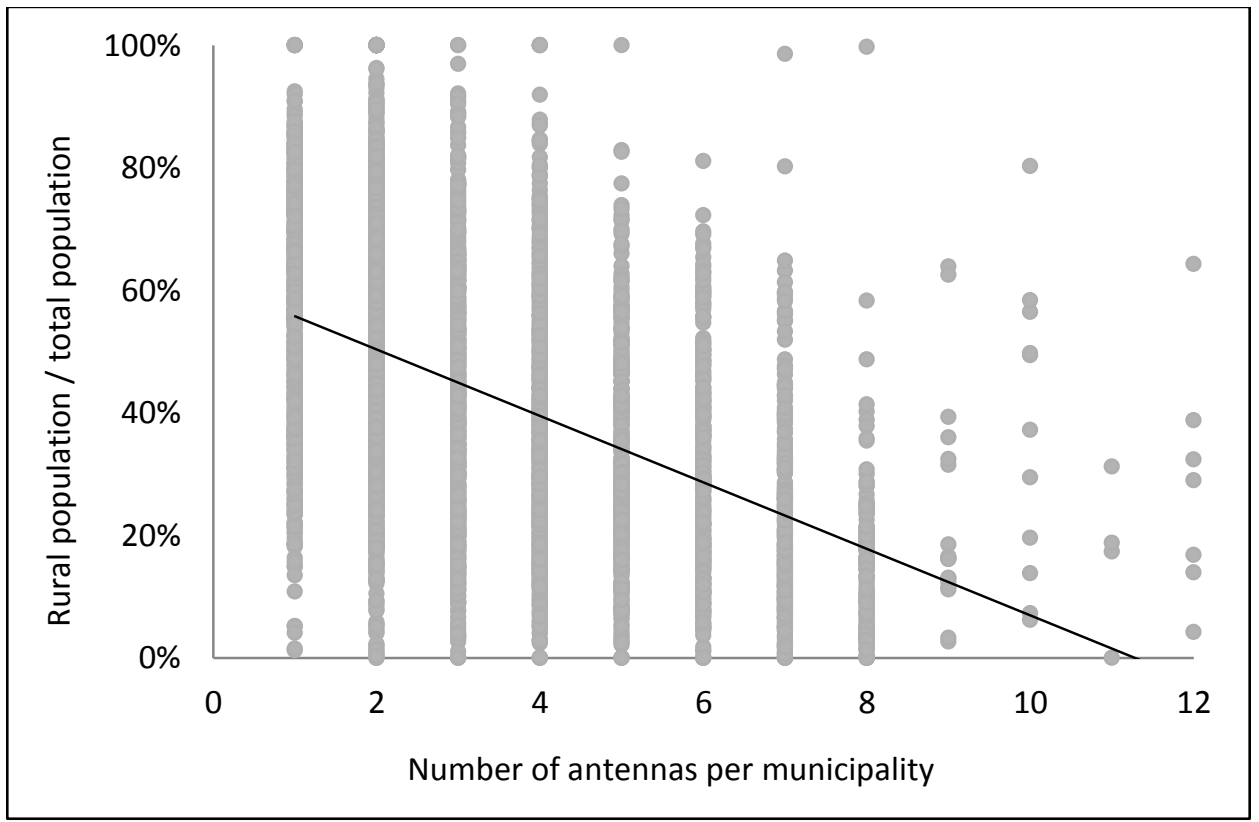

Figure 6 - Number of mobile transmission antennas vs. rural population 


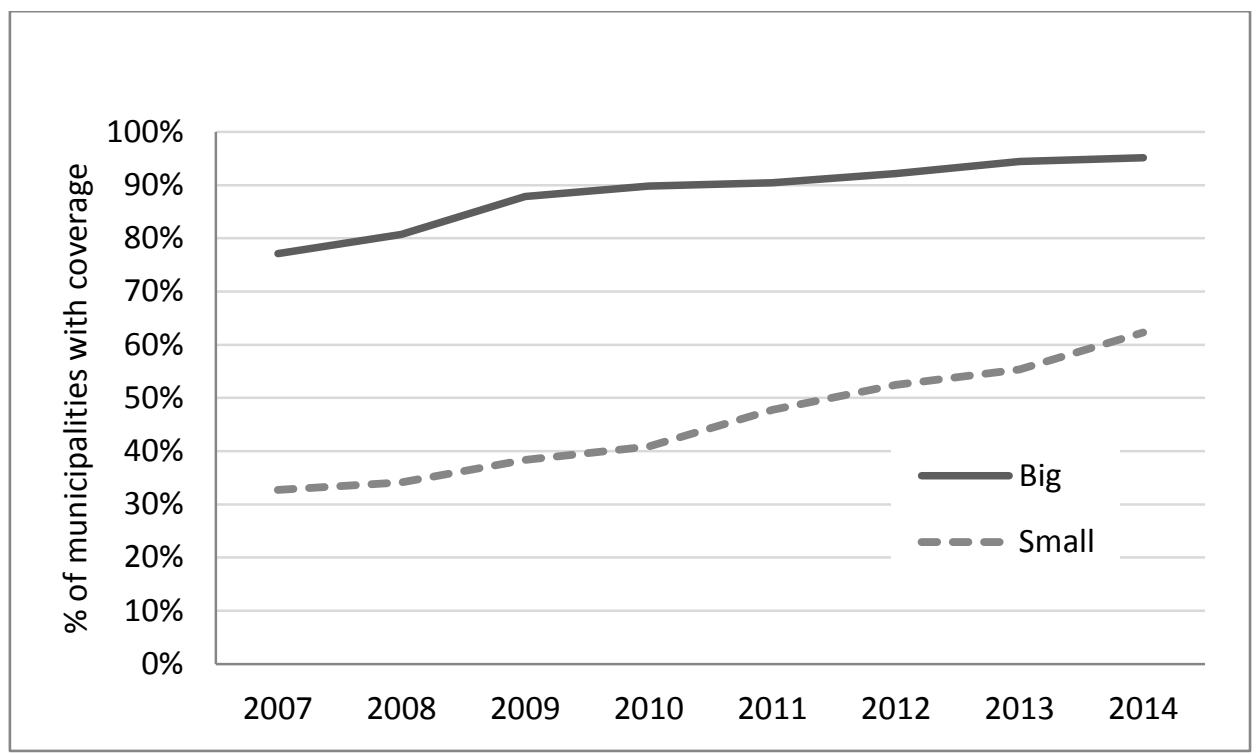

Figure 7 - Evolution of $3 G$ coverage according to population size (Big=>30,000) (Small= $<30,000)$

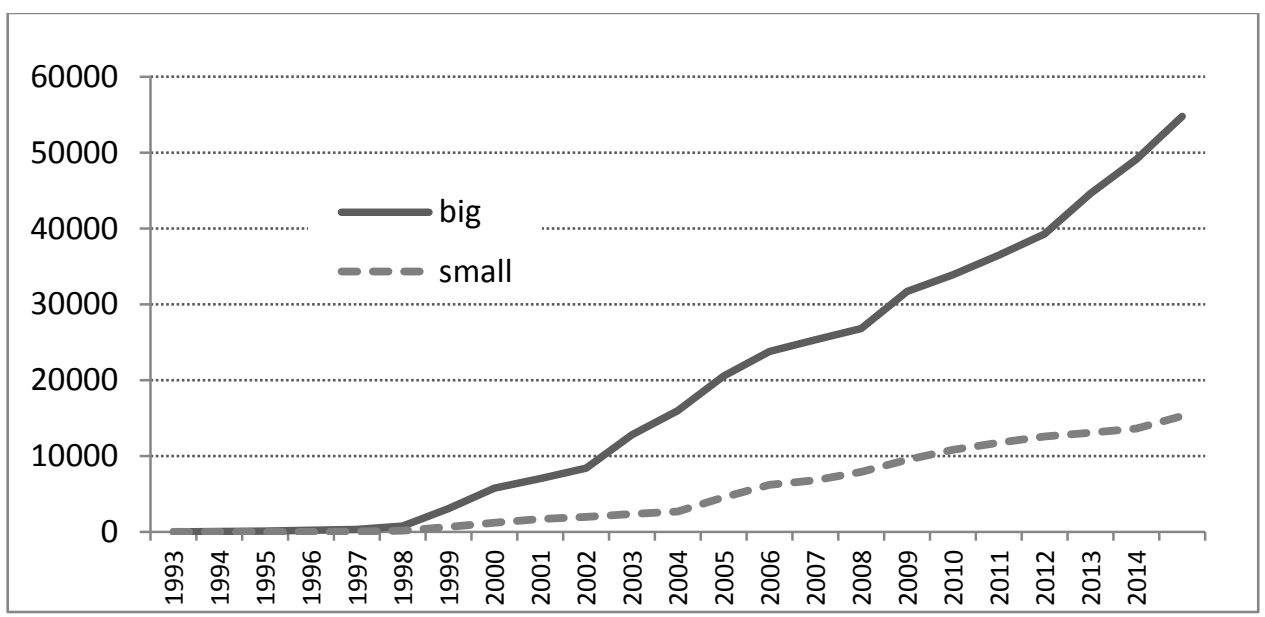

Figure 8 - Total number of mobile antennas installed in Brazil according to the category of the municipalities (Big $=>30,000)($ Small $=<30,000)$ 


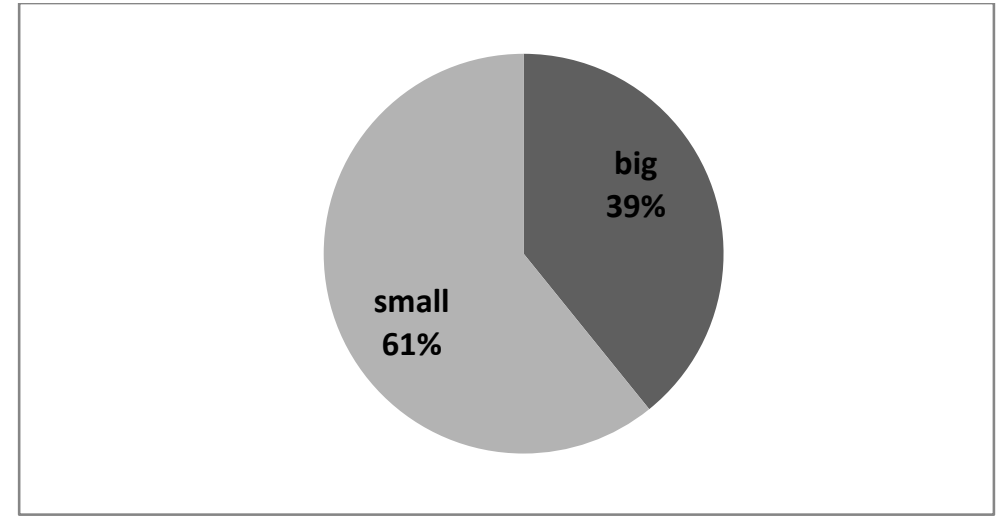

Figure 9 - Total area occupied by the municipalities

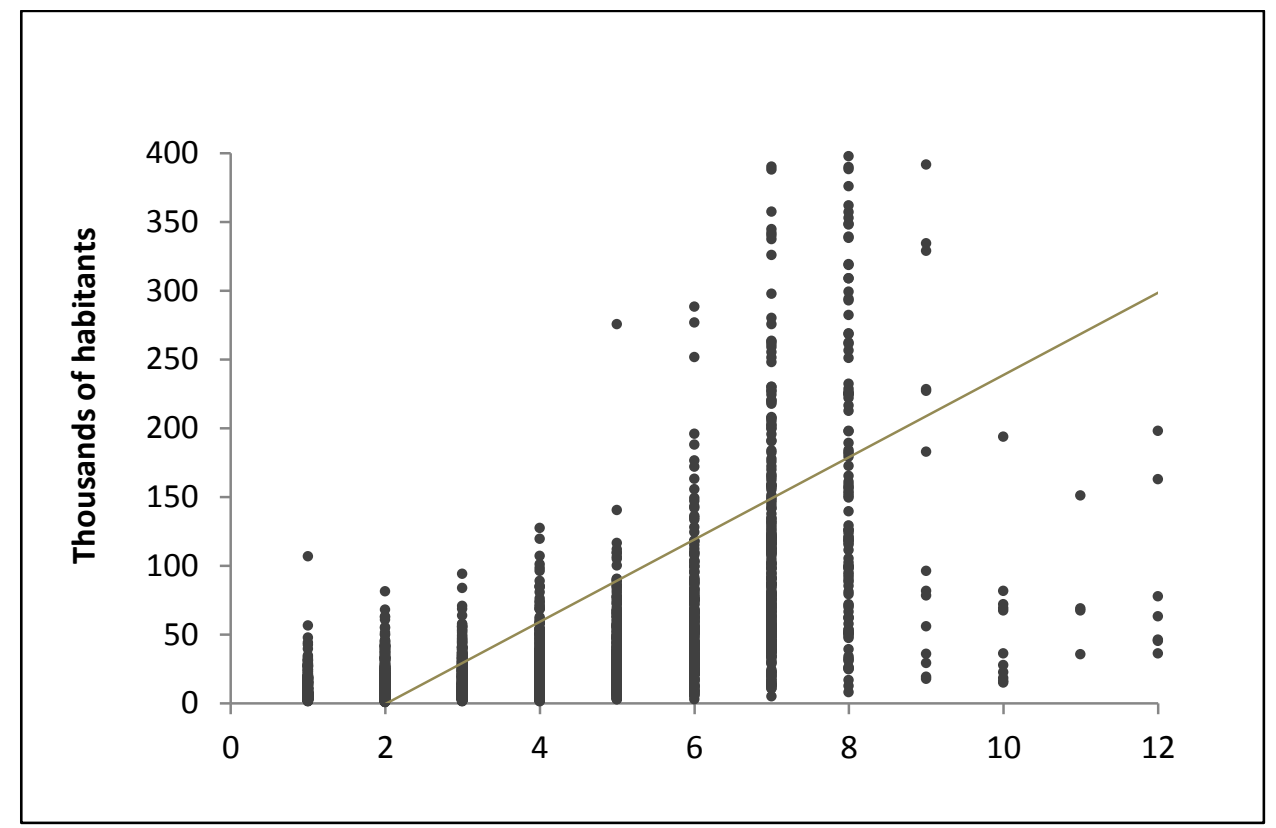

Figure 10 - Number of antennas per municipality vs total population Source: author's calculations based on ANATEL and IBGE databases.

\subsection{METHOD}

One of the main challenges when evaluating the impact of an intervention (in this case, the installation of ICT infrastructure) is to successfully establish a counterfactual. In other words, what would have happened to the actors (municipalities) if they had not participated in the 
treatment (received $3 G$ infrastructure)? Without tackling that question, no plausible inferences can be made about the impact of an action on a selected outcome, because it is impossible to clarify whether such outcomes would have happened anyway, independent of the intervention.

The first, ideal option, is to randomly select study participants and randomly apply the treatment to members of the study and then calculate the impact as the difference in average outcomes between the group that received the intervention (treatment group) and the group that did not (control). This approach, defined as Randomized Control Trials (RCTs), commonly utilized in medical experiments, is increasingly being used in policy and economic evaluations (DUFLO et al 20017). However, in many cases the RCT is not a feasible option. This is especially true for academic research that evaluates an impact post-facto, after the interventions occurred, as is the case in the present study. RCTs are also not feasible for very large and costly interventions, such as infrastructure installation planned for different objectives and dependent on the government.

Assunção et al. 2014 analyzed the impact of electricity infrastructure on yields and deforestation in Brazil. The authors utilized an instrumental variable developed by Lipcomb et al. (2013) that predicted electricity availability considering minimized construction costs based exclusively on geographical characteristics. The authors intended to correct for bias caused by the endogenous placement of electricity infrastructure by isolating supply-side factors that influenced the investments. In other words, the study isolated unobserved factors that could explain both electricity infrastructure expansion (independent variable) and yield growth and increased deforestation (dependent variables studied). Lipcomb's instrument served as the counterfactual.

In this study, however, a different approach is taken given the much shorter time period and lesser time variance. While electrification investments in rural areas have occurred since the middle of the 20th century, the penetration of mobile communication technologies started only in the first decade of the 21st century. Therefore, data points on mobile communication technologies are much more tightly clustered on the time spectrum, weakening any counterfactual based on time variance. 
The best approach to create a counterfactual for this study proved to be quasi-experimental design strategies. In this case, a Propensity Score Matching Model created two groups of municipalities: one that was subject to the studied "treatment" - in this case the installation of $3 G$ network infrastructure - and a control group that was not. The model then matched each municipality in one group to another in the control group that shared the most characteristics. Several variables that could explain the studied outcome were included in this matching exercise, creating the counterfactual. Finally, the model compared the effects of the "treatment" in the matched municipalities in both groups.

The initial work on Propensity Score Matching dates from the 1980s (ROSENBAUM \& RUBIN 1983, ROSENBAUM \& RUBIN 1985). More recently, more sophisticated computing tools and wider availability of computing power opened method to wider audiences. The Propensity Score Matching statistical package for R software developed by Sekhon (2011) was used in this exercise.

A critical issue for model implementation was the classification of similarities. For the matching exercise to successfully mitigate potential bias, is must consider a full range of variables in which the treatment and control groups might differ. One should also chose control variables that affect the probability of participation in the treatment and the outcome (HEINRICH et al. 2010). As described in the next section, the current exercise adequately addressed these issues by clearly defining the following controls: population size, level of economic development, sub-national regions, agriculture's importance for the municipality's economy, agricultural expansion, an index for mobile coverage availability and the municipality's total area.

Additionally, as discussed previously, compelling evidence suggests that 36 network infrastructure would not have been installed in more sparsely areas without Brazilian regulatory mandates, limiting the endogeneity problem in this research. It was therefore relatively easy to create groups that tackle omitted-variable and endogeneity potential bias. If specific criteria determine participation in an intervention, those criteria should be included in the controls. Legislation specifically targeted municipalities with small populations for mandatory technology installations that would otherwise not occur, so the independent variable classifying municipalities according to their population size already captured several 
potential omitted variables. In other words, because the model compared municipalities that did not receive the treatment with municipalities that did because of the regulatory requirements, the quasi-experimental characteristics of the model became even more robust.

To successfully execute this comparison, it was necessary to discard some municipalities from the model: municipalities that were "treated" before the "treatment" period and municipalities in which ICT infrastructure was installed during the time period when outcomes of the treatment were evaluated. These cities were excluded from the model because one control group was needed that did not receive any treatment during the entire analyzed time period.

An additional group of municipalities were excluded from the model that were targeted by the "Municípios Prioritário na Amazonia" (Priority Municipalities in the Amazon), a program by the Ministry of Environment to tackle deforestation in areas with higher deforestation rates. Their exclusion helped assess ICT's impact on deforestation by avoiding bias created by those municipalities, which tended to reduce their deforestation rates more than others. A preferable means for addressing this would introduce a dependent variable to match 'treatment' and 'control' municipalities that were part of the program. However, the number of municipalities in the program was very limited, so the matching exercise would have been compromised (many non-similar municipalities would have been matched). Additionally, the fact that those municipalities tend to have the highest deforestation rates would have biased the dataset and could have significantly altered the results. Therefore, as a conservative measure, these municipalities were excluded.

The treatment period for $3 \mathrm{G}$ technology installation was set to 2005-2009. The pre-treatment period was set to 2004. The post-treatment year was set to 2010. 


\subsection{DATA}

This subchapter describes the variables chosen, the datasets used and how data was treated.

\subsection{1 "Treatment" variable}

4.3.1.1 Installation of $3 G$ infrastructure - availability of $3 G$ coverage (tr.3g.05.09)

Using a database from ANATEL, it was possible to identify when 3G technology became available in each Brazilian municipality. Considering that, in some cases, $3 \mathrm{G}$ technology could have been installed in a pre-existing frequency and that 3G technology debuted in Brazil in 2004, the model assumed that any frequency identified as $3 G$ with an implementation date defined as prior to 2004 began operating in 2004.

\subsubsection{Dependent variables:}

\subsubsection{Deforestation ((def.10/area) - (def.04/area))}

Official deforestation data is available from 2000 to 2015 . The source is the INPE's PRODES program. Data availability is limited to the Legal Amazon region.

Dates to test pre- and post- treatment outcomes were selected for the years before and after the treatment period. In other words, it compares the situation in 2004 to 2010 for each municipality.

Forest-loss values are given as a percentage of the municipality`s total area. In other words, total deforested area in a given year was divided by the municipality's total area. 


\subsubsection{Variables used to define the propensity score matching}

\subsection{Population (pop)}

A municipality's population correlates with its attractiveness for ICT infrastructure investment and other factors related to increased yields, such as human resources availability and other types of infrastructure, making this indicator a useful control. The data source is IBGE (2013).

\subsection{GDP per capita (gdp)}

GDP per capita describes the economic development level of a municipality and therefore also quantifies its potential appeal for ICT infrastructure investment separate from regulatory mandates. That makes it a useful control. GDP per capita also controls for other factors related to increased yields, such as other types of infrastructure, education and local institution development (for example, the quality and availability of environmental regulators and enforcement officials). The data source is IBGE (2013).

\subsection{Region (DDD)}

Region controls for the climate and soil conditions, as well as other infrastructure that could impact outcomes, such as logistics (it is assumed that municipalities in the same region would be share similar infrastructure). Regions are also likely to share drivers for deforestation.

In order to serve as a control for the treatment, and not only for the dependent variable, the ANATEL sub-division of the territory by codes for long-distances direct calls (DDD) was used, rather than geo-political definitions of subnational regions as defined by IBGE.

\subsection{Agriculture's importance (agi.perc)}

This variable is agricultural value added as a percentage of total value added. It controlled for agriculture's importance to the local economy. This variable serves as a control for both the 
treatment and the outcome, because ag-dependent municipalities are likely to face higher pressure to clear forested land for agriculture, and are likely to lack necessary economic incentives for voluntary 3 G network installation. The data source is IBGE (2012).

\subsection{Agricultural expansion (agg)}

This variable measured how much agriculture expanded in the period. It controlled for whether an agricultural area was new or consolidated, and whether it was growing or stable. The data source is an index measuring the variation of agricultural value added for the period 2000 to 2010 from IGBE. Values are published in current Reais (R\$). Data was deflated using the Brazilian Extended National Consumer Price Index - IPCA.

\subsection{Mobile coverage (ERB.dens)}

As discussed before, one of the challenges associated with tabular analysis on geographically explicit issues is potential variation within the unit of analysis. In the previous chapter, this challenge was addressed at the country level. Here, the units of analysis are geographically smaller. But non-3G mobile coverage - which allows the widespread use of $3 G$ technology still varies within the municipalities. Therefore, an index to serve as a proxy for varying mobile coverage within a municipality's total area was developed that measures the number of ERB (antennas transmitting mobile signals) per square kilometer. The index was calculated as the total number of antennas divided by the total area of the municipality. Data sources are ANATEL for antennas and IBGE for total area.

This index was not the ideal indicator for non-3G mobile coverage, but served as a functional proxy, controlling not only for the potential adoption of 36 technology once it is installed, but also the installation itself (a company might prefer to invest in building $3 \mathrm{G}$ network coverage for municipalities with larger mobile coverage). 


\subsection{Municipality area (area)}

The total area of the municipality served as a control to make the model's final results comparable and meaningful. The dependent variable was measured in sq $\mathrm{km}$ per year, so including this variable was important to guarantee that the model compared the outcomes of municipalities with similar sizes.

Also, municipality area is a proxy indicator for the difficulty of consistent 3G coverage: the larger the area, the more likely it is that the area is not covered. The data source is IBGE.

\subsection{Priority municipalities for deforestation in the Amazon (priority.mun)}

The list of the priority municipalities for deforestation in the Amazon came from the Brazilian Ministry of Environment. This dataset was used to avoid biases by identifying municipalities to exclude because they were included in governmental programs, as described above.

\subsection{RESULTS}

Given the model's limitations, the outputs created by following the methods detailed and using the datasets described, there is some indication that installing $3 \mathrm{G}$ technology may have negatively impacted the deforestation rate. In other words, the treatment group has demonstrated lower deforestation rates than the control group for the defined period, controlling for the afore-mentioned variables.

\subsubsection{Presentation}

The total number of observations included in the model amounted to 510 once the dataset was balanced by excluding municipalities for which complete dataset for all variables was not available. The propensity score-matching software utilized did not accept unbalanced datasets. Also, as discussed, the municipalities included in the Municipios Prioritários list and 
those that received the treatment during the period used to observe the outcomes (2010) were also excluded from the sample.

Based on the total number of observations (municipalities) in the final dataset, 86 received the treatment in the study period, while 424 did not. The distribution of the average deforestation rates for the sample appears on the graph below. Although there are fewer municipalities with higher deforestation rates, the treatment is well distributed in the sample. Regardless of this distribution, it is important to highlight once again that this propensity score matching exercise was carefully implemented to guarantee that only similar municipalities ere compared.

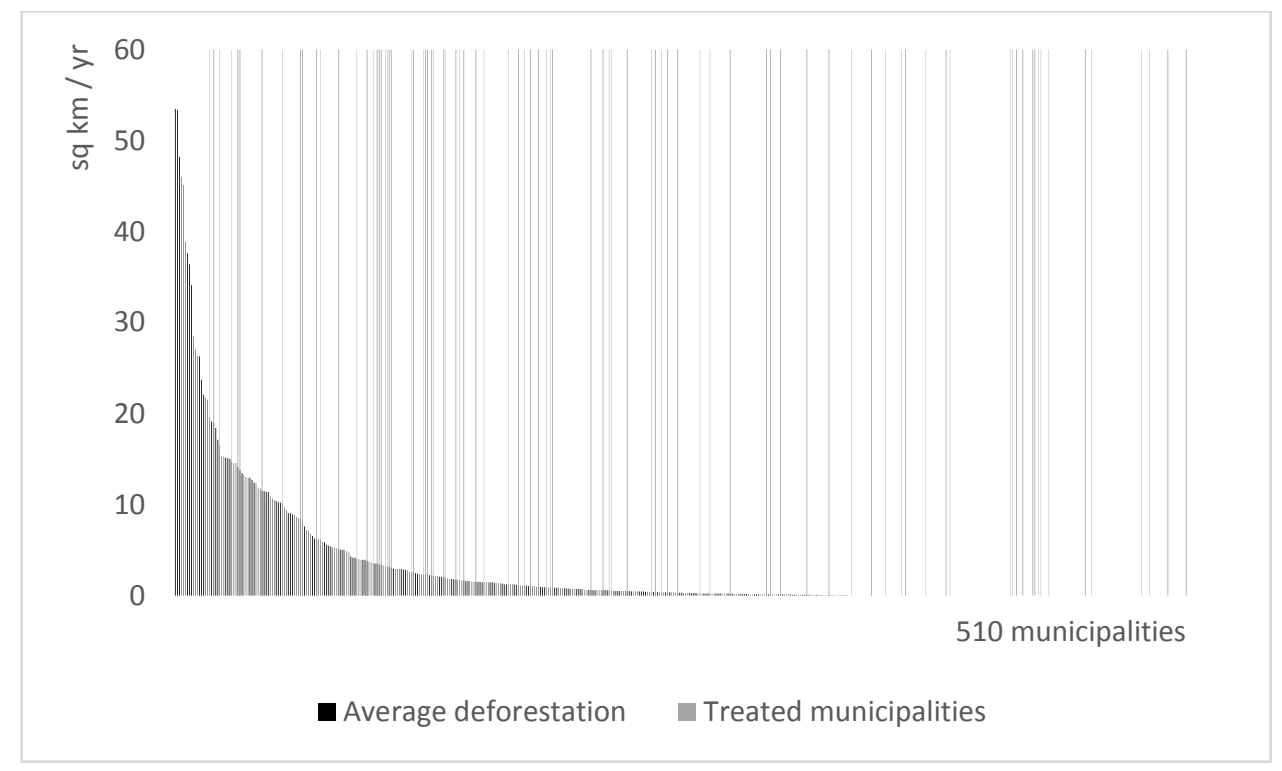

Figure 11 - Distribution of annual average deforestation rates in the sample and treated municipalities

The first step of the modeling exercise implemented a probit model. The model was not created to analyze coefficients and values, but rather to calculate the predicted probabilities to inform the matching exercise. However, it was interesting to identify which variables would be expected to exert the greatest influence on the treatment, such as the size of the population and the index for the extension of mobile coverage. In both cases the coefficients were positive and statistically significant, meaning that municipalities with bigger populations 
and better mobile coverage were more likely to receive the 36 technology, in line with expectations.

The matching exercise was then performed. As discussed, the matching exercise was designed to find the best possible matches between the control and treatment groups for comparing the outcomes. Different matching techniques were used to test the hypothesis under several modeling assumptions: Average Treatment Effect on the Control (ATC), Average Treatment Effect on the Treated (ATT) and Average Treatment Effect for all units (ATE). For each one of these estimands, the "ties" function was also changed: if one treated observation matched more than one control, the models either (a) randomly assigned one match ${ }^{15}$ or (b) matched all the observations and used the weighted result ${ }^{16}$ (SEKHON 2011). As a consequence, six regressions were run.

The matching model's results of are presented in Table 5. The estimate for the dependent variable (deforestation) was always negative, independent of the estimating model. This result indicates that treatment group municipalities had lower deforestation rates than municipalities in the control group after the matching was performed, controlling for all the variables included in the model. In the majority of cases - all models but two - the p-value was within the $90 \%$ confidence level. Even though there are two cases in which the model did not deliver statistically significant results, in aggregate, results support the hypothesis.

Beyond the overall values of the models, estimates and $p$-values, the quality of the matching exercise must be evaluated. In other words, how well compared were the municipalities? Figure 12 - Checking the matching balance proprietiesFigure 12 demonstrates the answer in visual form. The graphs plot the values for each specific match (control and treatment group), for each of the variables, for each estimand ${ }^{17}$. The treatment value is presented on the $Y$ axis and the control value is presented on the $X$ axis. The closer to the line the points are, the better the quality of the match. The lines in Figure 12 demonstrate a perfect match.

The matching exercise performance varied accordantly with the estimand choice. It worth noting that, as expected, the model with the best performance was the Average Treatment

\footnotetext{
${ }^{15}$ Ties=FALSE

${ }^{16}$ Ties=TRUE

${ }^{17}$ Only the ties=TRUE models were presented. Justified by the fact that those were the most conservative results.
} 
Effect on the Treated (ATT), which is the default recommendation by the R Matching package and the model which always tested significant at the $90 \%$ level. For almost all the control variables, the plotted values are very close to the line indicating the "perfect match". In theory, the ATT estimand with ties (using the weighted average of the matches when there is more than one) would be the most appropriate model choice. The matching exercise results demonstrate that.

Figure 13 shows in more detail how well the matching exercise performed for the ATT estimand model at an aggregate level. It shows the difference in the mean value for each variable in the treatment and control groups, before and after the treatment ${ }^{18}$. For all cases expect one, values significantly decreased. In other words, the control and treatment groups became much more similar. The area variable, apparently, experienced a worsening. It would not, however, impact the conclusions. As the results are showing the mean value, they would be biased by even a few extreme values in the sample. As illustrated on the graph, there is one municipality of exceptional size in the treatment group (Oriximiná, in the state of Pará, with a total area of $107^{\prime} 603$ squared $\mathrm{kms}$ ). As a consequence, that one point had to be matched with a municipality roughly half its size. Also, without this single municipality, the average size of the treated group would drop to 4384 squared kms, much similar to the 4813 sq km mean of the control group. Also, this municipality, in which $3 \mathrm{G}$ technology was installed, had an average deforestation rate among the highest in the treatment group ( $8.36 \mathrm{sq} \mathrm{km} / \mathrm{yr}$ ) -- much larger than the mean deforestation rate of the control group (3.16 sq km/yr). In other words, the potential bias caused by this municipality would contradict the main hypothesis of the paper. To conclude, this peculiar municipality impacted the mean values described on the graph above, but did not meaningfully affect the model's final estimation.

These results, even given the described limitations, tend to support this paper's hypothesis: the installation of $3 G$ technology could apply negative pressure on deforestation rates as farmers, local communities, law enforcement and public institutions gain access to information on regulatory requirements and market demands related to deforestation.

\footnotetext{
${ }^{18}$ The the non-numeric dummy variable for region (DDD) is not included as such annalysis is not applicable.
} 
Finally, by analyzing the estimates of the most suitable and theoretically sound regression ${ }^{19}$, it was possible to estimate how much deforestation decelerated after the treatment. Forest loss was 0.84 percentage points lower in the municipalities that received the 36 technology than in similar municipalities in the control group. That means that nearly $1 \%$ of the municipality's forested area was saved due to 3G technology implementation between 2005 and 2009. Obviously, such assertions are compelling, but given the methodology's limitations, need to be interpreted with care.

${ }^{19}$ Average Treatment Effect on the Treated (ATT), with ties=TRUE. 


\begin{tabular}{|l|c|c|c|c|c|c|}
\hline \multirow{2}{*}{ Estimand } & \multicolumn{2}{|c|}{$\begin{array}{c}\text { Average Treatment Effect on the } \\
\text { Control (ATC) }\end{array}$} & \multicolumn{2}{c|}{$\begin{array}{c}\text { Average Treatment Effect on the } \\
\text { Treated (ATT) }\end{array}$} & $\begin{array}{c}\text { Average Treatment Effect for all units } \\
\text { (ATE) }\end{array}$ \\
\hline Ties & FALSE & TRUE & FALSE & TRUE & FALSE \\
\hline Estimate & -0.0038 & -0.0037 & -0.0093 & -0.0084 & -0.0046 & -0.0045 \\
\hline p.value & 0.018 & 0.722 & 0.016 & 0.108 & 0.002 & 0.615 \\
\hline $\begin{array}{l}\text { Original number } \\
\text { of observations }\end{array}$ & 510 & 510 & 510 & 510 & 510 & 510 \\
\hline $\begin{array}{l}\text { Original number } \\
\text { of control obs }\end{array}$ & 424 & 424 & 86 & 86 & 86 \\
\hline $\begin{array}{l}\text { Matched number } \\
\text { of observations }\end{array}$ & 424 & 424 & 86 & 86 & 510 & 510 \\
\hline
\end{tabular}

Note: If ties=TRUE, "if ... one treated observation matches more than one control observation, the matched dataset will include the multiple matched control observations and the matched data will be weighted to reflect the multiple matches. The sum of the weighted observations will still equal the original number of observations" (SEKHON 2011). If ties = FALSE, ties will be randomly broken

Table 5 - Summary results of the propensity score matching model 


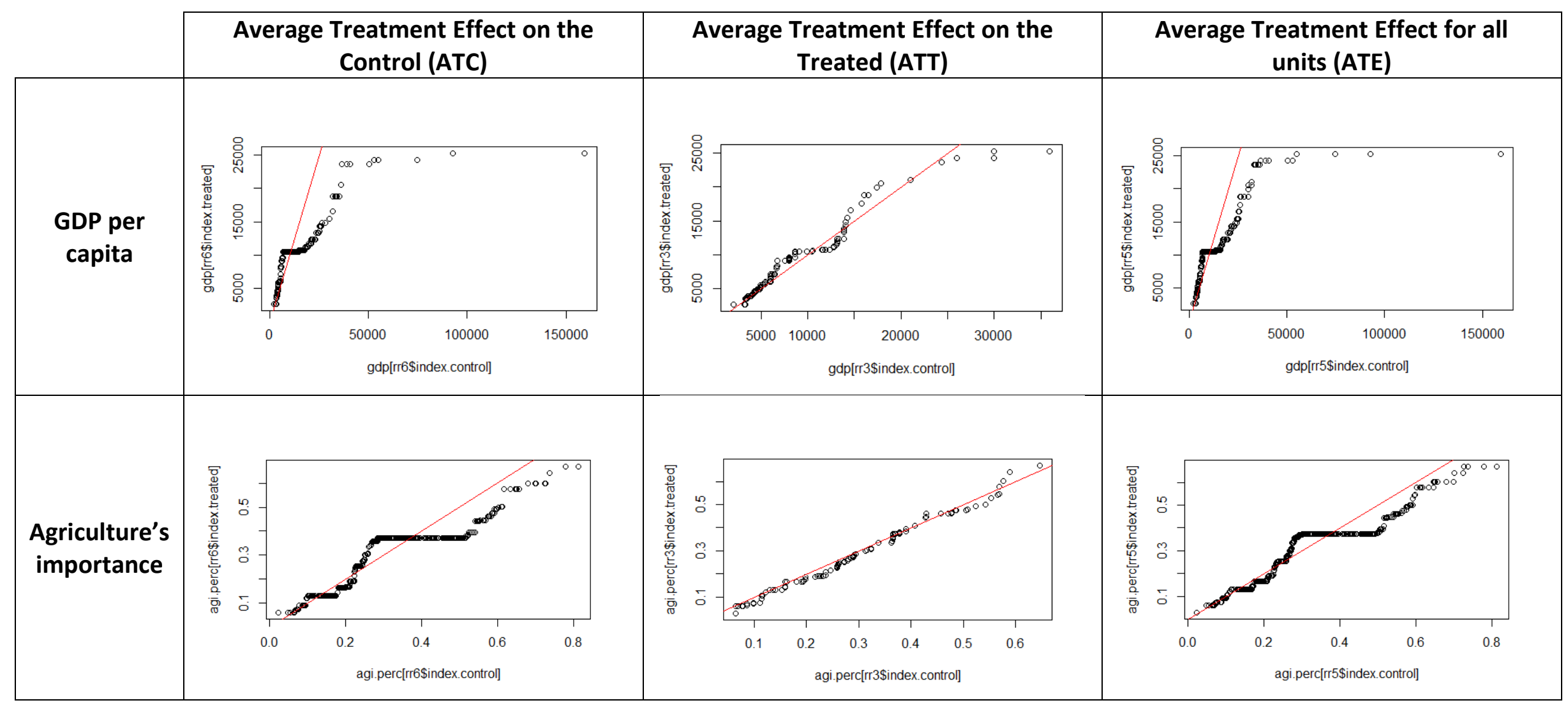




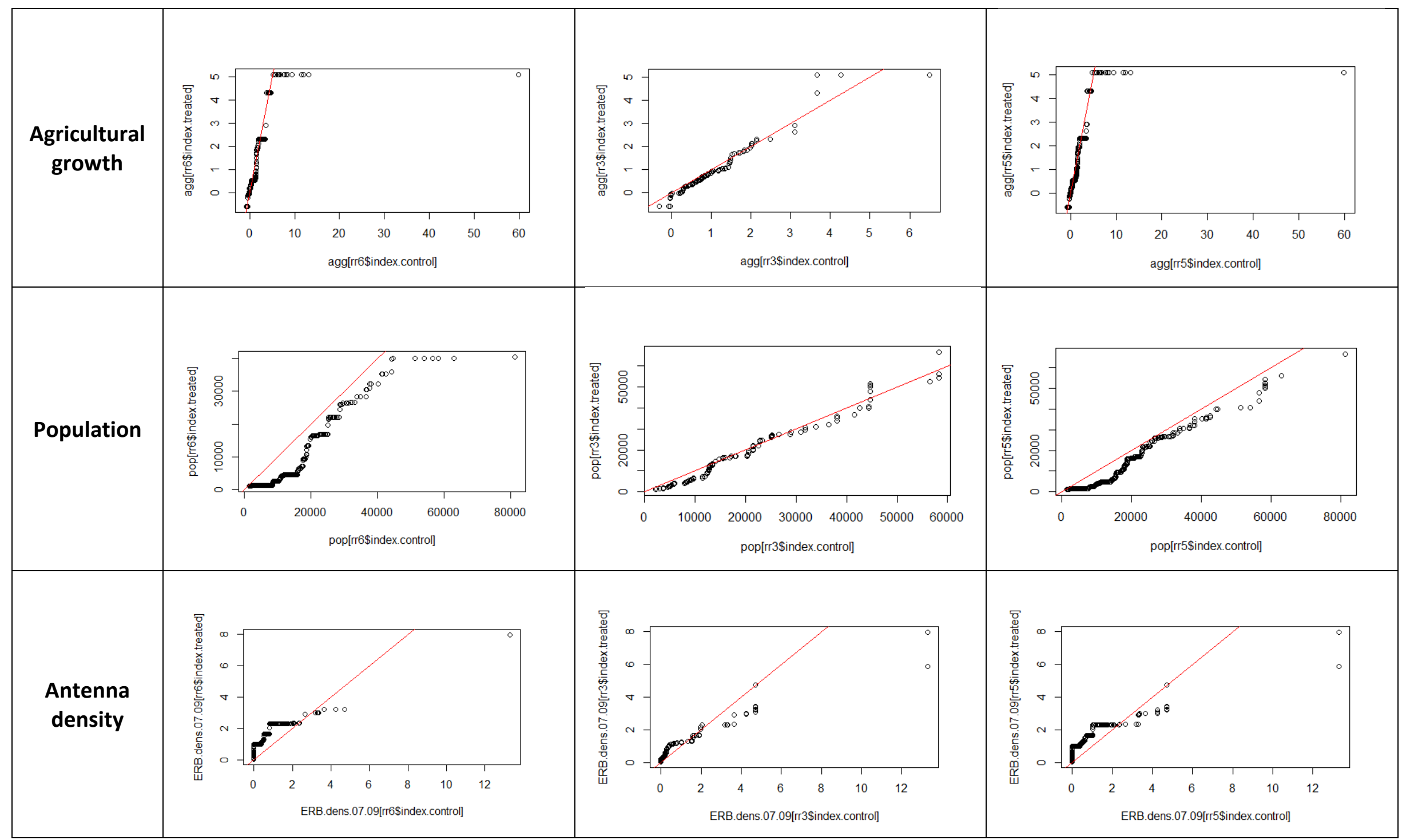




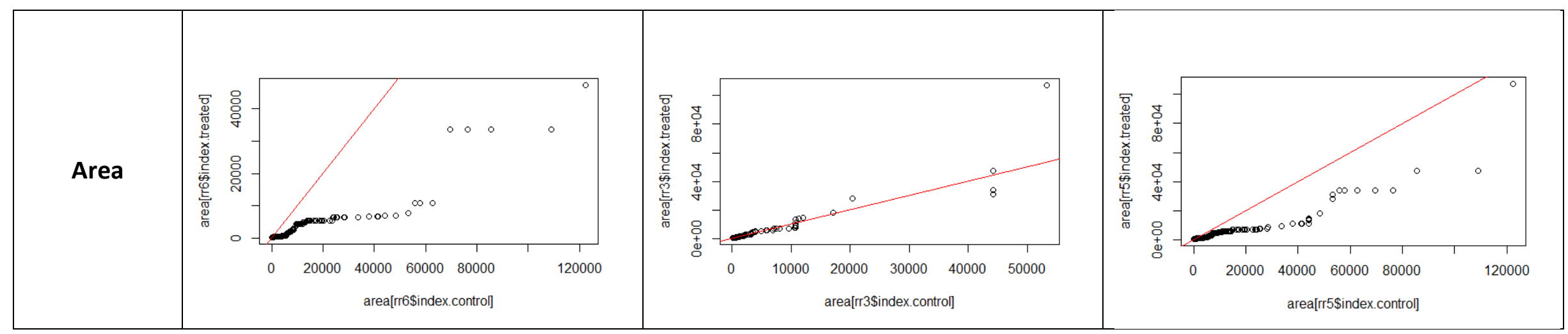

Figure 12 - Checking the matching balance proprieties

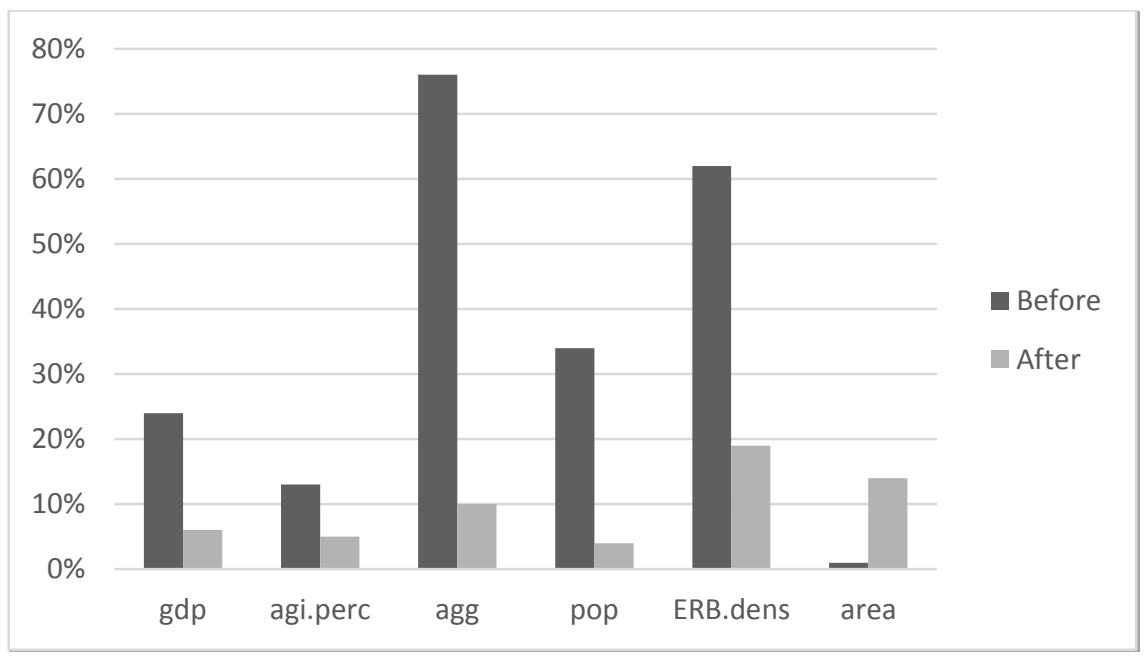

Figure 13 -. Control variables: difference in the mean value for treatment and control group, before and after matching (Model using Estimand=ATT, ties=TRUE) 


\subsubsection{Discussion and future research}

As a pioneering study analyzing mobile Internet infrastructure's influence on rural sustainable development, this thesis introduces some interesting initial insights to the debate.

The fact that all regressions using ICT infrastructure as the "treatment" consistently produced negative estimates for deforestation opens up a whole array of future research. Unfortunately, two out of the six regressions did not deliver statistically significant results. On the other side, the most promising and theoretically sound regression (using the ATC estimand with ties) performed very well.

The first opportunity emerging from these results is to further test the hypothesis and initial results by applying the same methodology to different periods and geographies. Obviously, the lack of deforestation data at the global level tends to be an issue. An initiative by the World Resources Institute (WRI) called Global Forest Watch (GFW) ${ }^{20}$ publishes a dataset on tree cover loss for the whole world. Although the data is not officially recognized by governments, unlike the INPE dataset used in this thesis, it is a powerful and interesting information source for similar exercises in other geographies.

A second emerging issue, assuming additional research supports the findings of the models presented here, is the cost-benefit evaluation interventions. Although it difficult to assume that any decision to invest in mobile Internet infrastructure would be solely based on forestconservation objectives, comparing the cost and impact of policy and investments directed exclusively to deforestation to on the cost and impact of policy and investments for communication infrastructure would be an interesting exercise.

Additionally, further research could emulate the exercise in the previous chapter to evaluate the impacts of $3 G$ technology implementation on agricultural yields and other rural development indicators. In other words, perform exercises that would test different dependent variables, such as yields, rather than deforestation.

\footnotetext{
${ }^{20}$ www.globalforestwatch.org, access on Feburary 2017.
} 
Finally, this thesis did not test the impact of ICT on legal compliance with public policies. For example, follow-up research could evaluate whether mobile Internet coverage has affected adoption of the Brazilian Environmental Rural Registry (CAR) - a virtual map of rural properties provided by farmers to national environmental regulators. Creation and official submission of these registries requires Internet connectivity. Therefore one might argue that greater mobile Internet coverage in farming regions could improve compliance with this important environmental regulation. The Brazilian Ministry of the Environment published the complete CAR database in December 2016, enabling future studies and assessments. Intriguingly, the CAR dataset is geographically explicit, allowing the unit of analysis to be even smaller. As discussed, using municipalities as unit of analysis, the unit chosen in this chapter, is a sound strategy for mitigating potential regional differences in mobile coverage. However, municipal analysis cannot account for discrepancies at the sub-municipal level. The ruralurban digital divide might still apply within a municipality, for example, if areas close to cities tend to have better coverage than far-flung regions. In this chapter, the use of the mobile coverage index (number of antennas per sq $\mathrm{km}$ ) as a control represented an effort to mitigate that problem. It was not, however, an ideal solution. With geographic explicit datasets, such as the CAR, the location of the antennas as provided by ANATEL and the deforestation data as published by both INPE and the World Resources Institute, a whole new avenue of geographically explicit econometric modelling opens up to facilitate ongoing evaluation of ICT's influence on rural development.

\subsection{CONCLUSION}

According to the model, using a quasi-experimental design, a constantly negative and mostly significant correlation between $3 G$ network installation and deforestation rates exists. Controlling for key variables and considering the most robust model ${ }^{21}$, municipalities in the treatment group (3G network installed) experienced total deforestation rates that were lower than similar municipalities in the control group by 0.84 percentage points. That means that nearly $1 \%$ of the municipality's forested area was saved due to $3 \mathrm{G}$ technology implementation

\footnotetext{
${ }^{21}$ Estimand $=$ ATT and ties=TRUE
} 
between 2005 and 2009. Obviously, such assertions are compelling, but given the methodology's limitations, need to be interpreted with care.

Three main characteristics should be evaluated in order to justify the quality of the model. The first is the choice of a comprehensive group of variables for matching that accounted for the most important issues affecting both the treatment and the outcome. The second is the actual result of the model, the direction and amplitude of the calculated coefficient, as well as the model's significance level. Even considering the potential limitations posed by the methodology, data availability and assumptions, the present research reached a high-quality standard. However, additional research on modeling impacts described utilizing new datasets, different variables and diverse estimation methodologies is needed to more thoroughly answer the question posed.

To conclude, the results tend to support the main hypothesis of this research: communication technology could be an important catalyst to delivering information to different agents involved in agricultural activities and therefore generate positive sustainability outcomes. Such an effect would likely be explained by the fact that - through higher connectivity farmers, local businesses, local authorities and other stakeholders involved in agricultural activities would be more informed about the legal and market demands related to deforestation, while also creating greater public awareness and knowledge about the importance of responsible land and natural resource management.

Further research is still needed but it appears that smartphones could be an important weapon to tackle deforestation. 


\section{CONCLUSIONS AND FINAL REMARKS}

Within the context of continuous population and economic growth, future projections for agricultural product demand are impressive. A study by the World Resources Institute indicates that the world must tackle a 70 percent "food gap" between the crop-based calories available in 2006 and expected demand in 2050 (RANGANATHAN et al 2016). That is no small task.

At the same time, agriculture already exerts significant pressure on natural resources, occupying roughly half of the planet's land (SMITH et al 2007) and driving $71 \%$ of tropical deforestation (LAWSON et al 2014). Yet, billions of people still depend on agriculture to make a living, and every habitant of this planet depends on it to survive.

As a consequence, in order to sustainably feed its population by 2050 , the world needs to be able to "produce more with less", achieving higher agricultural supplies while limiting agriculture's impacts on the environment. It will be a significant challenge.

Information and communication technology (ICT) infrastructure and utilization could be an important part of that answer. The emergence of the "big data revolution", the "Internet of things" and the "sharing economy" is changing life in urban areas (RIFKIN 2010, CASTELLS 2010, RIFKIN 2014), but it has not yet reached the rural world (BRIDGES 2001).

This thesis shed light on an emerging debate on how ICT could impact rural development. It asked whether there are empirical indications that information and communication infrastructure and utilization could impact the sustainable development of agriculture. In doing so, it posed two specific enquiries.

First, it asked if are there empirical indications that an increase in mobile and Internet users could impact productivity of agricultural commodities at a country level. If more food is produced in less area, the pressure for additional land resources is diminished. Secondly, it asked if empirical evidence exists on whether the installation of $3 G$ network coverage could impact the levels of deforestation in a given municipality. 
In line with previous findings in the literature, this thesis' assumption lies in the theory that advancing ICT infrastructure and utilization could catalyze increased access to information for farmers, agricultural supply chain actors, companies, policy makers and local communities. Greater access to information would, in turn, result in better use of economic, human and environmental assets. More specifically, given the characteristics of mobile phones and Internet usage, it is plausible to infer that investments in ICT infrastructure could also improve the capacity and quality of human capital, an important input for production, as defined in the literature. Consequently, ICT infrastructure would also be a significant variable in defining productivity, awareness about sustainability and regulatory requirements. It would help farmers and other stakeholders involved in agricultural supply chains gain access to relevant information and be more integrated into markets, generating efficiency gains in supply chains and surfacing disincentives for clearing forested land due to legal and market constraints.

Therefore, the specific hypothesis could be summarized as: higher ICT infrastructure and utilization would have positive and significant correlation with yields and negative and significant correlation with deforestation rates. By drawing from the literature about impacts of infrastructure on rural development and by using econometric modelling techniques, two models were created to test the hypothesis.

The first, developed at the global level and using data from international databanks, created a cross-sectional panel data model. It evaluated the impacts of mobile and Internet users on cereal yields in 212 countries for which data was available for five 5-year periods (1990-1994, 1995-1999, 2000-2004, 2005-2009 and 2010-2014). A Fixed Effects model was preferred but other regression models were also tested. Controls for economic development, human capital, use of farm-level inputs and other technologies, agricultural markets, region and income level were used. Based on the methodology, data and models utilized, results indicate that the growth of Internet users would have a positive impact on cereal productivity in a country (in the case of mobile users, the results are inconclusive). Results indicate that a $1 \%$ increase in the number of Internet users could be associated with an increase in cereal yield of 18-33 kg per hectare with a 95\% confidence level. Obviously, such numbers need to be interpreted with care and nuance, but the mitigation strategies adopted to account for potential omitted-variable bias support the validity of the conclusions. To describe the magnitude of this conclusion - while acknowledging the limitations of the simplified 
calculation described (more details in Chapter 3 ) - the additional grain produced would feed 131 million people, roughly equivalent to the total population across the Horn of Africa (Somalia, Ethiopia, Eritrea and Djibouti) plus South Sudan.

Additionally, because Internet usage tested as well as any of the other variables, it is possible to infer that, even with potential endogeneity issues, Internet usage explains yield growth as substantially as traditional variables used in the empirical literature. A compelling question for future research arises from the fact that as Internet usage tested as well as the variable chosen for human capital (education expenditure per capita) to explain yield variation. Based on such a finding, would the traditional model of rural extension agents present on-site perform better or worse than a hypothetical new web-based system created to deliver information through ICT devices? Finally, it is important to recognize that other hypothetical challenges related to ICT's potential impact on yields that were not assessed in this research. Indiscriminate use of farm-level agricultural inputs, for example, such as agro-chemicals could cause environmental and health problems if irresponsibly used. This study also introduced, but did not evaluate deeply, a discussion on ethical challenges associated with protecting data confidentiality and avoiding greater asymmetries of market power for data owners as a result of higher ICT use.

The second model was developed at a sub-national level - the municipalities located in the Brazilian Legal Amazon region - using the implementation of 3G technology as the key explanatory variable and the rate of deforestation as the dependent variable. One of the main challenges when evaluating the impact of an intervention (in this case, the installation of ICT infrastructure) is to successfully establish a counterfactual. In other words, what would have happened to the actors (municipalities) if they had not participated in the treatment (received $3 G$ infrastructure)? This study's strategy to establish a counterfactual relied on a quasiexperimental design. More specifically, a Propensity Score Matching Model was used. In a nutshell, this econometric method created two groups of individuals (municipalities): one that was subject to the studied "treatment" - in this case the implementation of $3 \mathrm{G}$ infrastructure - and a control group that was not. The model then matched each municipality in the treatment group to the municipality in the control group to which it was most similar. Several variables that could explain the outcome were accounted for in the matching exercise, creating a hypothetical counterfactual. Finally, the model compared the effects before and 
after the "treatment" - which further characterized the model as Difference-in-Difference for the matched municipalities in both groups. The variables utilized for the matching exercise were: population, GDP per capita, sub-national region, agriculture's importance at municipal economy, agricultural expansion in the municipality, mobile coverage and the municipalities' areas. The model results indicated that $3 \mathrm{G}$ technology installation had a negative and, in most cases, significant correlations with deforestation rates before and after the treatment. In other words, controlling for the afore-mentioned variables, the treatment group showed demonstrably lower deforestation rates than the control group for the defined period. By analyzing the results of the most suitable and theoretically sound regression ${ }^{22}$, it was possible to estimate how much deforestation decelerated after the treatment. Forest loss was 0.84 percentage points lower in the municipalities that received the $3 \mathrm{G}$ technology than in similar municipalities in the control group. That means that nearly $1 \%$ of the municipality's forested area was saved due to $3 G$ technology implementation between 2005 and 2009. Obviously, such assertions are potentially powerful, but given the limitations of the methodology, such values need to be interpreted with caveats and thorough explanations. The fact that some estimation methods did not yield statistically significant results also calls for caution. Still, the results tend to more strongly support, rather than refute, the hypothesis that $3 \mathrm{G}$ technology installation could have a negative impact on deforestation rates as farmers, local communities, law enforcement and public institutions are able to access more and better information on regulatory requirements and market demands related to deforestation.

To conclude, this thesis generated innovative and original research by introducing ICT infrastructure and utilization (especially Internet and mobile coverage) as the core independent variables. It also innovated on the choice of dependent variables. The small literature on ICT impacts on agriculture has traditionally focused on economic growth or social inequality. The present research introduced new dependent variables with a focus on the long-term sustainability of global agricultural production: (a) agricultural productivity and (b) deforestation rates. The results of the models developed tend to indicate that the infrastructure and utilization of Internet-related ICT does positively impact indicators of sustainable rural development and, therefore, positively contribute to the long-term sustainability of agricultural production. Further research is needed in order to re-test some

\footnotetext{
${ }^{22}$ Average Treatment Effect on the Treated (ATT), with ties=TRUE.
} 
of the assumptions and hypothesis of this thesis by: incorporating additional geographies (eg: subnational models in other countries), adopting different empirical modeling strategies, testing different ICT variables, and testing ICT's effect on different dependent variables such as, for example, compliance with regulations and access to financial services.

In an increasingly interconnected world, communication technologies are having a profound effect on all levels of our societies. These technologies may well be a critical missing piece in the urgent global mission to produce more food with fewer inputs and reverse deforestation. Smartphones, it appears, could be important assets for sustainable agricultural development at a global level. 


\section{REFERENCES}

\subsection{BIBLIOGRAPHY}

ABRAHAM, R. (2007). Mobile Phones and Economic Development: Evidence from the Fishing Industry in India. Information Technology and International Development. MIT Press, Volume 4, Number 1, Fall 2007, Pp 5-17.

AHMED, R. \& DONOVAN, C. (1992) Issues of Infrastructural Development: a synthesis of the literature. International Food Policy Research Institute. Washington DC, November 1992.

ALEKE, B.; OJIAKO, U. \& Wainwright, D.W. (2011). ICT adoption in developing countries: perspectives from small-scale agribusinesses, Journal of Enterprise Information Management, Vol. 24, Iss 1, pp. 68 - 84

ALI, A; MUSHTAQ, K; ASHFAQ, M; ABEDULLAH \& DAWSON, PJ. (to be published). Macro Determinants of Total Factor Productivity Growth of Agriculture in Pakistan. University of Agriculture Faisalabad.

ANATEL (2015a). Resumo obrigações de atendimento com SMP. Report available at http://www.anatel.gov.br/Portal/documentos/sala imprensa/2-7-2012--10h39min37s-

Regras Atendimento SMP DISTRITOS \%C3\%81rea\%20Rural com\%204G.pdf , access on April $6^{\text {th }}, 2015$.

ANTLE, J.M. (1983). Infrastructure and Aggregate Agricultural Productivity: International Evidence. Economic Development and Cultural Change,Vol. 31, No. 3, pp. 609-619. The University of Chicago Press. Apr., 1983.

ASSUNÇÃO, J.; LIPSCOMB, M.; MOBARAK, A. \& SZERMAN, D. (2014). Electrification, Agricultural Productivity and Deforestation in Brazil. In mimeo. July 2014.

ASSUNÇÃO, J. \& ROCHA, R. (2014). Getting Greener by Going Black: The Priority Municipalities in Brazil. Climate Policy Initiative report. August 2014. 
BINSWANGER, H.; YANG, C.; BOWERS, A. \& MUNDLAK, Y. (1987). On the determinants of cross-country aggregate agricultural supply. Journal of Econometrics 36 (1): 111-113.

BONGIOVANNI, R. and LOWENBERG-DEBOER, J. (2004). Precision Agriculture and Sustainability. Precision Agriculture. August 2004, Volume 5, Issue 4, pp 359-387.

BRIDGES (2001). Spanning The Digital Divide. Understanding And Tackling The Issues. Washington, DC: Bridges.org. Executive summary retrieved at http://unpan1.un.org/intradoc/groups/public/documents/apcity/unpan002531.pdf in April 11th 2015.

BRONSON, K. \& KNEZEVIC, I (2016). Big Data in food and agriculture. Big Data \& Society January-June 2016: 1-5.

BRUINSMA, J. (ed). (2003). World Agriculture : Towards 2015/2030: an FAO Perspective. Earthscan Publications Ltd. London, 2003.

BORLAUG, N. (1976). The Green Revolution: can we make it meet expectations? Proceedings of The American Phytopathological Society, Vol. 3, 1976.

BULL, J.K; DAVIS, A.W., SKROCH, P.W. (2011). How Smart-IT Systems Are Revolutionizing Agriculture. The Bridge. Vol41, no3, Fall 2011. Washington DC: National Academy of Engineering, 2011.

BYERLEE, D., DE JANVRY, A. SADOULET, E. (2010). Agriculture for development - revisited. Paper Presented at the Conference Agriculture for Development - Revisited. University of California at Berkeley, October1-2 2010. apud DETHIER, J.J. \& EFFENBERGER, A. (2012). Agriculture and development: A brief review of the literature. Economic Systems, 2012.

CANNING, D. (1998). A database of world infrastructure stocks, 1950-1995. World Bank, 1998.

CARBONELL, I. (2016). The ethics of big data in big agriculture. Internet Policy Review, 5(1)

CASSMAN, K.G. (1999). Ecological Intensification of Cereal Production Systems: Yield Potential, Soil Quality, and Precision Agriculture. Proceedings of the National Academy of Sciences of the United States of America, Vol. 96, No. 11 (May 25, 1999), pp. 5952-5959 
CASTELLS, M. (2010). “The Rise of the Network Society”. Wiley Blackwell, 2010.

CHAPMAN, R. \& SLAYMAKER, T. (2002) ICTs and Rural Development: review of the literature, current interventions and opportunities for action. Overseas Development Institute, Working Paper 192. London, November 2002.

COOK (2013) Electrification and Rural Development in BHATTACHARYYA, S. (ed.) Rural Electrification Through Decentralized Off-grid Systems in Developing Countries. Green Energy and Technology. Springer-Verlag London 2013.

CRAWFORD, K. MILTNER, K. \& GRAY, M.L. (2014). Critiquing Big Data: Politics, ethics, epistemology. International Journal of Communication 8: 1663-1672.

CROISSANT, Y. \& MILLO, G. (2008). Panel Data Econometrics in R: The plm Package. Journal of Statistical Software 27(2). URL http://www.jstatsoft.org/v27/i02/

CROPPER, M.; GRIFFITHS, C \& JYOTSNA (2001). Predicting spatial patterns on deforestation: the role of roads and protected areas in north Thailand. Land Economics. May 2001.

CROPPER, M.; GRIFFITHS, C. \& MANI, M. (1999). Roads, population pressures and deforestation in Thailand, 1976-1989. Land Economics, 75 (1):58-73.

DETHIER, J.J. \& EFFENBERGER, A. (2012). Agriculture and development: A brief review of the literature. Economic Systems, 2012.

DIAO, X., HAZELL, P. \& RESNICK, D. \& THURLOW, J. (2006). The Role of Agriculture in Development: Implications for Sub-Saharan Africa. International Food Policy Research Institute Research Report 153. Washington, 2006.

DIXIE, G. \& JAYARAMAN N. (2011). Strengthening Agricultural Marketing with ICT. in ICT in Agriculture e-Sourcebook. World Bank. Washington, DC. http://www.ictinagriculture.org/ictinag/sourcebook/module-9-strengthening-agriculturalmarketing

DOROSH, P., WANG, H., YOU, L. and SCHMIDT, E. (2010). Crop Production and Road Connectivity in Sub-Saharan Africa A Spatial Analysis. World Bank Policy Research Working Paper 5385. July 2010. Available at: $\underline{\text { http://www- }}$ 
wds.worldbank.org/servlet/WDSContentServer/WDSP/IB/2010/07/28/000158349 2010072 8133128/Rendered/PDF/WPS5835.pdf

DUFLO, E., GLENNESTER, R., \& KREMER, M. (2007). Using Randomization In Development Economics Research: A Toolkit. Centre for Economic Policy Research. Discussion Paper No. 6059. London, January 2007. Available at: http://economics.mit.edu/files/806

ESTEVA, G (1996). Hosting the otherness of the other: The case of the Green Revolution. In: APFEL-MARGLIN F, MARGLIN SA (eds) “Decolonizing Knowledge: From Development to Dialogue". Clarendon: Oxford University Press, pp. 249-278

EUROPEAN COMMISSION (2004). The Future Impact of ICTs on Environmental Sustainability. European Commission Joint research center \& Institute for Prospective Technological studies technical report series. Technical Report EUR 21384 EN. Brussels, 2004.

FAN, S. \& CHAN-KANG, C. (2005). Road development, economic growth and poverty reduction in China. International Food Policy Research Institute, Research paper 138. Washington DC, 2005.

FAN, S.; ZHANG, L. \& ZHANG, X. (2002). Growth, inequality and poverty in rural China: the role of public investments. International Food Policy Research Institute Research Report 125. IFPRI, Washington, D.C.

FELLONI, F.; WAHL, T.; WANDSCHNEIDER, P. \& GILBERT, J. (2001). Infrastructure and Agricultural production: cross-country evidence and implications for China. In mimeo, 2001.

FISCHER T., BYERLEE D., EDMEADES G. (2014). Crop yields and global food security: will yield increase continue to feed the world? ACIAR Monograph No. 158. Australian Centre for International Agricultural Research. Canberra. xxii +634 pp.

FREES, E.W. (2004) Longitudinal and Panel Data: Analysis and Applications in the Social Sciences. Cambridge University Press, August 2004.

FUGLIE, K.O. (2010) Total Factor Productivity in the Global Agricultural Economy: Evidence from FAO Data. in The Shifting Patterns of Agricultural Production and Productivity 
Worldwide. The Midwest Agribusiness Trade Research and Information Center, lowa State University, Ames, lowa.

GIBBS, A.; RAUSH, L.; MUNGER, J.; SCHELLY, I.; MORTON, D.C.; NOOJIPADY, P.; SOARES-FILHO, B.; BARRETO, P.; MICOL, L.; WALKER, N.F. (2015). Brazil's soy Moratorium. Science. Vol 347. Issue 6220. January $23^{\text {rd }} 2015$.

GOYAL, A.,(2010). Information, direct access to farmers, and rural market performance in Central India. World Bank Policy Research Working Paper 5315. Washington, DC. 2010.

HEINRICH, C. MAFFIOLI, A. \& VAZQUEZ, G. (2010). A Primer for Applying Propensity-Score Matching. Inter-American Development Bank: Impact-Evaluation Guidelines Technical Notes. No. IDB-TN-161. August 2010.

ITU (2014). Measuring the Information Society Report 2014. International Telecommunication Union. Geneva, 2014.

JENSEN, R. (2007). The Digital Provide: Information (Technology), Market Performance, and Welfare in the South Indian Fisheries Sector. Quarterly Journal of Economics, Vol. CXXII, Issue 3: 879-924.

KITCHIN, R. (2014). “The Data Revolution: Big Data, Open Data, Data Infrastructures and Their Consequences". London: Sage. 2014.

KITCHIN, R. (2017). "Thinking critically about and researching algorithms". Information, Communication \& Society. Volume 20, 2017 - Issue 1: The Social Power of Algorithms.

LAWSON, S., BLUNDELL, A., CABARLE, B., BASIK, N., JENKINS, M., CANBY, K. (2014). Consumer Goods and Deforestation: An Analysis of the Extent and Nature of Illegality in Forest Conversion for Agriculture and Timber Plantations. Forest Trends Report Series - Forest Trade and Finance. September 2014. Available at: http://www.foresttrends.org/documents/files/doc 4719.pdf

LIPSCOMB, M., MOBARAK, A.M. and BARHAM, T. (2013). Development effects of electrification: evidence from topographic placement of hydropower plants in Brazil. American Economic Journal: Applied Economics, 5(2):200-231. 
LLANTO, G.M. (2012). The impact of infrastructure on agricultural productivity. Discussion paper series no. 2012-12. Phillipine Institute of development studies.

MEBANE, W. \& SEKHON, J.S. 2011. Genetic Optimization Using Derivatives: The rgenoud package for R. Journal of Statistical Software, 42(11): 1-26.

MITTAL, S., GANDHI, S., \& TRIPATHI, G. (2010). Socio-Economic Impact of Mobile Phones on Indian Agriculture. Indian Council For Research On International Economic Relations. Working Paper No. 246. Feburary 2010.

MUTO, M \& YAMANO (2009). The Impact of Mobile Phone Coverage Expansion on Market Participation: Panel Data Evidence from Uganda. World Development 37 (12): 1887-96.

NAEF, E., MUELBERT, P., RAZA, S., FREDERICK, R., KENDALL, J. and GUPTA, N. (2014). Using mobile data for development. Gates Foundation Whitepaper.

NELSON G.C., ROSEGRANT M.W., PALAZZO A., GRAY I., INGERSTOLL C., ROBERTSON R. (2010). Food security, farming, and climate change to 2050: scenarios, results, policy options. Research Monograph. International Food Policy Research Institute, Washington, DC.

NEPSTAD, D.; MCGRATH, D.; STIKLER, C.; ALENCAR, A.; AZEVEDO, A.; SWETTE, B.; BEZERRA, T.; DIGIANO, M.; SHIMADA, J.; DA MOTTA, R.S., ARMIJO, E.; CASTELLO, L.; BRANDO, P.; HANSEN, M.; MCGRATH-HORN, M.; CARVALHO, O.; HESS, L. (2014). Slowing Amazon Deforestation Through Public Policy and Interventions in Beef and Soy Supply Chains. Science. Vol 344. Issue 6188. June $6^{\text {th }} 2014$.

PARK, M.H. \& KOO, W.W. (2005). Recent Development in Infrastructure and Its Impact on Agricultural and Non-agricultural Trade. Paper presented at the American Agricultural Economics Association Annual Meeting. Providence, Rhode Island, July 24-27, 2005.

PIERSKALLA, J.H. \& HOLLENBACH, F.M. (2013). Technology and Collective Action: The Effect of Cell Phone Coverage on Political Violence in Africa. American Political Science Review. Volume 107, Issue 2, May 2013.

RANGANATHAN, J., VENNARD, D., WAITE, R., DUMAS, P., LIPINSKI, B., SEARCHINGER, T. \& GLOBAGRI-WRR MODEL AUTHORS (2016). Shifting Diets For A Sustainable Food Future. WRI 
Working Paper: Installment 11 of "Creating a Sustainable Food Future". Available at http://www.wri.org/sites/default/files/Shifting Diets for a Sustainable Food Future 0.pd $\underline{f}$

RESTUCCIA, D., TAO YANG, D., ZHU, X. (2008). Agriculture and Aggregate Productivity: A Quantitative Cross-Country Analysis. Journal of Monetary Economics. Volume 55, Issue 2, March 2008, Pages 234-250

REZENDE, C.V. (2014). Telefonia móvel 4G no Brasil: avaliação dos investimentos pela teoria das opções reais. Masters thesis for the business and administration masters degree at Federal University of Uberlândia. Unberlândia, Feb. 20 th 2014 . Available at http://penelope.dr.ufu.br/handle/123456789/4141

RIFKIN, J. (2010) “The Age Of Access". Putnam Publishing Group , 2010.

RIFKIN, J. (2014) "The Zero Marginal Cost Society: The Internet of things, the collaborative commons, and the eclipse of capitalism". Palgrave Macmillan, 2014.

ROMP, W., DE HAAN, J. (2005). Public capital and economic growth: A critical survey. European Investment Bank Papers, 10(1), Luxemburg. apud WORLD BANK: Ag and development, brief review of the literature.

ROSENBAUM, P. \& RUBIN D. (1983). Constructing a Control Group Using Multivariate Matched Sampling Methods that Incorporate the Propensity Score. The American Statistican 39:33-38.

ROSENBAUM, P. \& RUBIN D. (1983). The Central Role of the Propensity Score in Observational Studies for Causal Effects. Biometrika 70(1): 41-55.

SAMARAJIVA R. (2012) How the Poor Use ICTs: Findings From Multi-Country Studies of Teleuse at the Bottom of the Pyramid, paper presented at the Regional FAO Workshop on the Use of Mobile Technologies in Agriculture. Bangkok, Thailand, April 3, 2012, http://lirneasia.net/wp-content/uploads/2012/04/Samarajiva FAO BKK.pdf.

SCARTEZINI, N. (2015). Personal interview, conducted by telephone. April $6^{\text {th }} 2015$. 
SEKHON, J.S. (2011). Multivariate and Propensity Score Matching. Software with Automated Balance Optimization: The Matching package for R. Journal of Statistical Software, 42(7): 152.

SEKHON, J.S. (2015). Package Matching (Version 4.9-2). Descriptive text on the $R$ software package, available on: https://cran.r-project.org/web/packages/Matching/Matching.pdf, retrieved on February $20^{\text {th }} 2017$.

SHIN, D. \& CHOI, M.J. (2015). Ecological views of big data: Perspectives and issues. Telematics and Informatics. 32: 311-320.

SMITH, P., MARTINO, D., CAI, Z., GWARY, D., JANZEN, H., KUMAR, P., MCCARL, B., ONGLE, S., O'MARA, F., RICE, C., SCHOLES, B., SIROTENKO, O. (2007). Agriculture. In: Climate Change 2007: Mitigation. Contribution of Working Group III to the Fourth Assessment Report of the Intergovernmental Panel on Climate Change], Cambridge University Press. Cambridge: 2007.

SMITH P, CLARK H, DONG H, ELSIDDIG EA, HABERL H, HARPER R, HOUSE J, JAFARI M, et al. (2014). Chapter 11 - Agriculture, forestry and other land use (AFOLU). In: Climate Change 2014: Mitigation of Climate Change. IPCC Working Group III Contribution to AR5. Cambridge University Press. Cambridge: 2014.

SOARES-FILHO, B.; RAJAO, R.; MACEDO, M.; CARNEIRO, A.; COSTA, W.; COE, M.; RODRIGUES, H.; ALNECAR, A. (2014). Craking Brazil's Forest Code. Science. Vol. 334. Issue 6182. April 25 th 2014.

STUBBS, M. (2016). Big Data in U.S. Agriculture. U.S. Congressional Research Service report. Washington DC. January 6, 2016.

TING, K.C.; ABDELZAHER, T., ALLEYNE, A.; RODRIGUEZ, L. (2011). Information technology and Agriculture: global challenges and opportunities. The Bridge. Vol41, no3, Fall 2011. Washington DC: National Academy of Engineering, 2011.

TNC (2015). Cadastro Ambiental Rural: nasce a identidade do imóvel rural. Curitiba, 2015. Available at: http://www.nature.org/media/brasil/cadastro-ambiental-rural.pdf 
TORRES-REYNA, O. (2010). Getting Started in Fixed/Random Effects Models using R. Power point presentation used in the Princeton Data and Statistic services. Fall 2010. Available at: http://www.princeton.edu/ otorres/Panel101R.pdf

UN (2000). Report of the High-level Panel on Information and Communication Technology. United Nations. New York. 17-20 April, 2000.

UNDP (2001) Human Development Report 2001: Making Technologies Work for Human Development. United Nations Development Program. Washington, D.C.

VERDIER-CHOUCHANE, A. \& KARAGUEUZIAN, C. (2016). Moving towards a green productive agriculture in Africa: The role of ICTs. African Development Bank: Africa Economic Brief. Volume 7, Issue 7, 2016.

WALL STREET JOURNAL, The (2015). Google Ventures Invests in Agricultural Technology Startup. May, $19^{\text {th }}$ 2015. Available at: http://www.wsj.com/articles/google-ventures-investsin-agricultural-technology-startup-1432040405

WARD, P.; FLORAX, R. \& FLORES-LAGUNES, A. (2014) Climate change and agricultural productivity in Sub-Saharan Africa: A spatial sample selection model. European Review of Agricultural Economics (2014) 41 (2): 199-226.

WORLD BANK (2001) World Development Report 2000-2001: Attacking Poverty. World Bank. Washington, 2001.

WORLD BANK (2007). World Development Report 2008: Agriculture for Development. World Bank and Oxford University Press. Washington, DC/Oxford. 2007.

WORLD BANK (2012). Information and Communications for Development 2012: Maximizing Mobile. Washington, DC: The World Bank.

WORLD WILDLIFE FUND (2012). Living Planet Report 2012. Available at: http://d2ouvy59p0dg6k.cloudfront.net/downloads/lpr living planet report 2012.pdf

ZEPEDA, L. (ed) (2001). Agricultural Investment and Productivity in Developing Countries. FAO Economic And Social Development Paper 148. 
ZHANG, X. \& FAN, S. (2001). How productive is infrastructure? New approach and evidence from rural India. Environment and Production Technology Division discussion paper no. 84. International Food Policy Research Institute. Washington, October 2001. 


\subsection{DATABASES}

ANATEL: http://www.anatel.gov.br/dados/

FAO STAT: http://www.faostat.fao.org

IBGE: http://www.sidra.ibge.gov.br/

INPE/PRODES: $\underline{\text { http://www.dpi.inpe.br/prodesdigital/prodesmunicipal.php }}$

WORLD BANK: http://data.worldbank.org/ 


\section{ANNEX A: COMMANDS IN “R”}

\section{PANEL DATA MODELS}

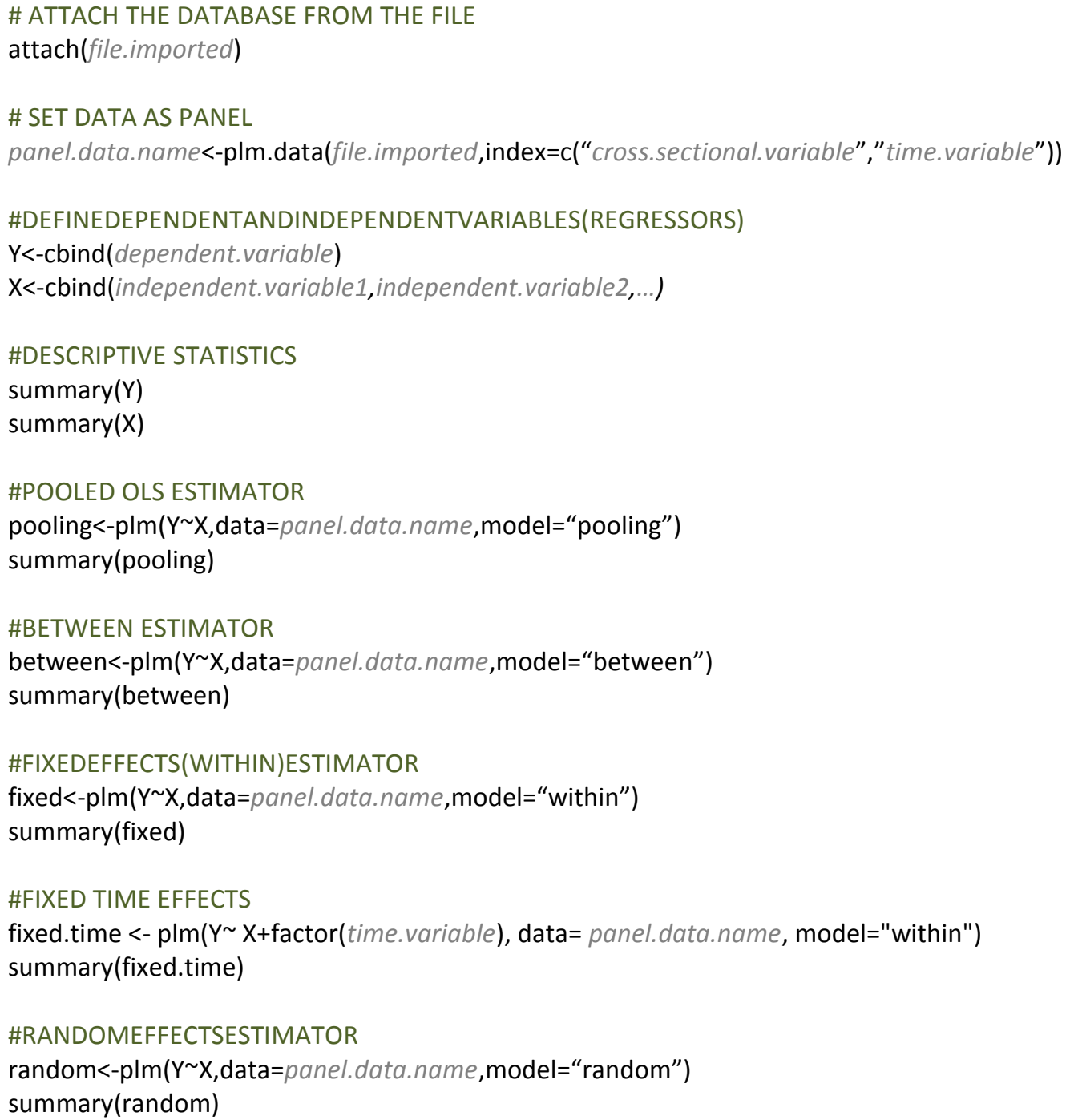

\section{PROPENSITY SCORE MATCHING MODELS}

\# $1^{\text {st }}$ it is needed to install the packages "Macthing" and "rbounds"

\# PROPENSITY SCORING MODEL (INCLUDES PROBIT MODEL AS $1^{\text {st }}$ STEP)

attach(panel.data.name)

$d f<-$ data.frame(panel.data.name)

$\operatorname{Tr}<-$ cbind(treatment.binary.variable)

$Y<-$ cbind(dependent.variable)

$X<-$ cbind(independent.variable1,independent.variable2,...)

glm1 <- glm(Tr X, family=binomial(link = "probit"), data= panel.data.name) summary(glm1) 
$\operatorname{rr} 1<-\operatorname{Match}(Y=Y, \operatorname{Tr}=\operatorname{Tr}, X=$ glm1Sfitted $)$

summary(rr1)

\#CHECKING THE BALANCE PROPRIETY

MatchBalance $\left(\operatorname{Tr}^{\sim} X\right.$, match.out $=r r 1$, nboots $=0$, data $=$ panel.data. name $)$

\#PLOTING THE BALANCE PROPRIETY

qqplot(var1[rr1șindex.control], var1[rr1șindex.treated])

abline $($ coef $=c(0,1), c o l=2)$

Sources: derived from:

KATCHOVA, A. (2013). Panel Data Models in R. Econometrics Academy's on line lecture. Available at https://sites.google.com/site/econometricsacademy. Access on June6th2015.

TORRES-REYNA, O. (2010). Getting Started in Fixed/Random Effects Models using R. Power point presentation used in the Princeton Data and Statistic services. Fall 2010. Available at: http://www.princeton.edu/ otorres/Panel101R.pdf 


\section{ANNEX B: Supporting material for the global model}

\section{SUMMARY OF VARIABLES}

\begin{tabular}{|c|c|c|c|c|}
\hline simbol & Variable & Unit & Database & Comments \\
\hline yld & cereal yield & $\mathrm{Kg} / \mathrm{ha} / \mathrm{yr}$ & World Bank & - \\
\hline int & Internet users & $\begin{array}{l}\text { per } 100 \\
\text { people }\end{array}$ & World Bank & - \\
\hline mob & $\begin{array}{l}\text { Mobile } \\
\text { subscription }\end{array}$ & $\begin{array}{l}\text { per } 100 \\
\text { people }\end{array}$ & World Bank & - \\
\hline gdp & GDP per capita & In 2005 usd & World Bank & - \\
\hline avr & $\begin{array}{l}\text { Agricultural } \\
\text { value added per } \\
\text { rural habitant }\end{array}$ & In 2005 usd & World Bank & $\begin{array}{l}\text { Calculated as: (Agricultural } \\
\text { value added) / (Agricultural } \\
\text { population) }\end{array}$ \\
\hline edu & $\begin{array}{l}\text { Education } \\
\text { expenditure per } \\
\text { capita }\end{array}$ & In 2005 usd & World Bank & $\begin{array}{l}\text { Calculated as: (GDP per capita) }{ }^{*} \\
\text { (Education expenditure as } \\
\text { percentage of GDP) }\end{array}$ \\
\hline wat & $\begin{array}{l}\text { Water used per } \\
\text { ha of arable land }\end{array}$ & $\mathrm{m} 3 / \mathrm{ha} / \mathrm{yr}$ & World Bank & $\begin{array}{l}\text { The variable is calculated proxy. } \\
\text { Three other variables were used to } \\
\text { calculate it: (total freshwater } \\
\text { withdraws per year) * (percentage } \\
\text { of water withdrawn used for } \\
\text { agriculture) / (total arable land) }\end{array}$ \\
\hline fer & $\begin{array}{l}\text { Fertilizers per } \\
\text { hectare }\end{array}$ & $\mathrm{Kg} / \mathrm{ha}$ & World Bank & ( \\
\hline pic & $\begin{array}{l}\text { Producer price } \\
\text { index for cereals }\end{array}$ & $2004-06=100$ & World Bank & - \\
\hline reg.inc & $\begin{array}{l}\text { Index for yield } \\
\text { variation } \\
\text { according to } \\
\text { region and } \\
\text { income level }\end{array}$ & $1990-94=1$ & Several & $\begin{array}{l}\text { An index created by the author to } \\
\text { control for other ommited } \\
\text { variables. It groups countries to } \\
\text { measure yield variation at the } \\
\text { regional level and according to } \\
\text { income level. } \\
\text { It uses FAO yield data (yld) and } \\
\text { World Bank classification for } \\
\text { income and regions (see table } \\
\text { below). The yield average of all } \\
\text { uper-medium-income latin- } \\
\text { american countries is created for } \\
\text { each period. An index is calculated } \\
\text { in which average yield in } 1990-94 \text { is } \\
\text { equal to } 1 . \text { Then it is applied to all } \\
\text { countries in the category. }\end{array}$ \\
\hline
\end{tabular}




\section{DESCRIPTIVE STATISTICS}

\begin{tabular}{|c|c|c|c|}
\hline$y>d$ & int & mob & gdp \\
\hline Min. : 194.1 & Min. : 0.0000 & 0.0000 & Min. : \\
\hline 1st Qu.: 1354.9 & 1st Qu.: 0.1391 & 1st Qu.: & 1st Qu.: \\
\hline Median : 2245.6 & Median : 3.5376 & Median : 15.6977 & Median : \\
\hline Mean : 2844.5 & $: 16.2954$ & 38.9193 & 10621.28 \\
\hline 3rd Qu.: 3586.7 & 3rd Qu.:23.6458 & 3rd Qu.: 74.6980 & 12678.09 \\
\hline Max. $\quad: 73270.1$ & Max. $\quad: 95.2416$ & Max. $\quad: 262.8727$ & Max. $: 140840.95$ \\
\hline$: 177$ & NA'S & NA's & NA's \\
\hline$a v r$ & edu & wat & pic \\
\hline Min. : & Min. : & Min. : & Min. : \\
\hline 1st Qu.: & 1st Qu.: & 1st Qu.: & 1st Qu.: 70.91 \\
\hline Median : 524.07 & Median : 154.445 & Median : & Median :103.22 \\
\hline Mean : 1238.23 & Mean : 539.587 & Mean : & Mean $: 106.16$ \\
\hline 3rd Qu.: 1053.92 & 3rd Qu.: 643.660 & 3rd Qu.: 3530.6 & 3rd Qu.: 131.05 \\
\hline Max. $: 38640.05$ & Max. $\quad: 4497.326$ & Max. $\quad: 115185.2$ & Max. $\quad: 431.58$ \\
\hline$: 260$ & $: 356$ & NA's & NA's \\
\hline reg.inc & fer & & \\
\hline Min. $\quad: 0.7592$ & Min. : & & \\
\hline 1st Qu.: 1.0000 & 1st Qu.: & & \\
\hline Median : 1.1380 & Median : & & \\
\hline Mean $\quad: 1.2231$ & 248.71 & & \\
\hline 3rd Qu.:1.2545 & 3rd Qu.: 189.46 & & \\
\hline Max. $\quad: 7.0787$ & $\begin{array}{ll}\text { Max. } & : 13491.64 \\
\text { NA's } & : 577\end{array}$ & & \\
\hline
\end{tabular}

NUMBER OF OBSERVATIONS PER PERIOD PER VARIABLE

\begin{tabular}{|ccccccccccc|}
\hline period & yld & int & mob & gdp & avr & edu & wat & fer & pic & reg.inc \\
$1990-$ & 175 & 204 & 203 & 183 & 141 & 107 & 52 & 0 & 123 & 212 \\
94 & & & & & & & & & & \\
$1995-$ & 175 & 194 & 201 & 192 & 158 & 155 & 57 & 0 & 132 & 212 \\
99 & & & & & & & & & & \\
$2000-$ & 177 & 203 & 206 & 195 & 166 & 157 & 131 & 158 & 135 & 212 \\
04 & & & & & & & & \\
$2005-$ & 178 & 203 & 204 & 197 & 177 & 155 & 94 & 163 & 136 & 212 \\
09 & & & & & & & \\
$2010-$ & 178 & 203 & 202 & 186 & 158 & 130 & 171 & 162 & 135 & 212 \\
14 & & & & & & & & & & \\
\hline Tota1 & 883 & 1007 & 1016 & 953 & 800 & 704 & 505 & 483 & 661 & 1060 \\
\hline
\end{tabular}




\section{RESULTS OF REGRESSIONS}

OLS

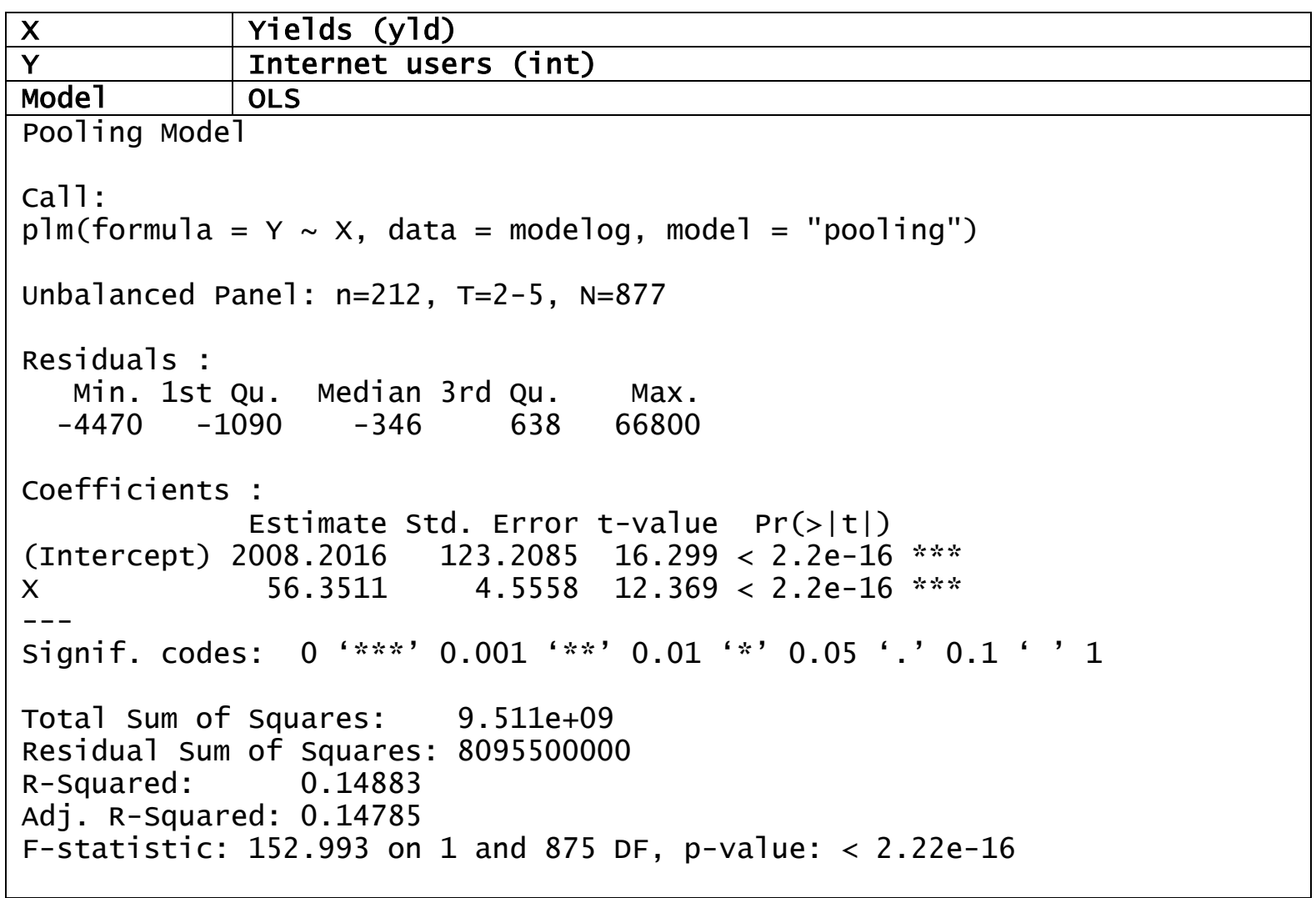

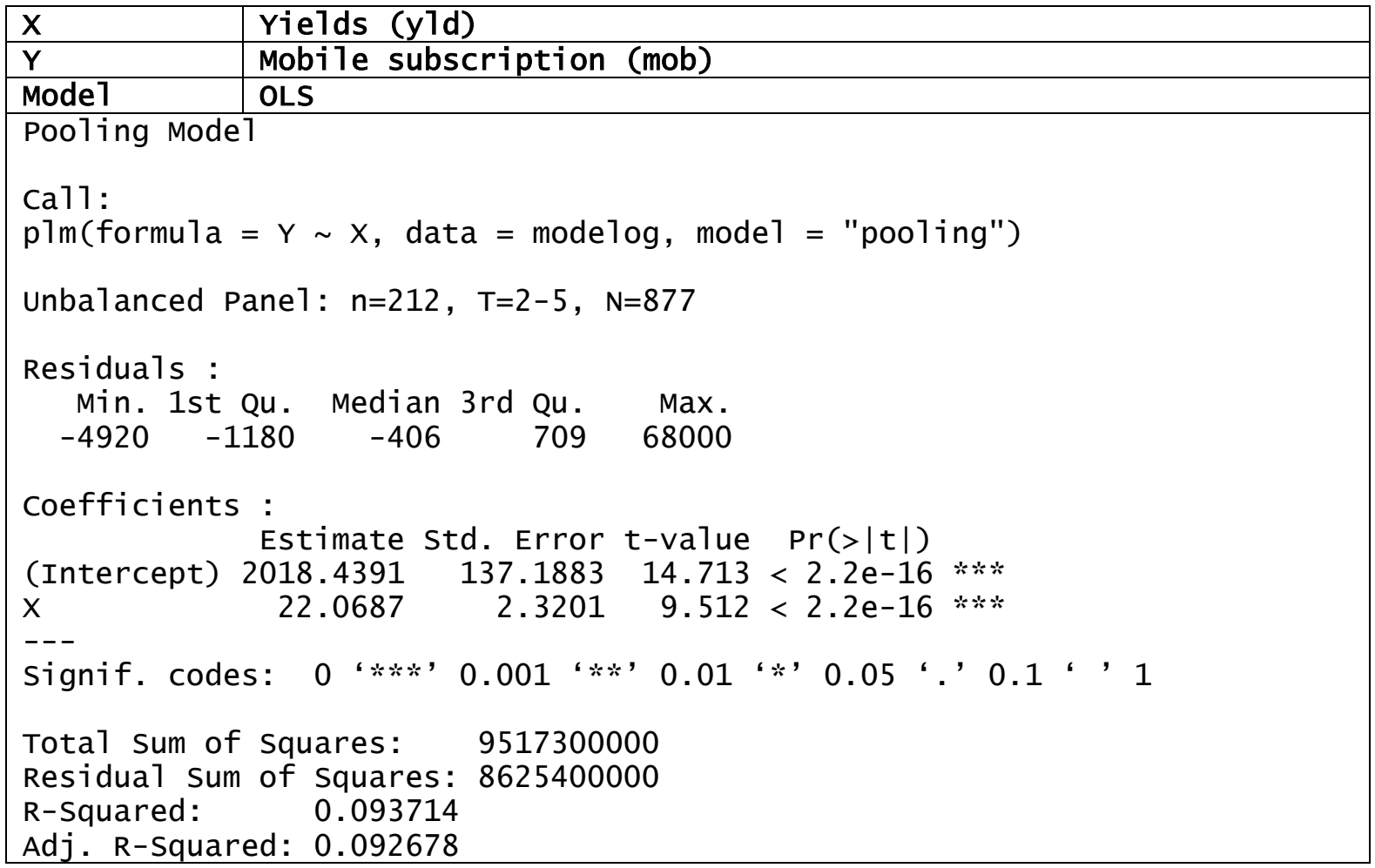


F-statistic: 90.4786 on 1 and 875 DF, p-value: $<2.22 \mathrm{e}-16$

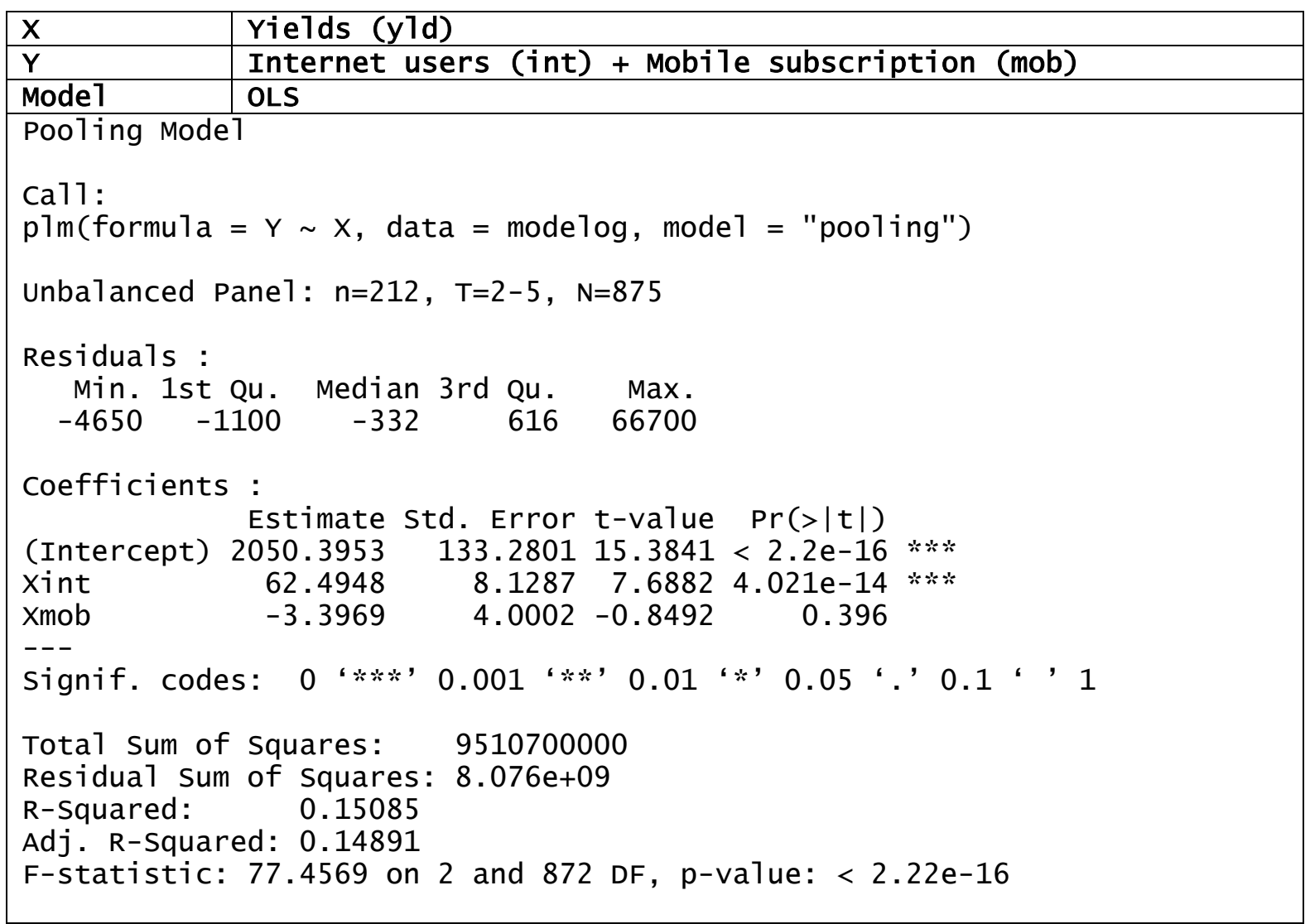

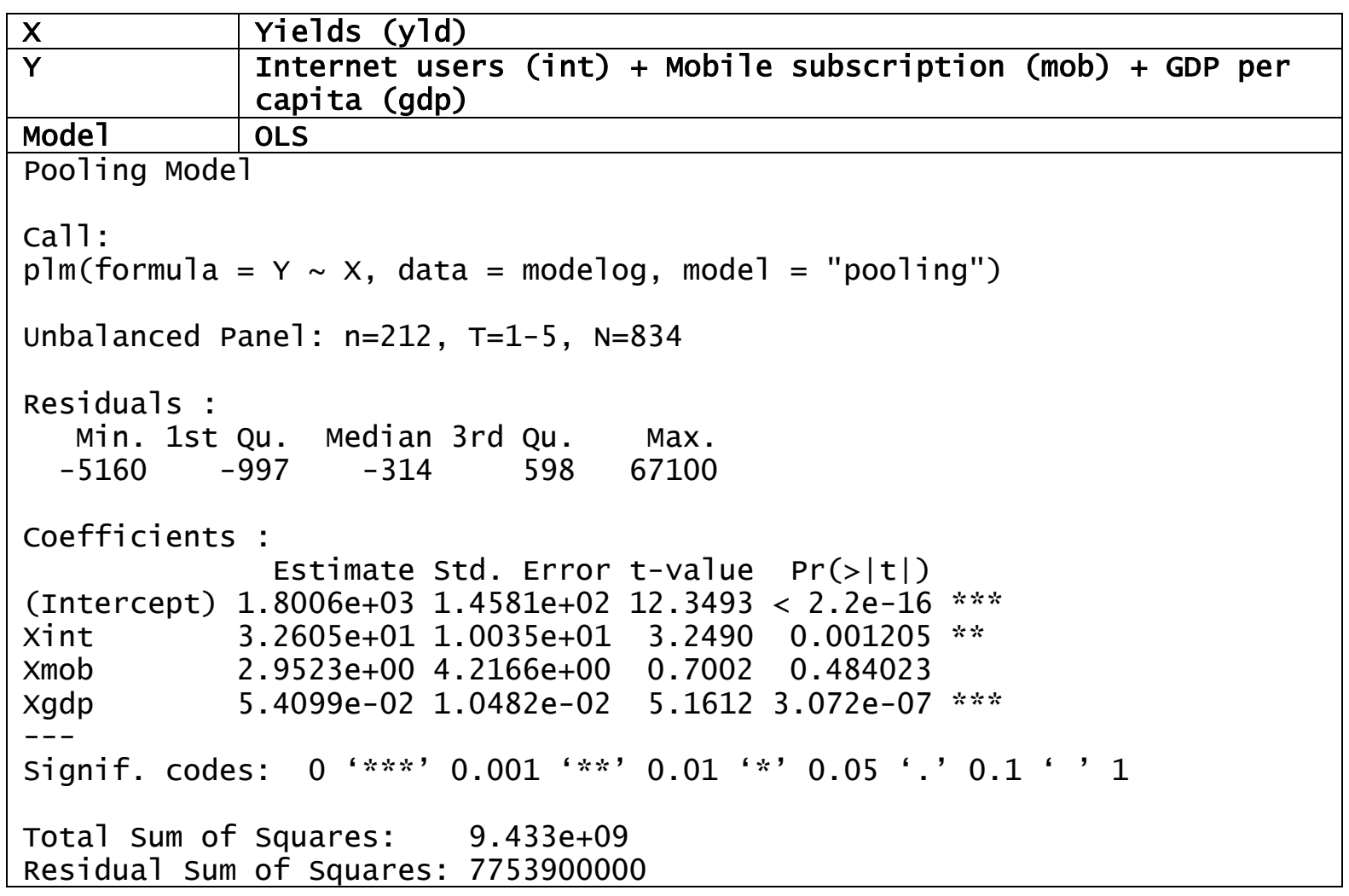


R-Squared: $\quad 0.17801$

Adj. R-Squared: 0.17504

F-statistic: 59.9148 on 3 and 830 DF, p-value: $<2.22 \mathrm{e}-16$

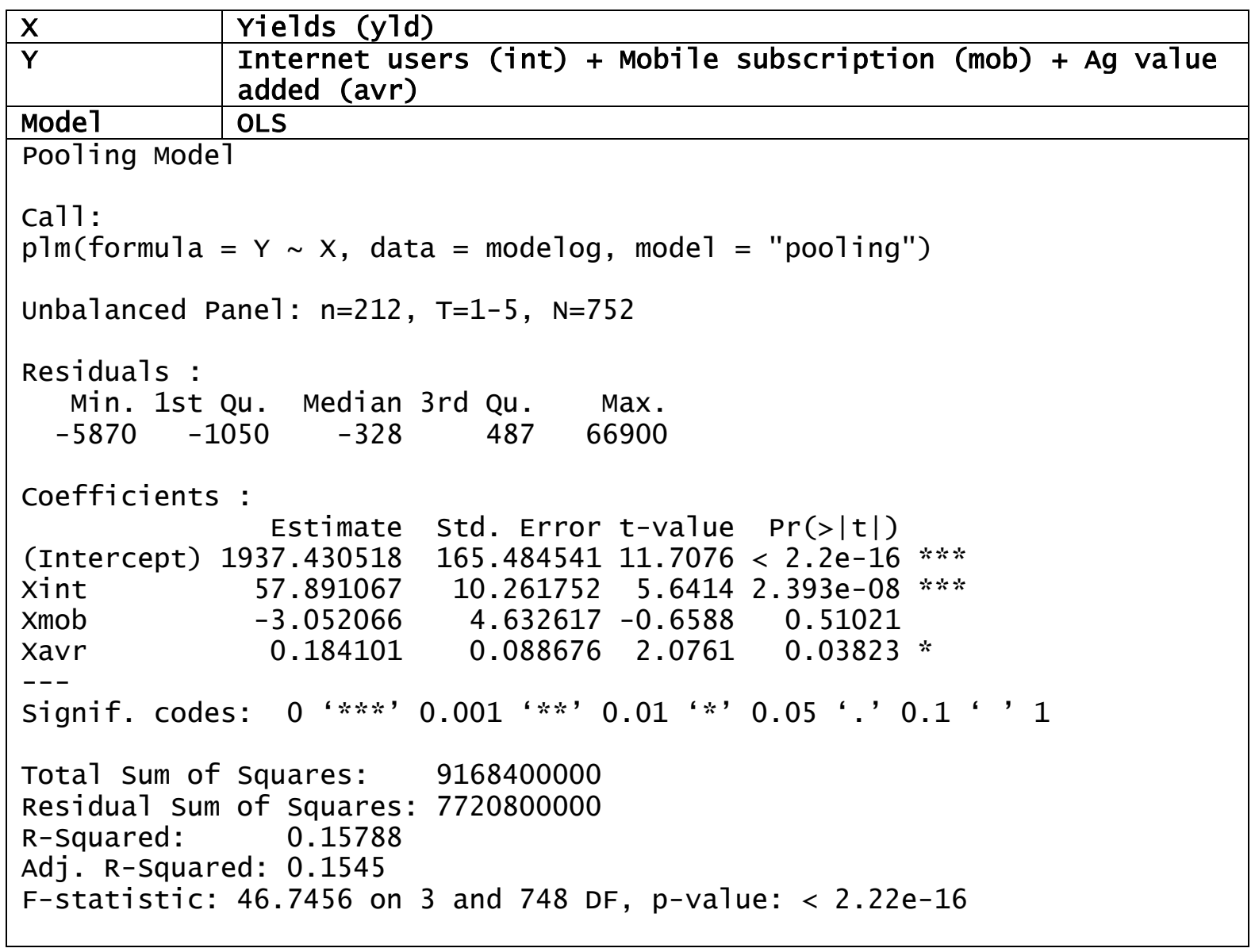

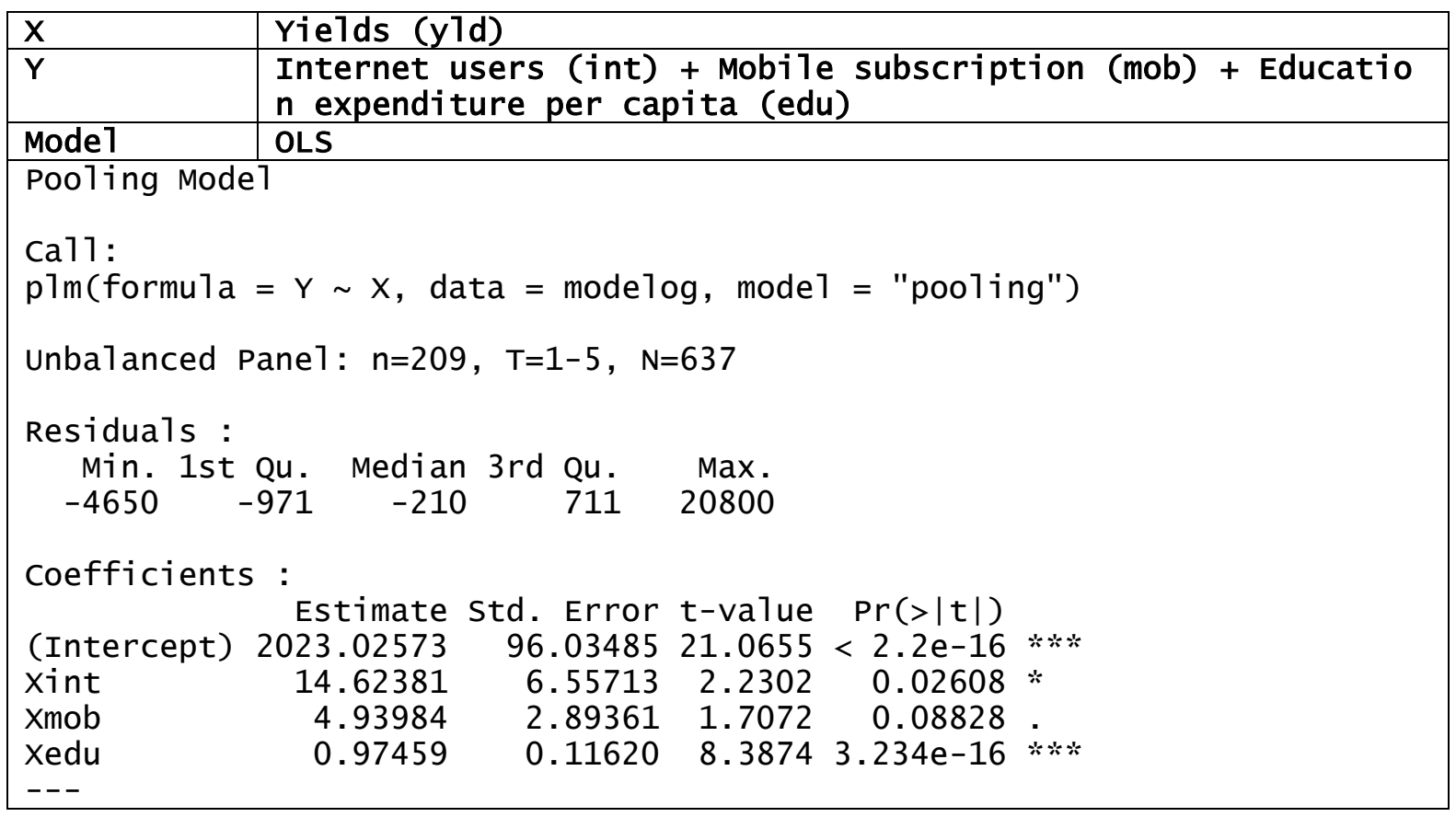




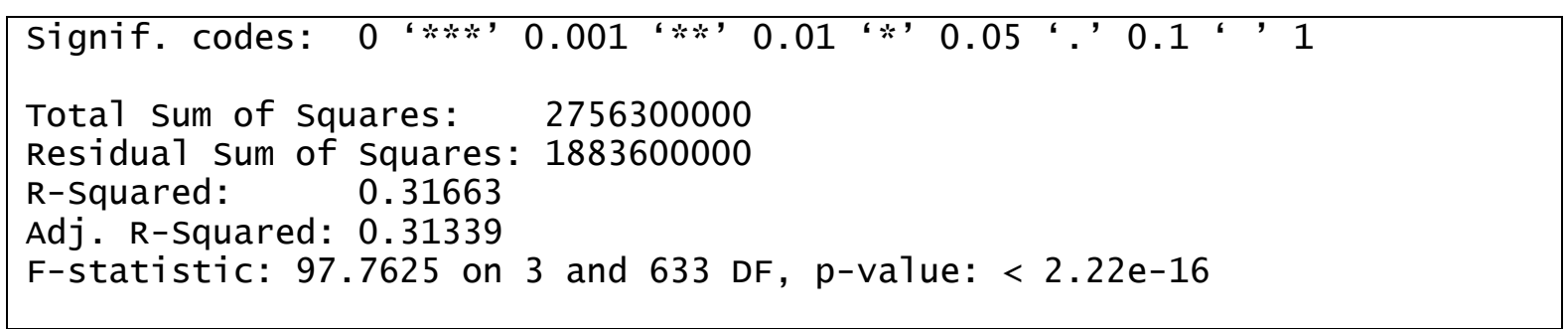

\begin{tabular}{|c|c|}
\hline $\mathbf{X}$ & Yields (y1d) \\
\hline $\mathbf{Y}$ & $\begin{array}{l}\text { Internet users (int) + Mobile subscription (mob) + water us } \\
\text { ed per hectare of arable land (wat) }\end{array}$ \\
\hline Mode1 & OLS \\
\hline Pooling Mode & \\
\hline $\begin{array}{l}\text { Ca11: } \\
\text { p1m(formu1a }\end{array}$ & $=\mathrm{Y} \sim \mathrm{X}$, data $=$ modelog, $\operatorname{mode} 1=$ "pooling") \\
\hline Unbalanced $\mathrm{F}$ & Pane1: $\mathrm{n}=187, \mathrm{~T}=1-5, \mathrm{~N}=492$ \\
\hline $\begin{array}{l}\text { Residuals: } \\
\text { Min. 1st } \\
-12000\end{array}$ & $\begin{array}{lrrr}\text { Qu. } & \text { Median } & 3 \text { rd Qu. } & \text { Max. } \\
-923 & -109 & 816 & 49300\end{array}$ \\
\hline Coefficients & S: \\
\hline (Intercept) & $\begin{array}{rrrr}\text { Estimate } & \text { Std. Error t-value } & \operatorname{Pr}(>|\mathrm{t}|) \\
1218.419713 & 207.729778 & 5.8654 & 8.270 \mathrm{e}-09\end{array} * * *$ \\
\hline Xint & $9.122881 \quad 7.8613 \quad 2.455 \mathrm{e}-14 * * *$ \\
\hline $\begin{array}{l}\text { Xmob } \\
\text { Xwat }\end{array}$ & $\begin{array}{rlll}-10.331530 & 4.696542 & -2.1998 & 0.02829 \\
0.275793 & 0.018266 & 15.0989<2.2 \mathrm{e}-16 * * *\end{array}$ \\
\hline Signif. code & es: 0 ،***, $0.001 ، * *, 0.01 ، *, 0.05 ،, \quad 0.1 ،, 1$ \\
\hline $\begin{array}{l}\text { Total Sum of } \\
\text { Residual Sun } \\
\text { R-Squared: } \\
\text { Adj. R-Squar } \\
\text { F-statistic: }\end{array}$ & $\begin{array}{l}\text { f Squares: } 7761900000 \\
\text { n of Squares: } 4525200000 \\
\quad 0.41699 \\
\text { red: } 0.4134 \\
\text { : } 116.345 \text { on } 3 \text { and } 488 \text { DF, p-value: }<2.22 \mathrm{e}-16\end{array}$ \\
\hline
\end{tabular}

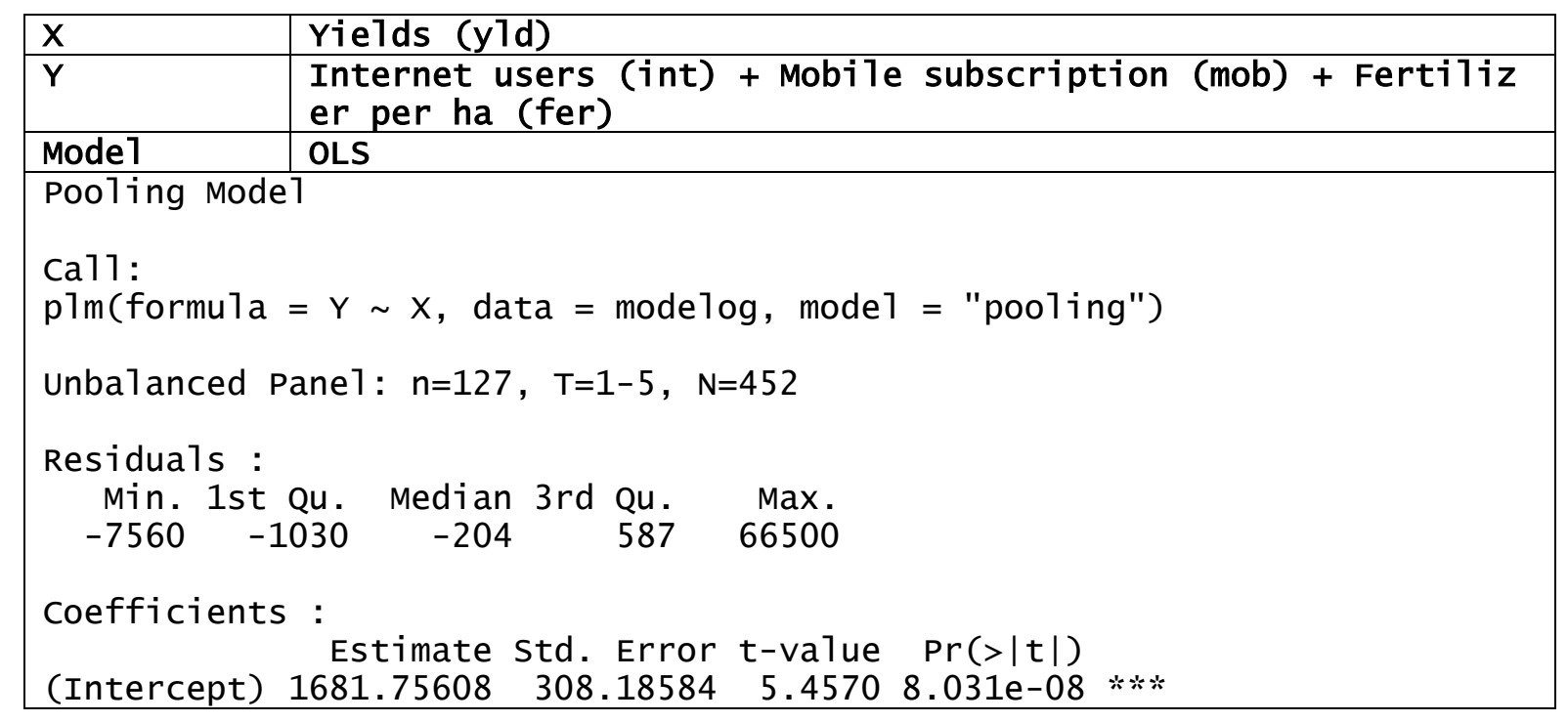




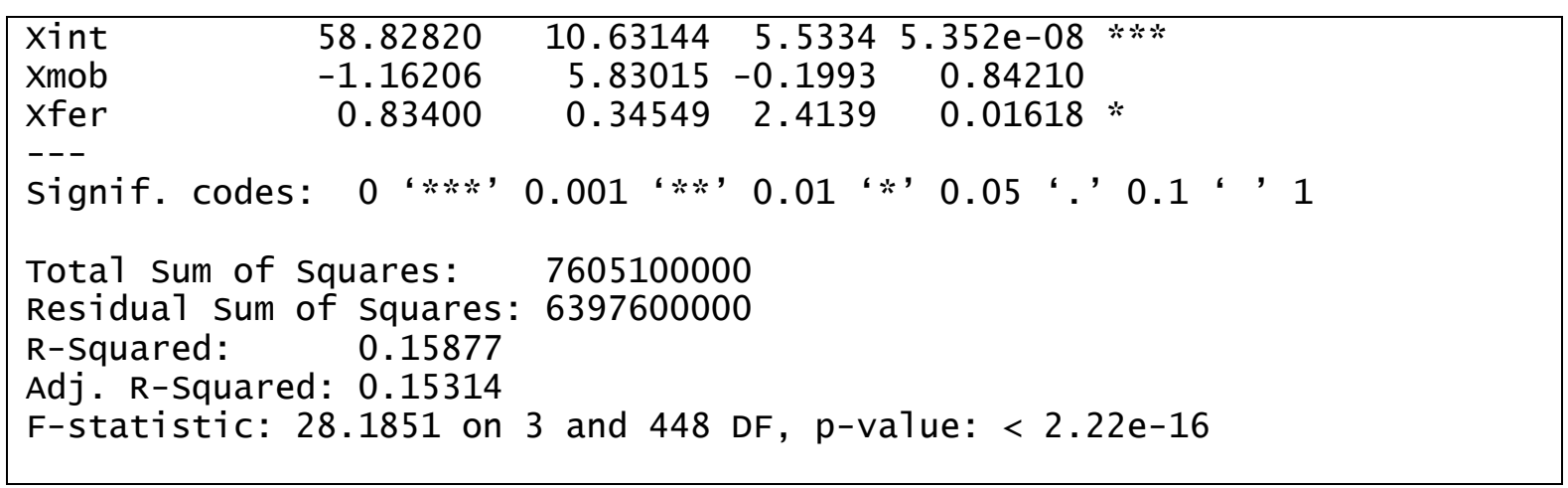

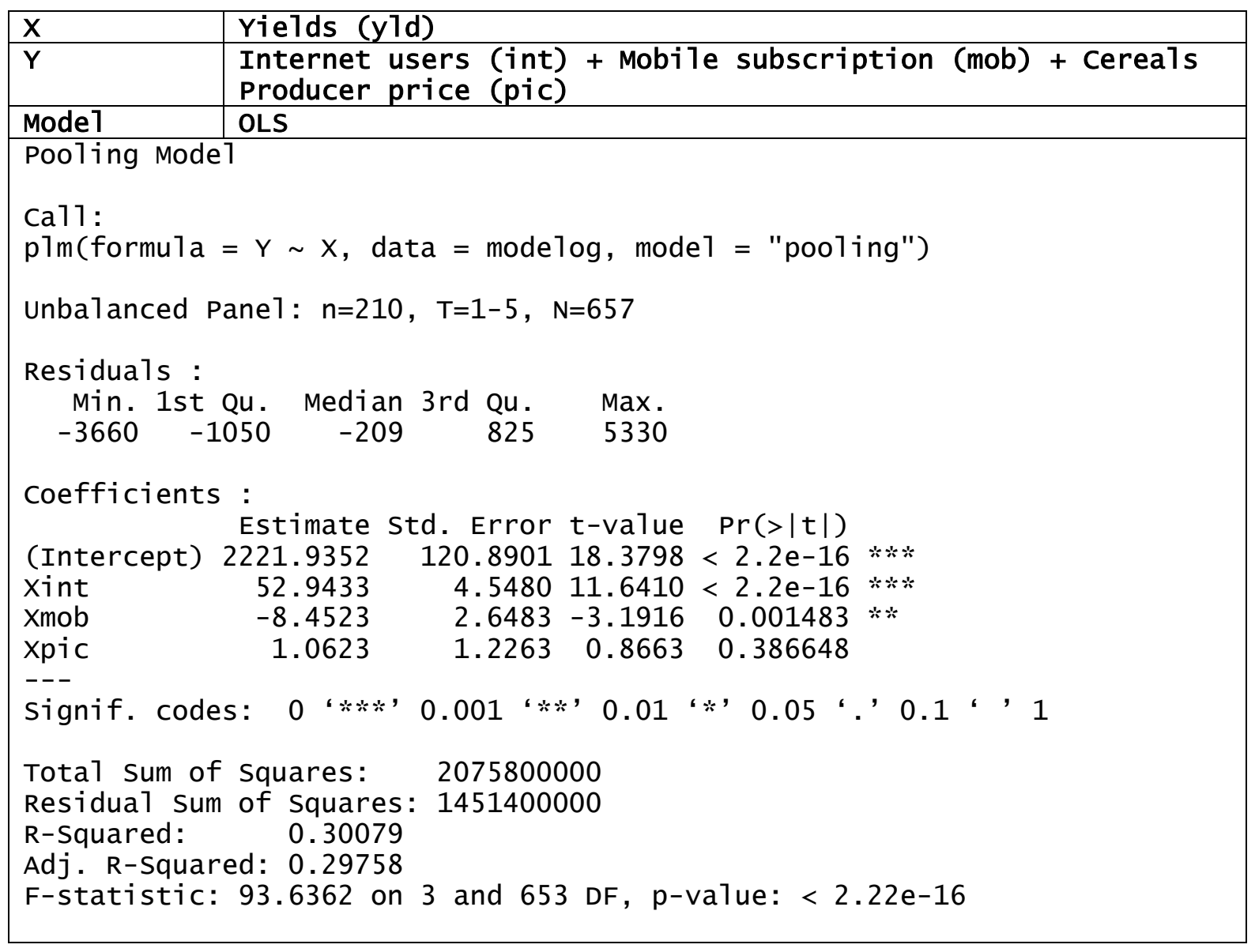

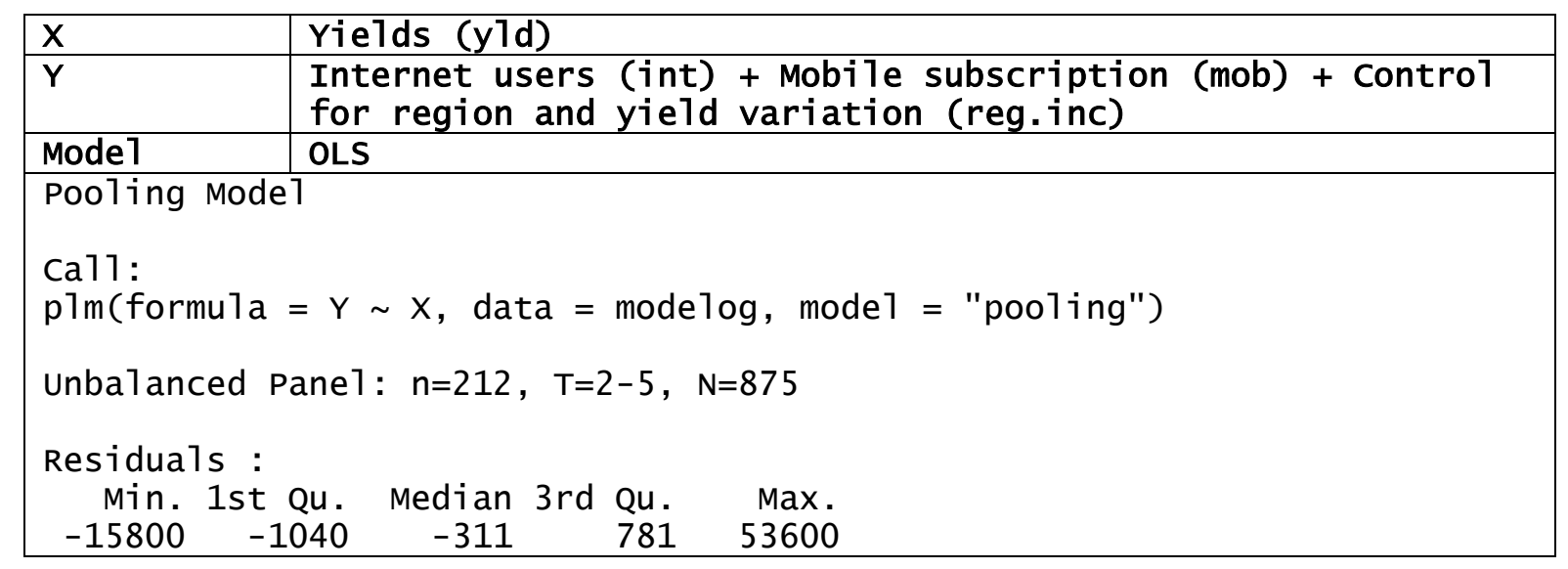




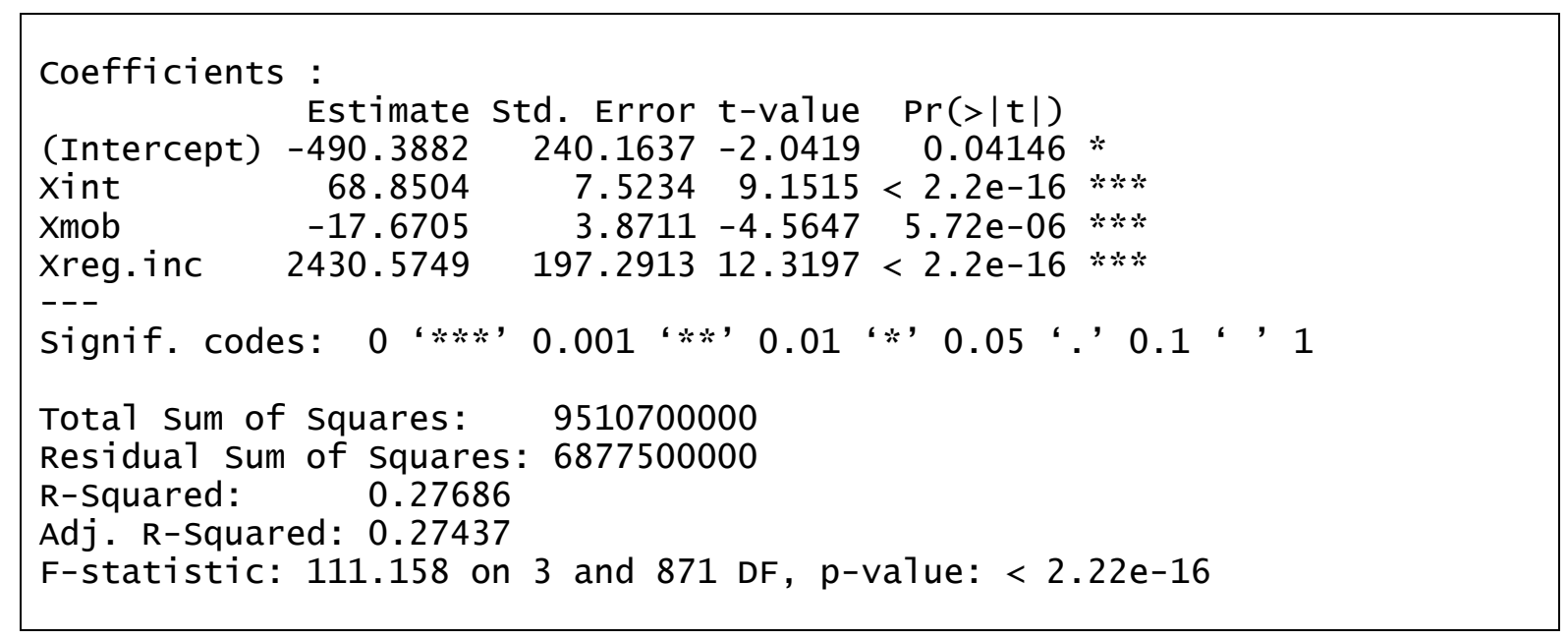

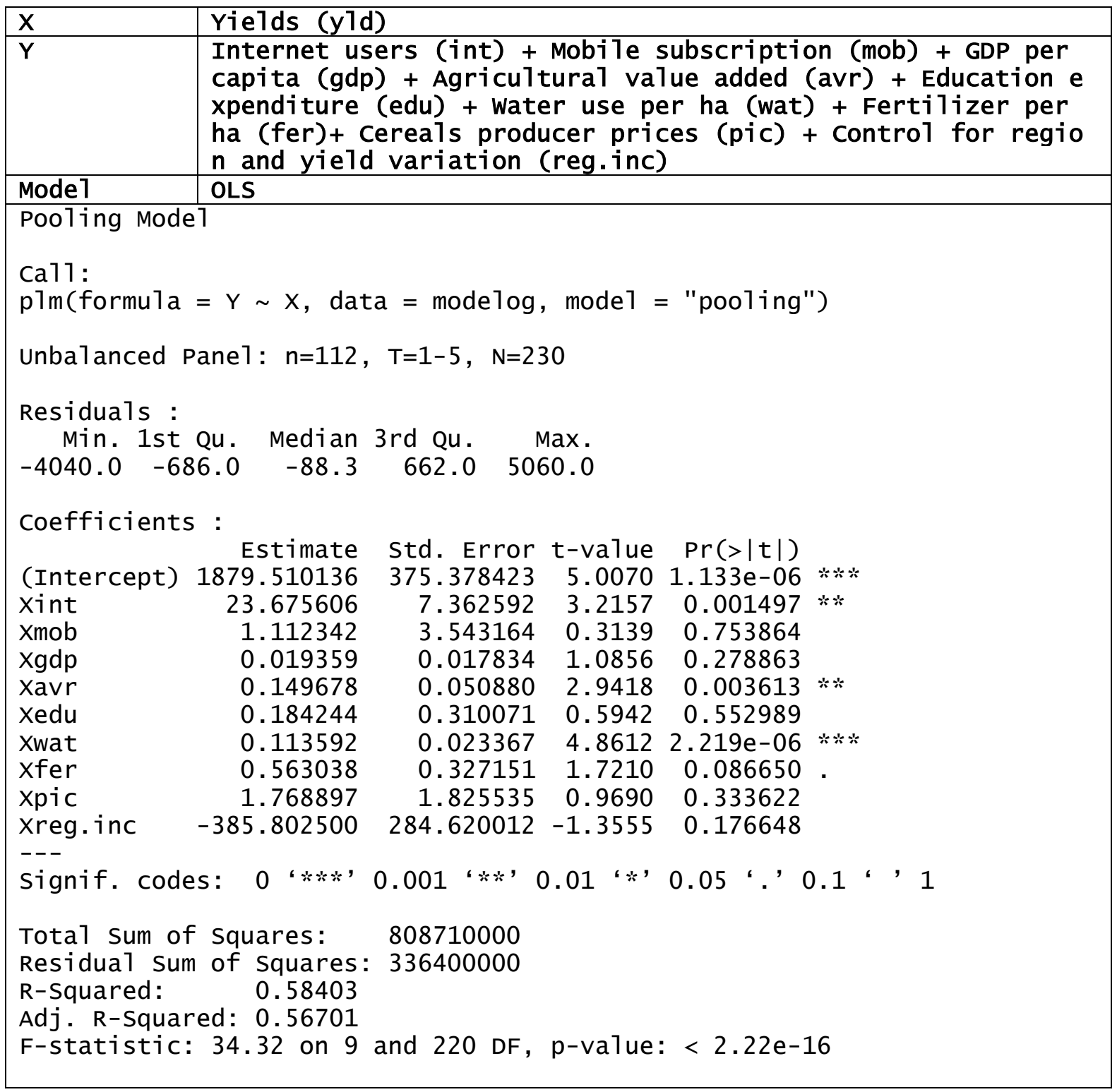

\section{Fixed effects}




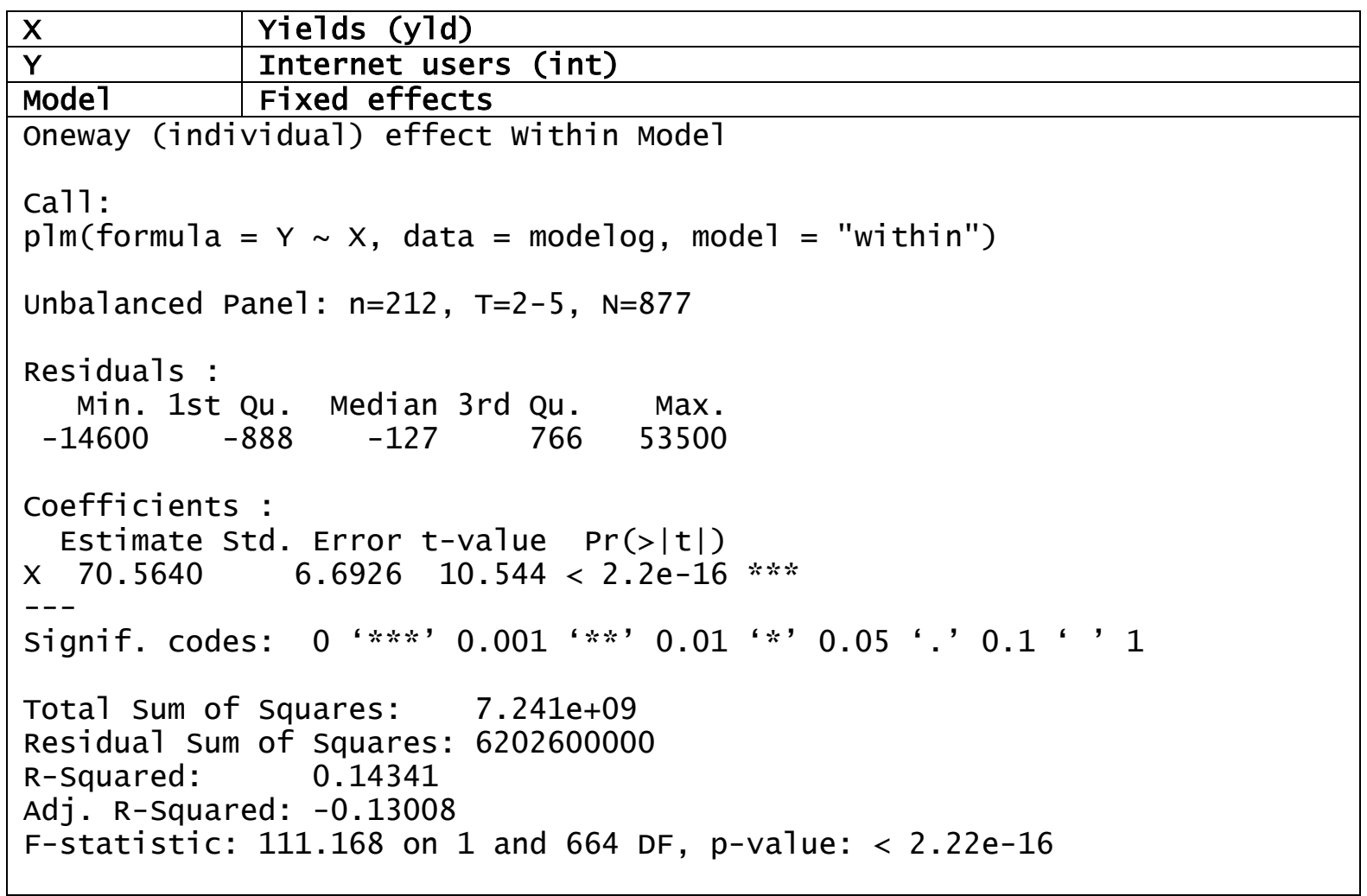

\begin{tabular}{|c|c|}
\hline $\mathbf{x}$ & Yields (yld) \\
\hline $\mathbf{Y}$ & Mobile subscription (mob) \\
\hline Mode1 & Fixed effects \\
\hline \multicolumn{2}{|c|}{ Oneway (individua1) effect within Mode1 } \\
\hline \multicolumn{2}{|c|}{$\begin{array}{l}\text { Ca11: } \\
\text { plm(formula }=Y \sim X, \text { data }=\text { modelog, mode1 = "within") } \\
\text { Unbalanced Pane1: } n=212, T=2-5, N=877\end{array}$} \\
\hline \multicolumn{2}{|c|}{ 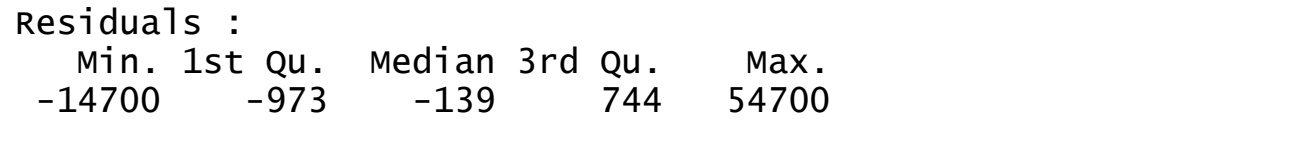 } \\
\hline \multirow{2}{*}{\multicolumn{2}{|c|}{ 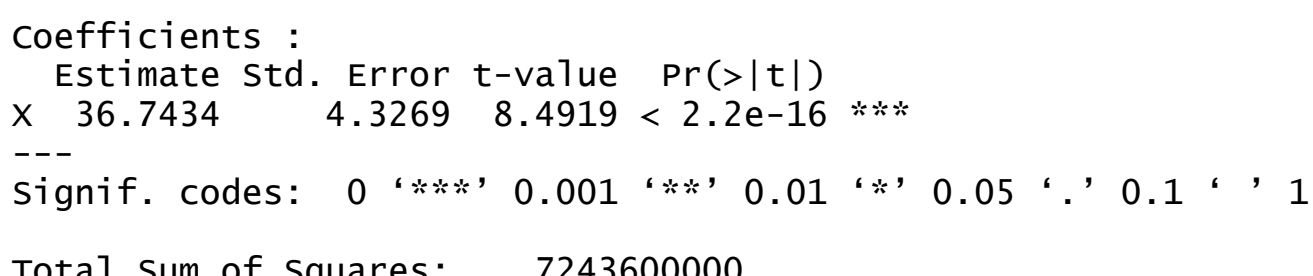 }} \\
\hline & \\
\hline $\begin{array}{l}\text { Total Sum o } \\
\text { Residual Su } \\
\text { R-Squared: } \\
\text { Adj. R-Squa } \\
\text { F-statistic }\end{array}$ & $\begin{array}{l}\text { Squares: } 7243600000 \\
\text { of Squares: } 6.534 \mathrm{e}+09 \\
0.097964 \\
\text { ed: }-0.19004 \\
72.1123 \text { on } 1 \text { and } 664 \text { DF, p-value: }<2.22 \mathrm{e}-16\end{array}$ \\
\hline
\end{tabular}

\begin{tabular}{|l|l|}
\hline$X$ & Yields (yld) \\
\hline$Y$ & Internet users (int) + Mobile subscription (mob) \\
\hline Mode1 & Fixed effects \\
\hline Oneway (individual) effect Within Mode1 \\
\hline
\end{tabular}




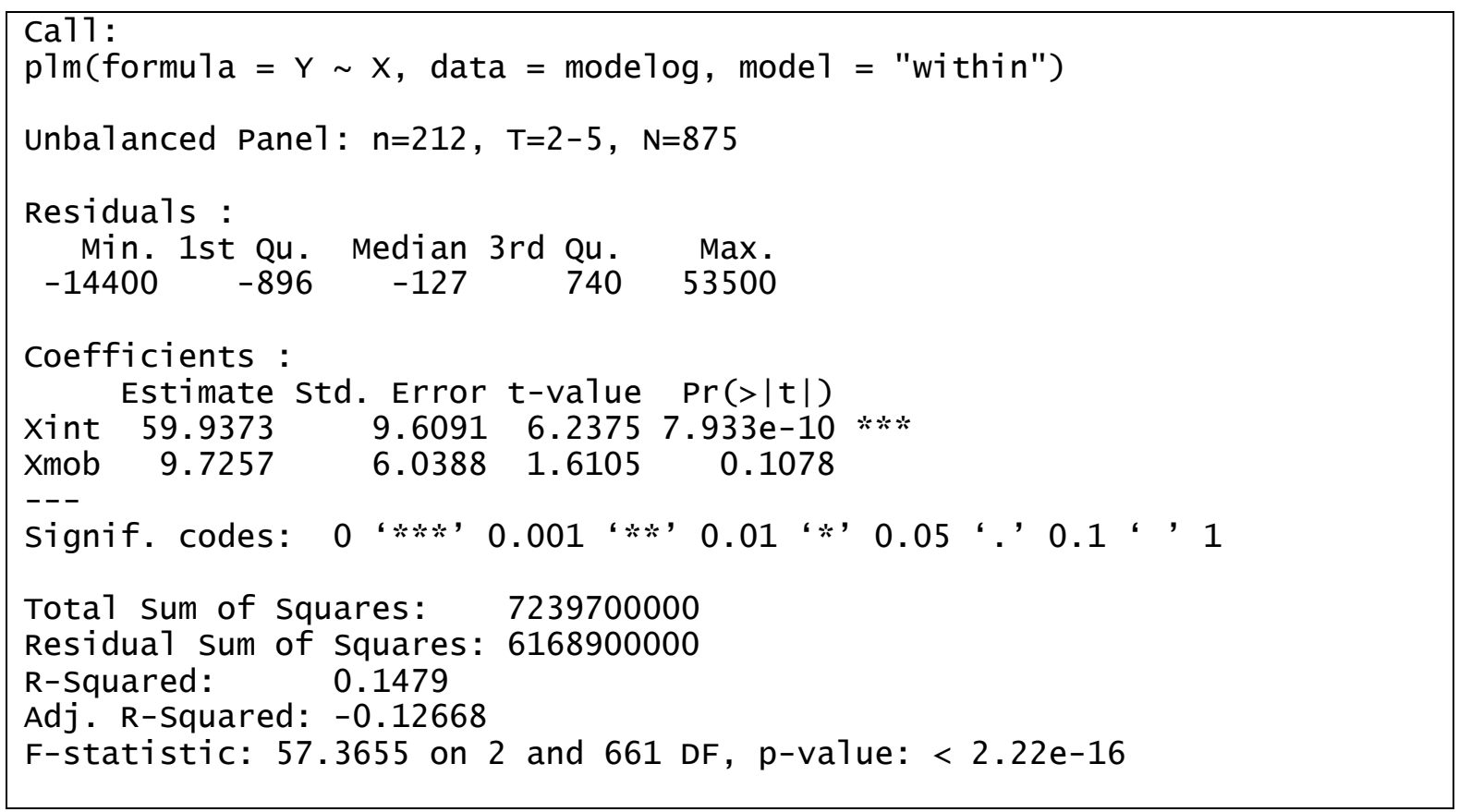

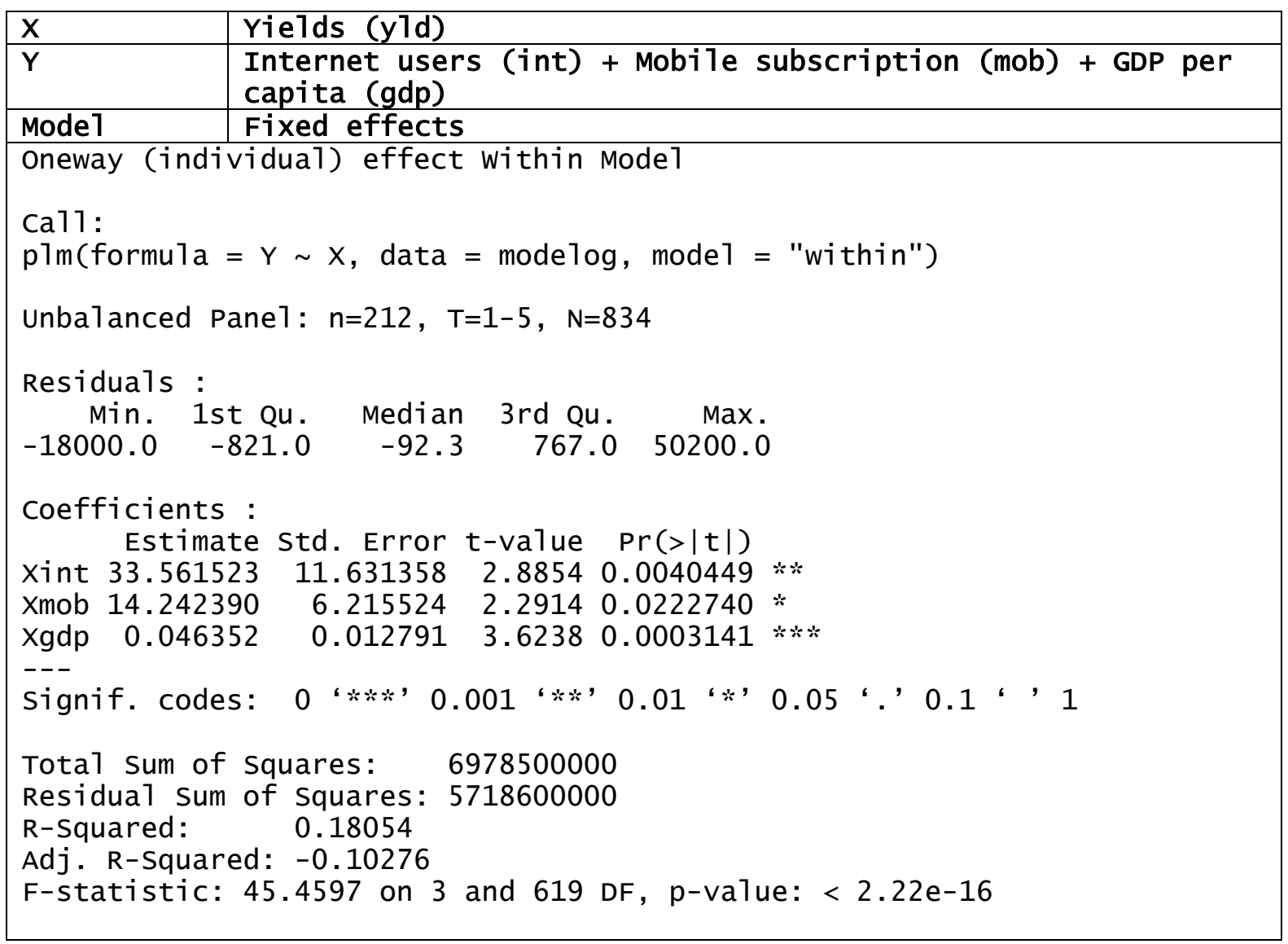

\begin{tabular}{|l|l|}
\hline$X$ & Yields (yld) \\
\hline$Y$ & $\begin{array}{l}\text { Internet users (int) + Mobile subscription (mob) + Agricult } \\
\text { ural value added (avr) }\end{array}$ \\
\hline Mode1 & Fixed effects \\
\hline Oneway (individual) effect Within Mode1 \\
\hline
\end{tabular}




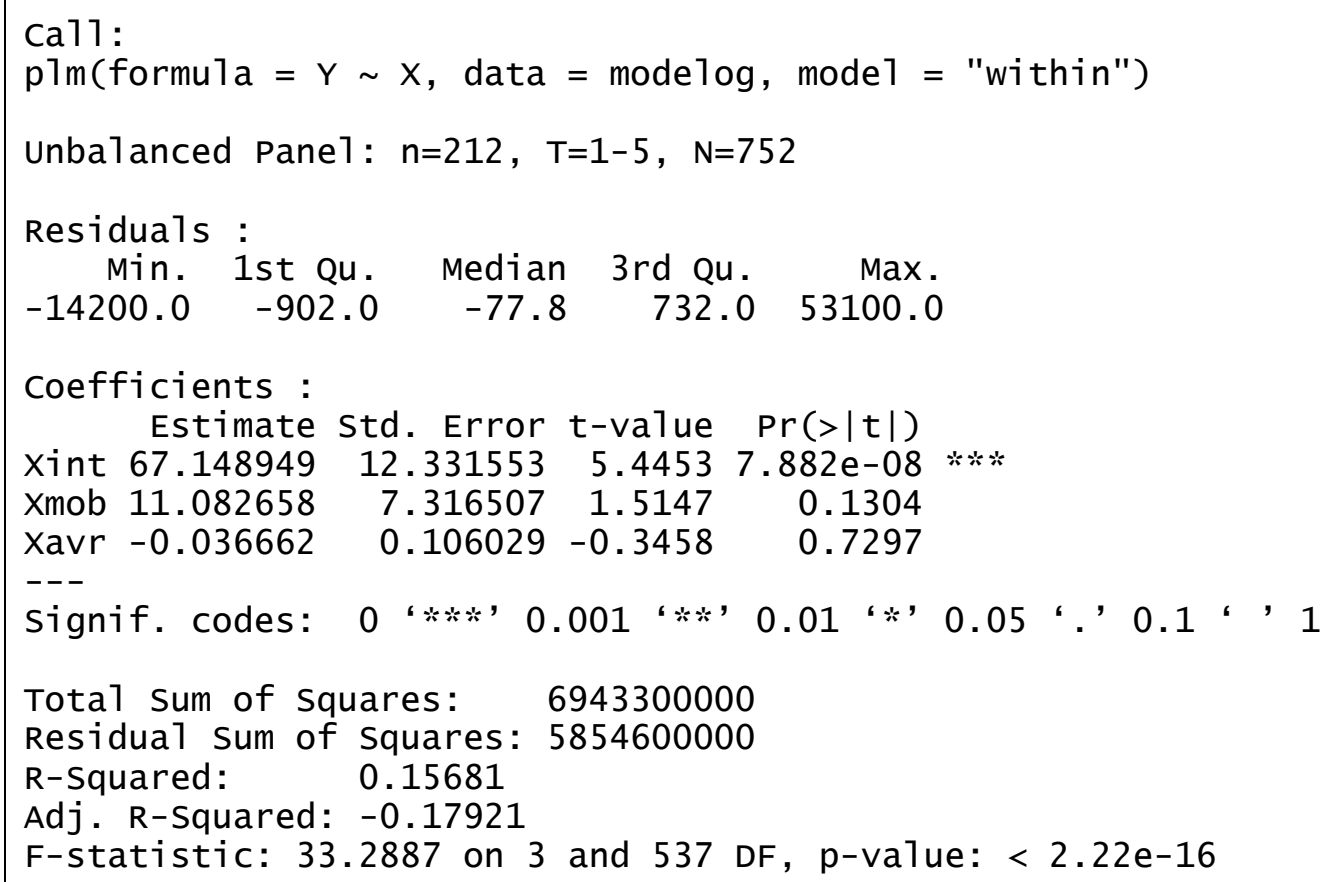

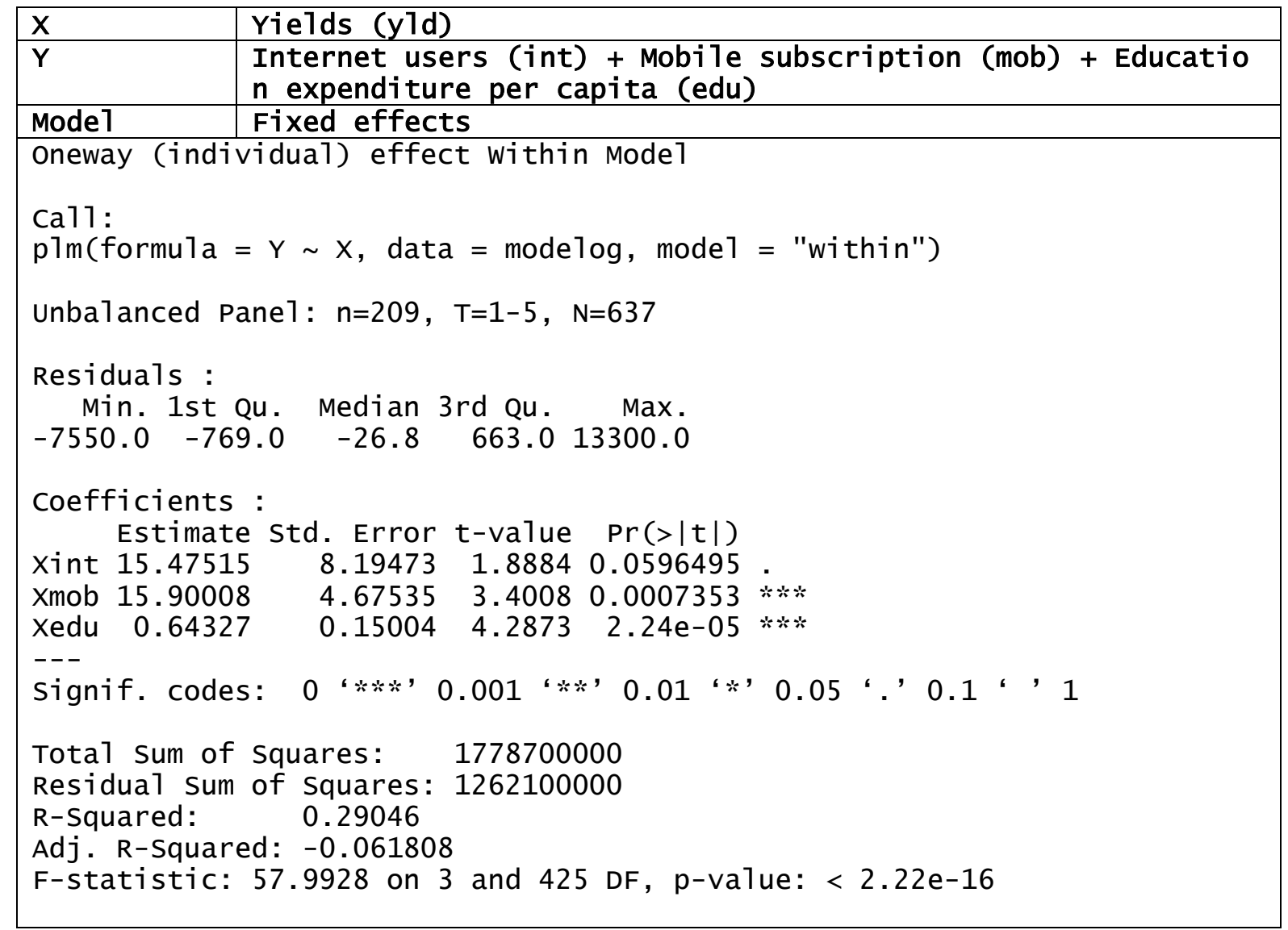

\begin{tabular}{|l|l|}
\hline $\mathrm{X}$ & Yields (yld) \\
\hline $\mathrm{Y}$ & $\begin{array}{l}\text { Internet users (int) }+ \text { Mobile subscription (mob) + Water us } \\
\text { ed per hectare of arable land (wat) }\end{array}$ \\
\hline Mode1 & Fixed effects \\
\hline
\end{tabular}




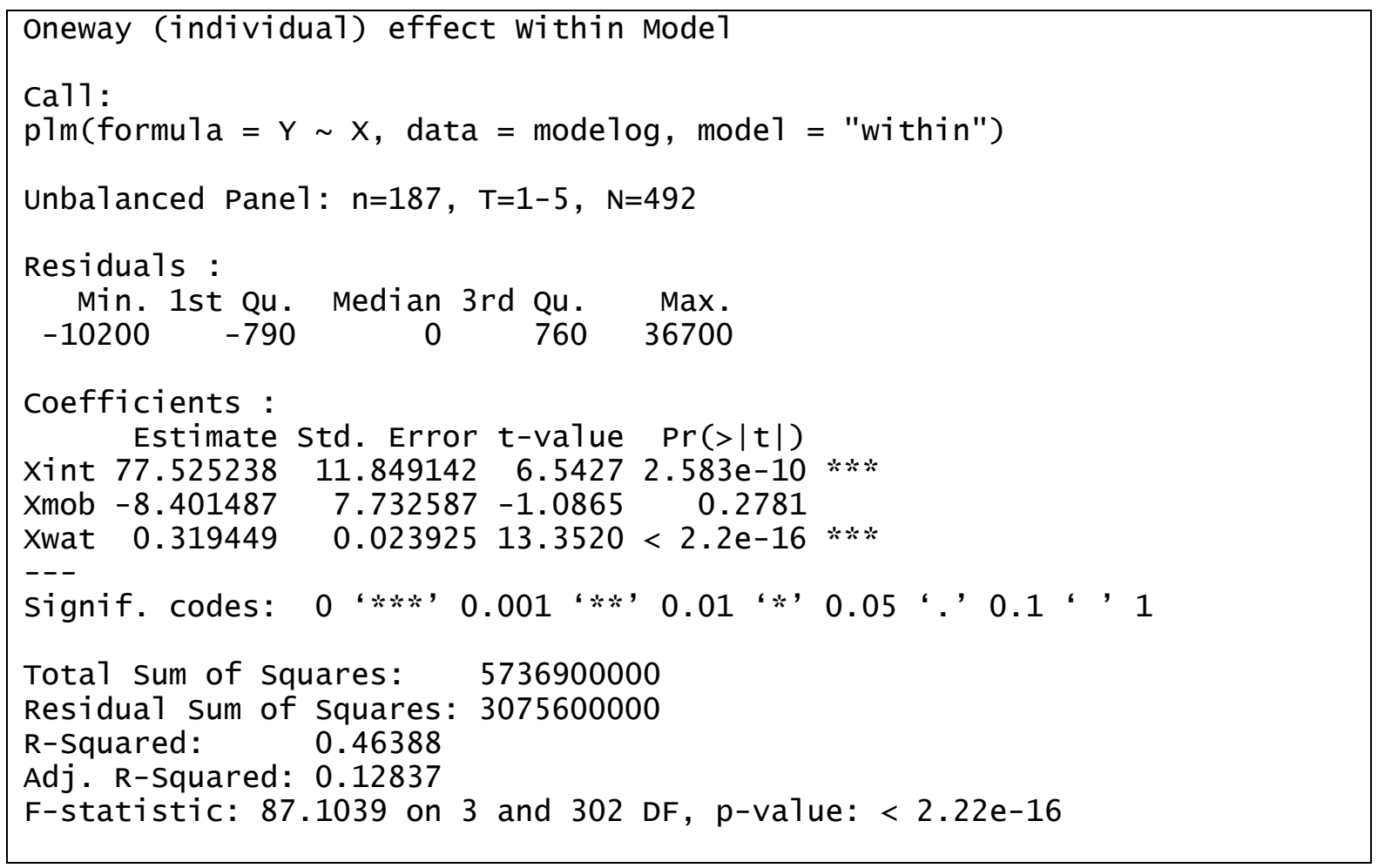

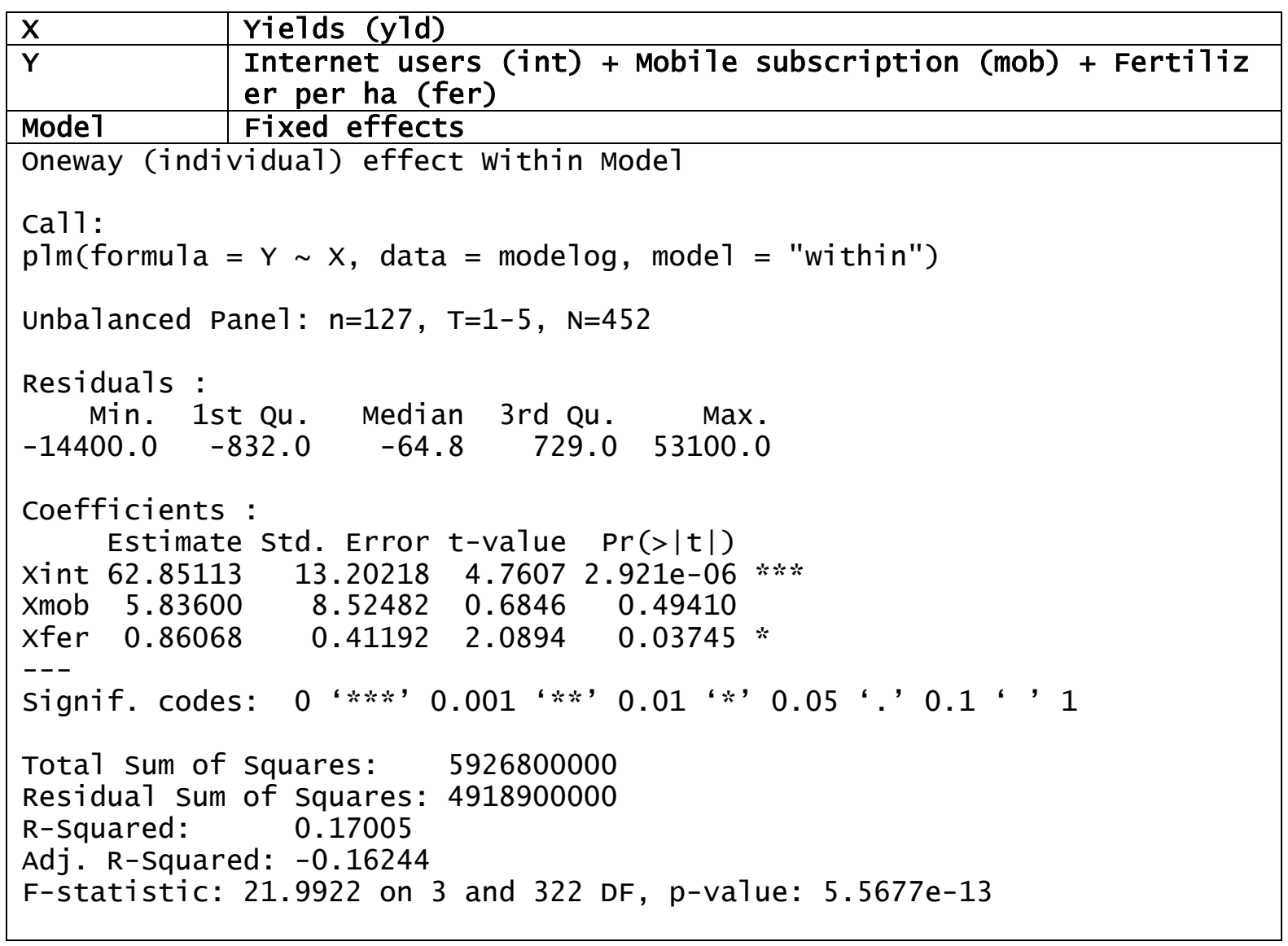

\begin{tabular}{|l|l|}
\hline$X$ & Yields (yld) \\
\hline$Y$ & $\begin{array}{l}\text { Internet users (int) + Mobile subscription (mob) + Cereals } \\
\text { Producer price (pic) }\end{array}$ \\
\hline
\end{tabular}




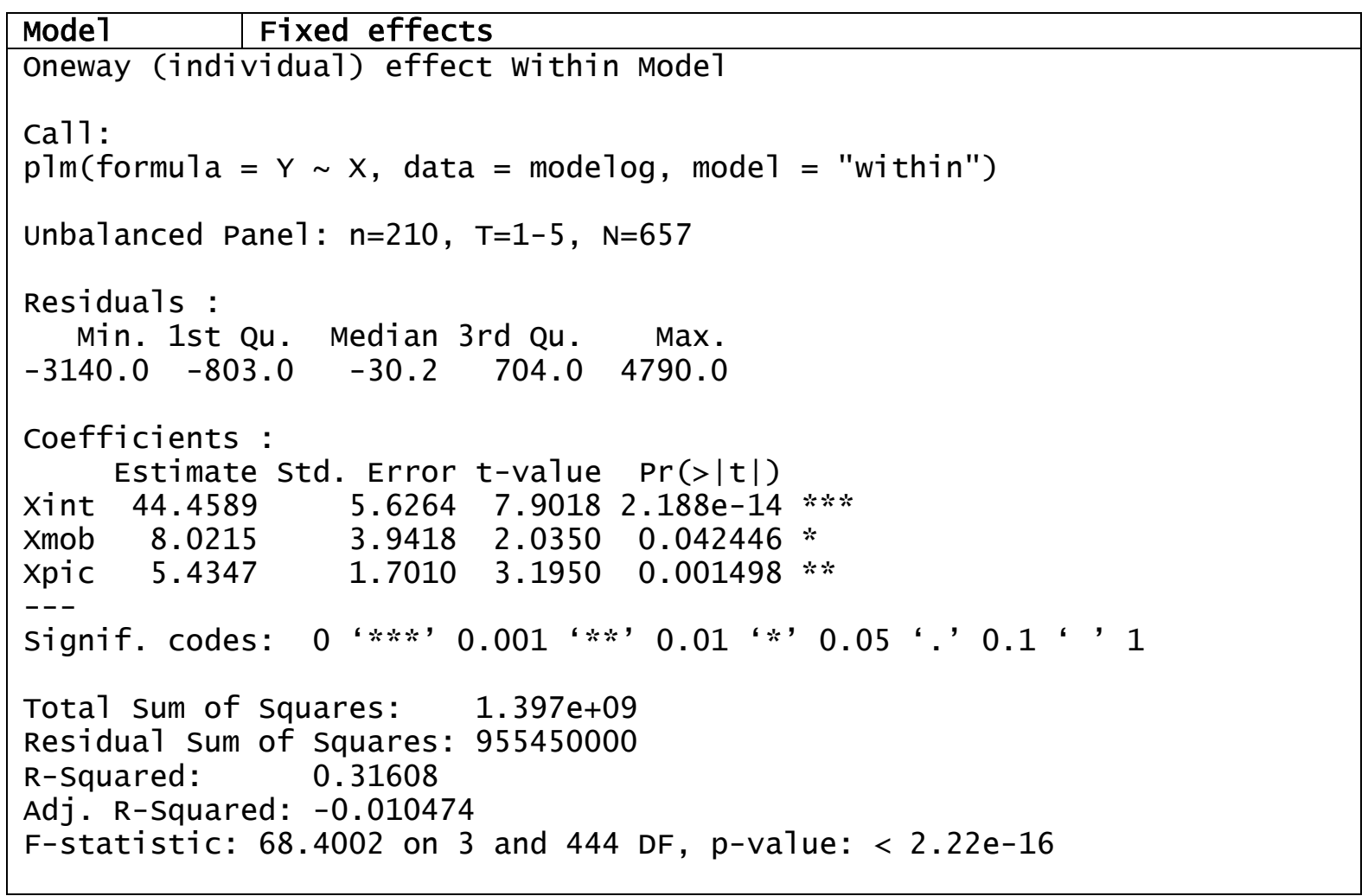

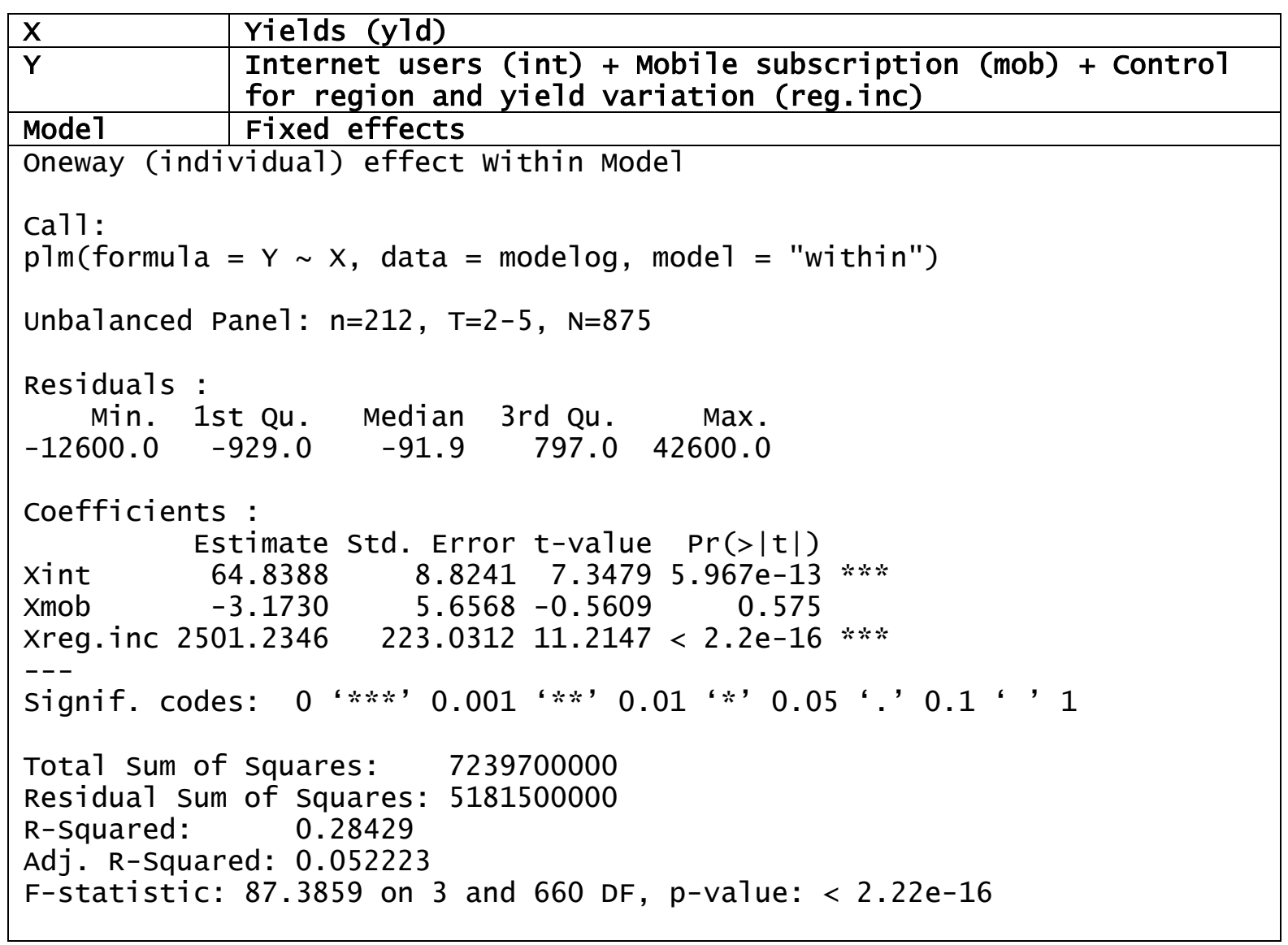




\begin{tabular}{|c|c|}
\hline $\mathbf{Y}$ & $\begin{array}{l}\text { Internet users (int) + Mobile subscription (mob) + GDP per } \\
\text { capita (gdp) + Agricultural value added (avr) + Education e } \\
\text { xpenditure (edu) + Water use per ha (wat) + Fertilizer use } \\
\text { (fer) + Cereals producer prices (pic) + Control for region } \\
\text { and yield variation (reg.inc) }\end{array}$ \\
\hline Mode1 & Fixed effects \\
\hline \multicolumn{2}{|c|}{ Oneway (individual) effect within Mode1 } \\
\hline \multicolumn{2}{|c|}{$\begin{array}{l}\text { Ca11: } \\
\text { plm(formula }=Y \sim X, \text { data }=\text { modelog, } \operatorname{model}=\text { "within") }\end{array}$} \\
\hline \multicolumn{2}{|c|}{$\begin{array}{rrrrr}\text { Min. } & \text { 1st Qu. } & \text { Median } & \text { 3rd Qu. } & \text { Max. } \\
-3070 & -368 & 0 & 459 & 3070\end{array}$} \\
\hline \multicolumn{2}{|c|}{ Coefficients : } \\
\hline \multicolumn{2}{|c|}{ 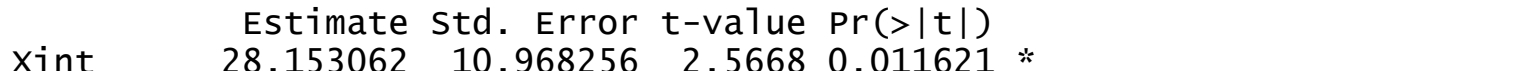 } \\
\hline \multicolumn{2}{|c|}{$\begin{array}{lllll}\text { Xmob } & 0.661575 & 5.668816 & 0.1167 & 0.907309 \\
\text { Xadp } & 0.040043 & 0.025293 & 1.5832 & 0.116282\end{array}$} \\
\hline \multicolumn{2}{|c|}{$\begin{array}{lllll}\text { Xavr } & 0.186060 & 0.067217 & 2.7680 & 0.006628\end{array} * *$} \\
\hline \multicolumn{2}{|c|}{ Xedu $\quad \begin{array}{lllll}-0.477237 & 0.432080 & -1.1045 & 0.271804\end{array}$} \\
\hline \multicolumn{2}{|c|}{ Xwat $\quad 0.086568 \quad 0.034407 \quad 2.51600 .013326 *$} \\
\hline \multicolumn{2}{|c|}{$\begin{array}{lllll}\text { Xfer } & 0.754503 & 0.455822 & 1.6553 & 0.100749\end{array}$} \\
\hline \multicolumn{2}{|c|}{$\begin{array}{lrrrr}\text { xpic } & 4.583317 & 2.947909 & 1.5548 & 0.122900\end{array}$} \\
\hline \multicolumn{2}{|c|}{ Signif. codes: 0 “***, $0.001 ، * *, 0.01 ، * 0.05 ،, 0.1 ،, 1$} \\
\hline \multicolumn{2}{|c|}{$\begin{array}{l}\text { Total sum of Squares: } 391220000 \\
\text { Residual sum of Squares: } 179210000 \\
\text { R-Squared: } 0.54191 \\
\text { Adj. R-Squared: } 0.037589 \\
\text { F-statistic: } 14.3271 \text { on } 9 \text { and } 109 \text { DF, p-value: } 4.8642 \mathrm{e}-15\end{array}$} \\
\hline
\end{tabular}

\section{Fixed time effects}

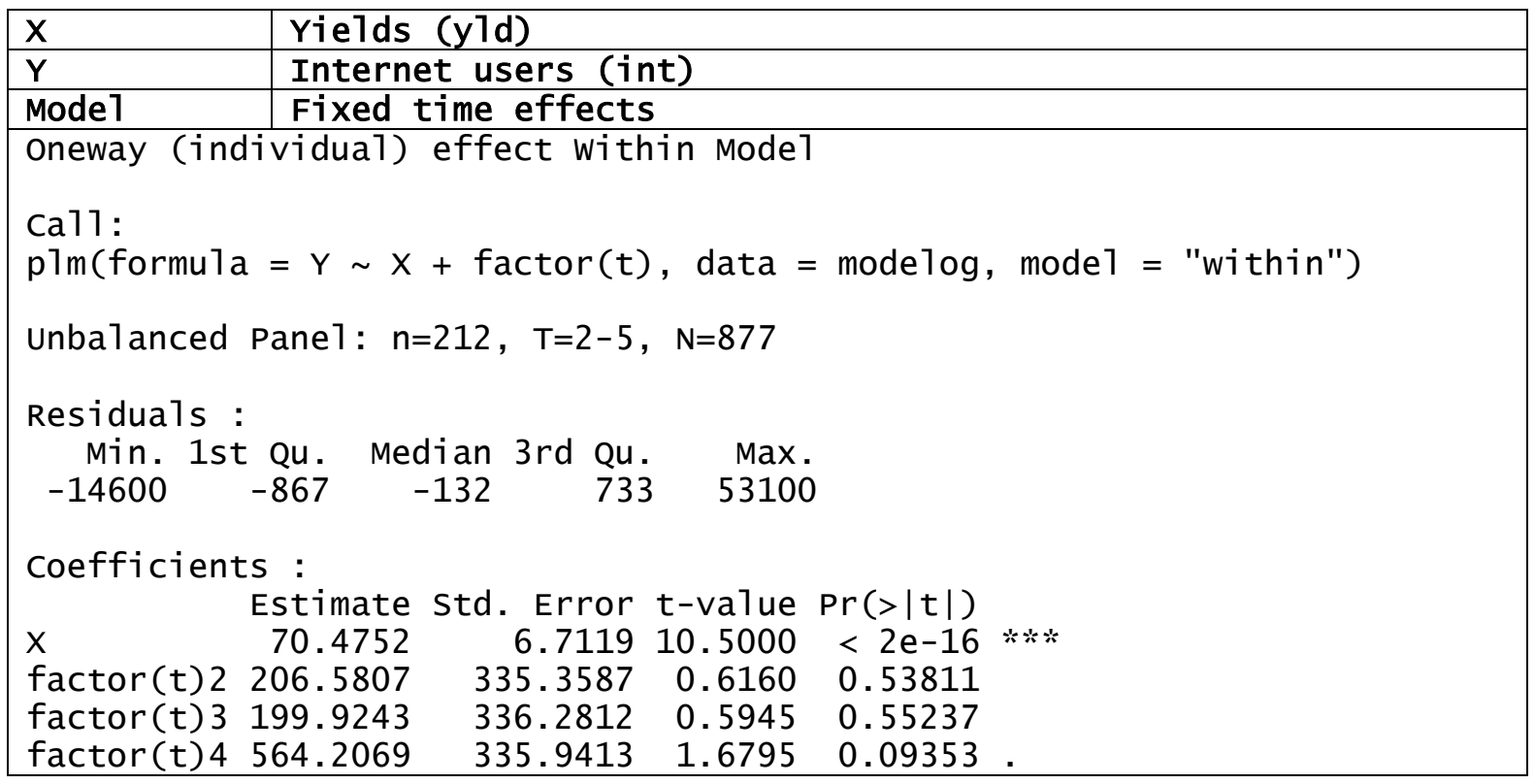



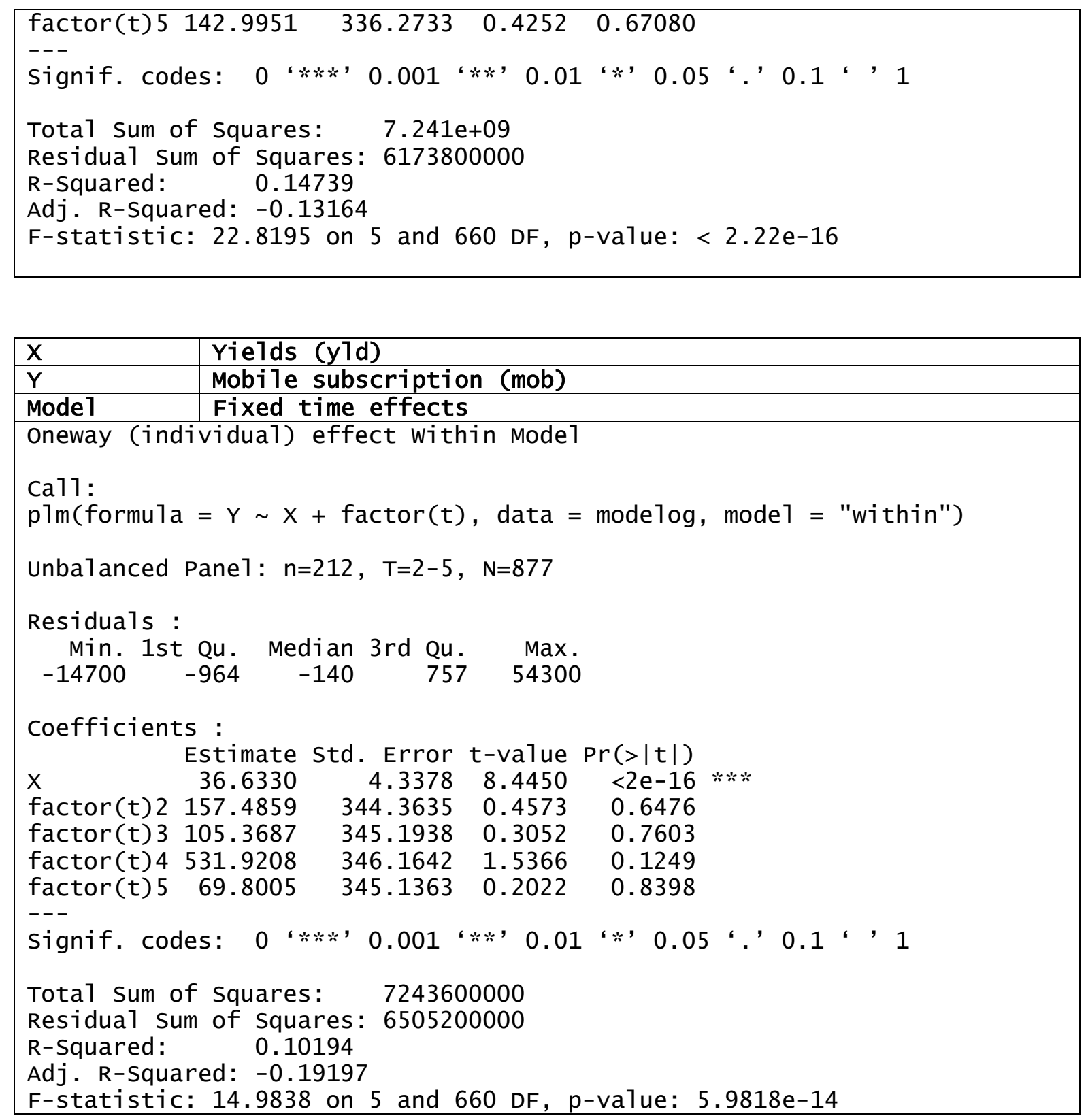

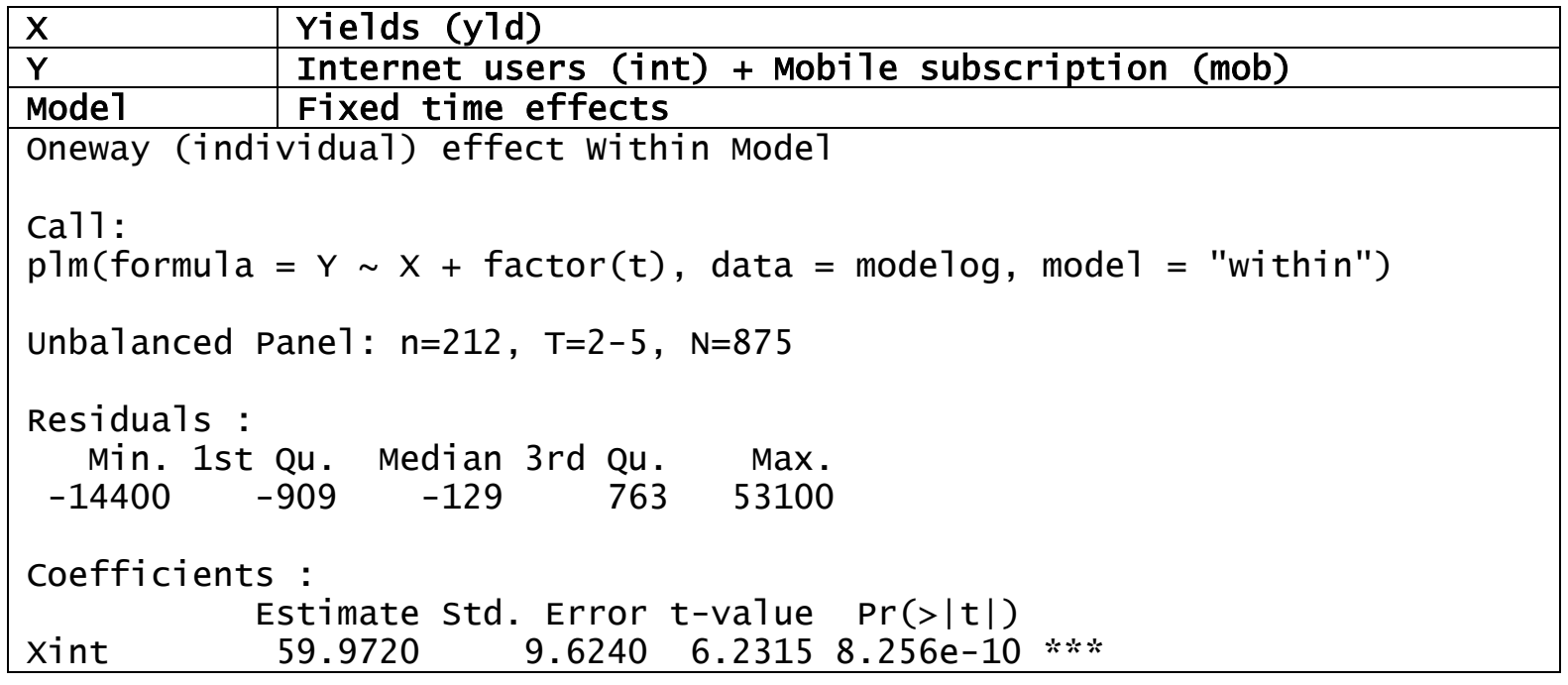




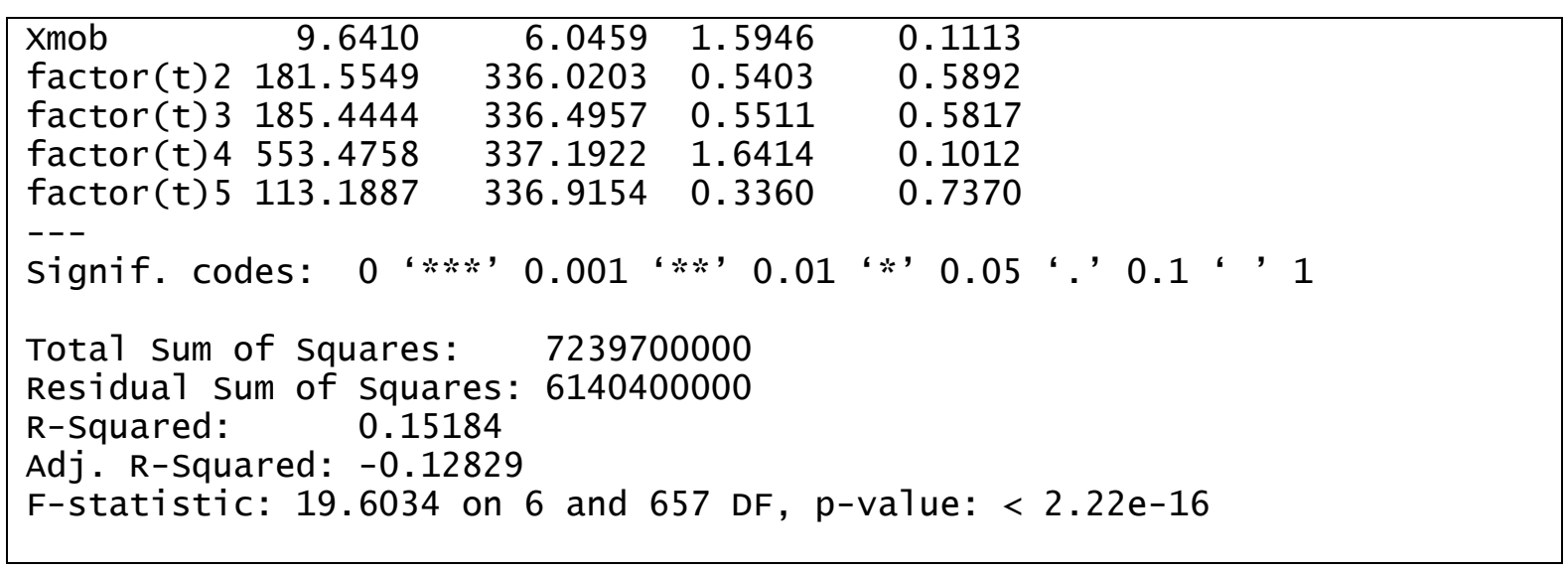

\begin{tabular}{|c|c|}
\hline $\mathbf{x}$ & Yields (yld) \\
\hline $\mathbf{Y}$ & $\begin{array}{l}\text { Internet users (int) + Mobile subscription (mob) + GDP per } \\
\text { capita (gdp) }\end{array}$ \\
\hline Mode1 & Fixed time effects \\
\hline \multicolumn{2}{|c|}{ Oneway (individua1) effect within Model } \\
\hline \multicolumn{2}{|c|}{$\begin{array}{l}\text { Ca11: } \\
\text { plm(formula }=Y \sim X+\text { factor }(t), \text { data }=\operatorname{modelog}, \operatorname{mode} 1=\text { "within") }\end{array}$} \\
\hline \multirow{2}{*}{\multicolumn{2}{|c|}{ 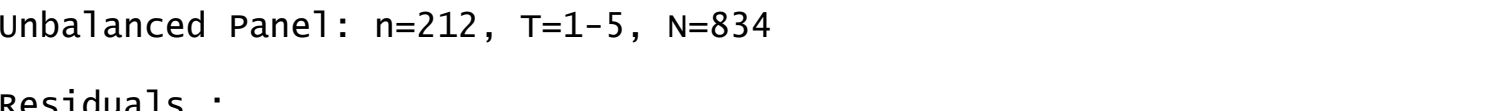 }} \\
\hline & \\
\hline \multicolumn{2}{|c|}{$\begin{array}{rrrrr}\text { Min. } & \text { 1st Qu. } & \text { Median } & \text { 3rd Qu. } & \text { Max. } \\
-18000.0 & -806.0 & -67.6 & 741.0 & 49800.0\end{array}$} \\
\hline \multicolumn{2}{|c|}{ Coefficients : } \\
\hline \multicolumn{2}{|c|}{ Estimate std. Error t-value $\operatorname{Pr}(>|t|)$} \\
\hline \multicolumn{2}{|c|}{$\begin{array}{llrrrr}\text { Xint } & 33.0 / 6 / 19 & 11.653699 & 2.83 / 8 & 0.0046922 & * * \\
\text { Xmob } & 14.006308 & 6.220215 & 2.2517 & 0.0246907 & *\end{array}$} \\
\hline \multicolumn{2}{|c|}{$\begin{array}{lllll}\text { Xgdp } & 0.047368 & 0.012826 & 3.6931 & 0.0002413\end{array} * * *$} \\
\hline \multicolumn{2}{|c|}{$\begin{array}{lllll}\text { factor }(t) 2 & 207.509094 & 344.365906 & 0.6026 & 0.5470081 \\
\text { factor }(t) 3 & 154.749315 & 345.193195 & 0.4483 & 0.6540963\end{array}$} \\
\hline \\
\hline \multicolumn{2}{|c|}{ factor $(t) 5 \quad 171.829184 \quad 344.843412 \quad 0.4983 \quad 0.6184636$} \\
\hline \multicolumn{2}{|c|}{ Signif. codes: 0 “***; $0.001 ، * *, 0.01 ، * 0.05 ،, 0.1 ،, 1$} \\
\hline \multicolumn{2}{|c|}{$\begin{array}{l}\text { Total Sum of Squares: } 6978500000 \\
\text { Residual sum of Squares: } 5686100000 \\
\text { R-Squared: } 0.18521 \\
\text { Adj. R-Squared: }-0.10362 \\
\text { F-statistic: } 19.9703 \text { on } 7 \text { and } 615 \text { DF, p-value: }<2.22 \mathrm{e}-16\end{array}$} \\
\hline
\end{tabular}

\begin{tabular}{|l|l|}
\hline$X$ & Yields (yld) \\
\hline$Y$ & $\begin{array}{l}\text { Internet users (int) }+ \text { Mobile subscription (mob) + Agricu1t } \\
\text { ural value added (avr) }\end{array}$ \\
\hline Mode1 & Fixed time effects \\
\hline Oneway (individual) effect Within Mode1 \\
$\begin{array}{l}\text { Ca11: } \\
\text { p1m(formu1a }=Y \sim X+\text { factor }(t), \text { data }=\text { mode1og, mode1 = "within") }\end{array}$ \\
\hline
\end{tabular}




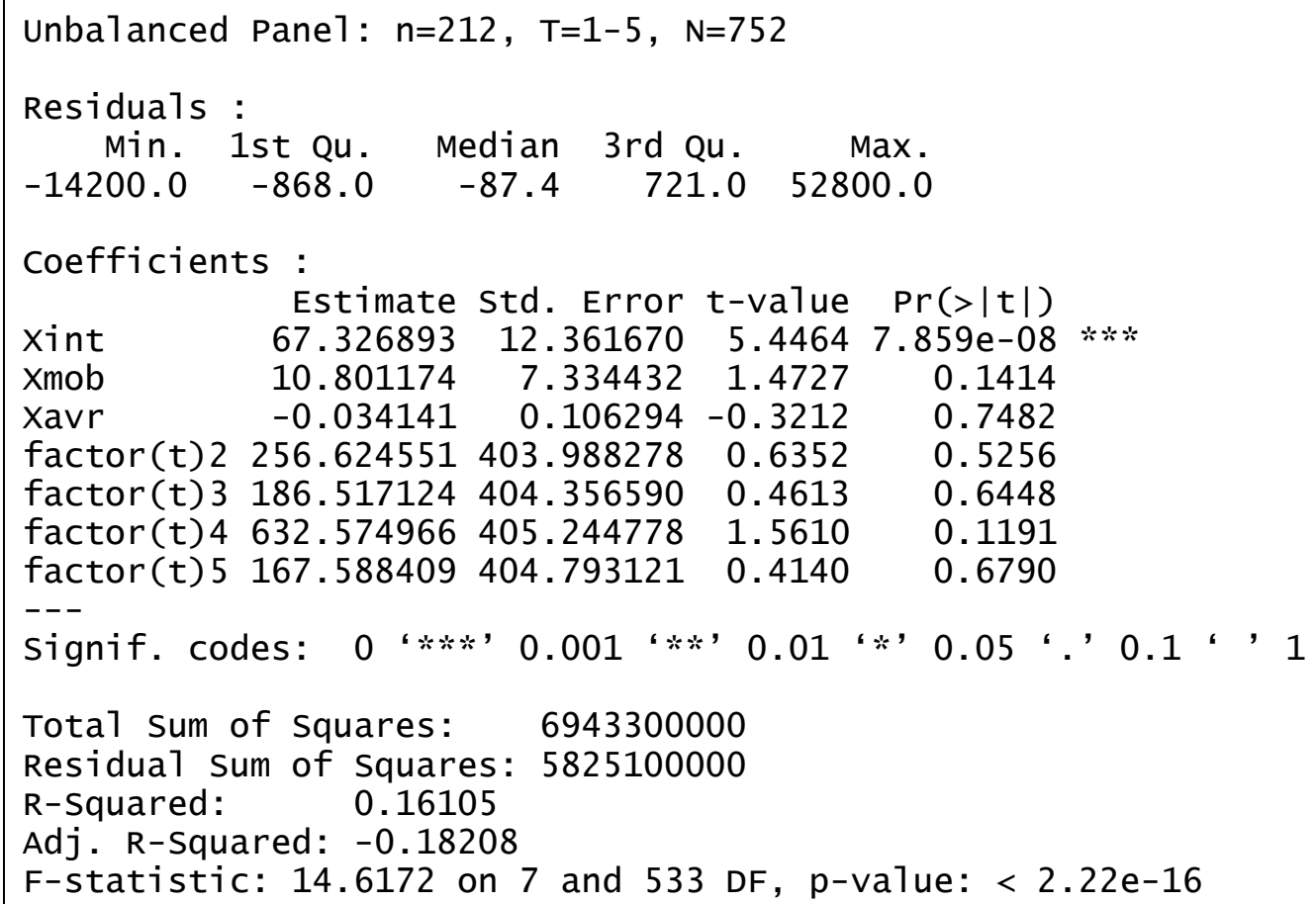

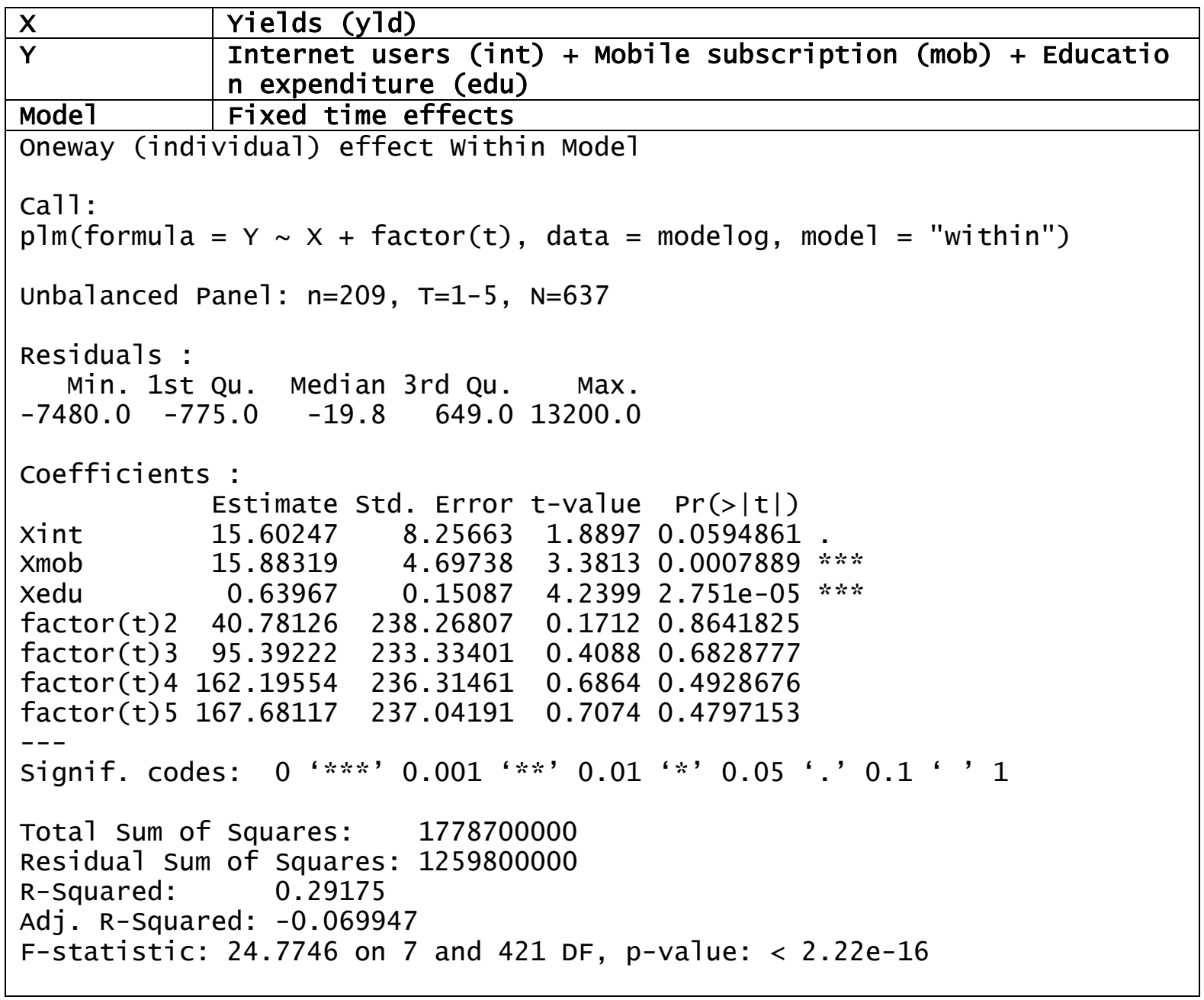




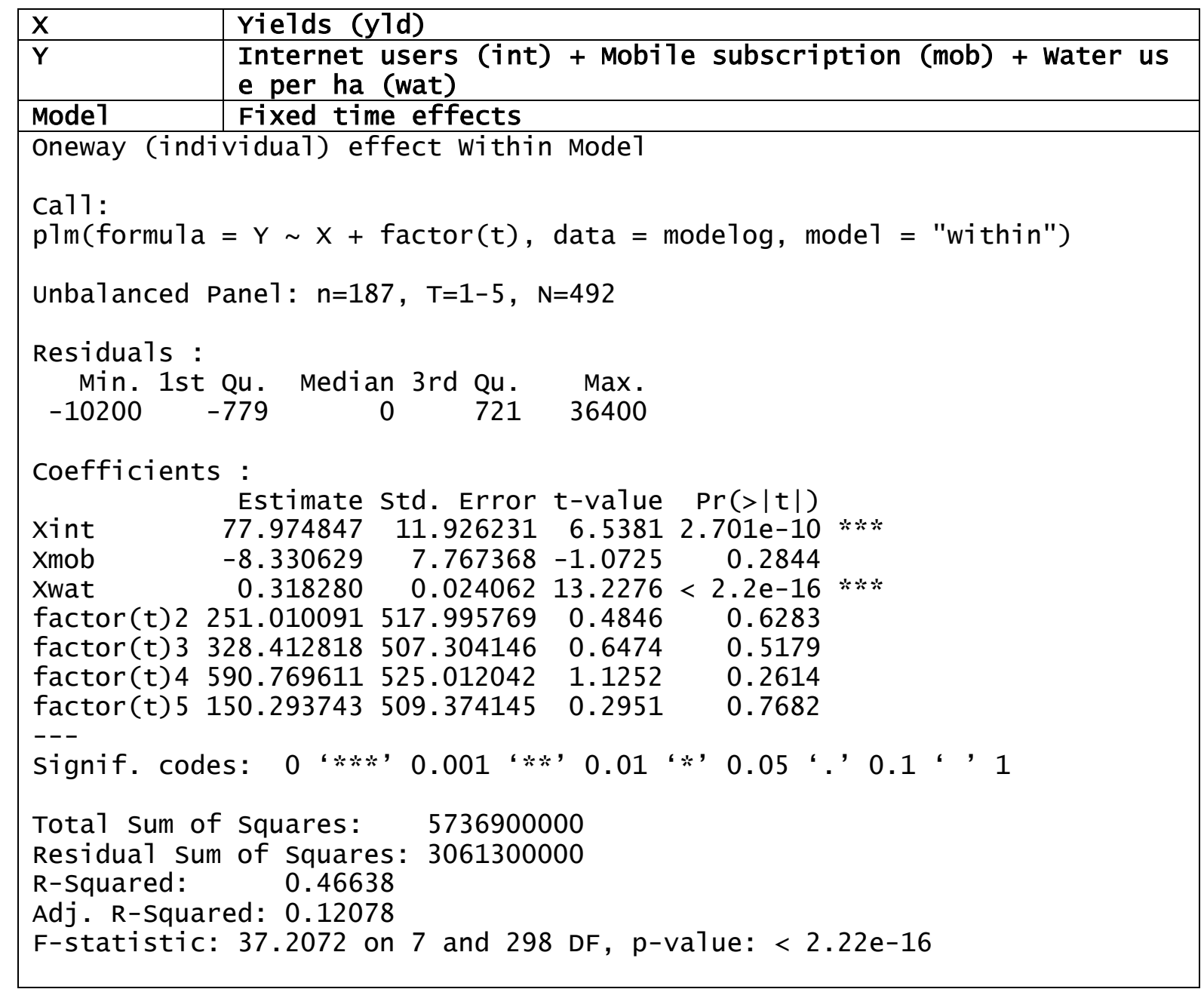

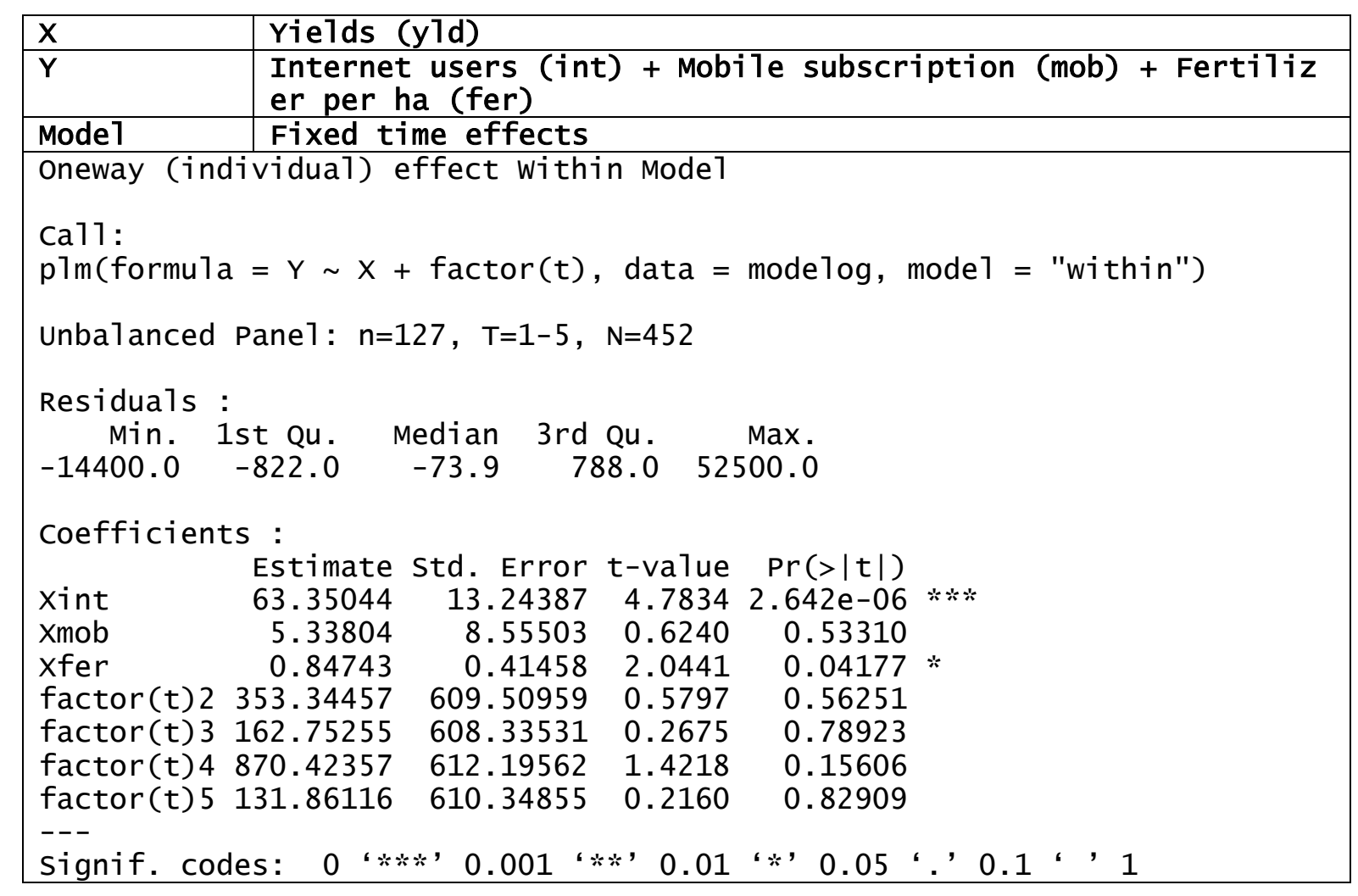


Total Sum of Squares: $\quad 5926800000$

Residual Sum of Squares: 4881300000

R-Squared: $\quad 0.1764$

Adj. R-Squared: -0.16806

F-statistic: 9.72989 on 7 and 318 DF, p-value: $5.5069 \mathrm{e}-11$

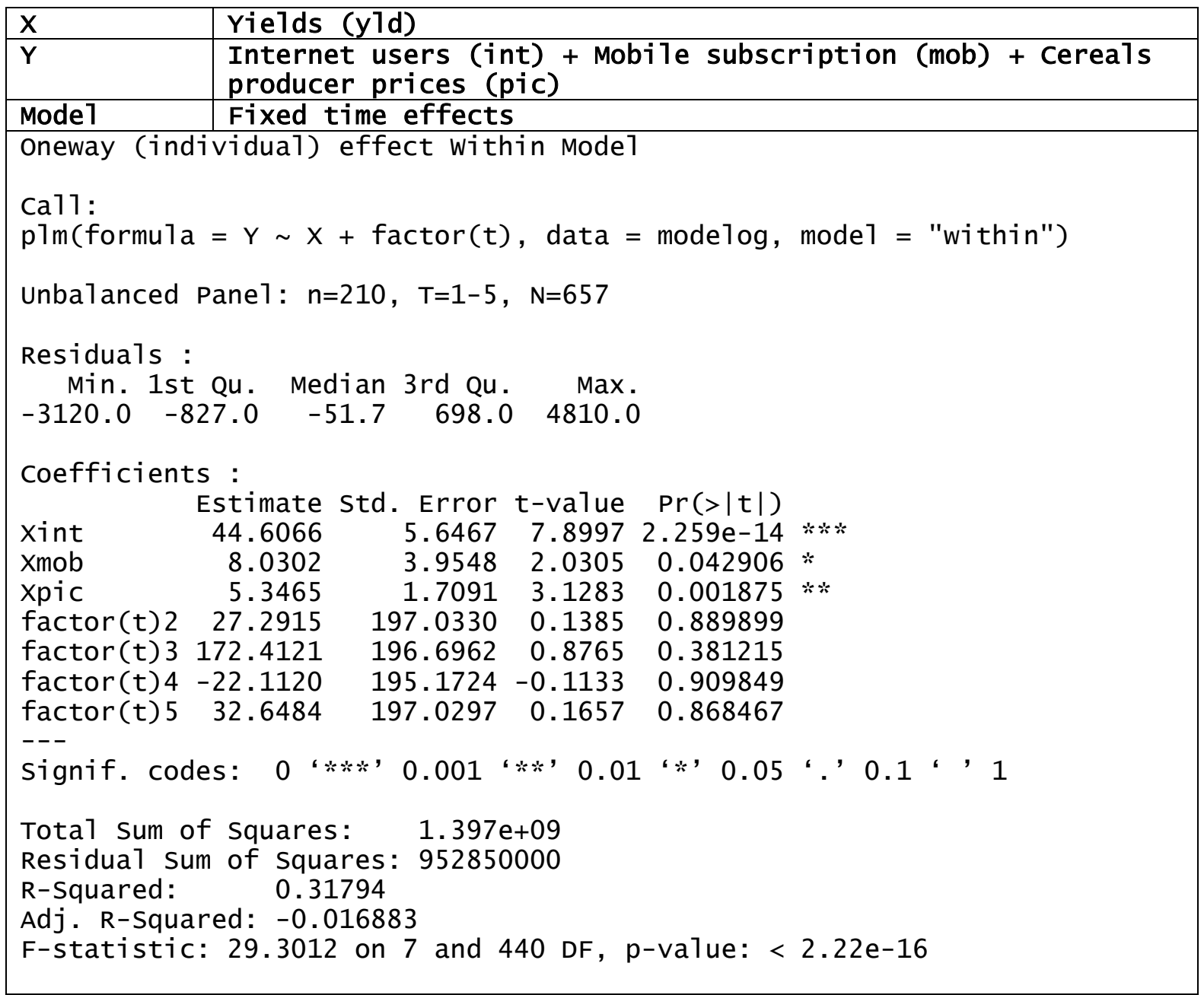

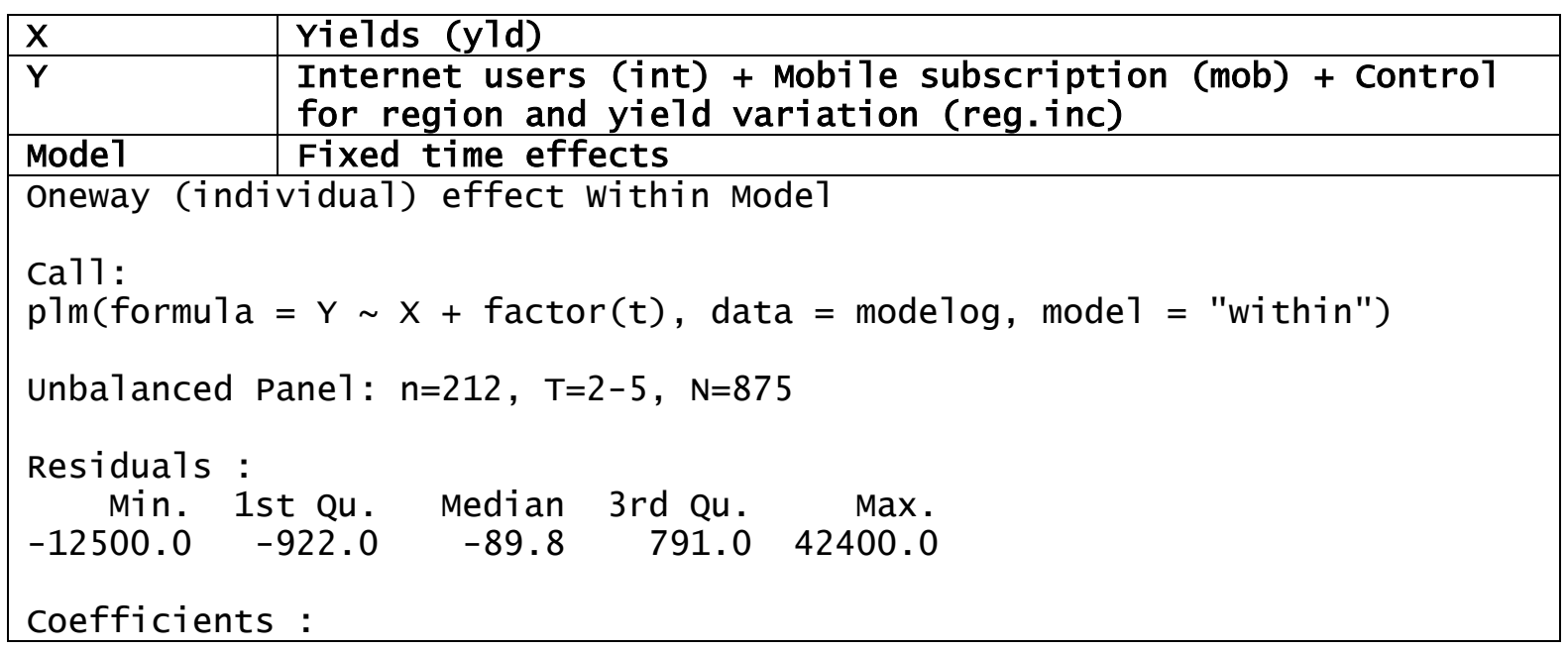




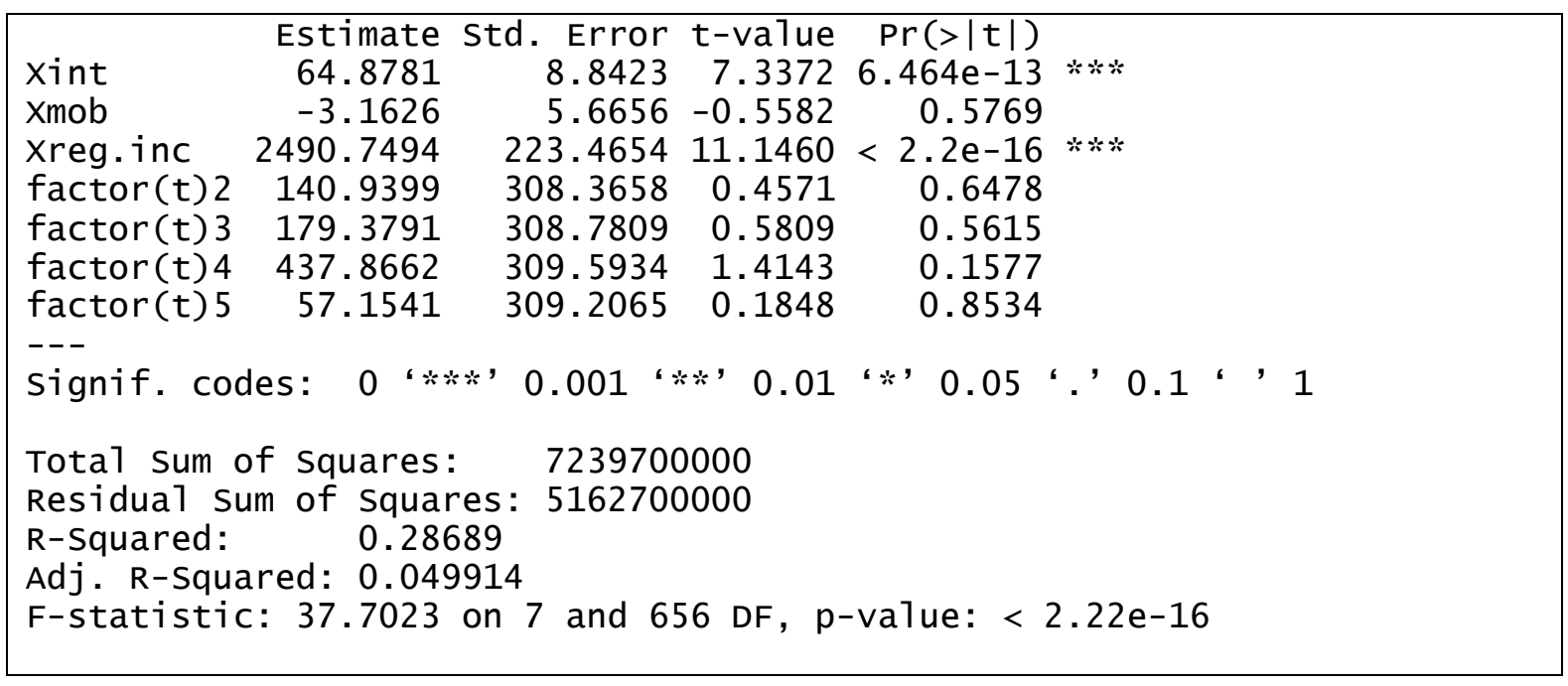

\begin{tabular}{|c|c|}
\hline $\mathbf{X}$ & Yields (yld) \\
\hline $\mathbf{Y}$ & $\begin{array}{l}\text { Internet users (int) + Mobile subscription (mob) + GDP per } \\
\text { capita (gdp) + Agricultural value added (avr) + Education e } \\
\text { xpenditure (edu) + Water use per ha (wat) + Fertilizer use } \\
\text { per ha (fer) + Cereals producer prices (pic) + Control for } \\
\text { region and yield variation (reg.inc) }\end{array}$ \\
\hline Mode1 & Fixed time effects \\
\hline \multicolumn{2}{|c|}{ Oneway (individua1) effect within Model } \\
\hline \multicolumn{2}{|c|}{$\begin{array}{l}\text { Cal1: } \\
\operatorname{plm}(\text { formula }=Y \sim X+\operatorname{factor}(t), \text { data }=\operatorname{model} \text { og, model }=\text { "within") }\end{array}$} \\
\hline \multicolumn{2}{|c|}{$\begin{array}{rrrrr}\text { Min. } & \text { 1st Qu. } & \text { Median } 3 r d \text { Qu. } & \text { Max. } \\
-2890 & -381 & 0 & 391 & 2760\end{array}$} \\
\hline \multicolumn{2}{|c|}{ Coefficients : } \\
\hline \multicolumn{2}{|c|}{ Estimate std. Error t-value $\operatorname{Pr}(>|t|)$} \\
\hline Xmob & $\begin{array}{llll}0.811399 & 5.669968 & 0.1431 & 0.886482\end{array}$ \\
\hline Xgdp & $1.5874 \quad 0.115420$ \\
\hline Xavr & $0.068081 \quad 3.0557 \quad 0.002847 * *$ \\
\hline Xedu & $0.432491-1.2191 \quad 0.225535$ \\
\hline Xwat & $0.0346582 .27610 .024870 *$ \\
\hline xfer & 1.69020 .093950$. \\
\hline Xpic & $4.408976 \quad 2.968482$ \\
\hline Xreg.inc & $51.928370 \quad 452.194417$ \\
\hline factor $(t) 2$ & $\begin{array}{llll}72.685565 & 340.267505 & 1.0953 & 0.275903\end{array}$ \\
\hline $\begin{array}{l}\text { factor }(t) 3 \\
\text { factor }(t) 4\end{array}$ & $\begin{array}{rrrr}74.867065 & 337.884722 & 0.8135 & 0.417776 \\
23.680034 & 329.596615 & -0.0718 & 0.942862\end{array}$ \\
\hline factor $(t) 5$ & $55.643205 \quad 342.415997 \quad 1.9148 \quad 0.058245$ \\
\hline Signif. cod & 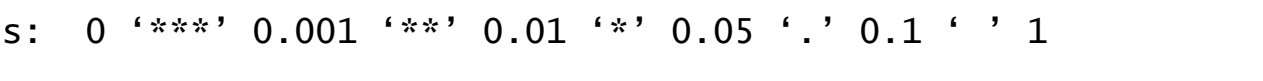 \\
\hline $\begin{array}{l}\text { Total sum o } \\
\text { Residual sur } \\
\text { R-Squared: } \\
\text { Adj. R-Squa } \\
\text { F-statistic }\end{array}$ & $\begin{array}{l}\text { Squares: } 391220000 \\
\text { of Squares: } 170730000 \\
\quad 0.56359 \\
\text { ed: } 0.048206 \\
10.4306 \text { on } 13 \text { and } 105 \text { DF, p-value: } 8.0254 \mathrm{e}-14\end{array}$ \\
\hline
\end{tabular}




\section{Random effects}

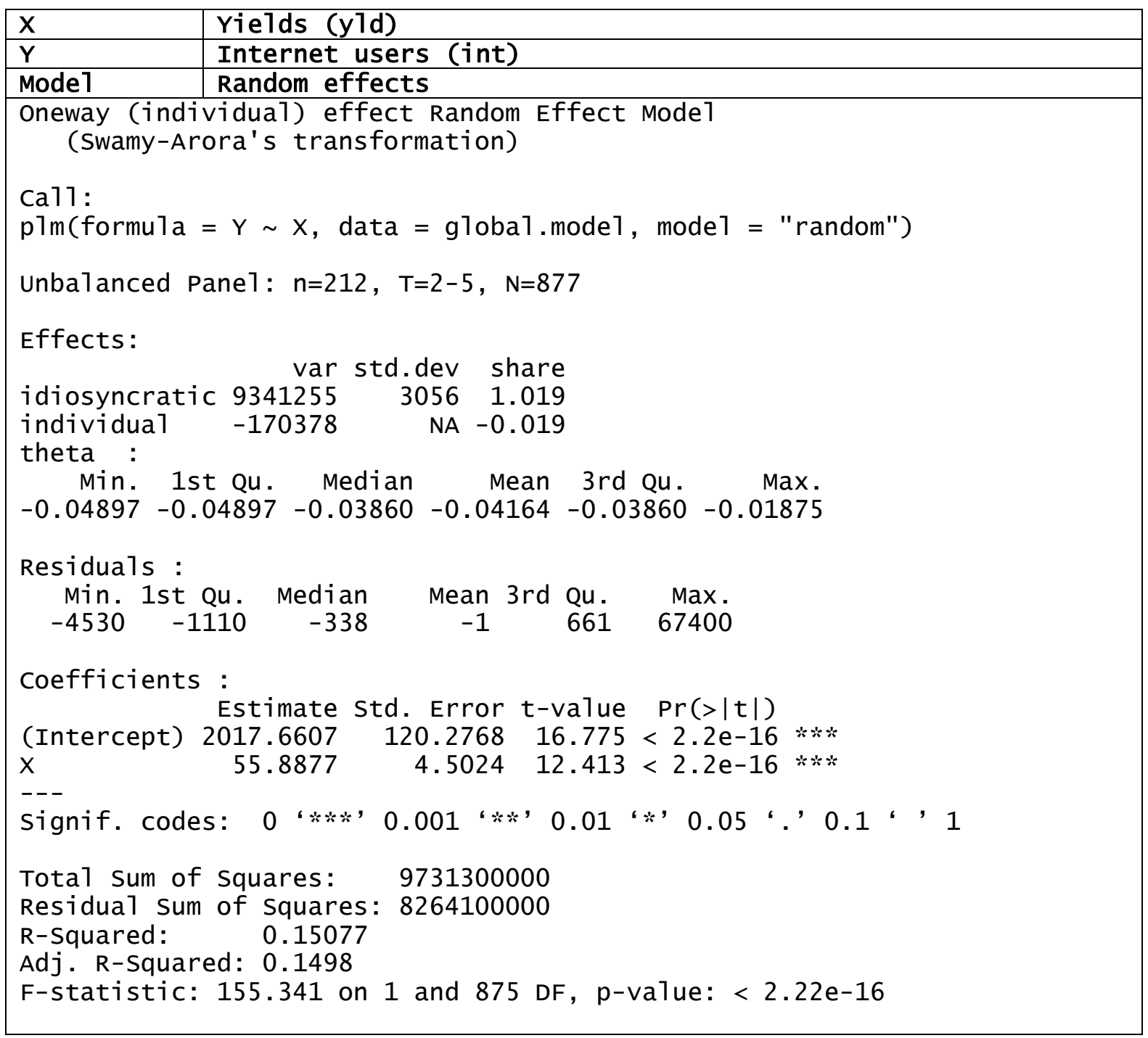

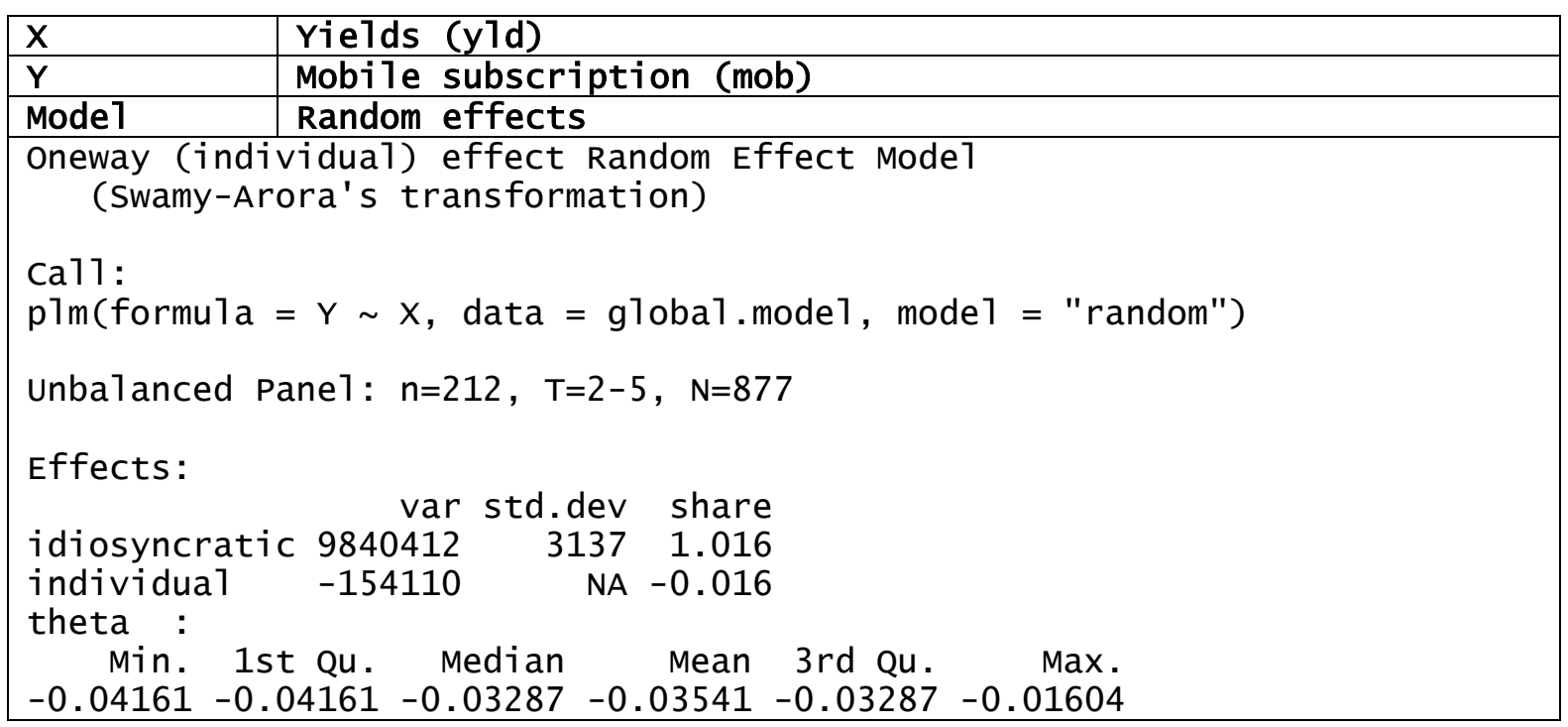




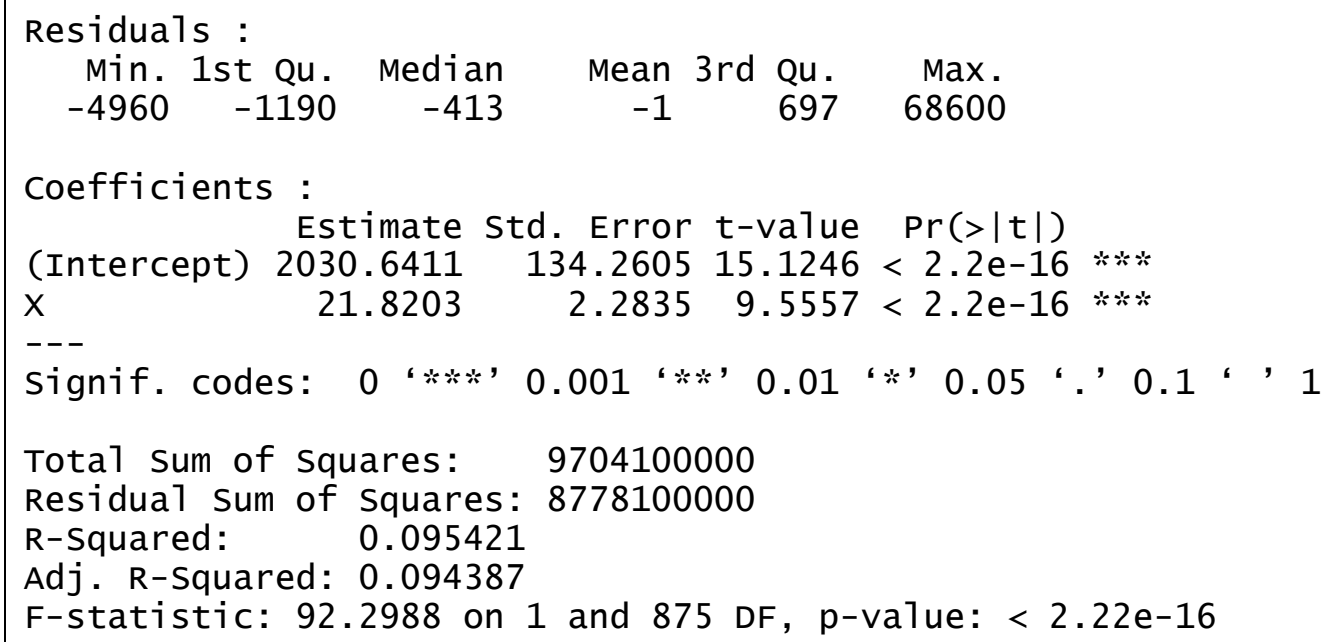

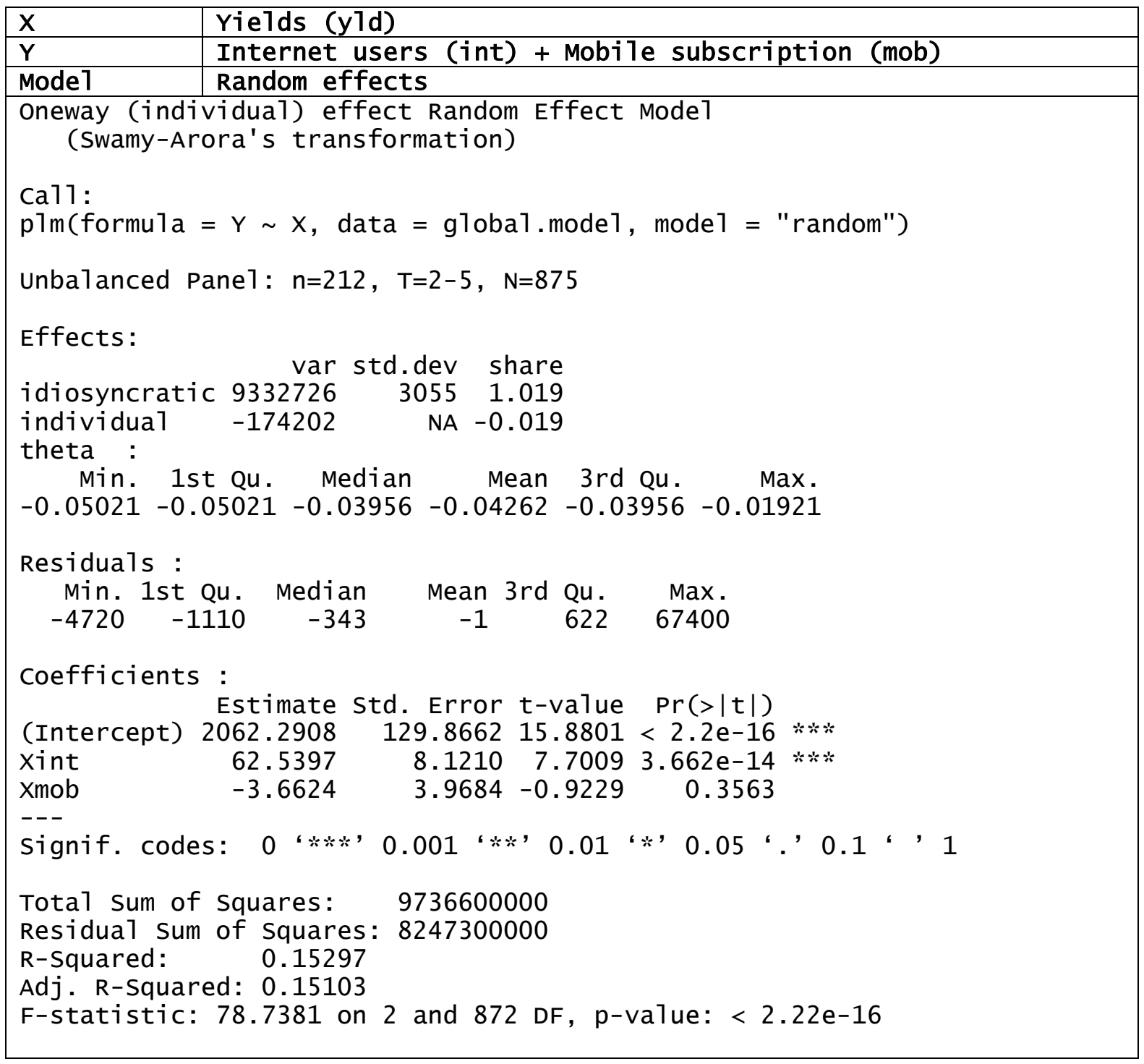




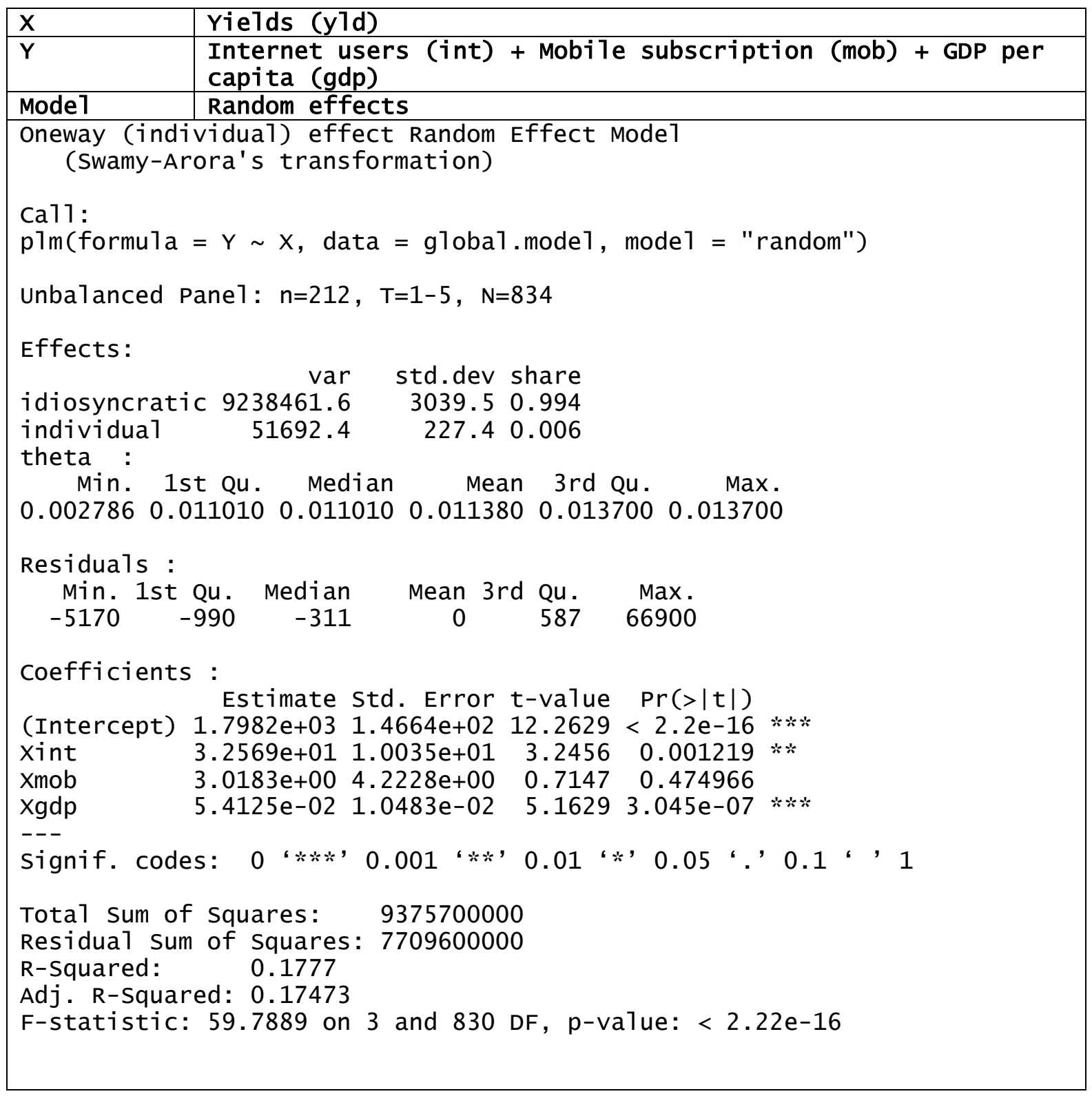

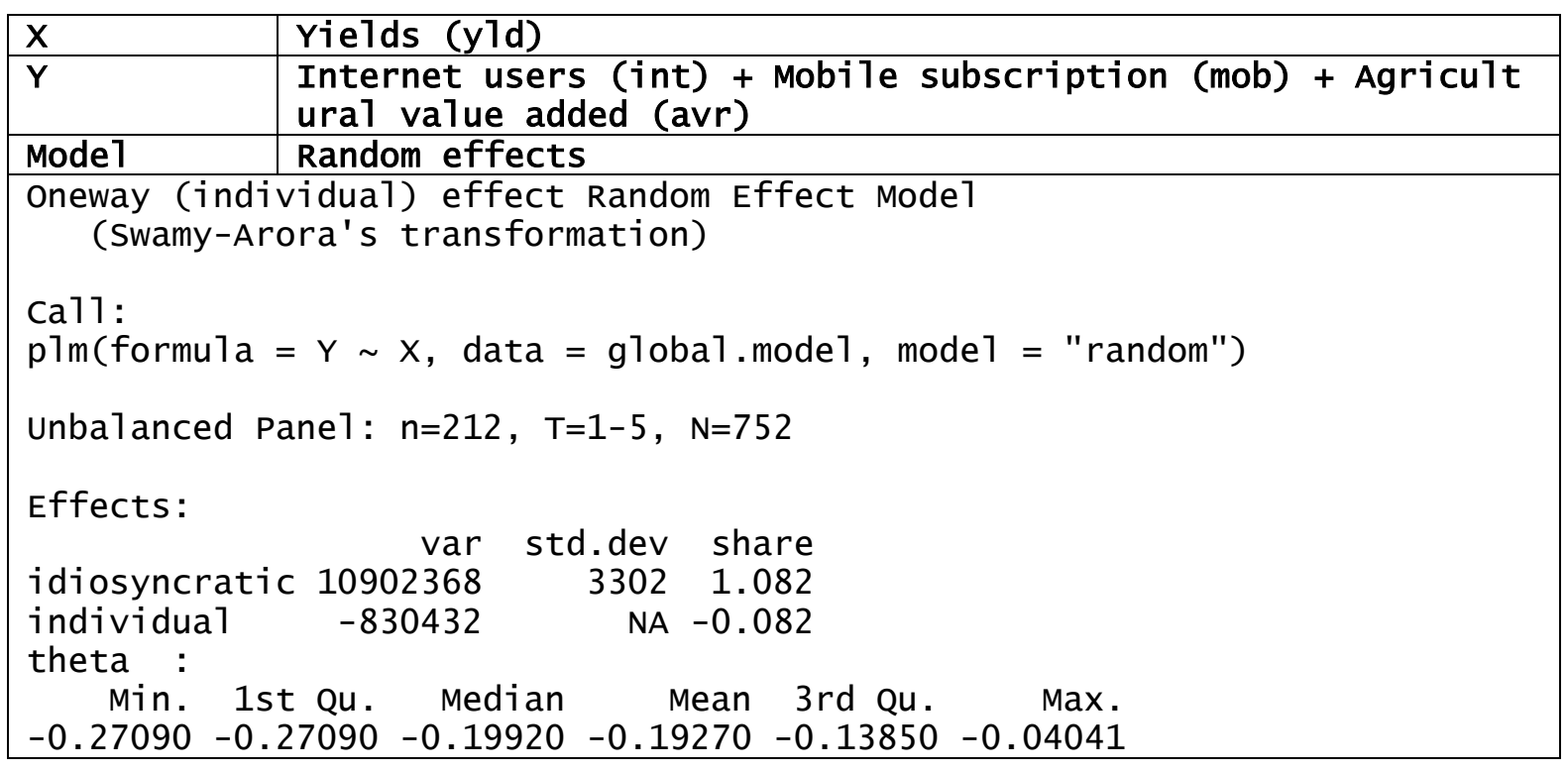




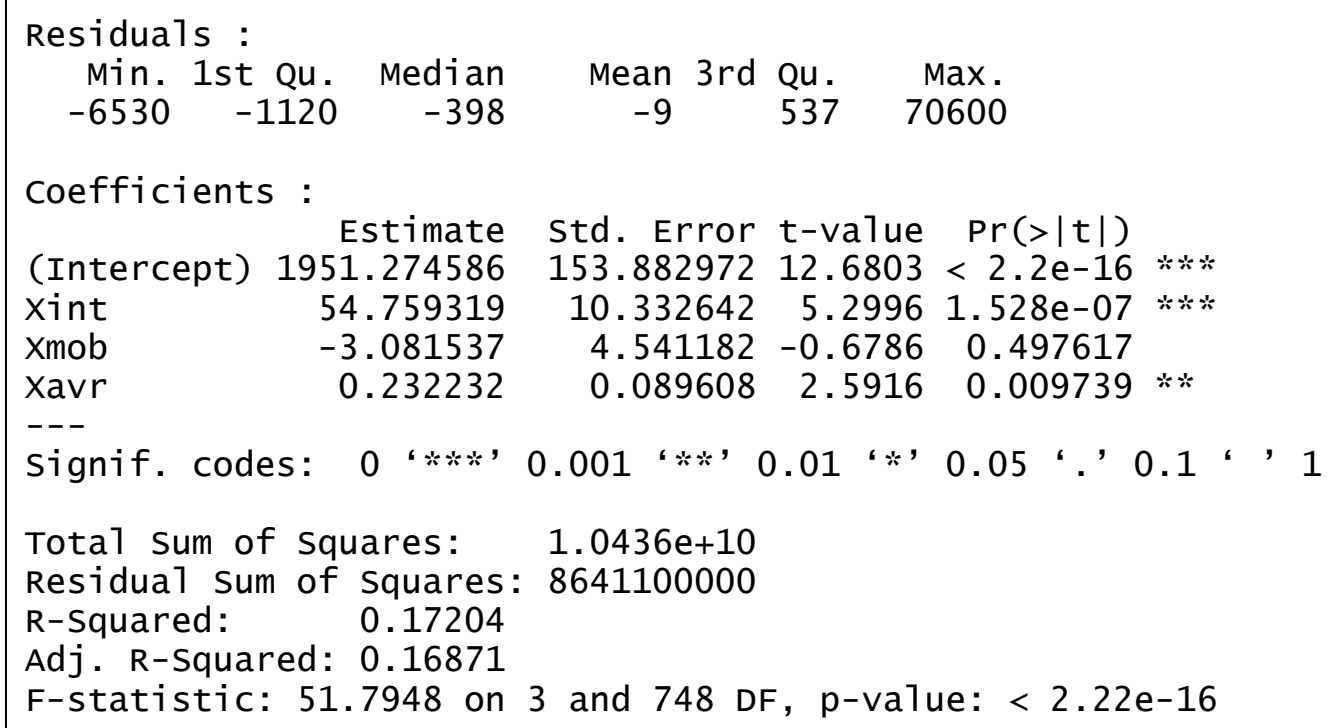

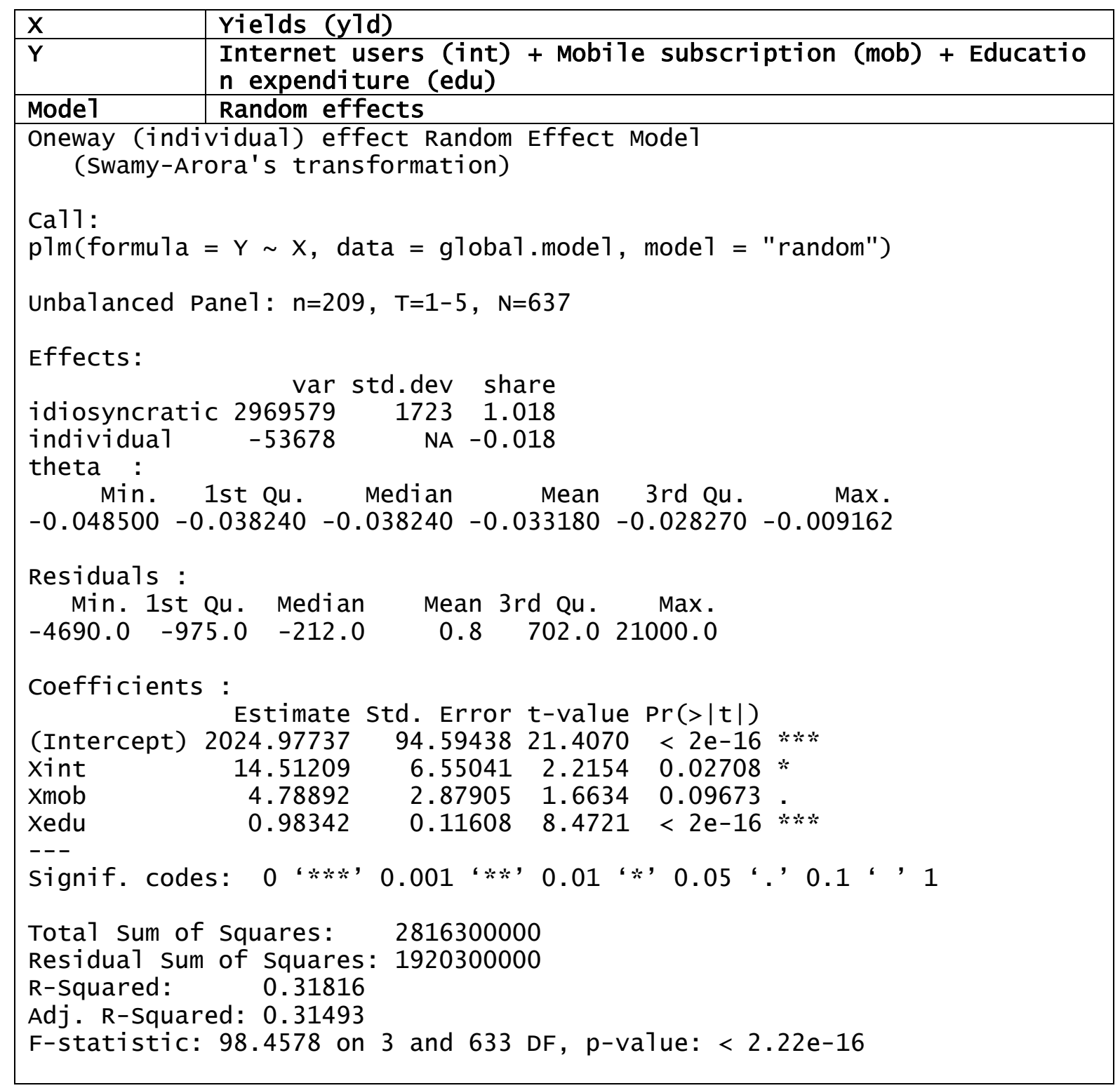




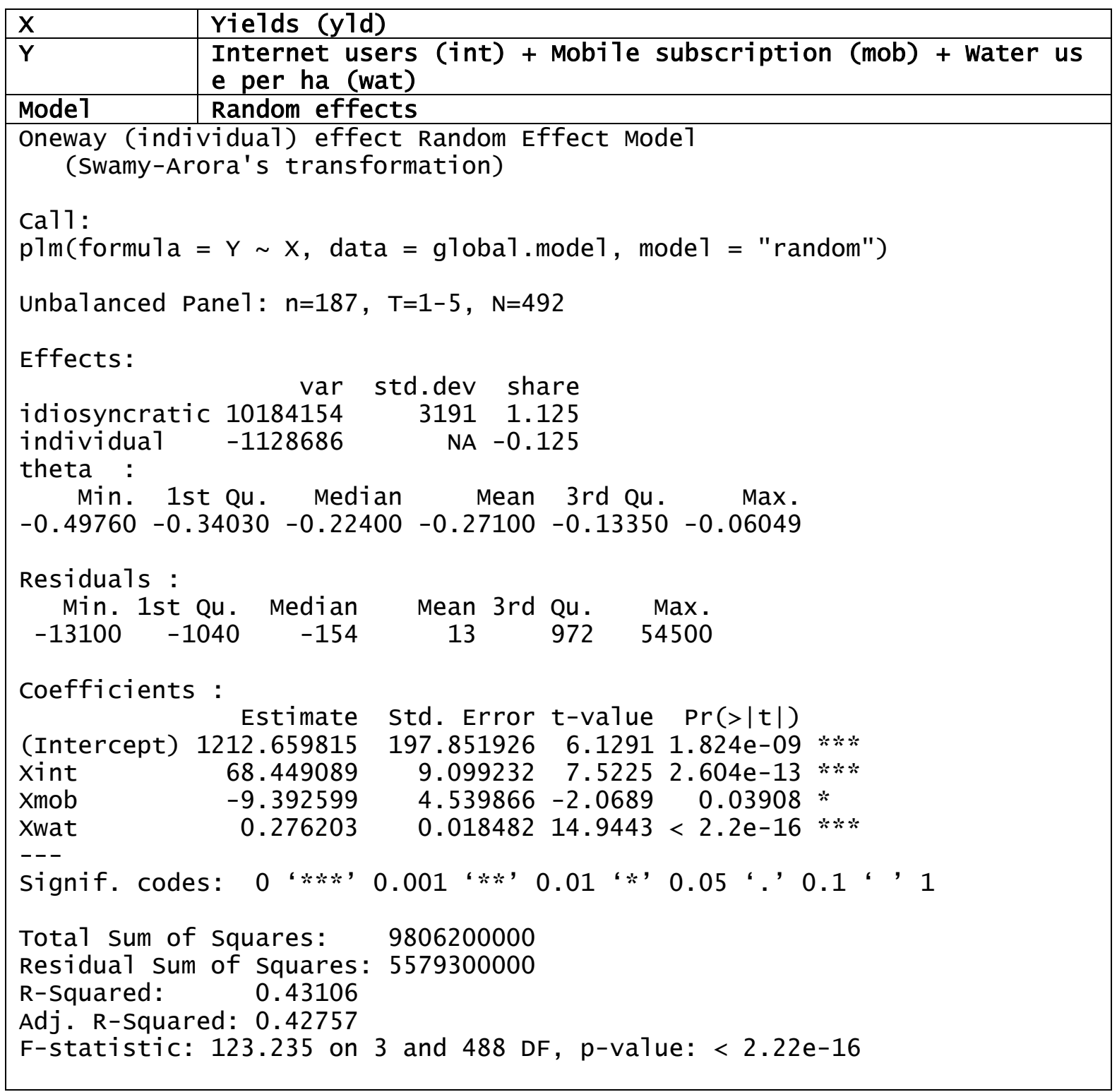

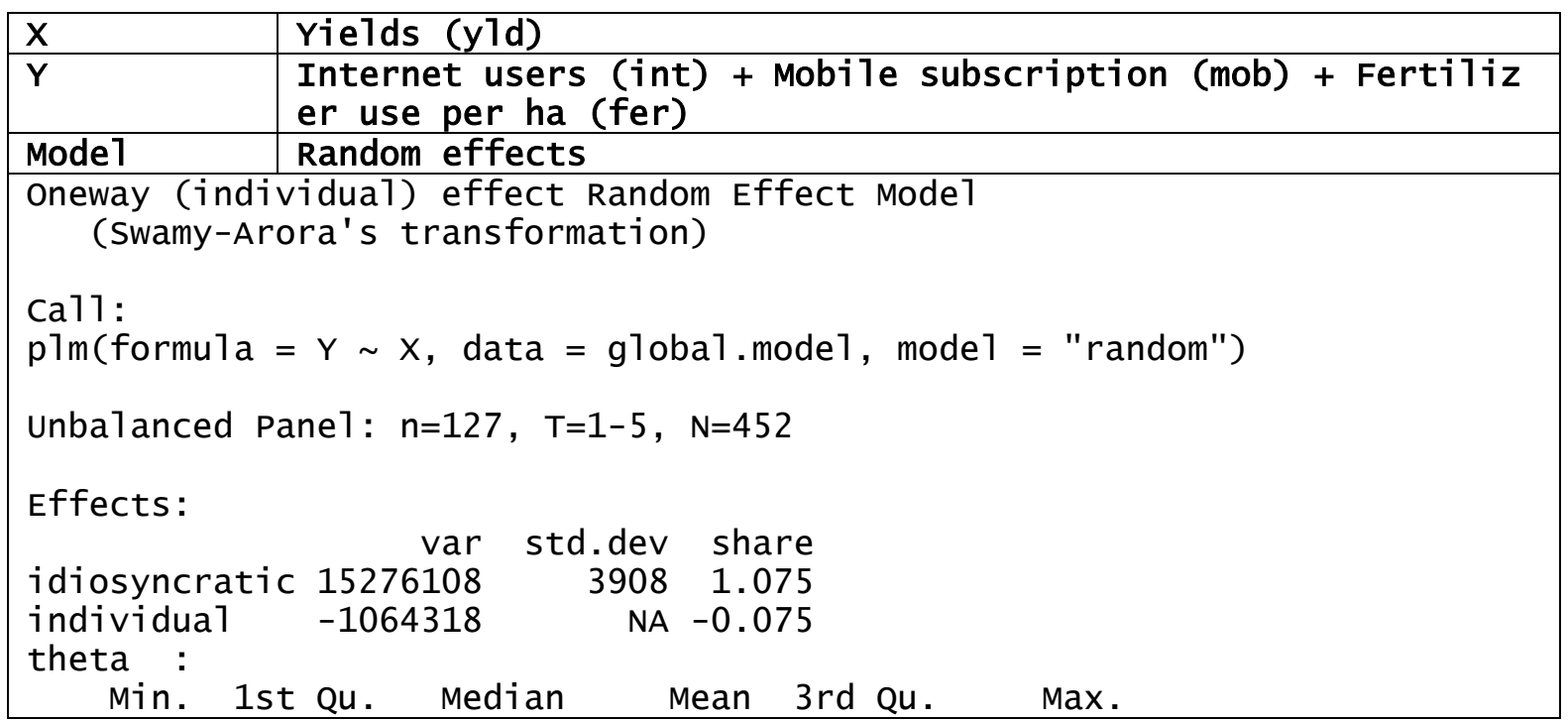




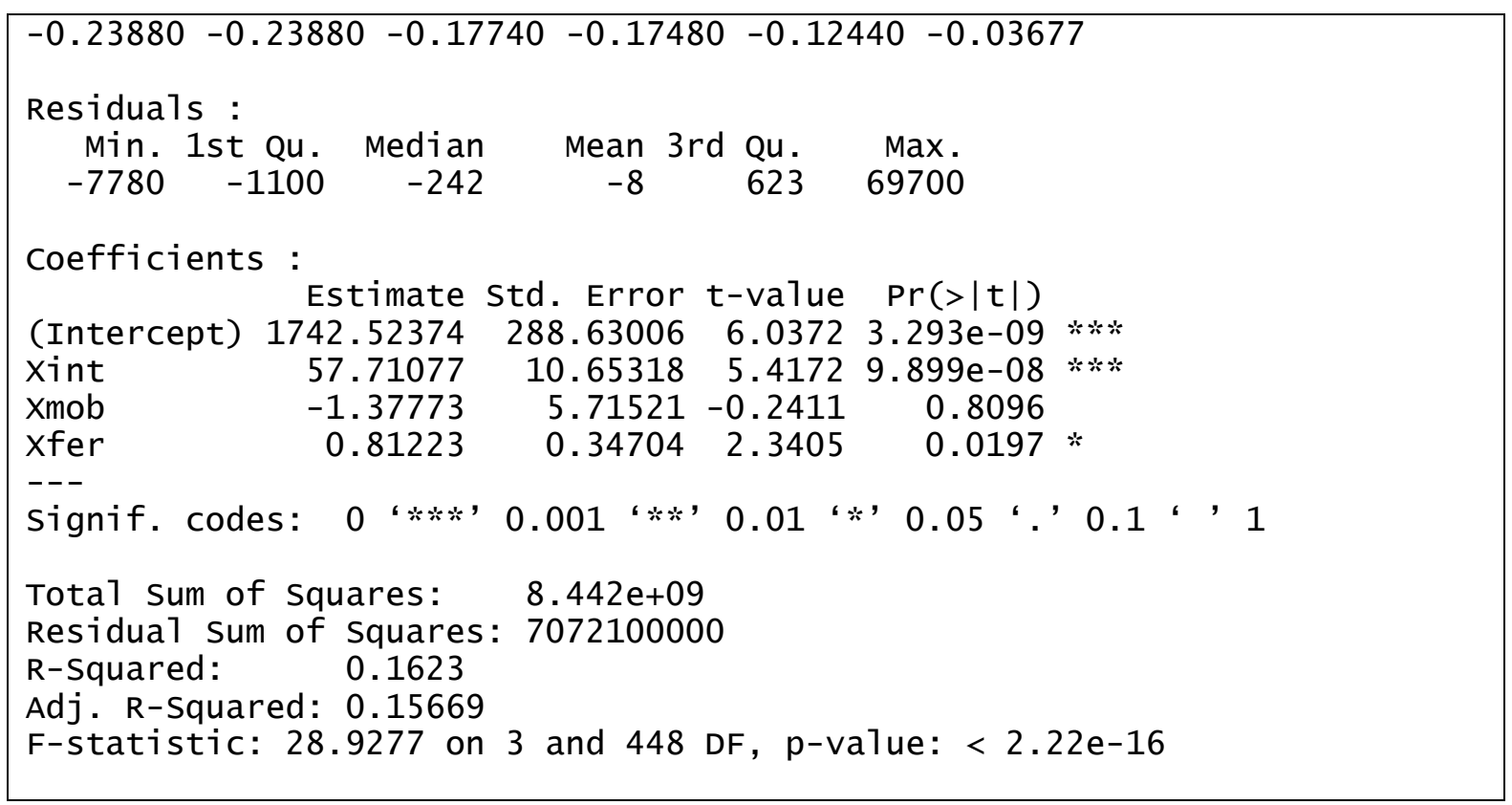

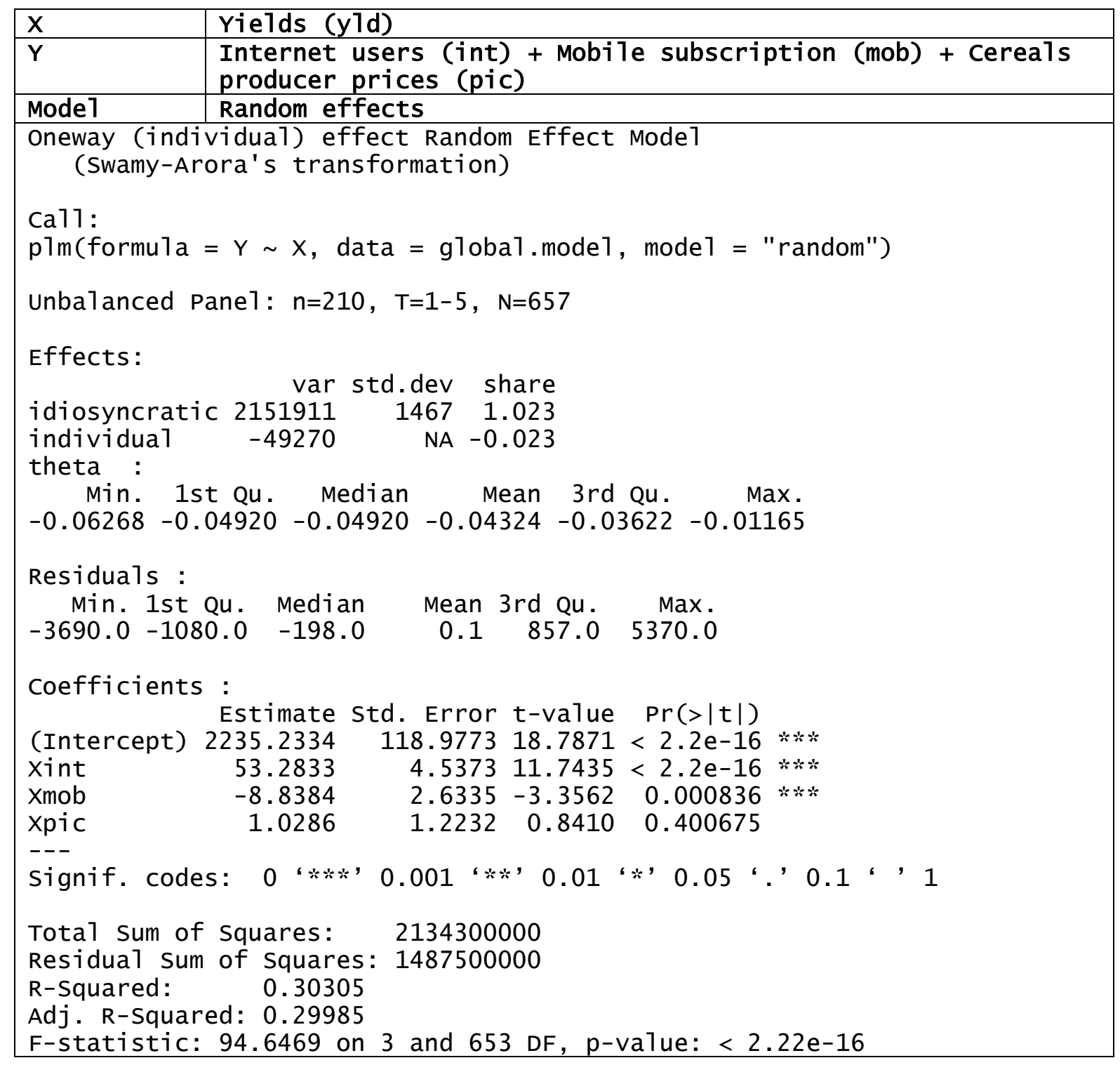




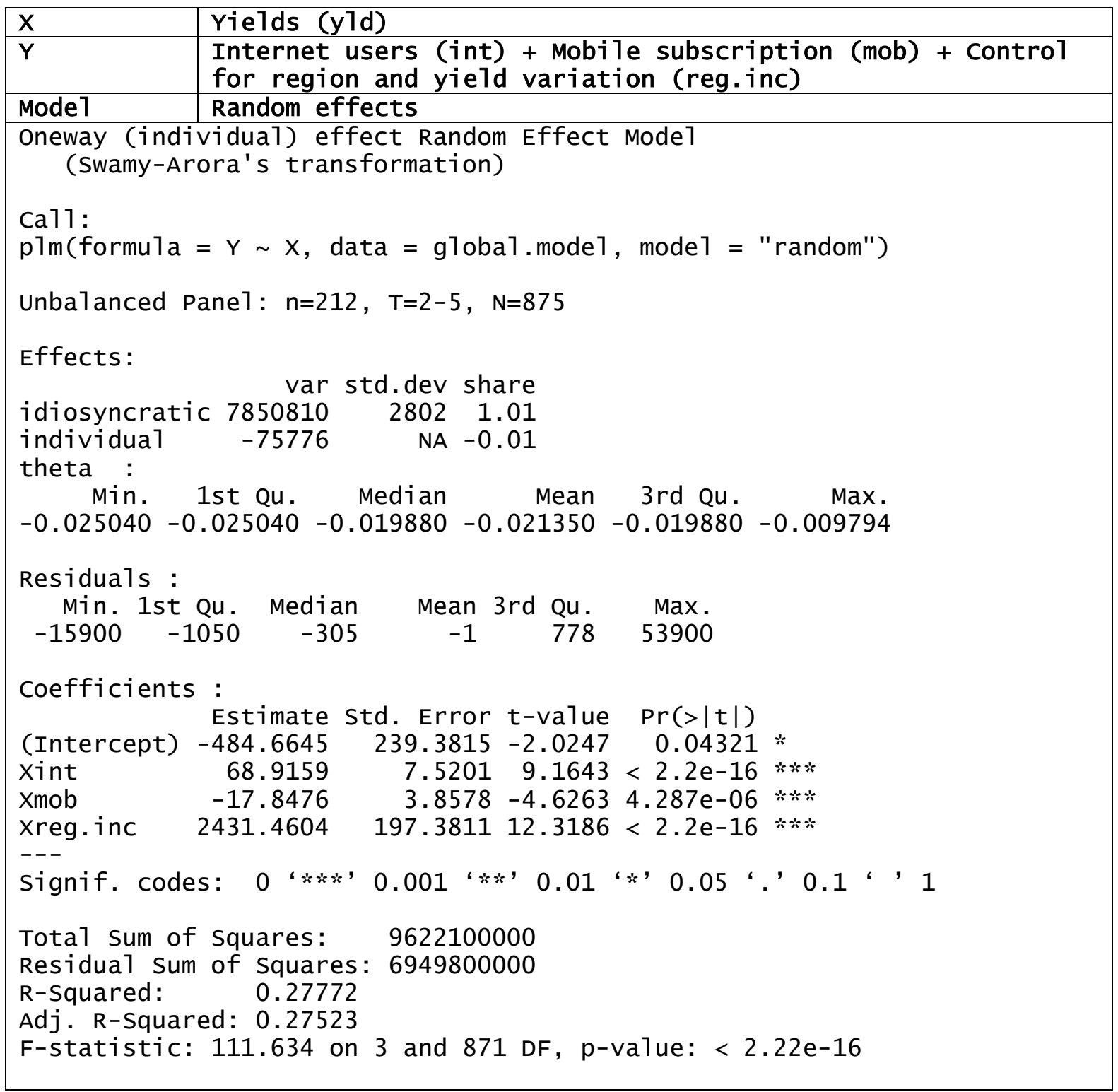

\begin{tabular}{|l|l|}
\hline $\mathbf{X}$ & Yields (yld) \\
\hline $\mathrm{Y}$ & $\begin{array}{l}\text { Internet users (int) + Mobile subscription (mob) + GDP per } \\
\text { capita (gdp) + Agricultura1 value added (avr) + Education e } \\
\text { xpenditure (edu) + Water use per ha (wat) + Fertilizer use } \\
\text { per ha (fer) + Cereals producer prices (pic) + Contro1 for } \\
\text { region and yie1d variation (reg.inc) }\end{array}$ \\
\hline Random effects \\
\hline $\begin{array}{l}\text { Onede1 } \\
\quad \text { (Swamy-Arora's transformation) }\end{array}$ \\
$\begin{array}{l}\text { Ca11: } \\
\text { p1m(formu1a }=\mathrm{Y} \sim \mathrm{X}, \text { data }=\text { globa1.mode1, mode1 = "random") }\end{array}$ \\
Unbalanced Pane1: $\mathrm{n}=112, \mathrm{~T}=1-5, \mathrm{~N}=230$ \\
Effects:
\end{tabular}




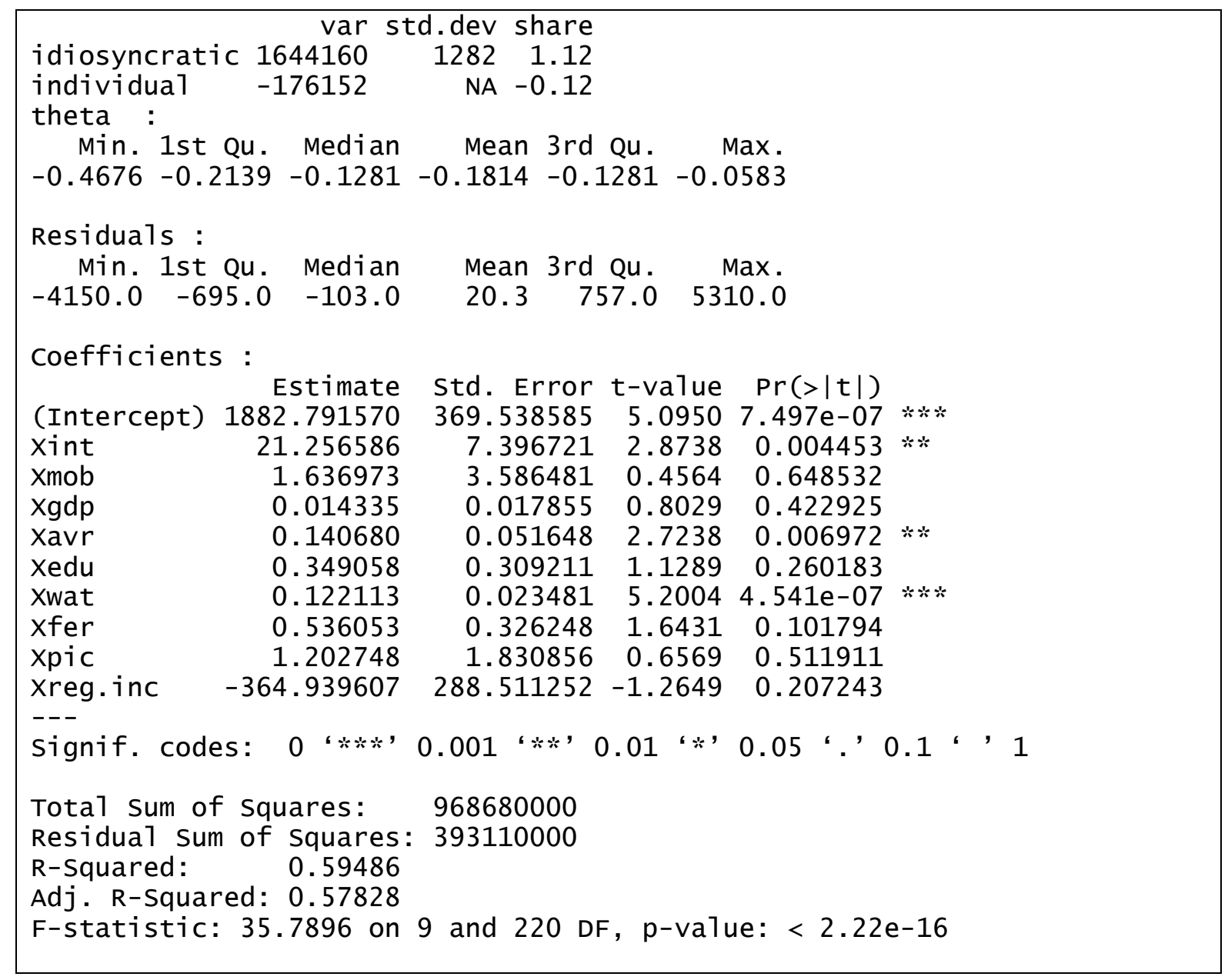

Testing different models with dummies for region and income level

(as an additional mean to control for additional non-observed variables)

\begin{tabular}{|c|c|}
\hline $\mathbf{X}$ & Yields (yld) \\
\hline $\mathbf{Y}$ & $\begin{array}{l}\text { Internet users (int) + Mobile subscription (mob) + GDP per } \\
\text { capita (gdp) + Agricultural value added (avr) + Education e } \\
\text { xpenditure (edu) + Water use per ha (wat) + Fertilizer use } \\
\text { per ha (fer) + Cereals producer prices (pic) + Control for } \\
\text { region and yield variation (reg.inc) }\end{array}$ \\
\hline Dummies & $\begin{array}{l}\text { Region and income categories (D.hi.eap,D.hi.eca,D.hi.1ac,D. } \\
\text { hi.mea,D.hi.nao,D.hi.sms,D.hi.weu,D.7m.eap,D.1m.eca,D.7m.1a } \\
\text { C,D.7m.mea,D.1m.sas,D.7m.ssa,D.10.eap,D.10.eca,D.10.1ac,D.1 } \\
\text { o.sas,D.10.ssa,D.ot.sms,D.ot.ssa,D.um.eap,D.um.eca,D.um.1ac } \\
\text {,D.um.mea,D.um.sas,D.um.ssa,D.um.weu) }\end{array}$ \\
\hline Mode1 & OLS \\
\hline \multirow{2}{*}{\multicolumn{2}{|c|}{$\begin{array}{l}\text { Pooling Mode1 } \\
\text { Ca11: } \\
\text { p1m(formula }=Y \sim x, \text { data }=\text { g1obal.mode1, mode1 = "pooling") } \\
\text { Unbalanced Pane1: } n=112, T=1-5, N=230\end{array}$}} \\
\hline & \\
\hline $\begin{array}{l}\text { Residuals } \\
\quad \text { Min. } \\
-3280.00\end{array}$ & 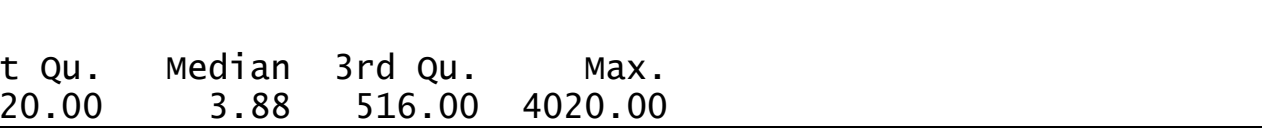 \\
\hline
\end{tabular}




\begin{tabular}{|c|c|c|c|c|c|}
\hline \multicolumn{6}{|l|}{ Coefficients } \\
\hline & Estimate & Std. Error & t-value & $\operatorname{Pr}(>|t|)$ & \\
\hline (Intercept) & $1.5083 e+03$ & $8.6064 \mathrm{e}+02$ & 1.7526 & 0.0812263 & \\
\hline Xint & $1.8745 \mathrm{e}+01$ & $8.5003 e+00$ & 2.2052 & 0.0285890 & $*$ \\
\hline Xmob & $-4.3724 e+00$ & $3.8966 \mathrm{e}+00$ & -1.1221 & 0.2631821 & \\
\hline Xgdp & $2.1912 \mathrm{e}-02$ & $2.1173 e-02$ & 1.0349 & 0.3019739 & \\
\hline Xavr & $1.2990 \mathrm{e}-01$ & $5.4646 \mathrm{e}-02$ & 2.3771 & 0.0184023 & $*$ \\
\hline Xedu & $2.2516 \mathrm{e}-02$ & $3.3993 e-01$ & 0.0662 & 0.9472565 & \\
\hline Xwat & $1.2194 \mathrm{e}-01$ & $3.3045 \mathrm{e}-02$ & 3.6903 & 0.0002895 & $* * *$ \\
\hline xfer & $8.8372 \mathrm{e}-01$ & $3.8143 e-01$ & 2.3169 & 0.0215322 & $*$ \\
\hline Xpic & $1.8164 \mathrm{e}+00$ & $1.8746 \mathrm{e}+00$ & 0.9690 & 0.3337415 & \\
\hline Xreg.inc & $6.9960 \mathrm{e}+02$ & $5.1288 \mathrm{e}+02$ & 1.3641 & 0.1740970 & \\
\hline XD.hi.eap & $7.0405 e+01$ & $1.0343 e+03$ & 0.0681 & 0.9457999 & \\
\hline XD.hi.eca & $-8.7639 e+02$ & $1.3768 \mathrm{e}+03$ & -0.6365 & 0.5251720 & \\
\hline XD.hi.lac & $-5.6950 e+02$ & $9.9510 \mathrm{e}+02$ & -0.5723 & 0.5677645 & \\
\hline XD.hi.mea & $-3.4107 e+03$ & $1.6001 \mathrm{e}+03$ & -2.1315 & 0.0342819 & $*$ \\
\hline XD.hi.nao & $-5.3702 e+02$ & $9.0591 \mathrm{e}+02$ & -0.5928 & 0.5539906 & \\
\hline XD.hi.sms & $-1.5842 \mathrm{e}+03$ & $9.1766 e+02$ & -1.7263 & 0.0858470 & - \\
\hline XD.hi.weu & $3.6548 \mathrm{e}+02$ & $7.4012 \mathrm{e}+02$ & 0.4938 & 0.6219900 & \\
\hline XD. $7 \mathrm{~m}$.eap & $-2.6455 e+02$ & $8.4775 e+02$ & -0.3121 & 0.7553244 & \\
\hline XD. $7 \mathrm{~m}$. eca & $-6.6757 e+02$ & $7.7461 e+02$ & -0.8618 & 0.3898293 & \\
\hline XD. $7 \mathrm{~m} .7 \mathrm{ac}$ & $-4.9769 e+02$ & $8.1418 \mathrm{e}+02$ & -0.6113 & 0.5417156 & \\
\hline XD. $7 \mathrm{~m} . \mathrm{mea}$ & $-1.1076 e+03$ & $8.9211 e+02$ & -1.2416 & 0.2158681 & \\
\hline XD.7m.sas & $-8.3222 e+02$ & $8.6817 \mathrm{e}+02$ & -0.9586 & 0.3389322 & \\
\hline XD.7m.ssa & $-1.3214 e+03$ & $8.3109 \mathrm{e}+02$ & -1.5899 & 0.1134438 & \\
\hline XD.7o.eap & $4.5627 e+02$ & $1.0970 \mathrm{e}+03$ & 0.4159 & 0.6779240 & \\
\hline XD.1o.eca & $-2.8405 e+03$ & 1. $2916 \mathrm{e}+03$ & -2.1992 & 0.0290243 & $*$ \\
\hline XD.7o.sas & $-8.3370 e+02$ & $9.9907 e+02$ & -0.8345 & 0.4050178 & \\
\hline XD.7o.ssa & $-1.2710 e+03$ & $7.3792 \mathrm{e}+02$ & -1.7225 & 0.0865481 & 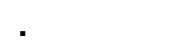 \\
\hline XD.um.eap & $-8.8025 e+02$ & $8.6264 \mathrm{e}+02$ & -1.0204 & 0.3087792 & \\
\hline XD.um.eca & $-5.6589 e+01$ & $7.3536 \mathrm{e}+02$ & -0.0770 & 0.9387377 & \\
\hline XD.um. 1ac & $-5.6986 e+02$ & $7.9665 e+02$ & -0.7153 & 0.4752507 & \\
\hline XD.um.mea & $-1.4576 e+03$ & $8.4390 e+02$ & -1.7272 & 0.0856924 & \\
\hline XD.um.ssa & $-5.1662 e+01$ & $8.6329 \mathrm{e}+02$ & -0.0598 & 0.9523411 & \\
\hline \multicolumn{6}{|c|}{ 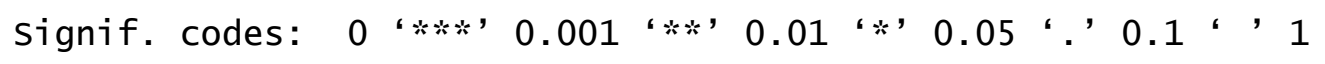 } \\
\hline \\
\hline \multirow{3}{*}{\multicolumn{6}{|c|}{$\begin{array}{l}\text { Residual sum of Squares: } 277810000 \\
\text { R-Squared: }\end{array}$}} \\
\hline & & & & & \\
\hline & & & & & \\
\hline F-statistic: & 12.2062 on & 31 and 198 & DF, p-val & lue: $<2.22$ & $2 e-16$ \\
\hline
\end{tabular}

\begin{tabular}{|c|c|}
\hline $\mathbf{X}$ & Yields (yld) \\
\hline $\mathrm{Y}$ & $\begin{array}{l}\text { Internet users (int) + Mobile subscription (mob) + GDP per } \\
\text { capita (gdp) + Agricultural value added (avr) + Education e } \\
\text { xpenditure (edu) + Water use per ha (wat) + Fertilizer use } \\
\text { per ha (fer) + Cereals producer prices (pic) + Control for } \\
\text { region and yield variation (reg.inc) }\end{array}$ \\
\hline Dummies & $\begin{array}{l}\text { Region and income categories (D.hi.eap,D.hi.eca,D.hi.1ac,D. } \\
\text { hi.mea,D.hi.nao,D.hi.sms,D.hi.weu,D.1m.eap,D.1m.eca,D.1m.1a } \\
\text { C,D.7m.mea,D.1m.sas,D.7m.ssa,D.10.eap,D.10.eca,D.10.1ac,D.1 } \\
\text { o.sas,D.10.ssa,D.ot.sms,D.ot.ssa,D.um.eap,D.um.eca,D.um.1ac } \\
\text {,D.um.mea,D.um.sas,D.um.ssa,D.um.weu) }\end{array}$ \\
\hline Mode1 & Fixed effects \\
\hline \multicolumn{2}{|c|}{$\begin{array}{l}\text { Oneway (individua1) effect within Mode1 } \\
\text { ca11: }\end{array}$} \\
\hline
\end{tabular}




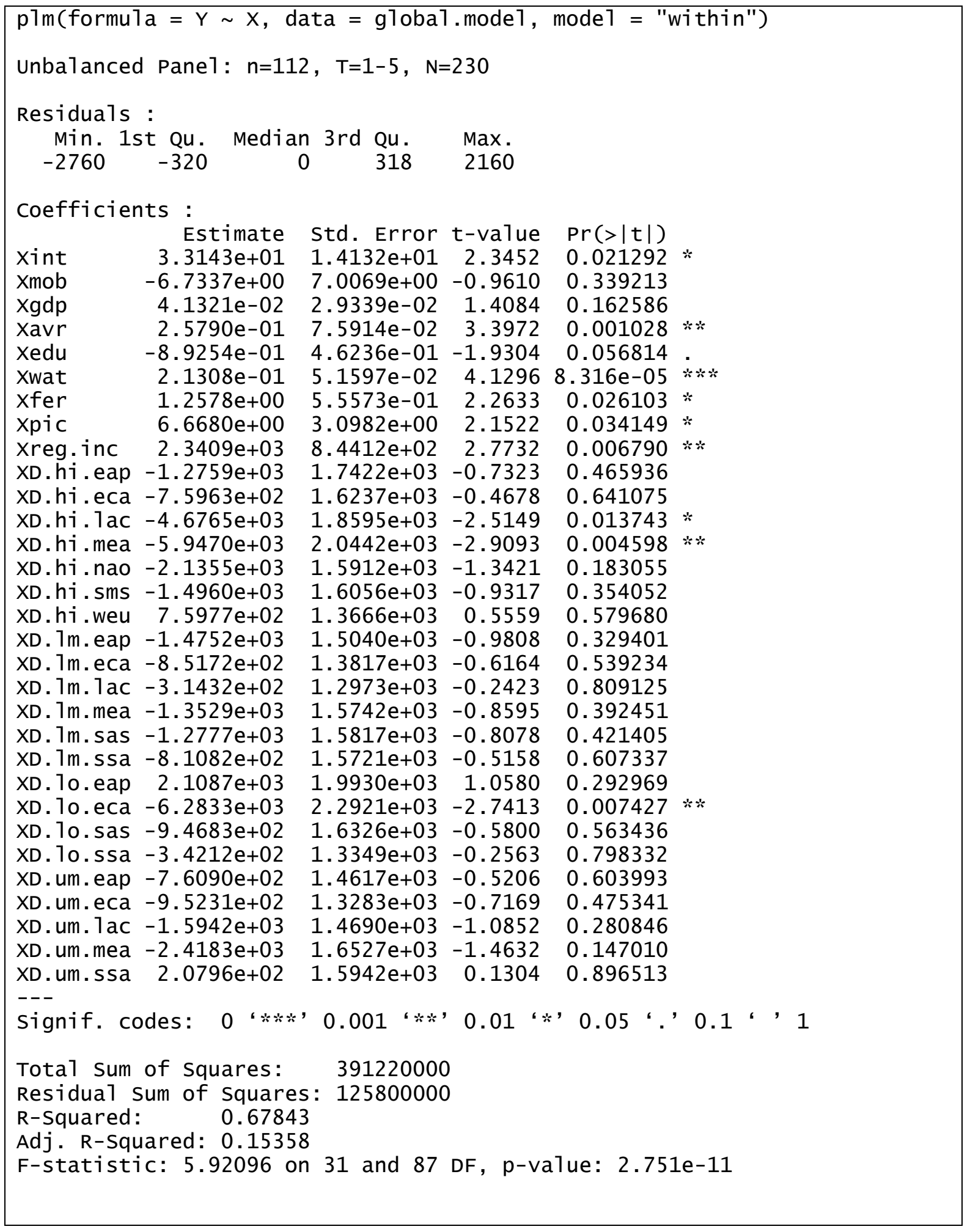

\begin{tabular}{|l|l|}
\hline$X$ & Yields (yld) \\
\hline$Y$ & $\begin{array}{l}\text { Internet users (int) + Mobile subscription (mob) + GDP per } \\
\text { capita (gdp) + Agricultural value added (avr) + Education e } \\
\text { xpenditure (edu) + water use per ha (wat) + Fertilizer use } \\
\text { per ha (fer) + Cereals producer prices (pic) + Control for } \\
\text { region and yield variation (reg.inc) }\end{array}$ \\
\hline Dummies & $\begin{array}{l}\text { Region and income categories (D.hi.eap,D.hi.eca,D.hi.1ac,D. } \\
\text { hi.mea,D.hi.nao,D.hi.sms,D.hi.weu,D.1m.eap,D.7m.eca,D.1m.1a }\end{array}$ \\
\hline
\end{tabular}




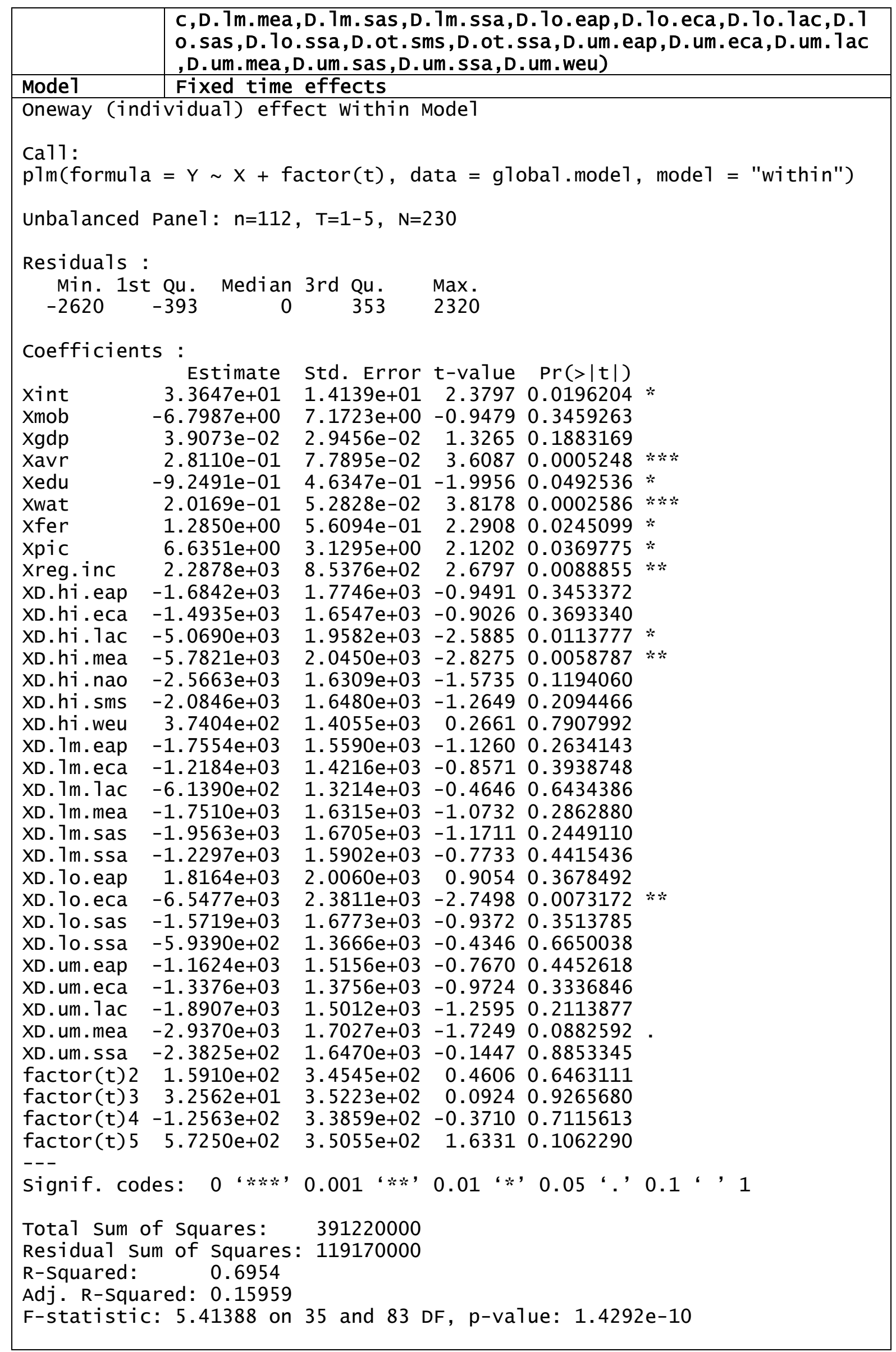




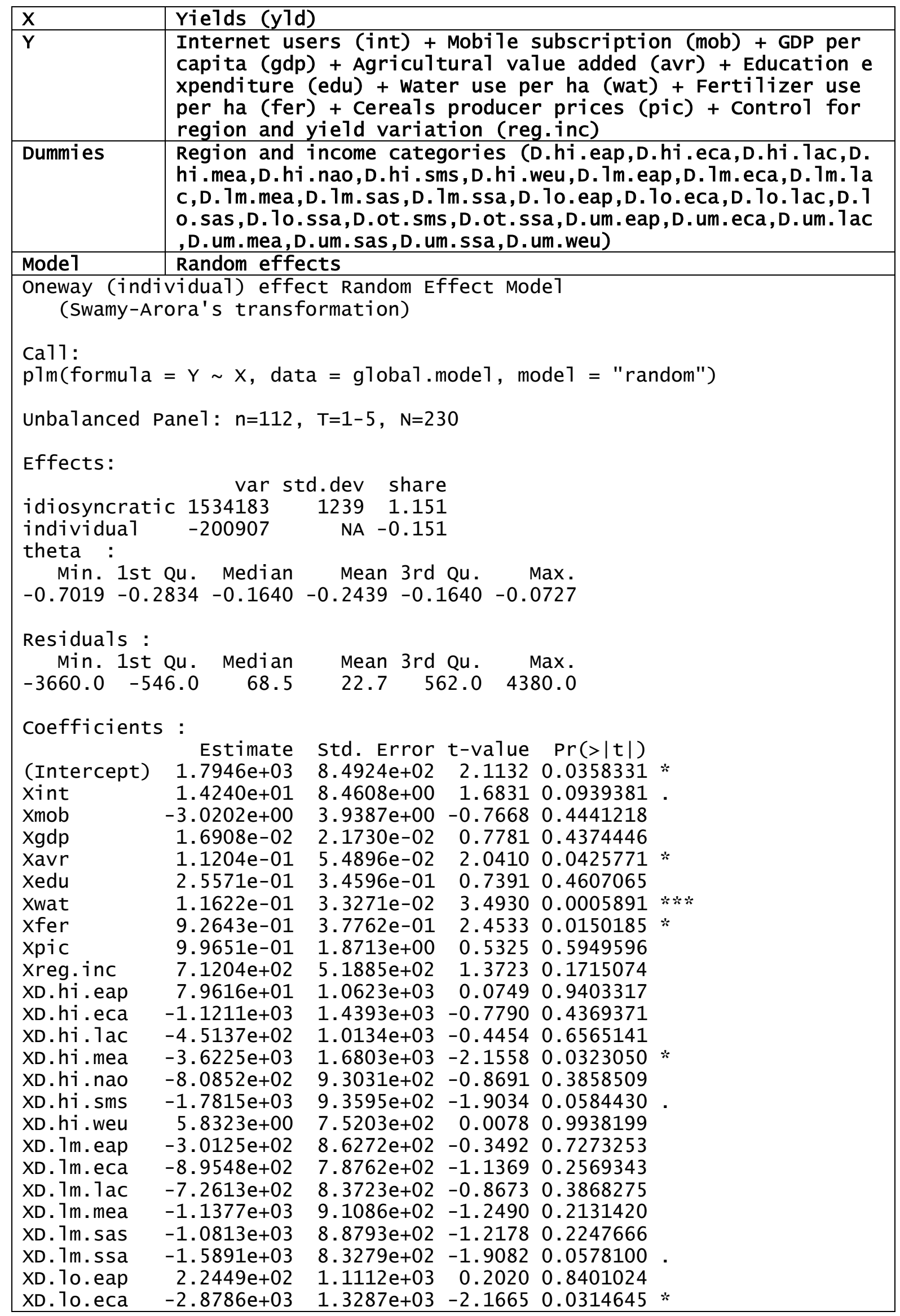




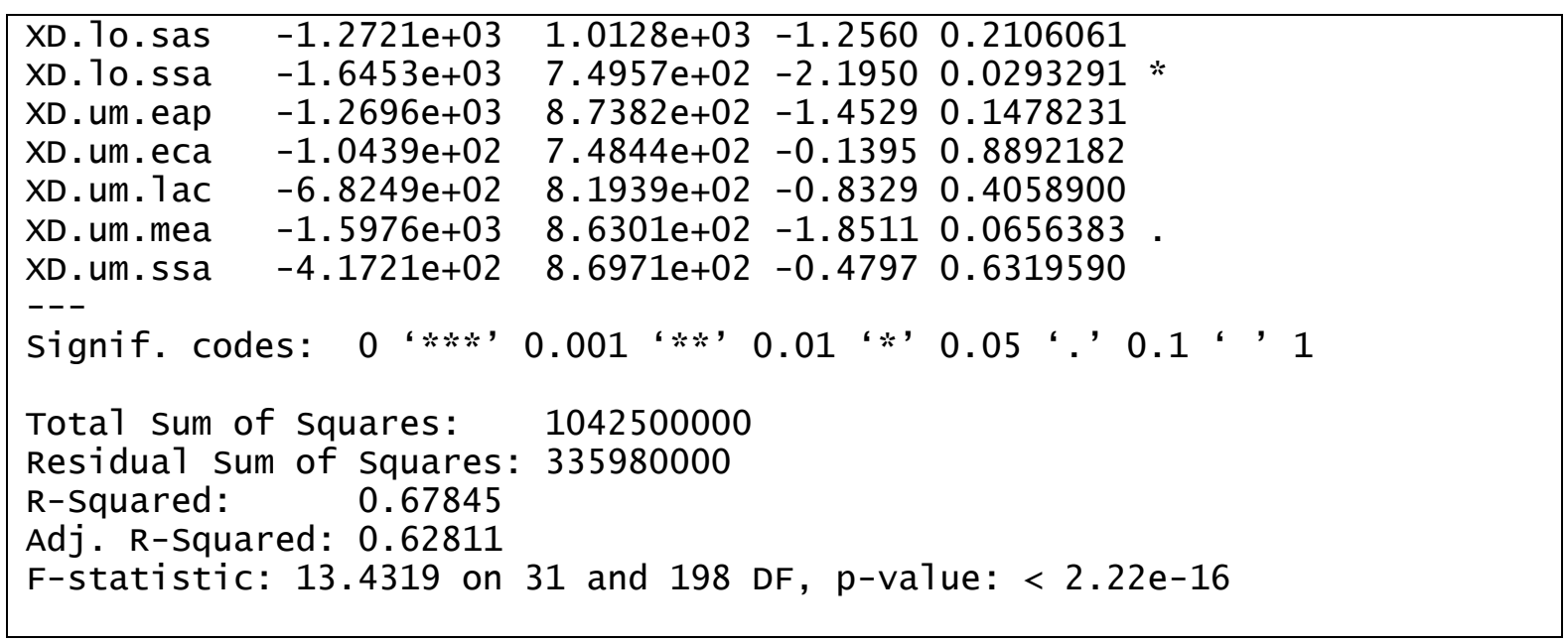

\section{Lagrane multiplier test}

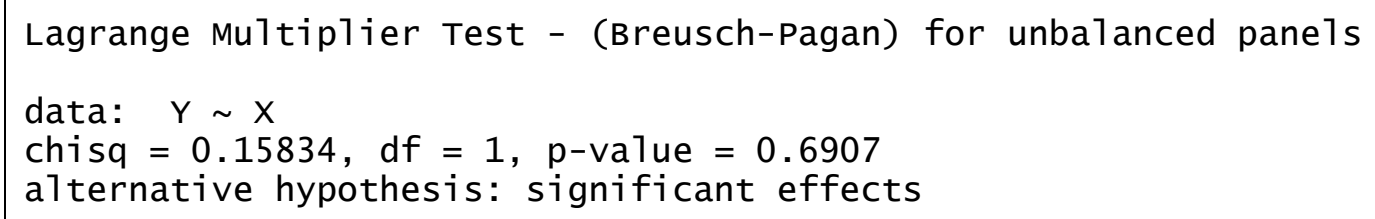

\section{DESCRIPTION OF THE INDEX FOR YIELD VARIATION ACCORDING TO REGION AND INCOME LEVEL}

An index created by the author to control for other ommited variables. It groups countries to measure yield variation at the regional level and according to income level.

It uses FAO yield data (yld) and World Bank classification for income and regions (see table below). The yield average of all uper-medium-income latin-american countries is created for each period. An index is calculated in which average yield in 1990-94 is equal to 1 . Then it is applied to all countries in the category. Below the region-income classification and the final index values.

\section{Country categories}

Created by the author, based on World Bank classification

\begin{tabular}{|l|l|l|l|l|}
\hline \multicolumn{1}{|c|}{ Country } & Code & \multicolumn{1}{c|}{ Income category } & \multicolumn{1}{c|}{ Regional category } & $\begin{array}{c}\text { Combined } \\
\text { category }\end{array}$ \\
\hline Aruba & ABW & High income & Small states & hi-sms \\
\hline Andorra & AND & Upper middle income & Small states & ot-sms \\
\hline Afghanistan & AFG & Low income & South Asia & lo-sas \\
\hline Angola & AGO & Upper middle income & Sub-Saharan Africa & um-ssa \\
\hline Albania & ALB & Upper middle income & Europe \& Central Asia & um-eca \\
\hline $\begin{array}{l}\text { United Arab } \\
\text { Emirates }\end{array}$ & ARE & High income & Middle East \& North Africa & hi-mea \\
\hline Argentina & ARG & Upper middle income & Latin America \& Caribbean & um-lac \\
\hline Armenia & ARM & Lower middle income & Europe \& Central Asia & Im-eca \\
\hline
\end{tabular}




\begin{tabular}{|c|c|c|c|c|}
\hline $\begin{array}{l}\text { American } \\
\text { Samoa }\end{array}$ & ASM & Upper middle income & East Asia \& Pacific & um-eap \\
\hline $\begin{array}{l}\text { Antigua and } \\
\text { Barbuda }\end{array}$ & ATG & High income & Small states & hi-sms \\
\hline Australia & AUS & High income & North America and Oceania & hi-nao \\
\hline Austria & AUT & High income & Western Europe & hi-weu \\
\hline Azerbaijan & AZE & Upper middle income & Europe \& Central Asia & um-eca \\
\hline Burundi & BDI & Low income & Sub-Saharan Africa & lo-ssa \\
\hline Belgium & BEL & High income & Western Europe & hi-weu \\
\hline Benin & BEN & Low income & Sub-Saharan Africa & lo-ssa \\
\hline Burkina Faso & BFA & Low income & Sub-Saharan Africa & lo-ssa \\
\hline Bangladesh & BGD & Low income & South Asia & lo-sas \\
\hline Bulgaria & BGR & Upper middle income & Europe \& Central Asia & um-eca \\
\hline Bahrain & $\mathrm{BHR}$ & High income & Middle East \& North Africa & hi-mea \\
\hline $\begin{array}{l}\text { Bahamas, } \\
\text { The }\end{array}$ & BHS & High income & Small states & hi-sms \\
\hline $\begin{array}{l}\text { Bosnia and } \\
\text { Herzegovina }\end{array}$ & $\mathrm{BIH}$ & Upper middle income & Europe \& Central Asia & um-eca \\
\hline Belarus & BLR & Upper middle income & Europe \& Central Asia & um-eca \\
\hline Belize & $\mathrm{BLZ}$ & Upper middle income & Latin America \& Caribbean & um-lac \\
\hline Bermuda & BMU & High income & Small states & hi-sms \\
\hline Bolivia & $\mathrm{BOL}$ & Lower middle income & Latin America \& Caribbean & Im-lac \\
\hline Brazil & BRA & Upper middle income & Latin America \& Caribbean & um-lac \\
\hline Barbados & BRB & High income & Small states & hi-sms \\
\hline $\begin{array}{l}\text { Brunei } \\
\text { Darussalam }\end{array}$ & BRN & High income & Small states & hi-sms \\
\hline Bhutan & BTN & Lower middle income & South Asia & Im-sas \\
\hline Botswana & BWA & Upper middle income & Sub-Saharan Africa & um-ssa \\
\hline $\begin{array}{l}\text { Central } \\
\text { African } \\
\text { Republic }\end{array}$ & CAF & Low income & Sub-Saharan Africa & lo-ssa \\
\hline Canada & CAN & High income & North America and Oceania & hi-nao \\
\hline Switzerland & $\mathrm{CHE}$ & High income & Western Europe & hi-weu \\
\hline Chile & $\mathrm{CHL}$ & High income & Latin America \& Caribbean & hi-lac \\
\hline China & $\mathrm{CHN}$ & Upper middle income & East Asia \& Pacific & um-eap \\
\hline Cote d'Ivoire & CIV & Lower middle income & Sub-Saharan Africa & Im-ssa \\
\hline Cameroon & CMR & Lower middle income & Sub-Saharan Africa & Im-ssa \\
\hline Congo, Rep. & COG & Lower middle income & Sub-Saharan Africa & Im-ssa \\
\hline Colombia & $\mathrm{COL}$ & Upper middle income & Latin America \& Caribbean & um-lac \\
\hline Comoros & $\mathrm{COM}$ & Low income & Sub-Saharan Africa & lo-ssa \\
\hline Cabo Verde & CPV & Lower middle income & Sub-Saharan Africa & Im-ssa \\
\hline Costa Rica & CRI & Upper middle income & Latin America \& Caribbean & um-lac \\
\hline Cuba & CUB & Upper middle income & Latin America \& Caribbean & um-lac \\
\hline Curacao & CUW & High income & Small states & hi-sms \\
\hline $\begin{array}{l}\text { Cayman } \\
\text { Islands }\end{array}$ & CYM & High income & Small states & hi-sms \\
\hline Cyprus & CYP & High income & Western Europe & hi-weu \\
\hline $\begin{array}{l}\text { Czech } \\
\text { Republic }\end{array}$ & CZE & High income & Western Europe & hi-weu \\
\hline Germany & DEU & High income & Western Europe & hi-weu \\
\hline Djibouti & DJI & Lower middle income & Middle East \& North Africa & Im-mea \\
\hline
\end{tabular}




\begin{tabular}{|c|c|c|c|c|}
\hline Dominica & DMA & Upper middle income & Latin America \& Caribbean & um-lac \\
\hline Denmark & DNK & High income & Western Europe & hi-weu \\
\hline $\begin{array}{l}\text { Dominican } \\
\text { Republic }\end{array}$ & DOM & Upper middle income & Latin America \& Caribbean & um-lac \\
\hline Algeria & $\mathrm{DZA}$ & Upper middle income & Middle East \& North Africa & um-mea \\
\hline Ecuador & ECU & Upper middle income & Latin America \& Caribbean & um-lac \\
\hline $\begin{array}{l}\text { Egypt, Arab } \\
\text { Rep. }\end{array}$ & EGY & Lower middle income & Middle East \& North Africa & Im-mea \\
\hline Eritrea & ERI & Low income & Sub-Saharan Africa & lo-ssa \\
\hline Spain & ESP & High income & Western Europe & hi-weu \\
\hline Estonia & EST & High income & Western Europe & hi-weu \\
\hline Ethiopia & ETH & Low income & Sub-Saharan Africa & Io-ssa \\
\hline Finland & FIN & High income & Western Europe & hi-weu \\
\hline Fiji & FJI & Upper middle income & East Asia \& Pacific & um-eap \\
\hline France & FRA & High income & Western Europe & hi-weu \\
\hline $\begin{array}{l}\text { Faeroe } \\
\text { Islands }\end{array}$ & FRO & High income & Small states & hi-sms \\
\hline $\begin{array}{l}\text { Micronesia, } \\
\text { Fed. Sts. }\end{array}$ & FSM & Lower middle income & East Asia \& Pacific & Im-eap \\
\hline Gabon & GAB & Upper middle income & Sub-Saharan Africa & um-ssa \\
\hline $\begin{array}{l}\text { United } \\
\text { Kingdom }\end{array}$ & GBR & High income & Western Europe & hi-weu \\
\hline Georgia & GEO & Lower middle income & Europe \& Central Asia & Im-eca \\
\hline Ghana & GHA & Lower middle income & Sub-Saharan Africa & Im-ssa \\
\hline Guinea & GIN & Low income & Sub-Saharan Africa & lo-ssa \\
\hline Gambia, The & GMB & Low income & Sub-Saharan Africa & lo-ssa \\
\hline $\begin{array}{l}\text { Guinea- } \\
\text { Bissau }\end{array}$ & GNB & Low income & Sub-Saharan Africa & lo-ssa \\
\hline $\begin{array}{l}\text { Equatorial } \\
\text { Guinea }\end{array}$ & GNQ & High income & Sub-Saharan Africa & hi-sms \\
\hline Greece & GRC & High income & Western Europe & hi-weu \\
\hline Grenada & GRD & Upper middle income & Latin America \& Caribbean & um-lac \\
\hline Greenland & GRL & High income & Small states & hi-sms \\
\hline Guatemala & GTM & Lower middle income & Latin America \& Caribbean & Im-lac \\
\hline Guam & GUM & High income & Small states & hi-sms \\
\hline Guyana & GUY & Lower middle income & Latin America \& Caribbean & Im-lac \\
\hline $\begin{array}{l}\text { Hong Kong } \\
\text { SAR, China }\end{array}$ & HKG & High income & Small states & hi-sms \\
\hline Honduras & HND & Lower middle income & Latin America \& Caribbean & Im-lac \\
\hline Croatia & HRV & High income & Western Europe & hi-weu \\
\hline Haiti & HTI & Low income & Latin America \& Caribbean & lo-lac \\
\hline Hungary & HUN & Upper middle income & Europe \& Central Asia & um-eca \\
\hline Indonesia & IDN & Lower middle income & East Asia \& Pacific & Im-eap \\
\hline Isle of Man & IMN & Low income & Small states & ot-sms \\
\hline India & IND & Lower middle income & South Asia & Im-sas \\
\hline Ireland & IRL & High income & Western Europe & hi-weu \\
\hline $\begin{array}{l}\text { Iran, Islamic } \\
\text { Rep. }\end{array}$ & IRN & Upper middle income & Middle East \& North Africa & um-mea \\
\hline Iraq & IRQ & Upper middle income & Middle East \& North Africa & um-mea \\
\hline Iceland & ISL & High income & Western Europe & hi-weu \\
\hline Israel & ISR & High income & Middle East \& North Africa & hi-mea \\
\hline Italy & ITA & High income & Western Europe & hi-weu \\
\hline
\end{tabular}




\begin{tabular}{|c|c|c|c|c|}
\hline Jamaica & JAM & Upper middle income & Latin America \& Caribbean & um-lac \\
\hline Jordan & JOR & Upper middle income & Middle East \& North Africa & um-mea \\
\hline Japan & JPN & High income & East Asia \& Pacific & hi-eap \\
\hline Kazakhstan & $\mathrm{KAZ}$ & Upper middle income & Europe \& Central Asia & um-eca \\
\hline Kenya & KEN & Low income & Sub-Saharan Africa & lo-ssa \\
\hline $\begin{array}{l}\text { Kyrgyz } \\
\text { Republic }\end{array}$ & KGZ & Lower middle income & Europe \& Central Asia & Im-eca \\
\hline Cambodia & KHM & Low income & East Asia \& Pacific & lo-eap \\
\hline Kiribati & KIR & Lower middle income & East Asia \& Pacific & Im-eap \\
\hline $\begin{array}{l}\text { St. Kitts and } \\
\text { Nevis }\end{array}$ & KNA & High income & Small states & hi-sms \\
\hline Korea, Rep. & KOR & High income & East Asia \& Pacific & hi-eap \\
\hline Kuwait & KWT & High income & Small states & hi-sms \\
\hline Lao PDR & LAO & Lower middle income & East Asia \& Pacific & Im-eap \\
\hline Lebanon & LBN & Upper middle income & Middle East \& North Africa & um-mea \\
\hline Liberia & LBR & Low income & Sub-Saharan Africa & lo-ssa \\
\hline Libya & LBY & Upper middle income & Middle East \& North Africa & um-mea \\
\hline St. Lucia & LCA & Upper middle income & Latin America \& Caribbean & um-lac \\
\hline Liechtenstein & LIE & High income & Small states & hi-sms \\
\hline Sri Lanka & LKA & Lower middle income & South Asia & Im-sas \\
\hline Lesotho & LSO & Lower middle income & Sub-Saharan Africa & Im-ssa \\
\hline Lithuania & LTU & High income & Western Europe & hi-weu \\
\hline Luxembourg & LUX & High income & Western Europe & hi-weu \\
\hline Latvia & LVA & High income & Small states & hi-sms \\
\hline $\begin{array}{l}\text { Macao SAR, } \\
\text { China }\end{array}$ & MAC & High income & Small states & hi-sms \\
\hline $\begin{array}{l}\text { St. Martin } \\
\text { (French part) }\end{array}$ & MAF & High income & Small states & hi-sms \\
\hline Morocco & MAR & Lower middle income & Middle East \& North Africa & Im-mea \\
\hline Monaco & $\mathrm{MCO}$ & High income & Small states & hi-sms \\
\hline Moldova & MDA & Lower middle income & Europe \& Central Asia & Im-eca \\
\hline Madagascar & MDG & Low income & Sub-Saharan Africa & lo-ssa \\
\hline Maldives & MDV & Upper middle income & South Asia & um-sas \\
\hline Mexico & MEX & Upper middle income & Latin America \& Caribbean & um-lac \\
\hline $\begin{array}{l}\text { Marshall } \\
\text { Islands }\end{array}$ & MHL & Upper middle income & East Asia \& Pacific & um-eap \\
\hline $\begin{array}{l}\text { Macedonia, } \\
\text { FYR }\end{array}$ & MKD & Upper middle income & Europe \& Central Asia & um-eca \\
\hline Mali & MLI & Low income & Sub-Saharan Africa & lo-ssa \\
\hline Malta & MLT & High income & Western Europe & hi-weu \\
\hline Myanmar & MMR & Low income & East Asia \& Pacific & lo-eap \\
\hline Montenegro & MNE & Upper middle income & Europe \& Central Asia & um-eca \\
\hline Mongolia & MNG & Lower middle income & East Asia \& Pacific & Im-eap \\
\hline $\begin{array}{l}\text { Northern } \\
\text { Mariana } \\
\text { Islands }\end{array}$ & MNP & High income & Small states & hi-sms \\
\hline Mozambique & $\mathrm{MOZ}$ & Low income & Sub-Saharan Africa & lo-ssa \\
\hline Mauritania & MRT & Lower middle income & Sub-Saharan Africa & Im-ssa \\
\hline Mauritius & MUS & Upper middle income & Sub-Saharan Africa & um-ssa \\
\hline Malawi & MWI & Low income & Sub-Saharan Africa & lo-ssa \\
\hline Malaysia & MYS & Upper middle income & East Asia \& Pacific & um-eap \\
\hline
\end{tabular}




\begin{tabular}{|c|c|c|c|c|}
\hline Namibia & NAM & Upper middle income & Sub-Saharan Africa & um-ssa \\
\hline $\begin{array}{l}\text { New } \\
\text { Caledonia }\end{array}$ & $\mathrm{NCL}$ & High income & Small states & hi-sms \\
\hline Niger & NER & Low income & Sub-Saharan Africa & lo-ssa \\
\hline Nigeria & NGA & Lower middle income & Sub-Saharan Africa & Im-ssa \\
\hline Nicaragua & NIC & Lower middle income & Latin America \& Caribbean & Im-lac \\
\hline Netherlands & NLD & High income & Western Europe & hi-weu \\
\hline Norway & NOR & High income & Western Europe & hi-weu \\
\hline Nepal & NPL & Low income & South Asia & lo-sas \\
\hline New Zealand & NZL & High income & North America and Oceania & hi-nao \\
\hline Oman & OMN & High income & Middle East \& North Africa & hi-mea \\
\hline Pakistan & PAK & Lower middle income & South Asia & Im-sas \\
\hline Panama & PAN & Upper middle income & Latin America \& Caribbean & um-lac \\
\hline Peru & PER & Upper middle income & Latin America \& Caribbean & um-lac \\
\hline Philippines & $\mathrm{PHL}$ & Lower middle income & East Asia \& Pacific & Im-eap \\
\hline Palau & PLW & Upper middle income & East Asia \& Pacific & um-eap \\
\hline $\begin{array}{l}\text { Papua New } \\
\text { Guinea }\end{array}$ & PNG & Lower middle income & East Asia \& Pacific & Im-eap \\
\hline Poland & POL & High income & Western Europe & hi-weu \\
\hline Puerto Rico & PRI & High income & Latin America \& Caribbean & hi-lac \\
\hline $\begin{array}{l}\text { Korea, Dem. } \\
\text { Rep. }\end{array}$ & PRK & Low income & East Asia \& Pacific & lo-eap \\
\hline Portugal & PRT & High income & Western Europe & hi-weu \\
\hline Paraguay & PRY & Lower middle income & Latin America \& Caribbean & Im-lac \\
\hline $\begin{array}{l}\text { French } \\
\text { Polynesia }\end{array}$ & PYF & High income & Small states & hi-sms \\
\hline Qatar & QAT & High income & Middle East \& North Africa & hi-mea \\
\hline Romania & ROU & Upper middle income & Western Europe & um-weu \\
\hline $\begin{array}{l}\text { Russian } \\
\text { Federation }\end{array}$ & RUS & High income & Europe \& Central Asia & hi-eca \\
\hline Rwanda & RWA & Low income & Sub-Saharan Africa & lo-ssa \\
\hline Saudi Arabia & SAU & High income & Middle East \& North Africa & hi-mea \\
\hline Sudan & SDN & Lower middle income & Sub-Saharan Africa & Im-ssa \\
\hline Senegal & SEN & Lower middle income & Sub-Saharan Africa & Im-ssa \\
\hline Singapore & SGP & High income & Small states & hi-sms \\
\hline $\begin{array}{l}\text { Solomon } \\
\text { Islands }\end{array}$ & SLB & Lower middle income & East Asia \& Pacific & Im-eap \\
\hline Sierra Leone & SLE & Low income & Sub-Saharan Africa & lo-ssa \\
\hline El Salvador & SLV & Lower middle income & Latin America \& Caribbean & Im-lac \\
\hline San Marino & SMR & High income & Small states & hi-sms \\
\hline Somalia & SOM & Low income & Sub-Saharan Africa & lo-ssa \\
\hline Serbia & SRB & Upper middle income & Europe \& Central Asia & um-eca \\
\hline South Sudan & SSD & Lower middle income & Sub-Saharan Africa & Im-ssa \\
\hline $\begin{array}{l}\text { Sao Tome } \\
\text { and Principe }\end{array}$ & STP & Lower middle income & Sub-Saharan Africa & Im-ssa \\
\hline Suriname & SUR & Upper middle income & Latin America \& Caribbean & um-lac \\
\hline $\begin{array}{l}\text { Slovak } \\
\text { Republic }\end{array}$ & SVK & High income & Western Europe & hi-weu \\
\hline Slovenia & SVN & High income & Western Europe & hi-weu \\
\hline Sweden & SWE & High income & Western Europe & hi-weu \\
\hline Swaziland & SWZ & Lower middle income & Sub-Saharan Africa & Im-ssa \\
\hline
\end{tabular}




\begin{tabular}{|c|c|c|c|c|}
\hline $\begin{array}{l}\text { Sint Maarten } \\
\text { (Dutch part) }\end{array}$ & SXM & High income & Small states & hi-sms \\
\hline Seychelles & SYC & Upper middle income & Sub-Saharan Africa & um-ssa \\
\hline $\begin{array}{l}\text { Syrian Arab } \\
\text { Republic }\end{array}$ & SYR & Lower middle income & Middle East \& North Africa & Im-mea \\
\hline $\begin{array}{l}\text { Turks and } \\
\text { Caicos } \\
\text { Islands }\end{array}$ & TCA & High income & Small states & hi-sms \\
\hline Chad & TCD & Low income & Sub-Saharan Africa & lo-ssa \\
\hline Togo & TGO & Low income & Sub-Saharan Africa & lo-ssa \\
\hline Thailand & THA & Upper middle income & East Asia \& Pacific & um-eap \\
\hline Tajikistan & TJK & Low income & Europe \& Central Asia & lo-eca \\
\hline Turkmenistan & TKM & Upper middle income & Europe \& Central Asia & um-eca \\
\hline Timor-Leste & TLS & Low income & South Asia & lo-sas \\
\hline Tonga & TON & Upper middle income & East Asia \& Pacific & um-eap \\
\hline $\begin{array}{l}\text { Trinidad and } \\
\text { Tobago }\end{array}$ & ТТО & High income & Small states & hi-sms \\
\hline Tunisia & TUN & Upper middle income & Middle East \& North Africa & um-mea \\
\hline Turkey & TUR & Upper middle income & Europe \& Central Asia & um-eca \\
\hline Tuvalu & TUV & Upper middle income & East Asia \& Pacific & um-eap \\
\hline Tanzania & TZA & Low income & Sub-Saharan Africa & lo-ssa \\
\hline Uganda & UGA & Low income & Sub-Saharan Africa & lo-ssa \\
\hline Ukraine & UKR & Lower middle income & Europe \& Central Asia & Im-eca \\
\hline Uruguay & URY & High income & Latin America \& Caribbean & hi-lac \\
\hline United States & USA & High income & North America and Oceania & hi-nao \\
\hline Uzbekistan & UZB & Lower middle income & Europe \& Central Asia & Im-eca \\
\hline $\begin{array}{l}\text { St. Vincent } \\
\text { and the } \\
\text { Grenadines }\end{array}$ & VCT & Upper middle income & Latin America \& Caribbean & um-lac \\
\hline $\begin{array}{l}\text { Venezuela, } \\
\text { RB }\end{array}$ & VEN & Upper middle income & Latin America \& Caribbean & um-lac \\
\hline $\begin{array}{l}\text { Virgin Islands } \\
\text { (U.S.) }\end{array}$ & VIR & High income & Small states & hi-sms \\
\hline Vietnam & VNM & Lower middle income & East Asia \& Pacific & Im-eap \\
\hline Vanuatu & VUT & Lower middle income & East Asia \& Pacific & Im-eap \\
\hline $\begin{array}{l}\text { West Bank } \\
\text { and Gaza }\end{array}$ & PSE & Low income & Small states & ot-sms \\
\hline Samoa & WSM & Lower middle income & East Asia \& Pacific & Im-eap \\
\hline Yemen, Rep. & YEM & Lower middle income & Middle East \& North Africa & Im-mea \\
\hline South Africa & ZAF & Upper middle income & Sub-Saharan Africa & um-ssa \\
\hline $\begin{array}{l}\text { Congo, Dem. } \\
\text { Rep. }\end{array}$ & COD & Low income & Sub-Saharan Africa & ot-ssa \\
\hline Zambia & ZMB & Lower middle income & Sub-Saharan Africa & Im-ssa \\
\hline Zimbabwe & ZWE & Low income & Sub-Saharan Africa & lo-ssa \\
\hline
\end{tabular}


Index values:

\begin{tabular}{|l|l|l|l|l|l|}
\hline $\begin{array}{c}\text { Combined } \\
\text { category }\end{array}$ & 1990-1994 & \multicolumn{1}{|c|}{$\mathbf{1 9 9 5 - 1 9 9 9}$} & \multicolumn{1}{|c|}{$\mathbf{2 0 0 0 - 2 0 0 4}$} & \multicolumn{1}{|c|}{$\mathbf{2 0 0 5 - 2 0 0 9}$} & \multicolumn{1}{|c|}{$\mathbf{2 0 1 0 - 2 0 1 4}$} \\
\hline hi-eap & 1 & 1.075458 & 1.069806 & 1.110455 & 1.106546 \\
\hline hi-eca & 1 & 0.887796 & 1.133654 & 1.290734 & 1.271604 \\
\hline hi-lac & 1 & 1.19746 & 1.350885 & 1.47489 & 1.581664 \\
\hline hi-mea & 1 & 1.168721 & 1.287858 & 3.882933 & 7.078665 \\
\hline hi-nao & 1 & 1.097547 & 1.18396 & 1.289619 & 1.37939 \\
\hline hi-sms & 1 & 1.073879 & 0.947475 & 1.113952 & 1.51913 \\
\hline hi-weu & 1 & 1.075408 & 1.155342 & 1.20196 & 1.240499 \\
\hline Im-eap & 1 & 1.039641 & 1.150499 & 1.221258 & 1.361211 \\
\hline Im-eca & 1 & 0.977505 & 1.069233 & 1.191523 & 1.31289 \\
\hline Im-lac & 1 & 1.077969 & 1.134086 & 1.25786 & 1.375398 \\
\hline Im-mea & 1 & 1.113917 & 1.207471 & 1.182717 & 1.216909 \\
\hline Im-sas & 1 & 1.109894 & 1.220322 & 1.370624 & 1.495025 \\
\hline Im-ssa & 1 & 1.143978 & 1.150982 & 1.170869 & 1.254513 \\
\hline lo-eap & 1 & 0.759183 & 0.889816 & 1.036025 & 1.109764 \\
\hline lo-eca & 1 & 1.211419 & 1.867667 & 2.537717 & 2.988045 \\
\hline lo-lac & 1 & 0.989572 & 0.93867 & 1.001147 & 1.006887 \\
\hline lo-sas & 1 & 1.077866 & 1.146654 & 1.306185 & 1.501434 \\
\hline lo-ssa & 1 & 1.038041 & 1.038184 & 1.146756 & 1.30366 \\
\hline ot-sms & 1 & 1.23042 & 1.7533 & 1.496547 & 1.402287 \\
\hline ot-ssa & 1 & 0.994514 & 0.979852 & 0.972223 & 0.961482 \\
\hline um-eap & 1 & 1.059509 & 1.137957 & 1.22352 & 1.284252 \\
\hline um-eca & 1 & 0.98298 & 1.074499 & 1.236319 & 1.25852 \\
\hline um-lac & 1 & 1.08253 & 1.471766 & 1.50091 & 1.824252 \\
\hline um-mea & 1 & 1.070522 & 1.198425 & 1.26632 & 1.514888 \\
\hline um-sas & 1 & 1.396807 & 1.93519 & 1.919287 & 2.504734 \\
\hline um-ssa & 1 & 1.121115 & 1.516298 & 1.705479 & 1.318708 \\
\hline um-weu & 1 & 1.095075 & 1.028291 & 1.046217 & 1.252033 \\
\hline
\end{tabular}


COMPLETE DATASET

\begin{tabular}{|c|c|c|c|c|c|c|c|c|c|c|c|c|}
\hline id & $\mathbf{t}$ & id.sub & yld & int & mob & gdp & edu & wat & fer & pic & avr & reg.inc \\
\hline ABW & 1 & hi-sms & NA & 0.0000 & 0.0098 & 23086.9380 & NA & NA & NA & NA & NA & 1.0000 \\
\hline AND & 1 & ot-sms & NA & 0.0000 & 0.7672 & 23342.5497 & NA & NA & NA & NA & NA & 1.0000 \\
\hline AFG & 1 & lo-sas & 1146.8894 & 0.0000 & 0.0000 & NA & NA & NA & NA & 31.7175 & NA & 1.0000 \\
\hline AGO & 1 & um-ssa & 340.3448 & 0.0000 & 0.0050 & 1263.3299 & NA & NA & NA & NA & 139.6534 & 1.0000 \\
\hline ALB & 1 & um-eca & 2456.2986 & 0.0000 & 0.0000 & 1331.7543 & 43.5108 & 1730.6334 & NA & 68.0550 & 564.5443 & 1.0000 \\
\hline ARE & 1 & hi-mea & 1767.9746 & 0.0000 & 2.7939 & 45947.5624 & NA & NA & NA & NA & NA & 1.0000 \\
\hline ARG & 1 & um-lac & 2723.6582 & 0.0191 & 0.2564 & 4732.9879 & 50.6147 & NA & NA & 36.3650 & 2690.5108 & 1.0000 \\
\hline ARM & 1 & Im-eca & 1657.2013 & 0.0046 & 0.0000 & 789.7092 & NA & NA & NA & NA & 489.8910 & 1.0000 \\
\hline ASM & 1 & um-eap & NA & 0.0000 & 1.1004 & NA & NA & NA & NA & NA & NA & 1.0000 \\
\hline ATG & 1 & hi-sms & 1844.5542 & 0.0000 & 0.0000 & 9916.3318 & NA & 250.0000 & NA & NA & 374.1893 & 1.0000 \\
\hline AUS & 1 & hi-nao & 1692.4420 & 1.5316 & 3.2601 & 25021.0836 & 1245.3140 & NA & NA & 84.4050 & 5250.9541 & 1.0000 \\
\hline AUT & 1 & hi-weu & 5339.7546 & 0.6382 & 2.1952 & 29871.3595 & 1555.3426 & 69.9468 & NA & 228.5300 & 1338.0772 & 1.0000 \\
\hline AZE & 1 & um-eca & 1788.1360 & 0.0007 & 0.0013 & 1246.5907 & 75.0603 & NA & NA & 4.7950 & 240.1928 & 1.0000 \\
\hline BDI & 1 & lo-ssa & 1356.9816 & 0.0000 & 0.0024 & 211.3498 & 8.0322 & NA & NA & 14.5725 & 107.9781 & 1.0000 \\
\hline BEL & 1 & hi-weu & NA & 0.2033 & 0.6982 & 29053.5650 & 1585.8691 & NA & NA & NA & NA & 1.0000 \\
\hline BEN & 1 & lo-ssa & 903.1710 & 0.0000 & 0.0000 & 460.0041 & NA & NA & NA & NA & 226.6604 & 1.0000 \\
\hline BFA & 1 & lo-ssa & 814.4644 & 0.0000 & 0.0000 & 280.5820 & 9.6850 & 87.9283 & NA & 64.4650 & 140.9798 & 1.0000 \\
\hline BGD & 1 & lo-sas & 2565.1236 & 0.0000 & 0.0003 & 279.7701 & 4.4647 & NA & NA & 77.7325 & 88.0646 & 1.0000 \\
\hline BGR & 1 & um-eca & 3241.7206 & 0.0073 & 0.0177 & 2590.9746 & 125.8196 & 560.9825 & NA & 1.1275 & 1000.0658 & 1.0000 \\
\hline BHR & 1 & hi-mea & NA & 0.0000 & 1.9323 & 16508.5590 & NA & 67505.5500 & NA & NA & NA & 1.0000 \\
\hline BHS & 1 & hi-sms & 1645.2874 & 0.0000 & 0.8465 & 20545.1609 & NA & NA & NA & NA & 2987.8789 & 1.0000 \\
\hline $\mathrm{BIH}$ & 1 & um-eca & 3558.0900 & 0.0000 & 0.0000 & 570.5338 & NA & NA & NA & NA & NA & 1.0000 \\
\hline BLR & 1 & um-eca & 2602.8100 & 0.0002 & 0.0040 & 2061.3655 & NA & 154.4362 & NA & 0.1000 & 743.4459 & 1.0000 \\
\hline BLZ & 1 & um-lac & 2054.6046 & 0.0000 & 0.1226 & 2962.3422 & NA & NA & NA & 72.0875 & 573.9102 & 1.0000 \\
\hline BMU & 1 & hi-sms & NA & 0.0000 & 4.2873 & 54329.8510 & 1768.1208 & NA & NA & NA & NA & 1.0000 \\
\hline
\end{tabular}




\begin{tabular}{|c|c|c|c|c|c|c|c|c|c|c|c|c|}
\hline $\mathrm{BOL}$ & 1 & Im-lac & 1416.4406 & 0.0000 & 0.0234 & 859.0378 & 41.1239 & NA & NA & 58.5850 & 251.8970 & 1.0000 \\
\hline BRA & 1 & um-lac & 2077.4184 & 0.0159 & 0.1003 & 4023.3702 & NA & NA & NA & 7.0250 & 692.2883 & 1.0000 \\
\hline BRB & 1 & hi-sms & 2627.5030 & 0.0000 & 0.4437 & 11642.5781 & 768.5774 & NA & NA & NA & 392.0193 & 1.0000 \\
\hline BRN & 1 & hi-sms & 1662.1378 & 0.0000 & 2.3498 & 26931.7143 & 1055.0438 & NA & NA & 102.6975 & 484.4117 & 1.0000 \\
\hline BTN & 1 & Im-sas & 1304.7842 & 0.0000 & 0.0000 & 684.0128 & NA & NA & NA & 24.1825 & 313.4549 & 1.0000 \\
\hline BWA & 1 & um-ssa & 317.1852 & 0.0000 & 0.0000 & 3858.4025 & 242.8080 & 157.4423 & NA & 25.8300 & 233.4930 & 1.0000 \\
\hline CAF & 1 & lo-ssa & 906.2958 & 0.0000 & 0.0000 & 348.5440 & 7.8653 & NA & NA & NA & 240.7004 & 1.0000 \\
\hline CAN & 1 & hi-nao & 2583.9496 & 1.0821 & 3.9172 & 27396.6609 & 1871.2064 & NA & NA & 73.1750 & NA & 1.0000 \\
\hline $\mathrm{CHE}$ & 1 & hi-weu & 6137.3696 & 1.6829 & 3.2265 & 48654.5743 & 2488.7193 & NA & NA & 188.7950 & 2064.7566 & 1.0000 \\
\hline $\mathrm{CHL}$ & 1 & hi-lac & 4116.6484 & 0.0624 & 0.4538 & 4724.7733 & 117.1432 & NA & NA & 66.8375 & 1410.3869 & 1.0000 \\
\hline $\mathrm{CHN}$ & 1 & um-eap & 4395.4358 & 0.0004 & 0.0402 & 573.0999 & 10.2450 & 3381.8197 & NA & 37.0450 & 200.2061 & 1.0000 \\
\hline CIV & 1 & Im-ssa & 1116.4996 & 0.0000 & 0.0000 & 1052.4676 & 63.2710 & NA & NA & 51.6800 & NA & 1.0000 \\
\hline CMR & 1 & Im-ssa & 1087.9420 & 0.0000 & 0.0024 & 875.8069 & 26.9241 & 23.5136 & NA & 46.1875 & 236.4646 & 1.0000 \\
\hline COG & 1 & Im-ssa & 636.1794 & 0.0000 & 0.0000 & 1759.0109 & 111.9406 & NA & NA & 46.9675 & 182.7913 & 1.0000 \\
\hline $\mathrm{COL}$ & 1 & um-lac & 2497.5392 & 0.0536 & 0.0483 & 2920.3162 & NA & NA & NA & 25.5225 & 1134.9591 & 1.0000 \\
\hline COM & 1 & lo-ssa & 1291.1624 & 0.0000 & 0.0000 & 646.5175 & NA & NA & NA & NA & 325.0769 & 1.0000 \\
\hline CPV & 1 & Im-ssa & 299.8060 & 0.0000 & 0.0000 & 783.4703 & NA & NA & NA & 73.4875 & 181.8226 & 1.0000 \\
\hline CRI & 1 & um-lac & 3359.9080 & 0.0906 & 0.0871 & 3396.5319 & NA & NA & NA & 26.9875 & 693.7921 & 1.0000 \\
\hline CUB & 1 & um-lac & 1879.0106 & 0.0000 & 0.0035 & 2895.5481 & 191.1992 & NA & NA & NA & 866.4842 & 1.0000 \\
\hline CUW & 1 & hi-sms & NA & NA & NA & NA & NA & NA & NA & NA & NA & 1.0000 \\
\hline CYM & 1 & hi-sms & NA & 0.0000 & 3.2336 & NA & NA & NA & NA & NA & NA & 1.0000 \\
\hline CYP & 1 & hi-weu & 2305.9322 & 0.0544 & 1.3781 & 17030.0671 & 492.0228 & 1573.4313 & NA & 125.2950 & 1567.5693 & 1.0000 \\
\hline CZE & 1 & hi-weu & 4055.8570 & 0.6135 & 0.0974 & 9407.0359 & 409.9469 & NA & NA & 85.8500 & 1050.7033 & 1.0000 \\
\hline DEU & 1 & hi-weu & 5654.1938 & 0.4395 & 1.4708 & 29913.8988 & 1346.3249 & NA & NA & 133.8050 & 1246.5561 & 1.0000 \\
\hline DJI & 1 & Im-mea & 1633.3334 & 0.0000 & 0.0000 & 1103.3773 & NA & NA & NA & NA & 135.0138 & 1.0000 \\
\hline DMA & 1 & um-lac & 1340.5806 & 0.0000 & 0.0000 & 4090.3227 & NA & NA & NA & NA & 2003.9012 & 1.0000 \\
\hline DNK & 1 & hi-weu & 5510.3846 & 0.5202 & 5.3858 & 37965.0000 & 2684.5557 & 185.3282 & NA & 141.2075 & 2877.6414 & 1.0000 \\
\hline DOM & 1 & um-lac & 3921.2362 & 0.0000 & 0.1235 & 2327.7303 & 19.6165 & NA & NA & 43.0225 & 505.1445 & 1.0000 \\
\hline DZA & 1 & um-mea & 847.3810 & 0.0002 & 0.0117 & 2407.3564 & NA & 365.7248 & NA & 42.5975 & 340.2044 & 1.0000 \\
\hline ECU & 1 & um-lac & 1839.1748 & 0.0141 & 0.0342 & 2693.1339 & NA & NA & NA & 6.1650 & 517.1694 & 1.0000 \\
\hline
\end{tabular}




\begin{tabular}{|c|c|c|c|c|c|c|c|c|c|c|c|c|}
\hline EGY & 1 & Im-mea & 5814.1210 & 0.0025 & 0.0094 & 896.6040 & 38.5067 & NA & NA & 46.0025 & 249.2570 & 1.0000 \\
\hline ERI & 1 & lo-ssa & 410.6205 & 0.0000 & 0.0000 & 205.6296 & NA & NA & NA & 17.9850 & 65.9130 & 1.0000 \\
\hline ESP & 1 & hi-weu & 2400.4354 & 0.1046 & 0.5169 & 19552.3234 & 803.9545 & 1567.8912 & NA & 111.4800 & NA & 1.0000 \\
\hline EST & 1 & hi-weu & 1687.2850 & 0.3815 & 0.3257 & NA & NA & NA & NA & 55.5100 & NA & 1.0000 \\
\hline ETH & 1 & lo-ssa & 1197.6994 & 0.0000 & 0.0000 & 127.1128 & 3.0410 & NA & NA & 85.8100 & 73.6338 & 1.0000 \\
\hline FIN & 1 & hi-weu & 3386.0532 & 2.2338 & 8.4310 & 26743.8348 & 1777.8351 & 8.7507 & NA & 280.9825 & 4675.0629 & 1.0000 \\
\hline FJI & 1 & um-eap & 2245.6226 & 0.0049 & 0.0287 & 2929.7092 & NA & NA & NA & NA & 821.2581 & 1.0000 \\
\hline FRA & 1 & hi-weu & 6432.8592 & 0.3925 & 0.8876 & 28605.5834 & 1467.1538 & 272.6008 & NA & 141.4525 & 2076.3255 & 1.0000 \\
\hline FRO & 1 & hi-sms & NA & 0.0000 & 2.9234 & NA & NA & NA & NA & NA & NA & 1.0000 \\
\hline FSM & 1 & Im-eap & NA & 0.0000 & 0.0000 & 2095.1283 & NA & NA & NA & NA & NA & 1.0000 \\
\hline GAB & 1 & um-ssa & 1614.4126 & 0.0000 & 0.0780 & 7111.6247 & 199.4627 & NA & NA & NA & 1229.4092 & 1.0000 \\
\hline GBR & 1 & hi-weu & 6388.6204 & 0.4157 & 3.5017 & 28946.4059 & 1346.4519 & 105.2282 & NA & NA & 1050.3094 & 1.0000 \\
\hline GEO & 1 & Im-eca & 1927.0887 & 0.0000 & 0.0000 & 1391.6878 & 95.9138 & NA & NA & 51.6800 & 839.4277 & 1.0000 \\
\hline GHA & 1 & Im-ssa & 1183.9756 & 0.0000 & 0.0068 & 389.6171 & NA & NA & NA & 3.8475 & NA & 1.0000 \\
\hline GIN & 1 & lo-ssa & 1419.4162 & 0.0001 & 0.0023 & 273.6174 & 5.5622 & NA & NA & 27.1200 & 79.8222 & 1.0000 \\
\hline GMB & 1 & lo-ssa & 1135.9630 & 0.0000 & 0.0289 & 421.5837 & 10.9244 & NA & NA & 23.5775 & 182.6791 & 1.0000 \\
\hline GNB & 1 & lo-ssa & 1482.6448 & 0.0000 & 0.0000 & 505.0454 & NA & 23.0740 & NA & NA & NA & 1.0000 \\
\hline GNQ & 1 & hi-sms & NA & 0.0000 & 0.0000 & 478.0070 & NA & NA & NA & NA & NA & 1.0000 \\
\hline GRC & 1 & hi-weu & 3633.5538 & 0.1333 & 0.3812 & 15916.7585 & 332.1876 & 1990.3181 & NA & 103.8175 & NA & 1.0000 \\
\hline GRD & 1 & um-lac & 1021.5802 & 0.0000 & 0.2267 & 4246.5586 & NA & NA & NA & NA & 549.2642 & 1.0000 \\
\hline GRL & 1 & hi-sms & NA & 0.0324 & 0.5635 & 23650.2616 & NA & NA & NA & NA & NA & 1.0000 \\
\hline GTM & 1 & Im-lac & 1870.8454 & 0.0000 & 0.0357 & 1823.0021 & 28.3319 & NA & NA & NA & 429.8022 & 1.0000 \\
\hline GUM & 1 & hi-sms & 2213.3334 & 0.1742 & 1.1669 & NA & NA & NA & NA & NA & NA & 1.0000 \\
\hline GUY & 1 & Im-lac & 3341.3072 & 0.0000 & 0.0862 & 788.7342 & 29.3778 & 2995.7375 & NA & NA & 363.1953 & 1.0000 \\
\hline HKG & 1 & hi-sms & 2000.0000 & 1.0178 & 4.4781 & 19325.1767 & 512.1987 & NA & NA & NA & NA & 1.0000 \\
\hline HND & 1 & Im-lac & 1350.6294 & 0.0000 & 0.0000 & 1167.1272 & 39.6877 & NA & NA & 26.5450 & 290.0157 & 1.0000 \\
\hline HRV & 1 & hi-weu & 4124.3500 & 0.1218 & 0.1752 & NA & NA & NA & NA & 70.9433 & NA & 1.0000 \\
\hline $\mathrm{HTI}$ & 1 & lo-lac & 965.9258 & 0.0000 & 0.0000 & NA & NA & 1179.3796 & NA & NA & NA & 1.0000 \\
\hline HUN & 1 & um-eca & 4142.1440 & 0.1457 & 0.4306 & 7384.5014 & 440.1582 & NA & NA & 34.4075 & NA & 1.0000 \\
\hline IDN & 1 & Im-eap & 3852.2308 & 0.0005 & 0.0224 & 949.1234 & 9.4955 & 3775.8224 & NA & 17.9225 & 221.8669 & 1.0000 \\
\hline
\end{tabular}




\begin{tabular}{|c|c|c|c|c|c|c|c|c|c|c|c|c|}
\hline IMN & 1 & ot-sms & NA & NA & NA & 17742.2747 & NA & NA & NA & NA & NA & 1.0000 \\
\hline IND & 1 & Im-sas & 2008.5526 & 0.0003 & 0.0000 & 416.9180 & NA & 2823.9639 & NA & 44.4125 & 151.0400 & 1.0000 \\
\hline IRL & 1 & hi-weu & 6368.0632 & 0.2132 & 1.4038 & 24904.6517 & 1252.8138 & NA & NA & 120.9200 & NA & 1.0000 \\
\hline IRN & 1 & um-mea & 1604.8368 & 0.0002 & 0.0031 & 1956.3048 & 81.3043 & NA & NA & 10.0725 & 487.5894 & 1.0000 \\
\hline IRQ & 1 & um-mea & 822.8292 & 0.0000 & 0.0000 & 1147.4926 & NA & 7472.5389 & NA & 3.2575 & 347.2633 & 1.0000 \\
\hline ISL & 1 & hi-weu & NA & 2.3014 & 5.9371 & 40172.3961 & 1923.5962 & NA & NA & NA & NA & 1.0000 \\
\hline ISR & 1 & hi-mea & 2860.1686 & 0.3224 & 1.0925 & 14095.3655 & 932.6225 & 3508.5874 & NA & 108.7700 & NA & 1.0000 \\
\hline ITA & 1 & hi-weu & 4509.0894 & 0.0875 & 1.7792 & 26925.8873 & 1280.9572 & NA & NA & 127.8350 & 1799.5511 & 1.0000 \\
\hline JAM & 1 & um-lac & 1374.5866 & 0.0184 & 0.4240 & NA & NA & NA & NA & 9.8825 & 640.9149 & 1.0000 \\
\hline JOR & 1 & um-mea & 1319.1744 & 0.0000 & 0.0390 & 1766.5225 & NA & 3583.6624 & NA & 73.8675 & 342.6440 & 1.0000 \\
\hline JPN & 1 & hi-eap & 5603.3428 & 0.2717 & 1.6875 & 32056.7195 & 1145.5736 & 12431.9048 & NA & 150.8175 & 2327.5399 & 1.0000 \\
\hline KAZ & 1 & um-eca & 1055.5307 & 0.0003 & 0.0005 & 2561.9753 & NA & NA & NA & 16.4500 & 684.4200 & 1.0000 \\
\hline KEN & 1 & lo-ssa & 1662.9948 & 0.0000 & 0.0033 & 527.8170 & 32.4081 & 302.4315 & NA & 35.2975 & 152.1382 & 1.0000 \\
\hline KGZ & 1 & Im-eca & 2349.1617 & 0.0000 & 0.0000 & 538.1131 & 30.0087 & NA & NA & NA & 176.8529 & 1.0000 \\
\hline KHM & 1 & lo-eap & 1370.1952 & 0.0000 & 0.0292 & 248.3205 & NA & NA & NA & 41.7625 & 149.7476 & 1.0000 \\
\hline $\mathrm{KIR}$ & 1 & Im-eap & NA & 0.0000 & 0.0000 & 928.8105 & NA & NA & NA & NA & 563.9342 & 1.0000 \\
\hline KNA & 1 & hi-sms & NA & 0.0000 & 0.0000 & 7817.5141 & 224.7455 & NA & NA & NA & 237.2707 & 1.0000 \\
\hline KOR & 1 & hi-eap & 5829.0838 & 0.1458 & 0.8854 & 10081.0726 & 339.5777 & NA & NA & 48.3550 & 2035.1969 & 1.0000 \\
\hline KWT & 1 & hi-sms & 4181.1368 & 0.0794 & 2.9367 & NA & 2876.2623 & NA & NA & NA & NA & 1.0000 \\
\hline LAO & 1 & Im-eap & 2372.7088 & 0.0000 & 0.0054 & 274.5433 & 6.4201 & NA & NA & 9.4500 & 144.7836 & 1.0000 \\
\hline LBN & 1 & um-mea & 2045.1344 & 0.0000 & 0.0000 & 4512.3381 & 83.5255 & NA & NA & 52.3050 & 1323.3213 & 1.0000 \\
\hline LBR & 1 & lo-ssa & 1009.7546 & 0.0000 & 0.0000 & 111.3947 & NA & NA & NA & NA & NA & 1.0000 \\
\hline LBY & 1 & um-mea & 700.4064 & 0.0000 & 0.0000 & NA & NA & 2359.5325 & NA & NA & NA & 1.0000 \\
\hline LCA & 1 & um-lac & NA & 0.0000 & 0.1804 & 4667.9979 & 420.7348 & NA & NA & NA & 831.5857 & 1.0000 \\
\hline LIE & 1 & hi-sms & NA & 0.0000 & 0.0000 & 72568.7365 & NA & NA & NA & NA & NA & 1.0000 \\
\hline LKA & 1 & Im-sas & 2954.9422 & 0.0014 & 0.0549 & 766.2309 & 21.5654 & 10488.9476 & NA & 51.2300 & 168.8181 & 1.0000 \\
\hline LSO & 1 & Im-ssa & 782.1064 & 0.0000 & 0.0000 & 541.4774 & 48.8628 & NA & NA & NA & 81.5592 & 1.0000 \\
\hline LTU & 1 & hi-weu & 1933.8183 & 0.0000 & 0.0329 & 5214.8575 & 253.4414 & NA & NA & 47.2867 & NA & 1.0000 \\
\hline LUX & 1 & hi-weu & NA & 0.2380 & 1.0563 & 54916.5514 & NA & NA & NA & NA & NA & 1.0000 \\
\hline LVA & 1 & hi-sms & 1755.8060 & 0.0000 & 0.1037 & 3975.1303 & 165.0119 & NA & NA & 95.8200 & 727.3349 & 1.0000 \\
\hline
\end{tabular}




\begin{tabular}{|c|c|c|c|c|c|c|c|c|c|c|c|c|}
\hline MAC & 1 & hi-sms & NA & 0.0185 & 2.8239 & 15847.2320 & NA & NA & NA & NA & NA & 1.0000 \\
\hline MAF & 1 & hi-sms & NA & NA & NA & NA & NA & NA & NA & NA & NA & 1.0000 \\
\hline MAR & 1 & Im-mea & 1085.7642 & 0.0000 & 0.0201 & 1450.9128 & 77.9150 & 1144.3070 & NA & 105.2675 & 517.0185 & 1.0000 \\
\hline $\mathrm{MCO}$ & 1 & hi-sms & NA & 0.0000 & 2.4454 & 109872.2531 & 1003.7819 & NA & NA & NA & NA & 1.0000 \\
\hline MDA & 1 & Im-eca & 2980.7227 & 0.0004 & 0.0000 & 1104.8869 & NA & 443.8562 & NA & 43.5200 & 351.0404 & 1.0000 \\
\hline MDG & 1 & lo-ssa & 1931.1044 & 0.0000 & 0.0005 & 298.3682 & 6.3724 & NA & NA & 23.3200 & 109.5049 & 1.0000 \\
\hline MDV & 1 & um-sas & 1000.0000 & 0.0000 & 0.0000 & NA & NA & NA & NA & NA & NA & 1.0000 \\
\hline MEX & 1 & um-lac & 2543.4458 & 0.0190 & 0.3271 & 6780.4946 & 195.1179 & NA & NA & 38.9350 & 937.5451 & 1.0000 \\
\hline MHL & 1 & um-eap & NA & 0.0000 & 0.1107 & 2482.9557 & NA & NA & NA & NA & NA & 1.0000 \\
\hline MKD & 1 & um-eca & 2452.9163 & 0.0000 & 0.0000 & 2695.6440 & 131.3625 & NA & NA & 55.4433 & 753.4112 & 1.0000 \\
\hline MLI & 1 & lo-ssa & 820.0478 & 0.0000 & 0.0000 & 332.4549 & NA & NA & NA & 51.9950 & 188.1931 & 1.0000 \\
\hline MLT & 1 & hi-weu & 3046.6766 & 0.0000 & 0.9582 & 10508.3137 & 422.9643 & NA & NA & 70.5375 & 3166.2230 & 1.0000 \\
\hline MMR & 1 & lo-eap & 2816.6768 & 0.0000 & 0.0012 & NA & NA & NA & NA & 5.4250 & NA & 1.0000 \\
\hline MNE & 1 & um-eca & NA & NA & NA & NA & NA & NA & NA & NA & NA & 1.0000 \\
\hline MNG & 1 & Im-eap & 901.0776 & 0.0000 & 0.0000 & 721.6623 & NA & NA & NA & 13.3200 & 561.1257 & 1.0000 \\
\hline MNP & 1 & hi-sms & NA & 0.0000 & 0.9333 & NA & NA & NA & NA & NA & NA & 1.0000 \\
\hline MOZ & 1 & lo-ssa & 415.9910 & 0.0000 & 0.0000 & 185.5675 & NA & 153.7651 & NA & 10.7575 & 75.3245 & 1.0000 \\
\hline MRT & 1 & Im-ssa & 784.4374 & 0.0000 & 0.0000 & 560.5066 & NA & NA & NA & NA & 386.1074 & 1.0000 \\
\hline MUS & 1 & um-ssa & 4064.1994 & 0.0000 & 0.3182 & 3283.5418 & 109.5600 & NA & NA & 91.3050 & 534.4083 & 1.0000 \\
\hline MWI & 1 & lo-ssa & 999.8526 & 0.0000 & 0.0000 & 191.2190 & 6.2532 & NA & NA & NA & 49.1776 & 1.0000 \\
\hline MYS & 1 & um-eap & 2903.1502 & 0.0315 & 1.3540 & 3587.1443 & 173.6076 & 8228.8332 & NA & 65.3125 & 1041.5263 & 1.0000 \\
\hline NAM & 1 & um-ssa & 370.7366 & 0.0000 & 0.0000 & 2918.8276 & NA & 248.1639 & NA & 28.7125 & 430.4564 & 1.0000 \\
\hline $\mathrm{NCL}$ & 1 & hi-sms & 2532.8244 & 0.0000 & 0.0000 & NA & NA & NA & NA & NA & NA & 1.0000 \\
\hline NER & 1 & lo-ssa & 322.4214 & 0.0000 & 0.0000 & 282.1620 & 8.4905 & 33.0187 & NA & 38.6125 & NA & 1.0000 \\
\hline NGA & 1 & Im-ssa & 1138.2724 & 0.0000 & 0.0042 & 565.4977 & NA & NA & NA & 12.0250 & 200.3145 & 1.0000 \\
\hline $\mathrm{NIC}$ & 1 & Im-lac & 1628.4042 & 0.0066 & 0.0110 & 898.7391 & 26.8036 & NA & NA & 28.5625 & 308.1522 & 1.0000 \\
\hline NLD & 1 & hi-weu & 7335.1030 & 1.4821 & 1.1825 & 31799.3326 & 1700.4789 & 208.2272 & NA & 134.6375 & 2289.6660 & 1.0000 \\
\hline NOR & 1 & hi-weu & 3781.5368 & 2.2535 & 7.7876 & 47270.7761 & 3358.5810 & NA & NA & 136.3950 & 2717.5003 & 1.0000 \\
\hline NPL & 1 & lo-sas & 1825.2336 & 0.0000 & 0.0000 & 246.4842 & NA & NA & NA & 50.9425 & 106.2187 & 1.0000 \\
\hline NZL & 1 & hi-nao & 5395.2912 & 1.0215 & 3.4372 & 20337.5040 & 1219.5818 & NA & NA & 94.4800 & 7043.3965 & 1.0000 \\
\hline
\end{tabular}




\begin{tabular}{|c|c|c|c|c|c|c|c|c|c|c|c|c|}
\hline OMN & 1 & hi-mea & 2003.3516 & 0.0000 & 0.2361 & 10985.8736 & 350.0079 & 35215.6472 & NA & NA & NA & 1.0000 \\
\hline PAK & 1 & Im-sas & 1850.0640 & 0.0000 & 0.0108 & 549.2187 & 13.9060 & 7282.3701 & NA & 37.6675 & 173.3639 & 1.0000 \\
\hline PAN & 1 & um-lac & 1890.7570 & 0.0038 & 0.0000 & 3419.7048 & 143.9648 & NA & NA & 100.8100 & 524.1316 & 1.0000 \\
\hline PER & 1 & um-lac & 2598.1180 & 0.0043 & 0.1015 & 1942.4056 & NA & NA & NA & 42.0875 & NA & 1.0000 \\
\hline PHL & 1 & Im-eap & 2137.0478 & 0.0029 & 0.1095 & 969.9234 & NA & NA & NA & 51.9750 & 274.6957 & 1.0000 \\
\hline PLW & 1 & um-eap & NA & 0.0000 & NA & 9224.9928 & NA & NA & NA & NA & NA & 1.0000 \\
\hline PNG & 1 & Im-eap & 2646.5984 & 0.0000 & 0.0000 & 850.2977 & NA & NA & NA & NA & NA & 1.0000 \\
\hline $\mathrm{POL}$ & 1 & hi-weu & 2838.5280 & 0.1153 & 0.0296 & 4649.5845 & 194.2609 & 118.1038 & NA & 40.3000 & NA & 1.0000 \\
\hline PRI & 1 & hi-lac & 1288.4484 & 0.0136 & 2.1199 & 15395.9259 & NA & 4351.9241 & NA & NA & 2518.2257 & 1.0000 \\
\hline PRK & 1 & lo-eap & 5220.0970 & 0.0000 & 0.0000 & NA & NA & NA & NA & NA & NA & 1.0000 \\
\hline PRT & 1 & hi-weu & 2049.8612 & 0.3039 & 0.6613 & 14764.8602 & 643.1867 & NA & NA & 130.8250 & NA & 1.0000 \\
\hline PRY & 1 & Im-lac & 1894.4806 & 0.0000 & 0.0542 & 1499.7532 & 15.9379 & NA & NA & 32.4375 & 461.4089 & 1.0000 \\
\hline PYF & 1 & hi-sms & NA & 0.0000 & 0.0000 & NA & NA & NA & NA & NA & NA & 1.0000 \\
\hline QAT & 1 & hi-mea & 3008.3996 & 0.0000 & 1.1404 & 34901.0065 & NA & NA & NA & 126.9500 & 2404.2823 & 1.0000 \\
\hline ROU & 1 & um-weu & 2705.2370 & 0.0100 & 0.0031 & 3334.0999 & NA & 970.0297 & NA & 2.1425 & 829.6283 & 1.0000 \\
\hline RUS & 1 & hi-eca & 1612.2157 & 0.0170 & 0.0059 & 4712.5698 & NA & NA & NA & 1.9133 & 904.0267 & 1.0000 \\
\hline RWA & 1 & lo-ssa & 1153.5996 & 0.0000 & 0.0000 & 234.3597 & NA & NA & NA & 18.7375 & 86.8399 & 1.0000 \\
\hline SAU & 1 & hi-mea & 4329.1964 & 0.0000 & 0.0904 & 12677.4848 & 742.3589 & 4262.5821 & NA & 96.2250 & 2230.7065 & 1.0000 \\
\hline SDN & 1 & Im-ssa & 561.4354 & 0.0000 & 0.0000 & 464.7319 & NA & NA & NA & 3.3100 & 317.2835 & 1.0000 \\
\hline SEN & 1 & Im-ssa & 799.0814 & 0.0000 & 0.0002 & 662.4295 & NA & NA & NA & 70.9200 & 196.6432 & 1.0000 \\
\hline SGP & 1 & hi-sms & NA & 0.5163 & 4.1012 & 18361.4909 & NA & NA & NA & NA & NA & 1.0000 \\
\hline SLB & 1 & Im-eap & 3484.6160 & 0.0000 & 0.0082 & 1088.0516 & 30.0449 & NA & NA & NA & 313.9765 & 1.0000 \\
\hline SLE & 1 & lo-ssa & 1203.6442 & 0.0000 & 0.0000 & 332.8133 & NA & NA & NA & NA & 247.9149 & 1.0000 \\
\hline SLV & 1 & Im-lac & 1841.7376 & 0.0000 & 0.0230 & 1973.7753 & NA & 584.7478 & NA & 82.4875 & 529.3421 & 1.0000 \\
\hline SMR & 1 & hi-sms & NA & 0.0000 & 4.0736 & 30068.1236 & 1086.9811 & NA & NA & NA & NA & 1.0000 \\
\hline SOM & 1 & lo-ssa & 547.2026 & 0.0000 & 0.0000 & NA & NA & NA & NA & NA & NA & 1.0000 \\
\hline SRB & 1 & um-eca & 3098.9393 & NA & NA & NA & NA & NA & NA & 2.1600 & NA & 1.0000 \\
\hline SSD & 1 & Im-ssa & NA & NA & NA & NA & NA & NA & NA & NA & NA & 1.0000 \\
\hline STP & 1 & Im-ssa & 2099.8268 & 0.0000 & 0.0000 & NA & NA & NA & NA & NA & NA & 1.0000 \\
\hline SUR & 1 & um-lac & 3805.2844 & 0.0000 & 0.1151 & 3027.1232 & NA & NA & NA & 3.9000 & 639.3346 & 1.0000 \\
\hline
\end{tabular}




\begin{tabular}{|c|c|c|c|c|c|c|c|c|c|c|c|c|}
\hline SVK & 1 & hi-weu & 4038.9815 & 0.1488 & 0.0402 & 6982.6790 & 330.4057 & NA & NA & 86.0550 & NA & 1.0000 \\
\hline SVN & 1 & hi-weu & 4020.8993 & 0.4938 & 0.2689 & NA & NA & NA & NA & 71.4433 & NA & 1.0000 \\
\hline SWE & 1 & hi-weu & 4293.2114 & 1.6744 & 8.8239 & 31402.0668 & 1772.3335 & 57.3566 & NA & 119.9325 & 2513.5498 & 1.0000 \\
\hline SWZ & 1 & Im-ssa & 1312.0378 & 0.0000 & 0.0000 & 2020.9560 & 107.3828 & NA & NA & NA & 215.9596 & 1.0000 \\
\hline SXM & 1 & hi-sms & NA & NA & NA & NA & NA & NA & NA & NA & NA & 1.0000 \\
\hline SYC & 1 & um-ssa & NA & 0.0000 & 0.0000 & 9325.7401 & 848.5417 & 899.9970 & NA & NA & 734.4741 & 1.0000 \\
\hline SYR & 1 & Im-mea & 1174.5466 & 0.0000 & 0.0000 & 1248.0044 & NA & NA & NA & 77.2150 & NA & 1.0000 \\
\hline TCA & 1 & hi-sms & NA & NA & NA & NA & NA & NA & NA & NA & NA & 1.0000 \\
\hline TCD & 1 & lo-ssa & 631.0358 & 0.0000 & 0.0000 & 409.9627 & NA & NA & NA & NA & NA & 1.0000 \\
\hline TGO & 1 & lo-ssa & 794.4340 & 0.0000 & 0.0000 & 380.3068 & 21.5199 & NA & NA & 51.9550 & 192.3644 & 1.0000 \\
\hline THA & 1 & um-eap & 2238.4568 & 0.0105 & 0.5470 & 1823.7513 & 58.4002 & NA & NA & 55.2075 & 350.8118 & 1.0000 \\
\hline TJK & 1 & lo-eca & 947.5887 & 0.0000 & 0.0000 & 497.8254 & 40.4077 & NA & NA & NA & 116.1458 & 1.0000 \\
\hline TKM & 1 & um-eca & 2384.6260 & 0.0000 & 0.0000 & 1780.0652 & NA & NA & NA & NA & 432.8009 & 1.0000 \\
\hline TLS & 1 & lo-sas & 1827.5922 & 0.0000 & 0.0000 & NA & NA & NA & NA & NA & NA & 1.0000 \\
\hline TON & 1 & um-eap & NA & 0.0000 & 0.0000 & 1994.7755 & NA & NA & NA & NA & 544.6665 & 1.0000 \\
\hline TTO & 1 & hi-sms & 3402.9586 & 0.0000 & 0.0961 & 6567.9751 & 232.6916 & NA & NA & 73.3500 & 90.0307 & 1.0000 \\
\hline TUN & 1 & um-mea & 1260.6058 & 0.0037 & 0.0213 & 2147.8275 & 127.8384 & 938.0209 & NA & 84.9425 & 633.8367 & 1.0000 \\
\hline TUR & 1 & um-eca & 2148.7184 & 0.0194 & 0.1416 & 5128.7798 & 174.2008 & 930.8171 & NA & 0.5625 & 1662.1058 & 1.0000 \\
\hline TUV & 1 & um-eap & NA & 0.0000 & 0.0000 & 1914.9685 & 144.7215 & NA & NA & NA & 823.9293 & 1.0000 \\
\hline TZA & 1 & lo-ssa & 1241.4360 & 0.0000 & 0.0003 & 289.6809 & 6.0130 & NA & NA & 35.3200 & 113.9341 & 1.0000 \\
\hline UGA & 1 & lo-ssa & 1499.5612 & 0.0000 & 0.0000 & 205.7054 & NA & NA & NA & NA & 86.6559 & 1.0000 \\
\hline UKR & 1 & Im-eca & 2951.5913 & 0.0048 & 0.0020 & 2106.6909 & NA & NA & NA & 7.4700 & 529.3738 & 1.0000 \\
\hline URY & 1 & hi-lac & 2556.6140 & 0.0312 & 0.0848 & 4314.4693 & 103.0721 & NA & NA & 13.6425 & 3377.4437 & 1.0000 \\
\hline USA & 1 & hi-nao & 4898.0830 & 2.1613 & 4.8946 & 33386.7957 & 1624.2305 & 1058.0832 & NA & 93.6700 & NA & 1.0000 \\
\hline UZB & 1 & Im-eca & 1677.6380 & 0.0000 & 0.0013 & 478.8510 & NA & NA & NA & NA & 180.7291 & 1.0000 \\
\hline VCT & 1 & um-lac & 3212.1846 & 0.0000 & 0.0701 & 3231.3556 & 188.8774 & NA & NA & NA & 571.2663 & 1.0000 \\
\hline VEN & 1 & um-lac & 2711.5972 & 0.0273 & 0.5675 & 5612.5335 & 226.0221 & NA & NA & 3.0850 & 1332.4404 & 1.0000 \\
\hline VIR & 1 & hi-sms & NA & 0.4703 & 0.0000 & NA & NA & NA & NA & NA & NA & 1.0000 \\
\hline VNM & 1 & Im-eap & 3222.4336 & 0.0000 & 0.0047 & 336.9966 & NA & NA & NA & 39.9025 & 120.9360 & 1.0000 \\
\hline VUT & 1 & Im-eap & 532.8650 & 0.0000 & 0.0078 & 1849.8206 & 81.1941 & NA & NA & NA & 497.4431 & 1.0000 \\
\hline
\end{tabular}




\begin{tabular}{|c|c|c|c|c|c|c|c|c|c|c|c|c|}
\hline PSE & 1 & ot-sms & 1111.2880 & 0.0000 & 0.0000 & 879.6077 & NA & NA & NA & NA & 383.8465 & 1.0000 \\
\hline WSM & 1 & Im-eap & NA & 0.0000 & 0.0000 & 1713.7275 & NA & NA & NA & NA & 505.1022 & 1.0000 \\
\hline YEM & 1 & Im-mea & 983.7282 & 0.0000 & 0.0213 & 683.0939 & NA & 1758.3217 & NA & 13.2475 & NA & 1.0000 \\
\hline ZAF & 1 & um-ssa & 1910.8744 & 0.0826 & 0.2012 & 4815.2086 & 279.7262 & 728.6799 & NA & 50.5650 & 295.1163 & 1.0000 \\
\hline COD & 1 & ot-ssa & 793.6792 & 0.0000 & 0.0000 & 390.0141 & NA & NA & NA & NA & 101.4718 & 1.0000 \\
\hline ZMB & 1 & Im-ssa & 1494.9690 & 0.0034 & 0.0000 & 635.4177 & 13.8567 & 476.3698 & NA & NA & 196.0920 & 1.0000 \\
\hline ZWE & 1 & lo-ssa & 1265.2490 & 0.0009 & 0.0000 & 653.9962 & 172.3115 & NA & NA & 0.0000 & 144.7671 & 1.0000 \\
\hline ABW & 2 & hi-sms & NA & 3.6373 & 5.8746 & 23613.7080 & 1082.5518 & NA & NA & NA & NA & 1.0739 \\
\hline AND & 2 & ot-sms & NA & 4.7747 & 16.1364 & 25103.7374 & 932.1570 & NA & NA & NA & NA & 1.2304 \\
\hline AFG & 2 & lo-sas & 1297.3552 & NA & 0.0000 & NA & NA & NA & NA & 87.1540 & NA & 1.0779 \\
\hline AGO & 2 & um-ssa & 588.9966 & 0.0242 & 0.0701 & 1167.1661 & 30.3163 & NA & NA & NA & 112.2753 & 1.1211 \\
\hline ALB & 2 & um-eca & 2759.1632 & 0.0477 & 0.1336 & 1692.2884 & 58.0986 & NA & NA & 112.4840 & 784.1072 & 0.9830 \\
\hline ARE & 2 & hi-mea & 3886.3120 & 5.1250 & 14.3752 & 45008.2558 & 498.7393 & 33050.0751 & NA & NA & NA & 1.1687 \\
\hline ARG & 2 & um-lac & 3181.2004 & 0.9248 & 5.3243 & 5504.3345 & 186.3201 & 787.7630 & NA & 45.5020 & 3327.6165 & 1.0825 \\
\hline ARM & 2 & Im-eca & 1734.5682 & 0.2717 & 0.1368 & 755.8797 & 15.4152 & 4320.4009 & NA & 102.8633 & 526.2976 & 0.9775 \\
\hline ASM & 2 & um-eap & NA & NA & 2.6354 & NA & NA & NA & NA & NA & NA & 1.0595 \\
\hline ATG & 2 & hi-sms & 1971.2052 & 3.5824 & 4.2471 & 10204.1910 & 330.6963 & NA & NA & NA & 317.9803 & 1.0739 \\
\hline AUS & 2 & hi-nao & 2010.2324 & 18.8003 & 23.6289 & 28174.9169 & 1458.6739 & 376.5046 & NA & 108.2460 & 5969.5401 & 1.0975 \\
\hline AUT & 2 & hi-weu & 5786.0374 & 11.3598 & 21.6911 & 32970.4114 & 1920.6735 & 71.0570 & NA & 121.2260 & 1408.0943 & 1.0754 \\
\hline AZE & 2 & um-eca & 1688.0196 & 0.0341 & 1.2420 & 705.1157 & 25.4841 & 5678.2919 & NA & 75.1820 & 177.3224 & 0.9830 \\
\hline $\mathrm{BDI}$ & 2 & lo-ssa & 1350.9970 & 0.0128 & 0.0099 & 159.4835 & 6.6496 & NA & NA & 30.6880 & 88.6222 & 1.0380 \\
\hline BEL & 2 & hi-weu & NA & 6.1114 & 12.9698 & 31772.0646 & 971.1601 & NA & NA & NA & 9242.6440 & 1.0754 \\
\hline BEN & 2 & lo-ssa & 1086.2970 & 0.0573 & 0.0665 & 486.1417 & 13.5935 & NA & NA & NA & 258.1821 & 1.0380 \\
\hline BFA & 2 & lo-ssa & 854.8028 & 0.0317 & 0.0177 & 320.2805 & 4.6248 & NA & NA & 89.1260 & 169.6515 & 1.0380 \\
\hline BGD & 2 & lo-sas & 2790.3056 & 0.0135 & 0.0399 & 317.1392 & 7.3783 & NA & NA & 79.1520 & 91.0472 & 1.0779 \\
\hline BGR & 2 & um-eca & 2724.1158 & 1.3636 & 1.4653 & 2649.5490 & 85.5216 & NA & NA & 57.4600 & 857.1960 & 0.9830 \\
\hline BHR & 2 & hi-mea & NA & 2.1549 & 11.4685 & 18130.5392 & NA & NA & NA & NA & NA & 1.1687 \\
\hline BHS & 2 & hi-sms & 1895.2262 & 2.0340 & 2.7152 & 21545.7004 & NA & NA & NA & NA & 2910.8681 & 1.0739 \\
\hline $\mathrm{BIH}$ & 2 & um-eca & 3576.8738 & 0.1031 & 0.4783 & 1618.2011 & NA & NA & NA & 75.6200 & NA & 0.9830 \\
\hline BLR & 2 & um-eca & 2012.2404 & 0.1300 & 0.1115 & 1746.6736 & 95.8178 & NA & NA & 4.1880 & 626.0895 & 0.9830 \\
\hline
\end{tabular}




\begin{tabular}{|c|c|c|c|c|c|c|c|c|c|c|c|c|}
\hline BLZ & 2 & um-lac & 2388.6918 & 1.6770 & 1.4707 & 3128.3961 & 170.4512 & NA & NA & 80.2540 & 646.8544 & 1.0825 \\
\hline BMU & 2 & hi-sms & NA & 23.8562 & 16.0913 & 60264.8589 & 1297.5689 & NA & NA & NA & NA & 1.0739 \\
\hline BOL & 2 & Im-lac & 1484.7660 & 0.4638 & 1.9987 & 944.4553 & 50.6785 & NA & NA & 81.5620 & 283.1601 & 1.0780 \\
\hline BRA & 2 & um-lac & 2582.1154 & 0.9717 & 3.6254 & 4330.9808 & 192.3058 & 578.0753 & NA & 47.3880 & 906.5769 & 1.0825 \\
\hline BRB & 2 & hi-sms & 2643.3334 & 1.1054 & 3.8626 & 12678.0931 & 539.5125 & NA & NA & NA & 392.1012 & 1.0739 \\
\hline BRN & 2 & hi-sms & 1429.0566 & 4.6215 & 15.3795 & 26474.4481 & 1347.1719 & 2650.0600 & NA & 106.8460 & 553.4282 & 1.0739 \\
\hline BTN & 2 & Im-sas & 1525.2300 & 0.1376 & 0.0000 & 879.0051 & NA & NA & NA & 35.6480 & 356.3910 & 1.1099 \\
\hline BWA & 2 & um-ssa & 316.0018 & 0.4509 & 1.2462 & 4371.9097 & NA & 218.4886 & NA & 32.1440 & 248.5715 & 1.1211 \\
\hline CAF & 2 & lo-ssa & 925.0134 & 0.0222 & 0.0473 & 345.1707 & 5.8351 & NA & NA & NA & 259.0863 & 1.0380 \\
\hline CAN & 2 & hi-nao & 2799.7228 & 17.4160 & 15.0335 & 30033.5654 & 1745.7504 & NA & NA & 114.5420 & NA & 1.0975 \\
\hline $\mathrm{CHE}$ & 2 & hi-weu & 6460.2610 & 16.4003 & 19.4419 & 49296.7630 & 2596.8405 & NA & NA & 146.9680 & 1931.7782 & 1.0754 \\
\hline $\mathrm{CHL}$ & 2 & hi-lac & 4471.4722 & 1.5707 & 5.5014 & 6191.1264 & 196.8300 & NA & NA & 85.5920 & 1594.7790 & 1.1975 \\
\hline $\mathrm{CHN}$ & 2 & um-eap & 4854.9800 & 0.1854 & 1.4365 & 911.9883 & 17.1168 & 3411.4086 & NA & 89.2460 & 250.2758 & 1.0595 \\
\hline CIV & 2 & Im-ssa & 1391.6314 & 0.0414 & 0.5100 & 1094.0047 & 44.1656 & 273.9934 & NA & 81.5940 & NA & 1.1440 \\
\hline CMR & 2 & Im-ssa & 1449.9562 & 0.0497 & 0.0290 & 824.6123 & NA & NA & NA & 72.2380 & 278.0581 & 1.1440 \\
\hline COG & 2 & Im-ssa & 796.7926 & 0.0068 & 0.0786 & 1600.4144 & 71.7834 & NA & NA & 70.9240 & 164.5121 & 1.1440 \\
\hline $\mathrm{COL}$ & 2 & um-lac & 2888.3384 & 0.7785 & 3.0344 & 3142.8823 & 131.4400 & NA & NA & 51.1200 & 943.3741 & 1.0825 \\
\hline COM & 2 & lo-ssa & 1195.3826 & 0.0620 & 0.0000 & 603.1744 & 22.8060 & NA & NA & NA & 324.0551 & 1.0380 \\
\hline CPV & 2 & Im-ssa & 406.0946 & 0.6246 & 0.4205 & 1249.8421 & 82.7520 & NA & NA & 98.2120 & 305.2555 & 1.1440 \\
\hline CRI & 2 & um-lac & 3699.4914 & 1.8938 & 2.0201 & 3840.1533 & 154.0700 & NA & NA & 46.9780 & 834.3744 & 1.0825 \\
\hline CUB & 2 & um-lac & 2159.7440 & 0.1283 & 0.0300 & 2655.8164 & 172.1888 & 741.3235 & NA & 29.9600 & 718.3260 & 1.0825 \\
\hline CUW & 2 & hi-sms & NA & NA & NA & NA & NA & NA & NA & NA & NA & 1.0739 \\
\hline CYM & 2 & hi-sms & NA & 3.9490 & 13.5920 & NA & NA & NA & NA & NA & NA & 1.0739 \\
\hline CYP & 2 & hi-weu & 1832.3768 & 5.1389 & 10.5670 & 19031.3464 & 654.5562 & 1568.0770 & NA & 134.1740 & 1590.9459 & 1.0754 \\
\hline CZE & 2 & hi-weu & 4163.8572 & 3.4077 & 7.1666 & 10281.6157 & 429.2531 & 6.1252 & NA & 98.4540 & 927.4184 & 1.0754 \\
\hline DEU & 2 & hi-weu & 6380.2686 & 8.4655 & 13.1493 & 31743.9318 & 1453.2486 & 135.1350 & NA & 109.2180 & 957.7926 & 1.0754 \\
\hline DJI & 2 & Im-mea & 1833.3334 & 0.0661 & 0.0233 & 881.4080 & 67.1914 & NA & NA & NA & 112.5589 & 1.1139 \\
\hline DMA & 2 & um-lac & 1581.2390 & 1.8929 & 0.7006 & 4551.7036 & 276.4789 & NA & NA & NA & 1886.9045 & 1.0825 \\
\hline DNK & 2 & hi-weu & 6102.6302 & 14.8367 & 30.7994 & 42769.2558 & 3421.5481 & NA & NA & 113.1540 & 3675.9714 & 1.0754 \\
\hline DOM & 2 & um-lac & 3873.4372 & 0.3147 & 2.1811 & 2864.2224 & 32.7555 & 8429.4344 & NA & 36.2580 & 546.7065 & 1.0825 \\
\hline
\end{tabular}




\begin{tabular}{|c|c|c|c|c|c|c|c|c|c|c|c|c|}
\hline DZA & 2 & um-mea & 972.7230 & 0.0467 & 0.0802 & 2381.2783 & NA & NA & NA & 90.8300 & 420.9336 & 1.0705 \\
\hline ECU & 2 & um-lac & 1949.1956 & 0.2378 & 1.4410 & 2745.2941 & 52.5205 & NA & NA & 23.5140 & 593.6661 & 1.0825 \\
\hline EGY & 2 & Im-mea & 6594.4358 & 0.1243 & 0.2016 & 1025.0662 & 47.5906 & 17732.2253 & NA & 59.7180 & 265.8873 & 1.1139 \\
\hline ERI & 2 & lo-ssa & 530.5462 & 0.0087 & 0.0000 & 263.5523 & 10.1306 & NA & NA & 32.5640 & 71.4408 & 1.0380 \\
\hline ESP & 2 & hi-weu & 2783.0870 & 3.1926 & 14.9401 & 21698.7004 & 975.3080 & 1673.9142 & NA & 106.3900 & 3241.3621 & 1.0754 \\
\hline EST & 2 & hi-weu & 1748.8132 & 7.4615 & 12.6648 & 5904.8044 & 374.0991 & 9.1069 & NA & 70.2800 & 876.6527 & 1.0754 \\
\hline ETH & 2 & lo-ssa & 1155.3786 & 0.0058 & 0.0021 & 133.9047 & 3.7738 & NA & NA & 76.4460 & 74.3077 & 1.0380 \\
\hline FIN & 2 & hi-weu & 3040.2236 & 21.5773 & 42.0637 & 30119.7410 & 2022.5462 & 23.2785 & NA & 123.2640 & 4814.3788 & 1.0754 \\
\hline FJI & 2 & um-eap & 2090.8610 & 0.3745 & 1.0616 & 3177.2344 & 169.4875 & NA & NA & 65.0400 & 847.2307 & 1.0595 \\
\hline FRA & 2 & hi-weu & 7017.3360 & 4.7844 & 14.3890 & 30705.0344 & 1797.3827 & 183.3969 & NA & 114.2940 & 2369.4791 & 1.0754 \\
\hline FRO & 2 & hi-sms & NA & 8.1111 & 12.3523 & NA & NA & NA & NA & NA & NA & 1.0739 \\
\hline FSM & 2 & Im-eap & 1032.7450 & 1.3763 & 0.0000 & 2152.8805 & 137.9824 & NA & NA & NA & 672.8190 & 1.0396 \\
\hline GAB & 2 & um-ssa & 1573.2824 & 0.1168 & 0.6786 & 7313.2647 & 237.5990 & NA & NA & NA & 1468.7645 & 1.1211 \\
\hline GBR & 2 & hi-weu & 6918.6558 & 9.6736 & 21.8410 & 32471.6430 & 1567.2090 & 281.8697 & NA & NA & 993.9588 & 1.0754 \\
\hline GEO & 2 & Im-eca & 2110.0562 & 0.1264 & 0.9333 & 880.5834 & 18.7265 & NA & NA & 109.5540 & 415.9561 & 0.9775 \\
\hline GHA & 2 & Im-ssa & 1339.1750 & 0.0341 & 0.1698 & 422.5029 & 17.3830 & NA & NA & 17.4460 & NA & 1.1440 \\
\hline GIN & 2 & lo-ssa & 1463.7624 & 0.0147 & 0.1212 & 275.4901 & 6.5111 & NA & NA & 49.3960 & 82.6155 & 1.0380 \\
\hline GMB & 2 & lo-ssa & 1075.5994 & 0.2036 & 0.3436 & 411.9957 & 9.1876 & NA & NA & 33.3200 & 184.2429 & 1.0380 \\
\hline GNB & 2 & lo-ssa & 1206.3686 & 0.0527 & 0.0000 & 499.8933 & 26.1386 & 529.4393 & NA & 159.3100 & NA & 1.0380 \\
\hline GNQ & 2 & hi-sms & NA & 0.0778 & 0.0515 & 2290.6362 & 51.3003 & NA & NA & NA & NA & 1.0739 \\
\hline GRC & 2 & hi-weu & 3699.3580 & 2.8187 & 14.1209 & 17064.1051 & 540.1584 & NA & NA & 117.2220 & 3494.2578 & 1.0754 \\
\hline GRD & 2 & um-lac & 1101.2644 & 1.0494 & 1.0610 & 4719.3918 & NA & NA & NA & NA & 498.2053 & 1.0825 \\
\hline GRL & 2 & hi-sms & NA & 9.2124 & 12.5376 & 25476.0037 & NA & NA & NA & NA & NA & 1.0739 \\
\hline GTM & 2 & Im-lac & 1720.4548 & 0.2355 & 1.0939 & 1994.4725 & 31.6234 & NA & NA & NA & 456.8869 & 1.0780 \\
\hline GUM & 2 & hi-sms & 2154.7620 & 3.4717 & 6.5052 & NA & NA & NA & NA & NA & NA & 1.0739 \\
\hline GUY & 2 & Im-lac & 3917.1416 & 1.1070 & 0.2205 & 1044.6344 & 63.5840 & NA & NA & NA & 478.3185 & 1.0780 \\
\hline HKG & 2 & hi-sms & NA & 10.8526 & 36.2050 & 21038.8674 & 573.9419 & NA & NA & NA & NA & 1.0739 \\
\hline HND & 2 & Im-lac & 1390.1158 & 0.2253 & 0.4314 & 1211.0670 & 43.3496 & NA & NA & 63.5360 & 306.0824 & 1.0780 \\
\hline HRV & 2 & hi-weu & 4635.4354 & 2.1562 & 3.0555 & 7415.2303 & NA & NA & NA & 95.2020 & 841.5991 & 1.0754 \\
\hline $\mathrm{HTI}$ & 2 & lo-lac & 955.8532 & 0.0340 & 0.0834 & 499.6939 & NA & NA & NA & NA & NA & 0.9896 \\
\hline
\end{tabular}




\begin{tabular}{|c|c|c|c|c|c|c|c|c|c|c|c|c|}
\hline HUN & 2 & um-eca & 4422.2234 & 2.6683 & 8.0538 & 7975.5991 & 368.1318 & NA & NA & 71.1840 & 878.2359 & 0.9830 \\
\hline IDN & 2 & Im-eap & 3902.3276 & 0.1955 & 0.4911 & 1133.5913 & 11.9123 & NA & NA & 39.4060 & 250.6699 & 1.0396 \\
\hline IMN & 2 & ot-sms & NA & NA & NA & 22787.1936 & NA & NA & NA & NA & NA & 1.2304 \\
\hline IND & 2 & Im-sas & 2216.6776 & 0.1111 & 0.0866 & 513.5320 & 18.3068 & NA & NA & 58.3320 & 164.2711 & 1.1099 \\
\hline IRL & 2 & hi-weu & 6800.3698 & 5.2852 & 19.4780 & 34465.2050 & 1589.9769 & NA & NA & 104.3480 & 1629.5977 & 1.0754 \\
\hline IRN & 2 & um-mea & 1960.6622 & 0.1090 & 0.3748 & 2097.4101 & 88.5466 & 4515.3396 & NA & 29.1860 & 590.8887 & 1.0705 \\
\hline IRQ & 2 & um-mea & 791.1254 & NA & 0.0000 & 1519.1668 & NA & 9847.1034 & NA & 69.7320 & 381.0501 & 1.0705 \\
\hline ISL & 2 & hi-weu & NA & 26.2120 & 30.5376 & 43612.5245 & 2586.6686 & NA & NA & NA & 38107.0823 & 1.0754 \\
\hline ISR & 2 & hi-mea & 2407.4274 & 6.2483 & 28.6577 & 18511.4689 & 1279.8087 & NA & NA & 159.5960 & NA & 1.1687 \\
\hline ITA & 2 & hi-weu & 4898.1970 & 4.5523 & 25.6219 & 29049.6038 & 1334.9798 & NA & NA & 122.2400 & 1989.8161 & 1.0754 \\
\hline JAM & 2 & um-lac & 1253.3496 & 1.1666 & 3.0815 & NA & NA & 4633.8216 & NA & 41.8360 & 649.6445 & 1.0825 \\
\hline JOR & 2 & um-mea & 1492.8708 & 0.9001 & 1.2210 & 1878.1932 & 117.6333 & NA & NA & 78.6680 & 283.0257 & 1.0705 \\
\hline JPN & 2 & hi-eap & 6005.5590 & 9.9872 & 28.9256 & 33499.4612 & 1169.0481 & 12891.1461 & NA & 125.6820 & 2403.4246 & 1.0755 \\
\hline KAZ & 2 & um-eca & 807.9658 & 0.1406 & 0.1410 & 2035.5018 & 82.5111 & 1027.6898 & NA & 47.7320 & 416.0100 & 0.9830 \\
\hline KEN & 2 & lo-ssa & 1514.0520 & 0.0417 & 0.0312 & 513.5343 & 27.3329 & NA & NA & 73.7520 & 148.1439 & 1.0380 \\
\hline KGZ & 2 & Im-eca & 2227.5916 & 0.1388 & 0.0161 & 376.5814 & 18.9117 & 7085.2850 & NA & 54.6900 & 171.5389 & 0.9775 \\
\hline KHM & 2 & lo-eap & 1810.3594 & 0.0180 & 0.3807 & 280.1473 & 3.1259 & NA & NA & 88.9420 & 151.3661 & 0.7592 \\
\hline KIR & 2 & Im-eap & NA & 0.9141 & 0.0547 & 1030.8695 & 109.7345 & NA & NA & NA & 466.5950 & 1.0396 \\
\hline KNA & 2 & hi-sms & NA & 2.9871 & 0.9269 & 9327.9351 & 413.6344 & NA & NA & NA & 243.7749 & 1.0739 \\
\hline KOR & 2 & hi-eap & 6289.5324 & 7.2757 & 21.6065 & 13155.2632 & 432.1050 & NA & NA & 88.8580 & 2428.4960 & 1.0755 \\
\hline KWT & 2 & hi-sms & 4122.0518 & 2.2083 & 12.1589 & 30649.6158 & 1750.4869 & 53997.2667 & NA & NA & NA & 1.0739 \\
\hline LAO & 2 & Im-eap & 2664.4918 & 0.0237 & 0.1112 & 333.5649 & 6.1752 & NA & NA & 32.7040 & 167.1021 & 1.0396 \\
\hline LBN & 2 & um-mea & 2067.8534 & 1.9104 & 11.7164 & 5445.2057 & 114.2167 & 5063.5017 & NA & 98.6220 & 1522.4646 & 1.0705 \\
\hline LBR & 2 & lo-ssa & 1237.8910 & 0.0066 & 0.0000 & 93.3853 & NA & NA & NA & NA & NA & 1.0380 \\
\hline LBY & 2 & um-mea & 709.9578 & 0.1336 & 0.2383 & 6802.9882 & 188.0802 & 2093.0096 & NA & NA & NA & 1.0705 \\
\hline LCA & 2 & um-lac & NA & 1.0411 & 1.0808 & 5170.7476 & 378.5265 & NA & NA & NA & 657.0615 & 1.0825 \\
\hline LIE & 2 & hi-sms & NA & NA & 25.4078 & 91253.3379 & NA & NA & NA & NA & NA & 1.0739 \\
\hline LKA & 2 & Im-sas & 3159.2794 & 0.1734 & 0.7201 & 930.5609 & 29.0363 & NA & NA & 67.5700 & 173.2844 & 1.1099 \\
\hline LSO & 2 & Im-ssa & 1053.6220 & 0.0183 & 0.2914 & 603.4735 & 75.2441 & NA & NA & NA & 83.6910 & 1.1440 \\
\hline LTU & 2 & hi-weu & 2258.3800 & 1.5377 & 4.6716 & 4523.6371 & 238.6246 & 2.7675 & NA & 144.0500 & 891.7025 & 1.0754 \\
\hline
\end{tabular}




\begin{tabular}{|c|c|c|c|c|c|c|c|c|c|c|c|c|}
\hline LUX & 2 & hi-weu & NA & 8.6838 & 22.5198 & 61589.0967 & 2226.1833 & NA & NA & NA & 3526.9398 & 1.0754 \\
\hline LVA & 2 & hi-sms & 2024.8260 & 2.6422 & 4.6643 & 3763.4194 & 220.9023 & 34.6978 & NA & 100.6820 & 558.9736 & 1.0739 \\
\hline MAC & 2 & hi-sms & NA & 3.9173 & 16.0497 & 16404.2933 & 604.0481 & NA & NA & NA & NA & 1.0739 \\
\hline MAF & 2 & hi-sms & NA & NA & NA & NA & NA & NA & NA & NA & NA & 1.0739 \\
\hline MAR & 2 & Im-mea & 966.6820 & 0.0698 & 0.4509 & 1542.6496 & 84.8698 & 1101.9475 & NA & 105.6800 & 490.0249 & 1.1139 \\
\hline MCO & 2 & hi-sms & NA & NA & 25.5628 & 114245.2238 & 1317.2608 & NA & NA & NA & NA & 1.0739 \\
\hline MDA & 2 & Im-eca & 2780.6590 & 0.1795 & 0.1342 & 611.4695 & 44.5173 & NA & NA & 36.4660 & 172.1683 & 0.9775 \\
\hline MDG & 2 & lo-ssa & 1962.3280 & 0.0623 & 0.0751 & 277.3882 & 6.0005 & NA & NA & 46.3880 & 104.7091 & 1.0380 \\
\hline MDV & 2 & um-sas & 1396.8070 & 0.4452 & 0.4437 & NA & NA & NA & NA & NA & NA & 1.3968 \\
\hline MEX & 2 & um-lac & 2619.7250 & 0.8107 & 2.8831 & 7040.1154 & 259.8221 & NA & NA & 77.0300 & 978.5941 & 1.0825 \\
\hline MHL & 2 & um-eap & NA & 0.3344 & 0.7288 & 2477.1085 & 359.9082 & NA & NA & NA & NA & 1.0595 \\
\hline MKD & 2 & um-eca & 2845.9444 & 0.6242 & 0.9128 & 2494.7688 & 112.5345 & 1782.5293 & NA & 105.5440 & 757.4492 & 0.9830 \\
\hline MLI & 2 & lo-ssa & 1070.7040 & 0.0232 & 0.0306 & 354.6343 & 10.5959 & NA & NA & 99.0080 & 198.4869 & 1.0380 \\
\hline MLT & 2 & hi-weu & 3516.1000 & 3.8915 & 5.0210 & 13017.4833 & 573.7836 & 777.7778 & NA & 86.7040 & 3886.6619 & 1.0754 \\
\hline MMR & 2 & lo-eap & 2865.5664 & 0.0002 & 0.0164 & NA & NA & NA & NA & 16.7220 & NA & 0.7592 \\
\hline MNE & 2 & um-eca & NA & NA & NA & 3275.9644 & NA & NA & NA & NA & NA & 0.9830 \\
\hline MNG & 2 & Im-eap & 679.7540 & 0.1588 & 0.3925 & 732.3645 & 35.6256 & 177.2141 & NA & 60.1060 & 562.8184 & 1.0396 \\
\hline MNP & 2 & hi-sms & NA & NA & 3.2023 & NA & NA & NA & NA & NA & NA & 1.0739 \\
\hline MOZ & 2 & lo-ssa & 824.3296 & 0.0228 & 0.0245 & 212.3499 & 6.3625 & NA & NA & 43.6060 & 91.8938 & 1.0380 \\
\hline MRT & 2 & Im-ssa & 832.3896 & 0.0544 & 0.0000 & 568.0554 & 13.5593 & NA & NA & NA & 392.6564 & 1.1440 \\
\hline MUS & 2 & um-ssa & 4769.1834 & 1.9692 & 4.0825 & 3957.8521 & 156.0676 & 5077.4834 & NA & 92.4600 & 508.6022 & 1.1211 \\
\hline MWI & 2 & lo-ssa & 1364.3420 & 0.0367 & 0.0820 & 219.1157 & 10.5154 & 324.8935 & NA & 24.2100 & 74.0693 & 1.0380 \\
\hline MYS & 2 & um-eap & 3019.1884 & 4.4725 & 8.8145 & 4573.1984 & 223.7152 & 2564.9848 & NA & 85.5740 & 1052.9763 & 1.0595 \\
\hline NAM & 2 & um-ssa & 299.4332 & 0.1394 & 0.8010 & 2933.2246 & 211.7800 & 234.6930 & NA & 44.1540 & 468.2412 & 1.1211 \\
\hline $\mathrm{NCL}$ & 2 & hi-sms & 3579.4508 & 1.7743 & 4.5886 & NA & NA & NA & NA & NA & NA & 1.0739 \\
\hline NER & 2 & lo-ssa & 328.2210 & 0.0085 & 0.0070 & 268.3723 & 7.7652 & NA & NA & 54.1180 & NA & 1.0380 \\
\hline NGA & 2 & Im-ssa & 1210.9454 & 0.0231 & 0.0151 & 542.7276 & NA & NA & NA & 36.9940 & 216.4714 & 1.1440 \\
\hline $\mathrm{NIC}$ & 2 & Im-lac & 1679.5080 & 0.2244 & 0.3219 & 968.4166 & 24.9621 & NA & NA & 63.6480 & 333.5448 & 1.0780 \\
\hline NLD & 2 & hi-weu & 7603.0018 & 18.3215 & 17.0350 & 35809.4704 & 1757.2644 & NA & NA & 106.3540 & 2793.0110 & 1.0754 \\
\hline NOR & 2 & hi-weu & 3858.6462 & 21.5303 & 39.1151 & 56332.0784 & 4193.6075 & NA & NA & 112.5700 & 3303.0431 & 1.0754 \\
\hline
\end{tabular}




\begin{tabular}{|c|c|c|c|c|c|c|c|c|c|c|c|c|}
\hline NPL & 2 & lo-sas & 1951.8188 & 0.0477 & 0.0048 & 275.9596 & 7.9909 & NA & NA & 68.7240 & 108.2748 & 1.0779 \\
\hline NZL & 2 & hi-nao & 5879.2576 & 20.1317 & 19.1405 & 22789.0705 & 1433.0014 & NA & NA & 96.2100 & 8065.0138 & 1.0975 \\
\hline OMN & 2 & hi-mea & 3033.0554 & 0.9545 & 2.7161 & 12464.1745 & 450.5664 & NA & NA & NA & NA & 1.1687 \\
\hline PAK & 2 & Im-sas & 2109.3166 & 0.0260 & 0.1035 & 582.1167 & 16.3892 & NA & NA & 61.6000 & 194.9584 & 1.1099 \\
\hline PAN & 2 & um-lac & 1882.8796 & 1.4805 & 2.3546 & 3829.4654 & 172.7991 & NA & NA & 103.2200 & 595.5018 & 1.0825 \\
\hline PER & 2 & um-lac & 2778.7194 & 0.7652 & 1.9472 & 2296.0698 & 77.6183 & NA & NA & 86.9380 & NA & 1.0825 \\
\hline PHL & 2 & Im-eap & 2332.5690 & 0.5513 & 1.9965 & 1028.8902 & 35.4659 & NA & NA & 76.1820 & 265.9196 & 1.0396 \\
\hline PLW & 2 & um-eap & NA & NA & NA & 9644.5540 & NA & NA & NA & NA & NA & 1.0595 \\
\hline PNG & 2 & Im-eap & 3790.9212 & 0.2512 & 0.0737 & 912.3595 & NA & NA & NA & NA & NA & 1.0396 \\
\hline $\mathrm{POL}$ & 2 & hi-weu & 2961.5682 & 2.7150 & 3.6387 & 5901.4808 & 302.0861 & NA & NA & 101.2880 & 474.4963 & 1.0754 \\
\hline PRI & 2 & hi-lac & 1684.9376 & 1.9297 & 12.6590 & 17708.1998 & NA & 4025.3659 & NA & NA & 2540.3317 & 1.1975 \\
\hline PRK & 2 & lo-eap & 2465.6892 & 0.0000 & 0.0000 & NA & NA & NA & NA & NA & NA & 0.7592 \\
\hline PRT & 2 & hi-weu & 2535.4812 & 6.8082 & 20.0625 & 16592.6270 & 823.8013 & NA & NA & 113.1700 & 1000.3403 & 1.0754 \\
\hline PRY & 2 & Im-lac & 2183.5454 & 0.1741 & 3.1002 & 1606.3360 & 70.3554 & NA & NA & 47.2540 & 534.8462 & 1.0780 \\
\hline PYF & 2 & hi-sms & NA & 1.2676 & 3.6912 & NA & NA & NA & NA & NA & NA & 1.0739 \\
\hline QAT & 2 & hi-mea & 3420.6522 & 2.3590 & 8.8407 & 42777.2186 & 1539.7936 & 16199.8523 & NA & 138.1860 & 2810.3674 & 1.1687 \\
\hline ROU & 2 & um-weu & 2962.4372 & 1.1354 & 1.9746 & 3431.5716 & 116.3009 & 319.2613 & NA & 18.1840 & 819.5694 & 1.0951 \\
\hline RUS & 2 & hi-eca & 1431.3182 & 0.5445 & 0.3948 & 3437.9403 & NA & 120.9992 & NA & 24.4600 & 647.0815 & 0.8878 \\
\hline RWA & 2 & lo-ssa & 1068.3636 & 0.0204 & 0.0420 & 210.8282 & 9.6772 & NA & NA & 70.7520 & 100.0941 & 1.0380 \\
\hline SAU & 2 & hi-mea & 3578.5276 & 0.1370 & 2.0715 & 12579.1621 & 773.8186 & NA & NA & 99.2400 & 2299.8775 & 1.1687 \\
\hline SDN & 2 & Im-ssa & 497.1810 & 0.0030 & 0.0169 & 522.4986 & NA & NA & NA & 37.4800 & 400.4018 & 1.1440 \\
\hline SEN & 2 & Im-ssa & 760.4748 & 0.0860 & 0.2599 & 664.1129 & 21.1104 & NA & NA & 102.8760 & 194.5941 & 1.1440 \\
\hline SGP & 2 & hi-sms & NA & 13.6882 & 23.2111 & 22564.6041 & NA & NA & NA & NA & NA & 1.0739 \\
\hline SLB & 2 & Im-eap & 3682.8408 & 0.3377 & 0.1561 & 1202.5614 & 27.0054 & NA & NA & NA & 349.5993 & 1.0396 \\
\hline SLE & 2 & lo-ssa & 1176.8676 & 0.0142 & 0.0000 & 278.4551 & NA & NA & NA & NA & 236.2602 & 1.0380 \\
\hline SLV & 2 & Im-lac & 2008.7186 & 0.4035 & 2.4544 & 2379.5079 & 55.2245 & NA & NA & 94.1140 & 601.4237 & 1.0780 \\
\hline SMR & 2 & hi-sms & NA & 9.6841 & 16.3698 & 38438.1771 & 1297.1413 & NA & NA & NA & NA & 1.0739 \\
\hline SOM & 2 & lo-ssa & 494.9676 & 0.0051 & 0.0000 & NA & NA & NA & NA & NA & NA & 1.0380 \\
\hline SRB & 2 & um-eca & 3832.9396 & NA & NA & 2516.9831 & NA & NA & NA & 11.3740 & 720.4181 & 0.9830 \\
\hline SSD & 2 & Im-ssa & NA & NA & NA & NA & NA & NA & NA & NA & NA & 1.1440 \\
\hline
\end{tabular}




\begin{tabular}{|c|c|c|c|c|c|c|c|c|c|c|c|c|}
\hline STP & 2 & Im-ssa & 2163.1716 & 0.3295 & 0.0000 & NA & NA & NA & NA & NA & NA & 1.1440 \\
\hline SUR & 2 & um-lac & 3836.6268 & 0.9812 & 1.3129 & 2953.8639 & NA & NA & NA & 26.2780 & 524.0101 & 1.0825 \\
\hline SVK & 2 & hi-weu & 4087.6490 & 2.1215 & 5.0913 & 8503.3949 & 361.8518 & 43.2523 & NA & 94.3080 & 660.6483 & 1.0754 \\
\hline SVN & 2 & hi-weu & 5296.0594 & 7.6557 & 9.6033 & 13520.2905 & 676.2527 & NA & NA & 91.2320 & 841.6190 & 1.0754 \\
\hline SWE & 2 & hi-weu & 4525.3256 & 22.5540 & 38.1766 & 34269.5017 & 2437.9540 & 53.9800 & NA & 110.1080 & 2406.9159 & 1.0754 \\
\hline sWZ & 2 & Im-ssa & 1871.2958 & 0.1414 & 0.3585 & 2145.6681 & 112.2057 & NA & NA & NA & 200.9894 & 1.1440 \\
\hline SXM & 2 & hi-sms & NA & NA & NA & NA & NA & NA & NA & NA & NA & 1.0739 \\
\hline SYC & 2 & um-ssa & NA & 2.6724 & 6.3466 & 10521.9820 & 705.9966 & NA & NA & NA & 672.6962 & 1.1211 \\
\hline SYR & 2 & Im-mea & 1488.9540 & 0.0441 & 0.0050 & 1422.7241 & 52.6213 & 2706.6516 & NA & 89.1700 & NA & 1.1139 \\
\hline TCA & 2 & hi-sms & NA & NA & NA & NA & NA & NA & NA & NA & NA & 1.0739 \\
\hline TCD & 2 & lo-ssa & 625.1874 & 0.0057 & 0.0000 & 387.6418 & 9.2425 & NA & NA & NA & NA & 1.0380 \\
\hline TGO & 2 & lo-ssa & 907.6192 & 0.2236 & 0.1175 & 415.4596 & 17.4501 & NA & NA & 94.8760 & 223.0154 & 1.0380 \\
\hline THA & 2 & um-eap & 2518.8070 & 0.8137 & 3.2000 & 2239.5017 & 93.7198 & NA & NA & 78.4340 & 354.5339 & 1.0595 \\
\hline TJK & 2 & lo-eca & 1147.9268 & 0.0328 & 0.0049 & 219.3046 & 4.7748 & 13583.9998 & NA & NA & 63.1326 & 1.2114 \\
\hline TKM & 2 & um-eca & 1626.1204 & 0.0450 & 0.0432 & 1221.6269 & NA & 13248.0842 & NA & 37.0367 & 251.2301 & 0.9830 \\
\hline TLS & 2 & lo-sas & 1898.8304 & NA & NA & 434.7538 & NA & NA & NA & NA & NA & 1.0779 \\
\hline TON & 2 & um-eap & NA & 0.5162 & 0.2057 & 2237.6301 & 123.6613 & NA & NA & NA & 568.3972 & 1.0595 \\
\hline TTO & 2 & hi-sms & 3245.9298 & 2.0527 & 1.5527 & 7444.9613 & 228.2644 & 459.4670 & NA & 78.2460 & 103.3310 & 1.0739 \\
\hline TUN & 2 & um-mea & 1211.6884 & 0.3586 & 0.2383 & 2453.1343 & 157.5928 & 854.0076 & NA & 93.8340 & 679.6106 & 1.0705 \\
\hline TUR & 2 & um-eca & 2141.9494 & 0.7478 & 4.7073 & 5827.4795 & 101.2404 & NA & NA & 9.9380 & 1754.7321 & 0.9830 \\
\hline TUV & 2 & um-eap & NA & NA & 0.0000 & 2141.8968 & NA & NA & NA & NA & 875.4417 & 1.0595 \\
\hline TZA & 2 & lo-ssa & 1471.2474 & 0.0235 & 0.0751 & 287.9866 & 6.6913 & NA & NA & 64.8980 & 118.4151 & 1.0380 \\
\hline UGA & 2 & lo-ssa & 1430.8932 & 0.0377 & 0.0842 & 252.0378 & NA & NA & NA & NA & 89.0366 & 1.0380 \\
\hline UKR & 2 & Im-eca & 2224.1092 & 0.2094 & 0.1737 & 1165.3120 & 52.5547 & NA & NA & 34.0940 & 395.4474 & 0.9775 \\
\hline URY & 2 & hi-lac & 3377.4168 & 4.4961 & 4.1869 & 5091.7473 & 129.6442 & NA & NA & 41.0820 & 4867.2200 & 1.1975 \\
\hline USA & 2 & hi-nao & 5301.7914 & 22.6430 & 20.8904 & 37301.7454 & 1817.1614 & 1098.0241 & NA & 106.0680 & 1690.5420 & 1.0975 \\
\hline UZB & 2 & Im-eca & 2161.7620 & 0.0136 & 0.0810 & 413.4679 & NA & 12149.6380 & NA & NA & 158.9692 & 0.9775 \\
\hline VCT & 2 & um-lac & 3347.3034 & 1.2349 & 0.5579 & 3694.6566 & 212.6825 & NA & NA & NA & 541.7191 & 1.0825 \\
\hline VEN & 2 & um-lac & 3098.7820 & 0.9971 & 6.6855 & 5505.9099 & NA & NA & NA & 21.2040 & 1422.3828 & 1.0825 \\
\hline VIR & 2 & hi-sms & NA & 6.9435 & 21.8574 & NA & NA & NA & NA & NA & NA & 1.0739 \\
\hline
\end{tabular}




\begin{tabular}{|c|c|c|c|c|c|c|c|c|c|c|c|c|}
\hline VNM & 2 & Im-eap & 3760.9078 & 0.0365 & 0.2035 & 462.8435 & NA & NA & NA & 64.2920 & 140.5859 & 1.0396 \\
\hline VUT & 2 & Im-eap & 550.7104 & 0.2522 & 0.1138 & 1936.9881 & 133.7551 & NA & NA & 66.6700 & 520.0785 & 1.0396 \\
\hline PSE & 2 & ot-sms & 1367.3506 & NA & NA & 1162.6094 & NA & NA & NA & NA & 446.1456 & 1.2304 \\
\hline WSM & 2 & Im-eap & NA & 0.2301 & 0.5400 & 1889.3700 & 85.1831 & NA & NA & NA & 524.9897 & 1.0396 \\
\hline YEM & 2 & Im-mea & 1026.0290 & 0.0239 & 0.0895 & 728.7873 & NA & NA & NA & 35.0560 & NA & 1.1139 \\
\hline ZAF & 2 & um-ssa & 2114.5946 & 2.0346 & 5.4456 & 4806.2826 & 282.6833 & 637.3518 & NA & 72.2620 & 282.8834 & 1.1211 \\
\hline COD & 2 & ot-ssa & 789.3252 & 0.0004 & 0.0211 & 260.7115 & NA & NA & NA & NA & 102.5710 & 0.9945 \\
\hline ZMB & 2 & Im-ssa & 1438.2550 & 0.0409 & 0.0938 & 599.0041 & 12.4964 & 473.3715 & NA & NA & 210.0074 & 1.1440 \\
\hline ZWE & 2 & lo-ssa & 1100.5084 & 0.0602 & 0.3216 & 696.0889 & NA & NA & NA & 0.0120 & 168.1126 & 1.0380 \\
\hline ABW & 3 & hi-sms & NA & 19.0286 & 62.0733 & 23284.5049 & 1093.6282 & NA & NA & NA & NA & 0.9475 \\
\hline AND & 3 & ot-sms & NA & 15.5459 & 53.4951 & 29219.5714 & 574.8685 & NA & NA & NA & NA & 1.7533 \\
\hline AFG & 3 & lo-sas & 1255.1360 & 0.0507 & 0.6952 & 236.1968 & NA & 2588.5452 & 3.7380 & 109.3040 & 111.3955 & 1.1467 \\
\hline AGO & 3 & um-ssa & 582.8564 & 0.2694 & 1.7097 & 1350.5416 & 35.3345 & 66.8853 & 2.6498 & NA & 164.1265 & 1.5163 \\
\hline ALB & 3 & um-eca & 3229.9498 & 0.8445 & 22.4094 & 2350.5154 & 74.3456 & 1833.8661 & 98.9054 & 104.9900 & 919.6571 & 1.0745 \\
\hline ARE & 3 & hi-mea & 3589.0196 & 27.5646 & 74.4699 & 45913.9285 & NA & 34220.1081 & 702.3991 & NA & 4331.0940 & 1.2879 \\
\hline ARG & 3 & um-lac & 3448.4750 & 11.1304 & 21.8093 & 5096.6548 & 174.9077 & NA & 39.1299 & 77.3240 & 3690.1755 & 1.4718 \\
\hline ARM & 3 & Im-eca & 1890.8838 & 2.8732 & 2.8461 & 1141.7505 & 27.3962 & 2510.9414 & 29.7238 & 96.3860 & 655.7637 & 1.0692 \\
\hline ASM & 3 & um-eap & NA & NA & 3.5970 & NA & NA & NA & NA & NA & NA & 1.1380 \\
\hline ATG & 3 & hi-sms & 1598.0590 & 13.8753 & 46.1580 & 10869.6442 & 372.8001 & 325.0000 & 15.9167 & NA & 275.6543 & 0.9475 \\
\hline AUS & 3 & hi-nao & 1812.7768 & 49.7227 & 63.8522 & 31902.8584 & 1561.3474 & 347.5180 & 48.2397 & 115.3480 & 7448.1764 & 1.1840 \\
\hline AUT & 3 & hi-weu & 5975.2138 & 41.2911 & 85.5310 & 36786.9448 & 2070.9166 & 71.9919 & 220.1256 & 108.9500 & 1417.7174 & 1.1553 \\
\hline AZE & 3 & um-eca & 2550.1784 & 1.8177 & 10.7028 & 1058.0224 & 36.5454 & 4137.5896 & 10.0169 & 81.9300 & 255.3901 & 1.0745 \\
\hline BDI & 3 & lo-ssa & 1281.4208 & 0.1704 & 0.7384 & 148.9527 & 4.5781 & 226.7059 & 0.9198 & 64.0760 & 76.7795 & 1.0382 \\
\hline BEL & 3 & hi-weu & 8491.1892 & 42.1760 & 75.6463 & 35301.8660 & 2122.3603 & 45.0837 & 327.1950 & 100.2660 & 11142.9783 & 1.1553 \\
\hline BEN & 3 & lo-ssa & 1082.3724 & 0.6851 & 2.8739 & 528.9810 & 18.1707 & 23.0806 & 5.7406 & NA & 288.3862 & 1.0382 \\
\hline BFA & 3 & lo-ssa & 941.3024 & 0.2419 & 1.3353 & 366.4933 & NA & 93.0727 & 7.7866 & 94.2040 & 108.3935 & 1.0382 \\
\hline BGD & 3 & lo-sas & 3401.8276 & 0.1407 & 0.8663 & 373.9341 & 8.8278 & NA & 173.1925 & 83.6100 & 104.6886 & 1.1467 \\
\hline BGR & 3 & um-eca & 2992.8346 & 10.4466 & 33.5352 & 3144.1840 & 105.3926 & 218.7688 & 113.9825 & 108.4040 & 940.8688 & 1.0745 \\
\hline BHR & 3 & hi-mea & NA & 16.4513 & 52.6693 & 18226.6229 & NA & NA & 3022.6765 & NA & NA & 1.2879 \\
\hline BHS & 3 & hi-sms & 3095.2380 & 15.9600 & 33.2783 & 23724.7338 & 675.9049 & NA & NA & NA & 3021.5981 & 0.9475 \\
\hline
\end{tabular}




\begin{tabular}{|c|c|c|c|c|c|c|c|c|c|c|c|c|}
\hline $\mathrm{BIH}$ & 3 & um-eca & 3307.0496 & 4.8732 & 19.3821 & 2427.0397 & NA & NA & 36.2658 & 99.0820 & NA & 1.0745 \\
\hline BLR & 3 & um-eca & 2371.3212 & 5.0373 & 8.2098 & 2407.2206 & 143.1906 & 146.6861 & 139.5100 & 70.6260 & 751.1378 & 1.0745 \\
\hline BLZ & 3 & um-lac & 704.2674 & 5.8139 & 19.0480 & 3834.9757 & 206.4910 & 1008.8083 & 276.2524 & 89.6760 & 838.6538 & 1.4718 \\
\hline BMU & 3 & hi-sms & NA & 52.0008 & 45.7278 & 72738.9876 & 1252.2145 & NA & NA & NA & NA & 0.9475 \\
\hline $\mathrm{BOL}$ & 3 & Im-lac & 1744.1904 & 2.9258 & 12.2419 & 972.5551 & 58.3269 & NA & 4.2609 & 95.2460 & 307.3297 & 1.1341 \\
\hline BRA & 3 & um-lac & 3034.7464 & 9.7660 & 22.0285 & 4473.2024 & 175.4648 & NA & 141.3640 & 86.0440 & 1215.6225 & 1.4718 \\
\hline BRB & 3 & hi-sms & 2625.7886 & 26.6472 & 38.3452 & 13597.0127 & 771.3878 & 3859.0014 & 113.2674 & NA & 354.3772 & 0.9475 \\
\hline BRN & 3 & hi-sms & 744.0710 & 17.3109 & 44.2844 & 26303.6346 & 975.0120 & NA & 196.5000 & 107.1280 & 771.4226 & 0.9475 \\
\hline BTN & 3 & Im-sas & 1842.9910 & 1.7071 & 0.6770 & 1106.2720 & 65.2753 & NA & 9.0158 & 65.8440 & 397.1820 & 1.2203 \\
\hline BWA & 3 & um-ssa & 506.3802 & 3.2739 & 20.4255 & 4892.4904 & NA & 329.2412 & NA & 64.0840 & 216.3175 & 1.5163 \\
\hline CAF & 3 & lo-ssa & 1007.7694 & 0.1271 & 0.6707 & 342.8270 & 5.3961 & 0.2077 & NA & NA & 286.7296 & 1.0382 \\
\hline CAN & 3 & hi-nao & 2705.8860 & 60.6499 & 37.9760 & 34201.8864 & 1765.3630 & NA & 57.0635 & 120.6880 & NA & 1.1840 \\
\hline $\mathrm{CHE}$ & 3 & hi-weu & 6202.4140 & 59.3000 & 77.5112 & 52891.2724 & 2908.2936 & 122.4552 & 205.3378 & 113.3100 & 1858.5140 & 1.1553 \\
\hline $\mathrm{CHL}$ & 3 & hi-lac & 5105.7264 & 22.2903 & 39.3636 & 6847.5186 & 257.8786 & 13060.7227 & 376.4229 & 99.6320 & 2159.0358 & 1.3509 \\
\hline $\mathrm{CHN}$ & 3 & um-eap & 4899.5522 & 4.5023 & 16.0158 & 1326.0468 & NA & NA & 374.7543 & 79.1580 & 304.9932 & 1.1380 \\
\hline CIV & 3 & Im-ssa & 1766.8060 & 0.5466 & 6.1736 & 1014.7244 & 42.4621 & 215.8101 & 29.1944 & 97.3720 & NA & 1.1510 \\
\hline CMR & 3 & Im-ssa & 1667.7882 & 0.4907 & 4.4590 & 894.5810 & 25.0085 & 123.6538 & 9.6622 & 92.8920 & 319.1152 & 1.1510 \\
\hline COG & 3 & Im-ssa & 791.4166 & 0.3507 & 6.9217 & 1624.1701 & 45.1244 & 8.1636 & 2.6510 & 93.0180 & 177.5788 & 1.1510 \\
\hline $\mathrm{COL}$ & 3 & um-lac & 3378.5190 & 5.2339 & 12.8179 & 3142.8313 & 125.1048 & 2056.1050 & 318.2583 & 89.3080 & 919.3723 & 1.4718 \\
\hline COM & 3 & lo-ssa & 1219.2896 & 0.6890 & 0.3564 & 627.1941 & 23.9260 & 58.7500 & NA & NA & 357.7151 & 1.0382 \\
\hline CPV & 3 & Im-ssa & 468.9884 & 3.5341 & 9.2232 & 1748.7949 & 134.4075 & 432.9048 & NA & 100.0000 & 430.4402 & 1.1510 \\
\hline CRI & 3 & um-lac & 3417.9930 & 15.2761 & 13.2406 & 4240.2778 & 204.7430 & NA & 703.6652 & 69.7700 & 958.6632 & 1.4718 \\
\hline CUB & 3 & um-lac & 2928.5124 & 3.8082 & 0.2563 & 3163.9064 & 290.1380 & NA & 24.3792 & 30.5340 & 837.8592 & 1.4718 \\
\hline CUW & 3 & hi-sms & NA & NA & NA & NA & NA & NA & NA & NA & NA & 0.9475 \\
\hline CYM & 3 & hi-sms & NA & NA & 44.9095 & NA & NA & NA & NA & NA & NA & 0.9475 \\
\hline CYP & 3 & hi-weu & 1908.7182 & 25.2628 & 43.7135 & 21578.5627 & 970.7531 & 1534.9962 & 149.7631 & 133.4880 & 1486.6650 & 1.1553 \\
\hline CZE & 3 & hi-weu & 4425.3344 & 23.6415 & 79.0746 & 11649.6394 & 475.9609 & 5.8809 & 86.7539 & 112.2720 & 930.9132 & 1.1553 \\
\hline DEU & 3 & hi-weu & 6572.5286 & 46.2635 & 71.5842 & 34138.2750 & NA & 96.3969 & 218.2993 & 100.1260 & 1011.9336 & 1.1553 \\
\hline DJI & 3 & Im-mea & 1742.8572 & 0.4865 & 2.0009 & 866.4704 & 76.3982 & 3000.1000 & NA & NA & 115.9608 & 1.2075 \\
\hline DMA & 3 & um-lac & 2013.7420 & 18.8850 & 24.7346 & 4978.1528 & NA & NA & 144.4667 & NA & 1853.7833 & 1.4718 \\
\hline
\end{tabular}




\begin{tabular}{|c|c|c|c|c|c|c|c|c|c|c|c|c|}
\hline DNK & 3 & hi-weu & 6042.8430 & 60.7140 & 80.9271 & 46797.4383 & 3924.1819 & 72.5430 & 126.2477 & 104.4180 & 4044.9047 & 1.1553 \\
\hline DOM & 3 & um-lac & 4120.2660 & 6.3444 & 18.4384 & 3360.9808 & 65.4160 & 2639.2059 & 62.4485 & 51.4960 & 667.4667 & 1.4718 \\
\hline DZA & 3 & um-mea & 1172.6530 & 1.9119 & 4.1880 & 2694.6835 & NA & 463.3533 & 13.5793 & 93.7440 & 526.6890 & 1.1984 \\
\hline ECU & 3 & um-lac & 2423.5480 & 3.5376 & 13.3608 & 2731.5469 & 31.4681 & 5726.0905 & 180.6579 & 97.9400 & 673.1674 & 1.4718 \\
\hline EGY & 3 & Im-mea & 7379.3394 & 4.0316 & 6.3942 & 1175.1568 & 56.5316 & 20387.5665 & 539.2924 & 70.9160 & 292.3078 & 1.2075 \\
\hline ERI & 3 & lo-ssa & 341.7732 & 0.1739 & 0.0857 & 244.2296 & 8.6529 & 503.6473 & 2.6233 & 66.9200 & 45.3826 & 1.0382 \\
\hline ESP & 3 & hi-weu & 3333.4864 & 27.2207 & 78.6222 & 25249.6309 & 1075.8384 & 1761.0924 & 168.3751 & 98.4920 & 3600.5920 & 1.1553 \\
\hline EST & 3 & hi-weu & 2084.0878 & 40.0289 & 65.3672 & 8189.0905 & 429.8602 & 46.9237 & 66.7426 & 85.4320 & 1065.8679 & 1.1553 \\
\hline ETH & 3 & lo-ssa & 1190.7722 & 0.0772 & 0.0841 & 142.0488 & 5.4614 & 506.5722 & 11.0080 & 76.3280 & 70.7338 & 1.0382 \\
\hline FIN & 3 & hi-weu & 3269.3198 & 56.8788 & 85.1660 & 36233.2476 & 2248.6899 & 22.7095 & 129.0914 & 108.9440 & 5063.0414 & 1.1553 \\
\hline FJI & 3 & um-eap & 2410.3854 & 4.7292 & 11.7077 & 3436.0242 & 205.1788 & 294.1200 & 45.3412 & 71.9200 & 835.5072 & 1.1380 \\
\hline FRA & 3 & hi-weu & 7023.8298 & 29.2208 & 63.4629 & 33881.8356 & 1938.4117 & 246.3613 & 215.5862 & 100.0560 & 2517.7945 & 1.1553 \\
\hline FRO & 3 & hi-sms & NA & 50.9818 & 64.9150 & NA & NA & NA & NA & NA & NA & 0.9475 \\
\hline FSM & 3 & Im-eap & 1063.8650 & 6.8432 & 3.5163 & 2307.9814 & 154.8200 & NA & 0.6667 & NA & 678.8037 & 1.1505 \\
\hline GAB & 3 & um-ssa & 1560.5504 & 2.0284 & 20.5193 & 6362.2043 & 243.3699 & 124.0015 & 4.7662 & NA & 1720.2717 & 1.5163 \\
\hline GBR & 3 & hi-weu & 6918.4076 & 49.4426 & 85.0264 & 37236.6893 & 1835.4875 & 227.1545 & 306.8582 & NA & 1021.9089 & 1.1553 \\
\hline GEO & 3 & Im-eca & 1875.0264 & 1.9020 & 11.1271 & 1173.4749 & 27.0447 & NA & 26.2924 & 117.5400 & 406.4326 & 1.0692 \\
\hline GHA & 3 & Im-ssa & 1322.7984 & 0.8188 & 3.1926 & 463.6894 & 29.9181 & 160.0039 & 7.9283 & 56.7220 & NA & 1.1510 \\
\hline GIN & 3 & lo-ssa & 1487.6854 & 0.3266 & 0.9947 & 298.7610 & 7.0840 & 124.4972 & 0.9428 & 91.8140 & 97.1652 & 1.0382 \\
\hline GMB & 3 & lo-ssa & 1181.3588 & 1.9600 & 7.2202 & 439.5893 & 5.6851 & 130.2178 & 8.5310 & 60.6220 & 239.7457 & 1.0382 \\
\hline GNB & 3 & lo-ssa & 1108.5842 & 0.9430 & 0.5861 & 412.3095 & NA & 503.5227 & NA & 91.4900 & 277.0438 & 1.0382 \\
\hline GNQ & 3 & hi-sms & NA & 0.3967 & 5.4874 & 8106.6716 & 60.5160 & 7.6921 & NA & NA & NA & 0.9475 \\
\hline GRC & 3 & hi-weu & 3843.9304 & 14.7928 & 75.2561 & 20317.4196 & 730.5965 & 3278.1963 & 164.9616 & 102.9220 & 3504.9926 & 1.1553 \\
\hline GRD & 3 & um-lac & 1662.0652 & 12.4333 & 20.2868 & 5676.7424 & 221.2880 & NA & NA & NA & 576.5934 & 1.4718 \\
\hline GRL & 3 & hi-sms & NA & 44.4000 & 42.2798 & 29006.0191 & NA & NA & NA & NA & NA & 0.9475 \\
\hline GTM & 3 & Im-lac & 1705.7334 & 3.0982 & 14.7048 & 2109.6527 & NA & NA & 105.4694 & NA & 484.0336 & 1.1341 \\
\hline GUM & 3 & hi-sms & 2054.5454 & 28.5128 & 39.1402 & NA & NA & NA & NA & NA & NA & 0.9475 \\
\hline GUY & 3 & Im-lac & 4040.6550 & 9.9092 & 13.3971 & 1089.4259 & 82.7442 & 3555.5200 & 33.6667 & NA & 484.6616 & 1.1341 \\
\hline HKG & 3 & hi-sms & NA & 43.6363 & 96.3076 & 22935.9227 & 961.4230 & NA & 493.0000 & NA & NA & 0.9475 \\
\hline HND & 3 & Im-lac & 1415.3100 & 3.1233 & 5.4862 & 1277.4227 & NA & NA & 73.9402 & 90.4340 & 325.4889 & 1.1341 \\
\hline
\end{tabular}




\begin{tabular}{|c|c|c|c|c|c|c|c|c|c|c|c|c|}
\hline HRV & 3 & hi-weu & 384.4874 & 17.9247 & 47.3527 & 8984.8118 & 349.2739 & NA & 287.4583 & 101.8040 & 945.5970 & 1.1553 \\
\hline $\mathrm{HTI}$ & 3 & lo-lac & 906.6852 & 1.7028 & 2.2418 & 475.0372 & NA & 1033.3333 & NA & NA & NA & 0.9387 \\
\hline HUN & 3 & um-eca & 4221.9260 & 17.5136 & 62.2227 & 9725.9100 & 517.5569 & 147.8167 & 96.2981 & 103.8440 & 937.1774 & 1.0745 \\
\hline IDN & 3 & Im-eap & 4152.6744 & 2.0131 & 6.4921 & 1148.2369 & 31.8111 & 4300.2378 & 128.7669 & 68.1380 & 282.6179 & 1.1505 \\
\hline IMN & 3 & ot-sms & NA & NA & NA & 31558.7144 & NA & NA & NA & NA & NA & 1.7533 \\
\hline IND & 3 & Im-sas & 2330.8074 & 1.2776 & 1.9900 & 623.4929 & 23.0928 & 3487.7647 & 106.9259 & 73.0820 & 170.9702 & 1.2203 \\
\hline IRL & 3 & hi-weu & 7476.6802 & 27.6279 & 79.8979 & 46468.6249 & 2026.3353 & NA & 532.4075 & 97.9780 & 1723.9774 & 1.1553 \\
\hline IRN & 3 & um-mea & 2167.2190 & 4.2937 & 4.0601 & 2417.9822 & 113.3549 & 5275.7061 & 87.5942 & 63.7860 & 684.0153 & 1.1984 \\
\hline IRQ & 3 & m-mea & 952.7200 & 0.5250 & 0.5079 & 1781.4547 & NA & 11791.7007 & 24.3627 & 49.2200 & 336.8426 & 1.1984 \\
\hline ISL & 3 & hi-weu & NA & 68.0007 & 89.9885 & 50570.4638 & 3672.9632 & 542.5752 & 135.5194 & NA & 38193.6985 & 1.1553 \\
\hline ISR & 3 & hi-mea & 2784.7630 & 19.6762 & 95.9561 & 19719.6035 & 1315.0859 & 3049.4791 & 285.2323 & 89.3020 & NA & 1.2879 \\
\hline ITA & 3 & hi-weu & 4905.2378 & 28.1306 & 92.7558 & 31530.1827 & 1459.8512 & 2437.9537 & 176.7475 & 103.6760 & 2027.7602 & 1.1553 \\
\hline JAM & 3 & um-lac & 1190.2924 & 6.1758 & 42.6082 & NA & NA & NA & 110.2713 & 71.8300 & 537.4687 & 1.4718 \\
\hline JOR & 3 & um-mea & 1424.4000 & 6.6959 & 21.8848 & 2044.8048 & NA & NA & 994.3763 & 83.1940 & 278.7171 & 1.1984 \\
\hline JPN & 3 & hi-eap & 5968.7068 & 45.1892 & 63.4828 & 34366.8413 & 1238.3721 & 12852.6776 & 340.7997 & 108.4660 & 2685.1110 & 1.0698 \\
\hline KAZ & 3 & um-eca & 1053.5192 & 1.6001 & 7.5635 & 2917.7371 & 83.1121 & 663.4427 & 1.4670 & 87.1120 & 483.6771 & 1.0745 \\
\hline KEN & 3 & lo-ssa & 1580.7602 & 1.6222 & 3.5747 & 501.4439 & 29.9438 & NA & 29.3636 & 85.8900 & 156.4019 & 1.0382 \\
\hline KGZ & 3 & Im-eca & 2770.4512 & 3.2086 & 1.9583 & 444.4860 & 18.5980 & 7028.1124 & 17.8144 & 85.3840 & 209.7190 & 1.0692 \\
\hline KHM & 3 & lo-eap & 2066.7320 & 0.1824 & 3.2509 & 371.0688 & 6.3425 & NA & 5.0165 & 78.2040 & 154.2990 & 0.8898 \\
\hline KIR & 3 & Im-eap & NA & 2.6245 & 0.5403 & 1176.0746 & 136.0363 & NA & NA & NA & 469.1602 & 1.1505 \\
\hline KNA & 3 & hi-sms & NA & 16.4875 & 24.7731 & 10200.8108 & 430.4279 & NA & 46.0000 & NA & 225.5462 & 0.9475 \\
\hline KOR & 3 & hi-eap & 6261.7706 & 59.7800 & 68.2376 & 16580.9818 & 660.9661 & 9412.0344 & 468.7801 & 107.5120 & 2604.9740 & 1.0698 \\
\hline KWT & 3 & hi-sms & 2384.2068 & 14.1724 & 55.4181 & 29711.9984 & 1878.4335 & 42408.6931 & 587.7778 & NA & NA & 0.9475 \\
\hline LAO & 3 & Im-eap & 3146.9466 & 0.2512 & 1.4702 & 409.9294 & 8.9600 & NA & NA & 78.3100 & 205.3830 & 1.1505 \\
\hline LBN & 3 & um-mea & 2579.3258 & 7.7472 & 22.4713 & 5334.6853 & 133.4079 & 7062.6900 & 210.8978 & 96.0000 & 1533.1566 & 1.1984 \\
\hline LBR & 3 & lo-ssa & 1012.0202 & 0.0294 & 0.9514 & 187.7146 & NA & 31.7021 & NA & NA & 278.2156 & 1.0382 \\
\hline LBY & 3 & um-mea & 602.9432 & 1.8291 & 2.8911 & 6835.3553 & NA & 1988.9517 & 50.3395 & NA & NA & 1.1984 \\
\hline LCA & 3 & um-lac & NA & 14.0584 & 27.0433 & 5469.9818 & 290.5286 & NA & NA & NA & 330.2362 & 1.4718 \\
\hline LIE & 3 & hi-sms & NA & 52.7840 & 48.8096 & 102609.9047 & 2509.8597 & NA & NA & NA & NA & 0.9475 \\
\hline LKA & 3 & Im-sas & 3402.8960 & 1.0793 & 5.7947 & 1101.8268 & NA & 12995.9108 & 283.5857 & 87.6460 & 179.6301 & 1.2203 \\
\hline
\end{tabular}




\begin{tabular}{|c|c|c|c|c|c|c|c|c|c|c|c|c|}
\hline LSO & 3 & Im-ssa & 731.5518 & 1.0530 & 5.6843 & 668.6967 & 84.2254 & 12.1022 & NA & NA & 83.5583 & .1510 \\
\hline LTU & 3 & hi-weu & 2855.2780 & 17.6873 & 49.2488 & 6067.5609 & 334.0240 & 32.2890 & 143.7665 & 104.5140 & 916.2425 & 1.1553 \\
\hline LUX & 3 & hi-weu & 5658.7490 & 43.8642 & 98.7591 & 74804.0265 & 2802.5415 & 3.2256 & 394.0753 & 105.0840 & 3261.1737 & 1.1553 \\
\hline LVA & 3 & hi-sms & 2323.5576 & 20.2077 & 41.1764 & 5441.1954 & 293.0548 & 54.4508 & 54.7394 & 90.6020 & 666.4696 & 0.9475 \\
\hline MAC & 3 & hi-sms & NA & 23.7056 & 62.8601 & 18291.3704 & 540.8745 & NA & NA & NA & NA & 0.9475 \\
\hline MAF & 3 & hi-sms & NA & NA & NA & NA & NA & NA & NA & NA & NA & 0.9475 \\
\hline MAR & 3 & Im-mea & 1055.0854 & 3.8800 & 20.3792 & 1763.9283 & 101.3060 & 1282.5347 & 56.6077 & 105.4740 & 539.2767 & 1.2075 \\
\hline $1 \mathrm{CO}$ & 3 & hi-sms & NA & 47.7719 & 45.2257 & 124189.0837 & 1552.0573 & NA & NA & NA & NA & 0.9475 \\
\hline ADA & 3 & Im-eca & 2343.2678 & 4.9190 & 10.0497 & 672.2808 & 36.3271 & NA & 7.9960 & 98.1320 & 174.7394 & 1.0692 \\
\hline IDG & 3 & lo-ssa & 2086.6394 & 0.3414 & 1.1616 & 273.1524 & 8.2833 & 5486.5306 & 2.1485 & 61.2580 & 100.7393 & 1.0382 \\
\hline MDV & 3 & um-sas & 1935.1904 & 4.7468 & 17.2494 & 3234.8863 & 190.5849 & NA & 8.1111 & NA & 350.6588 & 1.9352 \\
\hline MEX & 3 & um-lac & 2914.3586 & 10.2039 & 24.3018 & 7564.3730 & 350.7916 & 2311.9285 & 68.4668 & 87.6280 & 1064.1208 & 1.4718 \\
\hline MHL & 3 & um-eap & NA & 2.3492 & 1.0473 & 2518.0403 & 263.2563 & NA & 1.5000 & NA & NA & 1.1380 \\
\hline MKD & 3 & um-eca & 2754.6268 & 13.3588 & 23.7221 & 2642.8335 & 92.4431 & 550.1613 & 39.0487 & 109.1220 & 692.5242 & 1.0745 \\
\hline MLI & 3 & lo-ssa & 925.7154 & 0.2597 & 1.2940 & 416.2535 & 15.7717 & NA & 52.0416 & 96.6820 & 204.1197 & 1.0382 \\
\hline MLT & 3 & hi-weu & 4269.3904 & 25.2343 & 59.7097 & 14576.5752 & 663.3087 & 2144.4413 & 109.1386 & 101.0440 & 4798.0577 & 1.1553 \\
\hline MMR & 3 & lo-eap & 3249.3422 & 0.0123 & 0.0982 & NA & NA & 2985.5602 & 11.5036 & 62.2980 & NA & 0.8898 \\
\hline MNE & 3 & um-eca & NA & 25.3501 & 78.7034 & 3335.3911 & NA & NA & NA & NA & 664.1655 & 1.0745 \\
\hline MNG & 3 & Im-eap & 735.2338 & 1.6495 & 10.6888 & 834.1204 & 47.5578 & NA & 6.6440 & 77.1320 & 428.3221 & 1.1505 \\
\hline MNP & 3 & hi-sms & NA & NA & 21.4191 & NA & NA & NA & NA & NA & NA & 0.9475 \\
\hline MOZ & 3 & lo-ssa & 807.4468 & 0.3256 & 1.6135 & 268.1180 & 11.9813 & 160.8461 & 2.9912 & 65.4120 & 97.9103 & 1.0382 \\
\hline MRT & 3 & Im-ssa & 789.9978 & 0.3444 & 8.4092 & 563.6263 & 16.2310 & 3507.8973 & NA & NA & 283.4117 & 1.1510 \\
\hline MUS & 3 & um-ssa & 7379.2204 & 10.4383 & 30.1466 & 4762.3125 & 181.5526 & NA & 308.5050 & 86.4980 & 498.7091 & 1.5163 \\
\hline MWI & 3 & lo-ssa & 1225.2572 & 0.2264 & 0.9010 & 210.2335 & 9.7902 & 403.4602 & 31.7323 & 62.3520 & 82.4493 & 1.0382 \\
\hline MYS & 3 & um-eap & 3208.3816 & 31.5285 & 38.4221 & 5017.1624 & 346.9660 & 1723.9071 & 1369.6534 & 103.1200 & 1209.1128 & 1.1380 \\
\hline NAM & 3 & um-ssa & 383.9518 & 2.7720 & 8.6141 & 3161.4104 & 211.8842 & 246.4385 & 2.8397 & 80.2160 & 529.2687 & 1.5163 \\
\hline $\mathrm{NCL}$ & 3 & hi-sms & 3831.2500 & 22.2546 & 37.5732 & NA & NA & NA & 342.7941 & NA & NA & 0.9475 \\
\hline NER & 3 & lo-ssa & 378.4532 & 0.1228 & 0.5106 & 260.3989 & 7.5017 & NA & 0.3818 & 70.9080 & NA & 1.0382 \\
\hline NGA & 3 & Im-ssa & 1268.3928 & 0.4638 & 2.1104 & 618.6789 & NA & 166.9595 & 5.0717 & 66.6160 & 325.5666 & 1.1510 \\
\hline NIC & 3 & Im-lac & 1754.1700 & 1.6690 & 6.3915 & 1083.2070 & 28.2256 & 599.9282 & 31.0932 & 75.5560 & 391.1092 & 1.1341 \\
\hline
\end{tabular}




\begin{tabular}{|c|c|c|c|c|c|c|c|c|c|c|c|c|}
\hline NLD & 3 & hi-weu & 922.4164 & 57.5035 & 78.5558 & 39995.0832 & 2085.2966 & 55.6193 & 408.1427 & 98.0260 & 3406.7950 & 1.1553 \\
\hline NOR & 3 & hi-weu & 3897.4858 & 68.9320 & 84.5139 & 62311.8590 & 4497.3257 & 922.9284 & 211.4391 & 105.0120 & 3631.9888 & 1.1553 \\
\hline NPL & 3 & lo-sas & 2198.2046 & 0.3181 & 0.2021 & 304.5127 & 9.8235 & 3957.2356 & 9.9216 & 88.9260 & 119.1985 & 1.1467 \\
\hline NZL & 3 & hi-nao & 6697.5700 & 56.5023 & 59.8389 & 25752.1075 & 1686.8929 & 4097.5469 & 1958.7068 & 100.8400 & 8569.1288 & 1.1840 \\
\hline OMN & 3 & hi-mea & 3508.9794 & 6.0605 & 19.8914 & 13126.7641 & 507.4380 & 40195.5556 & 415.7508 & NA & NA & 1.2879 \\
\hline PAK & 3 & Im-sas & 2330.2984 & 3.7754 & 1.3337 & 614.6372 & 11.6459 & 7584.1076 & 148.1554 & 81.4740 & 201.7945 & 1.2203 \\
\hline PAN & 3 & um-lac & 1907.1980 & 8.6939 & 20.9464 & 4140.0529 & 182.5068 & NA & 44.5736 & 100.3200 & 760.7895 & 1.4718 \\
\hline PER & 3 & um-lac & 3283.7736 & 9.0644 & 9.2176 & 2425.4983 & 73.9146 & NA & 83.6214 & 92.7780 & NA & 1.4718 \\
\hline PHL & 3 & Im-eap & 2758.9824 & 3.7880 & 21.7998 & 1099.5822 & 32.8082 & NA & 160.1586 & 85.5060 & 276.9270 & 1.1505 \\
\hline PLW & 3 & um-eap & NA & 22.9386 & 17.4296 & 9623.9604 & 701.3821 & NA & NA & NA & 1536.7926 & 1.1380 \\
\hline PNG & 3 & Im-eap & 3987.6464 & 1.1887 & 0.3463 & 782.7273 & NA & 4.5877 & 209.8244 & NA & NA & 1.1505 \\
\hline POL & 3 & hi-weu & 3046.9836 & 19.1472 & 37.1849 & 7182.8247 & 380.8277 & 84.2103 & 124.7340 & 109.9240 & 553.9084 & 1.1553 \\
\hline PRI & 3 & hi-lac & 1894.7998 & 17.0980 & 43.0194 & 20859.0478 & NA & 2020.4479 & NA & NA & 2347.9233 & 1.3509 \\
\hline PRK & 3 & lo-eap & 3054.3940 & 0.0000 & 0.0000 & NA & NA & NA & NA & NA & NA & 0.8898 \\
\hline PRT & 3 & hi-weu & 2778.6518 & 23.0675 & 84.3700 & 18530.0619 & 980.3755 & 3904.6834 & 193.1026 & 102.5360 & 996.1073 & 1.1553 \\
\hline PRY & 3 & Im-lac & 2172.9108 & 1.8412 & 25.5337 & 1452.9846 & 58.3656 & 109.4798 & 64.1257 & 106.6400 & 582.5344 & 1.1341 \\
\hline PYF & 3 & hi-sms & NA & 10.5635 & 25.6678 & NA & NA & NA & 312.5556 & NA & NA & 0.9475 \\
\hline QAT & 3 & hi-mea & 4027.4504 & 12.2408 & 43.3772 & 53019.7715 & 1140.0855 & 17212.4221 & 1433.0012 & 100.1340 & 2497.2142 & 1.2879 \\
\hline ROU & 3 & um-weu & 2781.7700 & 7.7265 & 25.8355 & 3835.4625 & 125.2003 & 128.4365 & 38.6803 & 106.3720 & 809.7325 & 1.0283 \\
\hline RUS & 3 & hi-eca & 1827.6940 & 6.0416 & 19.1293 & 4375.2125 & 149.6395 & 107.0749 & 11.9919 & 79.2720 & 817.2456 & 1.1337 \\
\hline RWA & 3 & lo-ssa & 938.6902 & 0.2768 & 1.0078 & 238.9238 & 11.6880 & 97.5330 & 2.0286 & 66.8300 & 116.7494 & 1.0382 \\
\hline SAU & 3 & hi-mea & 4079.9982 & 6.3025 & 22.4087 & 12465.0000 & 867.8554 & NA & 93.5509 & 100.0000 & 2334.9122 & 1.2879 \\
\hline SDN & 3 & Im-ssa & 583.8888 & 0.3871 & 1.0263 & 606.6829 & 10.2709 & NA & 3.8590 & 76.2260 & 403.6087 & 1.1510 \\
\hline SEN & 3 & Im-ssa & 895.9632 & 1.7763 & 5.6803 & 720.6492 & 24.8226 & 675.7922 & 11.6206 & 109.3060 & 182.8055 & 1.1510 \\
\hline SGP & 3 & hi-sms & NA & 48.1017 & 79.9702 & 25701.2330 & 949.0046 & NA & 8975.0794 & NA & NA & 0.9475 \\
\hline SLB & 3 & Im-eap & 4046.0094 & 0.5314 & 0.3260 & 862.1878 & NA & NA & NA & NA & 311.5483 & 1.1505 \\
\hline SLE & 3 & lo-ssa & 1019.1032 & 0.1696 & 1.2020 & 289.8596 & 10.7400 & 55.3808 & NA & NA & 233.8152 & 1.0382 \\
\hline SLV & 3 & Im-lac & 2300.0976 & 2.0555 & 18.1926 & 2638.5483 & 71.9247 & 1112.6864 & 78.8415 & 92.8220 & 649.0586 & 1.1341 \\
\hline SMR & 3 & hi-sms & NA & 50.1092 & 57.6859 & 44589.7914 & NA & NA & NA & NA & NA & 0.9475 \\
\hline SOM & 3 & lo-ssa & 716.5634 & 0.3289 & 2.4054 & NA & NA & 2785.4365 & NA & NA & NA & 1.0382 \\
\hline
\end{tabular}




\begin{tabular}{|c|c|c|c|c|c|c|c|c|c|c|c|c|}
\hline SRB & 3 & um-eca & 3702.9394 & 23.5000 & 47.1849 & 2919.4550 & NA & NA & NA & 88.9960 & 720.3413 & 1.0745 \\
\hline SSD & 3 & Im-ssa & NA & NA & NA & NA & NA & NA & NA & NA & NA & 1.1510 \\
\hline STP & 3 & Im-ssa & 2157.6496 & 8.4030 & 1.9547 & 767.0716 & 23.9462 & NA & NA & NA & NA & 1.1510 \\
\hline SUR & 3 & um-lac & 3767.4586 & 4.1057 & 25.4991 & 3138.9586 & NA & 11610.8240 & 114.0900 & 88.1340 & 560.1911 & 1.4718 \\
\hline SVK & 3 & hi-weu & 3693.4082 & 31.6050 & 52.9635 & 9945.4356 & 412.0224 & 38.9627 & 81.9072 & 108.2500 & 802.4922 & 1.1553 \\
\hline SVN & 3 & hi-weu & 5094.2826 & 29.1580 & 79.7554 & 16332.7491 & 945.7648 & 40.5636 & 387.4880 & 106.2080 & 841.9567 & 1.1553 \\
\hline SWE & 3 & hi-weu & 4680.2842 & 66.2087 & 87.6045 & 39956.6094 & 2868.0772 & 50.4044 & 98.6596 & 100.6800 & 2625.1838 & 1.1553 \\
\hline SWZ & 3 & Im-ssa & 1254.8896 & 1.9379 & 7.1123 & 2230.2885 & 130.7571 & 5651.9719 & NA & NA & 201.1449 & 1.1510 \\
\hline SXM & 3 & hi-sms & NA & NA & NA & NA & NA & NA & NA & NA & NA & 0.9475 \\
\hline SYC & 3 & um-ssa & NA & 14.3159 & 50.7566 & 10860.8786 & 574.5982 & NA & 17.5000 & NA & 723.8186 & 1.5163 \\
\hline SYR & 3 & Im-mea & 1813.6934 & 2.0696 & 4.7714 & 1461.5673 & 77.7509 & 3112.0180 & 72.4609 & 93.2140 & NA & 1.2075 \\
\hline TCA & 3 & hi-sms & NA & NA & NA & NA & NA & NA & NA & NA & NA & 0.9475 \\
\hline TCD & 3 & lo-ssa & 659.1382 & 0.1858 & 0.5348 & 443.2704 & 9.9340 & 178.7837 & NA & NA & NA & 1.0382 \\
\hline TGO & 3 & lo-ssa & 1117.8412 & 1.0800 & 3.3894 & 392.5830 & 16.1085 & 31.9325 & 5.3516 & 78.9620 & 216.9996 & 1.0382 \\
\hline THA & 3 & um-eap & 2889.8436 & 7.3506 & 23.8350 & 2360.2448 & 107.4313 & NA & 130.4661 & 78.4020 & 411.8456 & 1.1380 \\
\hline TJK & 3 & lo-eca & 1769.7802 & 0.0595 & 0.6012 & 278.1670 & 7.0736 & 14022.7021 & 33.9434 & 69.6640 & 82.0063 & 1.8677 \\
\hline TKM & 3 & um-eca & 2612.7056 & 0.3580 & 0.3576 & 1457.1401 & NA & 13311.5399 & NA & 79.6420 & 424.3105 & 1.0745 \\
\hline TLS & 3 & lo-sas & 1589.7536 & 0.0000 & 2.4045 & 516.0708 & NA & NA & NA & NA & 181.0446 & 1.1467 \\
\hline TON & 3 & um-eap & NA & 3.0211 & 6.2782 & 2505.4883 & 106.8413 & NA & 137.5111 & NA & 586.3848 & 1.1380 \\
\hline TTO & 3 & hi-sms & 1694.0874 & 19.6201 & 26.0245 & 10003.3359 & 313.3355 & 662.2840 & 344.0949 & 77.5900 & 107.5909 & 0.9475 \\
\hline TUN & 3 & um-mea & 1407.6390 & 5.4643 & 13.6396 & 2918.8530 & 185.3477 & 773.7169 & 32.5661 & 97.5800 & 792.6023 & 1.1984 \\
\hline TUR & 3 & um-eca & 2288.1188 & 9.4482 & 37.2315 & 6120.5014 & 173.9257 & 1325.0437 & 80.9061 & 66.0420 & 1855.0770 & 1.0745 \\
\hline TUV & 3 & um-eap & NA & 5.2416 & 1.0367 & 2376.7880 & NA & NA & NA & NA & 853.9109 & 1.1380 \\
\hline TZA & 3 & lo-ssa & 1524.5512 & 0.4131 & 2.2965 & 329.7034 & 14.9272 & 529.1186 & 4.4815 & 65.1880 & 130.2657 & 1.0382 \\
\hline UGA & 3 & lo-ssa & 1592.9658 & 0.3941 & 2.0513 & 286.0174 & 10.6267 & 21.3539 & 1.4666 & NA & 91.0934 & 1.0382 \\
\hline UKR & 3 & Im-eca & 2424.1210 & 2.0933 & 11.2888 & 1459.5161 & 73.4128 & NA & 16.0486 & 93.3740 & 447.8286 & 1.0692 \\
\hline URY & 3 & hi-lac & 3754.8302 & 13.2160 & 15.2879 & 4845.9268 & 117.3991 & 2385.9145 & 107.1933 & 72.2580 & 5506.7427 & 1.3509 \\
\hline USA & 3 & hi-nao & 6033.7940 & 55.4802 & 49.8807 & 41702.3300 & 2266.2999 & 1139.2646 & 118.2496 & 87.9100 & 2074.2039 & 1.1840 \\
\hline UZB & 3 & Im-eca & 3177.3004 & 1.3340 & 0.9655 & 475.8039 & NA & 12204.2626 & NA & NA & 183.6886 & 1.0692 \\
\hline VCT & 3 & um-lac & 14682.4602 & 5.5446 & 28.5477 & 4483.8960 & 368.2249 & NA & NA & NA & 520.7656 & 1.4718 \\
\hline
\end{tabular}




\begin{tabular}{|c|c|c|c|c|c|c|c|c|c|c|c|c|}
\hline VEN & 3 & um-lac & 3244.9608 & 5.7621 & 26.6850 & 4941.1636 & NA & 1533.6599 & 157.5882 & 52.4240 & 1614.2750 & 1.4718 \\
\hline VIR & 3 & hi-sms & NA & 22.8983 & 43.3293 & NA & NA & NA & NA & NA & NA & 0.9475 \\
\hline VNM & 3 & Im-eap & 4383.6496 & 2.9595 & 2.7988 & 590.5971 & NA & NA & 350.3912 & 76.3960 & 166.7290 & 1.1505 \\
\hline VUT & 3 & Im-eap & 510.4998 & 3.4198 & 2.3949 & 1879.9755 & 152.6790 & NA & NA & 80.0020 & 534.8508 & 1.1505 \\
\hline PSE & 3 & ot-sms & 1948.4212 & 2.9160 & 6.6530 & 1280.2379 & NA & 1640.5639 & NA & NA & 364.0139 & 1.7533 \\
\hline WSM & 3 & Im-eap & NA & 2.0753 & 3.8486 & 2295.2258 & 96.6530 & NA & 1.9829 & NA & 440.2600 & 1.1505 \\
\hline YEM & 3 & Im-mea & 918.6914 & 0.4356 & 2.9381 & 792.9265 & 74.9976 & 2184.7780 & 8.7863 & 69.8920 & NA & 1.2075 \\
\hline ZAF & 3 & um-ssa & 2654.1190 & 6.7677 & 30.3513 & 5010.0419 & 264.8067 & 575.3741 & 58.8809 & 110.8700 & 304.3466 & 1.5163 \\
\hline COD & 3 & ot-ssa & 777.6880 & 0.0883 & 1.5424 & 207.4243 & NA & 10.7317 & 0.2417 & NA & 81.1242 & 0.9799 \\
\hline ZMB & 3 & Im-ssa & 1603.9836 & 0.7792 & 1.9650 & 647.5603 & 15.5555 & 415.6905 & 27.3841 & NA & 182.5312 & 1.1510 \\
\hline ZWE & 3 & lo-ssa & 997.9694 & 3.6309 & 2.7059 & 593.2404 & NA & 909.5848 & 32.8114 & 1.2400 & 164.9154 & 1.0382 \\
\hline ABW & 4 & hi-sms & NA & 38.8600 & 113.8299 & 22141.9717 & 1124.5675 & NA & NA & NA & 159.7839 & 1.1140 \\
\hline AND & 4 & ot-sms & NA & 61.1965 & 80.8450 & 33465.7473 & 918.3301 & NA & NA & NA & NA & 1.4965 \\
\hline AFG & 4 & lo-sas & 1750.7044 & 2.1243 & 19.8983 & 285.2867 & NA & NA & 4.3319 & 77.1900 & 101.9137 & 1.3062 \\
\hline AGO & 4 & um-ssa & 543.5166 & 3.3702 & 27.0839 & 2245.4815 & 63.7184 & 42.1452 & 4.5913 & NA & 291.7495 & 1.7055 \\
\hline ALB & 4 & um-eca & 3837.9180 & 19.1500 & 63.6785 & 3158.2477 & 100.2569 & 886.5755 & 89.8240 & 109.6180 & 1164.1119 & 1.2363 \\
\hline ARE & 4 & hi-mea & 36164.5112 & 56.0000 & 126.3517 & 35307.2277 & NA & 62560.3173 & 796.6865 & NA & 2241.7212 & 3.8829 \\
\hline ARG & 4 & um-lac & 4001.3584 & 25.3414 & 97.8440 & 5981.5210 & 260.2202 & NA & 37.1621 & 143.6320 & 4466.8361 & 1.5009 \\
\hline ARM & 4 & Im-eca & 2117.7574 & 7.6832 & 47.5046 & 1959.8986 & 60.5733 & 4184.3496 & 22.7374 & 103.3520 & 951.0911 & 1.1915 \\
\hline ASM & 4 & um-eap & NA & NA & NA & NA & NA & NA & NA & NA & NA & 1.2235 \\
\hline ATG & 4 & hi-sms & 1740.6058 & 34.2000 & 137.1404 & 13489.2459 & 344.7244 & 325.0800 & 5.5500 & NA & 290.7353 & 1.1140 \\
\hline AUS & 4 & hi-nao & 1550.9058 & 68.8740 & 97.4924 & 35252.8347 & 1695.0070 & NA & 42.7968 & 130.3580 & 8081.3559 & 1.2896 \\
\hline AUT & 4 & hi-weu & 6192.4568 & 67.4580 & 120.5583 & 39752.2677 & 2196.1491 & NA & 113.5644 & 125.5580 & 1487.4981 & 1.2020 \\
\hline AZE & 4 & um-eca & 2641.6164 & 15.8085 & 55.2288 & 2421.5531 & 66.8730 & 5030.7144 & 14.3372 & 141.1520 & 316.5701 & 1.2363 \\
\hline BDI & 4 & lo-ssa & 1308.6842 & 0.7219 & 4.7169 & 147.7649 & 7.4655 & NA & 2.5881 & 100.7300 & 58.8101 & 1.1468 \\
\hline BEL & 4 & hi-weu & 8851.2546 & 63.1960 & 99.7319 & 37774.7383 & 2335.2889 & 43.9402 & 307.4890 & 124.2520 & 12906.8719 & 1.2020 \\
\hline BEN & 4 & lo-ssa & 1158.8716 & 1.7378 & 27.6449 & 543.3929 & 21.7106 & NA & 1.5397 & NA & 297.8642 & 1.1468 \\
\hline BFA & 4 & lo-ssa & 1061.8350 & 0.7805 & 14.2174 & 424.6494 & 19.1126 & 79.9805 & 11.5471 & 119.0520 & 111.3582 & 1.1468 \\
\hline BGD & 4 & lo-sas & 3948.4808 & 1.7283 & 21.4966 & 468.0352 & 11.2860 & NA & 192.8534 & 141.6680 & 123.0884 & 1.3062 \\
\hline BGR & 4 & um-eca & 3313.1050 & 33.0740 & 119.9593 & 4293.1150 & 181.6981 & 325.7923 & 93.2049 & 122.1980 & 901.9250 & 1.2363 \\
\hline
\end{tabular}




\begin{tabular}{|c|c|c|c|c|c|c|c|c|c|c|c|c|}
\hline BHR & 4 & hi-mea & NA & 37.4815 & 107.5000 & 17646.5399 & 466.1999 & 115185.2098 & 3216.5835 & NA & NA & .8829 \\
\hline BHS & 4 & hi-sms & 4432.3810 & 28.6840 & 91.5877 & 22804.0567 & NA & NA & NA & NA & 2386.2289 & 1.1140 \\
\hline $\mathrm{BIH}$ & 4 & um-eca & 4139.5012 & 29.3538 & 64.0022 & 3132.0637 & NA & NA & 29.2009 & 118.6140 & 394.1856 & 1.2363 \\
\hline BLR & 4 & um-eca & 3046.3254 & 21.5825 & 72.7444 & 3745.4241 & 202.2819 & NA & 227.3113 & 138.4200 & 1123.2095 & 1.2363 \\
\hline BLZ & 4 & um-lac & 2665.0412 & 10.7024 & 45.4407 & 4120.5916 & 242.7641 & NA & 80.4648 & 108.1560 & 826.5665 & 1.5009 \\
\hline MU & 4 & hi-sms & NA & 75.0495 & 107.1766 & 79312.2547 & 1825.9009 & NA & NA & NA & NA & 1.1140 \\
\hline BOL & 4 & Im-lac & 2030.5554 & 10.2455 & 41.1318 & 1086.3845 & 77.6991 & NA & 5.5944 & 109.8080 & 350.1715 & 1.2579 \\
\hline BRA & 4 & um-lac & 3401.7150 & 30.6262 & 65.8392 & 5068.4306 & 259.5545 & 460.8312 & 133.8795 & 110.0840 & 1497.4560 & 1.5009 \\
\hline BRB & 4 & hi-sms & 2539.4190 & 58.4200 & 95.9276 & 14772.0537 & 781.3310 & 4215.5846 & 118.7692 & NA & 6.5721 & 1.1140 \\
\hline BRN & 4 & hi-sms & 724.5828 & 43.6665 & 89.4453 & 25624.8864 & NA & NA & 193.4333 & 101.0780 & 848.6396 & 1.1140 \\
\hline BTN & 4 & Im-sas & 2287.1492 & 5.6011 & 24.9171 & 1458.1230 & 80.4280 & NA & 12.2582 & 98.2520 & 412.9431 & 1.3706 \\
\hline BWA & 4 & um-ssa & 434.9098 & 5.0465 & 61.2930 & 5802.3679 & 561.5184 & NA & 48.6044 & 136.9280 & 259.3255 & 1.7055 \\
\hline CAF & 4 & lo-ssa & 933.5426 & 0.7510 & 9.4790 & 378.0743 & 5.2610 & 0.2068 & NA & NA & 316.5891 & 1.1468 \\
\hline CAN & 4 & hi-nao & 3182.3848 & 74.8520 & 61.6958 & 36505.0961 & 1746.3521 & NA & 60.7186 & 139.1580 & NA & 1.2896 \\
\hline CHE & 4 & hi-weu & 6374.5548 & 76.7000 & 107.3603 & 57200.2728 & 3009.7244 & NA & 220.9235 & 97.3400 & 1786.6351 & 1.2020 \\
\hline $\mathrm{CHL}$ & 4 & hi-lac & 5772.1034 & 36.0866 & 81.7156 & 8055.5278 & 282.1647 & 22008.5817 & 548.9995 & 134.0760 & 2753.9014 & 1.4749 \\
\hline $\mathrm{CHN}$ & 4 & um-eap & 5392.7804 & 17.3093 & 41.7366 & 2177.5328 & NA & 3171.3125 & 501.6828 & 92.4700 & 415.6295 & 1.2235 \\
\hline CIV & 4 & Im-ssa & 1753.9454 & 1.6528 & 41.2463 & 988.6666 & 43.3207 & 208.1401 & 19.6124 & 123.9880 & 415.5033 & 1.1709 \\
\hline CMR & 4 & Im-ssa & 1731.2086 & 2.7203 & 24.8549 & 922.1758 & 29.5143 & NA & 7.8429 & 113.2640 & 358.6035 & 1.1709 \\
\hline COG & 4 & Im-ssa & 771.8064 & 3.0037 & 39.1166 & 1745.0325 & 32.0504 & NA & 1.1605 & 110.6000 & 210.7073 & 1.1709 \\
\hline $\mathrm{COL}$ & 4 & um-lac & 3569.2496 & 20.7498 & 75.6832 & 3677.5044 & 151.6856 & NA & 508.9348 & 120.5860 & 1024.4998 & 1.5009 \\
\hline COM & 4 & lo-ssa & 1336.0380 & 2.6400 & 10.1830 & 620.3684 & 47.1663 & NA & NA & NA & 364.9529 & 1.1468 \\
\hline CPV & 4 & Im-ssa & 212.3316 & 11.2332 & 37.6509 & 2397.6107 & 136.5180 & NA & NA & 149.5180 & 446.4519 & 1.1709 \\
\hline CRI & 4 & um-lac & 3618.2838 & 28.4380 & 35.2317 & 5062.1672 & 262.3795 & NA & 823.2244 & 156.0020 & 1277.6714 & 1.5009 \\
\hline CUB & 4 & um-lac & 2600.0618 & 11.9715 & 2.5490 & 4412.3286 & 517.7199 & 690.5329 & 29.9491 & 191.7780 & 789.4692 & 1.5009 \\
\hline CUW & 4 & hi-sms & NA & NA & 140.2497 & NA & NA & NA & NA & NA & NA & 1.1140 \\
\hline CYM & 4 & hi-sms & NA & 52.0069 & 186.9529 & NA & NA & NA & NA & NA & NA & 1.1140 \\
\hline CYP & 4 & hi-weu & 1155.2032 & 40.3060 & 87.1116 & 23417.6065 & 1247.7617 & 1440.6962 & 124.2605 & 111.2840 & 1135.5951 & 1.2020 \\
\hline CZE & 4 & hi-weu & 4772.7308 & 52.5060 & 124.1456 & 14385.8519 & 599.3331 & 9.3916 & 91.9559 & 111.3480 & 931.0923 & 1.2020 \\
\hline DEU & 4 & hi-weu & 6742.1940 & 74.6060 & 112.9527 & 36224.9114 & 1679.3766 & 6.8047 & 193.2090 & 123.0960 & 1102.3781 & 1.2020 \\
\hline
\end{tabular}




\begin{tabular}{|c|c|c|c|c|c|c|c|c|c|c|c|c|}
\hline DJI & 4 & Im-mea & 1549.2064 & 2.0207 & 9.9338 & 981.4251 & 82.0375 & NA & NA & NA & 123.0735 & 1827 \\
\hline DMA & 4 & um-lac & 1418.0010 & 40.2793 & 113.5393 & 5794.9280 & NA & NA & 144.1533 & NA & 1839.2277 & 1.5009 \\
\hline DNK & 4 & hi-weu & 6080.7840 & 85.2560 & 113.2144 & 49457.7636 & 4005.9042 & 49.5096 & 133.7409 & 127.2400 & 3881.7612 & 1.2020 \\
\hline DOM & 4 & um-lac & 4176.2386 & 18.5056 & 61.1925 & 4090.4875 & 89.6080 & 4863.0166 & 78.8847 & 158.2980 & 879.5930 & 1.5009 \\
\hline DZA & 4 & um-mea & 1389.2086 & 8.8162 & 69.0467 & 3072.3473 & 133.2722 & NA & 11.6435 & 148.3080 & 723.4353 & 1.2663 \\
\hline ECU & 4 & um-lac & 2952.2864 & 13.4789 & 69.1516 & 3132.3676 & NA & 6556.0180 & 191.8248 & 108.6100 & 776.6135 & 1.5009 \\
\hline EGY & 4 & Im-mea & 7413.2390 & 17.2280 & 42.1958 & 1380.0889 & 56.1251 & NA & 577.2425 & 129.9780 & 317.3635 & 1.1827 \\
\hline ERI & 4 & lo-ssa & 649.4884 & 0.4733 & 1.6482 & 205.0149 & 4.3447 & 828.2982 & 2.1512 & 127.1240 & 52.8417 & 1.1468 \\
\hline ESP & 4 & hi-weu & 3136.2882 & 55.0720 & 106.3679 & 27031.8131 & 1214.8254 & 1593.1932 & 129.1326 & 117.8900 & 3352.3507 & 1.2020 \\
\hline EST & 4 & hi-weu & 2693.6684 & 66.8460 & 121.5320 & 11232.4691 & 596.3319 & 13.5998 & 76.5325 & 110.4160 & 1111.9947 & 1.2020 \\
\hline ETH & 4 & lo-ssa & 1499.2044 & 0.3781 & 2.0580 & 190.3806 & 10.1646 & NA & 14.5872 & 190.5940 & 91.1496 & 1.1468 \\
\hline FIN & 4 & hi-weu & 3533.7954 & 80.2160 & 119.0967 & 40560.7166 & 2539.0736 & 22.1968 & 126.1561 & 119.8440 & 5573.9236 & 1.2020 \\
\hline FJI & 4 & um-eap & 2475.2672 & 11.7903 & 53.7856 & 3634.5531 & 182.5744 & NA & 30.2346 & 109.6960 & 862.0239 & 1.2235 \\
\hline FRA & 4 & hi-weu & 7021.6792 & 59.6180 & 87.1109 & 35413.5552 & 2012.7610 & 212.9978 & 173.0652 & 125.6360 & 2660.0667 & 1.2020 \\
\hline FRO & 4 & hi-sms & NA & 72.7984 & 103.4811 & 35211.5527 & NA & NA & NA & NA & NA & 1.1140 \\
\hline FSM & 4 & Im-eap & 1301.9072 & 13.6186 & 21.9508 & 2325.3273 & NA & NA & 0.0800 & NA & 702.7081 & 1.2213 \\
\hline GAB & 4 & um-ssa & 1622.0654 & 5.8119 & 76.1687 & 6232.0891 & NA & 123.9916 & 9.6800 & NA & 1981.2136 & 1.7055 \\
\hline GBR & 4 & hi-weu & 7111.5464 & 75.1720 & 118.2871 & 40498.3311 & 2189.0824 & 222.0084 & 245.8217 & NA & 1101.8403 & 1.2020 \\
\hline GEO & 4 & Im-eca & 1940.4504 & 10.3893 & 50.0399 & 1691.3924 & 48.4720 & 2219.3384 & 44.5865 & 104.6260 & 420.1867 & 1.1915 \\
\hline GHA & 4 & Im-ssa & 1468.3480 & 3.6229 & 36.9531 & 542.1469 & 31.8061 & NA & 15.4695 & 139.2640 & 347.7647 & 1.1709 \\
\hline GIN & 4 & lo-ssa & 1488.8128 & 0.7640 & 20.3693 & 306.6136 & 7.6684 & NA & 0.9897 & 137.1980 & 104.9268 & 1.1468 \\
\hline GMB & 4 & lo-ssa & 978.5762 & 5.9503 & 50.2729 & 435.6848 & 8.9439 & NA & 8.0032 & 92.2620 & 236.7084 & 1.1468 \\
\hline GNB & 4 & lo-ssa & 1533.7070 & 2.1646 & 21.3682 & 418.1977 & NA & NA & NA & 115.9400 & 311.1167 & 1.1468 \\
\hline GNQ & 4 & hi-sms & NA & 1.5872 & 23.1429 & 13725.2285 & NA & NA & NA & NA & NA & 1.1140 \\
\hline GRC & 4 & hi-weu & 4078.7546 & 34.5460 & 109.5335 & 23483.5621 & 960.8006 & 3558.7585 & 109.3232 & 124.3180 & 3208.3490 & 1.2020 \\
\hline GRD & 4 & um-lac & 941.5434 & 22.2808 & 61.4628 & 6668.9349 & NA & NA & NA & NA & 416.6102 & 1.5009 \\
\hline GRL & 4 & hi-sms & NA & 60.7570 & 97.2332 & 31894.6216 & NA & NA & NA & NA & NA & 1.1140 \\
\hline GTM & 4 & Im-lac & 1913.0856 & 7.4200 & 82.6793 & 2242.1471 & 68.8633 & 1290.5690 & 119.7783 & NA & 515.1605 & 1.2579 \\
\hline GUM & 4 & hi-sms & 2546.6666 & 45.5245 & NA & NA & NA & NA & NA & NA & NA & 1.1140 \\
\hline GUY & 4 & Im-lac & 4219.9000 & 18.6333 & 55.8894 & 1082.9428 & 55.0853 & NA & 32.8771 & NA & 446.0978 & 1.2579 \\
\hline
\end{tabular}




\begin{tabular}{|c|c|c|c|c|c|c|c|c|c|c|c|c|}
\hline HKG & 4 & hi-sms & NA & 63.7200 & 152.3129 & 28967.0133 & 1106.0600 & NA & 262.7600 & NA & NA & .1140 \\
\hline HND & 4 & Im-lac & 1624.1198 & 8.6200 & 61.1719 & 1487.8773 & NA & 1135.2458 & 139.5463 & 138.8400 & 368.4140 & 1.2579 \\
\hline HRV & 4 & hi-weu & 5666.2614 & 41.4760 & 102.1401 & 10883.6124 & 463.0600 & NA & 349.0535 & 115.5200 & 1064.8623 & 1.2020 \\
\hline HTI & 4 & lo-lac & 967.0334 & 7.2144 & 23.0038 & 457.8187 & NA & NA & NA & NA & NA & 1.0011 \\
\hline HUN & 4 & um-eca & 4926.2814 & 52.4660 & 108.0166 & 11403.2498 & 602.2500 & 66.4197 & 93.7973 & 130.7160 & 1221.5742 & 1.2363 \\
\hline IDN & 4 & Im-eap & 4529.7728 & 5.7981 & 43.6565 & 1387.2208 & 42.8601 & NA & 169.9256 & 123.6000 & 333.8856 & 1.2213 \\
\hline IMN & 4 & ot-sms & NA & NA & NA & 38762.5434 & NA & NA & NA & NA & NA & 1.4965 \\
\hline IND & 4 & Im-sas & 2532.0254 & 3.7287 & 23.2655 & 846.7504 & 26.6741 & NA & 145.5321 & 133.6140 & 190.0798 & 1.3706 \\
\hline IRL & 4 & hi-weu & 7229.1104 & 58.0617 & 110.4398 & 50543.1754 & 2673.2377 & NA & 434.5837 & 118.8860 & 863.7616 & 1.2020 \\
\hline IRN & 4 & um-mea & 2302.8846 & 9.5280 & 41.1812 & 2961.2864 & 145.2827 & 5098.3425 & 91.7785 & 129.3060 & 5746 & 1.2663 \\
\hline IRQ & 4 & um-mea & 1344.0390 & 0.9685 & 42.7881 & 1966.7622 & NA & NA & 50.9729 & 143.9280 & 317.4428 & 1.2663 \\
\hline ISL & 4 & hi-weu & NA & 90.2220 & 103.9800 & 59001.4275 & 4470.4464 & 553.7421 & 163.8549 & NA & 38339.0009 & 1.2020 \\
\hline ISR & 4 & hi-mea & 2744.8550 & 44.7426 & 124.1356 & 21701.2032 & 1250.4377 & 3704.6240 & 284.7251 & 131.1640 & NA & 3.8829 \\
\hline ITA & 4 & hi-weu & 5258.2750 & 41.4280 & 141.8679 & 31990.7672 & 1448.1140 & NA & 160.5205 & 123.7580 & 2001.8286 & 1.2020 \\
\hline JAM & 4 & m-lac & 1263.1068 & 19.6400 & 93.1638 & 4189.6559 & 234.0067 & NA & 62.2817 & 152.7200 & 1928 & 1.5009 \\
\hline JOR & 4 & um-mea & 1122.8998 & 19.1600 & 82.2883 & 2585.5092 & NA & 3530.5490 & 643.5157 & 135.8040 & 397.1980 & 1.2663 \\
\hline JPN & 4 & hi-eap & 6050.2254 & 72.6613 & 83.3763 & 36133.2734 & 1251.1669 & NA & 309.6857 & 93.4300 & 3709.4695 & 1.1105 \\
\hline KAZ & 4 & um-eca & 1150.5628 & 7.8900 & 74.2187 & 4272.2974 & 114.3835 & 614.3594 & 1.9977 & 140.6780 & 565.9596 & 1.2363 \\
\hline KEN & 4 & lo-ssa & 1545.3538 & 7.4591 & 30.7186 & 547.1333 & 39.3806 & 405.8308 & 33.8043 & 124.6480 & 158.7843 & 1.1468 \\
\hline KGZ & 4 & Im-eca & 2631.1674 & 13.9141 & 45.6660 & 523.2840 & 30.4199 & 5815.3038 & 22.0644 & 150.0100 & 193.2202 & 1.1915 \\
\hline KHM & 4 & lo-eap & 2692.4770 & 0.4631 & 22.8304 & 542.4596 & 8.6888 & 537.4241 & 8.2957 & 134.0440 & 194.2704 & 1.0360 \\
\hline KIR & 4 & Im-eap & NA & 6.0940 & 2.7256 & 1155.7523 & NA & NA & NA & NA & 463.5659 & 1.2213 \\
\hline KNA & 4 & hi-sms & NA & 52.8000 & 125.1279 & 11520.3108 & 472.0312 & NA & 16.4497 & NA & 193.9141 & 1.1140 \\
\hline KOR & 4 & hi-eap & 6644.9658 & 78.6000 & 90.9210 & 20118.0410 & 843.4159 & NA & 479.4506 & 98.9200 & 3046.8452 & 1.1105 \\
\hline KWT & 4 & hi-sms & 3797.9992 & 36.4635 & 62.4376 & 34569.7034 & 1464.2107 & NA & 1551.8180 & NA & NA & 1.1140 \\
\hline LAO & 4 & Im-eap & 3846.9108 & 2.6421 & 27.5216 & 532.1581 & 14.3064 & 2715.0946 & NA & 131.0460 & 243.1929 & 1.2213 \\
\hline LBN & 4 & m-mea & 2576.8468 & 19.3100 & 34.5698 & 5845.7053 & 139.4312 & 5927.7550 & 277.1239 & 117.7440 & 1375.8358 & 1.2663 \\
\hline LBR & 4 & lo-ssa & 1347.4330 & 0.5305 & 16.1626 & 194.1261 & 6.3703 & NA & NA & NA & 238.4507 & 1.1468 \\
\hline LBY & 4 & um-mea & 624.8552 & 6.5482 & 93.6120 & 8420.3170 & NA & NA & 46.2667 & NA & 873.1428 & 1.2663 \\
\hline LCA & 4 & um-lac & NA & 28.3935 & 84.5785 & 5928.2511 & 298.0385 & NA & 47.6000 & NA & 249.0690 & 1.5009 \\
\hline
\end{tabular}




\begin{tabular}{|c|c|c|c|c|c|c|c|c|c|c|c|c|}
\hline LIE & 4 & hi-sms & NA & 67.5331 & 89.0215 & 113569.2942 & 2306.9864 & NA & NA & NA & NA & 1.1140 \\
\hline LKA & 4 & Im-sas & 3636.4396 & 4.5579 & 43.2768 & 1388.4388 & 28.5720 & 10376.6330 & 285.6440 & 149.1300 & 196.2110 & 1.3706 \\
\hline LSO & 4 & Im-ssa & 491.8116 & 3.2611 & 23.8761 & 766.5606 & 106.4383 & NA & NA & NA & 72.4827 & 1.1709 \\
\hline LTU & 4 & hi-weu & 2934.8880 & 49.0000 & 150.3689 & 8906.8573 & 442.2664 & 42.9911 & 84.1469 & 129.7920 & 1058.7153 & 1.2020 \\
\hline LUX & 4 & hi-weu & 5748.5978 & 78.1940 & 139.5334 & 82378.9830 & NA & NA & 275.6588 & 117.3520 & 2131.8381 & 1.2020 \\
\hline LVA & 4 & hi-sms & 2837.5442 & 57.8100 & 100.4505 & 8050.4127 & 431.1421 & NA & 66.0502 & 129.1300 & 809.4965 & 1.1140 \\
\hline MAC & 4 & hi-sms & NA & 46.3660 & 158.0219 & 29423.7137 & 676.8013 & NA & NA & NA & NA & 1.1140 \\
\hline MAF & 4 & hi-sms & NA & NA & NA & NA & NA & NA & NA & NA & NA & 1.1140 \\
\hline MAR & 4 & Im-mea & 1175.0500 & 26.1511 & 62.7473 & 2129.9490 & 128.6716 & NA & 55.5355 & 112.8040 & 689.1224 & 1.1827 \\
\hline $1 \mathrm{CO}$ & 4 & hi-sms & NA & 63.7337 & 57.4729 & 140840.9510 & 1857.7988 & NA & NA & NA & NA & 1.1140 \\
\hline ADA & 4 & Im-eca & 2390.2850 & 21.1182 & 48.5336 & 899.4220 & 73.2070 & 19.7504 & 10.0604 & 133.6680 & 179.0496 & 1.1915 \\
\hline IDG & 4 & lo-ssa & 2645.3900 & 1.0211 & 14.9435 & 286.2545 & 9.5040 & NA & 3.5036 & 136.9760 & 101.3795 & 1.1468 \\
\hline MDV & 4 & um-sas & 1919.2872 & 16.4412 & 108.3326 & 4128.0826 & 247.1711 & NA & 69.1333 & NA & 373.5210 & 1.9193 \\
\hline MEX & 4 & um-lac & 3316.4452 & 21.1180 & 57.5110 & 8053.2950 & 393.9276 & 2438.8555 & 65.5070 & 134.0280 & 1142.4095 & 1.5009 \\
\hline MHL & 4 & um-eap & NA & 4.3649 & 1.2678 & 2709.7780 & NA & NA & 0.5000 & NA & NA & 1.2235 \\
\hline MKD & 4 & um-eca & 3199.3414 & 37.8360 & 77.2637 & 3138.0613 & NA & 291.4727 & 59.8936 & 109.9620 & 735.2171 & 1.2363 \\
\hline MLI & 4 & lo-ssa & 1277.6256 & 1.0833 & 19.5226 & 469.9405 & 19.3886 & 871.6969 & 18.5629 & 109.8980 & 239.5220 & 1.1468 \\
\hline MLT & 4 & hi-weu & 4407.0754 & 47.4980 & 88.1690 & 15471.9596 & 907.9857 & NA & 98.5220 & 119.5700 & 5246.9168 & 1.2020 \\
\hline MMR & 4 & lo-eap & 3700.5910 & 0.1809 & 0.5720 & NA & NA & NA & 9.0313 & 132.0080 & NA & 1.0360 \\
\hline MNE & 4 & um-eca & 2979.7345 & 30.9600 & 146.8723 & 4226.0255 & NA & NA & 15.1137 & NA & 862.4482 & 1.2363 \\
\hline MNG & 4 & Im-eap & 1091.1634 & 9.6000 & 49.8989 & 1139.3968 & 56.1134 & 315.4817 & 8.7349 & 165.7580 & 638.9546 & 1.2213 \\
\hline MNP & 4 & hi-sms & NA & NA & NA & NA & NA & NA & NA & NA & NA & 1.1140 \\
\hline MOZ & 4 & lo-ssa & 768.5058 & 1.3695 & 15.3592 & 337.2015 & 17.2442 & NA & 4.9651 & 155.3160 & 123.1327 & 1.1468 \\
\hline MRT & 4 & Im-ssa & 740.6568 & 1.4466 & 44.4171 & 619.7906 & 19.5361 & 3072.7764 & NA & NA & 278.9761 & 1.1709 \\
\hline MUS & 4 & um-ssa & 8065.4948 & 19.2824 & 73.3634 & 5576.1608 & 197.5438 & 6002.0782 & 269.7960 & 110.5320 & 457.4129 & 1.7055 \\
\hline MWI & 4 & lo-ssa & 1682.4880 & 0.7091 & 8.6603 & 226.8826 & NA & 355.4678 & 34.9502 & 145.5360 & 78.2157 & 1.1468 \\
\hline MYS & 4 & um-eap & 3533.0134 & 53.5334 & 89.3206 & 5897.7323 & 277.2809 & 1391.9111 & 1700.0683 & 109.7080 & 1499.3134 & 1.2235 \\
\hline NAM & 4 & um-ssa & 483.3214 & 5.0147 & 43.2438 & 3873.1491 & 241.3173 & NA & 1.8198 & 107.4360 & 518.4282 & 1.7055 \\
\hline $\mathrm{NCL}$ & 4 & hi-sms & 3689.5094 & 33.8849 & 73.7044 & NA & NA & NA & 217.7941 & NA & NA & 1.1140 \\
\hline NER & 4 & lo-ssa & 436.3494 & 0.4732 & 8.4372 & 264.7807 & 10.2964 & 44.8594 & 0.3554 & 143.3700 & 71.3783 & 1.1468 \\
\hline
\end{tabular}




\begin{tabular}{|c|c|c|c|c|c|c|c|c|c|c|c|c|}
\hline NGA & 4 & Im-ssa & 491.7226 & 10.3448 & 0.5859 & 878.8494 & NA & 195.1974 & 6.5158 & 125.5500 & 479.4903 & \\
\hline NIC & 4 & Im-lac & 1878.2234 & 4.3744 & 42.2867 & 1211.0896 & NA & NA & 30.8021 & 148.6260 & 457.3945 & 1.2579 \\
\hline NLD & 2 & hi-weu & 8141.8170 & 85.5140 & 113.3351 & 43377.4136 & 2397.0321 & 66.2029 & 299.7943 & 123.6040 & 4900.6642 & .2020 \\
\hline NOR & 4 & hi-weu & 3891.2904 & 86.8240 & 106.7199 & 66481.8259 & 4488.7409 & 993.5359 & 209.6918 & 106.3740 & 4365.7225 & 1.2020 \\
\hline NPL & 4 & lo-sas & 2304.7486 & 1.4156 & 11.0196 & 339.7188 & 12.8892 & 3957.6882 & 6.0775 & 116.5160 & 132.3801 & 1.3062 \\
\hline NZL & 4 & hi-nao & 7373.8088 & 70.6420 & 98.6780 & 27855.2964 & 1690.0037 & NA & 2103.3402 & 123.2500 & 8432.6778 & 1.2896 \\
\hline OMN & 4 & hi-mea & 5808.6620 & 15.6927 & 98.9040 & 13494.9581 & 524.2216 & 39195.5772 & 829.9438 & NA & 735.6438 & 3.8829 \\
\hline PAK & 4 & Im-sas & 2671.5824 & 6.8265 & 35.2084 & 730.1848 & 18.7827 & NA & 180.4718 & 126.7720 & 227.6387 & 1.3706 \\
\hline PAN & 4 & um-lac & 2156.2892 & 24.8047 & 95.9154 & 5312.9680 & 188.5527 & NA & 38.0521 & 122.2040 & 828.7282 & 1.5009 \\
\hline PER & 4 & um-lac & 3662.9616 & 24.9940 & 53.1317 & 3067.3989 & 87.2808 & NA & 85.9855 & 115.3640 & NA & 1.5009 \\
\hline PHL & 4 & Im-eap & 3222.5790 & 6.4656 & 62.3502 & 1280.4871 & 33.0701 & 12613.3788 & 135.6804 & 118.8400 & 291.5918 & 1.2213 \\
\hline PLW & 4 & um-eap & NA & NA & 49.1126 & 9805.7018 & NA & NA & NA & NA & 2453.1887 & 1.2235 \\
\hline PNG & 4 & Im-eap & 4073.5500 & 1.6042 & 8.4009 & 839.9357 & NA & 3.7308 & 76.1402 & NA & NA & 1.2213 \\
\hline POL & 4 & hi-weu & 3155.1096 & 48.8180 & 102.6521 & 8935.2350 & 461.1735 & 90.3119 & 157.0827 & 121.1460 & 596.1944 & 1.2020 \\
\hline PRI & 4 & hi-lac & 1765.1784 & 31.2405 & 63.5654 & 21334.7504 & NA & 1186.4815 & NA & NA & 2539.4910 & 1.4749 \\
\hline PRK & 4 & lo-eap & 3352.7850 & 0.0000 & 0.0568 & NA & NA & 2824.9500 & NA & NA & NA & 1.0360 \\
\hline PRT & 4 & hi-weu & 3091.3554 & 41.4980 & 119.4033 & 19136.7159 & 997.7677 & NA & 166.5668 & 121.2760 & 1045.4333 & 1.2020 \\
\hline PRY & 4 & Im-lac & 2382.1978 & 12.0498 & 68.7454 & 1555.2017 & 55.1828 & NA & 74.1168 & 115.9160 & 682.4695 & 1.2579 \\
\hline PYF & 4 & hi-sms & NA & 30.7420 & 64.5741 & NA & NA & NA & 274.5467 & NA & NA & 1.1140 \\
\hline QAT & 4 & hi-mea & 4519.4484 & 37.6215 & 104.3626 & 56606.7979 & 1387.4318 & 19670.0000 & 1843.7069 & 87.2860 & 3491.5917 & 3.8829 \\
\hline ROU & 4 & um-weu & 2830.2642 & 28.6960 & 90.2935 & 5379.2886 & 214.1763 & 124.5938 & 46.1423 & 128.6720 & 856.8949 & 1.0462 \\
\hline RUS & 4 & hi-eca & 2080.9420 & 22.7480 & 121.2723 & 6045.6428 & 236.5348 & NA & 14.0063 & 134.5320 & 910.7507 & 1.2907 \\
\hline RWA & 4 & lo-ssa & 1272.2224 & 3.7179 & 9.6046 & 308.3419 & 12.7676 & NA & 4.9964 & 127.6700 & 136.7982 & 1.1468 \\
\hline SAU & 4 & hi-mea & 5003.5684 & 27.2329 & 109.7128 & 14282.7320 & 784.7751 & 6151.3201 & 86.5858 & 100.0000 & 2266.8932 & 3.8829 \\
\hline SDN & 4 & Im-ssa & 606.4910 & 4.9760 & 20.4152 & 743.7107 & 18.8698 & NA & 4.2173 & 125.1700 & 374.5647 & 1.1709 \\
\hline SEN & 4 & Im-ssa & 1021.2500 & 8.6397 & 34.0926 & 782.4203 & 40.0993 & NA & 4.5151 & 130.6940 & 181.7729 & 1.1709 \\
\hline SGP & 4 & hi-sms & NA & 65.5800 & 119.4972 & 31380.0327 & 945.0265 & NA & 13491.6390 & NA & NA & 1.1140 \\
\hline SLB & 4 & Im-eap & 2833.9538 & 2.2981 & 4.1233 & 943.9360 & 87.0985 & NA & NA & NA & 360.4947 & 1.2213 \\
\hline SLE & 4 & lo-ssa & 1352.8186 & 0.2386 & 17.7087 & 339.6775 & 9.0027 & 38.3006 & NA & NA & 283.2635 & 1.1468 \\
\hline SLV & 4 & Im-lac & 2736.6116 & 7.6000 & 87.6952 & 2940.6892 & 97.1160 & 2168.7190 & 127.4409 & 124.1480 & 812.3031 & 1.2579 \\
\hline
\end{tabular}




\begin{tabular}{|c|c|c|c|c|c|c|c|c|c|c|c|c|}
\hline SMR & 4 & hi-sms & NA & 51.9126 & 70.0726 & 47895.1058 & NA & NA & NA & NA & NA & 1.1140 \\
\hline SOM & 4 & lo-ssa & 510.4860 & 1.1206 & 6.5325 & NA & NA & 2882.9968 & NA & NA & NA & 1.1468 \\
\hline SRB & 4 & um-eca & 4351.7484 & 32.0700 & 99.4397 & 3888.2115 & 188.5366 & 39.0464 & 132.2820 & 119.7640 & 767.4633 & 1.2363 \\
\hline SSD & 4 & Im-ssa & NA & NA & NA & NA & NA & NA & NA & NA & NA & 1.1709 \\
\hline STP & 4 & Im-ssa & 2167.8444 & 14.8844 & 22.8912 & 876.7453 & 56.7266 & NA & NA & NA & 329.5697 & 1.1709 \\
\hline SUR & 4 & um-lac & 4075.3728 & 16.4865 & 91.7499 & 3821.2092 & NA & 8657.2289 & 229.2163 & 161.4980 & 568.3305 & 1.5009 \\
\hline SVK & 4 & hi-weu & 4311.1362 & 61.8240 & 98.0794 & 13382.5989 & 507.8460 & 15.9206 & 83.1260 & 110.6280 & 996.3249 & 1.2020 \\
\hline SVN & 4 & hi-weu & 5434.3870 & 55.9120 & 95.5653 & 19563.0025 & 1073.1362 & 28.2828 & 301.4842 & 118.6600 & 835.3849 & 1.2020 \\
\hline SWE & 4 & hi-weu & 4854.9362 & 87.1200 & 107.5079 & 44420.8850 & 3038.8539 & 40.3935 & 85.3913 & 132.1400 & 3085.3566 & 1.2020 \\
\hline SWZ & 4 & Im-ssa & 1068.4158 & 5.4567 & 35.3252 & 2410.4303 & 181.2041 & NA & NA & NA & 200.1647 & 1.1709 \\
\hline SXM & 4 & hi-sms & NA & NA & NA & NA & NA & NA & NA & NA & NA & 1.1140 \\
\hline SYC & 4 & um-ssa & NA & 34.7963 & 92.0234 & 12145.8131 & 579.7433 & 899.9530 & 32.2000 & NA & 684.6022 & 1.7055 \\
\hline SYR & 4 & Im-mea & 1588.1048 & 11.2561 & 31.0606 & 1612.4152 & 79.3044 & 3127.9377 & 80.7089 & 115.3500 & 672.2202 & 1.1827 \\
\hline TCA & 4 & hi-sms & NA & NA & NA & NA & NA & NA & NA & NA & NA & 1.1140 \\
\hline TCD & 4 & lo-ssa & 783.1896 & 0.9035 & 9.9503 & 650.7142 & 13.0325 & 153.8193 & NA & NA & 428.1148 & 1.1468 \\
\hline TGO & 4 & lo-ssa & 1154.4458 & 2.2000 & 20.4315 & 385.3510 & 14.1237 & NA & 5.5216 & 118.5120 & 217.7166 & 1.1468 \\
\hline THA & 4 & um-eap & 3015.2684 & 18.1033 & 76.0951 & 2880.8089 & 116.8489 & 3383.0298 & 121.5313 & 129.3140 & 489.5161 & 1.2235 \\
\hline TJK & 4 & lo-eca & 2404.7122 & 6.0237 & 36.2179 & 373.4574 & 13.3862 & 14020.7010 & 64.2548 & 117.2520 & 107.1602 & 2.5377 \\
\hline TKM & 4 & um-eca & 2858.1912 & 1.4846 & 16.1012 & 2081.2979 & NA & 13946.9021 & NA & 115.2500 & 660.0388 & 1.2363 \\
\hline TLS & 4 & lo-sas & 1615.9090 & 0.1411 & 12.1143 & 535.2452 & 52.1723 & 6374.8429 & NA & NA & 190.3624 & 1.3062 \\
\hline TON & 4 & um-eap & NA & 7.2105 & 40.9703 & 2517.9079 & NA & NA & 88.5233 & NA & 541.0541 & 1.2235 \\
\hline TTO & 4 & hi-sms & 1617.8624 & 34.0761 & 115.9650 & 14092.1447 & NA & NA & 462.2880 & 92.8880 & 65.3654 & 1.1140 \\
\hline TUN & 4 & um-mea & 1530.0880 & 20.2683 & 76.2144 & 3514.0186 & 226.1755 & NA & 40.7308 & 118.3840 & 909.3846 & 1.2663 \\
\hline TUR & 4 & um-eca & 2573.8096 & 26.6200 & 82.3924 & 7485.0456 & 214.2919 & 1325.1065 & 89.0952 & 122.3920 & 2081.6684 & 1.2363 \\
\hline TUV & 4 & um-eap & NA & 15.0000 & 14.6204 & 2417.5886 & NA & NA & NA & NA & 1056.7396 & 1.2235 \\
\hline TZA & 4 & lo-ssa & 1259.9740 & 1.6600 & 22.4973 & 401.7862 & 19.2000 & NA & 5.6850 & 122.7620 & 148.6687 & 1.1468 \\
\hline UGA & 4 & lo-ssa & 1743.3824 & 5.1247 & 16.0931 & 351.3224 & 11.4713 & NA & 1.6892 & NA & 86.3995 & 1.1468 \\
\hline UKR & 4 & Im-eca & 2749.8284 & 8.7412 & 105.0761 & 2008.3384 & 129.1426 & 36.5394 & 25.2951 & 145.0020 & 556.2126 & 1.1915 \\
\hline URY & 4 & hi-lac & 4205.3672 & 32.9176 & 84.3579 & 5773.2729 & 161.5503 & NA & 138.3617 & 121.0000 & 7555.5064 & 1.4749 \\
\hline USA & 4 & hi-nao & 6682.3488 & 71.3798 & 80.1016 & 44577.0018 & 2340.7975 & 1186.2092 & 117.7969 & 141.8780 & 2397.7450 & 1.2896 \\
\hline
\end{tabular}




\begin{tabular}{|c|c|c|c|c|c|c|c|c|c|c|c|c|}
\hline UZB & 4 & Im-eca & 4307.7906 & 8.6722 & 27.8884 & 627.2943 & NA & 11575.5627 & 173.8854 & NA & 234.5459 & 1.1915 \\
\hline VCT & 4 & um-lac & 13929.8250 & 17.8397 & 95.3549 & 5481.7655 & 323.5802 & NA & NA & NA & 588.9133 & 1.5009 \\
\hline VEN & 4 & um-lac & 3565.4380 & 21.4375 & 79.5739 & 6064.0417 & 286.7856 & 6305.6574 & 153.8232 & 149.2160 & 1782.0747 & 1.5009 \\
\hline VIR & 4 & hi-sms & NA & 27.3549 & 74.5119 & NA & NA & NA & NA & NA & NA & 1.1140 \\
\hline VNM & 4 & Im-eap & 4859.9656 & 20.2440 & 56.4812 & 779.7635 & 38.1462 & 12302.6438 & 331.7712 & 145.8020 & 199.5049 & 1.2213 \\
\hline VUT & 4 & Im-eap & 550.1034 & 6.5004 & 19.5772 & 2040.8996 & 110.3383 & NA & NA & 119.9980 & 547.6813 & 1.2213 \\
\hline PSE & 4 & ot-sms & 1663.0952 & 22.4358 & 29.2738 & 1322.4362 & NA & 2216.7187 & NA & NA & 305.1272 & 1.4965 \\
\hline WSM & 4 & Im-eap & NA & 4.7207 & 28.5524 & 2660.3684 & 153.6125 & NA & 3.8692 & NA & 393.6236 & 1.2213 \\
\hline YEM & 4 & Im-mea & 919.4120 & 4.8313 & 22.6688 & 847.6158 & 38.6780 & 2510.7738 & 12.0628 & 154.7460 & 119.2986 & 1.1827 \\
\hline ZAF & 4 & um-ssa & 3548.0856 & 8.3182 & 83.5057 & 5765.2691 & 304.0297 & NA & 57.4460 & 147.2580 & 335.6648 & 1.7055 \\
\hline COD & 4 & ot-ssa & 771.6330 & 0.3808 & 11.4170 & 233.1897 & NA & 10.6889 & 0.5790 & NA & 79.2739 & 0.9722 \\
\hline ZMB & 4 & Im-ssa & 2042.7150 & 4.7483 & 21.3921 & 806.1628 & 13.1268 & NA & 30.0859 & 132.7880 & 153.4087 & 1.1709 \\
\hline ZWE & 4 & lo-ssa & 565.1326 & 10.2836 & 13.0586 & 403.3489 & NA & NA & 26.3926 & 392.9200 & 94.6210 & 1.1468 \\
\hline ABW & 5 & hi-sms & NA & 70.9750 & 132.1529 & NA & NA & NA & NA & NA & NA & 1.5191 \\
\hline AND & 5 & ot-sms & NA & 85.6086 & 82.4518 & NA & NA & NA & NA & NA & NA & 1.4023 \\
\hline AFG & 5 & lo-sas & 1937.3008 & 5.0886 & 60.5545 & 391.5540 & NA & 2567.0820 & 5.0621 & 62.1600 & 112.9111 & 1.5014 \\
\hline AGO & 5 & um-ssa & 664.6575 & 15.2033 & 57.8017 & 2638.0220 & 91.7819 & 33.5875 & 8.7758 & NA & 397.2738 & 1.3187 \\
\hline ALB & 5 & um-eca & 4750.5750 & 52.1890 & 102.6509 & 3812.2261 & NA & 831.6364 & 89.8507 & 140.4967 & 1622.6292 & 1.2585 \\
\hline ARE & 5 & hi-mea & 73270.1450 & 79.7500 & 145.5856 & 24352.4515 & NA & 67043.3846 & 679.3609 & NA & 1254.8778 & 7.0787 \\
\hline ARG & 5 & um-lac & 4636.1748 & 52.9250 & 152.3915 & NA & 380.2881 & 731.4524 & 41.7955 & 279.8767 & 4783.7139 & 1.8243 \\
\hline ARM & 5 & Im-eca & 2641.6063 & 35.6150 & 115.7759 & 2158.6088 & 64.3230 & 2606.1457 & 28.4253 & 147.0700 & 1029.8948 & 1.3129 \\
\hline ASM & 5 & um-eap & NA & NA & NA & NA & NA & NA & NA & NA & NA & 1.2843 \\
\hline ATG & 5 & hi-sms & 2018.7500 & 55.6000 & 165.5792 & 11491.6380 & NA & 325.0800 & 3.5833 & NA & 260.6278 & 1.5191 \\
\hline AUS & 5 & hi-nao & 2011.1278 & 79.3719 & 104.3665 & 36847.1982 & 1968.4054 & 363.8536 & 45.4314 & 118.0733 & 9037.0743 & 1.3794 \\
\hline AUT & 5 & hi-weu & 6496.5758 & 78.6397 & 154.2223 & 40968.5456 & 2398.9714 & 73.4085 & 104.9919 & 190.3867 & 1507.7036 & 1.2405 \\
\hline AZE & 5 & um-eca & 2464.7523 & 52.2250 & 106.6033 & 3145.5814 & 82.0582 & 5347.2731 & 14.4999 & 202.7833 & 345.5402 & 1.2585 \\
\hline BDI & 5 & lo-ssa & 1221.3273 & 1.1575 & 21.5050 & 152.7818 & 9.4820 & 226.5208 & 4.9872 & 128.5533 & 55.4987 & 1.3037 \\
\hline BEL & 5 & hi-weu & 9058.9750 & 79.8750 & 111.7125 & 37736.8591 & 2476.3556 & 45.0458 & 286.7060 & 178.8733 & 13654.7771 & 1.2405 \\
\hline BEN & 5 & lo-ssa & 1371.9138 & 4.1696 & 82.6772 & 563.1214 & 30.1199 & 22.6320 & 11.2824 & NA & 319.1022 & 1.3037 \\
\hline BFA & 5 & lo-ssa & 1104.3418 & 3.3813 & 52.9354 & 489.9898 & 17.8342 & 71.3046 & 10.3762 & 149.9533 & 122.2872 & 1.3037 \\
\hline
\end{tabular}




\begin{tabular}{|c|c|c|c|c|c|c|c|c|c|c|c|c|}
\hline BGD & 5 & lo-sas & 347.0355 & 5.2375 & 59.3470 & 578.2285 & NA & 4100.9852 & 254.3066 & 180.8167 & 150.2099 & 1.5014 \\
\hline BGR & 5 & um-eca & 4094.8868 & 49.7929 & 143.5510 & 4694.4993 & 185.8274 & 306.5148 & 117.3087 & 173.0767 & 848.5083 & 1.2585 \\
\hline BHR & 5 & hi-mea & NA & 77.5000 & 145.8236 & 16887.3259 & 452.5699 & 10545.8056 & 1220.2083 & NA & NA & .0787 \\
\hline BHS & 5 & hi-sms & 7387.6728 & 62.9371 & 89.2744 & 20949.5154 & NA & NA & NA & NA & 2135.1814 & 1.5191 \\
\hline $\mathrm{BIH}$ & 5 & um-eca & 3651.3335 & 61.3140 & 85.5352 & 3347.3223 & NA & NA & 93.7464 & 139.3800 & NA & 1.2585 \\
\hline BLR & 5 & um-eca & 3139.1263 & 43.1322 & 113.5857 & 4773.0481 & 244.6106 & 151.9058 & 280.6943 & 431.5833 & 1458.8354 & 1.2585 \\
\hline BLZ & 5 & um-lac & 3255.1770 & 22.3500 & 59.7671 & 4107.6382 & 271.6659 & 899.9632 & 101.4284 & 112.7233 & 757.4621 & 1.8243 \\
\hline $\mathrm{MU}$ & 5 & hi-sms & NA & 89.7863 & 139.8836 & 73825.9835 & 1950.7376 & NA & NA & NA & NA & 1.5191 \\
\hline BOL & 5 & Im-lac & 2075.9375 & 31.8500 & 84.9342 & 1244.4148 & 86.8864 & 484.9089 & 9.0894 & 119.3233 & 378.7223 & 1.3754 \\
\hline BRA & 5 & um-lac & 4372.3193 & 46.6250 & 120.0476 & 5723.2268 & 333.2599 & 626.9036 & 173.6475 & 128.6733 & 1788.2401 & 1.8243 \\
\hline BRB & 5 & hi-sms & 3166.6665 & 72.0489 & 119.9346 & 14384.5325 & 824.8271 & 4835.5235 & 134.9672 & NA & 277.7739 & 1.5191 \\
\hline BRN & 5 & hi-sms & 876.9355 & 58.4433 & 110.9500 & 24695.4706 & 797.6651 & 1590.0360 & 254.5833 & 106.3900 & 881.3902 & 1.5191 \\
\hline BTN & 5 & Im-sas & 2789.1423 & 22.4825 & 67.2968 & 1911.8532 & 90.2622 & 3277.1254 & 12.8100 & 129.2933 & 434.3008 & 1.4950 \\
\hline BWA & 5 & um-ssa & 354.5865 & 10.1250 & 145.1052 & 6588.3632 & NA & 298.9001 & 55.5972 & 261.5567 & 294.2367 & 1.3187 \\
\hline CAF & 5 & lo-ssa & 1592.3255 & 2.6750 & 24.9026 & 402.5190 & 4.8833 & 0.2222 & NA & NA & 379.7671 & 1.3037 \\
\hline CAN & 5 & hi-nao & 3700.4335 & 83.0250 & 78.4200 & 37056.8098 & 1972.3413 & NA & 74.1254 & 174.0333 & NA & 1.3794 \\
\hline CHE & 5 & hi-weu & 6200.7560 & 85.2483 & 129.8444 & 58560.3610 & 3078.7380 & 123.6442 & 213.4073 & 89.8967 & 1762.5161 & 1.2405 \\
\hline $\mathrm{CHL}$ & 5 & hi-lac & 6721.5003 & 56.2919 & 129.0121 & 9199.6834 & 392.7000 & 22487.5582 & 431.2770 & 145.7167 & 3166.1277 & 1.5817 \\
\hline $\mathrm{CHN}$ & 5 & um-eap & 5742.5353 & 40.1750 & 76.1782 & 3229.9858 & NA & 3265.7627 & 595.2981 & 112.5633 & 553.6081 & 1.2843 \\
\hline CIV & 5 & Im-ssa & 2510.6923 & 2.3197 & 89.5815 & 1010.2281 & NA & 205.2692 & 25.7032 & 161.6700 & NA & 1.2545 \\
\hline CMR & 5 & Im-ssa & 1649.7523 & 5.3497 & 55.5602 & 955.3190 & 30.6848 & 118.8672 & 10.1320 & 117.3267 & 405.6319 & 1.2545 \\
\hline COG & 5 & Im-ssa & 832.7563 & 5.8267 & 96.4770 & 1934.0323 & 120.3474 & 7.8435 & 5.4697 & 143.7467 & 240.0342 & 1.2545 \\
\hline $\mathrm{COL}$ & 5 & um-lac & 3350.5153 & 44.3827 & 100.2096 & 4181.1875 & 194.4668 & 3520.6261 & 691.4808 & 153.6400 & 1070.6362 & 1.8243 \\
\hline COM & 5 & lo-ssa & 1415.5530 & 5.7688 & 35.4760 & 606.2777 & NA & 55.9524 & NA & NA & 357.2239 & 1.3037 \\
\hline CPV & 5 & Im-ssa & 194.1028 & 33.5600 & 85.8038 & 2718.6653 & 144.2508 & 425.5362 & NA & 236.9400 & NA & 1.2545 \\
\hline CRI & 5 & um-lac & 3368.3288 & 42.2930 & 103.1363 & 5608.9900 & 385.3385 & 5356.1074 & 629.4741 & 233.1800 & 1576.9014 & 1.8243 \\
\hline CUB & 5 & um-lac & 2572.6025 & 20.8170 & 13.2972 & 4981.7175 & 639.8155 & 721.0579 & 38.9270 & 391.1067 & 906.9134 & 1.8243 \\
\hline CUW & 5 & hi-sms & NA & NA & 133.6027 & NA & NA & NA & NA & NA & NA & 1.5191 \\
\hline CYM & 5 & -sms & NA & 70.9231 & 172.9002 & NA & NA & NA & NA & NA & NA & 1.5191 \\
\hline CYP & 5 & hi-weu & 1783.5415 & 58.9986 & 96.5406 & 22030.4706 & 1213.9873 & 1853.0816 & 185.0675 & 105.1533 & NA & 1.2405 \\
\hline
\end{tabular}




\begin{tabular}{|c|c|c|c|c|c|c|c|c|c|c|c|c|}
\hline CZE & 5 & hi-weu & 4974.2823 & 71.7126 & 125.3067 & 14735.1944 & 645.0781 & 9.4830 & 100.7518 & 130.0533 & 803.3026 & 1.2405 \\
\hline DEU & 5 & hi-weu & 6864.9138 & 82.3953 & 112.1646 & 38523.5253 & 1937.5961 & 6.8352 & 200.6685 & 171.8400 & 970.7225 & 1.2405 \\
\hline DJI & 5 & Im-mea & 1861.1110 & 7.8168 & 23.8350 & 1134.8288 & 50.9824 & 1500.0500 & NA & NA & NA & 1.2169 \\
\hline MA & 5 & um-lac & 1537.5003 & 53.2351 & 145.8310 & 6120.8829 & NA & NA & 67.9444 & NA & 2029.1088 & 1.8243 \\
\hline DNK & 5 & hi-weu & 6095.7915 & 91.3549 & 125.4323 & 47701.0599 & 4186.3060 & 97.3001 & 112.9974 & 160.7133 & 4155.9756 & 1.2405 \\
\hline DOM & 5 & um-lac & 4534.6163 & 39.1250 & 87.6453 & 4716.5234 & 178.1616 & 4935.9619 & 94.7658 & 134.6033 & 1261.7737 & 1.8243 \\
\hline DZA & 5 & um-mea & 1583.6855 & 14.5570 & 95.2670 & 3193.6403 & NA & 465.7406 & 19.5452 & 217.6167 & 942.2661 & 1.5149 \\
\hline ECU & 5 & um-lac & 3129.3453 & 33.9714 & 104.1961 & 3507.7604 & 152.2742 & 6942.3158 & 258.2256 & 129.5133 & 838.9188 & 1.8243 \\
\hline EGY & 5 & Im-mea & 7068.2085 & 41.2025 & 109.2517 & 1556.8826 & NA & 20717.8532 & 593.6574 & 195.6767 & 338.6838 & 1.2169 \\
\hline ERI & 5 & lo-ssa & 581.1035 & 0.7525 & 4.4719 & 193.6712 & NA & 797.0870 & 0.8585 & 202.7300 & NA & 1.3037 \\
\hline ESP & 5 & hi-weu & 3520.6720 & 68.6955 & 109.8975 & 25664.4715 & 1278.1348 & 1573.8313 & 125.8510 & 147.8533 & 3446.1305 & 1.2405 \\
\hline EST & 5 & hi-weu & 2884.8973 & 77.2486 & 147.8201 & 11374.8738 & 615.0714 & 12.6439 & 73.6524 & 176.0100 & 1554.3309 & 1.2405 \\
\hline ETH & 5 & lo-ssa & 2014.4805 & 1.3082 & 18.3254 & 266.3967 & 12.6497 & 355.9558 & 22.1413 & 284.1100 & 111.7718 & 1.3037 \\
\hline FIN & 5 & hi-weu & 3471.0048 & 89.2486 & 166.5225 & 39766.6987 & 2705.6818 & 22.2188 & 154.5334 & 156.5667 & 6160.0992 & 1.2405 \\
\hline FJI & 5 & um-eap & 2509.5865 & 29.7106 & 92.1607 & 3713.5491 & 155.8645 & 299.8824 & 35.5394 & 143.2367 & 839.8646 & 1.2843 \\
\hline FRA & 5 & hi-weu & 6985.2395 & 79.6149 & 95.3343 & 35594.7612 & 2053.8699 & 213.9196 & 142.9139 & 187.4533 & 2785.0098 & 1.2405 \\
\hline FRO & 5 & hi-sms & NA & 82.8168 & 119.3010 & NA & NA & NA & NA & NA & NA & 1.5191 \\
\hline FSM & 5 & Im-eap & 1639.2198 & 24.1436 & 28.4371 & 2398.4410 & NA & NA & 0.0000 & NA & 742.1445 & 1.3612 \\
\hline GAB & 5 & um-ssa & 1690.1740 & 8.2617 & 161.5927 & 6594.2050 & NA & 123.9916 & 10.1508 & NA & 2039.5826 & 1.3187 \\
\hline GBR & 5 & hi-weu & 6695.1820 & 86.9260 & 124.1503 & 39824.7795 & 2441.4731 & 218.7617 & 241.6705 & NA & 1147.3453 & 1.2405 \\
\hline GEO & 5 & Im-eca & 1964.5108 & 34.6150 & 103.6913 & 2017.5831 & 47.2148 & 2592.5956 & 30.9302 & 124.3300 & 413.7226 & 1.3129 \\
\hline GHA & 5 & Im-ssa & 1716.3323 & 11.6275 & 91.5815 & 698.9244 & 47.9093 & 137.7566 & 22.3476 & 208.6267 & NA & 1.2545 \\
\hline GIN & 5 & lo-ssa & 1503.8505 & 1.3475 & 48.1025 & 305.0584 & 9.3841 & 101.0059 & 2.8158 & 160.3733 & 114.0776 & 1.3037 \\
\hline GMB & 5 & lo-ssa & 965.9418 & 11.6299 & 88.4760 & 448.1739 & 18.1661 & 87.7512 & 8.0115 & 92.2067 & 247.3587 & 1.3037 \\
\hline GNB & 5 & lo-ssa & 1449.1680 & 2.7790 & 56.2398 & 443.2362 & NA & 480.0250 & NA & 126.6800 & 337.5677 & 1.3037 \\
\hline GNQ & 5 & hi-sms & NA & 11.9608 & 64.9407 & 12928.4629 & NA & 7.8946 & NA & NA & NA & 1.5191 \\
\hline GRC & 5 & hi-weu & 4571.9343 & 52.7466 & 114.1603 & 19718.4979 & NA & 3365.0940 & 114.8277 & 146.9867 & 3226.2519 & 1.2405 \\
\hline GRD & 5 & um-lac & 980.3833 & 31.0000 & 120.0673 & 6348.9919 & NA & NA & NA & NA & 477.7386 & 1.8243 \\
\hline GRL & 5 & hi-sms & NA & 64.4240 & 103.9611 & NA & NA & NA & NA & NA & NA & 1.5191 \\
\hline GTM & 5 & Im-lac & 2008.5003 & 14.6250 & 134.1620 & 2307.9794 & 66.5256 & 1247.9296 & 158.6960 & NA & 545.6701 & 1.3754 \\
\hline
\end{tabular}




\begin{tabular}{|c|c|c|c|c|c|c|c|c|c|c|c|c|}
\hline UM & 5 & hi-sms & 2438.5965 & 59.6685 & NA & NA & NA & NA & NA & NA & NA & 1.5191 \\
\hline GUY & 5 & Im-lac & 4471.0763 & 31.7250 & 69.0836 & 1251.7713 & 43.6014 & 3245.4012 & 30.8794 & NA & 468.7899 & 1.3754 \\
\hline HKG & & hi-sms & NA & 72.8250 & 219.4424 & 32549.9040 & 1155.6083 & NA & 901.3180 & NA & NA & .5191 \\
\hline HND & 5 & Im-lac & 1661.0160 & 15.7275 & 104.2950 & 1550.7226 & NA & 1154.8343 & 83.9794 & 191.0067 & 416.8943 & 1.3754 \\
\hline HRV & 5 & hi-weu & 5181.4070 & 60.7569 & 115.4582 & 10634.0998 & 452.6832 & 9.5394 & 308.6658 & 162.5233 & 953.8382 & 1.2405 \\
\hline HTI & 5 & Io-lac & 972.5778 & 9.4425 & 52.8971 & 455.7160 & NA & 930.0000 & NA & NA & NA & 1.0069 \\
\hline HUN & 5 & um-eca & 4575.5860 & 69.0610 & 117.3462 & 11279.0572 & 541.8956 & 69.4021 & 91.5854 & 203.7767 & 1084.7315 & 1.2585 \\
\hline IDN & 5 & Im-eap & 4982.8088 & 13.1375 & 107.4573 & 1690.8004 & 55.5138 & 3941.5882 & 191.5804 & 310.7933 & 396.8101 & 1.3612 \\
\hline IMN & 5 & ot-sms & NA & NA & NA & NA & NA & NA & NA & NA & NA & 1.4023 \\
\hline IND & 5 & Im-sas & 2880.0745 & 11.3125 & 69.0734 & 1108.5744 & 40.5467 & 4381.7354 & 173.5684 & 172.0833 & 217.5848 & 1.4950 \\
\hline IRL & 5 & hi-weu & 7610.6755 & 74.9769 & 105.9209 & 47126.2431 & 2959.7526 & 73.0805 & 426.5476 & 169.6800 & 583.9232 & 1.2405 \\
\hline IRN & 5 & um-mea & 2317.1170 & 23.6500 & 76.8093 & 3268.6695 & 127.4696 & 4903.0238 & 35.1750 & 199.3667 & NA & 1.5149 \\
\hline IRQ & 5 & um-mea & 2002.9010 & 5.9500 & 83.2564 & 2361.3628 & NA & 13652.2447 & 46.7356 & 227.9033 & 274.5616 & 1.5149 \\
\hline ISL & 5 & hi-weu & NA & 95.2416 & 107.5625 & 57556.1953 & 4305.6787 & 571.8382 & 161.4499 & NA & 38640.0473 & 1.2405 \\
\hline ISR & 5 & hi-mea & 3509.4933 & 69.4935 & 122.0735 & 23833.9954 & 1338.5047 & 3766.3334 & 305.2214 & 185.7167 & NA & 7.0787 \\
\hline ITA & 5 & hi-weu & 5399.7103 & 55.5898 & 157.8470 & 30262.0188 & 1330.5810 & 2865.0232 & 135.9673 & 152.7900 & 1995.4758 & 1.2405 \\
\hline JAM & 5 & m-lac & 1274.8873 & 34.1747 & 105.8200 & NA & NA & 5800.0000 & 72.7694 & 269.7000 & 589.4005 & 1.8243 \\
\hline JOR & 5 & um-mea & 1502.0905 & 36.8250 & 120.9241 & 2834.9185 & NA & 3230.4896 & 891.9242 & 166.9500 & 472.5203 & 1.5149 \\
\hline JPN & 5 & hi-eap & 6026.4278 & 82.4410 & 107.4052 & 36746.3265 & 1397.4609 & 13341.1638 & 262.4298 & 88.8933 & 5230.1198 & 1.1065 \\
\hline KAZ & 5 & um-eca & 1104.7140 & 47.3789 & 162.2945 & 5091.5155 & NA & 595.6192 & 1.7211 & 192.7167 & 568.7463 & 1.2585 \\
\hline KEN & 5 & lo-ssa & 1652.0860 & 28.2750 & 67.6970 & 608.9557 & 40.4620 & 391.2698 & 39.9331 & 168.4567 & 160.5998 & 1.3037 \\
\hline KGZ & 5 & Im-eca & 2620.9415 & 20.8800 & 115.1743 & 587.5385 & 37.0668 & 5835.3833 & 21.7649 & 206.0067 & 190.8346 & 1.3129 \\
\hline KHM & 5 & lo-eap & 3082.9828 & 3.8250 & 103.3366 & 655.8053 & 17.0960 & 508.9983 & 14.5262 & 189.5700 & 220.8921 & 1.1098 \\
\hline KIR & 5 & Im-eap & NA & 10.3292 & 14.3041 & 1153.5712 & NA & NA & NA & NA & NA & 1.3612 \\
\hline KNA & 5 & hi-sms & NA & 78.2372 & 145.5244 & 10740.5024 & NA & NA & 10.7111 & NA & 170.5475 & 1.5191 \\
\hline KOR & 5 & hi-eap & 6624.0830 & 84.0756 & 108.2372 & 23078.8304 & 1122.7599 & 10483.3060 & 383.9920 & 104.2300 & 3134.8618 & 1.1065 \\
\hline KWT & 5 & hi-sms & 8631.2575 & 68.2698 & 159.5267 & 30082.2511 & NA & 46119.4538 & 730.9698 & NA & NA & 1.5191 \\
\hline LAO & 5 & Im-eap & 4026.6288 & 9.8119 & 69.8696 & 688.4538 & 19.1238 & 2253.8480 & NA & 170.8867 & 275.4269 & 1.3612 \\
\hline LBN & 5 & m-mea & 3165.0628 & 56.8574 & 76.1318 & 7181.6573 & 144.3660 & 5403.9769 & 332.9304 & 128.5833 & 1562.4692 & 1.5149 \\
\hline LBR & 5 & lo-ssa & 1139.9710 & 3.4235 & 51.3561 & 268.6534 & 7.5959 & 26.3581 & NA & NA & 300.1235 & 1.3037 \\
\hline
\end{tabular}




\begin{tabular}{|c|c|c|c|c|c|c|c|c|c|c|c|c|}
\hline LBY & 5 & um-mea & 763.6565 & 14.8333 & 166.2767 & 6391.2714 & NA & 2059.8224 & 29.3579 & NA & NA & .5149 \\
\hline LCA & 5 & um-lac & NA & 39.5800 & 117.0623 & 5772.7885 & 246.4639 & NA & 142.1111 & NA & 177.3183 & 1.8243 \\
\hline LIE & 5 & hi-sms & NA & 87.0519 & 100.5948 & NA & NA & NA & NA & NA & NA & 1.5191 \\
\hline LKA & 5 & Im-sas & 3792.7525 & 16.7964 & 89.5748 & 1805.5387 & 34.1989 & 9296.3260 & 229.2147 & 194.8200 & 235.0023 & 1.4950 \\
\hline LSO & 5 & Im-ssa & 655.6810 & 4.4186 & 67.8691 & 916.4579 & NA & 12.5099 & NA & NA & 84.0454 & 1.2545 \\
\hline LTU & 5 & hi-weu & 3373.0065 & 65.3607 & 159.5045 & 9785.4431 & 514.7611 & 37.4194 & 90.9339 & 177.0100 & 1172.9330 & 1.2405 \\
\hline LUX & 5 & hi-weu & 5569.1623 & 91.5941 & 146.3240 & 80676.8120 & NA & 3.2185 & 308.4007 & 172.4700 & 1925.5119 & 1.2405 \\
\hline LVA & 5 & hi-sms & 3177.1870 & 71.6311 & 159.6063 & 8152.1055 & 405.7288 & 45.3141 & 83.6635 & 189.5733 & 929.1289 & 1.5191 \\
\hline MAC & 5 & hi-sms & NA & 60.6279 & 262.8727 & 46970.7783 & 1356.1231 & NA & NA & NA & NA & 1.5191 \\
\hline MAF & 5 & hi-sms & NA & NA & NA & NA & NA & NA & NA & NA & NA & 1.5191 \\
\hline MAR & 5 & Im-mea & 1501.7295 & 52.3809 & 115.8978 & 2443.4370 & 158.7822 & 1386.6003 & 38.1144 & 115.3967 & 898.9316 & 1.2169 \\
\hline $1 \mathrm{CO}$ & 5 & hi-sms & NA & 83.2500 & 82.7347 & NA & NA & NA & NA & NA & NA & 1.5191 \\
\hline ADA & 5 & Im-eca & 2452.6568 & 40.6175 & 92.5483 & 1053.0227 & 91.3333 & 19.8622 & 14.4120 & 204.6300 & 171.9672 & 1.3129 \\
\hline IDG & 5 & lo-ssa & 2648.4885 & 1.9637 & 38.2278 & 272.1935 & 7.5318 & 4608.6857 & 2.5242 & 158.1033 & 98.4731 & 1.3037 \\
\hline MDV & 5 & um-sas & 2504.7343 & 35.8900 & 164.5987 & 4825.7542 & 313.3910 & 0000 & 114.4444 & NA & 349.7787 & 2.5047 \\
\hline MEX & 5 & um-lac & 3395.0123 & 37.8591 & 81.4866 & 8360.9164 & 432.3047 & 2498.9343 & 79.8427 & 208.1367 & 1187.8472 & 1.8243 \\
\hline MHL & 5 & um-eap & NA & 9.1900 & NA & 2925.9275 & NA & NA & NA & NA & NA & 1.2843 \\
\hline MKD & 5 & um-eca & 3263.0895 & 56.8125 & 104.9938 & 3483.8355 & NA & 304.4271 & 62.6063 & 142.2533 & 788.7292 & 1.2585 \\
\hline MLI & 5 & lo-ssa & 1451.6013 & 2.0922 & 88.9275 & 487.9058 & 22.2226 & 761.9006 & 22.5509 & 169.5867 & 281.0911 & 1.3037 \\
\hline MLT & 5 & hi-weu & 5096.7565 & 67.0334 & 120.9526 & 16426.0924 & 1221.8055 & 2111.0833 & 102.4056 & 121.7433 & 5279.3198 & 1.2405 \\
\hline MMR & 5 & lo-eap & 3615.9675 & 0.8748 & 5.8530 & NA & NA & 2736.6546 & 12.5237 & 154.9367 & NA & 1.1098 \\
\hline MNE & 5 & um-eca & 3212.8735 & 46.6876 & 173.7337 & 4602.7048 & NA & 9.8879 & 13.1055 & NA & 957.5809 & 1.2585 \\
\hline MNG & 5 & Im-eap & 1439.2380 & 14.2000 & 111.0630 & 1543.3971 & 84.0007 & 387.1987 & 22.0017 & 320.8600 & 732.7394 & 1.3612 \\
\hline MNP & 5 & hi-sms & NA & NA & NA & NA & NA & NA & NA & NA & NA & 1.5191 \\
\hline MOZ & 5 & lo-ssa & 873.8258 & 4.6798 & 36.2596 & 404.9264 & NA & 128.9775 & 7.1832 & 316.8800 & 141.9550 & 1.3037 \\
\hline MRT & 5 & Im-ssa & 1327.8285 & 5.0173 & 93.7504 & 644.9254 & 26.6157 & 2822.2269 & NA & NA & 312.0428 & 1.2545 \\
\hline MUS & 5 & um-ssa & 4337.2500 & 34.4250 & 111.1669 & 6577.3131 & 233.9485 & 6294.4872 & 210.2050 & 117.7600 & 486.3245 & 1.3187 \\
\hline MWI & 5 & lo-ssa & 2039.2608 & 3.8352 & 26.9679 & 260.7017 & 12.6595 & 319.4341 & 34.9285 & 219.9200 & 86.5126 & 1.3037 \\
\hline MYS & 5 & um-eap & 3798.9953 & 62.5175 & 133.3092 & 6660.5177 & 368.4988 & 1646.6908 & 1943.4462 & 120.7700 & 1768.4147 & 1.2843 \\
\hline NAM & 5 & um-ssa & 422.3403 & 12.6104 & 100.4762 & 4358.8635 & 370.5641 & 251.2440 & 5.7171 & 207.4933 & 500.4077 & 1.3187 \\
\hline
\end{tabular}




\begin{tabular}{|c|c|c|c|c|c|c|c|c|c|c|c|c|}
\hline $\mathrm{NCL}$ & 5 & hi-sms & 3334.9298 & 54.0000 & 91.4091 & NA & NA & NA & 174.5964 & NA & NA & 1.5191 \\
\hline NER & 5 & lo-ssa & 452.6343 & 1.3094 & 30.6368 & 281.9870 & 11.6441 & 43.0180 & 0.7689 & 199.7000 & NA & 1.3037 \\
\hline NGA & 5 & Im-ssa & 1451.1650 & 30.8075 & 63.1779 & 1024.3749 & NA & 197.5689 & 5.1469 & 210.6267 & 577.1742 & 1.2545 \\
\hline NIC & 5 & Im-lac & 2043.8498 & 12.4000 & 89.8453 & 1301.3949 & 57.2211 & 670.7632 & 46.6639 & 218.5867 & 492.7768 & 1.3754 \\
\hline NLD & 5 & hi-weu & 8391.9128 & 92.2391 & 116.5265 & 43524.2289 & 2591.8343 & 68.4380 & 283.4182 & 172.2967 & 6494.5122 & 2405 \\
\hline NOR & 5 & hi-weu & 3573.4710 & 94.1458 & 115.6620 & 65014.8194 & 4364.2353 & 1032.8773 & 183.5508 & 124.2467 & 5238.5290 & 1.2405 \\
\hline NPL & 5 & lo-sas & 2512.5780 & 10.3448 & 55.1826 & 392.2328 & 18.5093 & 4095.0597 & 29.3840 & 184.9133 & 147.7061 & 1.5014 \\
\hline NZL & 5 & hi-nao & 7618.0850 & 81.6175 & 108.2911 & 28577.4488 & 2056.4180 & 6838.3216 & 1512.3497 & 150.6967 & 8135.3968 & 1.3794 \\
\hline OMN & 5 & hi-mea & 10766.5575 & 52.5695 & 159.3087 & 13889.1586 & NA & 35792.4883 & 579.0815 & NA & NA & 7.0787 \\
\hline PAK & 5 & Im-sas & 2675.1593 & 9.4650 & 64.0727 & 765.4587 & 17.4818 & 8282.1393 & 183.5828 & 252.4767 & 239.9305 & 1.4950 \\
\hline PAN & 5 & um-lac & 2404.7125 & 41.5005 & 171.7921 & 6959.7931 & 229.5781 & 828.5084 & 67.4157 & 184.0967 & 713.5560 & 1.8243 \\
\hline PER & 5 & um-lac & 4011.3838 & 37.0450 & 101.2976 & 3845.2380 & 112.8382 & 3175.6816 & 98.3739 & 149.7667 & NA & 1.8243 \\
\hline PHL & 5 & Im-eap & 3399.2328 & 31.8088 & 99.5071 & 1478.9854 & 50.4779 & 12309.5971 & 131.6785 & 150.3767 & 246.5383 & 1.3612 \\
\hline PLW & 5 & m-eap & NA & NA & 78.5687 & 9309.0356 & NA & NA & NA & NA & 2429.4912 & 1.2843 \\
\hline PNG & 5 & Im-eap & 4658.0455 & 3.3200 & 35.2076 & 1045.2088 & NA & 3.3329 & 99.6967 & NA & NA & 1.3612 \\
\hline POL & 5 & hi-weu & 3584.3495 & 62.3573 & 136.2085 & 10461.9879 & 529.0756 & 105.5435 & 187.3342 & 176.5967 & 592.6125 & 1.2405 \\
\hline PRI & 5 & hi-lac & 1840.9935 & 59.0500 & 82.3171 & 19866.0496 & NA & 1229.3029 & NA & NA & 3966.2006 & 1.5817 \\
\hline PRK & 5 & lo-eap & 3740.5635 & 0.0000 & 5.6021 & NA & NA & 027 & NA & NA & NA & 1.1098 \\
\hline PRT & 5 & hi-weu & 3906.7743 & 57.7464 & 114.2796 & 18683.7275 & 1017.9802 & 5577.4812 & 151.2018 & 148.4000 & 1113.6257 & 1.2405 \\
\hline PRY & 5 & Im-lac & 3414.4130 & 27.7009 & 99.0670 & 1785.6131 & 78.0311 & 466.1181 & 87.7807 & 150.1933 & 839.6048 & 1.3754 \\
\hline PYF & 5 & hi-sms & NA & 51.9192 & 82.7280 & NA & NA & NA & 284.0000 & NA & NA & 1.5191 \\
\hline QAT & 5 & hi-mea & 6412.4448 & 73.1500 & 131.2349 & 59505.2571 & NA & 19171.0537 & 9763.4432 & 82.5667 & 5057.4452 & 7.0787 \\
\hline ROU & 5 & um-weu & 3387.0463 & 43.8961 & 107.3469 & 5833.9036 & 192.4695 & 130.4038 & 52.1540 & 193.6333 & 875.5529 & 1.2520 \\
\hline RUS & 5 & hi-eca & 2050.0993 & 54.3000 & 151.4281 & 6697.3954 & NA & 109.6217 & 16.0542 & 177.5367 & 922.1923 & 1.2716 \\
\hline RWA & 5 & lo-ssa & 2094.4013 & 7.9310 & 44.7780 & 380.6036 & 18.7323 & 84.4891 & 1.4037 & 177.4967 & 160.9857 & 1.3037 \\
\hline SAU & 5 & hi-mea & 4923.8685 & 50.7500 & 188.8113 & 17202.9803 & NA & 6661.9190 & 198.9755 & 114.9933 & 2294.1979 & 7.0787 \\
\hline SDN & 5 & Im-ssa & 519.3265 & 19.4260 & 64.3835 & 806.5952 & NA & 1364.6317 & 10.2535 & 217.7000 & 393.7493 & 1.2545 \\
\hline SEN & 5 & Im-ssa & 1163.1728 & 18.4009 & 77.7711 & 796.9270 & 44.6260 & 560.6568 & 7.9267 & 148.2933 & 189.7343 & 1.2545 \\
\hline SGP & 5 & hi-sms & NA & 71.7500 & 150.8898 & 35967.2895 & 1101.8692 & 12000.0000 & 3626.2897 & NA & NA & 1.5191 \\
\hline SLB & 5 & Im-eap & 3243.1818 & 6.4994 & 46.3945 & 1071.1953 & 105.6545 & NA & NA & NA & NA & 1.3612 \\
\hline
\end{tabular}




\begin{tabular}{|c|c|c|c|c|c|c|c|c|c|c|c|c|}
\hline SLE & 5 & lo-ssa & 1707.2365 & 1.1200 & 43.4569 & 390.0035 & 10.6036 & 34.8734 & NA & NA & 331.2155 & .3037 \\
\hline SLV & 5 & Im-lac & 2678.2993 & 19.5577 & 132.5728 & 3010.5825 & 103.9384 & 2112.2265 & 180.0086 & 157.5300 & 901.0261 & 1.3754 \\
\hline SMR & 5 & hi-sms & NA & 50.4275 & 111.3761 & NA & NA & NA & NA & NA & NA & 1.5191 \\
\hline SOM & 5 & lo-ssa & 796.6000 & 1.3756 & 24.2091 & NA & NA & 2982.5913 & NA & NA & NA & 1.3037 \\
\hline SRB & 5 & um-eca & 4402.5730 & 45.6750 & 123.1788 & 4195.6462 & 135.8355 & 23.4006 & 139.4599 & 217.4867 & 779.6866 & 1.2585 \\
\hline SSD & 5 & Im-ssa & NA & NA & 21.2734 & NA & NA & NA & NA & NA & NA & 1.2545 \\
\hline STP & 5 & Im-ssa & 862.0363 & 20.8709 & 62.5830 & 966.5674 & 91.6717 & NA & NA & NA & NA & 1.2545 \\
\hline SUR & 5 & um-lac & 4305.6883 & 33.9178 & 116.8786 & 4411.0991 & NA & 7433.2759 & 152.0023 & 260.6867 & 706.7934 & 1.8243 \\
\hline SVK & 5 & hi-weu & 4266.1013 & 76.1856 & 111.2120 & 15020.9283 & 622.4821 & 15.8081 & 94.4844 & 135.1600 & 1120.6671 & 1.2405 \\
\hline SVN & 5 & hi-weu & 5678.7938 & 69.5914 & 106.7664 & 19055.5866 & 1082.6496 & 11.7524 & 277.3760 & 161.4667 & 789.0508 & 1.2405 \\
\hline SWE & 5 & hi-weu & 4861.4395 & 92.6834 & 121.8377 & 45353.9456 & 3130.3037 & 40.9731 & 74.3579 & 173.6700 & 2993.0012 & 1.2405 \\
\hline SWZ & 5 & Im-ssa & 1176.2063 & 18.6629 & 65.2327 & 2416.2859 & 178.7479 & 5748.8629 & NA & NA & 193.5136 & 1.2545 \\
\hline SXM & 5 & hi-sms & NA & NA & NA & NA & NA & NA & NA & NA & NA & 1.5191 \\
\hline SYC & 5 & um-ssa & NA & 45.4100 & 140.4928 & 13953.0593 & 506.0479 & 899.9530 & 63.3333 & NA & 604.6097 & 1.3187 \\
\hline SYR & 5 & Im-mea & 1532.6678 & 23.4250 & 57.2461 & NA & NA & 3151.9075 & 37.6311 & 178.6600 & NA & 1.2169 \\
\hline TCA & 5 & hi-sms & NA & NA & NA & NA & NA & NA & NA & NA & NA & 1.5191 \\
\hline TCD & 5 & lo-ssa & 869.6695 & 2.0000 & 31.4514 & 724.6615 & 15.3715 & 141.0189 & NA & NA & NA & 1.3037 \\
\hline TGO & 5 & lo-ssa & 1226.3050 & 3.7500 & 48.8267 & 408.2329 & 17.5328 & 29.8036 & 8.0563 & 128.3467 & 177.2879 & 1.3037 \\
\hline THA & 5 & um-eap & 3080.7903 & 25.3675 & 122.9230 & 3287.3472 & 187.5047 & 3231.5545 & 158.9548 & 168.2867 & 581.2646 & 1.2843 \\
\hline TJK & 5 & lo-eca & 2831.4378 & 13.7725 & 83.0371 & 448.3938 & 17.9016 & 12286.9525 & 57.4440 & 285.9433 & 137.8628 & 2.9880 \\
\hline TKM & 5 & um-eca & 2091.3338 & 6.1990 & 99.5386 & 3110.0551 & 94.9833 & 13776.8179 & NA & 128.7567 & NA & 1.2585 \\
\hline TLS & 5 & lo-sas & 2260.9050 & 0.7812 & 53.2392 & 737.0224 & 72.3613 & 6909.5071 & NA & NA & 169.5419 & 1.5014 \\
\hline TON & 5 & um-eap & NA & 27.7152 & 53.1810 & 2637.0377 & NA & NA & 240.9167 & NA & 503.5519 & 1.2843 \\
\hline TTO & 5 & hi-sms & 1597.3845 & 56.7541 & 141.3506 & 14216.8331 & NA & 800.0390 & 474.9867 & 104.9000 & 80.8473 & 1.5191 \\
\hline TUN & 5 & um-mea & 1694.0778 & 40.2854 & 113.3619 & 3883.9012 & 242.3563 & 763.9784 & 49.1501 & 146.2400 & 966.3977 & 1.5149 \\
\hline TUR & 5 & um-eca & 2967.9433 & 43.5664 & 89.8666 & 8363.2758 & NA & 1420.8874 & 101.7910 & 159.7700 & 2418.6776 & 1.2585 \\
\hline TUV & 5 & um-eap & NA & 31.7500 & 25.1859 & 2581.0875 & NA & NA & NA & NA & 1347.5667 & 1.2843 \\
\hline TZA & 5 & lo-ssa & 1442.7745 & 3.6875 & 53.6776 & 463.1868 & 27.8359 & 368.5865 & 6.3175 & 196.3733 & 162.3599 & 1.3037 \\
\hline UGA & 5 & lo-ssa & 2056.9738 & 14.1008 & 43.5855 & 410.1943 & 12.3516 & 17.6484 & 1.7769 & NA & 83.0004 & 1.3037 \\
\hline UKR & 5 & Im-eca & 3432.5663 & 32.2696 & 126.7130 & 2072.9499 & 132.7990 & 36.4931 & 37.6102 & 291.2967 & 677.7300 & 1.3129 \\
\hline
\end{tabular}




\begin{tabular}{|c|c|c|c|c|c|c|c|c|c|c|c|c|}
\hline URY & 5 & hi-lac & 4030.2603 & 52.5896 & 143.4863 & 7342.5682 & 324.7644 & 1808.6303 & 181.5333 & 128.3833 & 10246.5149 & 1.5817 \\
\hline USA & 5 & hi-nao & 6767.7480 & 76.2299 & 94.3229 & 44762.8131 & 2383.0900 & 1214.9733 & 127.8166 & 240.6300 & 2592.2834 & 1.3794 \\
\hline UZB & 5 & Im-eca & 4668.7175 & 31.2303 & 77.7912 & 822.7121 & NA & 11675.6757 & 187.1978 & NA & 279.7410 & 1.3129 \\
\hline VCT & 5 & um-lac & 24287.5313 & 45.2575 & 117.9583 & 5420.7466 & 275.5548 & NA & NA & NA & 580.7273 & 1.8243 \\
\hline VEN & 5 & um-lac & 3105.7655 & 45.3850 & 99.3061 & 6246.9878 & NA & 6345.5666 & 169.5410 & 348.4000 & 1849.3917 & 1.8243 \\
\hline VIR & 5 & hi-sms & NA & 38.1670 & NA & NA & NA & NA & NA & NA & NA & 1.5191 \\
\hline VNM & 5 & Im-eap & 5361.3815 & 37.2775 & 136.3600 & 965.4836 & 60.8047 & 12062.0625 & 310.6088 & 245.7067 & 229.3738 & 1.3612 \\
\hline VUT & 5 & Im-eap & 575.2110 & 9.7745 & 59.4956 & 2107.2958 & NA & NA & NA & 132.3000 & 583.7937 & 1.3612 \\
\hline PSE & 5 & ot-sms & 1558.3445 & 42.1200 & 70.7617 & 1441.0524 & NA & 4257.1982 & NA & NA & 300.7661 & 1.4023 \\
\hline WSM & 5 & Im-eap & NA & 11.5556 & NA & 2686.5001 & NA & NA & 1.6667 & NA & 323.9389 & 1.3612 \\
\hline YEM & 5 & Im-mea & 1046.8533 & 16.1754 & 56.5139 & 769.4559 & NA & 2625.7151 & 13.8802 & 221.1300 & NA & 1.2169 \\
\hline ZAF & 5 & um-ssa & 3895.2913 & 36.9675 & 124.3250 & 6015.6931 & 374.3872 & 642.9128 & 58.7073 & 189.5200 & 370.5732 & 1.3187 \\
\hline COD & 5 & ot-ssa & 763.1083 & 1.4500 & 28.9686 & 268.7501 & 4.3131 & 10.4730 & 1.1975 & NA & 84.2810 & 0.9615 \\
\hline ZMB & 5 & Im-ssa & 2621.6728 & 12.5921 & 61.8441 & 1004.2003 & NA & 317.0537 & 31.1466 & 366.3733 & 142.4247 & 1.2545 \\
\hline ZWE & 5 & lo-ssa & 766.6290 & 15.6975 & 79.0025 & 444.4800 & 8.7557 & 815.9423 & 30.8652 & NA & 80.1389 & 1.3037 \\
\hline
\end{tabular}




\section{ANNEX C: Supporting material for the sub-national model}

\section{SUMMARY OF VARIABLES}

\begin{tabular}{|c|c|c|c|c|}
\hline simbol & Variable & Unit & Source & Comments \\
\hline $\begin{array}{l}\operatorname{tr} .3 G .05 . \\
09\end{array}$ & $\begin{array}{l}\text { Treatment variable: } 3 G \\
\text { technology }\end{array}$ & $\begin{array}{l}\text { Binary } \\
\text { variable }\end{array}$ & ANATEL & $\begin{array}{l}\text { Implementation of } 3 \mathrm{G} \text { technology in } \\
\text { the period between } 2005-09 \text {. } \\
1=y e s, 0=\text { no. }\end{array}$ \\
\hline $\begin{array}{l}\text { def.10/ } \\
\text { area }\end{array}$ & $\begin{array}{l}\text { Total accumulated } \\
\text { deforestation in } 2010 \\
\text { as a \% of the } \\
\text { municipality area }\end{array}$ & $\%$ of area & INPE & ( \\
\hline $\begin{array}{l}\text { def.04/ } \\
\text { area }\end{array}$ & $\begin{array}{l}\text { Total accumulated } \\
\text { deforestation in } 2004 \\
\text { as a \% of the } \\
\text { municipality area }\end{array}$ & $\%$ of area & INPE & - \\
\hline pop & Population & $\begin{array}{l}\text { Number of } \\
\text { inhabitants } \\
\text { in } 2013\end{array}$ & IBGE & - \\
\hline gdp & GDP per capita & $\begin{array}{l}\text { current R\$ } \\
\text { for } 2013\end{array}$ & IBGE & e \\
\hline DDD & Region & $\begin{array}{l}\text { Categoric } \\
\text { variable }\end{array}$ & ANATEL & $\begin{array}{l}\text { Division of regions, as defined by } \\
\text { ANATEL, for mobile coverage. Also } \\
\text { serves as control for location. }\end{array}$ \\
\hline agi.perc & $\begin{array}{l}\text { Agricultural } \\
\text { importance in the } \\
\text { economy }\end{array}$ & $\%$ & IBGE & $\begin{array}{l}\text { Agricultural value added as a } \\
\text { percentage of the total value added of } \\
\text { the economy at the municipality }\end{array}$ \\
\hline agg & $\begin{array}{l}\text { Index for agricultural } \\
\text { value added growth }\end{array}$ & $y r 2000=1$ & IBGE & $\begin{array}{l}\text { For the period } 2000 \text { to } 2010 \text {. Values in } \\
\text { current } R \$ \text { were deflated to } 2010 \\
\text { using the Brazilian Extended National } \\
\text { Consumer Price Index (IPCA) before } \\
\text { calculating the final index }\end{array}$ \\
\hline $\begin{array}{l}\text { ERB.dens } \\
.07 .09\end{array}$ & Antenna density & $\begin{array}{l}\text { No. of } \\
\text { antennas / } \\
\text { sq km }\end{array}$ & $\begin{array}{l}\text { ANATEL } \\
\& \text { IBGE }\end{array}$ & $\begin{array}{l}\text { Index calculated dividing the number } \\
\text { of antennas for mobile coverage by } \\
\text { the area of the municipality. } \\
\text { Calculated as teh average for the } \\
\text { period between } 2007 \text { and } 2009 \text {. }\end{array}$ \\
\hline area & Municipality area & Sq km & IBGE & $\begin{array}{l}\text { Total area of the municipality (data for } \\
\text { 2013) }\end{array}$ \\
\hline $\begin{array}{l}\text { priority. } \\
\text { mun }\end{array}$ & $\begin{array}{l}\text { Amazons priority } \\
\text { municipalities }\end{array}$ & $\begin{array}{l}\text { Binary } \\
\text { variable }\end{array}$ & MMA & $\begin{array}{l}\text { List of municipalities set by } \\
\text { government as priorities for } \\
\text { tacklingdeforestation. } Y=y e s, \mathrm{~N}=\text { no. }\end{array}$ \\
\hline
\end{tabular}




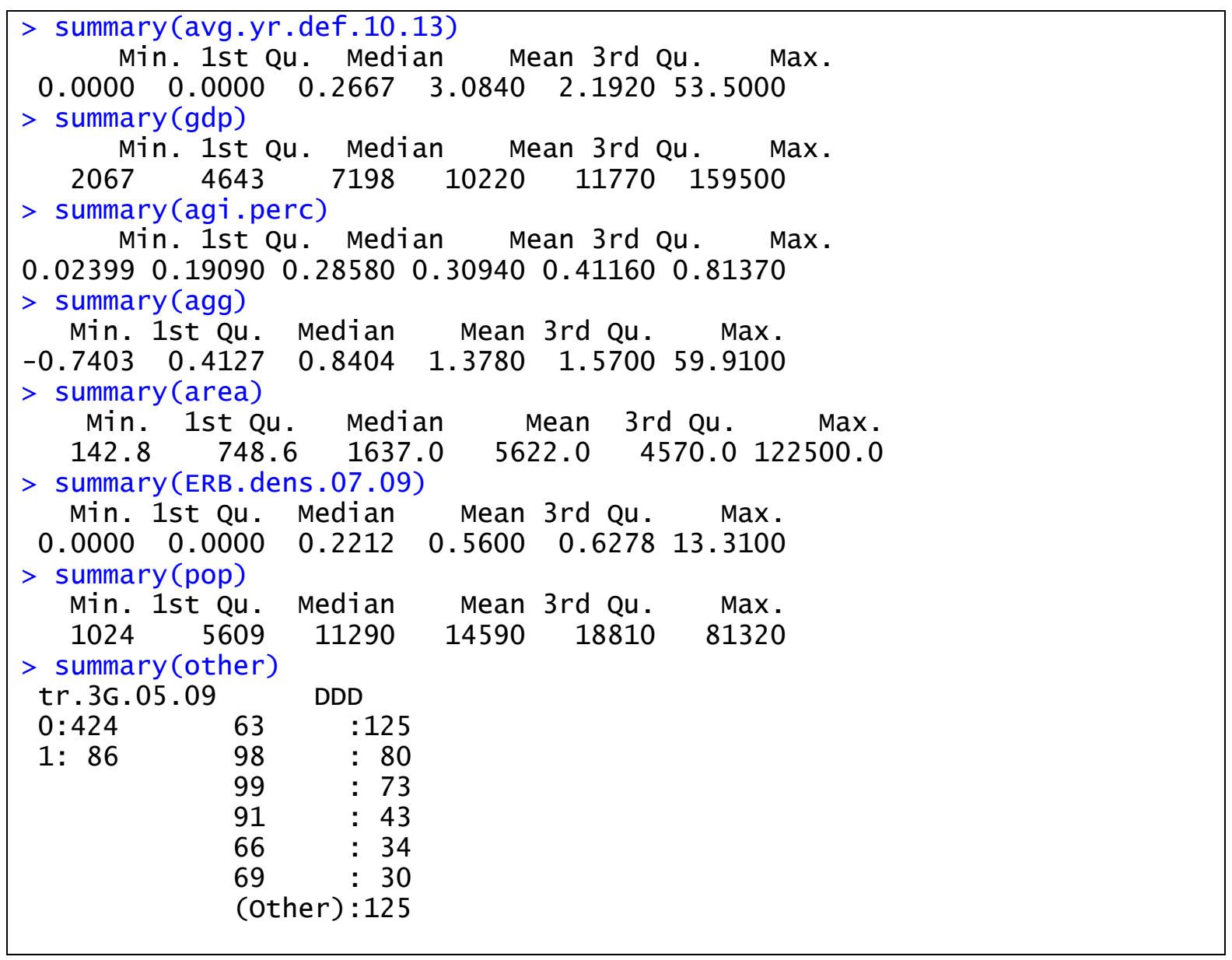

\section{CODES}

\#treating the data

$\operatorname{attach}(b r)$

$\mathrm{df}<-$ data. frame (br)

$\mathrm{Tr}<-$ cbind (tr.3G.05.09)

$Y<-$ cbind ((def.10/area)-(def.04/area))

$\mathrm{X}<-$ cbind (gdp, agi . perc, agg, DDD, pop, ERB . dens.07.09, area)

\section{\# initial probit model (step 1)}

g1m1<-g1m(Tr gdp+agi . perc+agg+DDD+pop+ERB . dens . 07.09+area, fami 1y=binomia1 , data $=\mathrm{df}$ )

summary (g1m1)

\section{\#propensity score model}

$r r 2<-M a t c h(Y=Y, T r=T r, X=g 1 \mathrm{~m} 1 \$$ fitted, estimand="ATC" , M=1, ties=FALSE, rep 1 ace $=T$ RUE)

summary $(r r 2)$ 
\#note: in order to run different estimation models the command "estimand" was varied between ATC, ATT and ATE. The command "ties" was varied between TRUE and FALSE

Description on the different estimation variables, described in SEKHON, J.S. (2015 ). Package Matching (Version 4.9-2). Descriptive text on the R software package, available on: https://cran.r-project.org/web/packages/Matching/Matching.pdf , retrie ved on February 20th 2017.

"estimand: This determines if the standardized mean difference returned by the sdif $f$ object is standardized by the variance of the treatment observations (which is don $e$ if the estimand is either "ATE" or "ATT") or by the variance of the control observat ions(which is done if the estimand is "ATC")."

replace: A logical flag for whether matching should be done with replacement. Note that if FALSE, the order of matches generally matters. Matches will be found in the same order as the data are sorted. Thus, the match(es) for the first observation will be found first, the match(es) for the second observation will be found second, etc. Matching without replacement will generally increase bias. Ties are randomly broken when replace $==F A L S E-$ see the ties option for details.

ties: A logical flag for whether ties should be handled deterministically. By default ties $==T R U E$. If, for example, one treated observation matches more than one control observation, the matched dataset will include the multiple matched control observations and the matched data will be weighted to reflect the multiple matches. The sum of the weighted observations will still equal the original number of observations. If ties==FALSE, ties will be randomly broken. If the dataset is large and there are many ties, setting ties=FALSE often results in a large speedup. Whether two potential matches are close enough to be considered tied, is controlled by the distance.tolerance option". (SEKHON 2015)

\# Checking the balance proprieties: statistics

MatchBalance(Tr gdp+agi . perc+agg+DDD+pop+ERB . dens . $07.09+$ area, match. out $=r r$ 2 , nboots $=0$, data $=$ df)

\# Checking the balance proprieties: graphs

qqplot(gdp[rr2\$index.control], gdp[rr2\$sindex.treated])

abline $($ coef $=c(0,1), \mathrm{col}=2)$

qqplot(agi.perc[rr2\$index.control], agi.perc[rr2\$index.treated])

abline $($ coef $=c(0,1), \mathrm{col}=2)$

qqplot(agg[rr2\$index.control], agg[rr2\$index.treated])

abline $($ coef $=c(0,1), \mathrm{col}=2)$

qqplot(pop[rr2\$index.control], pop[rr2\$index.treated])

abline $($ coef $=c(0,1), \mathrm{col}=2)$

qqplot(ERB.dens.07.09 [rr2\$index.control], ERB.dens.07.09 [rr2\$index.treated])

abline $($ coef $=c(0,1), \mathrm{col}=2)$ 
qqplot(area[rr2\$index.control], area[rr2\$index.treated])

abline $($ coef $=c(0,1), \mathrm{col}=2)$

\section{RESULTS OF REGRESSIONS}

Summary of the probit model (first step for calculating the propensity score matching)

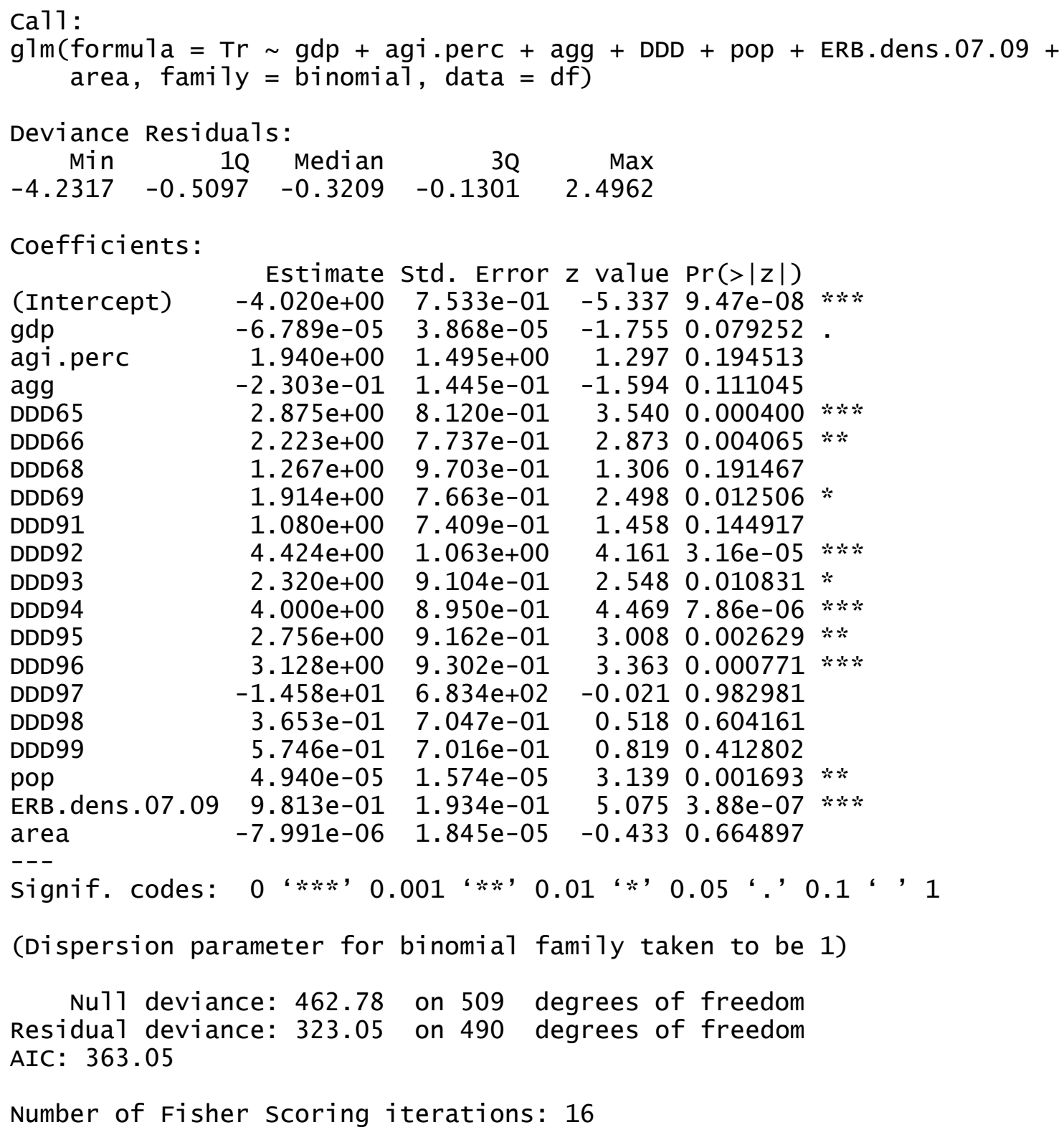

Summary of the propensity score matching model results

ESTIMAND $=$ ATC, TIES $=$ FALSE 
\begin{tabular}{|ll}
\hline Estimate... & -0.0038059 \\
SE........ & 0.0016124 \\
T-stat..... & -2.3603 \\
p.val..... & 0.01826
\end{tabular}

Original number of observations......... 510

Original number of control obs........... 424

Matched number of observations........... 424

Matched number of observations (unweighted). 424

ESTIMAND $=$ ATC, TIES $=$ TRUE

Estimate... -0.0037134

AI SE..... 0.010461

T-stat..... -0.35498

p.val..... 0.72261

Original number of observations......... 510

Original number of control obs............ 424

Matched number of observations........... 424

Matched number of observations (unweighted). 441

ESTIMAND $=$ ATT, TIES $=$ FALSE

Estimate... -0.0093746

SE........ 0.0039202

T-stat.... -2.3913

p.val..... 0.016787

original number of observations......... 510

Original number of treated obs............. 86

Matched number of observations.......... 86

Matched number of observations (unweighted). 86

ESTIMAND $=$ ATT, TIES $=$ TRUE

Estimate... -0.0084954

AI SE..... 0.0052921

T-stat..... -1.6053

p.val..... 0.10843

Original number of observations......... 510

Originat number of treated obs ............. 86

Matched number of observations.......... 86

Matched number of observations (unweighted). 122

ESTIMAND $=$ ATE, TIES $=$ FALSE

Estimate... -0.0046271

SE........ 0.0015011

$\begin{array}{lll}\text { T-stat..... } & -3.0825\end{array}$

p.val...... 0.0020526 
original number of observations......... 510

original number of treated obs........... 86

Matched number of observations.......... 510

Matched number of observations (unweighted). 510

ESTIMAND $=$ ATE, TIES $=$ TRUE

Estimate... -0.0045198

AI SE..... 0.0090095

T-stat..... -0.50167

p.val..... 0.6159

original number of observations......... 510

Original number of treated obs.......... 86

Matched number of observations.......... 510

Matched number of observations (unweighted). 563

Checking the balance proprieties: statistics

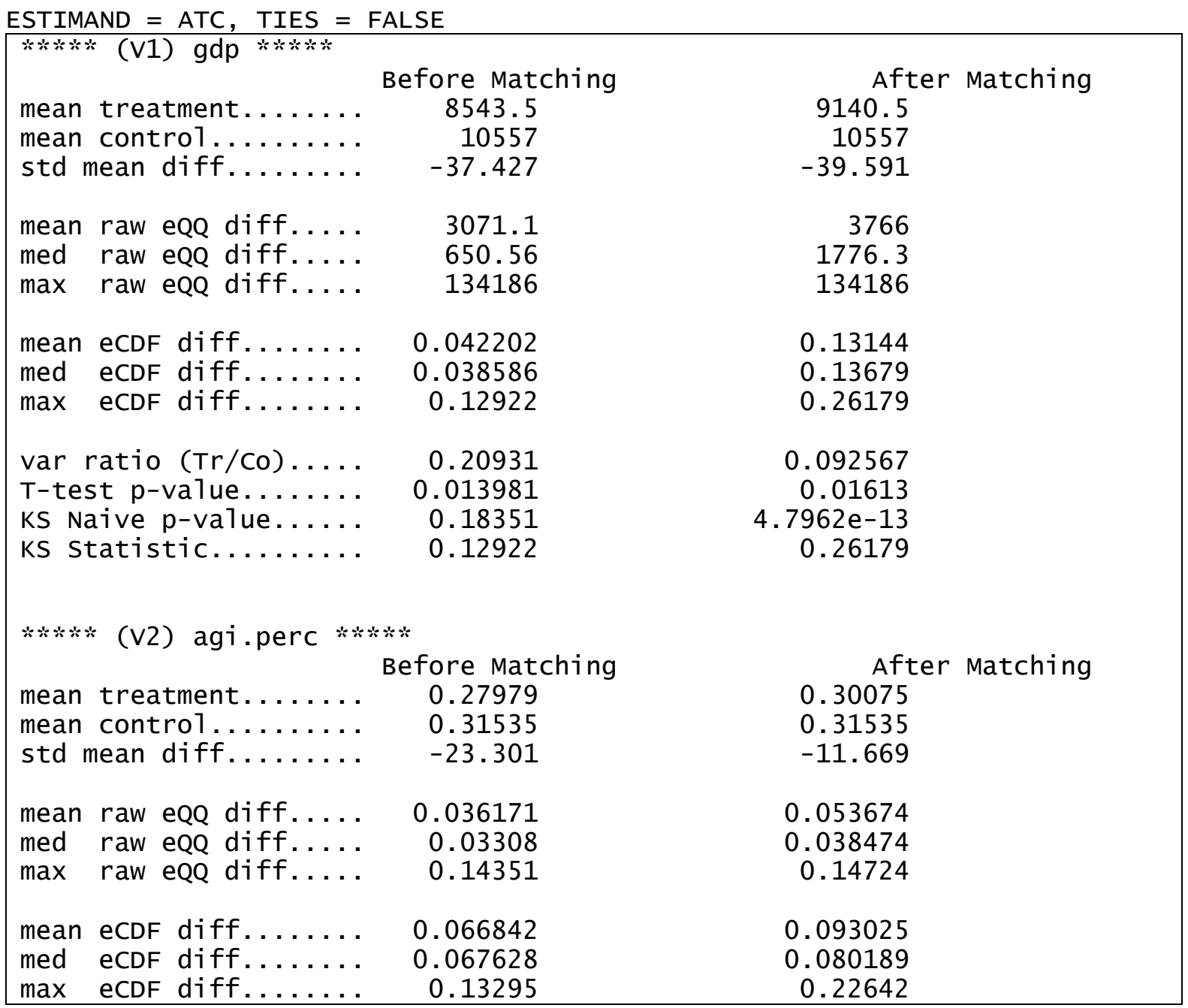




\begin{tabular}{|c|c|c|}
\hline $\begin{array}{l}\text { var ratio }(\mathrm{Tr} / \mathrm{Co}) \ldots . . \\
\text { T-test p-value....... } \\
\text { KS Naive p-value..... } \\
\text { KS Statistic........ }\end{array}$ & $\begin{array}{r}0.98947 \\
0.051275 \\
0.15961 \\
0.13295\end{array}$ & $\begin{array}{r}0.66529 \\
0.12656 \\
7.2656 \mathrm{e}-10 \\
0.22642\end{array}$ \\
\hline $\begin{array}{l}* * * * * \text { (V3) agg } * * * * * \\
\text { mean treatment....... } \\
\text { mean control } \ldots \ldots \ldots \\
\text { std mean diff........ }\end{array}$ & $\begin{array}{c}\text { Before Matching } \\
0.84539 \\
1.4855 \\
-68.479\end{array}$ & $\begin{array}{l}\text { After Matching } \\
1.141 \\
1.4855 \\
-28.614\end{array}$ \\
\hline $\begin{array}{l}\text { mean } \text { raw eQQ diff..... } \\
\text { med raw eQQ diff..... } \\
\text { max raw eQQ diff.... }\end{array}$ & $\begin{array}{r}1.1074 \\
0.24974 \\
54.81\end{array}$ & $\begin{array}{r}0.49901 \\
0.2206 \\
54.81\end{array}$ \\
\hline $\begin{array}{l}\text { mean eCDF diff. } \ldots \ldots \\
\text { med eCDF diff....... } \\
\max \text { eCDF diff...... }\end{array}$ & $\begin{array}{l}0.09977 \\
0.10306 \\
0.17798\end{array}$ & $\begin{array}{r}0.092431 \\
0.061321 \\
0.29717\end{array}$ \\
\hline $\begin{array}{l}\text { var ratio }(\mathrm{Tr} / \mathrm{Co}) \ldots . . \\
\text { T-test p-value....... } \\
\text { KS Naive p-value.... } \\
\text { KS Statistic........ }\end{array}$ & $\begin{array}{r}0.080589 \\
0.0007688 \\
0.021564 \\
0.17798\end{array}$ & $\begin{array}{r}0.13374 \\
0.049272 \\
<2.22 \mathrm{e}-16 \\
0.29717\end{array}$ \\
\hline $\begin{array}{l}* * * * * \text { (V4) DDD65 } * * * * * \\
\text { mean treatment } \ldots \ldots \ldots \\
\text { mean control } \ldots \ldots \ldots \\
\text { std mean diff. } \ldots \ldots \ldots\end{array}$ & $\begin{array}{c}\text { Before Matching } \\
0.069767 \\
0.03066 \\
15.261\end{array}$ & $\begin{array}{l}\text { After Matching } \\
0.028302 \\
0.03066 \\
-1.4205\end{array}$ \\
\hline $\begin{array}{ll}\text { mean } & \text { raw eQQ diff..... } \\
\text { med } & \text { raw eQQ diff..... } \\
\text { max } & \text { raw eQQ diff..... }\end{array}$ & $\begin{array}{r}0.034884 \\
0 \\
1\end{array}$ & $\begin{array}{r}0.0023585 \\
0 \\
1\end{array}$ \\
\hline $\begin{array}{l}\text { mean eCDF diff. } \ldots \ldots \\
\text { med eCDF diff........ } \\
\max \text { eCDF diff...... }\end{array}$ & $\begin{array}{l}0.019554 \\
0.019554 \\
0.039107\end{array}$ & $\begin{array}{l}0.0011792 \\
0.0011792 \\
0.0023585\end{array}$ \\
\hline $\begin{array}{l}\text { var ratio }(\mathrm{Tr} / \mathrm{Co}) \ldots . . \\
\text { T-test } p \text {-value...... }\end{array}$ & $\begin{array}{r}2.2042 \\
0.17865\end{array}$ & $\begin{array}{l}0.92532 \\
0.82736\end{array}$ \\
\hline $\begin{array}{l}* * * * * \text { (V5) DDD66 } * * * * * \\
\text { mean treatment } \ldots \ldots \ldots \\
\text { mean control } \ldots \ldots \ldots \\
\text { std mean diff....... }\end{array}$ & $\begin{array}{c}\text { Before Matching } \\
0.069767 \\
0.066038 \\
1.4555\end{array}$ & $\begin{array}{l}\text { After Matching } \\
0.044811 \\
0.066038 \\
-10.248\end{array}$ \\
\hline $\begin{array}{l}\text { mean } \\
\text { med } \text { raw eQQ diff..... } \\
\text { max } \\
\text { raw eQQ diff..... }\end{array}$ & $\begin{array}{l}0 \\
0 \\
0\end{array}$ & $\begin{array}{r}0.021226 \\
0 \\
1\end{array}$ \\
\hline $\begin{array}{l}\text { mean eCDF diff } \ldots \ldots \\
\text { med eCDF diff....... } \\
\text { max } \\
\text { eCDF diff...... }\end{array}$ & $\begin{array}{l}0.0018649 \\
0.0018649 \\
0.0037297\end{array}$ & $\begin{array}{l}0.010613 \\
0.010613 \\
0.021226\end{array}$ \\
\hline $\begin{array}{l}\text { var ratio }(\mathrm{Tr} / \mathrm{Co}) \ldots . . \\
\text { T-test } p \text {-value....... }\end{array}$ & $\begin{array}{r}1.0621 \\
0.90177\end{array}$ & $\begin{array}{l}0.69399 \\
0.17951\end{array}$ \\
\hline
\end{tabular}




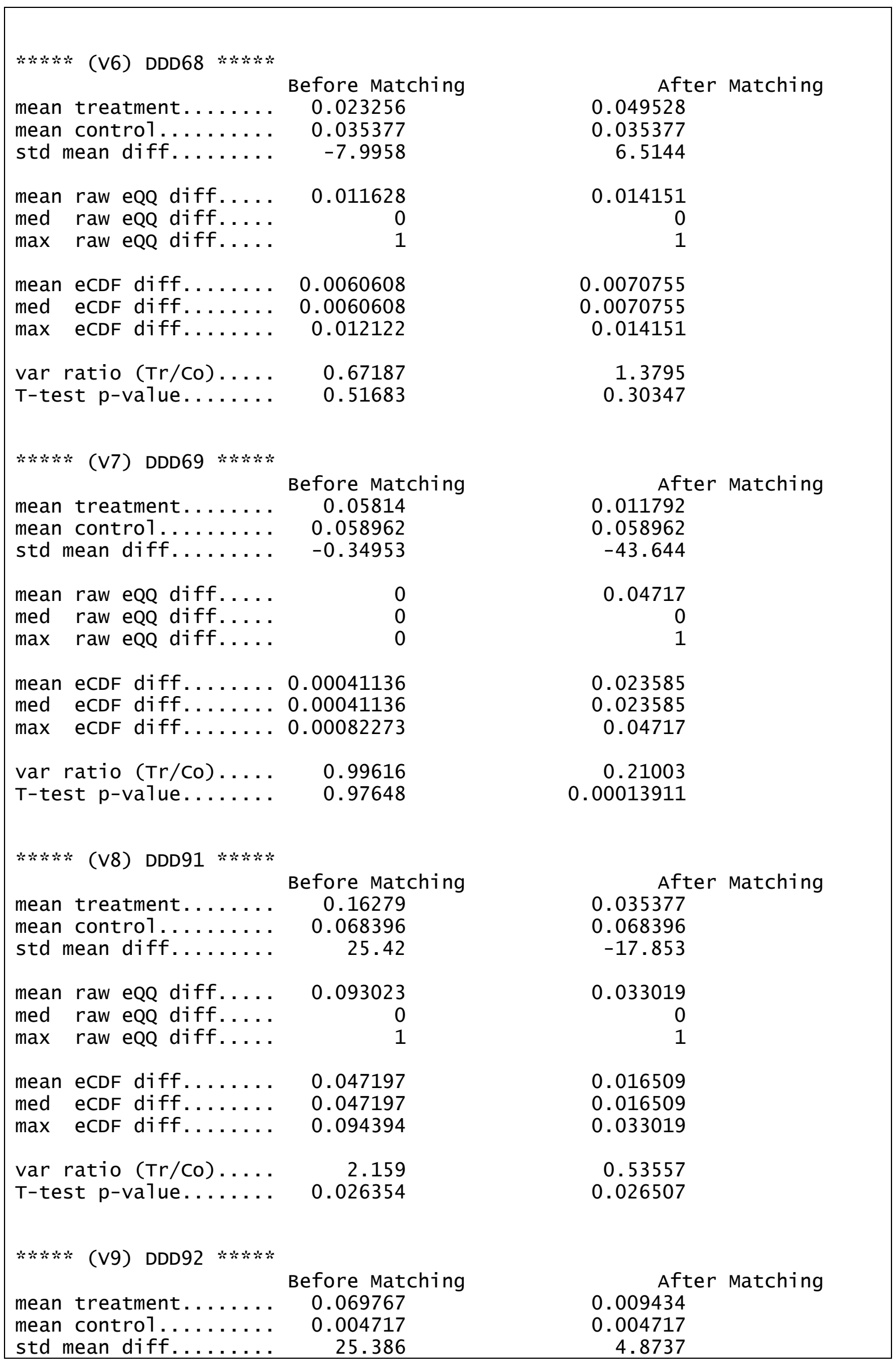




\begin{tabular}{|c|c|c|}
\hline $\begin{array}{ll}\text { mean } & \text { raw eQQ diff..... } \\
\text { med } & \text { raw eQQ diff..... } \\
\text { max } & \text { raw eQQ diff..... }\end{array}$ & $\begin{array}{r}0.05814 \\
0 \\
1\end{array}$ & $\begin{array}{r}0.004717 \\
0 \\
1\end{array}$ \\
\hline $\begin{array}{l}\text { mean eCDF diff....... } \\
\text { med eCDF diff....... } \\
\text { max } \\
\text { eCDF diff........ }\end{array}$ & $\begin{array}{r}0.032525 \\
0.032525 \\
0.06505\end{array}$ & $\begin{array}{r}0.0023585 \\
0.0023585 \\
0.004717\end{array}$ \\
\hline $\begin{array}{l}\text { var ratio }(\mathrm{Tr} / \mathrm{Co}) \ldots . . \\
\text { T-test p-value...... }\end{array}$ & $\begin{array}{r}13.954 \\
0.02171\end{array}$ & $\begin{array}{r}1.9905 \\
0.31731\end{array}$ \\
\hline \multicolumn{3}{|c|}{$* * * * *$ (V10) DDD93 $* * * * *$} \\
\hline $\begin{array}{l}\text { mean treatment. } \ldots \ldots \ldots \\
\text { mean control........ } \\
\text { std mean diff....... }\end{array}$ & $\begin{array}{c}\text { Before Matching } \\
0.081395 \\
0.018868 \\
22.734\end{array}$ & $\begin{array}{l}\text { After Matching } \\
0.025943 \\
0.018868 \\
4.4457\end{array}$ \\
\hline $\begin{array}{ll}\text { mean } & \text { raw eQQ diff..... } \\
\text { med } & \text { raw eQQ diff..... } \\
\text { max } & \text { raw eQQ diff..... }\end{array}$ & $\begin{array}{r}0.05814 \\
0 \\
1\end{array}$ & $\begin{array}{r}0.0070755 \\
0 \\
1\end{array}$ \\
\hline $\begin{array}{l}\text { mean eCDF diff. } \ldots \ldots \\
\text { med eCDF diff....... } \\
\text { max eCDF diff....... }\end{array}$ & $\begin{array}{l}0.031264 \\
0.031264 \\
0.062527\end{array}$ & $\begin{array}{l}0.0035377 \\
0.0035377 \\
0.0070755\end{array}$ \\
\hline $\begin{array}{l}\text { var ratio }(\mathrm{Tr} / \mathrm{Co}) \ldots . . \\
\text { T-test } p \text {-value...... }\end{array}$ & $\begin{array}{r}4.0769 \\
0.042403\end{array}$ & $\begin{array}{r}1.3651 \\
0.49143\end{array}$ \\
\hline \multicolumn{3}{|c|}{$* * * * *$ (V11) DDD94 $* * * * *$} \\
\hline $\begin{array}{l}\text { mean treatment....... } \\
\text { mean control........ } \\
\text { std mean diff....... }\end{array}$ & $\begin{array}{c}\text { Before Matching } \\
0.10465 \\
0.0070755 \\
31.691\end{array}$ & $\begin{array}{l}\text { After Matching } \\
0.004717 \\
0.0070755 \\
-3.4381\end{array}$ \\
\hline $\begin{array}{l}\text { mean } \text { raw eQQ diff..... } \\
\text { med raw eQQ diff..... } \\
\text { max raw eQQ diff..... }\end{array}$ & $\begin{array}{r}0.093023 \\
0 \\
1\end{array}$ & $\begin{array}{r}0.0023585 \\
0 \\
1\end{array}$ \\
\hline $\begin{array}{l}\text { mean eCDF diff....... } \\
\text { med eCDF diff...... } \\
\text { max eCDF diff...... }\end{array}$ & $\begin{array}{l}0.048788 \\
0.048788 \\
0.097576\end{array}$ & $\begin{array}{l}0.0011792 \\
0.0011792 \\
0.0023585\end{array}$ \\
\hline $\begin{array}{l}\text { var ratio }(\mathrm{Tr} / \mathrm{Co}) \ldots . . \\
\text { T-test } p \text {-value....... }\end{array}$ & $\begin{array}{r}13.462 \\
0.004489\end{array}$ & $\begin{array}{l}0.66825 \\
0.65487\end{array}$ \\
\hline \multicolumn{3}{|c|}{$* * * * *(\mathrm{~V} 12) \operatorname{DDD} 95 * * * * *$} \\
\hline $\begin{array}{l}\text { mean treatment....... } \\
\text { mean control........ } \\
\text { std mean diff........ }\end{array}$ & $\begin{array}{c}\text { Before Matching } \\
0.034884 \\
0.023585 \\
6.122\end{array}$ & $\begin{array}{l}\text { After Matching } \\
0.014151 \\
0.023585 \\
-7.9778\end{array}$ \\
\hline $\begin{array}{l}\text { mean } \text { raw eQQ diff..... } \\
\text { med raw eQQ diff..... } \\
\text { max raw eQQ diff..... }\end{array}$ & $\begin{array}{r}0.011628 \\
0 \\
1\end{array}$ & $\begin{array}{r}0.009434 \\
0 \\
1\end{array}$ \\
\hline $\begin{array}{l}\text { mean eCDF diff........ } \\
\text { med eCDF diff........ }\end{array}$ & $\begin{array}{l}0.0056494 \\
0.0056494\end{array}$ & $\begin{array}{l}0.004717 \\
0.004717\end{array}$ \\
\hline
\end{tabular}




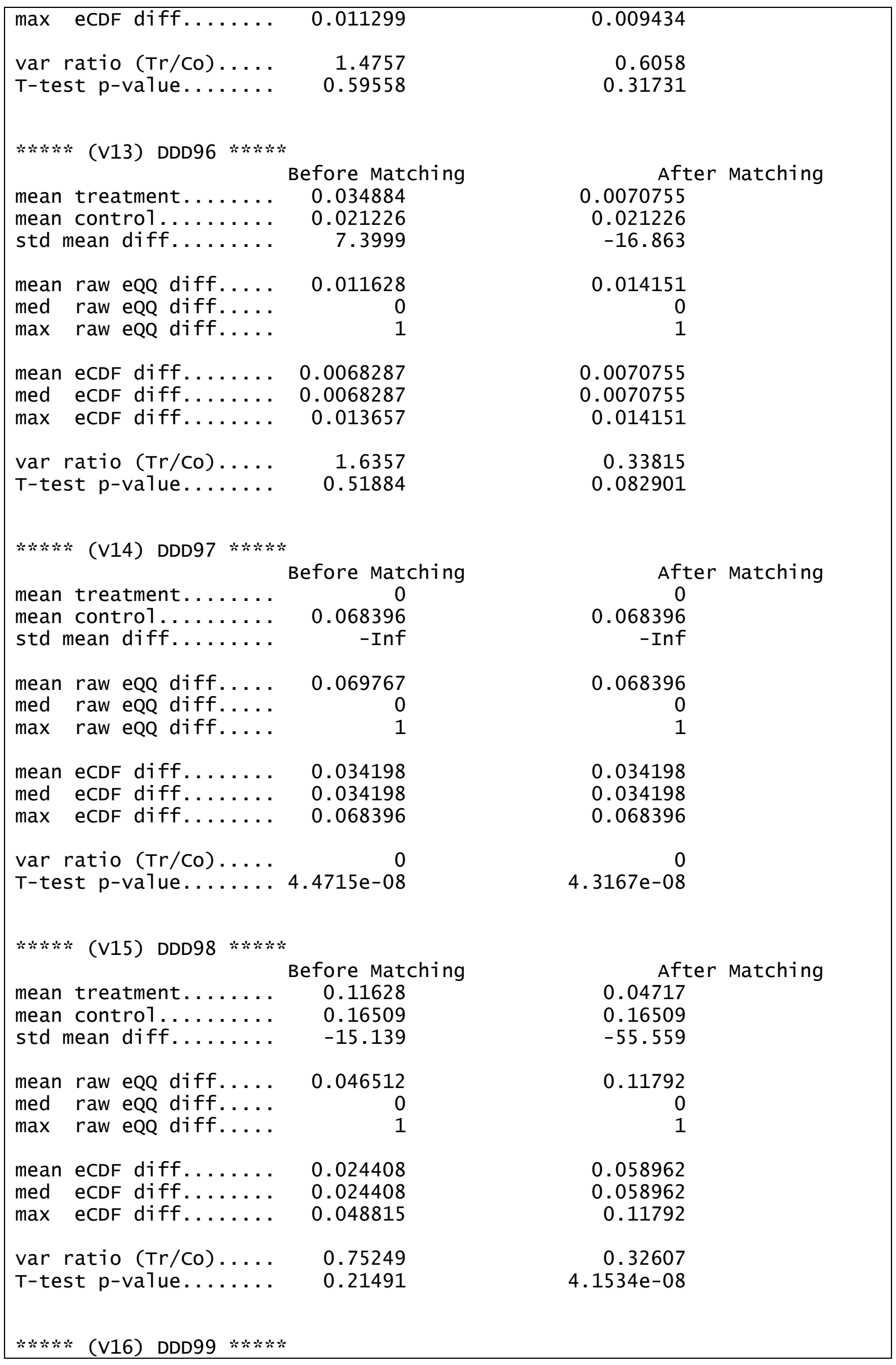




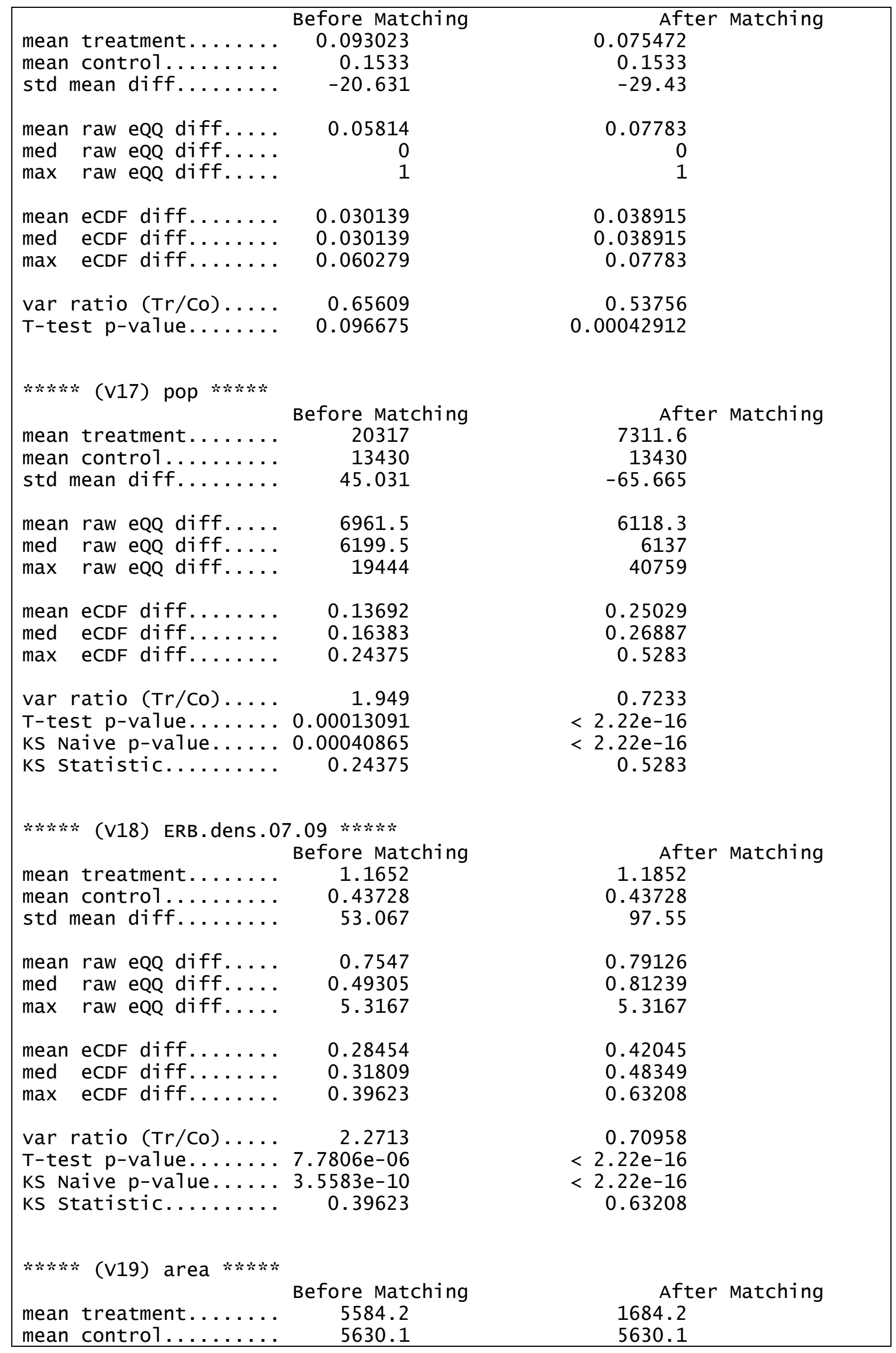




\begin{tabular}{|c|c|c|}
\hline std mean diff........... & -0.33685 & -93.393 \\
\hline $\begin{array}{ll}\text { mean } & \text { raw eQQ diff..... } \\
\text { med } & \text { raw eQQ diff..... } \\
\text { max } & \text { raw eQQ diff..... }\end{array}$ & $\begin{array}{r}779.71 \\
112.51 \\
15438\end{array}$ & $\begin{array}{r}3948.8 \\
984.37 \\
75588\end{array}$ \\
\hline $\begin{array}{l}\text { mean eCDF diff. } \ldots \ldots \ldots \\
\text { med eCDF diff........ } \\
\text { max eCDF diff....... }\end{array}$ & $\begin{array}{l}0.021088 \\
0.015687 \\
0.091433\end{array}$ & $\begin{array}{l}0.23364 \\
0.17099 \\
0.54481\end{array}$ \\
\hline $\begin{array}{l}\text { var ratio }(\mathrm{Tr} / \mathrm{Co}) \ldots \\
\text { T-test } \mathrm{p} \text {-value......... } \\
\text { KS Naive p-value..... } \\
\text { KS Statistic......... }\end{array}$ & $\begin{array}{r}1.1191 \\
0.97712 \\
0.58842 \\
0.091433\end{array}$ & $\begin{array}{r}0.10784 \\
4.5719 \mathrm{e}-09 \\
<2.22 \mathrm{e}-16 \\
0.54481\end{array}$ \\
\hline \multicolumn{3}{|c|}{$\begin{array}{l}\text { Before Matching Minimum p.value: } 3.5583 \mathrm{e}-10 \\
\text { Variable Name(s): ERB.dens.07.09 } \operatorname{Number}(\mathrm{s}): 18 \\
\text { After Matching Minimum p.value: }<2.22 \mathrm{e}-16 \\
\text { Variable Name(s): pop ERB.dens.07.09 area Number(s): } 17 \quad 1819\end{array}$} \\
\hline
\end{tabular}

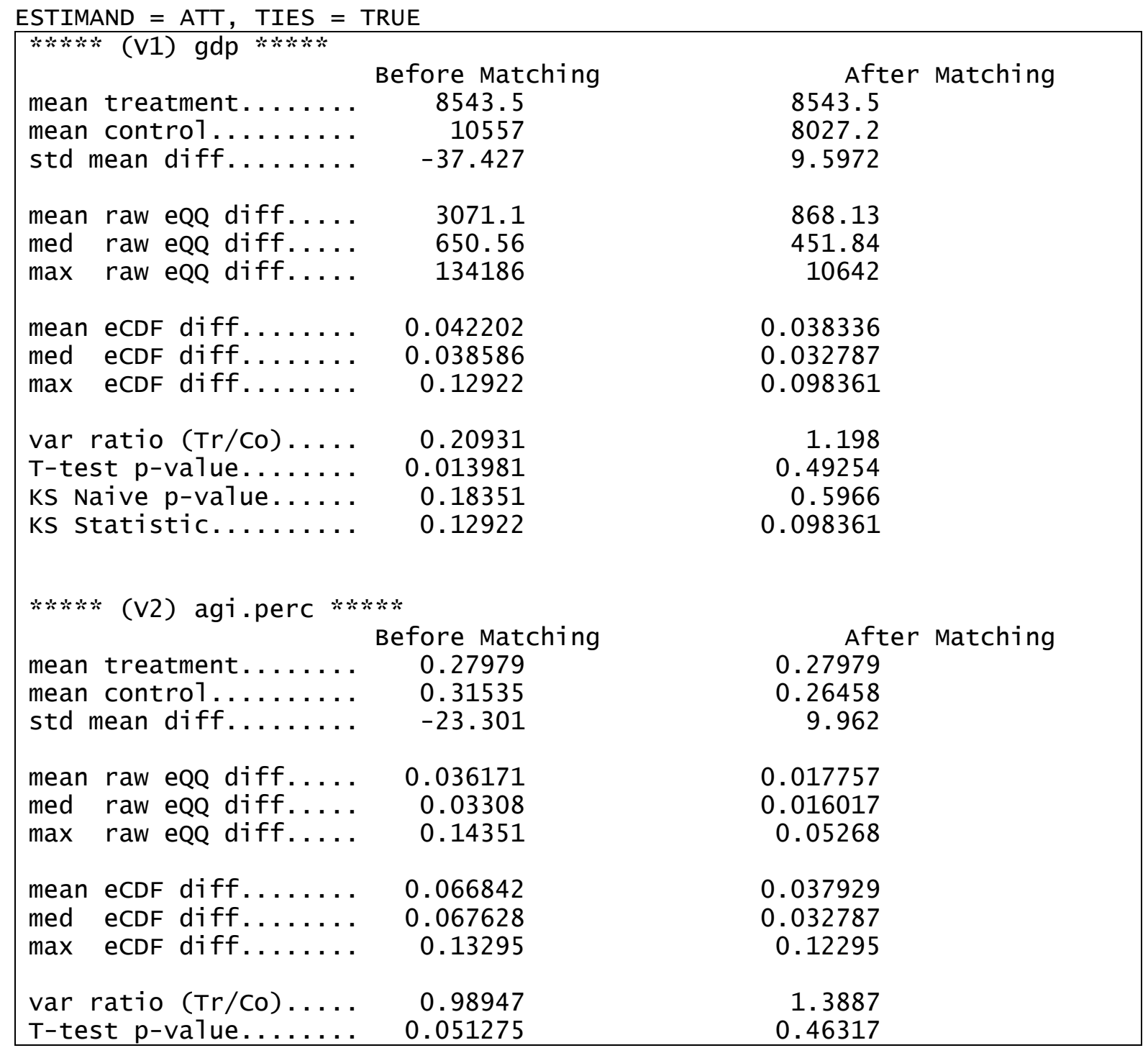




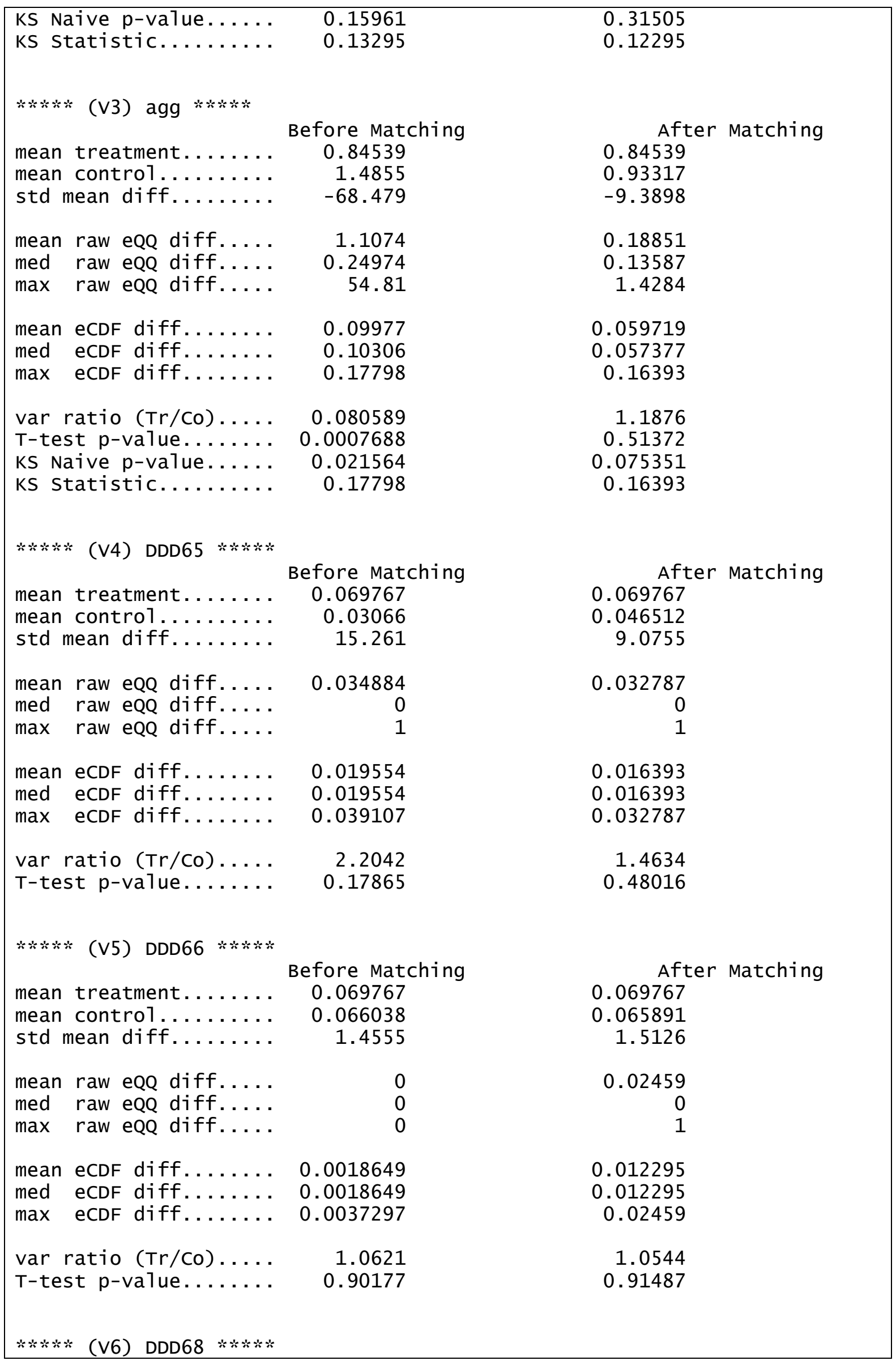




\begin{tabular}{|c|c|c|}
\hline $\begin{array}{l}\text { mean treatment } \ldots \ldots \\
\text { mean control } \ldots \ldots \\
\text { std mean diff. } \ldots \ldots\end{array}$ & $\begin{array}{c}\text { Before Matching } \\
0.023256 \\
0.035377 \\
-7.9958\end{array}$ & $\begin{array}{l}\text { After Matching } \\
0.023256 \\
0.025194 \\
-1.2784\end{array}$ \\
\hline $\begin{array}{ll}\text { mean } & \text { raw eQQ diff..... } \\
\text { med } & \text { raw eQQ diff..... } \\
\text { max } & \text { raw eQQ diff..... }\end{array}$ & $\begin{array}{r}0.011628 \\
0 \\
1\end{array}$ & $\begin{array}{r}0.02459 \\
0 \\
1\end{array}$ \\
\hline $\begin{array}{l}\text { mean eCDF diff. } \ldots \ldots \\
\text { med eCDF diff....... } \\
\text { max eCDF diff...... }\end{array}$ & $\begin{array}{r}0.0060608 \\
0.0060608 \\
0.012122\end{array}$ & $\begin{array}{r}0.012295 \\
0.012295 \\
0.02459\end{array}$ \\
\hline $\begin{array}{l}\text { var ratio }(\mathrm{Tr} / \mathrm{Co}) \ldots . . . \\
\text { T-test } p \text {-value...... }\end{array}$ & $\begin{array}{l}0.67187 \\
0.51683\end{array}$ & $\begin{array}{l}0.92491 \\
0.93511\end{array}$ \\
\hline $\begin{array}{l}* * * * \text { (V7) DDD69 }{ }^{*} * * * * \\
\text { mean treatment } \ldots \ldots \ldots \\
\text { mean control. } \ldots \ldots \ldots \\
\text { std mean diff........ }\end{array}$ & $\begin{array}{l}\text { Before Matching } \\
0.05814 \\
0.058962 \\
-0.34953\end{array}$ & $\begin{array}{l}\quad \text { After Matching } \\
0.05814 \\
0.09186 \\
-14.326\end{array}$ \\
\hline $\begin{array}{ll}\text { mean } & \text { raw eQQ diff..... } \\
\text { med } & \text { raw eQQ diff..... } \\
\text { max } & \text { raw eQQ diff..... }\end{array}$ & 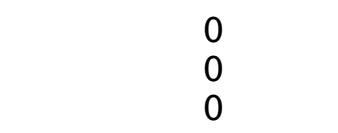 & $\begin{array}{r}0.04918 \\
0 \\
1\end{array}$ \\
\hline $\begin{array}{l}\text { mean eCDF diff. } \ldots \ldots \ldots \\
\text { med eCDF diff....... } \\
\max \text { eCDF diff....... }\end{array}$ & $\begin{array}{l}0.00041136 \\
0.00041136 \\
0.00082273\end{array}$ & $\begin{array}{l}0.02459 \\
0.02459 \\
0.04918\end{array}$ \\
\hline $\begin{array}{l}\text { var ratio }(\operatorname{Tr} / \mathrm{Co}) \ldots . . . \\
\text { T-test } p \text {-value....... }\end{array}$ & $\begin{array}{l}0.99616 \\
0.97648\end{array}$ & $\begin{array}{l}0.65641 \\
0.38008\end{array}$ \\
\hline $\begin{array}{l}* * * * \text { (V8) DDD91 } * * * * * \\
\text { mean treatment....... } \\
\text { mean control. } \ldots \ldots \ldots \\
\text { std mean diff....... }\end{array}$ & $\begin{array}{c}\text { Before Matching } \\
0.16279 \\
0.068396 \\
25.42\end{array}$ & $\begin{array}{l}\text { After Matching } \\
0.16279 \\
0.19767 \\
-9.394\end{array}$ \\
\hline $\begin{array}{l}\text { mean } \\
\text { med } \text { raw eQQ diff..... } \\
\text { max } \text { raw eQQ diff..... }\end{array}$ & $\begin{array}{r}0.093023 \\
0 \\
1\end{array}$ & $\begin{array}{r}0.016393 \\
0 \\
1\end{array}$ \\
\hline $\begin{array}{l}\text { mean eCDF diff. } \ldots \ldots \ldots \\
\text { med eCDF diff....... } \\
\max \text { eCDF diff...... }\end{array}$ & $\begin{array}{l}0.047197 \\
0.047197 \\
0.094394\end{array}$ & $\begin{array}{r}0.0081967 \\
0.0081967 \\
0.016393\end{array}$ \\
\hline $\begin{array}{l}\text { var ratio }(\mathrm{Tr} / \mathrm{Co}) \ldots . . \\
\text { T-test } p \text {-value...... }\end{array}$ & $\begin{array}{r}2.159 \\
0.026354\end{array}$ & $\begin{array}{l}0.85934 \\
0.54104\end{array}$ \\
\hline $\begin{array}{l}* * * * \text { (V9) DDD92 } * * * * * \\
\text { mean treatment } \ldots \ldots \ldots \\
\text { mean control } \ldots \ldots \ldots \\
\text { std mean diff....... }\end{array}$ & $\begin{array}{c}\text { Before Matching } \\
0.069767 \\
0.004717 \\
25.386\end{array}$ & $\begin{array}{l}\quad \text { After Matching } \\
0.069767 \\
0.034884 \\
13.613\end{array}$ \\
\hline $\begin{array}{l}\text { mean raw eQQ diff..... } \\
\text { med raw eQQ diff..... }\end{array}$ & $\begin{array}{r}0.05814 \\
0\end{array}$ & $\begin{array}{r}0.02459 \\
0\end{array}$ \\
\hline
\end{tabular}




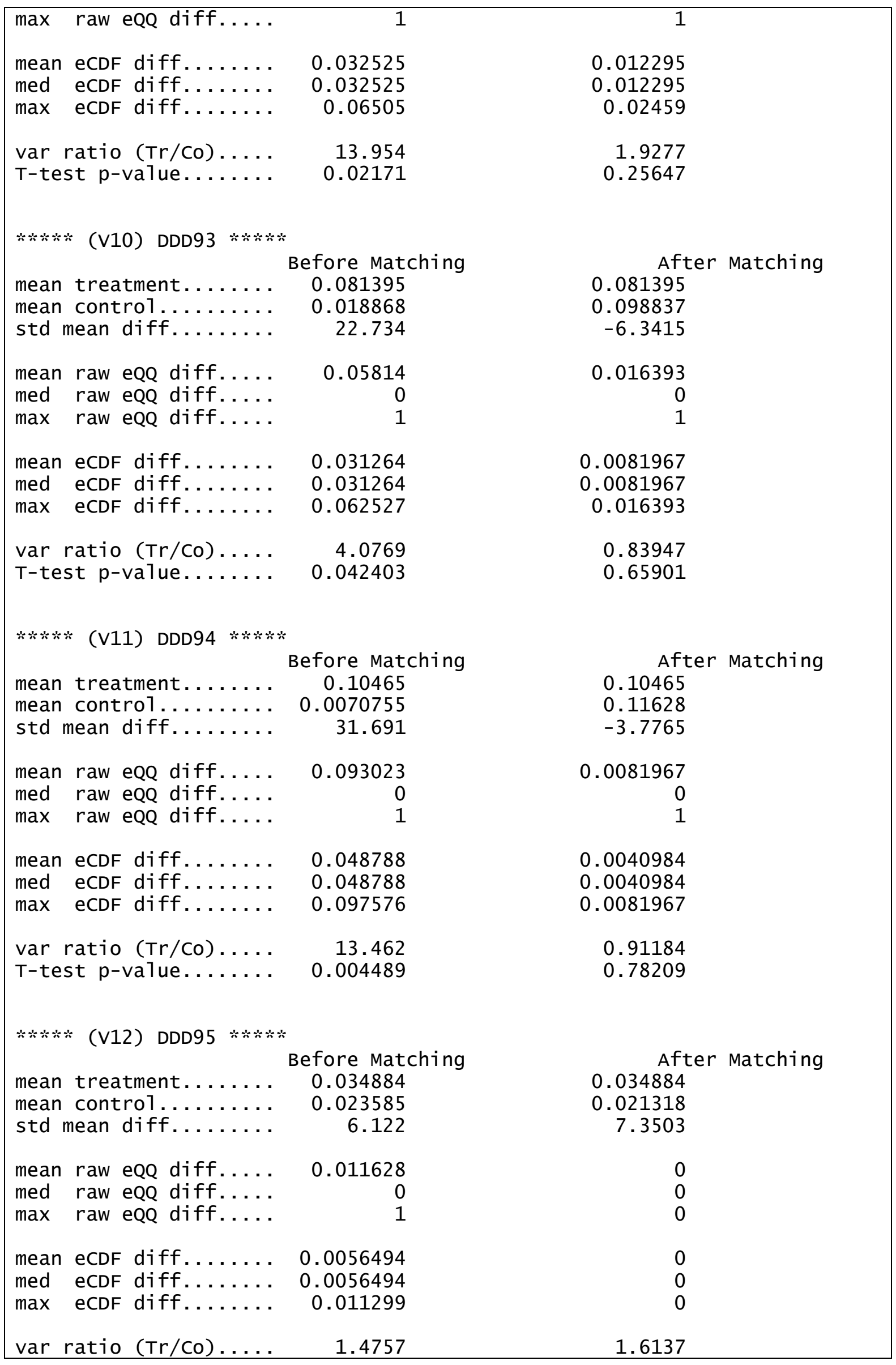




\begin{tabular}{|c|c|c|}
\hline T-test p-value....... & 0.59558 & 0.59643 \\
\hline \multicolumn{3}{|c|}{$* * * * *$ (V13) DDD96 $* * * * *$} \\
\hline & Before Matching & After Matching \\
\hline mean treatment. . . . . . & 0.034884 & 0.034884 \\
\hline mean control......... & 0.021226 & 0.017442 \\
\hline std mean diff........ & 7.3999 & 9.4504 \\
\hline mean raw eQQ diff..... & 0.011628 & 0.02459 \\
\hline med raw eQQ diff..... & 0 & 0 \\
\hline $\max$ raw eQQ diff.... & 1 & 1 \\
\hline mean eCDF diff....... & 0.0068287 & 0.012295 \\
\hline med eCDF diff........ & 0.0068287 & 0.012295 \\
\hline $\max$ eCDF diff........ & 0.013657 & 0.02459 \\
\hline var ratio $(\mathrm{Tr} / \mathrm{Co}) \ldots$. & 1.6357 & 1.9645 \\
\hline T-test $p$-value...... & 0.51884 & 0.48016 \\
\hline \multicolumn{3}{|c|}{$* * * * *$ (V14) DDD97 $* * * * *$} \\
\hline & Before Matching & After Matching \\
\hline mean treatment....... & 0 & 0 \\
\hline mean control......... & 0.068396 & 0 \\
\hline std mean diff........ & - Inf & 0 \\
\hline mean raw eQQ diff..... & 0.069767 & 0 \\
\hline med raw eQQ diff..... & 0 & 0 \\
\hline $\max$ raw eQQ diff.... & 1 & 0 \\
\hline mean eCDF diff....... & 0.034198 & 0 \\
\hline med eCDF diff........ & 0.034198 & 0 \\
\hline $\max$ eCDF diff....... & 0.068396 & 0 \\
\hline var ratio $(\operatorname{Tr} / \mathrm{Co}) \ldots$. & 0 & $\mathrm{NaN}$ \\
\hline T-test p-value....... & $4.4715 e-08$ & 1 \\
\hline \multicolumn{3}{|c|}{$* * * * *$ (V15) DDD98 $* * * * *$} \\
\hline & Before Matching & After Matching \\
\hline mean treatment........ & 0.11628 & 0.11628 \\
\hline mean control $\ldots \ldots \ldots$ & 0.16509 & 0.096899 \\
\hline std mean diff........ & -15.139 & 6.0104 \\
\hline mean raw eQQ diff..... & 0.046512 & 0.0081967 \\
\hline med raw eQQ diff..... & 0 & 0 \\
\hline $\max$ raw eQQ diff.... & 1 & 1 \\
\hline mean eCDF diff........ & 0.024408 & 0.0040984 \\
\hline med eCDF diff........ & 0.024408 & 0.0040984 \\
\hline $\max$ eCDF diff....... & 0.048815 & 0.0081967 \\
\hline var ratio $(\mathrm{Tr} / \mathrm{Co}) \ldots$. & 0.75249 & 1.1742 \\
\hline T-test $p$-value....... & 0.21491 & 0.69244 \\
\hline \multicolumn{3}{|c|}{$* * * * *$ (V16) DDD99 $* * * * *$} \\
\hline mean treatment........ & Before Matching & After Matching \\
\hline $\begin{array}{l}\text { mean treatment } . . . \ldots . . \\
\text { mean control........ }\end{array}$ & $\begin{array}{r}0.093023 \\
0.1533\end{array}$ & $\begin{array}{l}0.093023 \\
0.067442\end{array}$ \\
\hline
\end{tabular}




\begin{tabular}{|c|c|c|}
\hline std mean diff........ & -20.631 & 8.7557 \\
\hline mean raw eQQ diff..... & 0.05814 & 0.04918 \\
\hline med raw eQQ diff.... & 0 & 0 \\
\hline $\max$ raw eQQ diff..... & 1 & 1 \\
\hline mean ecDF diff....... & 0.030139 & 0.02459 \\
\hline med eCDF diff........ & 0.030139 & 0.02459 \\
\hline $\max$ eCDF diff....... & 0.060279 & 0.04918 \\
\hline var ratio $(\mathrm{Tr} / \mathrm{Co}) \ldots$. & 0.65609 & 1.3415 \\
\hline T-test p-value....... & 0.096675 & 0.55447 \\
\hline \multicolumn{3}{|l|}{$* * * * *$ (V17) pop $* * * * *$} \\
\hline & Before Matching & After Matching \\
\hline mean treatment....... & 20317 & 20317 \\
\hline mean control $\ldots \ldots \ldots$ & 13430 & 21126 \\
\hline std mean diff........ & 45.031 & -5.2875 \\
\hline mean raw eQQ diff..... & 6961.5 & 2251.5 \\
\hline med raw eQQ diff..... & 6199.5 & 2042 \\
\hline $\max$ raw eQQ diff..... & 19444 & 8498 \\
\hline mean ecDF diff....... & 0.13692 & 0.056398 \\
\hline med eCDF diff........ & 0.16383 & 0.040984 \\
\hline $\max$ eCDF diff....... & 0.24375 & 0.17213 \\
\hline var ratio $(\mathrm{Tr} / \mathrm{Co}) \ldots$. & 1.949 & 1.0752 \\
\hline T-test $p$-value........ & 0.00013091 & 0.69849 \\
\hline KS Naive $p$-value..... & 0.00040865 & 0.053846 \\
\hline KS statistic........ & 0.24375 & 0.17213 \\
\hline \multicolumn{3}{|c|}{$* * * * *$ (V18) ERB. dens.07.09 $* * * * *$} \\
\hline 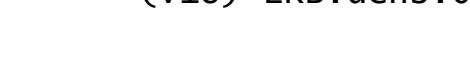 & Before Matching & After Matching \\
\hline mean treatment....... & 1.1652 & 1.1652 \\
\hline mean control........ & 0.43728 & 1.3848 \\
\hline std mean diff........ & 53.067 & -16.007 \\
\hline mean raw eQQ diff..... & 0.7547 & 0.47679 \\
\hline med raw eQQ diff..... & 0.49305 & 0.26208 \\
\hline $\max$ raw eQQ diff.... & 5.3167 & 7.4517 \\
\hline mean ecDF diff....... & 0.28454 & 0.14285 \\
\hline med eCDF diff........ & 0.31809 & 0.15574 \\
\hline $\max$ eCDF diff....... & 0.39623 & 0.27869 \\
\hline var ratio $(\mathrm{Tr} / \mathrm{Co}) \ldots$. & 2.2713 & 0.33824 \\
\hline T-test $p$-value....... & $7.7806 e-06$ & 0.23539 \\
\hline KS Naive p-value...... & $3.5583 e-10$ & 0.00015343 \\
\hline KS statistic......... & 0.39623 & 0.27869 \\
\hline \multicolumn{3}{|c|}{$* * * * *$ (V19) area $* * * * *$} \\
\hline 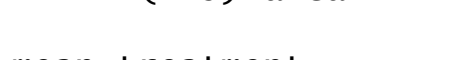 & Before Matching & After Matching \\
\hline mean treatment....... & 5584.2 & 5584.2 \\
\hline mean control $\ldots \ldots \ldots$. & 5630.1 & 4813.4 \\
\hline std mean diff......... & -0.33685 & 5.6635 \\
\hline mean raw eQQ diff..... & 779.71 & 1085.7 \\
\hline
\end{tabular}




\begin{tabular}{|c|c|c|c|}
\hline $\begin{array}{l}\operatorname{med} \\
\max \end{array}$ & $\begin{array}{l}\text { raw eQQ diff..... } \\
\text { raw eQQ diff..... }\end{array}$ & $\begin{array}{r}112.51 \\
15438\end{array}$ & $\begin{array}{r}131.28 \\
54300\end{array}$ \\
\hline $\begin{array}{l}\text { mean } \\
\text { med } \\
\max \end{array}$ & $\begin{array}{l}\text { eCDF diff...... } \\
\text { eCDF diff..... } \\
\text { eCDF diff...... }\end{array}$ & $\begin{array}{l}0.021088 \\
0.015687 \\
0.091433\end{array}$ & $\begin{array}{r}0.029019 \\
0.02459 \\
0.098361\end{array}$ \\
\hline $\begin{array}{l}\text { var } \\
\text { T-te } \\
\text { KS N } \\
\text { KS S }\end{array}$ & $\begin{array}{l}\text { ratio }(\mathrm{Tr} / \mathrm{Co}) \ldots \ldots \\
\text { est } \mathrm{p} \text {-value........ } \\
\text { vaive } \mathrm{p} \text {-value...... } \\
\text { statistic........ }\end{array}$ & $\begin{array}{r}1.1191 \\
0.97712 \\
0.58842 \\
0.091433\end{array}$ & $\begin{array}{r}1.9031 \\
0.6683 \\
0.5966 \\
0.098361\end{array}$ \\
\hline \multicolumn{4}{|c|}{ 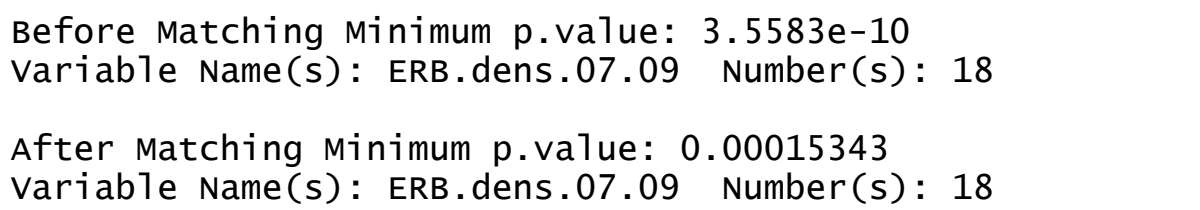 } \\
\hline
\end{tabular}

\begin{tabular}{|c|c|c|}
\hline \multicolumn{3}{|l|}{$* * * * *$ (V1) gdp $* * * * *$} \\
\hline & Before Matching & After Matching \\
\hline mean treatment....... & 8543.5 & 8543.5 \\
\hline mean control......... & 10557 & $\begin{array}{r}7991 \\
1097\end{array}$ \\
\hline std mean d $1+t \ldots . . . .$. & $-3 / .427$ & 10.27 \\
\hline mean raw eoo diff..... & 3071.1 & 792.85 \\
\hline med raw eQQ diff..... & 650.56 & 293.09 \\
\hline max raw eQQ diff.... & 134186 & 6273.4 \\
\hline mean eCDF diff....... & 0.042202 & 0.033101 \\
\hline med eCDF diff........... & 0.038586 & 0.023256 \\
\hline $\max$ eCDF diff......... & 0.12922 & 0.081395 \\
\hline var ratio $(\mathrm{Tr} / \mathrm{Co}) \ldots$ & 0.20931 & 1.3129 \\
\hline T-test $p$-value......... & 0.013981 & 0.45646 \\
\hline KS Naive p-value..... & 0.18351 & 0.93819 \\
\hline KS Statistic......... & 0.12922 & 0.081395 \\
\hline \multicolumn{3}{|c|}{$* * * * *$ (V2) agi perc $* * * * *$} \\
\hline & Before Matching & After Matching \\
\hline mean treatment..... & 0.27979 & 0.27979 \\
\hline mean control......... & 0.31535 & 0.2701 \\
\hline std mean diff........ & -23.301 & 6.3435 \\
\hline mean raw eQQ diff..... & 0.036171 & 0.015711 \\
\hline med raw eoo diff..... & 0.03308 & 0.010572 \\
\hline max raw eQQ diff...... & 0.14351 & 0.082256 \\
\hline mean eCDF diff...... & 0.066842 & 0.026481 \\
\hline med eCDF diff....... & 0.067628 & 0.023256 \\
\hline $\max$ eCDF diff....... & 0.13295 & 0.081395 \\
\hline var ratio $(\mathrm{Tr} / \mathrm{Co}) \ldots$ & 0.98947 & 1.216 \\
\hline T-test $p$-value....... & 0.051275 & 0.65362 \\
\hline KS Naive p-value...... & 0.15961 & 0.93819 \\
\hline KS statistic........... & 0.13295 & 0.081395 \\
\hline
\end{tabular}




\begin{tabular}{|c|c|c|}
\hline \multicolumn{3}{|l|}{$* * * * *$ (V3) agg $* * * * *$} \\
\hline mean treatment. . . . . & 0.84539 & 0.84539 \\
\hline mean control......... & 1.4855 & 0.911 \\
\hline std mean diff......... & -68.479 & -7.0181 \\
\hline mean raw eQQ diff..... & 1.1074 & 0.15727 \\
\hline med raw eQQ diff..... & 0.24974 & 0.11051 \\
\hline $\max$ raw eQQ diff..... & 54.81 & 1.4284 \\
\hline mean eCDF diff........ & 0.09977 & 0.051095 \\
\hline med eCDF diff........ & 0.10306 & 0.046512 \\
\hline $\max e C D F$ diff....... & 0.17798 & 0.12791 \\
\hline var ratio $(\mathrm{Tr} / \mathrm{Co}) \ldots$. & 0.080589 & 1.4282 \\
\hline T-test $p$-value....... & 0.0007688 & 0.62851 \\
\hline KS Naive $p$-value...... & 0.021564 & 0.48258 \\
\hline KS statistic......... & 0.17798 & 0.12791 \\
\hline \multicolumn{3}{|l|}{$* * * * *$ (V4) DDD65 $* * * * *$} \\
\hline & Before Matching & After Matching \\
\hline mean treatment....... & 0.069767 & 0.069767 \\
\hline mean control $\ldots \ldots \ldots$. & 0.03066 & 0.046512 \\
\hline std mean diff........ & 15.261 & 9.0755 \\
\hline mean raw eQQ diff..... & 0.034884 & 0.023256 \\
\hline med raw eQQ diff..... & 0 & 0 \\
\hline $\max$ raw eQQ diff.... & 1 & 1 \\
\hline mean eCDF diff........ & 0.019554 & 0.011628 \\
\hline med eCDF diff........ & 0.019554 & 0.011628 \\
\hline $\max$ eCDF diff....... & 0.039107 & 0.023256 \\
\hline var ratio $(\mathrm{Tr} / \mathrm{Co}) \ldots$. & 2.2042 & 1.4634 \\
\hline T-test p-value....... & 0.17865 & 0.48016 \\
\hline \multicolumn{3}{|l|}{$* * * *$ (V5) DDD66 $* * * * *$} \\
\hline & Before Matching & After Matching \\
\hline mean treatment....... & 0.069767 & 0.069767 \\
\hline mean control $\ldots \ldots \ldots$ & 0.066038 & 0.05814 \\
\hline std mean diff........ & 1.4555 & 4.5377 \\
\hline mean raw eQQ diff..... & 0 & 0.011628 \\
\hline med raw eQQ diff..... & 0 & 0 \\
\hline $\max$ raw eQQ diff.... & 0 & 1 \\
\hline mean ecDF diff....... & 0.0018649 & 0.005814 \\
\hline med ecDF diff....... & 0.0018649 & 0.005814 \\
\hline $\max$ eCDF diff....... & 0.0037297 & 0.011628 \\
\hline var ratio $(\operatorname{Tr} / \mathrm{Co}) \ldots$ & 1.0621 & 1.1852 \\
\hline T-test p-value....... & 0.90177 & 0.73954 \\
\hline$* * * * *$ (V6) DDD68 $* * * * *$ & & \\
\hline mean treatment....... & $\begin{array}{l}\text { Before Matching } \\
0.023256\end{array}$ & $\begin{array}{l}\text { After Matching } \\
0.023256\end{array}$ \\
\hline
\end{tabular}




\begin{tabular}{|c|c|c|}
\hline $\begin{array}{l}\text { mean control } \ldots \ldots \ldots \\
\text { std mean diff......... }\end{array}$ & $\begin{array}{r}0.035377 \\
-7.9958\end{array}$ & $\begin{array}{r}0.023256 \\
0\end{array}$ \\
\hline mean raw eQQ diff..... & 0.011628 & 0 \\
\hline med raw eQQ diff..... & 0 & 0 \\
\hline max raw eQQ diff..... & 1 & 0 \\
\hline mean eCDF diff........ & 0.0060608 & 0 \\
\hline med eCDF diff........ & 0.0060608 & 0 \\
\hline $\max e C D F$ diff....... & 0.012122 & 0 \\
\hline var ratio $(\operatorname{Tr} / \mathrm{Co}) \ldots \ldots$ & 0.67187 & 1 \\
\hline T-test p-value....... & 0.51683 & 1 \\
\hline \multicolumn{3}{|l|}{$* * * * *$ (V7) DDD69 $* * * * *$} \\
\hline & Before Matching & After Matching \\
\hline mean treatment....... & 0.05814 & 0.05814 \\
\hline mean control......... & 0.058962 & 0.10465 \\
\hline std mean diff........ & -0.34953 & -19.76 \\
\hline mean raw eQQ diff..... & 0 & 0.046512 \\
\hline med raw eQQ diff..... & 0 & 0 \\
\hline max raw eQQ diff.... & 0 & 1 \\
\hline mean eCDF diff........ & 0.00041136 & 0.023256 \\
\hline med eCDF diff........ & 0.00041136 & 0.023256 \\
\hline $\max$ eCDF diff....... & 0.00082273 & 0.046512 \\
\hline var ratio $(\mathrm{Tr} / \mathrm{Co}) \ldots$. & 0.99616 & 0.58442 \\
\hline T-test p-value....... & 0.97648 & 0.24778 \\
\hline \multicolumn{3}{|c|}{$* * * * *$ (V8) DDD91 $* * * * *$} \\
\hline & Before Matching & After Matching \\
\hline mean treatment. . . . . . & 0.16279 & 0.16279 \\
\hline mean control......... & 0.068396 & 0.22093 \\
\hline std mean diff......... & 25.42 & -15.657 \\
\hline mean raw eQQ diff..... & 0.093023 & 0.05814 \\
\hline med raw eQQ diff..... & 0 & 0 \\
\hline max raw eQQ diff..... & 1 & 1 \\
\hline mean eCDF diff........ & 0.047197 & 0.02907 \\
\hline med eCDF diff........ & 0.047197 & 0.02907 \\
\hline $\max$ eCDF diff....... & 0.094394 & 0.05814 \\
\hline var ratio $(\mathrm{Tr} / \mathrm{Co}) \ldots$. & 2.159 & 0.79183 \\
\hline T-test p-value....... & 0.026354 & 0.31734 \\
\hline \multicolumn{3}{|l|}{$* * * * *$ (V9) DDD92 $* * * * *$} \\
\hline & Before Matching & After Matching \\
\hline mean treatment. ....... & 0.069767 & 0.069767 \\
\hline mean control........ & 0.004717 & 0.034884 \\
\hline std mean diff........ & 25.386 & 13.613 \\
\hline mean raw eQQ diff..... & 0.05814 & 0.034884 \\
\hline med raw eQQ diff..... & 0 & 0 \\
\hline $\max$ raw eQQ diff..... & 1 & 1 \\
\hline
\end{tabular}




\begin{tabular}{|c|c|c|}
\hline $\begin{array}{l}\text { mean } \\
\text { med } \\
\text { meCDF diff } \\
\text { max }\end{array}$ & $\begin{array}{r}0.032525 \\
0.032525 \\
0.06505\end{array}$ & $\begin{array}{l}0.017442 \\
0.017442 \\
0.034884\end{array}$ \\
\hline $\begin{array}{l}\text { var ratio }(\operatorname{Tr} / \mathrm{Co}) \ldots . . . \\
\text { T-test } p \text {-value...... }\end{array}$ & $\begin{array}{r}13.954 \\
0.02171\end{array}$ & $\begin{array}{r}1.9277 \\
0.25647\end{array}$ \\
\hline 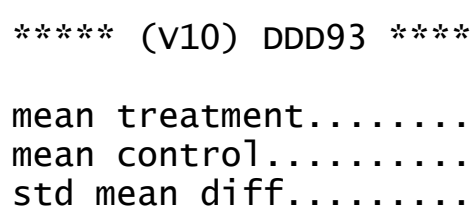 & $\begin{array}{l}\text { Before Matching } \\
0.081395 \\
0.018868 \\
22.734\end{array}$ & $\begin{array}{l}\text { After Matching } \\
0.081395 \\
0.10465 \\
-8.4553\end{array}$ \\
\hline $\begin{array}{l}\text { mean } \text { raw eQQ diff..... } \\
\text { med raw eQQ diff..... } \\
\text { max raw eQQ diff..... }\end{array}$ & $\begin{array}{r}0.05814 \\
0 \\
1\end{array}$ & $\begin{array}{r}0.023256 \\
0 \\
1\end{array}$ \\
\hline $\begin{array}{l}\text { mean eCDF diff. } \ldots \ldots \\
\text { med eCDF diff....... } \\
\text { max } \\
\text { eCDF diff. }\end{array}$ & $\begin{array}{l}0.031264 \\
0.031264 \\
0.062527\end{array}$ & $\begin{array}{l}0.011628 \\
0.011628 \\
0.023256\end{array}$ \\
\hline $\begin{array}{l}\text { var ratio }(\mathrm{Tr} / \mathrm{Co}) \ldots . . \\
\text { T-test } p \text {-value...... }\end{array}$ & $\begin{array}{r}4.0769 \\
0.042403\end{array}$ & $\begin{array}{l}0.79798 \\
0.56447\end{array}$ \\
\hline $\begin{array}{l}* * * * \text { (V11) DDD } 94 * * * * \\
\text { mean treatment....... } \\
\text { mean control........ } \\
\text { std mean diff....... }\end{array}$ & $\begin{array}{c}\text { Before Matching } \\
0.10465 \\
0.0070755 \\
31.691\end{array}$ & $\begin{array}{l}\quad \text { After Matching } \\
0.10465 \\
0.11628 \\
-3.7765\end{array}$ \\
\hline $\begin{array}{ll}\text { mean } & \text { raw eQQ diff..... } \\
\text { med } & \text { raw eQQ diff..... } \\
\text { max } & \text { raw eQQ diff..... }\end{array}$ & $\begin{array}{r}0.093023 \\
0 \\
1\end{array}$ & $\begin{array}{r}0.011628 \\
0 \\
1\end{array}$ \\
\hline $\begin{array}{l}\text { mean eCDF diff } \ldots \ldots \\
\text { med } \text { eCDF diff....... } \\
\text { max } \\
\text { eCDF diff. } \ldots\end{array}$ & $\begin{array}{l}0.048788 \\
0.048788 \\
0.097576\end{array}$ & $\begin{array}{l}0.005814 \\
0.005814 \\
0.011628\end{array}$ \\
\hline $\begin{array}{l}\text { var ratio }(\mathrm{Tr} / \mathrm{Co}) \ldots . . \\
\text { T-test } p \text {-value...... }\end{array}$ & $\begin{array}{r}13.462 \\
0.004489\end{array}$ & $\begin{array}{l}0.91184 \\
0.78209\end{array}$ \\
\hline 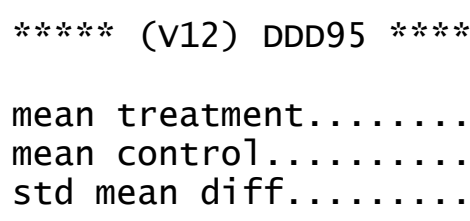 & $\begin{array}{c}\text { Before Matching } \\
0.034884 \\
0.023585 \\
6.122\end{array}$ & $\begin{array}{l}\text { After Matching } \\
0.034884 \\
0.011628 \\
12.601\end{array}$ \\
\hline $\begin{array}{ll}\text { mean } & \text { raw eQQ diff..... } \\
\text { med } & \text { raw eQQ diff..... } \\
\text { max } & \text { raw eQQ diff..... }\end{array}$ & $\begin{array}{r}0.011628 \\
0 \\
1\end{array}$ & $\begin{array}{r}0.023256 \\
0 \\
1\end{array}$ \\
\hline $\begin{array}{l}\text { mean eCDF diff } \ldots \ldots \ldots \\
\text { med } \text { eCDF diff } \ldots \ldots \\
\max \text { eCDF diff....... }\end{array}$ & $\begin{array}{r}0.0056494 \\
0.0056494 \\
0.011299\end{array}$ & $\begin{array}{l}0.011628 \\
0.011628 \\
0.023256\end{array}$ \\
\hline $\begin{array}{l}\text { var ratio }(\mathrm{Tr} / \mathrm{Co}) \ldots . . . \\
\text { T-test p-value...... }\end{array}$ & $\begin{array}{r}1.4757 \\
0.59558\end{array}$ & $\begin{array}{r}2.9294 \\
0.31734\end{array}$ \\
\hline
\end{tabular}




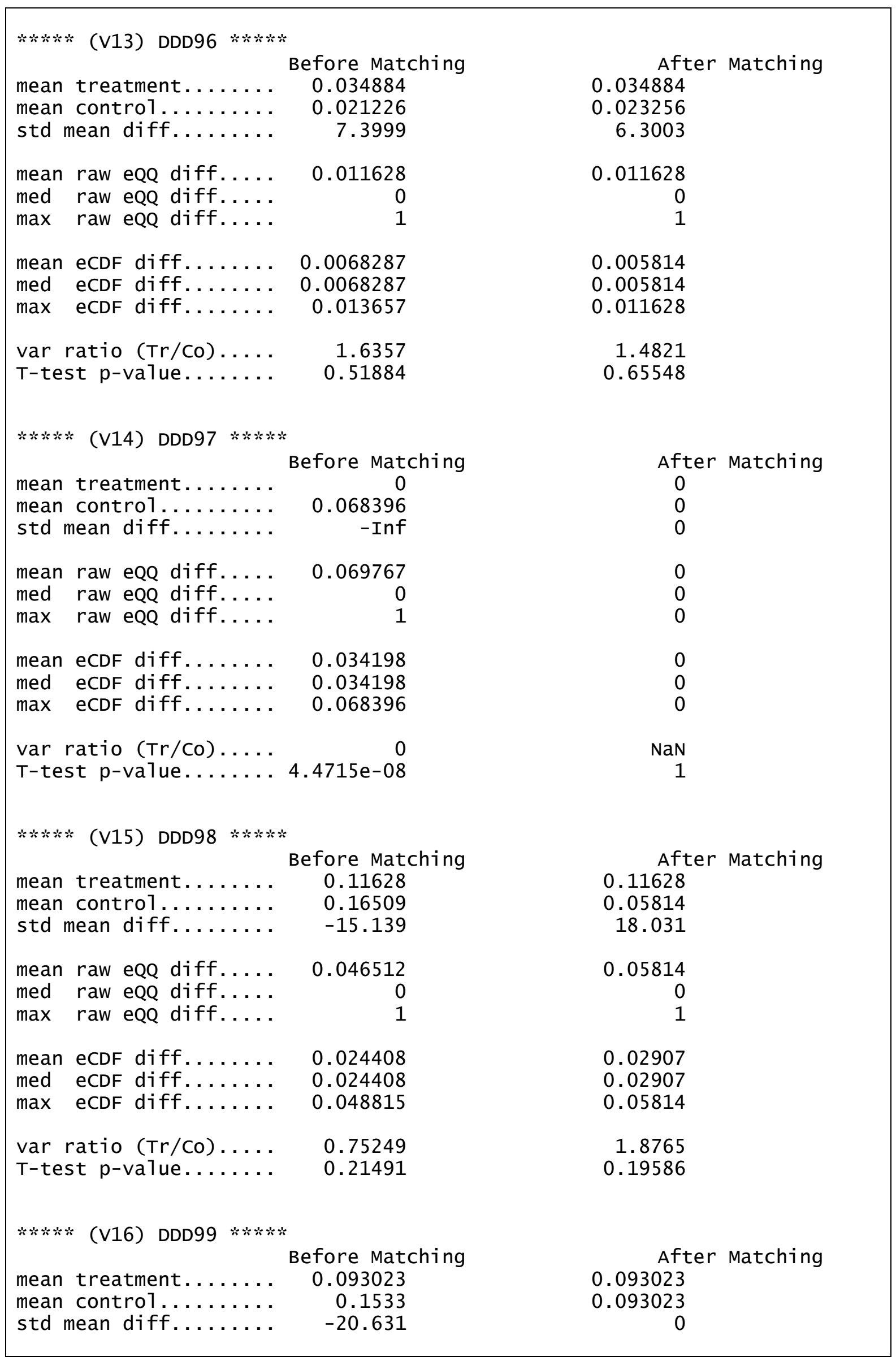




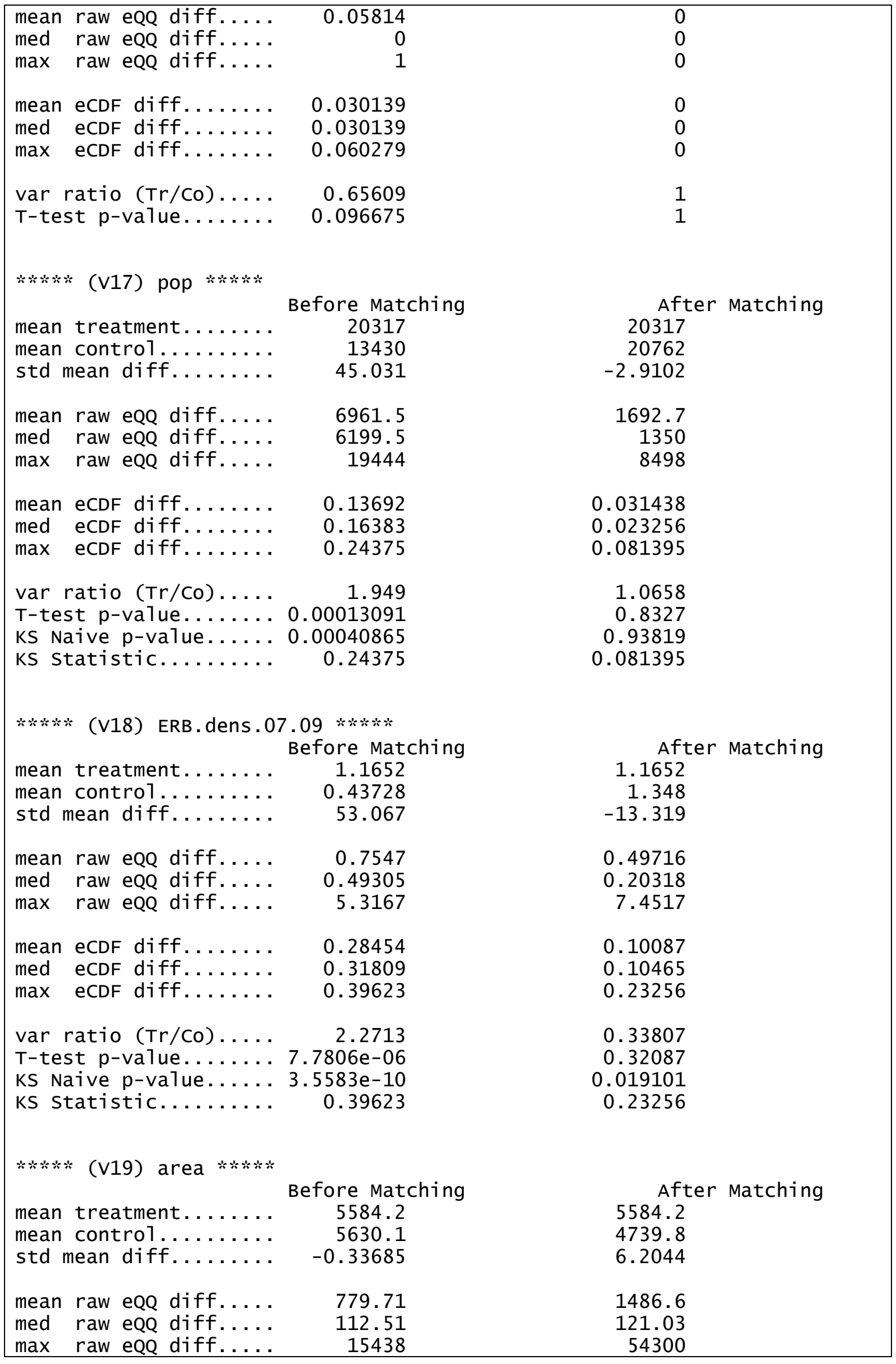




\begin{tabular}{|c|c|c|}
\hline $\begin{array}{l}\text { mean eCDF diff. } \ldots \ldots \\
\text { med } \text { eCDF diff........ } \\
\text { max } \\
\text { eCDF diff....... }\end{array}$ & $\begin{array}{l}0.021088 \\
0.015687 \\
0.091433\end{array}$ & $\begin{array}{r}0.02716 \\
0.023256 \\
0.10465\end{array}$ \\
\hline $\begin{array}{l}\text { var ratio }(\mathrm{Tr} / \mathrm{Co}) \ldots \\
\text { T-test p-value........ } \\
\text { KS Naive p-value..... } \\
\text { KS Statistic......... }\end{array}$ & $\begin{array}{r}1.1191 \\
0.97712 \\
0.58842 \\
0.091433\end{array}$ & $\begin{array}{r}1.8931 \\
0.63836 \\
0.734 \\
0.10465\end{array}$ \\
\hline \multicolumn{3}{|c|}{$\begin{array}{l}\text { Before Matching Minimum p.value: } 3.5583 e-10 \\
\text { variable Name(s): ERB.dens.07.09 } \operatorname{Number}(s): 18 \\
\text { After Matching Minimum p.value: } 0.019101 \\
\text { variable Name(s): ERB.dens.07.09 Number(s): } 18\end{array}$} \\
\hline
\end{tabular}

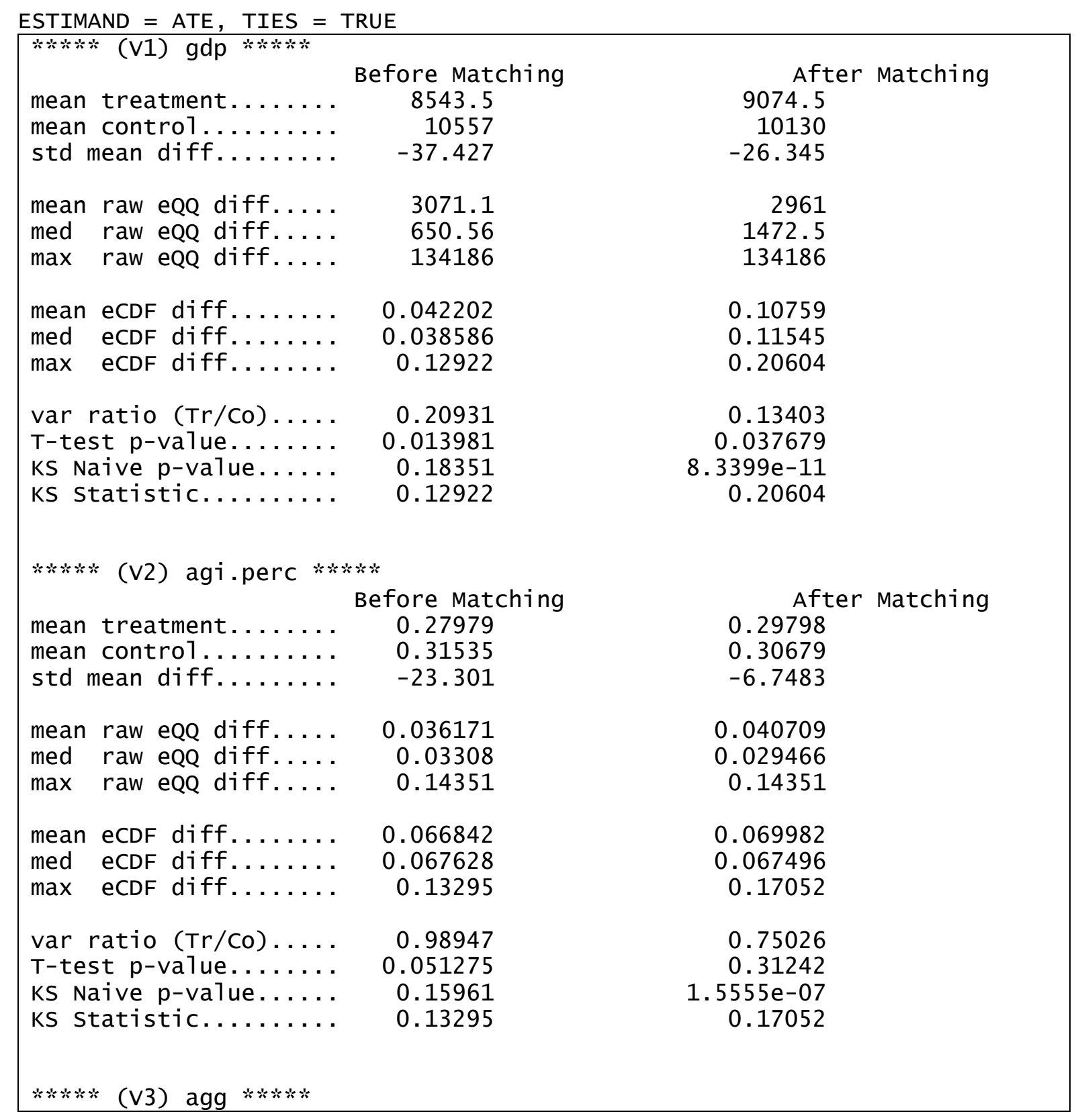




\begin{tabular}{|c|c|c|}
\hline $\begin{array}{l}\text { mean treatment } \ldots \ldots \\
\text { mean control } \ldots \ldots \\
\text { std mean diff. } \ldots \ldots\end{array}$ & $\begin{array}{c}\text { Before Matching } \\
0.84539 \\
1.4855 \\
-68.479\end{array}$ & $\begin{array}{l}\text { After Matching } \\
1.0911 \\
1.3924 \\
-25.853\end{array}$ \\
\hline $\begin{array}{ll}\text { mean } & \text { raw eQQ diff..... } \\
\text { med } & \text { raw eQQ diff..... } \\
\text { max } & \text { raw eQQ diff.... }\end{array}$ & $\begin{array}{r}1.1074 \\
0.24974 \\
54.81\end{array}$ & $\begin{array}{r}0.39518 \\
0.17279 \\
54.81\end{array}$ \\
\hline $\begin{array}{l}\text { mean eCDF diff } \ldots \ldots \ldots \\
\text { med eCDF diff } \ldots \ldots \ldots \\
\max \text { eCDF diff } \ldots \ldots \ldots\end{array}$ & $\begin{array}{l}0.09977 \\
0.10306 \\
0.17798\end{array}$ & $\begin{array}{r}0.074834 \\
0.040853 \\
0.26643\end{array}$ \\
\hline $\begin{array}{l}\text { var ratio }(\mathrm{Tr} / \mathrm{Co}) \ldots . . \\
\text { T-test } p \text {-value....... } \\
\text { KS Naive p-value..... } \\
\text { KS Statistic........ }\end{array}$ & $\begin{array}{r}0.080589 \\
0.0007688 \\
0.021564 \\
0.17798\end{array}$ & $\begin{array}{r}0.14797 \\
0.040916 \\
<2.22 \mathrm{e}-16 \\
0.26643\end{array}$ \\
\hline $\begin{array}{l}* * * * * \text { (V4) DDD65 } * * * * ; \\
\text { mean treatment...... } \\
\text { mean control } \ldots \ldots \ldots \\
\text { std mean diff....... }\end{array}$ & $\begin{array}{c}\text { Before Matching } \\
0.069767 \\
0.03066 \\
15.261\end{array}$ & $\begin{array}{l}\text { After Matching } \\
0.036275 \\
0.033333 \\
1.5715\end{array}$ \\
\hline $\begin{array}{ll}\text { mean } & \text { raw eQQ diff..... } \\
\text { med } & \text { raw eQQ diff..... } \\
\text { max } & \text { raw eQQ diff.... }\end{array}$ & $\begin{array}{r}0.034884 \\
0 \\
1\end{array}$ & $\begin{array}{r}0.0071048 \\
0 \\
1\end{array}$ \\
\hline $\begin{array}{l}\text { mean eCDF diff } \ldots \ldots \ldots \\
\text { med eCDF diff } \ldots \ldots \ldots \\
\max \text { eCDF diff....... }\end{array}$ & $\begin{array}{l}0.019554 \\
0.019554 \\
0.039107\end{array}$ & $\begin{array}{l}0.0035524 \\
0.0035524 \\
0.0071048\end{array}$ \\
\hline $\begin{array}{l}\text { var ratio }(\mathrm{Tr} / \mathrm{Co}) \ldots . . . \\
\text { T-test } p \text {-value...... }\end{array}$ & $\begin{array}{r}2.2042 \\
0.17865\end{array}$ & $\begin{array}{r}1.0849 \\
0.78251\end{array}$ \\
\hline $\begin{array}{l}* * * * * \text { (V5) DDD66 } * * * * ; \\
\text { mean treatment...... } \\
\text { mean control } \ldots \ldots \ldots \\
\text { std mean diff....... }\end{array}$ & $\begin{array}{c}\text { Before Matching } \\
0.069767 \\
0.066038 \\
1.4555\end{array}$ & $\begin{array}{l}\text { After Matching } \\
0.05 \\
0.066013 \\
-7.3401\end{array}$ \\
\hline $\begin{array}{ll}\text { mean } & \text { raw eQQ diff..... } \\
\text { med } & \text { raw eQQ diff..... } \\
\text { max } & \text { raw eQQ diff.... }\end{array}$ & $\begin{array}{l}0 \\
0 \\
0\end{array}$ & $\begin{array}{r}0.023091 \\
0 \\
1\end{array}$ \\
\hline $\begin{array}{l}\text { mean eCDF diff } \ldots \ldots \ldots \\
\text { med eCDF diff........ } \\
\max \text { eCDF diff...... }\end{array}$ & $\begin{array}{l}0.0018649 \\
0.0018649 \\
0.0037297\end{array}$ & $\begin{array}{l}0.011545 \\
0.011545 \\
0.023091\end{array}$ \\
\hline $\begin{array}{l}\text { var ratio }(\mathrm{Tr} / \mathrm{Co}) \ldots . . . \\
\text { T-test } p \text {-value...... }\end{array}$ & $\begin{array}{r}1.0621 \\
0.90177\end{array}$ & $\begin{array}{l}0.77041 \\
0.27149\end{array}$ \\
\hline $\begin{array}{l}* * * * * \text { (V6) DDD68 } * * * * ; \\
\text { mean treatment...... } \\
\text { mean control } \ldots \ldots \ldots \\
\text { std mean diff. } \ldots \ldots \ldots\end{array}$ & $\begin{array}{l}\text { Before Matching } \\
0.023256 \\
0.035377 \\
-7.9958\end{array}$ & $\begin{array}{l}\text { After Matching } \\
0.043137 \\
0.03366 \\
4.6601\end{array}$ \\
\hline
\end{tabular}




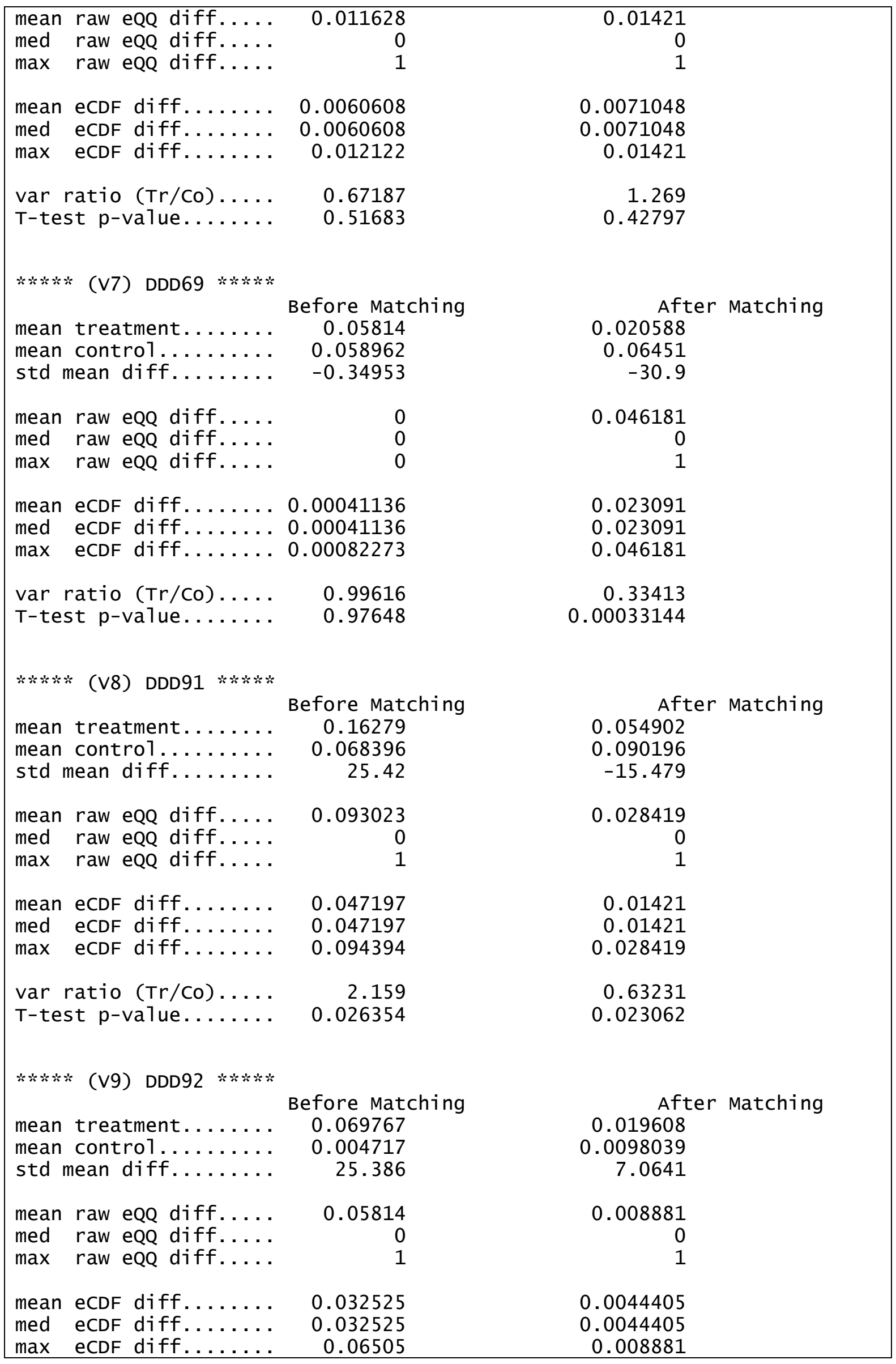




\begin{tabular}{|c|c|c|}
\hline $\begin{array}{l}\text { var ratio }(\mathrm{Tr} / \mathrm{Co}) \ldots . . \\
\text { T-test } p \text {-value...... }\end{array}$ & $\begin{array}{r}13.954 \\
0.02171\end{array}$ & $\begin{array}{r}1.9802 \\
0.13143\end{array}$ \\
\hline \multicolumn{3}{|c|}{$* * * * *$ (V10) DDD93 $* * * * *$} \\
\hline & Before Matching & After Matching \\
\hline mean treatment....... & 0.081395 & 0.034314 \\
\hline mean control $\ldots \ldots \ldots$ & 0.018868 & 0.032353 \\
\hline std mean diff........ & 22.734 & 1.0761 \\
\hline mean raw eQQ diff..... & 0.05814 & 0.0017762 \\
\hline med raw eQQ diff..... & 0 & 0 \\
\hline $\max$ raw eQQ diff.... & 1 & 1 \\
\hline mean eCDF diff....... & 0.031264 & 0.0008881 \\
\hline med eCDF diff........ & 0.031264 & 0.0008881 \\
\hline $\max$ eCDF diff....... & 0.062527 & 0.0017762 \\
\hline var ratio $(\mathrm{Tr} / \mathrm{Co}) \ldots$. & 4.0769 & 1.0585 \\
\hline T-test p-value....... & 0.042403 & 0.8552 \\
\hline \multicolumn{3}{|c|}{$* * * * *$ (V11) DDD94 $* * * * *$} \\
\hline & Before Matching & After Matching \\
\hline mean treatment....... & 0.10465 & 0.021569 \\
\hline mean control......... & 0.0070755 & 0.02549 \\
\hline std mean diff........ & 31.691 & -2.6969 \\
\hline mean raw eQQ diff..... & 0.093023 & 0.0035524 \\
\hline med raw eQQ diff..... & 0 & 0 \\
\hline max raw eQQ diff.... & 1 & 1 \\
\hline mean eCDF diff....... & 0.048788 & 0.0017762 \\
\hline med eCDF diff........ & 0.048788 & 0.0017762 \\
\hline $\max$ eCDF diff....... & 0.097576 & 0.0035524 \\
\hline var ratio $(\mathrm{Tr} / \mathrm{Co}) \ldots$. & 13.462 & 0.84956 \\
\hline T-test p-value....... & 0.004489 & 0.63748 \\
\hline \multicolumn{3}{|c|}{$* * * * *$ (V12) DDD95 $* * * * *$} \\
\hline & Before Matching & After Matching \\
\hline mean treatment....... & 0.034884 & 0.016667 \\
\hline mean control......... & 0.023585 & 0.023203 \\
\hline std mean diff........ & 6.122 & -5.1004 \\
\hline mean raw eQQ diff..... & 0.011628 & 0.0071048 \\
\hline med raw eQQ diff.... & 0 & 0 \\
\hline $\max$ raw eQQ diff.... & 1 & 1 \\
\hline mean eCDF diff........ & 0.0056494 & 0.0035524 \\
\hline med eCDF diff........ & 0.0056494 & 0.0035524 \\
\hline $\max$ eCDF diff....... & 0.011299 & 0.0071048 \\
\hline var ratio $(\operatorname{Tr} / \mathrm{Co}) \ldots$. & 1.4757 & 0.72312 \\
\hline T-test p-value....... & 0.59558 & 0.45987 \\
\hline \multicolumn{3}{|c|}{$* * * * *$ (V13) DDD96 $* * * * *$} \\
\hline & Before Matching & After Matching \\
\hline
\end{tabular}




\begin{tabular}{|c|c|c|}
\hline $\begin{array}{l}\text { mean treatment } \ldots \ldots \ldots \\
\text { mean control.......... } \\
\text { std mean diff....... }\end{array}$ & $\begin{array}{r}0.034884 \\
0.021226 \\
7.3999\end{array}$ & $\begin{array}{r}0.012745 \\
0.020588 \\
-6.9852\end{array}$ \\
\hline $\begin{array}{ll}\text { mean } & \text { raw eQQ diff..... } \\
\text { med } & \text { raw eQQ diff..... } \\
\text { max } & \text { raw eQQ diff..... }\end{array}$ & $\begin{array}{r}0.011628 \\
0 \\
1\end{array}$ & $\begin{array}{r}0.0017762 \\
0 \\
1\end{array}$ \\
\hline $\begin{array}{l}\text { mean eCDF diff....... } \\
\text { med eCDF diff....... } \\
\text { max eCDF diff....... }\end{array}$ & $\begin{array}{r}0.0068287 \\
0.0068287 \\
0.013657\end{array}$ & $\begin{array}{l}0.0008881 \\
0.0008881 \\
0.0017762\end{array}$ \\
\hline $\begin{array}{l}\text { var ratio }(\mathrm{Tr} / \mathrm{Co}) \ldots . \\
\text { T-test } p \text {-value....... }\end{array}$ & $\begin{array}{r}1.6357 \\
0.51884\end{array}$ & $\begin{array}{r}0.624 \\
0.33199\end{array}$ \\
\hline $\begin{array}{l}* * * * \text { (V14) DDD97 } * * * * * \\
\text { mean treatment } \ldots \ldots \ldots \\
\text { mean control } \ldots \ldots \ldots \\
\text { std mean diff........ }\end{array}$ & $\begin{array}{c}\text { Before Matching } \\
0 \\
0.068396 \\
\text {-Inf }\end{array}$ & $\begin{array}{c}\text { After Matching } \\
0 \\
0.056863 \\
\text {-Inf }\end{array}$ \\
\hline $\begin{array}{ll}\text { mean } & \text { raw eQQ diff..... } \\
\text { med } & \text { raw eQQ diff..... } \\
\text { max } & \text { raw eQQ diff..... }\end{array}$ & $\begin{array}{r}0.069767 \\
0 \\
1\end{array}$ & $\begin{array}{r}0.05151 \\
0 \\
1\end{array}$ \\
\hline $\begin{array}{l}\text { mean eCDF diff. } \ldots \ldots \\
\text { med eCDF diff....... } \\
\text { max } \\
\text { eCDF diff....... }\end{array}$ & $\begin{array}{l}0.034198 \\
0.034198 \\
0.068396\end{array}$ & $\begin{array}{r}0.025755 \\
0.025755 \\
0.05151\end{array}$ \\
\hline $\begin{array}{l}\text { var ratio }(\operatorname{Tr} / \mathrm{Co}) \ldots \\
\text { T-test } p \text {-value....... }\end{array}$ & $\begin{array}{r}0 \\
4.4715 \mathrm{e}-08\end{array}$ & $\begin{array}{r}0 \\
4.7254 \mathrm{e}-08\end{array}$ \\
\hline $\begin{array}{l}* * * * * \text { (V15) DDD98 } * * * * * \\
\text { mean treatment } \ldots \ldots \ldots \\
\text { mean control. } \ldots \ldots \ldots \\
\text { std mean diff....... }\end{array}$ & $\begin{array}{l}\text { Before Matching } \\
0.11628 \\
0.16509 \\
-15.139\end{array}$ & $\begin{array}{l}\text { After Matching } \\
0.061765 \\
0.15359 \\
-38.109\end{array}$ \\
\hline $\begin{array}{ll}\text { mean } & \text { raw eQQ diff..... } \\
\text { med } & \text { raw eQQ diff..... } \\
\text { max } & \text { raw eQQ diff..... }\end{array}$ & $\begin{array}{r}0.046512 \\
0 \\
1\end{array}$ & $\begin{array}{r}0.092362 \\
0 \\
1\end{array}$ \\
\hline $\begin{array}{l}\text { mean eCDF diff. } \ldots \ldots \\
\text { med eCDF diff...... } \\
\text { max } \text { eCDF diff...... }\end{array}$ & $\begin{array}{l}0.024408 \\
0.024408 \\
0.048815\end{array}$ & $\begin{array}{l}0.046181 \\
0.046181 \\
0.092362\end{array}$ \\
\hline $\begin{array}{l}\text { var ratio }(\mathrm{Tr} / \mathrm{Co}) \ldots . . \\
\text { T-test } p \text {-value...... }\end{array}$ & $\begin{array}{l}0.75249 \\
0.21491\end{array}$ & $\begin{array}{r}0.44576 \\
3.9835 \mathrm{e}-06\end{array}$ \\
\hline $\begin{array}{l}* * * * \text { (V16) DDD99 } * * * * * \\
\text { mean treatment....... } \\
\text { mean control........ } \\
\text { std mean diff........ }\end{array}$ & $\begin{array}{l}\text { Before Matching } \\
0.093023 \\
0.1533 \\
-20.631\end{array}$ & $\begin{array}{l}\text { After Matching } \\
0.077451 \\
0.13882 \\
-22.937\end{array}$ \\
\hline $\begin{array}{ll}\text { mean } & \text { raw eQQ diff..... } \\
\text { med } & \text { raw eQQ diff..... } \\
\text { max } & \text { raw eQQ diff..... }\end{array}$ & $\begin{array}{r}0.05814 \\
0 \\
1\end{array}$ & $\begin{array}{r}0.071048 \\
0 \\
1\end{array}$ \\
\hline
\end{tabular}




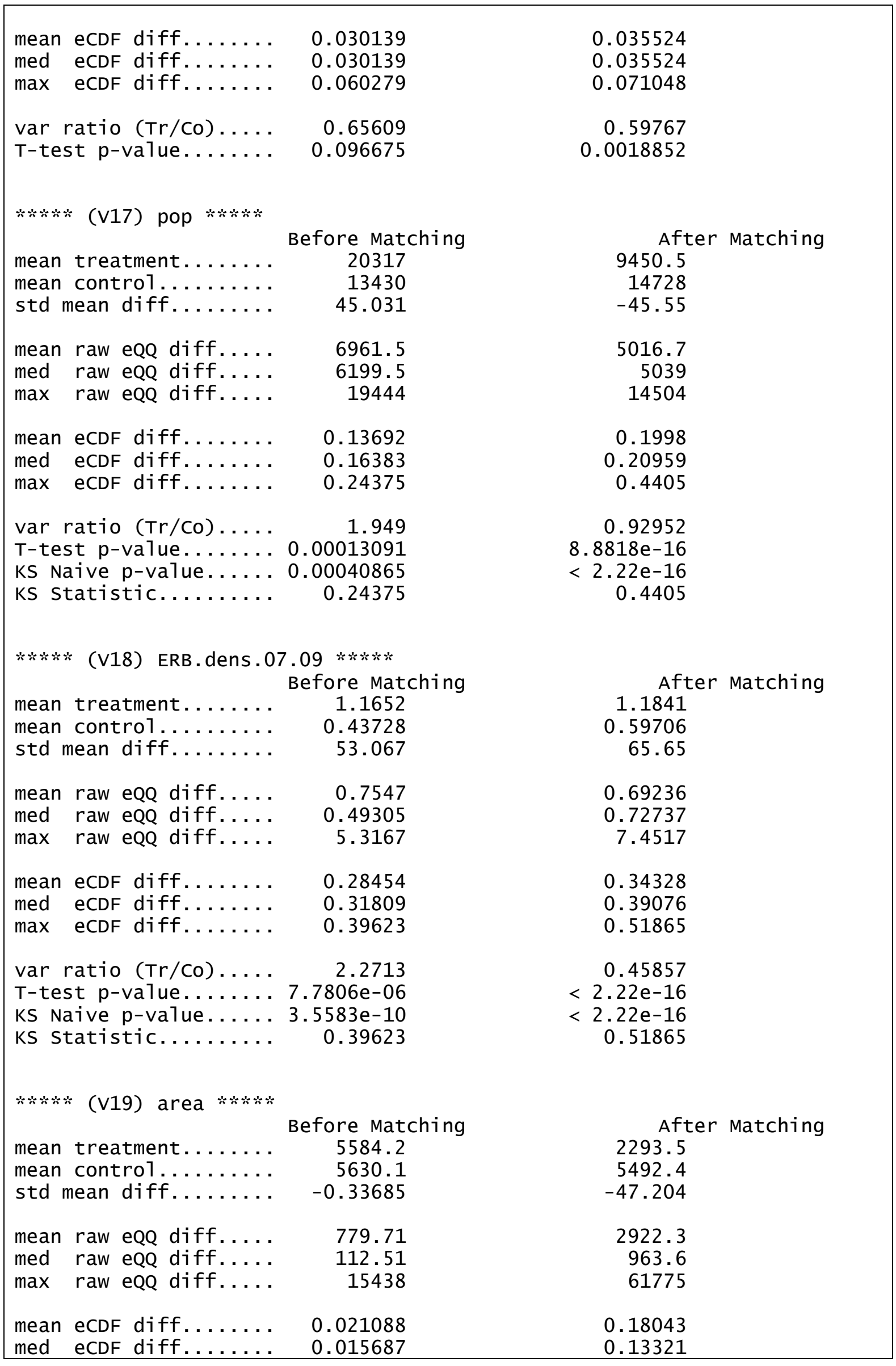




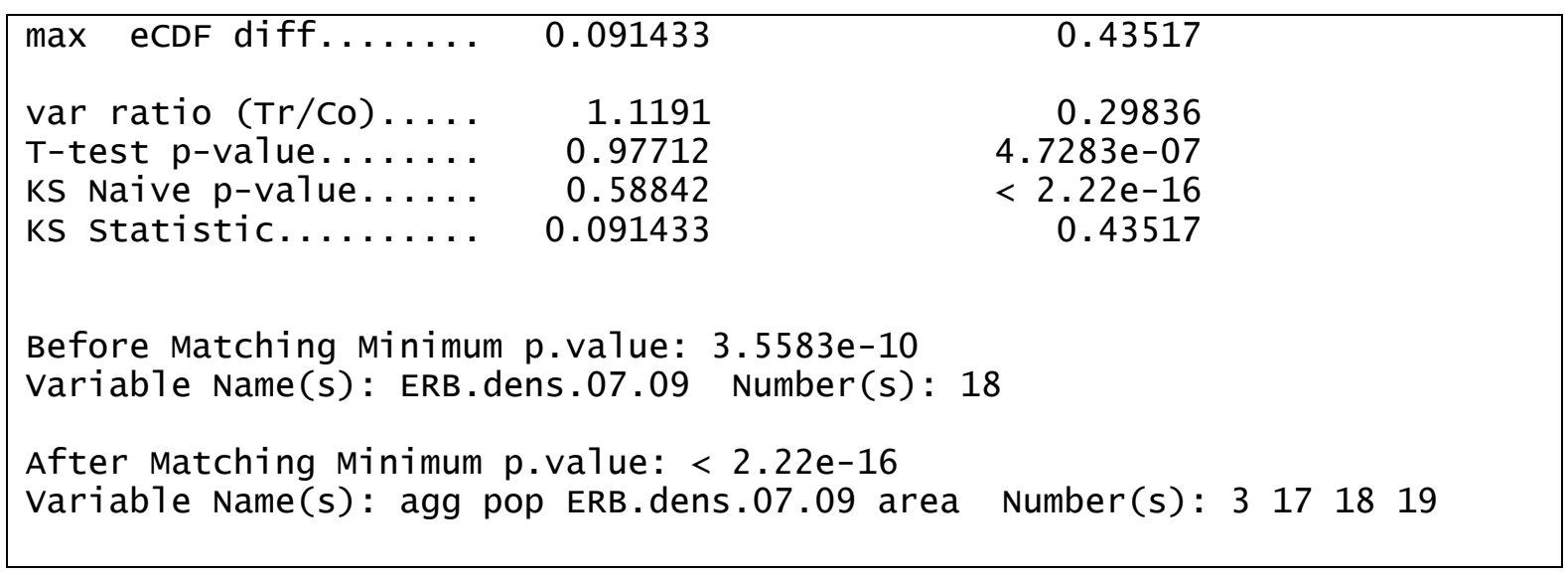

\begin{tabular}{|c|c|c|}
\hline \multicolumn{3}{|l|}{$* * * * *$ (V1) gdp $* * * * *$} \\
\hline & Before Matching & After Matching \\
\hline mean treatment....... & 8543.5 & 9182.2 \\
\hline mean control......... & 10557 & 10557 \\
\hline std mean diff........ & -37.427 & -37.494 \\
\hline mean raw eQQ diff..... & 3071.1 & 3625.9 \\
\hline med raw eQQ diff..... & 650.56 & 1752.9 \\
\hline $\max$ raw eQQ diff.... & 134186 & 134186 \\
\hline mean eCDF diff....... & 0.042202 & 0.12721 \\
\hline med eCDF diff....... & 0.038586 & 0.13379 \\
\hline $\max$ eCDF diff....... & 0.12922 & 0.25397 \\
\hline var ratio (Tr/Co) ..... & 0.20931 & 0.097224 \\
\hline T-test p-value....... & 0.013981 & 0.020069 \\
\hline KS Naive $p$-value...... & 0.18351 & $8.8662 \mathrm{e}-13$ \\
\hline KS statistic......... & 0.12922 & 0.25397 \\
\hline \multicolumn{3}{|c|}{$* * * * *$ (V2) agi.perc $* * * * *$} \\
\hline & Before Matching & After Matching \\
\hline mean treatment....... & 0.27979 & 0.30167 \\
\hline mean control........ & 0.31535 & 0.31535 \\
\hline std mean diff........ & -23.301 & -10.901 \\
\hline mean raw eQQ diff..... & 0.036171 & 0.051774 \\
\hline med raw eQQ diff..... & 0.03308 & 0.037986 \\
\hline $\max$ raw eQQ diff.... & 0.14351 & 0.14724 \\
\hline mean eCDF diff....... & 0.066842 & 0.089779 \\
\hline med eCDF diff....... & 0.067628 & 0.080499 \\
\hline $\max$ eCDF diff....... & 0.13295 & 0.21315 \\
\hline var ratio $(\mathrm{Tr} / \mathrm{Co}) \ldots$. & 0.98947 & 0.6693 \\
\hline T-test $p$-value....... & 0.051275 & 0.15452 \\
\hline KS Naive p-value...... & 0.15961 & $3.9754 \mathrm{e}-09$ \\
\hline KS statistic......... & 0.13295 & 0.21315 \\
\hline$* * * * *$ (V3) agg $* * * * *$ & & \\
\hline mean treatment....... & $\begin{array}{l}\text { Before Matching } \\
\quad 0.84539\end{array}$ & $\begin{array}{l}\text { After Matching } \\
1.141\end{array}$ \\
\hline
\end{tabular}




\begin{tabular}{|c|c|c|}
\hline $\begin{array}{l}\text { mean control } \ldots \ldots \ldots \\
\text { std mean diff......... }\end{array}$ & $\begin{array}{r}1.4855 \\
-68.479\end{array}$ & $\begin{array}{r}1.4855 \\
-28.678\end{array}$ \\
\hline $\begin{array}{ll}\text { mean } & \text { raw eQQ diff..... } \\
\text { med } & \text { raw eQQ diff..... } \\
\text { max } & \text { raw eQQ diff.... }\end{array}$ & $\begin{array}{r}1.1074 \\
0.24974 \\
54.81\end{array}$ & $\begin{array}{r}0.48457 \\
0.21471 \\
54.81\end{array}$ \\
\hline $\begin{array}{l}\text { mean eCDF diff........ } \\
\text { med eCDF diff...... } \\
\text { max eCDF diff....... }\end{array}$ & $\begin{array}{l}0.09977 \\
0.10306 \\
0.17798\end{array}$ & $\begin{array}{r}0.090917 \\
0.058957 \\
0.29478\end{array}$ \\
\hline $\begin{array}{l}\text { var ratio }(\mathrm{Tr} / \mathrm{Co}) \ldots . . \\
\text { T-test } p \text {-value...... } \\
\text { KS Naive p-value..... } \\
\text { KS Statistic........ }\end{array}$ & $\begin{array}{r}0.080589 \\
0.0007688 \\
0.021564 \\
0.17798\end{array}$ & $\begin{array}{r}0.13314 \\
0.049131 \\
<2.22 \mathrm{e}-16 \\
0.29478\end{array}$ \\
\hline 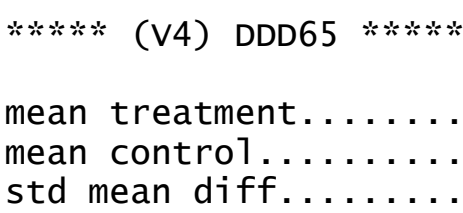 & $\begin{array}{c}\text { Before Matching } \\
0.069767 \\
0.03066 \\
15.261\end{array}$ & $\begin{array}{l}\text { After Matching } \\
0.029481 \\
0.03066 \\
-0.69633\end{array}$ \\
\hline $\begin{array}{ll}\text { mean } & \text { raw eQQ diff..... } \\
\text { med } & \text { raw eQQ diff..... } \\
\text { max } & \text { raw eQQ diff..... }\end{array}$ & $\begin{array}{r}0.034884 \\
0 \\
1\end{array}$ & $\begin{array}{l}0 \\
0 \\
0\end{array}$ \\
\hline $\begin{array}{l}\text { mean eCDF diff. } \ldots \ldots \ldots \\
\text { med eCDF diff....... } \\
\text { max eCDF diff....... }\end{array}$ & $\begin{array}{l}0.019554 \\
0.019554 \\
0.039107\end{array}$ & $\begin{array}{l}0 \\
0 \\
0\end{array}$ \\
\hline $\begin{array}{l}\text { var ratio }(\mathrm{Tr} / \mathrm{Co}) \ldots . . . \\
\text { T-test } p \text {-value...... }\end{array}$ & $\begin{array}{r}2.2042 \\
0.17865\end{array}$ & $\begin{array}{l}0.96271 \\
0.91418\end{array}$ \\
\hline $\begin{array}{l}* * * * * \text { (V5) DDD66 } * * * * * \\
\text { mean treatment....... } \\
\text { mean control........ } \\
\text { std mean diff....... }\end{array}$ & $\begin{array}{c}\text { Before Matching } \\
0.069767 \\
0.066038 \\
1.4555\end{array}$ & $\begin{array}{l}\text { After Matching } \\
0.045991 \\
0.066038 \\
-9.5594\end{array}$ \\
\hline $\begin{array}{ll}\text { mean } & \text { raw eQQ diff..... } \\
\text { med } & \text { raw eQQ diff..... } \\
\text { max } & \text { raw eQQ diff..... }\end{array}$ & $\begin{array}{l}0 \\
0 \\
0\end{array}$ & $\begin{array}{r}0.022676 \\
0 \\
1\end{array}$ \\
\hline $\begin{array}{l}\text { mean eCDF diff. } \ldots \ldots \ldots \\
\text { med eCDF diff. } \ldots \ldots \\
\text { max } \\
\max \end{array}$ & $\begin{array}{l}0.0018649 \\
0.0018649 \\
0.0037297\end{array}$ & $\begin{array}{l}0.011338 \\
0.011338 \\
0.022676\end{array}$ \\
\hline $\begin{array}{l}\text { var ratio }(\mathrm{Tr} / \mathrm{Co}) \ldots . . . \\
\text { T-test } p \text {-value...... }\end{array}$ & $\begin{array}{r}1.0621 \\
0.90177\end{array}$ & $\begin{array}{l}0.71138 \\
0.20747\end{array}$ \\
\hline 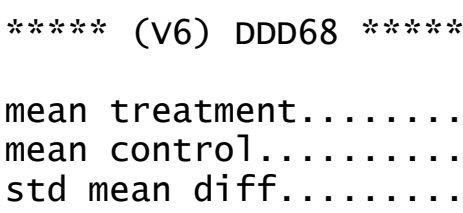 & $\begin{array}{l}\text { Before Matching } \\
0.023256 \\
0.035377 \\
-7.9958\end{array}$ & $\begin{array}{l}\text { After Matching } \\
0.04717 \\
0.035377 \\
5.5559\end{array}$ \\
\hline $\begin{array}{l}\text { mean raw eQQ diff..... } \\
\text { med raw eQQ diff..... }\end{array}$ & $\begin{array}{r}0.011628 \\
0\end{array}$ & $\begin{array}{r}0.011338 \\
0\end{array}$ \\
\hline
\end{tabular}




\begin{tabular}{|c|c|c|}
\hline $\max$ raw eQQ diff..... & 1 & 1 \\
\hline $\begin{array}{l}\text { mean eCDF diff } \ldots \ldots \ldots \\
\text { med eCDF diff. } \ldots \ldots \\
\max \text { eCDF diff....... }\end{array}$ & $\begin{array}{r}0.0060608 \\
0.0060608 \\
0.012122\end{array}$ & $\begin{array}{r}0.0056689 \\
0.0056689 \\
0.011338\end{array}$ \\
\hline $\begin{array}{l}\text { var ratio }(\mathrm{Tr} / \mathrm{Co}) \ldots . . \\
\text { T-test p-value...... }\end{array}$ & $\begin{array}{l}0.67187 \\
0.51683\end{array}$ & $\begin{array}{r}1.317 \\
0.38416\end{array}$ \\
\hline $\begin{array}{l}* * * * \text { (V7) DDD69 } * * * * * \\
\text { mean treatment....... } \\
\text { mean control....... } \\
\text { std mean diff....... }\end{array}$ & $\begin{array}{c}\text { Before Matching } \\
0.05814 \\
0.058962 \\
-0.34953\end{array}$ & $\begin{array}{l}\text { After Matching } \\
0.012972 \\
0.058962 \\
-40.597\end{array}$ \\
\hline $\begin{array}{ll}\text { mean } & \text { raw eQQ diff..... } \\
\text { med } & \text { raw eQQ diff..... } \\
\text { max } & \text { raw eQQ diff..... }\end{array}$ & $\begin{array}{l}0 \\
0 \\
0\end{array}$ & $\begin{array}{r}0.045351 \\
0 \\
1\end{array}$ \\
\hline $\begin{array}{l}\text { mean eCDF diff } \ldots \ldots \ldots \\
\text { med eCDF diff. } \ldots \ldots \\
\max \text { eCDF diff...... }\end{array}$ & $\begin{array}{l}0.00041136 \\
0.00041136 \\
0.00082273\end{array}$ & $\begin{array}{l}0.022676 \\
0.022676 \\
0.045351\end{array}$ \\
\hline $\begin{array}{l}\text { var ratio }(\mathrm{Tr} / \mathrm{Co}) \ldots . . \\
\text { T-test } p \text {-value...... }\end{array}$ & $\begin{array}{l}0.99616 \\
0.97648\end{array}$ & $\begin{array}{r}0.23075 \\
0.00023353\end{array}$ \\
\hline $\begin{array}{l}* * * * \text { (V8) DDD } 91 * * * * * \\
\text { mean treatment....... } \\
\text { mean control....... } \\
\text { std mean diff....... }\end{array}$ & $\begin{array}{c}\text { Before Matching } \\
0.16279 \\
0.068396 \\
25.42\end{array}$ & $\begin{array}{l}\text { After Matching } \\
0.033019 \\
0.068396 \\
-19.775\end{array}$ \\
\hline $\begin{array}{ll}\text { mean } & \text { raw eQQ diff..... } \\
\text { med } & \text { raw eQQ diff..... } \\
\text { max } & \text { raw eQQ diff..... }\end{array}$ & $\begin{array}{r}0.093023 \\
0 \\
1\end{array}$ & $\begin{array}{r}0.031746 \\
0 \\
1\end{array}$ \\
\hline $\begin{array}{l}\text { mean eCDF diff. } \ldots \ldots \\
\text { med eCDF diff. } \ldots \ldots \\
\max \text { eCDF diff...... }\end{array}$ & $\begin{array}{l}0.047197 \\
0.047197 \\
0.094394\end{array}$ & $\begin{array}{l}0.015873 \\
0.015873 \\
0.031746\end{array}$ \\
\hline $\begin{array}{l}\text { var ratio }(\mathrm{Tr} / \mathrm{Co}) \ldots . . . \\
\text { T-test } p \text {-value...... }\end{array}$ & $\begin{array}{r}2.159 \\
0.026354\end{array}$ & $\begin{array}{r}0.50109 \\
0.016009\end{array}$ \\
\hline $\begin{array}{l}* * * * \text { (V9) DDD92 } * * * * * \\
\text { mean treatment....... } \\
\text { mean control } \ldots \ldots \ldots \\
\text { std mean diff........ }\end{array}$ & $\begin{array}{c}\text { Before Matching } \\
0.069767 \\
0.004717 \\
25.386\end{array}$ & $\begin{array}{l}\text { After Matching } \\
0.009434 \\
0.004717 \\
4.8737\end{array}$ \\
\hline $\begin{array}{ll}\text { mean } & \text { raw eQQ diff..... } \\
\text { med } & \text { raw eQQ diff..... } \\
\text { max } & \text { raw eQQ diff..... }\end{array}$ & $\begin{array}{r}0.05814 \\
0 \\
1\end{array}$ & $\begin{array}{r}0.0045351 \\
0 \\
1\end{array}$ \\
\hline $\begin{array}{l}\text { mean eCDF diff. } \ldots \ldots \\
\text { med } \text { eCDF diff....... } \\
\max \text { eCDF diff...... }\end{array}$ & $\begin{array}{r}0.032525 \\
0.032525 \\
0.06505\end{array}$ & $\begin{array}{l}0.0022676 \\
0.0022676 \\
0.0045351\end{array}$ \\
\hline var ratio $(\mathrm{Tr} / \mathrm{Co}) \ldots$. & 13.954 & 1.9905 \\
\hline
\end{tabular}




\begin{tabular}{|c|c|c|}
\hline T-test p-value....... & 0.02171 & 0.31731 \\
\hline \multicolumn{3}{|c|}{$* * * * *$ (V10) DDD93 $* * * * *$} \\
\hline & Before Matching & After Matching \\
\hline mean treatment. ....... & 0.081395 & 0.024764 \\
\hline mean control........ & 0.018868 & 0.018868 \\
\hline std mean diff........ & 22.734 & 3.7896 \\
\hline mean raw eQQ diff..... & 0.05814 & 0.0068027 \\
\hline med raw eQQ diff..... & 0 & 0 \\
\hline max raw eQQ diff..... & 1 & 1 \\
\hline mean eCDF diff........ & 0.031264 & 0.0034014 \\
\hline med eCDF diff........ & 0.031264 & 0.0034014 \\
\hline $\max$ eCDF diff........ & 0.062527 & 0.0068027 \\
\hline var ratio $(\mathrm{Tr} / \mathrm{Co}) \ldots$. & 4.0769 & 1.3046 \\
\hline T-test p-value....... & 0.042403 & 0.56123 \\
\hline \multicolumn{3}{|c|}{$* * * * *$ (V11) DDD94 $* * * * *$} \\
\hline & Before Matching & After Matching \\
\hline mean treatment....... & 0.10465 & 0.004717 \\
\hline mean control........ & 0.0070755 & 0.0070755 \\
\hline std mean diff........ & 31.691 & -3.4381 \\
\hline mean raw eQQ diff..... & 0.093023 & 0.0022676 \\
\hline med raw eQQ diff.... & 0 & 0 \\
\hline $\max$ raw eQQ diff..... & 1 & 1 \\
\hline mean eCDF diff....... & 0.048788 & 0.0011338 \\
\hline med eCDF diff........ & 0.048788 & 0.0011338 \\
\hline $\max$ eCDF diff....... & 0.097576 & 0.0022676 \\
\hline var ratio $(\mathrm{Tr} / \mathrm{Co}) \ldots$. & 13.462 & 0.66825 \\
\hline T-test p-value....... & 0.004489 & 0.65487 \\
\hline \multicolumn{3}{|c|}{$* * * * *$ (V12) DDD95 $* * * * *$} \\
\hline & Before Matching & After Matching \\
\hline mean treatment........ & 0.034884 & 0.012972 \\
\hline mean control......... & 0.023585 & 0.023585 \\
\hline std mean diff........ & 6.122 & -9.3685 \\
\hline mean raw eQQ diff..... & 0.011628 & 0.0090703 \\
\hline med raw eQQ diff.... & 0 & 0 \\
\hline max raw eQQ diff..... & 1 & 1 \\
\hline mean eCDF diff........ & 0.0056494 & 0.0045351 \\
\hline med eCDF diff........ & 0.0056494 & 0.0045351 \\
\hline $\max$ eCDF diff....... & 0.011299 & 0.0090703 \\
\hline var ratio $(\mathrm{Tr} / \mathrm{Co}) \ldots$. & 1.4757 & 0.55598 \\
\hline T-test $p$-value...... & 0.59558 & 0.25295 \\
\hline \multicolumn{3}{|c|}{$* * * * *$ (V13) DDD96 $* * * * *$} \\
\hline mean treatment....... & Before Matching & After Matching \\
\hline $\begin{array}{l}\text { mean } \text { treatment } \ldots \ldots \ldots \\
\text { mean contro } 1 . . . \ldots \ldots\end{array}$ & $\begin{array}{l}0.034884 \\
0.021226\end{array}$ & $\begin{array}{r}0.0082547 \\
0.021226\end{array}$ \\
\hline
\end{tabular}




\begin{tabular}{|c|c|c|}
\hline std mean diff......... & 7.3999 & -14.32 \\
\hline mean raw eQQ diff..... & 0.011628 & 0.0090703 \\
\hline med raw eQQ diff..... & 0 & 0 \\
\hline $\max$ raw eQQ diff.... & 1 & 1 \\
\hline mean eCDF diff........ & 0.0068287 & 0.0045351 \\
\hline med eCDF diff........ & 0.0068287 & 0.0045351 \\
\hline $\max$ eCDF diff....... & 0.013657 & 0.0090703 \\
\hline var ratio $(\mathrm{Tr} / \mathrm{Co}) \ldots$ & 1.6357 & 0.39404 \\
\hline T-test p-value....... & 0.51884 & 0.11949 \\
\hline \multicolumn{3}{|l|}{ 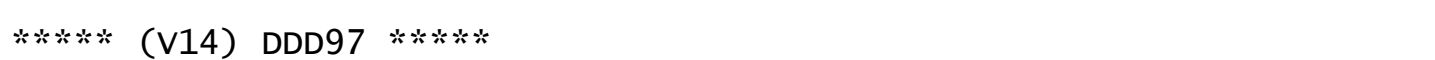 } \\
\hline & Before Matching & After Matching \\
\hline mean treatment....... & 0 & 0 \\
\hline mean control......... & 0.068396 & 0.068396 \\
\hline std mean diff......... & $-\operatorname{Inf}$ & - Inf \\
\hline mean raw eQQ diff.... & 0.069767 & 0.06576 \\
\hline med raw eQQ diff..... & 0 & 0 \\
\hline $\max$ raw eQQ diff.... & 1 & 1 \\
\hline mean eCDF diff....... & 0.034198 & 0.03288 \\
\hline med eCDF diff........ & 0.034198 & 0.03288 \\
\hline $\max$ eCDF diff....... & 0.068396 & 0.06576 \\
\hline var ratio $(\mathrm{Tr} / \mathrm{Co}) \ldots$. & 0 & 0 \\
\hline T-test p-value....... & $4.4715 e-08$ & $4.3167 e-08$ \\
\hline \multicolumn{3}{|l|}{$* * * * *$ (V15) DDD98 $* * * * *$} \\
\hline & Before Matching & After Matching \\
\hline mean treatment....... & 0.11628 & 0.050708 \\
\hline mean control......... & 0.16509 & 0.16509 \\
\hline std mean diff........ & -15.139 & -52.075 \\
\hline mean raw eQQ diff..... & 0.046512 & 0.11565 \\
\hline med raw eQQ diff..... & 0 & 0 \\
\hline $\max$ raw eQQ diff.... & 1 & 1 \\
\hline mean eCDF diff....... & 0.024408 & 0.057823 \\
\hline med eCDF diff........ & 0.024408 & 0.057823 \\
\hline $\max$ eCDF diff....... & 0.048815 & 0.11565 \\
\hline var ratio $(\mathrm{Tr} / \mathrm{Co}) \ldots$. & 0.75249 & 0.34922 \\
\hline T-test p-value....... & 0.21491 & $1.3889 \mathrm{e}-07$ \\
\hline \multicolumn{3}{|c|}{$* * * * *$ (V16) DDD99 $* * * * *$} \\
\hline & Before Matching & After Matching \\
\hline mean treatment....... & 0.093023 & 0.074292 \\
\hline mean control......... & 0.1533 & 0.1533 \\
\hline std mean diff......... & -20.631 & -30.092 \\
\hline mean raw eQQ diff..... & 0.05814 & 0.077098 \\
\hline med raw eQQ diff.... & 0 & 0 \\
\hline $\max$ raw eQQ diff..... & 1 & 1 \\
\hline mean eCDF diff.. & 0.030139 & 0.038549 \\
\hline
\end{tabular}




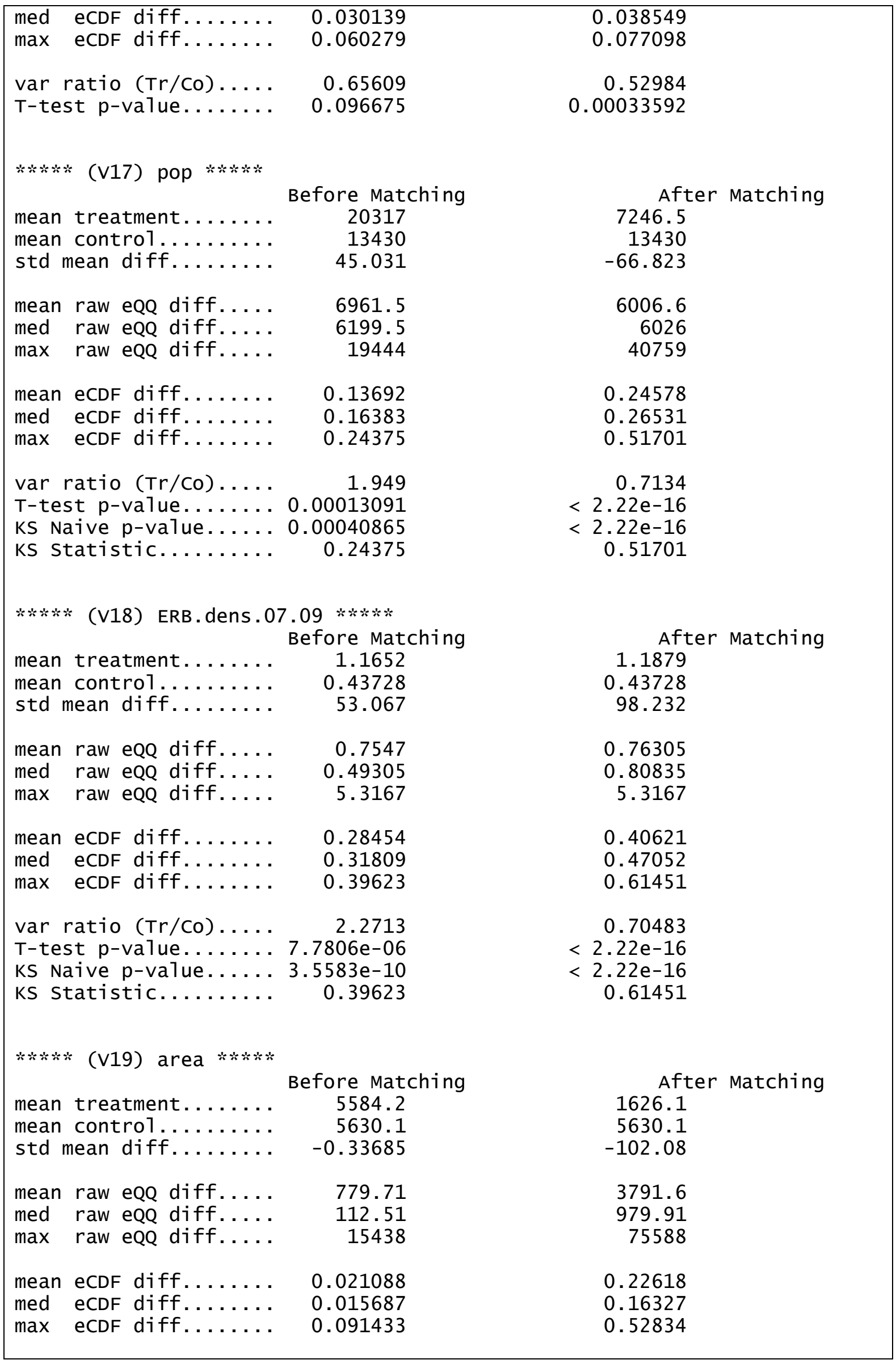




\begin{tabular}{|lrr|}
\hline var ratio (Tr/Co) ..... & 1.1191 & 0.09294 \\
T-test p-value....... & 0.97712 & $2.0649 \mathrm{e}-09$ \\
KS Naive p-value...... & 0.58842 & $2.22 \mathrm{e}-16$ \\
KS Statistic......... & 0.091433 & 0.52834
\end{tabular}

Before Matching Minimum p.value: $3.5583 \mathrm{e}-10$

variable Name(s): ERB.dens.07.09 Number(s): 18

After Matching Minimum p.value: $<2.22 \mathrm{e}-16$

Variable Name(s): agg pop ERB.dens.07.09 area Number(s): 3171819 
Checking the balance proprieties: graphs

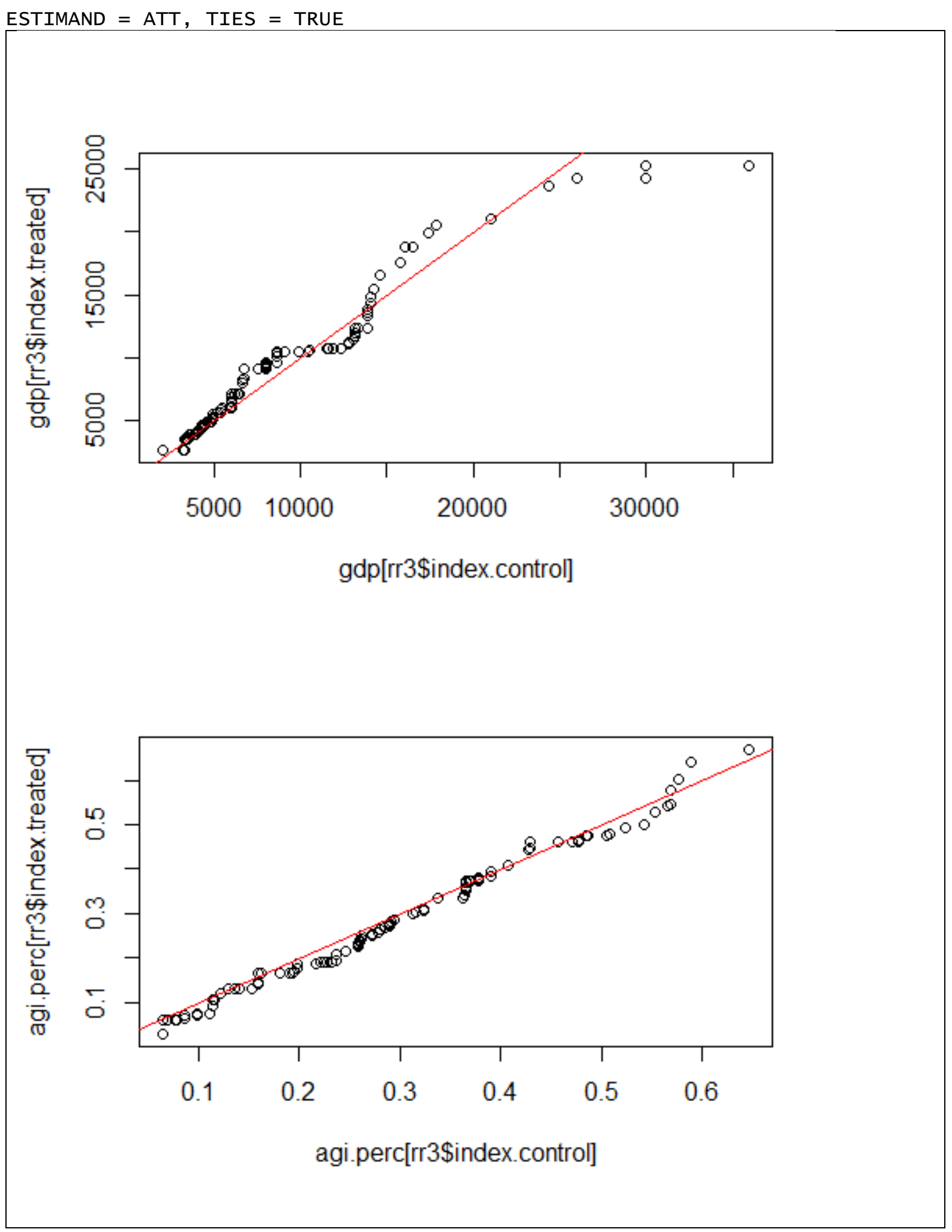




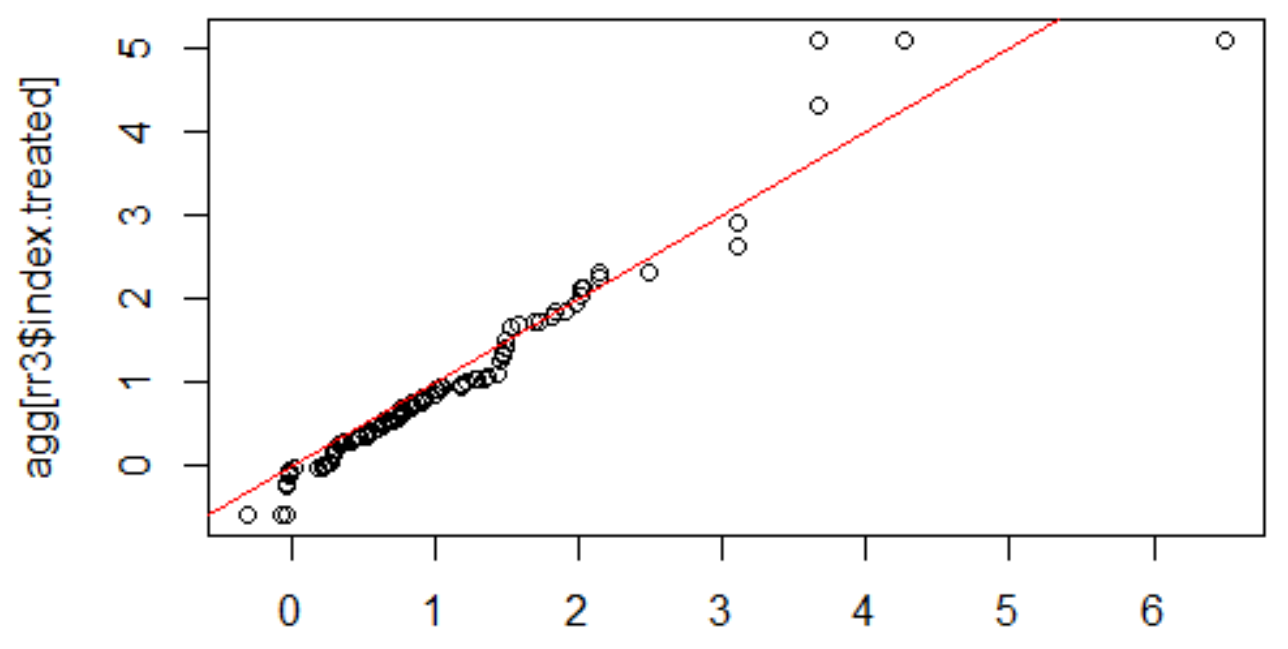

agg[rr3\$index.control]

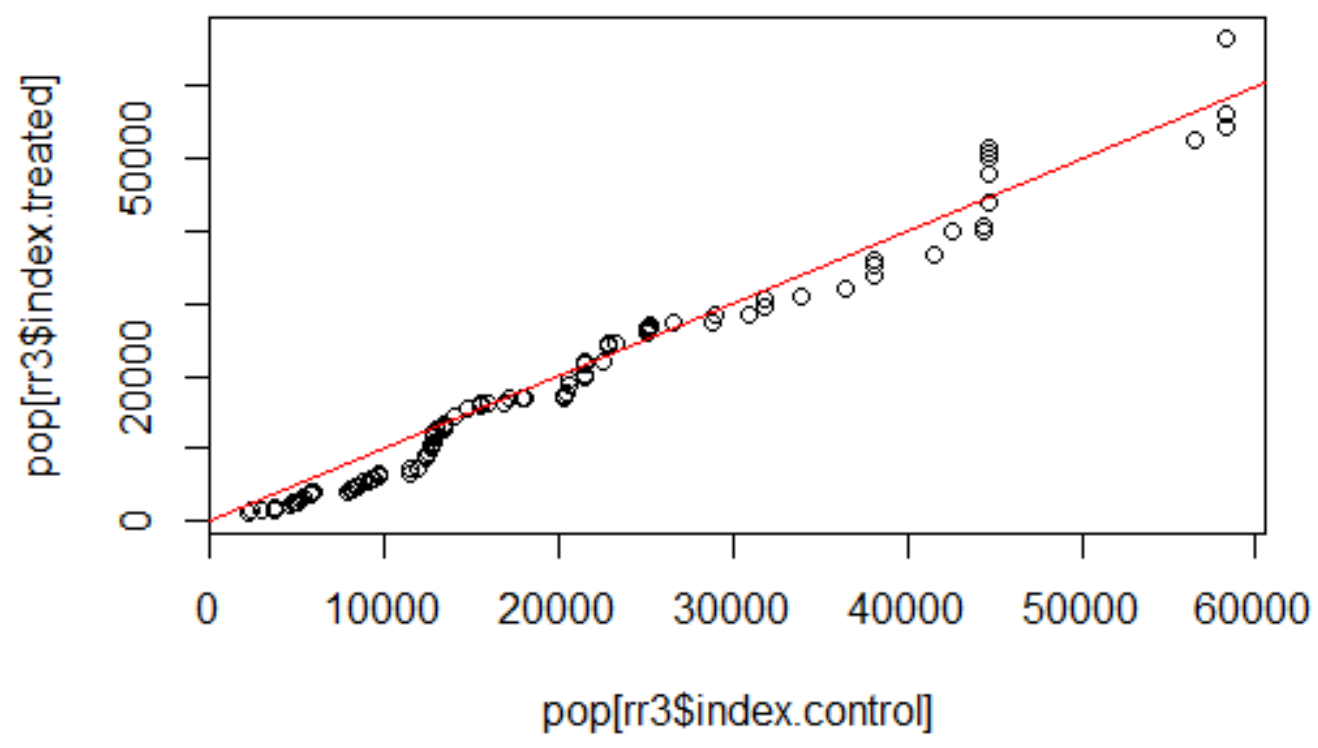




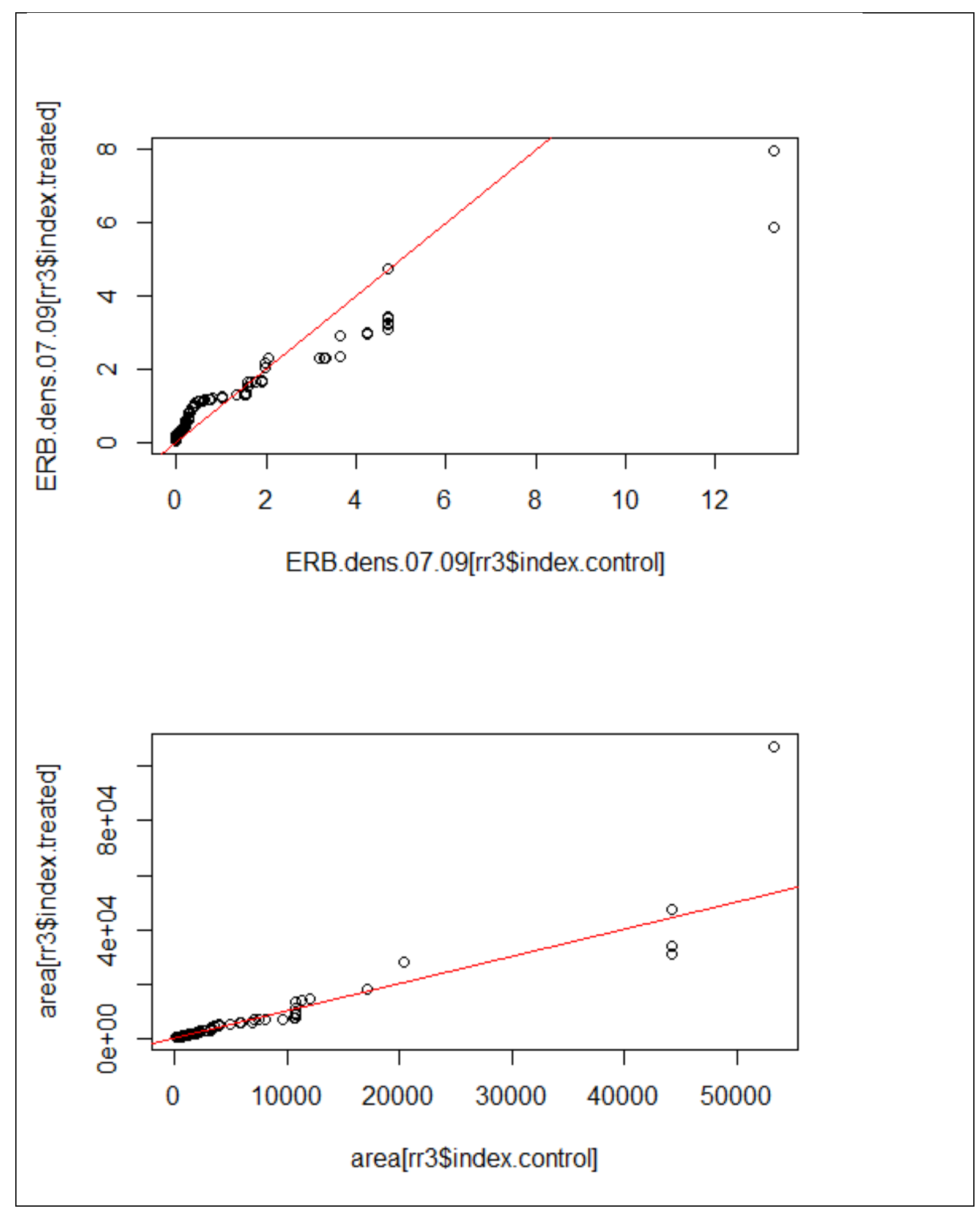


ESTIMAND $=$ ATE, TIES $=$ TRUE
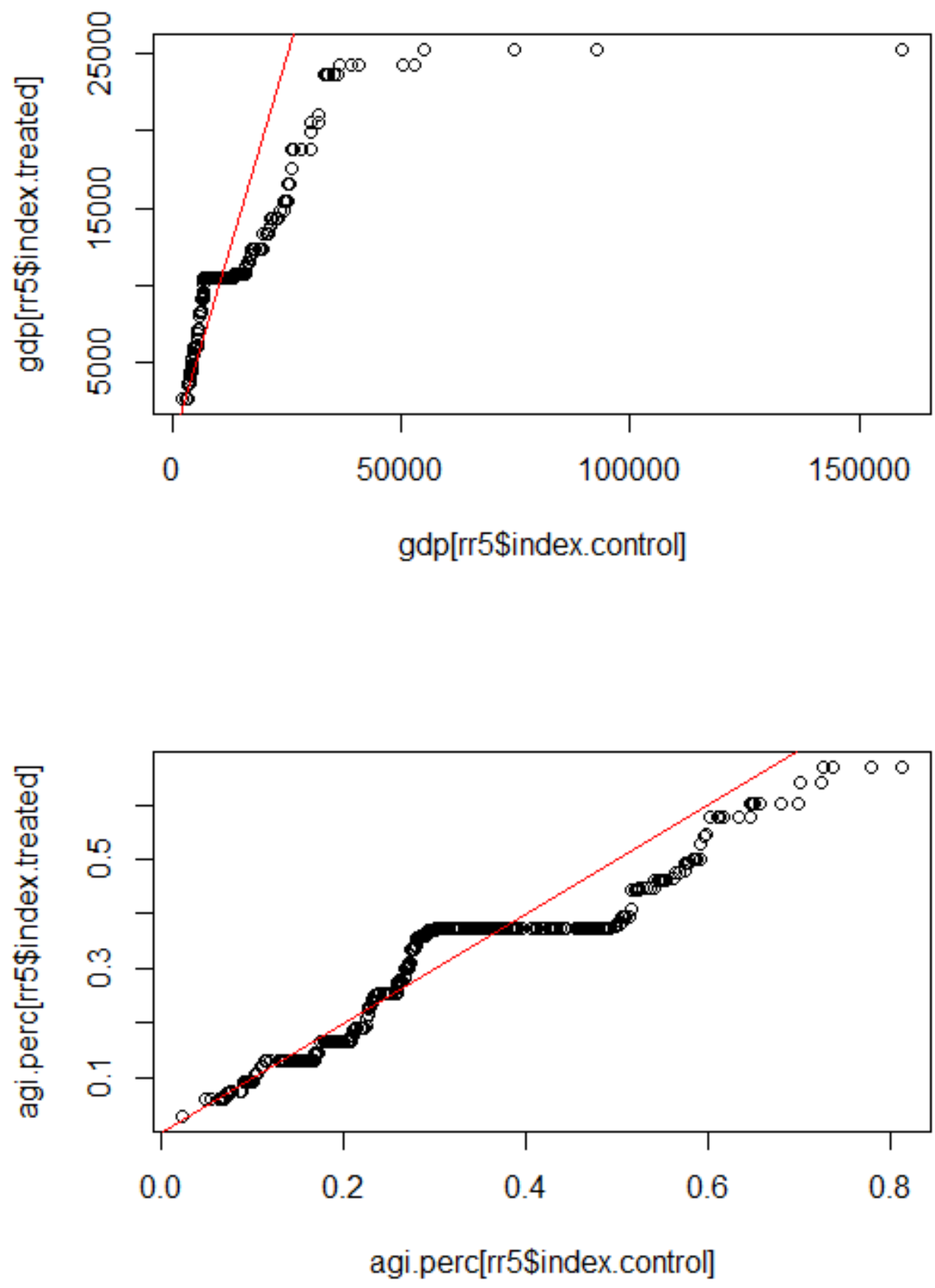


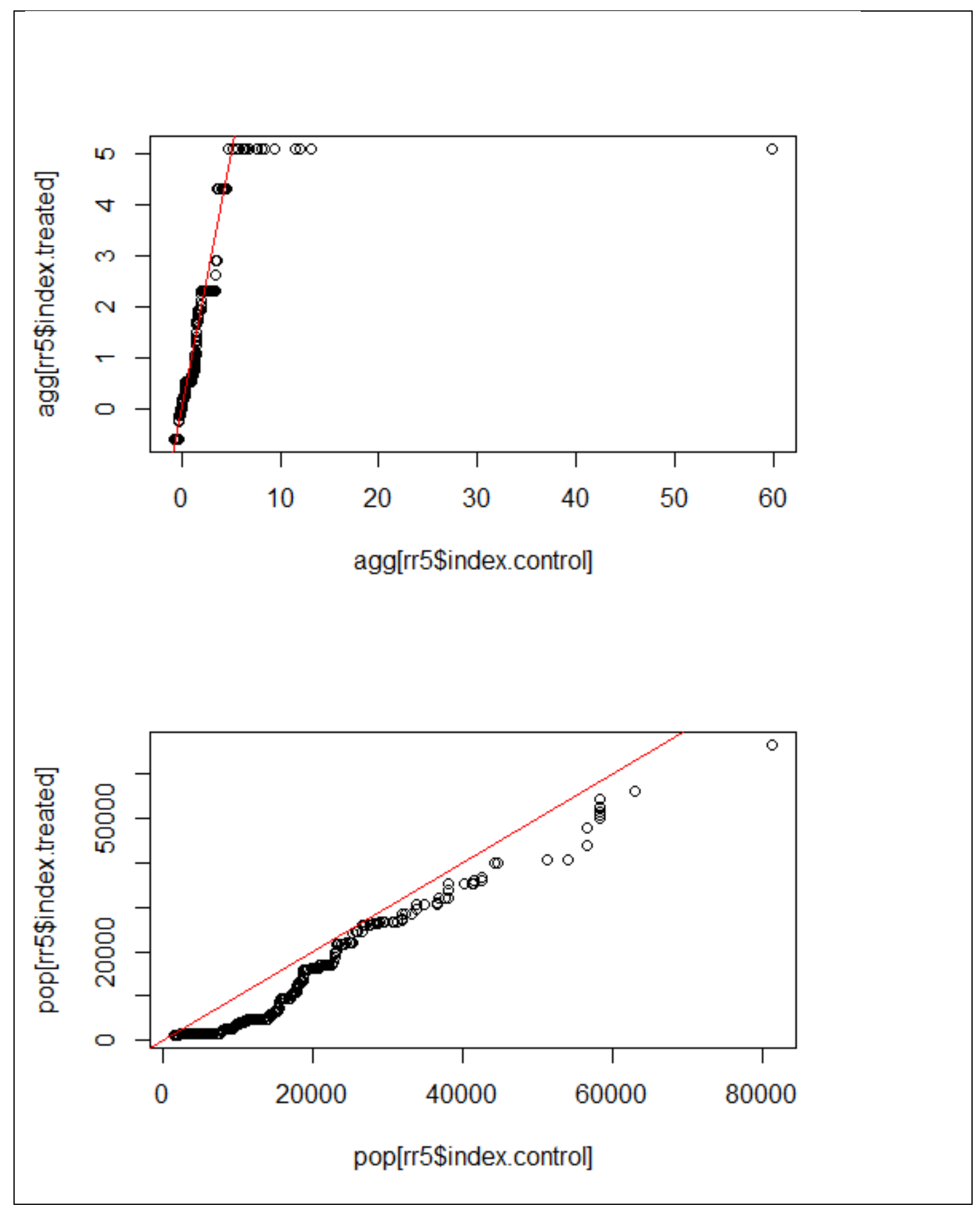




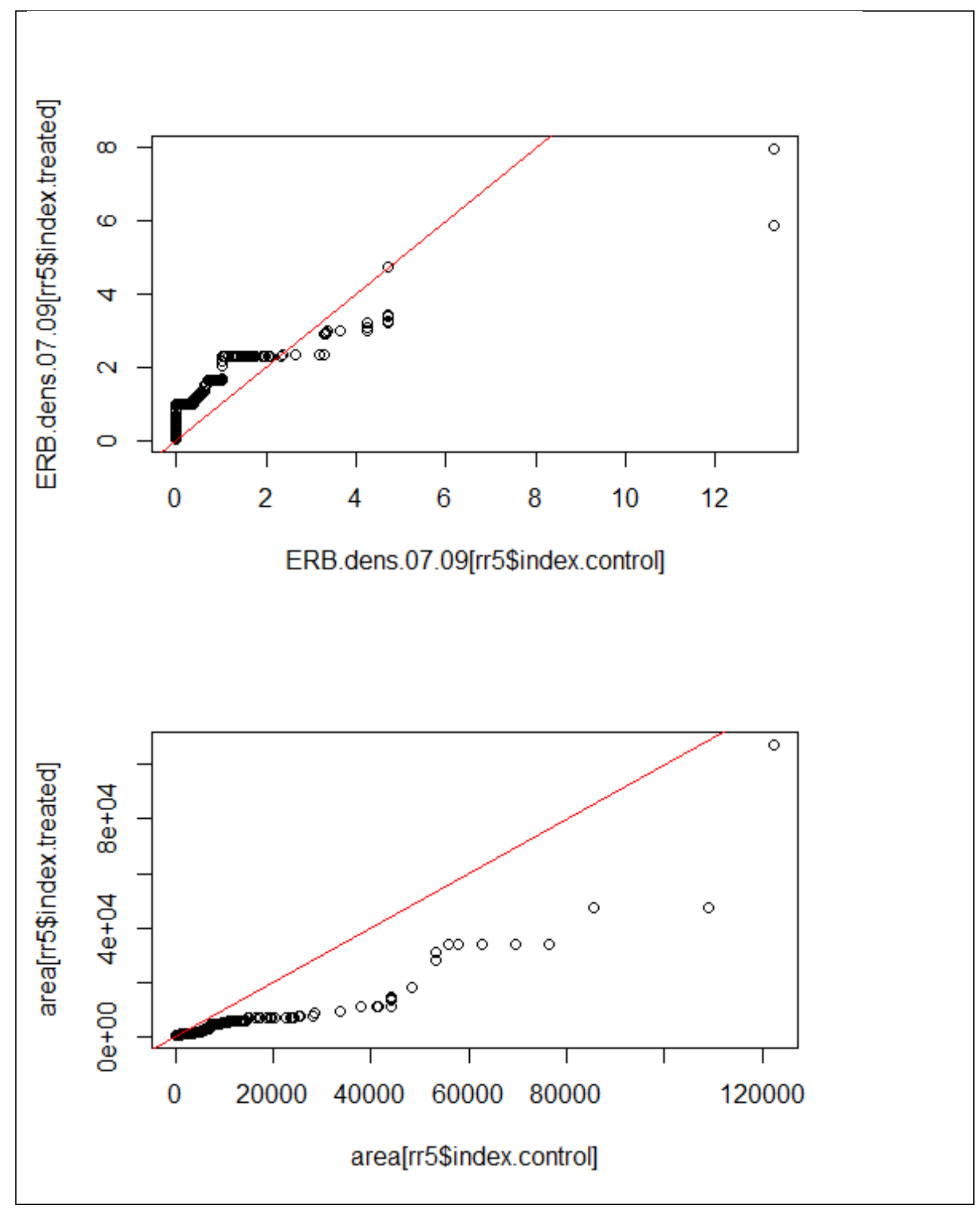


ESTIMAND $=$ ATC, TIES $=$ TRUE
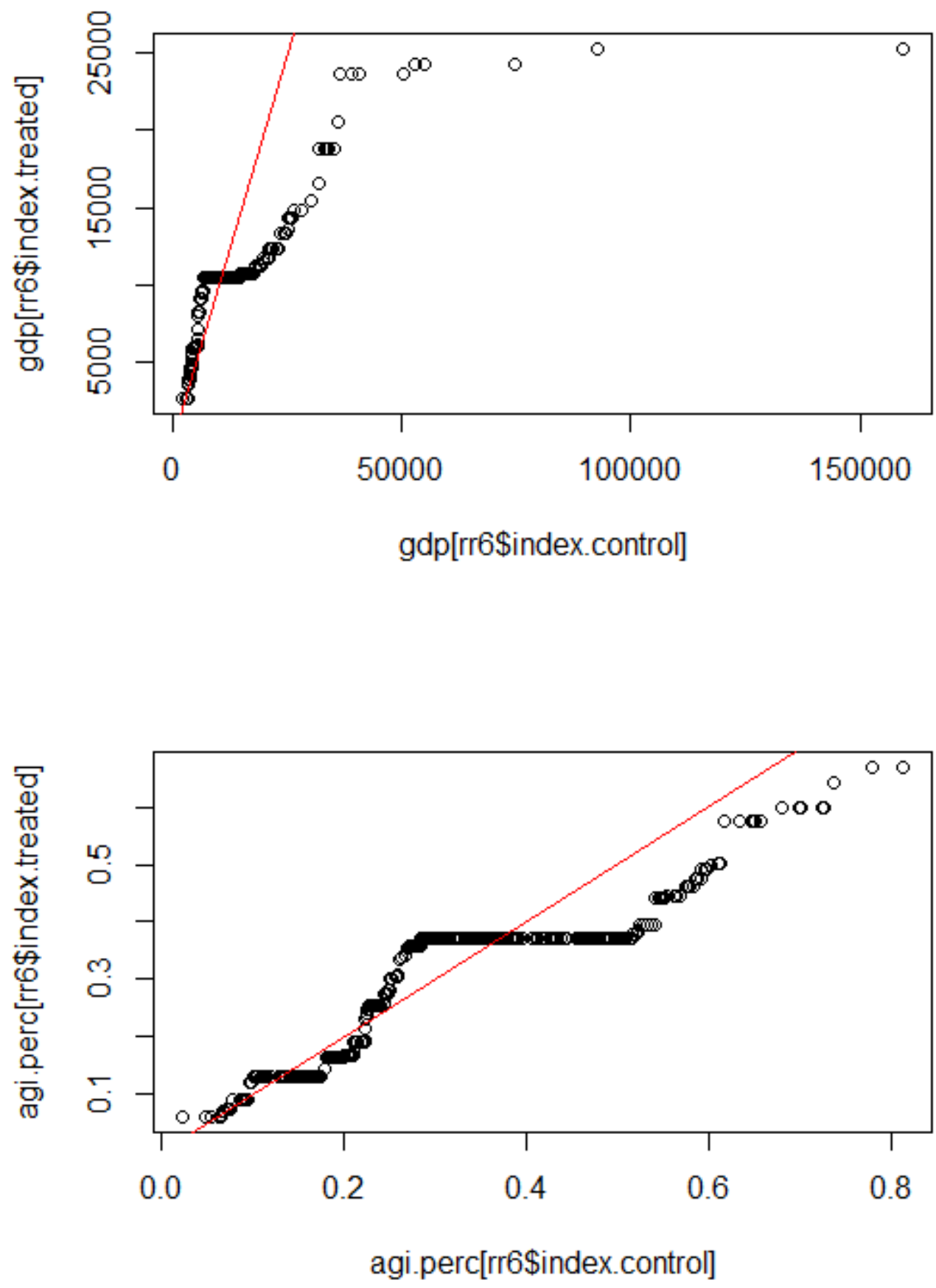


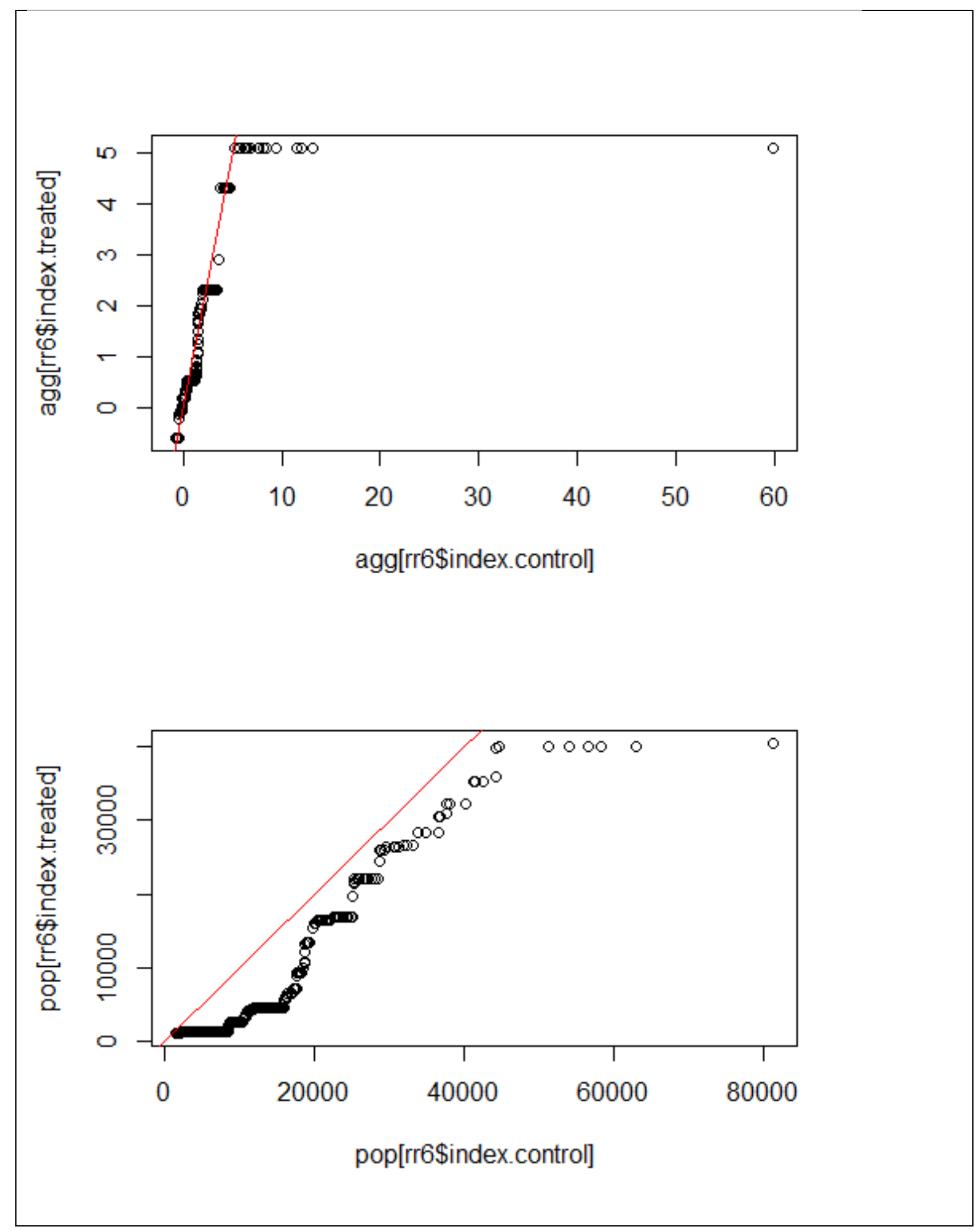




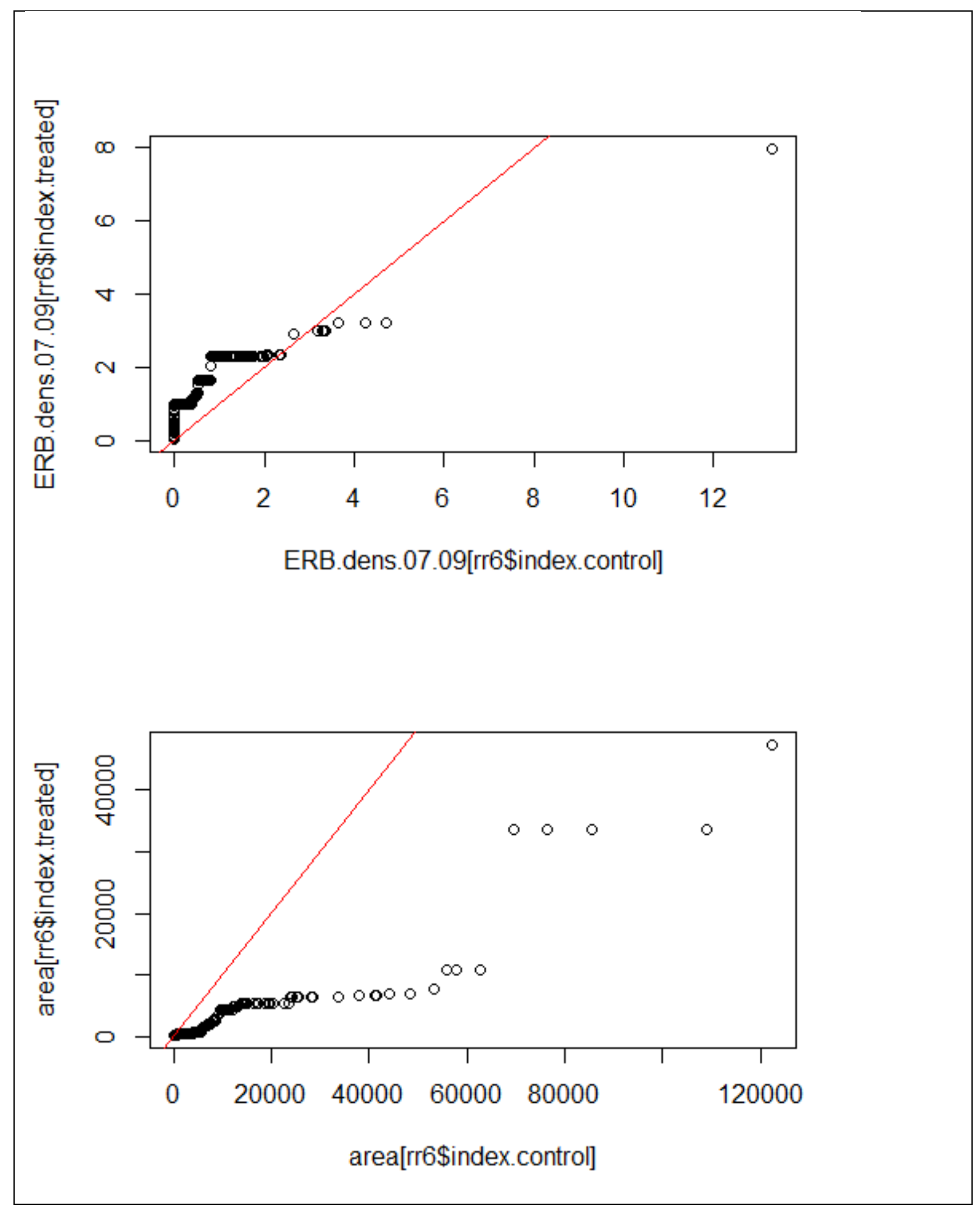




\section{COMPLETE DATABASE}

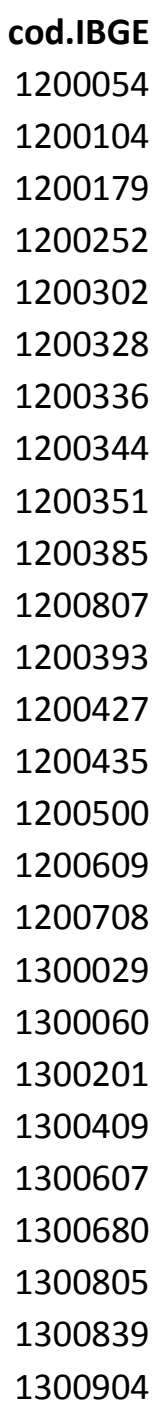

DDD

$68 \quad 4974.176$

$68 \quad 3916.495$

pop

gdp agi.perc agg

ERB.dens.07.09 tr.3G.05.09

0.134025548

0.76599102

0.391563299

0.604314321

0.142982743

$68 \quad 1654.768$

$68 \quad 27975.4$

$\begin{array}{lllll}22899 & 11669.94 & 0.280082 & 0.208817\end{array}$

$\begin{array}{lllll}9836 & 20407.79 & 0.601992 & 4.046067\end{array}$

$\begin{array}{lllll}16099 & 10980.99 & 0.246849 & 0.234254\end{array}$

$\begin{array}{llll}32411 & 8602.542 & 0.275322 & 2.029491\end{array}$

$68 \quad 5357.282$

$\begin{array}{llll}7147 & 8775.01 & 0.27519 & 0.39405\end{array}$

$\begin{array}{ll}68 & 5453.073\end{array}$

$\begin{array}{llll}16410 & 9095.186 & 0.254174 & 5.098209\end{array}$

$\begin{array}{lllll}8386 & 9865.013 & 0.284411 & 2.486997\end{array}$

$\begin{array}{lllll}15857 & 8427.824 & 0.289922 & 4.696089\end{array}$

$68 \quad 8191.694$

$\begin{array}{lllll}17795 & 15628.94 & 0.472615 & 0.981117\end{array}$

$\begin{array}{lllll}16029 & 12286.61 & 0.443215 & 0.332479\end{array}$

$\begin{array}{lllll}10143 & 8127.97 & 0.293706 & 6.872491\end{array}$

$\begin{array}{lllll}15968 & 8368.362 & 0.306514 & 11.59048\end{array}$

$\begin{array}{lllll}5374 & 7067.361 & 0.146955 & 4.689906\end{array}$

$\begin{array}{lllll}40311 & 10604.15 & 0.324706 & 0.771779\end{array}$

$\begin{array}{lllll}37571 & 8872.934 & 0.264002 & 1.370634\end{array}$

$\begin{array}{lllll}17021 & 11537.04 & 0.385507 & 1.42824\end{array}$

$\begin{array}{lllll}15166 & 5396.611 & 0.239747 & -0.63316\end{array}$

$\begin{array}{llll}10436 & 5145.171 & 0.2119 & 1.429834\end{array}$

$\begin{array}{lllll}17174 & 4564.167 & 0.17494 & 0.847815\end{array}$

$\begin{array}{llll}27110 & 4211.14 & 0.134224 & -0.41916\end{array}$

$\begin{array}{lllll}37564 & 4430.705 & 0.136819 & 0.398162\end{array}$

$\begin{array}{lllll}16820 & 4835.434 & 0.240557 & 0.489598\end{array}$

$\begin{array}{lllll}38073 & 5221.679 & 0.237211 & 3.669857\end{array}$

$\begin{array}{llll}12004 & 5532.656 & 0.207659 & 2.63098\end{array}$

$\begin{array}{llll}14754 & 4861.529 & 0.1591 & 0.58205\end{array}$

929456.618

$97 \quad 33659.61$
0.4890209

0.031348317

1.543809453

0.255932254

0.054239259

0.182434102

0.198303976

0.748020644

0
0

0.005443285

0.265350015

0.386570988

0.022597979

0.070497367 def.04

220.9

1178.4

790.8

784.9

1232.7

112.9

368.5

218.4

177.5

$1322.8 \quad 1427.1$

$1147.5 \quad 1250.1$

$137.1 \quad 178.2$

$444 \quad 479.6$

$56.2 \quad 75.2$

$1411.8 \quad 1642.8$

$1286.5 \quad 1436.3$

$1180.8 \quad 1270.5$

$290.8 \quad 319.7$

$110.3 \quad 112.5$

$227.4 \quad 237.4$

$192.5 \quad 201$

$182 \quad 187.4$

$196.7 \quad 203.5$

$489.6 \quad 524.2$

$230 \quad 239.8$

$669.3 \quad 913.1$ 


\begin{tabular}{|c|c|c|c|c|c|c|c|c|c|c|}
\hline 1301209 & 97 & 57921.91 & 81325 & 31878.28 & 0.023991 & 1.090275 & 0.063303626 & 0 & 751.1 & 767.2 \\
\hline 1301308 & 97 & 18711.55 & 25696 & 6929.561 & 0.413833 & 4.54218 & 0.035628614 & 0 & 253.9 & 261.4 \\
\hline 1301407 & 97 & 15011.77 & 33127 & 4691.521 & 0.182765 & -0.20957 & 0 & 0 & 356.7 & 371.8 \\
\hline 1301506 & 97 & 7499.33 & 18051 & 9298.377 & 0.547479 & 3.675773 & 0 & 0 & 206.7 & 253.4 \\
\hline 1301605 & 97 & 12110.93 & 21859 & 6314.973 & 0.276964 & 0.443163 & 0 & 0 & 94.1 & 99.8 \\
\hline 1301803 & 97 & 12044.63 & 25362 & 3569.947 & 0.109674 & 2.153725 & 0 & 0 & 189.8 & 213.1 \\
\hline 1301951 & 97 & 25275.93 & 8232 & 5959.913 & 0.240958 & 1.331965 & 0 & 0 & 112.8 & 124.5 \\
\hline 1302108 & 97 & 55791.84 & 6083 & 6990.794 & 0.161522 & 5.189844 & 0 & 0 & 48.1 & 56.4 \\
\hline 1302207 & 97 & 19400.69 & 12408 & 5043.44 & 0.186245 & 1.903099 & 0 & 0 & 135 & 148.2 \\
\hline 1302306 & 97 & 69551.83 & 17376 & 6122.007 & 0.271229 & 0.227338 & 0 & 0 & 221.1 & 234.1 \\
\hline 1302702 & 97 & 48282.54 & 51331 & 9062.886 & 0.529962 & 4.411259 & 0.013807615 & 0 & 1206.4 & 1562.2 \\
\hline 1302801 & 97 & 16910.37 & 18310 & 4944.511 & 0.223192 & 1.401581 & 0 & 0 & 102.3 & 114.4 \\
\hline 1303007 & 92 & 14105.59 & 19792 & 5854.082 & 0.284452 & 0.509081 & 0.047262586 & 1 & 444.9 & 474.2 \\
\hline 1303106 & 92 & 5608.565 & 33829 & 4878.98 & 0.186873 & 0.342415 & 0.118865818 & 1 & 399.7 & 415.6 \\
\hline 1303205 & 92 & 37770.82 & 16719 & 5098.81 & 0.198909 & 1.889646 & 0.017650308 & 0 & 110 & 116.8 \\
\hline 1303304 & 97 & 41187.69 & 23486 & 5425.956 & 0.324113 & 0.107639 & 0 & 0 & 651.4 & 897.1 \\
\hline 1303502 & 97 & 41610.05 & 19149 & 4748.655 & 0.181914 & 2.963653 & 0 & 0 & 185.7 & 219.3 \\
\hline 1303601 & 97 & 62846.41 & 20986 & 4155.056 & 0.188955 & 1.027651 & 0 & 0 & 203.8 & 213.1 \\
\hline 1303700 & 97 & 12307.21 & 24327 & 4862.457 & 0.179649 & 1.353759 & 0 & 0 & 128.6 & 134.3 \\
\hline 1303809 & 97 & 109183.4 & 41575 & 4648.563 & 0.093659 & 0.499052 & 0.009158899 & 0 & 1165.2 & 1195.4 \\
\hline 1303908 & 97 & 19745.9 & 34963 & 4262.907 & 0.146622 & 0.194343 & 0 & 0 & 171.1 & 176.2 \\
\hline 1303957 & 92 & 10741.08 & 12115 & 5696.822 & 0.280241 & 2.89776 & 0.062067005 & 1 & 185.1 & 202.6 \\
\hline 1304062 & 97 & 3224.875 & 58314 & 4562.695 & 0.055837 & 3.51877 & 1.033631795 & 0 & 149.9 & 156.6 \\
\hline 1304104 & 97 & 85488.03 & 18383 & 7673.666 & 0.431792 & 6.115927 & 0 & 0 & 291.7 & 311.5 \\
\hline 1304203 & 97 & 23704.48 & 62885 & 8853.288 & 0.291027 & 0.687326 & 0.154682467 & 0 & 594.9 & 634.1 \\
\hline 1304237 & 97 & 6432.659 & 18162 & 5445.711 & 0.267516 & 2.11519 & 0 & 0 & 77.9 & 82.3 \\
\hline 1304260 & 97 & 10246.24 & 12801 & 7536.442 & 0.372566 & 2.326604 & 0 & 0 & 225.1 & 243.2 \\
\hline 1304401 & 92 & 2906.701 & 20091 & 4877.856 & 0.224488 & 1.037879 & 0.573387723 & 1 & 92.1 & 94.6 \\
\hline 1600105 & 96 & 9167.855 & 8483 & 12553.81 & 0.200286 & 0.557863 & 0 & 0 & 92.8 & 107.9 \\
\hline 1600204 & 96 & 14231.32 & 9793 & 15283.47 & 0.099703 & 0.666714 & 0.046845031 & 0 & 132.7 & 181.2 \\
\hline
\end{tabular}




\begin{tabular}{|c|c|c|c|c|c|c|c|c|c|c|}
\hline 1600212 & 96 & 2109.068 & 5173 & 14590.37 & 0.362971 & 1.680083 & 0 & 0 & 171.7 & 182.6 \\
\hline 1600238 & 96 & 4969.503 & 6525 & 18739.62 & 0.060197 & 0.672108 & 0.134151577 & 1 & 124.6 & 137.2 \\
\hline 1600253 & 96 & 1622.852 & 4722 & 10408.09 & 0.170741 & 1.532432 & 0 & 0 & 86.4 & 92 \\
\hline 1600279 & 96 & 30971.9 & 43832 & 10650.37 & 0.028668 & 0.128599 & 0.032287334 & 1 & 156.6 & 184.7 \\
\hline 1600402 & 96 & 13130.98 & 18739 & 9410.107 & 0.108401 & 0.299896 & 0.152311522 & 1 & 76.6 & 109.7 \\
\hline 1600501 & 96 & 22625.29 & 22986 & 12652.57 & 0.130329 & 1.786611 & 0.058931115 & 0 & 165.7 & 199.5 \\
\hline 1600154 & 96 & 9562.92 & 12828 & 21046.77 & 0.0783 & 0.309869 & 0 & 0 & 203.7 & 229.6 \\
\hline 1600550 & 96 & 4950.593 & 4277 & 11758.24 & 0.225574 & 0.721092 & 0 & 0 & 61.5 & 78.2 \\
\hline 1600055 & 96 & 7720.789 & 4761 & 21250.79 & 0.104913 & 1.364121 & 0 & 0 & 68.9 & 71.4 \\
\hline 1600709 & 96 & 6757.618 & 14292 & 10330.88 & 0.159281 & 1.547721 & 0 & 0 & 253.8 & 309.9 \\
\hline 2100154 & 98 & 443.267 & 12028 & 3863.402 & 0.169095 & 1.008908 & 0 & 0 & 0 & 0 \\
\hline 2100204 & 98 & 1457.916 & 21644 & 4153.253 & 0.27541 & -0.0802 & 1.14318429 & 1 & 902.2 & 905 \\
\hline 2100303 & 99 & 1942.114 & 25177 & 6162.132 & 0.33724 & 4.269839 & 0.171634278 & 0 & 0 & 0 \\
\hline 2100477 & 98 & 1932.289 & 31253 & 4246.152 & 0.294669 & 0.692944 & 0 & 0 & 1852.6 & 1863.1 \\
\hline 2100501 & 99 & 11132.18 & 10904 & 13126.1 & 0.658141 & 3.225197 & 0 & 0 & 0 & 0 \\
\hline 2100808 & 98 & 608.296 & 14815 & 6403.51 & 0.38879 & 1.178329 & 0.547978835 & 0 & 0 & 0 \\
\hline 2100832 & 98 & 488.806 & 17474 & 3306.627 & 0.211602 & 0.341345 & 0.681933801 & 0 & 166.9 & 167 \\
\hline 2100873 & 98 & 805.194 & 14658 & 3557.648 & 0.299613 & -0.20178 & 0.413978909 & 0 & 749.8 & 757.5 \\
\hline 2100907 & 98 & 1782.6 & 44317 & 3660.649 & 0.208176 & 1.425081 & 0.373985564 & 0 & 0 & 0 \\
\hline 2100956 & 99 & 2976.038 & 31867 & 4484.42 & 0.361293 & 0.842229 & 0.112005738 & 0 & 1659 & 1794.9 \\
\hline 2101004 & 98 & 1100.275 & 28986 & 4469.468 & 0.293756 & 1.006331 & 0.605909129 & 0 & 383.6 & 406.4 \\
\hline 2101103 & 98 & 203.153 & 11706 & 6861.011 & 0.528692 & 1.28959 & 3.281598926 & 1 & 24.4 & 29.7 \\
\hline 2101301 & 98 & 823.723 & 17164 & 2770.508 & 0.199198 & 0.426167 & 0.404666779 & 0 & 501 & 502.4 \\
\hline 2101350 & 98 & 674.512 & 5440 & 3966.912 & 0.273155 & 0.282613 & 0.494184438 & 0 & 16.2 & 16.2 \\
\hline 2101509 & 99 & 2208.314 & 18074 & 6722.862 & 0.069382 & 0.300462 & 0.150944718 & 0 & 0 & 0 \\
\hline 2101772 & 98 & 142.814 & 10717 & 4224.503 & 0.220914 & 1.512507 & 0 & 0 & 127 & 127 \\
\hline 2101731 & 98 & 569.428 & 7105 & 5673.329 & 0.460327 & 0.742296 & 1.170765517 & 1 & 0 & 0 \\
\hline 2101806 & 99 & 1781.734 & 5510 & 4744.283 & 0.219368 & 0.065542 & 0 & 0 & 0 & 0 \\
\hline 2101905 & 98 & 797.716 & 20821 & 3987.08 & 0.227787 & 0.023131 & 0.417859656 & 0 & 466.8 & 468.6 \\
\hline 2101939 & 99 & 261.451 & 6176 & 7484.78 & 0.550227 & 1.59443 & 1.274936158 & 0 & 190.3 & 193 \\
\hline
\end{tabular}




\begin{tabular}{|c|c|c|c|c|c|c|c|c|c|c|}
\hline 2101970 & 98 & 403.46 & 8626 & 4097.96 & 0.238962 & 1.202599 & 0.826186817 & 0 & 308.8 & 326.2 \\
\hline 2102002 & 98 & 6590.53 & 40134 & 8286.366 & 0.575572 & 1.936049 & 0.252888109 & 1 & 3281.9 & 3531.1 \\
\hline 2102077 & 99 & 445.976 & 15604 & 5656.691 & 0.481301 & 1.583519 & 0.747424376 & 0 & 451.8 & 451.8 \\
\hline 2102200 & 98 & 1473.96 & 27697 & 4792.071 & 0.350983 & 0.541153 & 0.226148154 & 0 & 0 & 0 \\
\hline 2102309 & 99 & 1582.552 & 23238 & 6418.496 & 0.486793 & 0.172528 & 0.210630256 & 0 & 35.6 & 50.6 \\
\hline 2102358 & 99 & 818.424 & 15008 & 3884.928 & 0.301417 & 0.810342 & 0.40728685 & 0 & 579.2 & 678.3 \\
\hline 2102374 & 98 & 705.645 & 8698 & 3776.615 & 0.287405 & 1.667894 & 0 & 0 & 17.4 & 29 \\
\hline 2102408 & 98 & 908.729 & 10822 & 3847.348 & 0.230698 & 0.367183 & 0 & 0 & 84.6 & 84.9 \\
\hline 2102507 & 98 & 662.066 & 18751 & 4491.494 & 0.372583 & 1.074222 & 0 & 0 & 51.7 & 58.8 \\
\hline 2102556 & 99 & 615.384 & 13808 & 7232.329 & 0.34097 & -0.2098 & 0.541667208 & 0 & 382 & 408.2 \\
\hline 2102606 & 98 & 1640.756 & 19426 & 4112.993 & 0.301746 & 0.279329 & 0 & 0 & 888.9 & 929.4 \\
\hline 2102705 & 98 & 773.01 & 21125 & 4307.645 & 0.257621 & 2.285899 & 0.431214775 & 0 & 214.7 & 244.5 \\
\hline 2102754 & 99 & 590.529 & 10729 & 6567.061 & 0.376565 & 1.667291 & 1.128931292 & 1 & 208.4 & 221.5 \\
\hline 2102903 & 98 & 1232.08 & 22811 & 4917.233 & 0.299086 & 0.975829 & 0.541090405 & 0 & 635.4 & 649.4 \\
\hline 2103109 & 98 & 283.186 & 10414 & 5299.885 & 0.214054 & 0.586864 & 1.177082671 & 0 & 229.3 & 229.5 \\
\hline 2103125 & 98 & 319.053 & 8255 & 3656.208 & 0.174609 & 0.646465 & 1.044758499 & 0 & 258.9 & 258.9 \\
\hline 2103158 & 98 & 1167.848 & 12395 & 4630.093 & 0.411778 & 1.308227 & 0 & 0 & 834.2 & 907.6 \\
\hline 2103174 & 98 & 8369.793 & 20382 & 4684.967 & 0.383721 & 3.284121 & 0 & 0 & 2017.4 & 2286.9 \\
\hline 2103257 & 99 & 1464.034 & 14125 & 8381.239 & 0.478601 & 1.739162 & 0.227681415 & 0 & 1232.1 & 1297.7 \\
\hline 2103505 & 99 & 1980.552 & 39915 & 4381.11 & 0.229785 & 2.237161 & 1.178122732 & 1 & 147.6 & 185.9 \\
\hline 2103554 & 98 & 733.229 & 15313 & 4580.226 & 0.386342 & 0.841956 & 0.454610133 & 0 & 531 & 531 \\
\hline 2103752 & 99 & 335.776 & 12646 & 3844.14 & 0.195802 & 0.423947 & 2.978175927 & 1 & 273.3 & 286.6 \\
\hline 2103901 & 98 & 317.92 & 10942 & 3784.043 & 0.186364 & 0.482567 & 1.048481798 & 0 & 0 & 0 \\
\hline 2104073 & 99 & 1473.415 & 8263 & 5042.963 & 0.343878 & -0.11533 & 0 & 0 & 0 & 0 \\
\hline 2104081 & 99 & 5086.584 & 9783 & 4640.499 & 0.411011 & 1.639238 & 0 & 0 & 27.2 & 36.7 \\
\hline 2104099 & 99 & 3690.611 & 18087 & 5928.789 & 0.515728 & 1.381516 & 0 & 0 & 26 & 33.1 \\
\hline 2104107 & 99 & 1854.01 & 12343 & 8635.421 & 0.568899 & 1.717365 & 0 & 0 & 0 & 0 \\
\hline 2104206 & 99 & 694.997 & 15212 & 4562.319 & 0.310923 & 0.646882 & 0.479618377 & 0 & 213.1 & 272.9 \\
\hline 2104305 & 98 & 667.325 & 11046 & 9759.008 & 0.097453 & 0.998389 & 0 & 0 & 286.8 & 294 \\
\hline 2104404 & 99 & 883.589 & 17572 & 3965.115 & 0.229743 & 0.336888 & 0.377249302 & 0 & 444.1 & 530.4 \\
\hline
\end{tabular}




\begin{tabular}{|c|c|c|c|c|c|c|c|c|c|c|}
\hline 2104503 & 99 & 445.856 & 10466 & 4089.719 & 0.209759 & 0.032612 & 0.747625541 & 0 & 164.3 & 183.2 \\
\hline 2104552 & 99 & 615.852 & 17094 & 5379.899 & 0.115326 & -0.05277 & 0.541255583 & 0 & 277.1 & 286.4 \\
\hline 2104602 & 99 & 816.991 & 16312 & 3787.764 & 0.205414 & 0.659333 & 0.408001231 & 0 & 220.8 & 308.7 \\
\hline 2104628 & 99 & 373.164 & 7532 & 3543.415 & 0.190514 & 1.345649 & 0.893262301 & 0 & 104.3 & 167.1 \\
\hline 2104651 & 98 & 1144.069 & 10113 & 5234.253 & 0.464533 & 1.354987 & 0.291357718 & 0 & 1164 & 1165.5 \\
\hline 2104677 & 98 & 1037.13 & 25262 & 4853.812 & 0.18826 & 3.00941 & 0.964199281 & 0 & 1002.8 & 1010.7 \\
\hline 2104701 & 99 & 271.444 & 6151 & 5144.529 & 0.309133 & 1.096538 & 1.228000373 & 1 & 170.1 & 205.8 \\
\hline 2104909 & 98 & 595.382 & 11939 & 4222.715 & 0.277337 & 0.610471 & 0 & 0 & 370 & 371.9 \\
\hline 2105005 & 98 & 2131.247 & 27364 & 3859.158 & 0.230199 & 0.932686 & 0.469208872 & 1 & 0 & 0 \\
\hline 2105104 & 98 & 1448.779 & 26014 & 3813.908 & 0.245306 & 0.887895 & 0.2300788 & 0 & 8 & 15.3 \\
\hline 2105153 & 98 & 368.685 & 13347 & 4367.124 & 0.201049 & 1.211739 & 0.904114172 & 0 & 209.5 & 215.2 \\
\hline 2105203 & 99 & 374.248 & 11431 & 5092.205 & 0.315422 & 1.901851 & 0 & 0 & 380 & 380 \\
\hline 2105351 & 99 & 1066.192 & 14084 & 3402.442 & 0.290101 & 0.333956 & 0.312639124 & 0 & 893.3 & 918.8 \\
\hline 2105450 & 99 & 591.384 & 9360 & 4623.077 & 0.359357 & 1.940929 & 1.127299127 & 1 & 177.5 & 243.1 \\
\hline 2105476 & 99 & 1962.898 & 15899 & 3918.674 & 0.336295 & 0.597411 & 0.169816941 & 0 & 1075.7 & 1121.8 \\
\hline 2105609 & 99 & 703.511 & 15755 & 4951.825 & 0.363478 & 1.693785 & 0.473813961 & 0 & 466 & 495.5 \\
\hline 2105658 & 98 & 555.088 & 3653 & 8106.214 & 0.371053 & -0.13629 & 0 & 0 & 543.1 & 546 \\
\hline 2105708 & 99 & 1240.446 & 48002 & 4685.367 & 0.265571 & 1.016795 & 2.149764413 & 1 & 1552 & 1552.1 \\
\hline 2105948 & 99 & 220.776 & 8775 & 6853.447 & 0.473871 & 2.773819 & 1.509825947 & 0 & 196.8 & 196.8 \\
\hline 2105906 & 99 & 623.237 & 15742 & 5501.906 & 0.368684 & 1.200317 & 0.534842016 & 0 & 534.1 & 534.1 \\
\hline 2105922 & 99 & 1512.985 & 10989 & 4660.388 & 0.249288 & 0.531654 & 0 & 0 & 0 & 0 \\
\hline 2105963 & 99 & 937.714 & 12687 & 4369.197 & 0.32617 & 0.279423 & 0 & 0 & 704.2 & 712.6 \\
\hline 2105989 & 99 & 1047.733 & 7211 & 5570.24 & 0.38607 & 0.763137 & 0.318147212 & 0 & 242.9 & 255.2 \\
\hline 2106003 & 99 & 321.932 & 11580 & 4634.024 & 0.218777 & 2.060832 & 1.035415347 & 0 & 115.4 & 121 \\
\hline 2106102 & 99 & 3596.84 & 11714 & 9406.864 & 0.554468 & 2.91218 & 0 & 0 & 0 & 0 \\
\hline 2106201 & 98 & 464.06 & 6697 & 6104.226 & 0.413257 & 2.602409 & 0 & 0 & 301 & 307.5 \\
\hline 2106300 & 98 & 433.15 & 18680 & 3883.298 & 0.226436 & 1.897641 & 0 & 0 & 0 & 0 \\
\hline 2106326 & 98 & 635.824 & 20268 & 4397.671 & 0.259617 & 3.107923 & 1.572762274 & 0 & 536.5 & 541.6 \\
\hline 2106359 & 98 & 1402.594 & 7721 & 6233.13 & 0.507559 & 0.739888 & 0 & 0 & 739.9 & 767.1 \\
\hline 2106375 & 98 & 760.947 & 15011 & 4293.118 & 0.355322 & 8.402617 & 0.438050657 & 0 & 761.1 & 766.5 \\
\hline
\end{tabular}




\begin{tabular}{|c|c|c|c|c|c|c|c|c|c|c|}
\hline 2106409 & 98 & 548.414 & 15951 & 5095.856 & 0.313377 & 1.216575 & 0 & 0 & 0 & 0 \\
\hline 2106508 & 98 & 408.727 & 22515 & 4051.033 & 0.261511 & 1.180748 & 0.815540283 & 0 & 288.4 & 289.9 \\
\hline 2106672 & 98 & 634.737 & 8237 & 5051.475 & 0.462782 & 0.790261 & 0 & 0 & 0 & 0 \\
\hline 2106706 & 99 & 8521.084 & 20576 & 6356.435 & 0.506828 & 2.568617 & 0.039118654 & 0 & 0 & 0 \\
\hline 2106805 & 98 & 687.748 & 14504 & 3678.296 & 0.132568 & 0.161743 & 0.48467365 & 0 & 681.2 & 681.2 \\
\hline 2106904 & 98 & 1271.506 & 32180 & 3842.045 & 0.299918 & 0.390539 & 0.524312639 & 1 & 910.3 & 961.9 \\
\hline 2107100 & 98 & 1715.175 & 18544 & 3725.356 & 0.171103 & 1.11429 & 0 & 0 & 13.7 & 19.1 \\
\hline 2107209 & 98 & 572.507 & 13465 & 4467.583 & 0.382019 & 2.105607 & 1.164469023 & 1 & 0 & 0 \\
\hline 2107258 & 99 & 743.106 & 5120 & 6787.891 & 0.484471 & 0.36249 & 0 & 0 & 0 & 0 \\
\hline 2107357 & 98 & 2452.615 & 19963 & 4658.168 & 0.28935 & 1.095502 & 0.135909359 & 0 & 1144.7 & 1173.3 \\
\hline 2107407 & 98 & 695.333 & 18934 & 5128.076 & 0.301244 & 0.726371 & 0.479386615 & 0 & 704.6 & 704.6 \\
\hline 2107456 & 98 & 197.636 & 13911 & 4299.691 & 0.306293 & 0.387312 & 0 & 0 & 184.3 & 184.3 \\
\hline 2107605 & 98 & 532.164 & 19133 & 3855.381 & 0.251412 & -0.06109 & 0.626373324 & 0 & 439.7 & 440.4 \\
\hline 2107704 & 99 & 530.52 & 20636 & 3563.821 & 0.129334 & 0.425597 & 0.628314358 & 0 & 0 & 0 \\
\hline 2107803 & 99 & 3240.492 & 33883 & 4793.495 & 0.367579 & 1.516666 & 0.102865038 & 0 & 0 & 0 \\
\hline 2107902 & 99 & 1358.327 & 18216 & 4976.175 & 0.347207 & 1.559122 & 0 & 0 & 0 & 0 \\
\hline 2108009 & 99 & 1635.305 & 18687 & 6440.681 & 0.430779 & 0.441239 & 0 & 0 & 0 & 0 \\
\hline 2108058 & 98 & 979.178 & 15234 & 3928.253 & 0.225949 & 1.346166 & 0 & 0 & 0 & 0 \\
\hline 2108108 & 98 & 1098.497 & 20514 & 7525.934 & 0.523443 & 1.574226 & 0.303444919 & 0 & 1064 & 1064 \\
\hline 2108256 & 98 & 1749.885 & 23874 & 4024.797 & 0.248306 & 0.331839 & 0 & 0 & 1661.8 & 1673.4 \\
\hline 2108306 & 98 & 768.714 & 36520 & 3967.689 & 0.312572 & 0.518451 & 0.433624642 & 0 & 471.6 & 484.5 \\
\hline 2108405 & 98 & 398.72 & 13956 & 3391.373 & 0.189868 & -0.04496 & 0.836008561 & 0 & 243.9 & 245.6 \\
\hline 2108454 & 99 & 824.722 & 22123 & 3866.157 & 0.168273 & 0.452974 & 0.808353199 & 1 & 232.2 & 253.4 \\
\hline 2108504 & 98 & 273.526 & 31866 & 5418.157 & 0.086055 & 0.45372 & 3.65595958 & 0 & 202.4 & 202.4 \\
\hline 2108702 & 98 & 545.14 & 21512 & 4651.776 & 0.216271 & 1.638775 & 1.222927444 & 1 & 479 & 479 \\
\hline 2108801 & 98 & 688.761 & 17917 & 5929.676 & 0.471052 & 1.80479 & 0.483960813 & 0 & 253.3 & 285 \\
\hline 2108900 & 99 & 990.413 & 18633 & 7081.146 & 0.443472 & 2.009347 & 0.336559933 & 0 & 588.9 & 589.8 \\
\hline 2109056 & 98 & 218.831 & 5943 & 5951.203 & 0.40681 & 0.517983 & 1.523245488 & 0 & 117.9 & 118 \\
\hline 2109205 & 98 & 354.696 & 12103 & 3864.001 & 0.191406 & 1.52725 & 0 & 0 & 33.6 & 59 \\
\hline 2109239 & 98 & 437.687 & 6674 & 5003.296 & 0.344797 & 0.664154 & 0.761579241 & 0 & 440.1 & 440.1 \\
\hline
\end{tabular}




\begin{tabular}{|c|c|c|c|c|c|c|c|c|c|c|}
\hline 2109403 & 98 & 1367.676 & 14588 & 3493.899 & 0.215408 & 0.25852 & 0 & 0 & 0 & 0 \\
\hline 2109502 & 99 & 6373.017 & 20011 & 10379.94 & 0.488208 & 0.566339 & 0 & 0 & 0 & 0 \\
\hline 2109551 & 99 & 750.553 & 7514 & 7117.381 & 0.51634 & 2.101152 & 0.444116982 & 0 & 417.8 & 435 \\
\hline 2109700 & 99 & 2478.696 & 5538 & 23595.7 & 0.65174 & 0.608538 & 0 & 0 & 0 & 0 \\
\hline 2109759 & 99 & 623.214 & 7426 & 4074.737 & 0.327202 & 1.002392 & 0 & 0 & 48.1 & 55.8 \\
\hline 2110039 & 98 & 897.147 & 24507 & 6085.037 & 0.268783 & 1.310619 & 0.371548178 & 0 & 862.1 & 863.8 \\
\hline 2110104 & 98 & 1434.898 & 24879 & 4675.55 & 0.214613 & 2.104679 & 0.232304549 & 0 & 0 & 0 \\
\hline 2110203 & 98 & 706.385 & 35364 & 3635.392 & 0.091289 & 1.32335 & 2.359431 & 1 & 189.4 & 243 \\
\hline 2110237 & 98 & 932.016 & 12761 & 3578.403 & 0.246129 & 1.218521 & 0 & 0 & 0 & 0 \\
\hline 2110278 & 98 & 1601.18 & 15110 & 3192.985 & 0.286122 & 0.099039 & 0 & 0 & 0 & 0 \\
\hline 2110401 & 98 & 931.481 & 18189 & 4386.937 & 0.329232 & 0.812436 & 0.357853068 & 0 & 0 & 0 \\
\hline 2110609 & 98 & 1006.919 & 27599 & 4286.858 & 0.148332 & 1.449569 & 0.331042848 & 0 & 0 & 0 \\
\hline 2110658 & 99 & 960.929 & 7187 & 17122.72 & 0.323785 & 0.742577 & 0 & 0 & 0 & 0 \\
\hline 2110807 & 99 & 2032.364 & 4554 & 7563.022 & 0.497806 & 0.396931 & 0 & 0 & 0 & 0 \\
\hline 2110856 & 99 & 745.606 & 11242 & 5001.957 & 0.45679 & 0.306861 & 0 & 0 & 700.9 & 714.5 \\
\hline 2110906 & 99 & 2280.214 & 11961 & 3303.988 & 0.231086 & 0.31563 & 0 & 0 & 0 & 0 \\
\hline 2111003 & 98 & 690.683 & 20195 & 3909.928 & 0.229973 & 0.971661 & 0.482614069 & 0 & 148.6 & 148.6 \\
\hline 2111029 & 98 & 908.077 & 15558 & 5213.009 & 0.444145 & 0.55301 & 0 & 0 & 387.1 & 408.9 \\
\hline 2111052 & 99 & 2053.843 & 10933 & 5929.022 & 0.527982 & 0.424466 & 0.162297378 & 0 & 240.8 & 254 \\
\hline 2111078 & 99 & 1438.068 & 17956 & 3825.351 & 0.230841 & 0.167653 & 0.23179247 & 0 & 0.7 & 0.9 \\
\hline 2111102 & 99 & 1482.66 & 25287 & 4845.177 & 0.077161 & 1.050944 & 1.348926929 & 0 & 0 & 0 \\
\hline 2111250 & 99 & 353.234 & 7501 & 4116.918 & 0.224589 & 0.172028 & 0 & 0 & 255.8 & 272.1 \\
\hline 2111409 & 99 & 968.574 & 18807 & 7246.185 & 0.480042 & 0.779719 & 0.344148546 & 0 & 643.5 & 653.3 \\
\hline 2111532 & 99 & 720.452 & 12349 & 5039.193 & 0.234316 & 13.10865 & 1.388017522 & 0 & 447.3 & 453.9 \\
\hline 2111573 & 99 & 979.631 & 4542 & 8640.247 & 0.552872 & 0.295348 & 0 & 0 & 0 & 0 \\
\hline 2111607 & 99 & 3521.525 & 18255 & 17379.57 & 0.473521 & 2.27104 & 0 & 0 & 0 & 0 \\
\hline 2111631 & 99 & 419.352 & 5387 & 4579.915 & 0.281848 & 0.988521 & 0.794877176 & 0 & 279.6 & 280 \\
\hline 2111672 & 99 & 227.463 & 6432 & 5142.413 & 0.151301 & 1.3294 & 1.4654398 & 0 & 229.7 & 229.7 \\
\hline 2111748 & 99 & 426.436 & 10763 & 3524.017 & 0.195335 & 0.615525 & 0.781672592 & 0 & 78.4 & 119.8 \\
\hline 2111763 & 99 & 738.548 & 14195 & 6981.261 & 0.356874 & 0.874342 & 0.451336045 & 0 & 1096 & 1148.7 \\
\hline
\end{tabular}




\begin{tabular}{|c|c|c|c|c|c|c|c|c|c|c|}
\hline 2111789 & 98 & 1165.86 & 10758 & 4034.579 & 0.371725 & 0.111362 & 0.285911973 & 0 & 1100.3 & 1101.5 \\
\hline 2111805 & 99 & 3114.871 & 17559 & 5642.918 & 0.420227 & 0.248882 & 0.107013527 & 0 & 55.9 & 58.6 \\
\hline 2111953 & 99 & 863.909 & 5519 & 4082.08 & 0.314682 & 0.509475 & 0 & 0 & 0 & 0 \\
\hline 2112001 & 99 & 4382.975 & 8219 & 52748.63 & 0.592627 & 0.97616 & 0 & 0 & 0 & 0 \\
\hline 2112100 & 99 & 1486.587 & 28442 & 3163.526 & 0.186415 & 0.131672 & 0.672681787 & 0 & 16.7 & 17.8 \\
\hline 2112233 & 99 & 222.946 & 20747 & 5474.478 & 0.194318 & 1.758717 & 0 & 0 & 152.8 & 153.7 \\
\hline 2112274 & 98 & 271.01 & 5699 & 4657.659 & 0.278946 & 1.486627 & 0 & 0 & 249 & 249 \\
\hline 2112308 & 99 & 3369.123 & 40566 & 4396.169 & 0.30421 & 1.341778 & 0.296813147 & 1 & 1099.1 & 1195.2 \\
\hline 2112506 & 98 & 1651.656 & 56501 & 3456.788 & 0.15241 & 0.906178 & 0.20181765 & 0 & 0 & 0 \\
\hline 2112605 & 98 & 1708.294 & 31840 & 3519.975 & 0.322785 & 0.743094 & 0.195126444 & 0 & 0 & 0 \\
\hline 2112803 & 98 & 1168.443 & 50976 & 3625.667 & 0.188461 & 0.964016 & 2.282239413 & 1 & 489.8 & 503.2 \\
\hline 2112852 & 99 & 1188.781 & 12661 & 9210.805 & 0.648286 & 2.383594 & 0 & 0 & 948.5 & 965.6 \\
\hline 2113009 & 98 & 1193.385 & 30937 & 5487.248 & 0.362051 & 1.283539 & 0.279317516 & 0 & 1166.3 & 1166.3 \\
\hline 5100102 & 65 & 840.59 & 5431 & 13786.41 & 0.480396 & 0.249581 & 1.18964061 & 1 & 0 & 0 \\
\hline 5100508 & 65 & 1846.295 & 10476 & 7439.863 & 0.322407 & 0.359726 & 0.541625255 & 0 & 420 & 423.5 \\
\hline 5100805 & 66 & 20377.53 & 9094 & 17903.56 & 0.565627 & 6.503191 & 0.049073666 & 0 & 1717.2 & 2063.4 \\
\hline 5101001 & 66 & 6429.386 & 3133 & 20813.92 & 0.58481 & 0.626809 & 0 & 0 & 811.9 & 830.4 \\
\hline 5101209 & 66 & 687.973 & 1024 & 14373.05 & 0.334849 & 0.569919 & 0.969030277 & 1 & 0 & 0 \\
\hline 5101308 & 65 & 416.785 & 9955 & 10667.2 & 0.194318 & 0.942212 & 7.997728645 & 1 & 364.8 & 367.8 \\
\hline 5102603 & 66 & 5967.355 & 14827 & 10477.37 & 0.370126 & 0.985083 & 0 & 0 & 0.6 & 0.6 \\
\hline 5102686 & 65 & 6801.857 & 5778 & 159492.4 & 0.492465 & -0.02149 & 0.392049799 & 0 & 103.5 & 106.1 \\
\hline 5102694 & 66 & 3452.684 & 4728 & 16509.52 & 0.541147 & 1.361321 & 0.193086499 & 0 & 1484.9 & 1627 \\
\hline 5102702 & 66 & 10882.4 & 19681 & 33296.12 & 0.342934 & 0.298093 & 0.367565911 & 0 & 1811.5 & 1874.9 \\
\hline 5102850 & 66 & 3909.537 & 8353 & 14984.32 & 0.537364 & 1.293896 & 0.255784764 & 0 & 2318.9 & 2506.7 \\
\hline 5103106 & 66 & 16530.66 & 5525 & 22603.44 & 0.503012 & 0.946186 & 0.020164557 & 0 & 207.2 & 234.3 \\
\hline 5103452 & 65 & 1307.188 & 8816 & 20497.84 & 0.641455 & 0.786549 & 2.040002407 & 1 & 1134 & 1141.2 \\
\hline 5103601 & 66 & 2204.157 & 8101 & 31885.82 & 0.701728 & 1.103181 & 1.512293967 & 0 & 797.1 & 799.7 \\
\hline 5103809 & 65 & 899.246 & 3651 & 15771.57 & 0.456186 & 0.412236 & 0.370680919 & 0 & 735.7 & 740.6 \\
\hline 5103908 & 66 & 3794.94 & 5215 & 29903.36 & 0.698831 & -0.05137 & 0.263508777 & 0 & 0 & 0 \\
\hline 5103957 & 65 & 853.842 & 3072 & 15485.03 & 0.491714 & 0.759521 & 0.39039229 & 1 & 294.1 & 296.5 \\
\hline
\end{tabular}




\begin{tabular}{|c|c|c|c|c|c|c|c|c|c|c|}
\hline 5104500 & 65 & 603.289 & 2491 & 25637.49 & 0.222681 & 1.496239 & 1.105053576 & 0 & 562.3 & 564.5 \\
\hline 5105176 & 66 & 2778.961 & 12900 & 11524.34 & 0.289529 & 1.436925 & 0.479795626 & 0 & 925.7 & 1193.5 \\
\hline 5105234 & 65 & 1763.89 & 5647 & 24229.33 & 0.474387 & 1.715587 & 0.377952518 & 1 & 1141.2 & 1174.8 \\
\hline 5105309 & 66 & 4243.038 & 2148 & 10666.67 & 0.312226 & 0.598331 & 0 & 0 & 23.4 & 31.1 \\
\hline 5106208 & 66 & 3281.884 & 4252 & 13048.68 & 0.459145 & 0.610505 & 0.203135354 & 0 & 1156.3 & 1165.9 \\
\hline 5108808 & 66 & 1114.126 & 4731 & 14849.71 & 0.509349 & 0.921294 & 0.299188183 & 0 & 905.5 & 923.9 \\
\hline 5106182 & 65 & 4735.085 & 5824 & 25272.32 & 0.250531 & 1.958789 & 0.422378901 & 0 & 1649 & 1776.6 \\
\hline 5108857 & 65 & 1939.799 & 3052 & 36483.94 & 0.339139 & 0.087279 & 0.17183911 & 0 & 897.2 & 965.1 \\
\hline 5108956 & 66 & 5248.543 & 8444 & 19771.44 & 0.562668 & 3.163573 & 0.127019378 & 0 & 2164.6 & 2351.3 \\
\hline 5106257 & 66 & 5573.682 & 20143 & 15323.88 & 0.36685 & 0.297423 & 0.717658453 & 0 & 769.9 & 787.3 \\
\hline 5106273 & 66 & 879.662 & 3815 & 12967.76 & 0.500127 & 1.264407 & 0.757866847 & 0 & 683.6 & 703.3 \\
\hline 5106265 & 66 & 5790.968 & 7979 & 17418.1 & 0.575699 & 2.028981 & 0.115121801 & 0 & 2186 & 2475.1 \\
\hline 5106281 & 66 & 5035.15 & 5611 & 55063.63 & 0.780118 & -0.4616 & 0 & 0 & 0.8 & 1.1 \\
\hline 5106307 & 66 & 24166.08 & 20383 & 24707.5 & 0.4731 & 0.725433 & 0.16552128 & 0 & 2224.4 & 2554.7 \\
\hline 5106455 & 66 & 2455.431 & 2683 & 17937.38 & 0.595486 & -0.18656 & 0.135753492 & 0 & 550.2 & 551.6 \\
\hline 5106653 & 66 & 2738.777 & 5855 & 10510.5 & 0.367942 & 1.431512 & 0.365126478 & 0 & 0 & 0 \\
\hline 5106703 & 66 & 685.987 & 1679 & 16562.84 & 0.499661 & 1.233613 & 0.485917858 & 1 & 0 & 0 \\
\hline 5106778 & 66 & 3972.246 & 11336 & 16052.22 & 0.285523 & 1.944622 & 0.251746745 & 0 & 810.2 & 874.4 \\
\hline 5106851 & 65 & 2062.76 & 3354 & 13318.43 & 0.446171 & 1.061038 & 0.323191582 & 1 & 374.4 & 380.5 \\
\hline 5107008 & 66 & 6891.156 & 16919 & 25306.4 & 0.670213 & 0.908705 & 0.435340602 & 1 & 1840.1 & 1854.4 \\
\hline 5107156 & 65 & 1337.041 & 2612 & 13111.03 & 0.46108 & 1.64499 & 0.498613481 & 0 & 283.6 & 307.7 \\
\hline 5107180 & 66 & 11354.81 & 9316 & 16022.22 & 0.50853 & 1.02985 & 0.146780739 & 0 & 1495.9 & 1619.6 \\
\hline 5107198 & 66 & 625.581 & 2259 & 23691.46 & 0.600166 & 0.334647 & 0.532838007 & 1 & 0 & 0 \\
\hline 5107206 & 65 & 562.836 & 5063 & 10898.48 & 0.209078 & 0.529479 & 0 & 0 & 445.1 & 445.9 \\
\hline 5107750 & 65 & 1752.309 & 3666 & 14041.46 & 0.476193 & 0.295695 & 0.380450404 & 0 & 1328.8 & 1345.5 \\
\hline 5107776 & 66 & 6467.438 & 7709 & 15302.11 & 0.617478 & 1.301671 & 0.103080488 & 0 & 2268.2 & 2547.2 \\
\hline 5107263 & 65 & 1174.18 & 3025 & 13329.26 & 0.504976 & 0.266573 & 0.283886059 & 0 & 906.7 & 955.1 \\
\hline 5107297 & 66 & 443.876 & 3741 & 9570.168 & 0.393904 & 0.627824 & 1.501920957 & 1 & 27.4 & 27.4 \\
\hline 5107305 & 65 & 4536.199 & 18339 & 21304.81 & 0.505893 & 0.817151 & 0.88179553 & 0 & 1562.8 & 1745.8 \\
\hline 5107354 & 66 & 7459.645 & 5333 & 35948.43 & 0.588775 & 0.758675 & 0 & 0 & 4062.3 & 4293.3 \\
\hline
\end{tabular}




\begin{tabular}{|c|c|c|c|c|c|c|c|c|c|c|}
\hline 5107404 & 66 & 342.952 & 4341 & 7962.681 & 0.235744 & -0.03582 & 2.915859945 & 1 & 305.7 & 305.7 \\
\hline 5107875 & 65 & 13624.37 & 20934 & 92683.67 & 0.520511 & 0.327479 & 0.269125554 & 0 & 158.7 & 184.7 \\
\hline 5107941 & 66 & 8317.428 & 9678 & 50167.7 & 0.599465 & 4.79501 & 0.320611933 & 0 & 2129.6 & 2506.1 \\
\hline 5108105 & 66 & 4188.092 & 3482 & 22808.44 & 0.679701 & 0.419904 & 0 & 0 & 0 & 0 \\
\hline 5108303 & 66 & 4581.91 & 3639 & 40751.03 & 0.725579 & 3.421826 & 0.14549973 & 0 & 783.3 & 1028.7 \\
\hline 5105507 & 65 & 13420.98 & 14999 & 21483.63 & 0.465723 & 1.553622 & 0.298040873 & 0 & 4368.4 & 4567 \\
\hline 1500206 & 91 & 4343.805 & 54030 & 5187.877 & 0.299138 & 0.41822 & 0.076737637 & 0 & 2088.1 & 2306.8 \\
\hline 1500347 & 94 & 7113.961 & 25899 & 10314.84 & 0.408613 & 0.261624 & 0.28113733 & 1 & 4428.6 & 4599.9 \\
\hline 1500701 & 91 & 6921.746 & 26547 & 3254.454 & 0.11388 & -0.31353 & 0 & 0 & 161.2 & 176.2 \\
\hline 1500909 & 91 & 1091.541 & 42591 & 3842.619 & 0.189841 & 0.582961 & 0 & 0 & 720.8 & 728.6 \\
\hline 1500958 & 91 & 1811.84 & 28441 & 4626.56 & 0.275142 & 0.654619 & 0.367950077 & 1 & 1435.9 & 1537.7 \\
\hline 1501006 & 93 & 17074.05 & 15959 & 3703.929 & 0.193841 & 0.703498 & 0 & 0 & 990.5 & 1142.1 \\
\hline 1501105 & 91 & 4397.321 & 26666 & 2640.704 & 0.070567 & -0.60881 & 0.22741119 & 1 & 172.9 & 201.2 \\
\hline 1501204 & 91 & 3758.297 & 41232 & 3766.201 & 0.164945 & 0.016935 & 0.088692653 & 0 & 1472.1 & 1572.4 \\
\hline 1501451 & 93 & 4398.419 & 16808 & 5870.181 & 0.371514 & 4.317034 & 0.075784807 & 1 & 769.9 & 806.2 \\
\hline 1501576 & 94 & 2816.476 & 15916 & 6181.013 & 0.336595 & 0.465335 & 0.35505362 & 1 & 1664.9 & 1739.7 \\
\hline 1501600 & 91 & 586.737 & 14689 & 3615.903 & 0.194977 & 2.363055 & 0.568113709 & 0 & 509.8 & 539.3 \\
\hline 1501907 & 91 & 1005.168 & 27000 & 3095.259 & 0.103538 & -0.26238 & 0 & 0 & 608.3 & 652.2 \\
\hline 1502004 & 91 & 3100.258 & 21740 & 4490.386 & 0.303444 & 0.059841 & 0.107517933 & 0 & 71.2 & 73.1 \\
\hline 1501956 & 91 & 2461.972 & 29533 & 3127.349 & 0.144605 & -0.06016 & 0.135392821 & 0 & 1109.4 & 1390.7 \\
\hline 1502301 & 91 & 2899.553 & 52537 & 4410.454 & 0.169412 & 0.980966 & 1.264562733 & 1 & 2468.2 & 2557.8 \\
\hline 1502509 & 91 & 13084.96 & 22029 & 4307.867 & 0.376675 & 0.033234 & 0 & 0 & 89.6 & 95.5 \\
\hline 1502608 & 91 & 609.792 & 11600 & 4073.448 & 0.128841 & 0.511943 & 0.546634481 & 0 & 86.4 & 90.3 \\
\hline 1502806 & 91 & 3617.252 & 30915 & 2625.554 & 0.073613 & -0.02315 & 0.276452954 & 1 & 183 & 198.9 \\
\hline 1502855 & 93 & 1431.157 & 13097 & 4807.36 & 0.258393 & 2.02273 & 0.698735359 & 1 & 296.2 & 323.6 \\
\hline 1503044 & 94 & 3444.285 & 18741 & 20682.25 & 0.25313 & 0.742046 & 0.096778673 & 0 & 1686.6 & 1891.5 \\
\hline 1503077 & 91 & 1599.028 & 25287 & 4205.956 & 0.21578 & 1.833342 & 0.208459973 & 0 & 1345.2 & 1418.1 \\
\hline 1503101 & 91 & 8540.113 & 30727 & 3530.446 & 0.169474 & -0.08654 & 0.03903149 & 0 & 84 & 105.8 \\
\hline 1503200 & 91 & 785.983 & 36883 & 4628.501 & 0.170759 & -0.27155 & 3.392779063 & 1 & 666.8 & 686.4 \\
\hline 1503408 & 91 & 471.449 & 10693 & 4153.371 & 0.240293 & 0.359817 & 0.707040069 & 0 & 317.6 & 326.9 \\
\hline
\end{tabular}




\begin{tabular}{|c|c|c|c|c|c|c|c|c|c|c|}
\hline 1503754 & 93 & 53303.02 & 41487 & 2066.937 & 0.181057 & 0.510302 & 0.012507108 & 0 & 1097.3 & 1339.4 \\
\hline 1503903 & 93 & 8306.298 & 51483 & 9630.422 & 0.076575 & 0.64287 & 0.321041536 & 1 & 1096.3 & 1152.3 \\
\hline 1504000 & 91 & 1490.186 & 26542 & 4782.307 & 0.305617 & 0.016097 & 0.67105717 & 1 & 58.3 & 61.6 \\
\hline 1504109 & 91 & 325.265 & 8240 & 4328.641 & 0.159657 & 1.333955 & 1.024805415 & 0 & 154.3 & 161.9 \\
\hline 1504307 & 91 & 855.664 & 28631 & 4285.355 & 0.183907 & 0.389204 & 0 & 0 & 310 & 323.3 \\
\hline 1504406 & 91 & 795.987 & 27153 & 4390.786 & 0.168725 & 0.445259 & 5.862742314 & 1 & 381.3 & 399 \\
\hline 1504505 & 91 & 6774.018 & 25860 & 3570.959 & 0.122465 & 0.005726 & 0.098415249 & 1 & 147.2 & 155.5 \\
\hline 1504802 & 93 & 18152.56 & 56147 & 5534.223 & 0.271122 & 1.063569 & 0.12854018 & 1 & 4011.7 & 4156.8 \\
\hline 1504950 & 91 & 2809.312 & 20528 & 3986.945 & 0.163231 & 1.895749 & 0.118653013 & 0 & 1336.5 & 1494.3 \\
\hline 1504976 & 94 & 1564.184 & 15422 & 5095.902 & 0.233956 & 1.018499 & 0.639310976 & 1 & 1063.9 & 1136.3 \\
\hline 1505007 & 91 & 489.852 & 14305 & 4317.931 & 0.143931 & 0.675499 & 4.763343486 & 1 & 367.5 & 376.6 \\
\hline 1505106 & 93 & 28021.42 & 50171 & 5262.801 & 0.281737 & 0.793764 & 0.130852284 & 1 & 1601.1 & 1814.4 \\
\hline 1505304 & 93 & 107603.3 & 66821 & 17574.45 & 0.063457 & 0.701481 & 0.074347168 & 1 & 1334.2 & 1481.1 \\
\hline 1505403 & 91 & 562.387 & 16854 & 4582.414 & 0.09793 & 0.288578 & 1.778134985 & 0 & 472.2 & 496.7 \\
\hline 1505437 & 94 & 14410.57 & 29547 & 21041.05 & 0.062739 & -0.03912 & 0.208180566 & 1 & 1555.4 & 1666.6 \\
\hline 1505551 & 94 & 1671.419 & 5743 & 8318.823 & 0.463981 & -0.1222 & 0.199431341 & 1 & 892.1 & 930.6 \\
\hline 1505601 & 91 & 450.222 & 7889 & 4235.264 & 0.141033 & 0.325292 & 0.740375489 & 0 & 349.5 & 358.2 \\
\hline 1505635 & 94 & 3312.661 & 12720 & 10064.47 & 0.545475 & 0.010304 & 0.20124808 & 1 & 2715.6 & 2900.7 \\
\hline 1505650 & 93 & 7173.194 & 26842 & 3935.549 & 0.325821 & 0.751893 & 0 & 0 & 1402.3 & 1747.2 \\
\hline 1505700 & 91 & 3365.152 & 28025 & 3872.4 & 0.205981 & 0.031034 & 0.099054466 & 0 & 51.4 & 52.1 \\
\hline 1505908 & 93 & 17423.02 & 36841 & 3892.267 & 0.153758 & 0.198673 & 0.01913178 & 0 & 629.8 & 945.3 \\
\hline 1506005 & 93 & 14786.99 & 29342 & 5518.847 & 0.329688 & 0.753548 & 0.022542343 & 0 & 1308.2 & 1626.7 \\
\hline 1506112 & 91 & 326.113 & 12838 & 4492.756 & 0.289412 & 0.679152 & 1.022140587 & 0 & 72.7 & 80.2 \\
\hline 1506195 & 93 & 7021.321 & 44349 & 3682 & 0.197019 & 0.463394 & 0.094948894 & 0 & 1532.9 & 1762.5 \\
\hline 1506351 & 91 & 278.154 & 18736 & 4629.857 & 0.074171 & -0.46985 & 0 & 0 & 155.5 & 159.3 \\
\hline 1506401 & 91 & 1076.652 & 8957 & 4008.038 & 0.21491 & 0.005571 & 0 & 0 & 0 & 0 \\
\hline 1506906 & 91 & 229.51 & 6341 & 4275.509 & 0.132946 & 0.373483 & 0 & 0 & 133 & 147.9 \\
\hline 1507003 & 91 & 537.625 & 28575 & 4843.43 & 0.264161 & 0.829212 & 3.100054251 & 1 & 313.7 & 323.8 \\
\hline 1507102 & 91 & 743.466 & 17266 & 4791.729 & 0.244333 & 0.296112 & 1.345051421 & 1 & 218.7 & 231.4 \\
\hline 1507151 & 94 & 1392.464 & 24012 & 6115.526 & 0.269278 & 1.385613 & 1.196919035 & 1 & 1223.5 & 1282 \\
\hline
\end{tabular}




\begin{tabular}{|c|c|c|c|c|c|c|c|c|c|c|}
\hline 1507201 & 91 & 1677.249 & 30550 & 4191.26 & 0.249581 & 1.842486 & 0.596214396 & 1 & 1250.3 & 1331.2 \\
\hline 1507409 & 91 & 479.564 & 15301 & 4976.799 & 0.151936 & 0.338705 & 2.085227415 & 0 & 401.8 & 416.4 \\
\hline 1507458 & 94 & 3168.383 & 25056 & 8048.691 & 0.365244 & -0.02356 & 0.210412272 & 0 & 2437.8 & 2491.9 \\
\hline 1507466 & 91 & 195.918 & 5608 & 3978.959 & 0.167207 & -0.05575 & 0 & 0 & 92.8 & 106.1 \\
\hline 1507474 & 91 & 705.542 & 21536 & 4288.494 & 0.158533 & 0.625705 & 4.724500219 & 0 & 168.3 & 199.4 \\
\hline 1507508 & 94 & 1279.889 & 13419 & 4947.686 & 0.258893 & 0.752794 & 0.260439252 & 0 & 801.4 & 906.2 \\
\hline 1507607 & 91 & 1110.175 & 54417 & 4240.403 & 0.106708 & 0.600416 & 3.002529631 & 1 & 834.9 & 881.7 \\
\hline 1507706 & 91 & 1632.251 & 24363 & 3573.452 & 0.145403 & 0.436588 & 0.612650873 & 1 & 120.5 & 123.5 \\
\hline 1507755 & 94 & 1298.19 & 5395 & 9214.087 & 0.460894 & -0.59046 & 0.770303268 & 1 & 1144.7 & 1157.8 \\
\hline 1507961 & 91 & 206.414 & 10822 & 3308.076 & 0.112629 & 0.49753 & 1.614877544 & 0 & 165.4 & 170.6 \\
\hline 1507979 & 93 & 1896.506 & 17614 & 4532.077 & 0.129697 & 0.27377 & 0.52728544 & 1 & 314.3 & 340.9 \\
\hline 1508035 & 91 & 934.272 & 28775 & 3653.171 & 0.134966 & 0.234755 & 0.356784034 & 0 & 456.9 & 467.7 \\
\hline 1508050 & 93 & 11991.09 & 17670 & 6315.224 & 0.340738 & 0.610971 & 0 & 0 & 819.1 & 1081.5 \\
\hline 1508084 & 94 & 2512.594 & 36021 & 9446.767 & 0.176263 & -0.12579 & 1.06132016 & 1 & 2217.1 & 2275.6 \\
\hline 1508159 & 93 & 10791.37 & 44731 & 5995.596 & 0.271585 & 0.825567 & 0.154444386 & 0 & 2422 & 3045.5 \\
\hline 1508308 & 91 & 4915.073 & 58323 & 4095.726 & 0.193899 & 0.585234 & 0.203455778 & 0 & 3322.4 & 3455.2 \\
\hline 1100379 & 69 & 3958.273 & 13827 & 15071.17 & 0.499968 & 1.395792 & 0.25263543 & 0 & 1168.9 & 1287.8 \\
\hline 1100403 & 69 & 2651.822 & 19459 & 11979.03 & 0.351621 & 1.786755 & 1.131297651 & 1 & 1429.1 & 1672.5 \\
\hline 1100452 & 69 & 3265.809 & 36555 & 12140.91 & 0.354948 & 9.343735 & 1.224811371 & 0 & 1777.9 & 2206.4 \\
\hline 1100031 & 69 & 1314.351 & 6495 & 25016.47 & 0.634446 & 0.778973 & 0 & 0 & 942.3 & 971.4 \\
\hline 1100601 & 69 & 1961.778 & 6268 & 21638.16 & 0.614042 & 1.441676 & 0.169913891 & 0 & 1366.2 & 1456.6 \\
\hline 1100700 & 69 & 3442.005 & 13939 & 14396.15 & 0.46796 & 4.642725 & 0 & 0 & 1549.8 & 1878.7 \\
\hline 1100908 & 69 & 892.842 & 3689 & 17622.93 & 0.544844 & 0.856478 & 0 & 0 & 700.3 & 717.2 \\
\hline 1100056 & 69 & 2783.3 & 18041 & 24597.58 & 0.43197 & 0.495363 & 1.43714296 & 0 & 770.3 & 799.9 \\
\hline 1100924 & 69 & 5126.723 & 9636 & 36305.31 & 0.58003 & 2.361069 & 0 & 0 & 2500.5 & 2634.8 \\
\hline 1100072 & 69 & 3060.321 & 9036 & 35349.71 & 0.727506 & 2.393143 & 0 & 0 & 2092.8 & 2145.2 \\
\hline 1100080 & 69 & 4987.177 & 15853 & 10508.04 & 0.321164 & 11.96795 & 0.401028478 & 0 & 1260.5 & 1645.7 \\
\hline 1100940 & 69 & 3863.943 & 19410 & 11395.21 & 0.297147 & 7.684933 & 0.172535326 & 0 & 1055.8 & 1431 \\
\hline 1101005 & 69 & 5067.384 & 10534 & 14809.09 & 0.5012 & 1.50757 & 0.131560321 & 1 & 1265.9 & 1351.2 \\
\hline 1101104 & 69 & 4081.583 & 9661 & 12925.06 & 0.274483 & 1.695591 & 0.24500298 & 0 & 737 & 863.5 \\
\hline
\end{tabular}




\begin{tabular}{|c|c|c|c|c|c|c|c|c|c|c|}
\hline 1101203 & 69 & 798.083 & 10899 & 13550.23 & 0.385614 & 0.651751 & 1.253002507 & 1 & 697.3 & 710.3 \\
\hline 1101302 & 69 & 1191.875 & 12469 & 12338.2 & 0.323854 & 0.672846 & 1.678028317 & 0 & 604.5 & 631.1 \\
\hline 1101401 & 69 & 1931.378 & 15541 & 13855.48 & 0.378071 & 2.133162 & 1.553295108 & 0 & 1220.2 & 1357.7 \\
\hline 1101435 & 69 & 807.126 & 7883 & 11928.71 & 0.428314 & 0.337517 & 0.412987976 & 0 & 683.1 & 695.6 \\
\hline 1101450 & 69 & 2548.683 & 5477 & 15915.65 & 0.533487 & 2.413946 & 0.130786502 & 0 & 988 & 1126.4 \\
\hline 1101468 & 69 & 6014.733 & 2440 & 74469.67 & 0.813727 & 2.757528 & 0.055419473 & 0 & 1183.6 & 1256.7 \\
\hline 1101476 & 69 & 605.692 & 3597 & 14944.12 & 0.458547 & 0.159729 & 0.550334714 & 0 & 410.5 & 421.8 \\
\hline 1100262 & 69 & 1717.64 & 3666 & 25954.45 & 0.646077 & 2.012455 & 0.194064724 & 0 & 985.4 & 1060.5 \\
\hline 1100296 & 69 & 1197.796 & 8887 & 19891.53 & 0.543017 & 0.380209 & 1.66973341 & 1 & 944.7 & 974.4 \\
\hline 1101484 & 69 & 541.647 & 6219 & 13952.56 & 0.462666 & 0.880881 & 0.615406959 & 0 & 478 & 485.2 \\
\hline 1101492 & 69 & 10959.77 & 18265 & 14548.48 & 0.434478 & 8.15457 & 0.182485631 & 0 & 2125 & 2451 \\
\hline 1101500 & 69 & 3773.505 & 12505 & 13405.76 & 0.383582 & 1.608351 & 0.265005611 & 0 & 1074.2 & 1234.2 \\
\hline 1101559 & 69 & 459.978 & 5080 & 14215.94 & 0.428129 & 0.252416 & 0.724672339 & 0 & 439 & 441.5 \\
\hline 1101708 & 69 & 831.857 & 13491 & 11251.2 & 0.342439 & 0.797994 & 1.202129693 & 1 & 673 & 687.6 \\
\hline 1101757 & 69 & 3135.211 & 10518 & 17068.36 & 0.585328 & 2.7794 & 0 & 0 & 1067.8 & 1195.3 \\
\hline 1101807 & 69 & 965.676 & 8425 & 12841.19 & 0.427198 & 0.697479 & 0 & 0 & 860.8 & 868.2 \\
\hline 1400050 & 95 & 25567.01 & 16428 & 11048.15 & 0.18533 & -0.12626 & 0.013037633 & 0 & 669.9 & 743.2 \\
\hline 1400027 & 95 & 28472.33 & 10432 & 10697.57 & 0.195455 & -0.01345 & 0 & 0 & 241.6 & 307.3 \\
\hline 1400159 & 95 & 8095.421 & 11525 & 13046.33 & 0.278191 & -0.08753 & 0 & 0 & 323.7 & 374.3 \\
\hline 1400175 & 95 & 7664.831 & 15393 & 11498.34 & 0.190665 & -0.09882 & 0.086977347 & 1 & 1231.5 & 1478.5 \\
\hline 1400209 & 95 & 47408.9 & 19696 & 11109.21 & 0.062836 & -0.23102 & 0.042186169 & 1 & 868.9 & 984.4 \\
\hline 1400233 & 95 & 12066.05 & 8826 & 11640.15 & 0.192575 & 1.263635 & 0 & 0 & 733.6 & 923.1 \\
\hline 1400282 & 95 & 14412.69 & 9762 & 10536.26 & 0.159966 & 0.548605 & 0 & 0 & 546.8 & 726.2 \\
\hline 1400407 & 95 & 6966.811 & 9754 & 10472.22 & 0.227928 & 0.011578 & 0 & 0 & 18 & 19.5 \\
\hline 1400456 & 95 & 8028.483 & 11423 & 10440.86 & 0.075942 & -0.74025 & 0.124556532 & 0 & 62.3 & 75.2 \\
\hline 1400472 & 95 & 33595.46 & 26326 & 11682.98 & 0.092325 & -0.07174 & 0.019843953 & 1 & 975.5 & 1083.1 \\
\hline 1400506 & 95 & 4284.507 & 7284 & 11504.94 & 0.067162 & 0.107006 & 0 & 0 & 429.6 & 511.6 \\
\hline 1400605 & 95 & 1526.888 & 7210 & 10303.05 & 0.090473 & 0.042791 & 0 & 0 & 481.2 & 550.9 \\
\hline 1400704 & 95 & 8065.564 & 9127 & 8344.034 & 0.048798 & -0.15137 & 0 & 0 & 24.8 & 45.5 \\
\hline 1700251 & 63 & 1895.212 & 2506 & 9086.193 & 0.35777 & 0.646179 & 0 & 0 & 3.9 & 7.4 \\
\hline
\end{tabular}




\begin{tabular}{|c|c|c|c|c|c|c|c|c|c|c|}
\hline 1700301 & 63 & 235.394 & 5820 & 13125.95 & 0.064735 & 1.464998 & 4.248196641 & 0 & 104.3 & 107.6 \\
\hline 1700350 & 63 & 1579.751 & 5686 & 9472.388 & 0.27003 & 0.6861 & 1.899033455 & 0 & 0 & 0 \\
\hline 1700400 & 63 & 4013.243 & 7553 & 7469.88 & 0.182515 & 0.265795 & 0.41529174 & 0 & 0 & 0 \\
\hline 1700707 & 63 & 1212.167 & 8557 & 24334.81 & 0.223313 & 1.004082 & 3.299875347 & 0 & 0 & 0 \\
\hline 1701002 & 63 & 1576.973 & 9952 & 7785.169 & 0.209026 & 0.035441 & 1.902378798 & 0 & 1146.8 & 1157.4 \\
\hline 1701051 & 63 & 451.733 & 3332 & 7365.546 & 0.206594 & 1.124119 & 1.475798019 & 0 & 189.3 & 199.6 \\
\hline 1701101 & 63 & 1160.368 & 4504 & 12337.03 & 0.491352 & 2.622049 & 0.287265189 & 0 & 0 & 0 \\
\hline 1701309 & 63 & 1173.058 & 5958 & 8403.659 & 0.373831 & 0.901007 & 0.568315179 & 0 & 901.1 & 1006.4 \\
\hline 1701903 & 63 & 2778.475 & 6716 & 8212.775 & 0.313001 & 0.67721 & 0.239939775 & 0 & 41.6 & 53.2 \\
\hline 1702000 & 63 & 5167.797 & 8868 & 14407.98 & 0.431697 & 0.849759 & 0.516016141 & 0 & 0 & 0 \\
\hline 1702158 & 63 & 836.03 & 5379 & 8886.596 & 0.327153 & 0.682658 & 0.79741955 & 0 & 733.7 & 742.9 \\
\hline 1702307 & 63 & 1552.221 & 6844 & 11078.9 & 0.343435 & 0.626643 & 0.644238159 & 0 & 1462.4 & 1464 \\
\hline 1702406 & 63 & 5786.871 & 10833 & 12076.34 & 0.336727 & 2.646691 & 0.518414874 & 0 & 0 & 0 \\
\hline 1702703 & 63 & 752.83 & 3625 & 8635.586 & 0.346458 & 1.12094 & 0.885547423 & 0 & 0 & 0 \\
\hline 1702901 & 63 & 150.213 & 9632 & 6474.875 & 0.110169 & 1.477019 & 13.31442685 & 0 & 138.3 & 139.6 \\
\hline 1703008 & 63 & 1788.461 & 10720 & 6191.698 & 0.192504 & 0.433364 & 0 & 0 & 3.5 & 3.5 \\
\hline 1703057 & 63 & 1541.842 & 3336 & 18657.07 & 0.391167 & 0.440209 & 0.216191629 & 0 & 1496.8 & 1500.3 \\
\hline 1703073 & 63 & 1106.345 & 4371 & 9394.418 & 0.392806 & 3.603493 & 0.602584787 & 0 & 0 & 0 \\
\hline 1703107 & 63 & 713.3 & 5557 & 8549.937 & 0.267746 & 0.912355 & 2.336557783 & 0 & 0 & 0 \\
\hline 1703206 & 63 & 926.888 & 4547 & 11776.56 & 0.387064 & 0.484124 & 0 & 0 & 891 & 894.9 \\
\hline 1703602 & 63 & 641.467 & 2154 & 12620.71 & 0.335716 & 2.038248 & 0 & 0 & 218.9 & 218.9 \\
\hline 1703701 & 63 & 1724.45 & 5400 & 13017.59 & 0.497711 & 1.794932 & 0 & 0 & 0 & 0 \\
\hline 1703800 & 63 & 251.919 & 10522 & 5433.473 & 0.078719 & 1.104025 & 2.646353259 & 0 & 213.7 & 214 \\
\hline 1703826 & 63 & 352.345 & 2236 & 6650.268 & 0.121116 & 1.982227 & 1.892084936 & 0 & 104.2 & 108.7 \\
\hline 1703842 & 63 & 3240.177 & 9000 & 38938.33 & 0.467023 & 3.458857 & 0 & 0 & 0.1 & 0.1 \\
\hline 1703867 & 63 & 1128.601 & 4053 & 24138.17 & 0.302271 & 2.128228 & 0 & 0 & 0 & 0 \\
\hline 1703883 & 63 & 339.405 & 2457 & 10446.07 & 0.348366 & 1.394237 & 1.964221702 & 0 & 305.7 & 307.3 \\
\hline 1703891 & 63 & 192.939 & 3906 & 6182.796 & 0.141453 & 0.335275 & 3.455323531 & 1 & 130.5 & 131.3 \\
\hline 1703909 & 63 & 1691.614 & 4965 & 9078.55 & 0.351333 & 0.434895 & 0 & 0 & 241.3 & 269.1 \\
\hline 1704105 & 63 & 1954.699 & 2737 & 7844.355 & 0.271896 & 2.502181 & 0.170529239 & 0 & 0 & c \\
\hline
\end{tabular}




\begin{tabular}{|c|c|c|c|c|c|c|c|c|c|c|}
\hline 1705102 & 63 & 1646.472 & 3362 & 12574.06 & 0.50006 & 3.327627 & 0.404906167 & 0 & 0 & 0 \\
\hline 1704600 & 63 & 659.249 & 1386 & 10466.81 & 0.372383 & 0.509866 & 1.011251692 & 1 & 0.8 & 1.7 \\
\hline 1716703 & 63 & 990.72 & 8581 & 9705.046 & 0.199194 & 0.921195 & 1.682278208 & 0 & 748.8 & 753.3 \\
\hline 1705557 & 63 & 209.572 & 4827 & 9138.388 & 0.220837 & 0.871336 & 3.181086532 & 0 & 0 & 0 \\
\hline 1705607 & 63 & 2500.74 & 4240 & 7313.679 & 0.19075 & 0.041178 & 0.266587757 & 0 & 0 & 0 \\
\hline 1706001 & 63 & 1585.787 & 5314 & 9025.969 & 0.305142 & 1.215583 & 0 & 0 & 222.5 & 232.2 \\
\hline 1706100 & 63 & 1848.241 & 7399 & 9501.554 & 0.25688 & 0.534703 & 1.082109963 & 0 & 0 & 0 \\
\hline 1706258 & 63 & 986.693 & 1651 & 15969.11 & 0.484127 & 1.319393 & 0 & 0 & 0 & 0 \\
\hline 1706506 & 63 & 1639.162 & 5670 & 10293.12 & 0.390678 & 5.625173 & 0.406711885 & 0 & 103.5 & 108.3 \\
\hline 1707009 & 63 & 3217.313 & 20566 & 12953.52 & 0.31279 & 3.360004 & 1.346879627 & 0 & 0 & 0 \\
\hline 1707108 & 63 & 2347.434 & 6681 & 10101.48 & 0.277075 & 0.772256 & 0.283998045 & 0 & 17.4 & 18.4 \\
\hline 1707207 & 63 & 3757.036 & 7319 & 9269.846 & 0.417688 & 0.460943 & 0 & 0 & 60 & 64.9 \\
\hline 1707306 & 63 & 3424.852 & 4718 & 16901.23 & 0.591984 & 0.615384 & 0.194655613 & 0 & 31.3 & 34.6 \\
\hline 1707405 & 63 & 504.023 & 10203 & 5587.18 & 0.100724 & 2.518804 & 0.661345481 & 0 & 211.8 & 217.3 \\
\hline 1707553 & 63 & 382.908 & 3892 & 10204.01 & 0.261578 & 1.639789 & 1.741062257 & 0 & 0 & 0 \\
\hline 1707652 & 63 & 1930.072 & 5421 & 19807.23 & 0.3538 & 0.458786 & 1.554346159 & 0 & 0 & 0 \\
\hline 1707702 & 63 & 1988.081 & 8800 & 8286.364 & 0.245187 & 1.405509 & 0.335331743 & 0 & 0 & 0 \\
\hline 1708205 & 63 & 13423.38 & 18804 & 16714.79 & 0.514233 & 0.253034 & 0.297987475 & 0 & 173 & 186.8 \\
\hline 1708254 & 63 & 621.562 & 2527 & 27988.92 & 0.204572 & 1.435225 & 0 & 0 & 402.6 & 402.6 \\
\hline 1708304 & 63 & 1800.983 & 5115 & 9330.205 & 0.397242 & 1.041631 & 0 & 0 & 98.2 & 102.2 \\
\hline 1709005 & 63 & 6408.602 & 12644 & 9651.693 & 0.43791 & 6.146642 & 0.104026848 & 0 & 0 & 0 \\
\hline 1709807 & 63 & 815.254 & 1804 & 14356.43 & 0.522176 & 2.607788 & 0 & 0 & 0 & 0 \\
\hline 1710508 & 63 & 3051.36 & 7388 & 8298.457 & 0.293445 & 2.440124 & 0 & 0 & 0 & 0 \\
\hline 1710706 & 63 & 739.849 & 6063 & 6952.829 & 0.207481 & 1.506307 & 0 & 0 & 335.8 & 358.8 \\
\hline 1710904 & 63 & 1243.961 & 3711 & 10765.29 & 0.433396 & 3.117198 & 0.535922482 & 0 & 0 & 0 \\
\hline 1711100 & 63 & 972.977 & 2482 & 13276.79 & 0.492747 & 0.55401 & 0 & 0 & 925.6 & 928.1 \\
\hline 1711506 & 63 & 2173.047 & 3730 & 10102.41 & 0.391298 & 0.621692 & 0 & 0 & 0 & 0 \\
\hline 1711803 & 63 & 481.048 & 2253 & 8572.126 & 0.284546 & 0.558997 & 0 & 0 & 210.9 & 210.9 \\
\hline 1711902 & 63 & 10564.66 & 11859 & 26454.34 & 0.467869 & 3.243928 & 0.189310381 & 0 & 187.2 & 239.3 \\
\hline 1711951 & 63 & 911.342 & 3957 & 6193.328 & 0.168774 & 1.855757 & 0.365760969 & 0 & 0 & 0 \\
\hline
\end{tabular}




\begin{tabular}{lrrrrrr}
1712009 & 63 & 322.485 & 2991 & 9817.118 & 0.063744 & 0.838844 \\
1712157 & 63 & 519.614 & 1782 & 8586.42 & 0.332465 & 0.902036 \\
1712405 & 63 & 5723.234 & 3801 & 6072.086 & 0.164876 & 0.390925 \\
1712454 & 63 & 279.563 & 2896 & 7622.238 & 0.172782 & 1.415779 \\
1712504 & 63 & 2091.374 & 4814 & 10489.61 & 0.410204 & 0.496407 \\
1712702 & 63 & 9681.657 & 2478 & 33959.24 & 0.736893 & 59.90851 \\
1712801 & 63 & 738.105 & 3338 & 6468.544 & 0.174762 & 1.798709 \\
1713601 & 63 & 3616.674 & 7412 & 14267.4 & 0.499476 & 3.272565 \\
1713700 & 63 & 1091.553 & 2213 & 10795.75 & 0.422036 & 0.529187 \\
1713957 & 63 & 1186.647 & 3395 & 9665.685 & 0.38993 & 0.832317 \\
1714203 & 63 & 3240.715 & 9279 & 8651.148 & 0.162589 & 0.918533 \\
1714302 & 63 & 395.907 & 4239 & 7116.065 & 0.141887 & 1.104967 \\
1714880 & 63 & 1566.184 & 11408 & 15200.65 & 0.089538 & 1.94825 \\
1715002 & 63 & 516.308 & 4066 & 7164.535 & 0.190009 & 0.22917 \\
1715101 & 63 & 2674.682 & 4101 & 7030.237 & 0.143138 & 1.510919 \\
1715150 & 63 & 200.105 & 2350 & 8001.277 & 0.22129 & 0.902465 \\
1715259 & 63 & 1309.665 & 2625 & 10454.86 & 0.249482 & 5.745442 \\
1715507 & 63 & 205.85 & 1091 & 12309.81 & 0.356406 & 0.533296 \\
1715705 & 63 & 2640.816 & 5543 & 8596.969 & 0.3777 & 2.353116 \\
1713809 & 63 & 747.898 & 6272 & 6782.366 & 0.226873 & 1.591639 \\
1715754 & 63 & 1703.944 & 7623 & 9794.307 & 0.261516 & 0.817574 \\
1716208 & 63 & 11260.22 & 10579 & 19266.28 & 0.095362 & 0.328086 \\
1716307 & 63 & 1377.406 & 4793 & 9736.282 & 0.38976 & 0.738753 \\
1716505 & 63 & 2010.902 & 12698 & 29982.36 & 0.390217 & -0.05385 \\
1716604 & 63 & 5291.208 & 11209 & 32841.73 & 0.146496 & 1.216634 \\
1716653 & 63 & 1209.8 & 5344 & 9031.25 & 0.343138 & 0.647739 \\
1717008 & 63 & 1559.086 & 4562 & 8333.406 & 0.324868 & -0.00665 \\
1717206 & 63 & 1367.613 & 3024 & 11590.61 & 0.476576 & 1.073079 \\
1717503 & 63 & 10013.79 & 7264 & 14562.5 & 0.578164 & 0.440981 \\
1717800 & 63 & 1806.141 & 4652 & 7101.247 & 0.245023 & 0.878371 \\
\hline
\end{tabular}

0
1.283003666
0.058242129
2.384674176
0
0.034429368
0.45160693
0.184331423
0
0.561807064
1.028579598
1.683897144
1.064157638
1.291218937
0
0.331584252
0.509036026
0.238604162
0.252447223
0.445693575
0.978122912
0
0.48400157
0.377985105
0
0

$\begin{array}{rr}0 & 0 \\ 0 & 0 \\ 0 & 0 \\ 152.2 & 156.4 \\ 119.6 & 143 \\ 0 & 0 \\ 138.1 & 143.5 \\ 0 & 0 \\ 0.4 & 0.7 \\ 941.1 & 953.5 \\ 0 & 0 \\ 268.8 & 282.5 \\ 798.2 & 798.9 \\ 0 & 0 \\ 0 & 0 \\ 0 & 0 \\ 0 & 0 \\ 0 & 0 \\ 103.2 & 103.6 \\ 57.3 & 58.2 \\ 0 & 0 \\ 0 & 0 \\ 1112.5 & 1129.9 \\ 19.7 & 20.8 \\ 0 & 0 \\ 837.8 & 844.2 \\ 0 & 0 \\ 1075.9 & 1096.6 \\ 29 & 34.6 \\ 0 & 0\end{array}$




\begin{tabular}{|c|c|c|c|c|c|c|c|c|c|c|}
\hline 1717909 & 63 & 6491.125 & 7712 & 7437.5 & 0.272524 & 0.732729 & 0 & 0 & 0 & 0 \\
\hline 1718006 & 63 & 501.862 & 3007 & 6987.695 & 0.160954 & 0.942211 & 1.328386422 & 0 & 0 & 0 \\
\hline 1718303 & 63 & 289.054 & 8158 & 5525.864 & 0.074244 & 1.861276 & 0 & 0 & 208.8 & 222.9 \\
\hline 1718402 & 63 & 770.423 & 3750 & 20241.87 & 0.143684 & 0.95061 & 1.297988248 & 0 & 337.5 & 340 \\
\hline 1718451 & 63 & 401.834 & 2561 & 10765.72 & 0.165811 & 0.194776 & 1.659059877 & 1 & 0 & 0 \\
\hline 1718501 & 63 & 2216.663 & 4081 & 6922.568 & 0.198827 & 1.32224 & 0.150376189 & 0 & 32.8 & 37.7 \\
\hline 1718550 & 63 & 517.478 & 4478 & 6937.919 & 0.184472 & 0.47705 & 1.288299535 & 0 & 437.4 & 442.4 \\
\hline 1718659 & 63 & 787.116 & 1938 & 6621.259 & 0.092793 & 6.344084 & 0.423486924 & 0 & 0 & 0 \\
\hline 1718709 & 63 & 845.065 & 2740 & 9900.365 & 0.364826 & 3.725572 & 0 & 0 & 17.8 & 17.8 \\
\hline 1718758 & 63 & 6354.367 & 6473 & 6640.97 & 0.231449 & 0.567209 & 0.052457363 & 0 & 0 & 0 \\
\hline 1718808 & 63 & 222.29 & 4329 & 5514.438 & 0.074933 & 0.905755 & 2.999085279 & 1 & 73.5 & 75.3 \\
\hline 1718840 & 63 & 3528.621 & 3411 & 14708 & 0.525082 & 0.716248 & 0.188931219 & 0 & 4.1 & 4.1 \\
\hline 1718865 & 63 & 1678.091 & 7144 & 9756.859 & 0.359965 & 1.104884 & 0.397276826 & 0 & 1226.7 & 1264.5 \\
\hline 1718881 & 63 & 1410.457 & 3198 & 8301.438 & 0.286873 & 1.735481 & 0 & 0 & 0 & 0 \\
\hline 1718899 & 63 & 3274.947 & 2278 & 15821.77 & 0.580427 & 0.204953 & 0 & 0 & 17.3 & 20.7 \\
\hline 1718907 & 63 & 1796.257 & 4773 & 13905.72 & 0.523217 & 2.753821 & 0.37114214 & 0 & 0 & 0 \\
\hline 1719004 & 63 & 539.912 & 2729 & 7892.635 & 0.250827 & 1.334318 & 1.234769123 & 0 & 0 & 0 \\
\hline 1720002 & 63 & 269.677 & 2545 & 6555.599 & 0.159931 & 1.385894 & 0 & 0 & 71.8 & 73.3 \\
\hline 1720101 & 63 & 1105.901 & 5026 & 6243.733 & 0.135891 & 1.352283 & 0.602826715 & 0 & 341.5 & 349.5 \\
\hline 1720150 & 63 & 1908.678 & 1532 & 6795.692 & 0.130575 & 0.980539 & 0 & 0 & 0 & 0 \\
\hline 1720200 & 63 & 398.82 & 11436 & 4960.563 & 0.071727 & 0.587347 & 0 & 0 & 325 & 337.9 \\
\hline 1720259 & 63 & 1422.032 & 3044 & 7852.825 & 0.212002 & 0.791648 & 0.468812704 & 0 & 0 & 0 \\
\hline 1720309 & 63 & 287.275 & 4604 & 6052.563 & 0.131488 & 2.302116 & 2.320656746 & 1 & 135.4 & 135.6 \\
\hline 1720499 & 63 & 2519.585 & 4267 & 10070.78 & 0.323338 & 2.207475 & 0.264593839 & 0 & 0 & 0 \\
\hline 1720655 & 63 & 1258.831 & 5318 & 15568.82 & 0.525059 & 2.601039 & 0 & 0 & 0 & 0 \\
\hline 1720804 & 63 & 324.106 & 9270 & 6051.025 & 0.114387 & 0.895162 & 2.056940219 & 0 & 289.1 & 295.9 \\
\hline 1720853 & 63 & 1025.519 & 1878 & 20813.1 & 0.611814 & 1.266994 & 0 & 0 & 0 & 0 \\
\hline 1720903 & 63 & 2437.399 & 16086 & 10998.38 & 0.152542 & 0.41417 & 1.504335838 & 0 & 0 & 0 \\
\hline 1720937 & 63 & 1116.202 & 2075 & 7450.602 & 0.225858 & 0.111317 & 0 & 0 & 0 & 0 \\
\hline 1720978 & 63 & 2156.902 & 2716 & 16736.38 & 0.509412 & 0.595892 & 0 & 0 & 0 & 0 \\
\hline
\end{tabular}




$\begin{array}{rrrrrrrrrrr}1721109 & 63 & 2601.603 & 7236 & 5750.138 & 0.069316 & 0.142991 & 0 & 0 & 0 & 0 \\ 1721307 & 63 & 895.308 & 2402 & 8972.107 & 0.314073 & 3.201592 & 0 & 0 & 2.1 & 2.2 \\ 1722081 & 63 & 1373.061 & 11509 & 7960.726 & 0.155621 & 0.898601 & 1.9421327 & 0 & 297 & 315.1 \\ 1722107 & 63 & 1186.428 & 11722 & 15319.74 & 0.133775 & 0.612333 & 3.371464598 & 0 & 949.9 & 987.3\end{array}$

